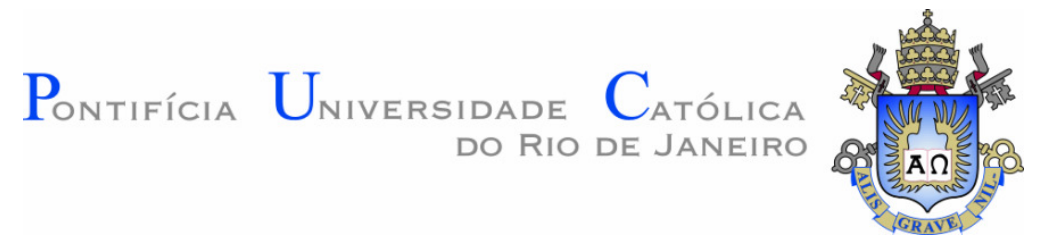

José Angel Florián Gutiérrez

Escoamento Viscoelástico através de Microcanais com Constrição

Tese de Doutorado

Tese apresentada ao Programa de Pós-graduação em Engenharia Mecânica da PUC-Rio como requisito parcial para obtenção do grau de Doutor em Engenharia Mecânica.

Orientador : Prof. Márcio da Silveira Carvalho Co-orientadora: Dra. Maria João Brito Moura

Rio de Janeiro

Junho de 2018 
Pontifícia Universidade Catálica $_{\text {a }}$

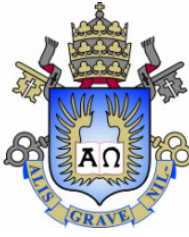

José Angel Florián Gutiérrez

\section{Escoamento Viscoelástico através de Microcanais com Constrição}

Tese apresentada como requisito parcial para obtenção do grau de Doutor pelo Programa de Pós-graduação em Engenharia Mecânica da PUC-Rio. Aprovada pela Comissão Examinadora abaixo assinada.

Prof. Márcio da Silveira Carvalho

Orientador

Departamento de Engenharia Mecânica - PUC-Rio

Dra. Maria João Brito Moura

Coorientadora

Departamento de Engenharia Mecânica - PUC-Rio

Prof. Luis Fernando Alzuguir Azevedo Departamento de Engenharia Mecânica - PUC-Rio

Prof. Roney Leon Thompson Departamento de Engenharia Mecânica - UFRJ

Dr. Rodrigo Neumann Barros Ferreira IBM Research Brazil

Dr. Marcelo Andreotti Repsol Brasil

Prof. Márcio da Silveira Carvalho Coordenador Setorial do Centro Técnico Científico - PUC-Rio

Rio de Janeiro, 06 de junho de 2018 
Todos os direitos reservados. É proibida a reprodução total ou parcial do trabalho sem autorização da universidade, do autor e dos orientadores.

\section{José Angel Florián Gutiérrez}

Engenheiro Mecânico pela Universidade Nacional de Trujillo UNT (Perú) e Mestre em Engenharia Mecânica pela Pontifícia Universidade Católica do Rio de Janeiro PUC-Rio (Brasil).

Ficha Catalográfica

Florián Gutiérrez, José Angel

Escoamento Viscoelástico através de Microcanais com Constrição / José Angel Florián Gutiérrez; orientador: Márcio da Silveira Carvalho; co-orientadora: Maria João Brito Moura. 2018.

262 f. : il. color. ; $30 \mathrm{~cm}$

Tese (doutorado)-Pontifícia Universidade Católica do Rio de Janeiro, Departamento de Engenharia Mecânica, 2018.

Inclui bibliografia

1. Engenharia Mecânica - Teses. 2. Viscoelasticidade. 3. Instabilidade de escoamento. 4. Microfluídica. 5. Micro-velocimetria por imagem de partículas ( $\mu$-PIV). I. Carvalho, Márcio da Silveira. II. Moura, Maria João Brito. III. Pontifícia Universidade 
Dedico este trabalho a Deus e a minha família. 


\section{Agradecimentos}

Agradeço a toda minha família pelo amor e formação recebida na minha vida.

Ao meu orientador, professor Márcio da Silveira Carvalho, pela confiança e orientação durante o desenvolvimento da tese de doutorado.

À minha co-orientadora Maria, pela amizade, orientação e conselhos recebidos na minha etapa profissional na IBM e na Universidade.

Ao Danmer pelas valiosas contribuições e aportes, e a todos que contribuíram de forma direta ou indireta para o desenvolvimento da minha tese.

Aos meus colegas e amigos da PUC-Rio, pela amizade e companheirismo mostrado em cada momento durante minha permanência no Brasil.

À Banca examinadora, pelas observações contribuídas ao presente trabalho.

Ao departamento de Engenharia Mecânica da Pontifícia Universidade Católica do Rio de Janeiro pela formação profissional proporcionado no curso de doutorado.

À PUC-Rio, pela bolsa de isenção do curso. À instituição CNPQ, pelo auxílio financeiro concedido durante o doutorado. 


\section{Resumo}

Florián Gutiérrez, José Angel; Carvalho, Márcio da Silveira (Orientador); Moura, Maria João Brito (Co-orientadora). Escoamento Viscoelástico através de Microcanais com Constrição. Rio de Janeiro, 2018. 262p. Tese de Doutorado - Departamento de Engenharia Mecânica, Pontifícia Universidade Católica do Rio de Janeiro.

Alguns projetos pilotos de injeção de polímeros em campos de produção de petróleo mostraram um incremento na recuperação de óleo, embora os mecanismos que governam a dinâmica do escoamento não são bem compreendidos. Recentes investigações experimentais mostraram que as propriedades viscoelásticas de soluções poliméricas podem alterar o comportamento do escoamento na escala de poros e reduzir a saturação residual de óleo. Para entender esses fenômenos em meios porosos, é importante estudar o escoamento de soluções viscoelásticas através das gargantas dos poros.

Este trabalho apresenta um estudo experimental do escoamento de uma solução viscoelástica de PEO (0,1\% em peso de óxido de polietileno) de alto peso molecular escoando através de uma constrição, utilizado como modelo de uma geometria de garganta de poro de um meio poroso.

Medições de queda de pressão e campos de velocidade do escoamento são obtidos utilizando a técnica de velocimetria por imagem de partículas (Micro-PIV). Experimentos com uma solução viscosa de glicerina (45\% em peso de glicerina em água) de viscosidade similar à solução de PEO foram também realizados com a finalidade de estimar os efeitos elásticos da solução de PEO.

O escoamento da solução de PEO exibiu uma queda de pressão extra (comportamento não linear) acima de uma condição crítica do escoamento, acima da qual os efeitos elásticos passam a ser preponderantes.

Para toda a faixa de vazão explorada, os campos de velocidade da solução de glicerina mostraram um regime de escoamento Newtoniano, enquanto a solução de PEO apresenta instabilidade no escoamento a partir de um número de Weissenberg crítico, coincidindo com o aumento da queda de pressão. Esta instabilidade pode ser relacionada ao aumento da viscosidade extensional na entrada da garganta acima de uma determinada taxa de extensão. 
Os resultados obtidos indicam a variação do padrão do escoamento da solução polimérica de PEO devido à presença dos efeitos elásticos do polímero, e fornecem informações importantes sobre o comportamento das soluções poliméricas viscoelásticas em um meio poroso e que podem impactar sua utilização na recuperação melhorada de óleo.

\section{Palavras-chave}

Viscoelasticidade; Instabilidade de escoamento; Microfluídica; MicroVelocimetria por imagem de partículas ( $\mu$-PIV). 


\section{Abstract}

Florián Gutiérrez, José Angel; Carvalho, Márcio da Silveira (Advisor); Moura, Maria João Brito (Co-advisor). Viscoelastic Flow through Microchannels with Constriction. Rio de Janeiro, 2018. 262p. Tese de Doutorado - Departamento de Engenharia Mecânica, Pontifícia Universidade Católica do Rio de Janeiro.

Some pilot projects of polymer injection in oil fields have shown an increase in oil recovery, although the mechanisms that govern the flow dynamics are still not well understood. Recent experimental investigations have shown that the viscoelastic properties of polymer solutions may change the pore-scale flow behavior and reduce the residual oil saturation. To understand these phenomena in porous media, it is important to understand viscoelastic flow behavior through the pores-throats.

This work presents experimental study of the flow of a high molecular viscoelastic PEO solution (0.1 wt\% Polyethylene Oxide) flowing through a constricted capillary, used as model for a pore-throat geometry of a porous media.

Pressure drop measurements are performed and velocity fields are obtained using the micro-particle image velocimetry (Micro-PIV) technique. Experiments with a viscous solution of glycerin (45 wt\% glycerin in water), of similar shear viscosity to the PEO solution were also performed in order to isolate the elastic effects of the PEO solution.

The flow of the PEO solution exhibited an extra pressure drop (nonlinear behavior) above a critical flow condition beyond which the elastic forces become relevant.

For the entire flow rate range explored, the velocity field of the glycerin solution showed a Newtonian flow regime, while the PEO solution shows instability in the flow above a critical Weissenberg number, coinciding with the onset of the extra pressure drop. This instability in the flow is associated with the high extensional viscosity near the constriction at high enough extension rates.

The results show the changes in the flow pattern of the PEO polymer solution due to the presence of the elastic effects of polymer, and provide important information on how viscoelastic polymer solutions behave in a porous media and can impact their use in Enhanced Oil Recovery operations. 


\section{Keywords}

Viscoelasticity; Flow instability; Microfluidics; Micro-Particle image velocimetry ( $\mu$-PIV). 


\section{Sumário}

1. Introdução 33

1.1. Microfluídica 36

1.1.1. Escoamentos em microcanais com constrição 38

1.2. Revisão da literatura 42

1.2.1. Investigações experimentais realizadas em canais na $\begin{array}{ll}\text { escala macro } & 48\end{array}$

1.2.1.1. Investigações experimentais realizadas em canais com constrição abrupta axissimétrica na escala macro 48

1.2.2. Investigações experimentais realizadas em constrições na escala micro 53

1.2.2.1. Investigações experimentais realizadas em canais retos na escala micro $\quad 54$

1.2.2.2. Investigações experimentais realizadas em canais com constrição abrupta planar na esca micro

1.2.2.3. Investigações experimentais realizadas em canais com diferentes constrições planar na escala micro 71

1.2.2.4. Investigações experimentais realizadas em micromodelos 81

1.3. Investigação experimental realizada neste trabalho 87

1.4. Diferenças entre a literatura e nossa investigação 88

1.5. Objetivo da tese 90

1.6. Estrutura da tese 90

2. Fluidos complexos em microcanais 92

2.1. Reologia dos fluidos complexos 92

2.1.1. Viscosidade extensional e cisalhamento 92

2.1.2. Tempo de relaxação 94

2.1.3. Concentração da solução 96

2.2. Parâmetros que caracterizam a dinâmica do escoamento 96

2.2.1. Número de Weissenberg 96 
3. Técnica de medição do Escoamento 101

3.1. Técnica de Micro-PIV 101

3.1.1. Princípio de funcionamento 101

3.1.2. lluminação no sistema Micro-PIV 103

3.1.3. Etapas de processamento de imagens 105

3.1.3.1. Pré-processamento de imagens 105

$\begin{array}{ll}\text { 3.1.3.2. Processamento de imagens } & 107\end{array}$

$\begin{array}{ll}\text { 3.1.3.3. Pós-processamento de imagens } & 108\end{array}$

$\begin{array}{ll}\text { 3.2. Movimento Browniano das partículas } & 110\end{array}$

4. Metodologia 113

4.1. Bancada experimental 113

$\begin{array}{lr}\text { 4.1.1. Micromodelo } & 114\end{array}$

4.1.2. Sistema de injeção 116

4.1.3. Sistema de medição de pressão 117

$\begin{array}{ll}\text { 4.1.4. Sistema de } \mu \text {-PIV } & 118\end{array}$

4.1.4.1. Microesferas com fluorescência 118

$\begin{array}{ll}\text { 4.1.4.2. Laser Nd:YAG } & 118\end{array}$

$\begin{array}{lr}\text { 4.1.4.3. Microscópio } & 119\end{array}$

4.1.4.4. Câmera digital 121

$\begin{array}{ll}\text { 4.1.4.5. Sincronizador } & 121\end{array}$

4.2. Soluções aquosas 122

4.2.1. Preparação das soluções aquosas 122

4.2.1.1. Solução polimérica 123

4.2.1.2. Solução de glicerina 125

4.2.2. Caracterização das soluções aquosas 126

$\begin{array}{ll}\text { 4.3. Procedimento experimental } & 137\end{array}$

4.3.1. Medicão da queda de pressão $\Delta P \quad 137$

$\begin{array}{ll}\text { 4.3.2. Determinação do campo de velocidade } & 138\end{array}$ 
5. Resultados 141

5.1. Medição da queda de pressão 141

5.1.1. Tempo de aquisição das medições da queda de pressão 142

5.1.2. Repetibilidade das medições da queda de pressão 144

5.1.3. Análises das medições da queda de pressão 146

5.1.3.1. Queda de pressão no escoamento de água 146

5.1.3.2. Queda de pressão nas soluções de glicerina e PEO 149

5.1.4. Regime do escoamento 153

5.2. Medição de campo de velocidade 157

5.2.1. Determinação dos parâmetros experimentais para as medições dos campos de velocidade 157

5.2.1.1. Calibração da resolução espacial 158

5.2.1.2. Seleção da máscara 158

5.2.1.3. Determinação da concentração de microesferas (partículas traçadoras) no escoamento e o tamanho da janela de interrogação 158

5.2.1.4. Determinação do tempo entre duas imagens consecutivas $\quad 160$

5.2.1.5. Determinação do número de pares de imagens 161

5.2.2. Determinação dos campos de velocidade 164

5.2.2.1. Campos de velocidade média 166

5.2.2.2. Campos de velocidade instantânea 200

5.2.2.3. Desvio padrão dos campos de velocidade 222

5.2.2.4. Taxa de deformação do campo de velocidade média 231

6. Comentarios Finais 239

6.1. Conclusões 239

6.2. Sugestões 244

7. Referências bibliográficas 246

Apêndice A 260

A.1. Calibração do transdutor de pressão 260

A.1.1. Bancada experimental do sistema de calibração 260

A.1.2. Procedimento de calibração 261 


\section{Lista de figuras}

Figura 1 - Demanda de energia global projetada. Fonte: Shell (2016) 33 Figura 2 - Frente de deslocamento de água e polímero realizado por Sheng (2012)

Figura 3 - Gânglio de óleo preso por forças capilares na injeção de água. b) Gânglio de óleo deslocado pela injeção da solução polimérica (Miranda, 2015)

Figura 4 - Demanda de dispositivos microfluídicos. Fonte: Yole (2015) 37 Figura 5 - Representação esquemática da formação de vórtices em fluxos Newtonianos e não Newtonianos escoando por uma constrição em particular 39

Figura 6 - Representação esquemática de uma constrição abrupta planar

Figura 7 - Representação esquemática da constrição utilizada em nossos experimentos

Figura 8 - Variáveis utilizadas geralmente no estudo de escoamentos viscoelásticos

Figura 9 - Esquema com um resumo dos temas discutidos na revisão bibliográfica

Figura 10 - Microcanal com contração-expansão abrupta

Figura 11 - Medidas da queda de pressão normalizada em função do número de Deborah para um fluido Boger ( $C=0,025 \%$ em peso) através da constrição axissimétrica de $R c=4: 1$ realizado por Rothstein e McKinley (1999)

Figura 12 - Linhas de tinta do escoamento da solução de Boger à montante da constrição mostrando a oscilação dos vórtices no tempo para o número de Deborah $D e=4,7$ realizado por Rothstein e McKinley (1999)

Figura 13 - Queda de pressão normalizada em função do número de 
Deborah. a) Efeito da $R c$. b) Efeito da curvatura do canto reentrante à $R c=4: 1$ realizado por Rothstein e McKinley (2001)

Figura 14 - Imagens com linhas de tinta mostrando o início e crescimento do vórtice de lábio à montante da constrição para diferentes números de Deborah à $R c=2: 1$ realizado por Rothstein e McKinley (2001)

Figura 15 - $O$ escoamento mostrando linhas de tinta para altos números de Deborah e para a $R c=4: 1$ a) Canto reentrante afiado b) Canto reentrante arredondado realizado por Rothstein e McKinley (2001)

Figura 16 - a) Microcanal reto. b) Perfil de velocidade para diferentes diferenças de pressão impostas. c) Propriedades reológicas da solução de PEO ( $P M=5 \times 10^{6} \mathrm{~g} / \mathrm{mol}, C=7,5 \mathrm{~g} / \mathrm{L}$ ) utilizando os resultados da velocimetria do escoamento e do reômetro Couette realizado por Degré et al. (2006)

Figura 17 - a) Comparação do perfil de velocidade experimental e de simulação LB do escoamento da solução de PPAm ( $C=1,25 \%$ em peso).

b) Comparação do índice de escoamento $n$ obtido através da técnica de micro-PIV e do rêometro para 6 soluções de PPAm realizado por Fu et al. (2015)

Figura 18 - Queda de pressão normalizada em função de Weissenberg para três soluções de PEO $\left(P M=2 \times 10^{6} \mathrm{~g} / \mathrm{mol}\right)$ realizado por

Rodd et al. (2005)

Figura 19 - O diagrama Re vs. Wi mostra um resumo dos diferentes regimes de escoamento para três soluções de PEO ( $E l=3,8, E l=8,4 \mathrm{e}$ $E l=89)$ realizado por Rodd et al. (2005)

Figura 20 - Queda de pressão normalizada em função de Weissenberg para quatro soluções de PEO ( $C=0,075 \%$ em peso) realizado por Rodd et al. (2007)

Figura 21 - Visualização do escoamento da solução de PEO (concentração em peso de glicerina/água $C=45 \%$ ) na entrada da constrição. a) Linhas de tinta. b) Linhas de correntes medidos através da técnica de micro-PIV realizado por Rodd et al. (2007)

Figura 22 - Medidas da queda de pressão normalizada no escoamento da solução de PEO ( $C=0,1 \%$ em peso) em função de Wi para 
diferentes $L c$ realizado por Rodd et al. (2010)

Figura 23 - Imagens com linhas de tinta do escoamento da solução de PEO ( $C=0,3 \%$ em peso) para diferentes $L C$ realizado por Rodd et al. (2010)

Figura 24 - Campos instantâneos de velocidade capturados no intervalo de tempo de 0,25 s por meio da técnica de micro-PIV a) Campo vetorial de velocidade. b) Linhas de corrente realizado por Haward et al. (2010)

Figura 25 - Imagens com linhas de corrente capturados a cada intervalo de 0,25 s para duas concentrações de solução de PEO. a) El=20 e $E l=120$ ambos a $W i \approx 30$. b) $E l=20$ e $E l=120$ ambos a $W i \approx 40$ realizado por Li et al. (2011)

Figura 26 - Dinâmica temporal do escoamento da solução de PEO $(C=0,3 \%$ em peso) à montante da constrição para diferentes $R C$ realizado por Li et al. (2011)

Figura 27 - Comprimento adimensional do vórtice em função do número de Wi. a) Para diferentes $R c$ e b) Para diferentes $L c$ realizado por Li et al. (2011)

Figura 28 - a) Geometria do dispositivo microfluídico. b-d) Linhas de corrente à montante da constrição (esquerda) e campos de velocidade do escoamento dentro da constrição (direita) para quatro valores de Weissenberg realizado por Li et al. (2015) Figura 29 - Padrões de escoamento. a) Para diferentes relações de aspecto $R a$ b) Para diferentes números de elasticidade $E /$ realizado por Lee et al. (2014)

Figura 30 - a) Regimes de escoamento da solução de PEO ( $C=1,0 \%$ em peso). b) Tamanho dos vórtices no regime de flutuação aperiódica variando no tempo realizado por Lee et al. (2015)

Figura 31 - Imagens com linhas de tinta à montante da constrição para o escoamento de $\lambda$-DNA e $R c=2: 1$ a) $W i=10,5$ e $E l=1,6 \times 10^{4}$. b) $W i=41,9$ e $E l=2,7 \times 10^{4}$. c) $W i=104,8$ e $E l=5,8 \times 10^{4}$. d) $W i=209,6$ e $E l=1,8 \times 10^{5}$ realizado por Gulati et al. (2008)

Figura 32 - a) Microcanais conectados em série (46 segmentos 
idênticos) de geometria elipsoidal planar. b) Microcanal de constrição cruzada. c) Microcanais conectados em série (43 segmentos idênticos) de geometria triangular planar realizado por Groisman et al. (2003) e (2004)

Figura 33 - Campo vetorial de velocidade média a) Escoamento de água b) Escoamento da solução de EHAC realizado por Boek et al. (2006) 73 Figura 34 - Campos de velocidade instantâneos consecutivos

a) Escoamento de água b) Escoamento de solução de EHAC realizado por Boek et al. (2006)

Figura 35 - Microcanal com contração hiperbólica e expansão abrupta planar. b) Queda de pressão vs. vazão c) Imagens com linhas de tinta do escoamento da solução de PEO ( $C=0,1 \%$ em peso) para diferentes vazões de injeção realizado por Neves et al. (2006)

Figura 36 - Imagens com linhas de tinta mostrando o início dos efeitos elásticos para a relação a) $L c / W c=2,4$ e b) $L c / W c=19,2$ realizado por Neves et al. (2006)

Figura 37 - Medidas da queda de pressão através da constrição reportados como viscosidade extensional aparente realizado por McKinley et al. (2007)

Figura 38 - a) Constrição de geometria contração abrupta-expansão hiperbólica. b) Regimes de escoamento realizados experimentalmente por Neves et al. (2011). c) Regimes de escoamento determinados numericamente por Alves et al. (2005)

Figura 39 - Microcanais conectados em série (42 segmentos idênticos) de geometria elipsoidal planar para duas condições de escoamento injetadas em ambas as direções. b) Perfil de velocidade axial normalizada ao longo da linha central do microcanal (5 segmentos) realizado por Sousa et al. (2011)

Figura 40 - Dispositivo microfluídico planar de entrada convexa utilizado por Gulati et al. (2015)

Figura 41 - Imagens do escoamento da solução de $\lambda$-DNA com partículas traçadoras e campos de velocidade à montante da 
constrição. a) Regime sem presença de vórtices. b) Regime com presença de vórtices realizado por Gulati et al. (2015)

Figura 42 - Dispositivo microfluídico de vidro utilizado por

Miranda (2015)

Figura 43 - a) Saturação ao final da injeção dos líquidos ( $Q=4,16 \mathrm{ml} / \mathrm{h})$.

b) Saturação de óleo residual em função do número de capilaridade realizado por Miranda (2015)

Figura 44 - Saturação de óleo residual em função do número de capilaridade (símbolos abertos: repetitividade do teste) realizado por Clarke et al. (2015)

Figura 45 - a) Dispositivo microfluídico 2D. b) Imagens com linhas de tinta dos escoamentos das soluções de glicerol e HPAM.

c) Imagem com gânglios de óleo remanescente realizado por Clarke et al. (2015)

Figura 46 - a) Dispositivo microfluídico 2D. b) Imagens com linhas de tinta do escoamento da solução de PEO. c) Imagens com linhas de tinta do escoamento de 2 soluções de HPAM realizado por Hincapie et al. (2017)

Figura 47 - Visualização das linhas de corrente em cinco poros diferentes à vazão de $30 \mu \mathrm{l} / \mathrm{min}$. a) Durante a injeção de PEO (6500 PPM sem presença de flutuações. b) Durante a injeção de HPAM (500 PPM) com presença de flutuações realizado por Hincapie et al. (2017)

Figura 48 - Resumo das diferenças entre a literatura e nossa investigação

Figura 49 - Comportamentos reológicos dos fluidos sob cisalhamento.

a) Tensão cisalhante. b) Viscosidade de cisalhamento

Figura 50 - Comportamentos reológicos dos fluidos sob taxa de deformação extensional

Figura 51 - Representação esquemática da constrição utilizada

Figura 52 - a) Dispositivo microfluídico utilizado neste trabalho.

b) Microcanal com constrição utilizado para as medidas da queda de pressão. b) Microcanal com diâmetro equivalente. c) Gráfico das 
medidas da queda de pressão em função da vazão do escoamento de água

Figura 53 - Imagem ilustrativa dos componentes de um sistema de micro-PIV

Figura 54 - a) Volume de iluminação da técnica de micro-PIV.

b) Profundidade de campo e profundidade de correlação

Figura 55 - a) Imagens sem pré-processamento. b) Imagem de fundo (ruído). c) Imagens com pré-processamento

Figura 56 - Método de correlação cruzada (Prasad, 2000)

Figura 57 - Método de correlação média. a) 5 pares de imagens consecutivas. b) 15 pares de imagens consecutivas

Figura 58 - Método do cálculo da mediana universal na etapa de pós-processamento

Figura 59 - a) Região do escoamento selecionado. b) Validação de vetores. c) Substituição de vetores

Figura 60 - Esquema da bancada experimental

Figura 61 - a) Micromodelo b) Geometria da seção transversal e da constrição

Figura 62 - Representação esquemática do processo litográfico.

Fonte: Dolomite (2012)

Figura 63 - Montagem experimental do sistema de injeção dos fluidos 116 Figura 64 - Esquema da montagem do sistema de injeção com o dispositivo microfluídico e o transdutor de pressão

Figura 65 - Montagem do transdutor de pressão diferencial

Figura 66 - a) Fonte b) Cabeça do laser Mod. SOLO III - Nd:YAG

Figura 67 - Microscópio de fluorescência e lâmpada de halogênio da Olympus $^{\circledR}$

Figura 68 - Esquema de iluminação do microscópio de fluorescência

Figura 69 - Câmera Mod. 630066 PowerView $^{\mathrm{TM}}$ da TSI ${ }^{\circledR}$

Figura 70 - Sincronizador Mod. 610034 LaserPulse da TSI ${ }^{\circledR}$

Figura 71 - Purificador de água Milli-Q ${ }^{\circledR}$

Figura 72 - Processo de preparação da solução polimérica 
Figura 74 - Pesagem da solução utilizando um picnômetro

Figura 75 - Reômetro rotacional Physica MCR 301 da Anton Paar 128

Figura 76 - Viscosidade de cisalhamento da solução polimérica

de PEO e glicerina em função da taxa de cisalhamento

Figura 77 - Reômetro extensional Haake CaBER 1 da Thermo

Fisher Scientific ${ }^{\circledR}$

Figura 78 - a) Evolução do filamento de uma amostra de PEO ( $C=0,1 \%)$

utilizando o reômetro extensional CaBER. b) Formação de gotas no filamento de uma amostra de PEO ( $C=0,1 \%)$. c) Oscilações no filamento de uma amostra de PEO $(C=0,1 \%)$ realizado por Scott (2004).

Figura 79 - Relação da variação do diâmetro do filamento da solução de PEO no tempo

Figura 80 - Viscosidade extensional da solução polimérica de PEO à $C=0,1 \%$

Figura 81 - Relação de Trouton em função do Hencky strain para a solução polimérica de $\mathrm{PEO}$ à $C=0,1 \%$

Figura 82 - Reologia da solução polimérica de PEO ( $C=0,3 \%$ e $P M=4,8 \times 10^{6} \mathrm{~g} / \mathrm{mol}$ ) diluída em água. a) Medições do diâmetro do filamento versus tempo utilizando o reômetro extensional CaBER.

b) Relação de Trouton versus Hencky strain realizado por Li e Haward (2015)

Figura 83 - Esquema da distribuição dos microcanais no micromodelo junto com as tomadas de medição da queda de pressão no microcanal com constrição

Figura 84 - Região de medição do campo de velocidade 138

Figura 85 - Plano focal para a captura de imagens

Figura 86 - Esquema dos experimentos da queda de pressão realizados

Figura 87 - Valores da queda de pressão para o escoamento de água medidos em tempo real para diferentes vazões de injeção

Figura 88 - Valores da queda de pressão da solução de glicerina e PEO medidos em tempo real para diferentes vazões de injeção 
Figura 89 - Repetibilidade das medições da queda de pressão para o escoamento de água

Figura 90 - Repetibilidade das medições da queda de pressão para a solução de glicerina

Figura 91 - Repetibilidade das medições da queda de pressão para a solução de PEO

Figura 92 - Esquema do dispositivo microfluídico utilizado neste trabalho b) Microcanal com constrição c) Microcanal com diâmetro equivalente circular. d) Gráfico das medidas da queda de pressão em função da vazão do escoamento de água na região da resposta linear $(Q<2 \mathrm{ml} / \mathrm{h})$

Figura 93 - Comparação dos valores médios experimentais da queda de pressão e os valores analíticos em função da vazão para o escoamento de água

Figura 94 - Comparação dos valores médios da queda de pressão da solução de PEO e da solução de glicerina em função da vazão

Figura 95 - Queda de pressão extra normalizada em função do número de Weissenberg

Figura 96 - Comparação dos valores de fator de Fanning experimental e teórico em função do número de Reynolds para o caso do fluido de água

Figura 97 - Comparação dos valores de fator de Fanning experimental e teórico em função do número de Reynolds para o caso da solução de glicerina

Figura 98 - Comparação dos valores de fator de Fanning experimental e teórico em função do número de Reynolds para o caso da solução polimérica de PEO

Figura 99 - Fator de Fanning experimental em função do número de Weissenberg para a solução de PEO

Figura 100 - Esquema dos experimentos dos campos de velocidade realizados

Figura 101 - Sequência de passos para determinar a concentração de microesferas e o tamanho da janela de interrogação 
Figura 102 - Sequência de passos para determinar o tempo $\Delta t$ entre dois imagens consecutivas

Figura 103 - Sequência de passos para determinar o número de pares de imagens utilizados

Figura 104 - Região do escoamento onde foi medido a velocidade média instantânea na direção axial com o tempo

Figura 105 - Velocidade média instantânea em função do tempo para o fluido de água

Figura 106 - Velocidade média instantânea em função do tempo para a solução de glicerina

Figura 107 - Velocidade média instantânea em função do tempo para a solução de PEO

Figura 108 - Esquema do dispositivo microfluídico mostrando a posição da constrição (região $A$ ), e a distância em relação às tomadas de pressão e à entrada do fluido

Figura 109 - Imagem de partículas grudadas no centro da garganta

Figura 110 - Efeito do número de pares de imagens na relação sinal/ruído do escoamento utilizando a técnica da média amostral (ensemble average)

Figura 111 - Campo vetorial de velocidade média normalizado (lado esquerdo) e linhas de corrente (lado direito) do escoamento de água para as vazões de injeção de $Q=0,2 \mathrm{ml} / \mathrm{h}, Q=0,4 \mathrm{ml} / \mathrm{h}$ e $Q=0,6 \mathrm{ml} / \mathrm{h}$

Figura 112 - Campo vetorial de velocidade média normalizado (lado esquerdo) e linhas de corrente (lado direito) do escoamento de água para as vazões de injeção de $Q=0,8 \mathrm{ml} / \mathrm{h}, Q=1,0 \mathrm{ml} / \mathrm{h}$ e $Q=2,0 \mathrm{ml} / \mathrm{h}$

Figura 113 - Campo vetorial de velocidade média normalizado (lado esquerdo) e linhas de corrente (lado direito) do escoamento de água para as vazões de injeção de $Q=3,0 \mathrm{ml} / \mathrm{h}, Q=4,0 \mathrm{ml} / \mathrm{h}$ e $Q=5,0 \mathrm{ml} / \mathrm{h}$

Figura 114 - Linhas de corrente do escoamento de água utilizando o software computacional Comsol 
Figura 115 - Campo vetorial de velocidade média normalizado para a solução de glicerina e PEO às vazões de injeção de $Q=0,02 \mathrm{ml} / \mathrm{h}$, $Q=0,04 \mathrm{ml} / \mathrm{h}$ e $Q=0,06 \mathrm{ml} / \mathrm{h}$

Figura 116 - Campo vetorial de velocidade média normalizado para a solução de glicerina e PEO às vazões de injeção de $Q=0,08 \mathrm{ml} / \mathrm{h}$, $Q=0,10 \mathrm{ml} / \mathrm{h}$ e $Q=0,12 \mathrm{ml} / \mathrm{h}$

Figura 117 - Campo vetorial de velocidade média normalizado para a solução de glicerina e PEO às vazões de injeção de $Q=0,14 \mathrm{ml} / \mathrm{h}$, $Q=0,16 \mathrm{ml} / \mathrm{h}$ e $Q=0,18 \mathrm{ml} / \mathrm{h}$

Figura 118 - Campo vetorial de velocidade média normalizado para a solução de glicerina e PEO às vazões de injeção de $Q=0,20 \mathrm{ml} / \mathrm{h}$, $Q=0,22 \mathrm{ml} / \mathrm{h}$ e $Q=0,24 \mathrm{ml} / \mathrm{h}$

Figura 119 - Campo vetorial de velocidade média normalizado para a solução de glicerina e PEO às vazões de injeção de $Q=0,26 \mathrm{ml} / \mathrm{h}$ e $Q=0,28 \mathrm{ml} / \mathrm{h}$

Figura 120 - Campo vetorial de velocidade média normalizado para a solução de glicerina e PEO às vazões de injeção de $Q=0,30 \mathrm{ml} / \mathrm{h}$ e $Q=0,32 \mathrm{ml} / \mathrm{h}$

Figura 121 - Perfil de velocidade média adimensional do escoamento da solução de glicerina e PEO em duas posições para diferentes vazões de injeção

Figura 122 - Campo vetorial de velocidade da região total (imagem superior) e da região inferior da constrição (imagem inferior) do escoamento da solução de PEO para a vazão de $Q=0,003 \mathrm{ml} / \mathrm{h}$ 184 Figura 123 - Campo vetorial de velocidade da região total (imagem superior) e da região inferior da constrição (imagem inferior) do escoamento da solução de PEO para a vazão de $Q=0,007 \mathrm{ml} / \mathrm{h}$ Figura 124 - Campo vetorial de velocidade da região total (imagem superior) e da região inferior da constrição (imagem inferior) do escoamento da solução de PEO para a vazão de $Q=0,009 \mathrm{ml} / \mathrm{h}$ 186 Figura 125 - Campo vetorial de velocidade da região total (imagem superior) e da região inferior da constrição (imagem inferior) do escoamento da solução de PEO para a vazão de $Q=0,01 \mathrm{ml} / \mathrm{h}$ 
Figura 126 - Campo do módulo de velocidade média com linhas de corrente para a solução de glicerina e $P E O$ às vazões de injeção $Q=0,02 \mathrm{ml} / \mathrm{h}, Q=0,04 \mathrm{ml} / \mathrm{h}$ e $Q=0,06 \mathrm{ml} / \mathrm{h}$

Figura 127 - Campo do módulo de velocidade média com linhas de corrente para a solução de glicerina e $P E O$ às vazões de injeção $Q=0,08 \mathrm{ml} / \mathrm{h}, Q=0,10 \mathrm{ml} / \mathrm{h}$ e $Q=0,12 \mathrm{ml} / \mathrm{h}$

Figura 128 - Campo do módulo de velocidade média com linhas de corrente para a solução de glicerina e $P E O$ às vazões de injeção $Q=0,14 \mathrm{ml} / \mathrm{h}, Q=0,16 \mathrm{ml} / \mathrm{h}$ e $Q=0,18 \mathrm{ml} / \mathrm{h}$

Figura 129 - Campo do módulo de velocidade média com linhas de corrente para a solução de glicerina e $P E O$ às vazões de injeção $Q=0,20 \mathrm{ml} / \mathrm{h}, Q=0,22 \mathrm{ml} / \mathrm{h}$ e $Q=0,24 \mathrm{ml} / \mathrm{h}$

Figura 130 - Campo do módulo de velocidade média com linhas de corrente para a solução de glicerina e $\mathrm{PEO}$ às vazões de injeção $Q=0,26 \mathrm{ml} / \mathrm{h}$ e $Q=0,28 \mathrm{ml} / \mathrm{h}$

Figura 131 - Campo do módulo de velocidade média com linhas de corrente para a solução de glicerina e PEO às vazões de injeção $Q=0,30 \mathrm{ml} / \mathrm{h}$ e $Q=0,32 \mathrm{ml} / \mathrm{h}$

Figura 132 - Campo do módulo de velocidade média da região total (imagem superior) e linhas de corrente na região inferior da constrição (imegem inferior) para o escoamento da solução de PEO à vazão de $Q=0,003 \mathrm{ml} / \mathrm{h}$

Figura 133 - Campo do módulo de velocidade média da região total (imagem superior) e linhas de corrente na região inferior da constrição (imegem inferior) para o escoamento da solução de PEO à vazão de $Q=0,007 \mathrm{ml} / \mathrm{h}$

Figura 134 - Campo do módulo de velocidade média da região total (imagem superior) e linhas de corrente na região inferior da constrição (imegem inferior) para o escoamento da solução de PEO à vazão de $Q=0,009 \mathrm{ml} / \mathrm{h}$

Figura 135 - Campo do módulo de velocidade média da região total (imagem superior) e linhas de corrente na região inferior da constrição 
(imegem inferior) para o escoamento da solução de PEO à vazão de $Q=0,01 \mathrm{ml} / \mathrm{h}$

Figura 136 - Campos instantâneos consecutivos do escoamento de água capturados à frequência de $4,8 \mathrm{~Hz}(0,2 \mathrm{~s})$ para as vazões de $Q=0,2 \mathrm{ml} / \mathrm{h}$ e $Q=5,0 \mathrm{ml} / \mathrm{h}$

Figura 137 - Diagrama mostrando os diferentes regimes de escoamento de água na faixa de Reynolds de $0,8 \leq R e \leq 20,4$

Figura 138 - Campos instantâneos consecutivos do escoamento da solução de glicerina capturados à frequência de $4,8 \mathrm{~Hz}(0,2 \mathrm{~s})$ para as vazões de $Q=0,02 \mathrm{ml} / \mathrm{h}, Q=0,08 \mathrm{ml} / \mathrm{h}, Q=0,16 \mathrm{ml} / \mathrm{h}$ e $Q=0,28 \mathrm{ml} / \mathrm{h}$ 203 Figura 139 - Diagrama mostrando o regime de escoamento da solução de glicerina na faixa de Reynolds de $0,02 \leq R e \leq 0,34$ 204 Figura 140 - Campos instantâneos consecutivos do escoamento da solução de PEO para a vazão de $Q=0,003 \mathrm{ml} / \mathrm{h}$ capturados à frequência de $4,8 \mathrm{~Hz}(0,2 \mathrm{seg}$.)

Figura 141 - Campos instantâneos consecutivos do escoamento da solução de PEO para a vazão de $Q=0,007 \mathrm{ml} / \mathrm{h}$ capturados à frequência de $4,8 \mathrm{~Hz}(0,2$ seg.)

Figura 142 - Campos instantâneos consecutivos do escoamento da solução de PEO para a vazão de $Q=0,02 \mathrm{ml} / \mathrm{h}$ em duas sequências diferentes capturados à frequência de $4,8 \mathrm{~Hz}(0,2 \mathrm{seg}$.)

Figura 143 - Campos instantâneos consecutivos do escoamento da solução de PEO para a vazão de $Q=0,08 \mathrm{ml} / \mathrm{h}$ em duas sequências diferentes capturados à frequência de $4,8 \mathrm{~Hz}(0,2 \mathrm{seg}$.)

Figura 144 - Campos instantâneos consecutivos do escoamento da solução de PEO para a vazão de $Q=0,16 \mathrm{ml} / \mathrm{h}$ em duas sequências diferentes capturados à frequência de $4,8 \mathrm{~Hz}(0,2$ seg.)

Figura 145 - Campos instantâneos consecutivos do escoamento da solução de PEO para a vazão de $Q=0,28 \mathrm{ml} / \mathrm{h}$ em duas sequências diferentes capturados à frequência de $4,8 \mathrm{~Hz}(0,2 \mathrm{seg}$.)

Figura 146 - Diagrama e sumário mostrando os regimes de escoamento da solução de PEO para o número de elasticidade de $E l=188$ 
Figura 147 - Comprimento adimensional dos vórtices em função do número de Weissenberg para a solução de PEO

Figura 148- A) Geometria da contração gradual. B) Comprimento adimendional do vórtice para um escoamento de DNA (entangled solution) realizado por Gulati et al. (2015)

Figura 149 - Queda de pressão extra adimensional da solução de PEO em função de Wi mostrando os regimes do escoamento 215 Figura 150 - Velocidade instantânea local adimensional. Para a solução de glicerina e PEO às vazões de injeção de $Q=0,02 \mathrm{ml} / \mathrm{h}$, $Q=0,04 \mathrm{ml} / \mathrm{h}, Q=0,06 \mathrm{ml} / \mathrm{h}, Q=0,08 \mathrm{ml} / \mathrm{h}, Q=0,10 \mathrm{ml} / \mathrm{h}$ e $Q=0,12 \mathrm{ml} / \mathrm{h}$

Figura 151 - Velocidade instantânea local adimensional. Para a solução de glicerina e PEO às vazões de injeção de $Q=0,14 \mathrm{ml} / \mathrm{h}$, $Q=0,16 \mathrm{ml} / \mathrm{h}, Q=0,18 \mathrm{ml} / \mathrm{h}, Q=0,20 \mathrm{ml} / \mathrm{h}, Q=0,22 \mathrm{ml} / \mathrm{h}$ e $Q=0,24 \mathrm{ml} / \mathrm{h} \quad 218$ Figura 152 - Velocidade instantânea local adimensional. Para a solução de glicerina e PEO às vazões de injeção de $Q=0,26 \mathrm{ml} / \mathrm{h}$, $Q=0,28 \mathrm{ml} / \mathrm{h}, Q=0,30 \mathrm{ml} / \mathrm{h}$ e $Q=0,32 \mathrm{ml} / \mathrm{h}$

Figura 153 - Velocidade instantânea local adimensional (média de 500 valores) em função da vazão para as soluções de glicerina e PEO Figura 154 - Comparação da queda de pressão extra e o aumento da velocidade instantânea local em função da vazão

Figura 155 - Campo de desvio para a solução de glicerina e PEO às vazões de injeção $Q=0,02 \mathrm{ml} / \mathrm{h}, Q=0,04 \mathrm{ml} / \mathrm{h}$ e $Q=0,06 \mathrm{ml} / \mathrm{h}$ Figura 156 - Campo de desvio para a solução de glicerina e PEO às vazões de injeção $Q=0,08 \mathrm{ml} / \mathrm{h}, Q=0,10 \mathrm{ml} / \mathrm{h}$ e $Q=0,12 \mathrm{ml} / \mathrm{h}$

Figura 157 - Campo de desvio para a solução de glicerina e PEO às vazões de injeção $Q=0,14 \mathrm{ml} / \mathrm{h}, Q=0,16 \mathrm{ml} / \mathrm{h}$ e $Q=0,18 \mathrm{ml} / \mathrm{h}$

Figura 158 - Campo de desvio para a solução de glicerina e PEO às vazões de injeção $Q=0,20 \mathrm{ml} / \mathrm{h}, Q=0,22 \mathrm{ml} / \mathrm{h}$ e $Q=0,24 \mathrm{ml} / \mathrm{h}$ Figura 159 - Campo de desvio para a solução de glicerina e PEO às vazões de injeção $Q=0,26 \mathrm{ml} / \mathrm{h}$ e $Q=0,28 \mathrm{ml} / \mathrm{h}$

Figura 160 - Campo de desvio para a solução de glicerina e PEO às vazões de injeção $Q=0,30 \mathrm{ml} / \mathrm{h}$ e $Q=0,32 \mathrm{ml} / \mathrm{h}$

Figura 161 - Campo de desvio padrão na direção axial e perpendicular 
do escoamento da solução de glicerina para a vazão de injeção de $Q=0,32 \mathrm{ml} / \mathrm{h}$

Figura 162 - Campo de desvio padrão na direção axial e perpendicular do escoamento da solução de PEO para a vazão de injeção de $Q=0,32 \mathrm{ml} / \mathrm{h}$

Figura 163 - Campo de desvio padrão. (a) Solução de glicerol de $84 \%$ em peso (b) Solução de 3630 S HPAM de $0,12 \%$ em peso realizado por Clarke et al. (2015)

Figura 164 - Taxa de deformação para a solução de glicerina e PEO às vazões de injeção $Q=0,02 \mathrm{ml} / \mathrm{h}, Q=0,04 \mathrm{ml} / \mathrm{h}$ e $Q=0,06 \mathrm{ml} / \mathrm{h}$ Figura 165 - Taxa de deformação para a solução de glicerina e PEO às vazões de injeção $Q=0,08 \mathrm{ml} / \mathrm{h}, Q=0,10 \mathrm{ml} / \mathrm{h}$ e $Q=0,12 \mathrm{ml} / \mathrm{h}$ 233 Figura 166 - Taxa de deformação para a solução de glicerina e PEO às vazões de injeção $Q=0,14 \mathrm{ml} / \mathrm{h}, Q=0,16 \mathrm{ml} / \mathrm{h}$ e $Q=0,18 \mathrm{ml} / \mathrm{h}$ Figura 167 - Taxa de deformação para a solução de glicerina e PEO às vazões de injeção $Q=0,20 \mathrm{ml} / \mathrm{h}, Q=0,22 \mathrm{ml} / \mathrm{h}$ e $Q=0,24 \mathrm{ml} / \mathrm{h}$ 235 Figura 168 - Taxa de deformação para a solução de glicerina e PEO às vazões de injeção $Q=0,26 \mathrm{ml} / \mathrm{h}$ e $Q=0,28 \mathrm{ml} / \mathrm{h}$ 236 Figura 169 - Taxa de deformação para a solução de glicerina e PEO às vazões de injeção $Q=0,30 \mathrm{ml} / \mathrm{h}$ e $Q=0,32 \mathrm{ml} / \mathrm{h}$

Figura 170 - Bancada experimental de calibração do transdutor de pressão. b) Montagem do sistema de injeção 


\section{Lista de tabelas}

Tabela 1 - Sumário das principais referências bibliográficas 44

Tabela 2 - Classificação da geometria de um poro 114

Tabela 3 - Propriedades da água deionizada Milli-Q a 23ํㅡ 123

$\begin{array}{ll}\text { Tabela } 4 \text { - Massa especifica das soluções aquosas } & 127\end{array}$

Tabela 5 - Coeficientes do modelo Carreau-Yasuda para a solução

$\begin{array}{ll}\text { polimérica de PEO } & 129\end{array}$

Tabela 6 - Valores das taxas de extensão e números de Weissenberg

para a solução viscoelástica de PEO a diferentes condições de fluxo 151

Tabela 7 - Faixa de valores do tempo $\Delta t$ entre duas imagens

$\begin{array}{ll}\text { consecutivas } & 161\end{array}$

Tabela 8 - Resumo dos padrões do escoamento da solução polimérica de PEO relacionado com as medidas da queda de pressão e os vórtices à montante da constrição. 


\section{Nomenclatura}

\section{Caracteres gregos}

$\eta \quad-\quad$ Viscosidade intrínseca [Pa.s].

$\eta_{s} \quad$ - Viscosidade do solvente [Pa.s].

$\mu \quad$ - Viscosidade dinâmica [Pa.s].

$\mu_{c} \quad$ - Viscosidade de cisalhamento [Pa.s].

$\mu_{c(j=0)}$ - Viscosidade de cisalhamento à taxa de cisalhamento zero [Pa.s].

$\mu_{c(\dot{\gamma}=\infty)}{ }^{-} \quad$ Viscosidade de cisalhamento à taxa de cisalhamento infinito [Pa.s].

$\mu_{\text {ext }} \quad$ - Viscosidade extensional [Pa.s].

$\mu_{\text {ext }(t)} \quad$ - Viscosidade extensional variando com o tempo [Pa.s].

$\mu_{\text {ext }(\dot{\varepsilon})}$ - Viscosidade extensional variando com a taxa de extensão [Pa.s].

$\lambda \quad$ - Tempo de relaxação [ms].

$\lambda_{\text {CaBER - }} \quad$ Tempo de relaxação determinado através do CaBER [ms].

$\lambda_{C Y s} \quad$ - Tempo de relaxação do modelo Carreau-Yasuda [ms].

$\lambda_{\text {glicerina }^{-}} \quad$ Tempo de relaxação da solução de glicerina [ms].

$\lambda_{\text {Zimm }} \quad$ - Tempo de relaxação determinado através da teoria de Zimm [ms].

$\lambda_{0} \quad$ - $\quad$ Comprimento de onda da luz no vácuo [m].

$\dot{\varepsilon} \quad$ - $\quad$ Taxa de extensão [1/s].

$\dot{\varepsilon}(t) \quad$ - Taxa de extensão em função do tempo [1/s].

$\varepsilon(t) \quad$ - Hencky strain.

$\varepsilon_{B} \quad-\quad$ Erro relativo devido ao movimento Browniano.

$\rho \quad$ - Massa específica do fluido $\left[\mathrm{kg} / \mathrm{m}^{3}\right]$.

$\rho_{p} \quad$ - Densidade da partícula $\left[\mathrm{kg} / \mathrm{m}^{3}\right]$.

$\Delta P \quad$ - $\quad$ Queda de pressão $[\mathrm{Pa}]$.

$\Delta t \quad$ - $\quad$ Tempo de captura entre duas imagens consecutivas [s].

$\delta z \quad-\quad$ Profundidade de campo da lente de objetiva $[\mu \mathrm{m}]$.

$\sigma_{\text {sup }} \quad$ - Tensão superficial da solução polimérica [N/m].

$\tau \quad$ - Tensão cisalhante $\left[\mathrm{N} / \mathrm{m}^{2}\right]$.

$\gamma \quad$ - Taxa de cisalhamento [1/s].

$\beta \quad$ - $\quad$ Constante de distribuição de probabilidade. 


\section{Caracteres latinos}

$2 Z_{\text {corr }}$ - $\quad$ Profundidade de correlação $[\mu \mathrm{m}]$.

$a \quad$ - $\quad$ Constante da equação de Mark-Houwink-Sakurada.

$b \quad$ - $\quad$ Constante da equação de Mark-Houwink-Sakurada.

$B_{o} \quad$ - $\quad$ Número de Bond.

$C \quad$ - Concentração do polímero em peso $[\mathrm{g} / \mathrm{g}]$.

$C^{*} \quad$ - $\quad$ Concentração crítica da solução em peso [PPM/PPM].

CV - $\quad$ Coeficiente de variação.

$d_{e} \quad$ - Diâmetro efetivo da partícula no plano focal da imagem $[\mu \mathrm{m}]$.

$d_{p} \quad$ - Diâmetro da partícula $[\mu \mathrm{m}]$.

$D \quad$ - Diâmetro do microcanal ou tubo circular $[\mu \mathrm{m}]$.

Dc - Diâmetro constante da constrição de seção axissimétrica $[\mu \mathrm{m}]$.

$D_{e q} \quad$ - Diâmetro equivalente $[\mu \mathrm{m}]$.

$D_{f} \quad$ - $\quad$ Coeficiente de difusão da partícula $\left[\mathrm{m}^{2} / \mathrm{s}\right]$.

$D_{f i l}(t)$ - Diâmetro do filamento em função do tempo [mm].

$D_{\text {fil }}(0)$ - Diâmetro inicial do filamento [mm].

$D_{\min } \quad$ - Diâmetro mínimo da constrição de seção axissimétrica $[\mu \mathrm{m}]$.

$D_{v} \quad$ - Difusividade das partículas $\left[\mathrm{m}^{2} / \mathrm{s}\right]$.

$e \quad-\quad$ Menor tamanho característico na imagem do microscópio $[\mu \mathrm{m}]$.

$g \quad$ - Gravidade $\left[\mathrm{m} / \mathrm{s}^{2}\right]$.

$G \quad$ - $\quad$ Módulo elástico do filamento $[\mathrm{Pa}]$.

$h \quad$ - $\quad$ Profundidade do microcanal na direção $[\mu \mathrm{m}]$.

$K \quad$ - $\quad$ Coeficiente de consistência da equação de power law.

$K_{B} \quad$ - $\quad$ Constante de Boltzmann [J/K].

$L \quad$ - Comprimento do microcanal com constrição $[\mu \mathrm{m}]$.

$L c \quad$ - $\quad$ Comprimento da contrição $[\mu \mathrm{m}]$.

$L_{e} \quad$ - $\quad$ Comprimento de desenvolvimento hidrodinâmico $[\mu \mathrm{m}]$.

Lv - Comprimento do vórtice $[\mu \mathrm{m}]$.

$M \quad$ - Magnificação total da lente.

$n \quad$ - $\quad$ Índice de escoamento.

$n_{r} \quad$ - $\quad$ Índice de refração.

$N \quad$ - $\quad$ Número total de partículas na janela de interrogação.

NA - $\quad$ Abertura numérica da lente da objetiva. 


\begin{tabular}{|c|c|c|}
\hline$N_{A}$ & - & Número de Avogadro [1/mol]. \\
\hline$P M$ & - & Peso molecular do polímero [g/mol]. \\
\hline$P c$ & - & Pressão capilar $[\mathrm{Pa}]$. \\
\hline$Q$ & - & Vazão $[\mathrm{ml} / \mathrm{h}]$. \\
\hline$Q_{\text {crit }}$ & - & Vazão crítica $[\mathrm{ml} / \mathrm{h}]$. \\
\hline$r_{c}$ & - & Raio de curvatura dos cantos na constrição abrupta $[\mu \mathrm{m}]$. \\
\hline$r_{o}$ & - & Raio da placa circular do reômetro CaBER $[\mu \mathrm{m}]$. \\
\hline$R$ & - & Raio do microcanal $[\mu \mathrm{m}]$. \\
\hline$t$ & - & Tempo $[\mathrm{s}]$. \\
\hline$t_{c}$ & - & Tempo característico do escoamento $[\mu \mathrm{m}]$. \\
\hline$t_{p}$ & - & Tempo de resposta da partícula $[\mu \mathrm{m}]$. \\
\hline$T$ & - & Temperatura absoluta $[\mathrm{K}]$ \\
\hline$U$ & - & Campo de velocidade média do escoamento. \\
\hline$U_{e}$ & - & Velocidade média à entrada da constrição [m/s]. \\
\hline$U m$ & - & Velocidade média do escoamento [m/s]. \\
\hline$U_{r}$ & - & Velocidade média no diâmetro mínimo da constrição [m/s]. \\
\hline$U x$ & - & Velocidade instantânea na direção axial do escoamento [m/s]. \\
\hline$W$ & - & Largura da entrada do microcanal de seção planar $[\mu \mathrm{m}]$. \\
\hline$W c$ & - & Largura constante da constrição de seção planar $[\mu \mathrm{m}]$. \\
\hline $\mathrm{X}$ & - & Direção axial do escoamento. \\
\hline $\mathrm{Y}$ & - & Direção perpendicular do escoamento. \\
\hline$z$ & - & Distância na direção z do plano focal (profundidade). \\
\hline
\end{tabular}

\section{Adimensionais}

$\varepsilon_{r} \quad$ - $\quad$ Relação entre o diâmetro efetivo da partícula no plano focal e na profundidade de correlação.

$\chi \quad$ - Comprimento adimensional do vórtice.

$\chi_{i} \quad$ - $\quad$ Comprimento adimensional do vórtice inferior.

$\chi_{s} \quad$ - Comprimento adimensional do vórtice superior.

$\Delta P_{N} \quad$ - $\quad$ Queda de pressão extra normalizada.

De - $\quad$ Número de Deborah.

$D e_{\text {crit }}$ - $\quad$ Número de Deborah crítico. 
El - $\quad$ Número de elasticidade.

$f \quad$ - $\quad$ Fator de Fanning.

$R a \quad$ - Relação de aspecto.

$R c \quad$ - Relação de contração.

Re - $\quad$ Número de Reynolds.

$R e_{\text {crit }} \quad$ - Número de Reynolds crítico.

$R e_{\text {vort }}$ - $\quad$ Número de Reynolds em que inicia a formação de vórtices.

Stk - Número de Stokes.

$\operatorname{Tr} \quad$ - $\quad$ Número de Trouton.

Wi - Número de Weissenberg.

$W i_{c r i t} \quad$ - Número de Weissenberg crítico.

$W i_{\text {vort }}$ - $\quad$ Número de Weissenberg em que inicia a formação de vórtices.

\section{Siglas}

CaBER- Capillary Break-up Extensional Rheometer.

DNA - Deoxyribonucleic acid.

DPIV - Velocimetria de imagem por partículas digital.

EHAC - Erucylbis (hydroxyethyl) methylammonium chloride.

EOR - $\quad$ Enhanced Oil Recovery.

FENE - $\quad$ Finite extensible nonlinear elastic.

FFT - $\quad$ Transformada rápida de Fourier.

FS - Full Scale.

HPAM - Hydrolyzed polyacrylamide.

LDV - Velocimetria Laser doppler.

LT - Lattice Boltzmann.

Nd:YAG Neodymium-doped yttrium aluminum garnet.

OOIP - Original oil in place.

PDMS - Polydimethylsiloxane.

PEO - Óxido de polietileno.

PIV - Velocimetria por imagem de partículas.

PMMA- Poly(methyl methacrylate).

PPAm - Polyacrylamide.

PPM - Partes por milhão. 
PPT - Phan-Thien-Tanner.

PTV - Velocimetria de rastreamento de partículas.

RPM - $\quad$ Revoluções por minuto.

SNR - $\quad$ Relação de sinal/ruído.

UCM - Maxwell Convectado Superior. 


\section{Introdução}

Atualmente, o petróleo é o responsável por aproximadamente $30 \%$ da energia consumida no mundo e a demanda da energia primaria mundial vai aumentar como resultado do crescimento da população. Uma projeção dessa demanda é representada na figura 1 (Shell, 2016). Devido a esses cenários, as companhias petroleiras estão investindo no desenvolvimento de novas tecnologias e técnicas de extração que busquem maximizar o fator de recuperação de petróleo dos reservatórios com o menor impacto possível sobre o meio ambiente.

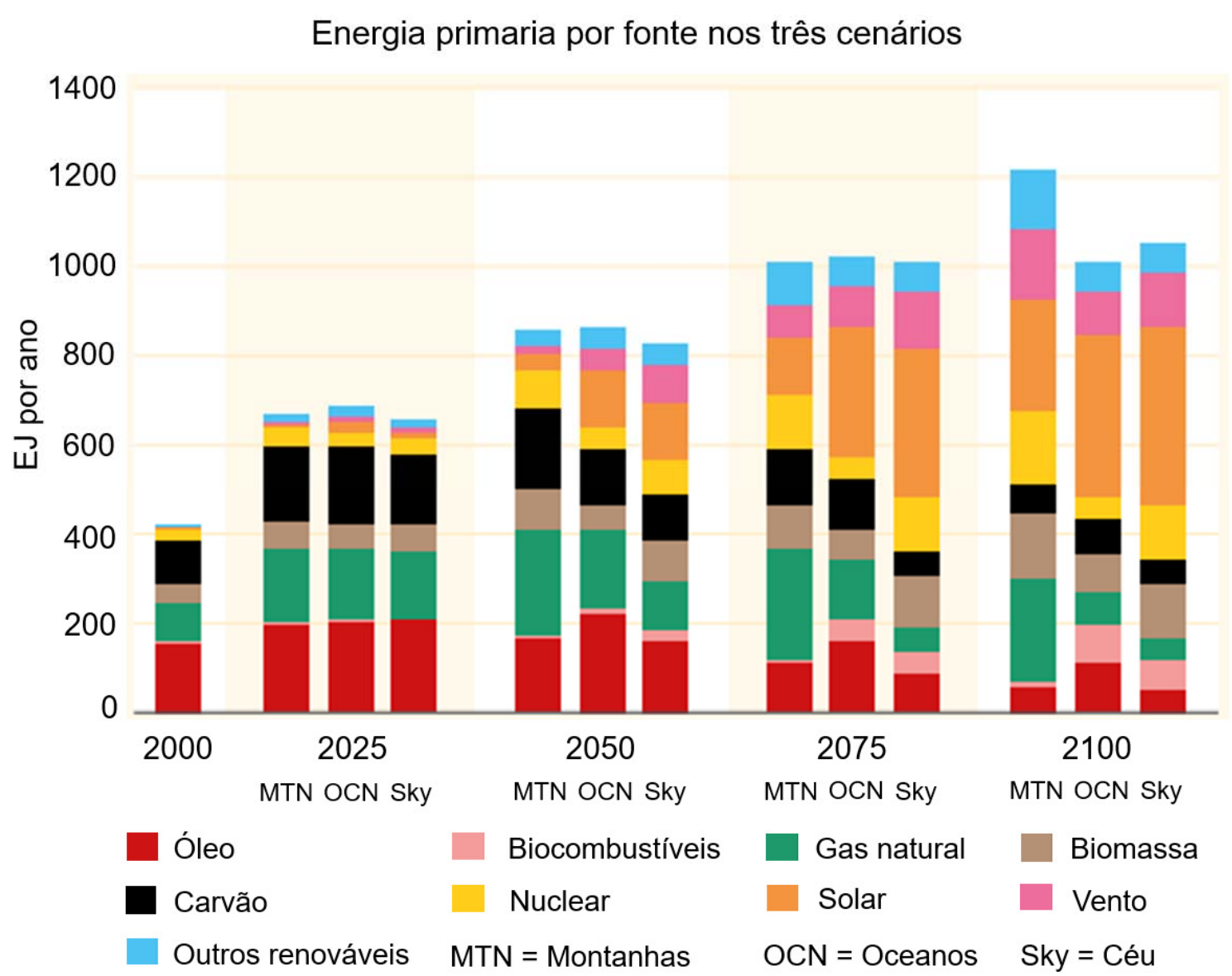

Figura 1 - Demanda de energia primaria projetada. Fonte: Shell (2016) 
A extração de petróleo é iniciada utilizando a energia de formação original do reservatório no chamado de método de recuperação primaria. Depois, um método de recuperação secundaria é utilizado para manter o gradiente de pressão entre o reservatório e o poço de produção.

O método de recuperação secundaria por injeção de água é amplamente utilizado devido a seu baixo custo operacional quando comparado com outros métodos de recuperação. Não obstante, a técnica é limitada devido a sua alta relação de mobilidade entre o óleo e a água, formando frentes de avanços não uniformes (Homsy, 1987) que causam a redução da eficiência de volume de óleo produzido e uma produção de grandes volumes de água (Ashraf et al., 2012). O valor de recuperação dos métodos de recuperação secundaria varia em torno de 30-50\% OOIP (Original oil in place). Os métodos de recuperação melhorada de petróleo EOR são utilizados para incrementar a produção de óleo.

A injeção de soluções poliméricas aumenta a viscosidade da fase aquosa e reduz a razão de mobilidade entre o fluido deslocante (água) e o fluido deslocado (óleo). Uma melhor eficiência de varredura pode ser alcançada e, consequentemente, reduzir o volume de óleo remanescente no reservatório e o volume de água produzido. A figura 2 representa a evolução da frente de deslocamento para a injeção de água e a injeção de polímero. Percebe-se claramente uma frente mais uniforme no caso da injeção de solução polimérica.

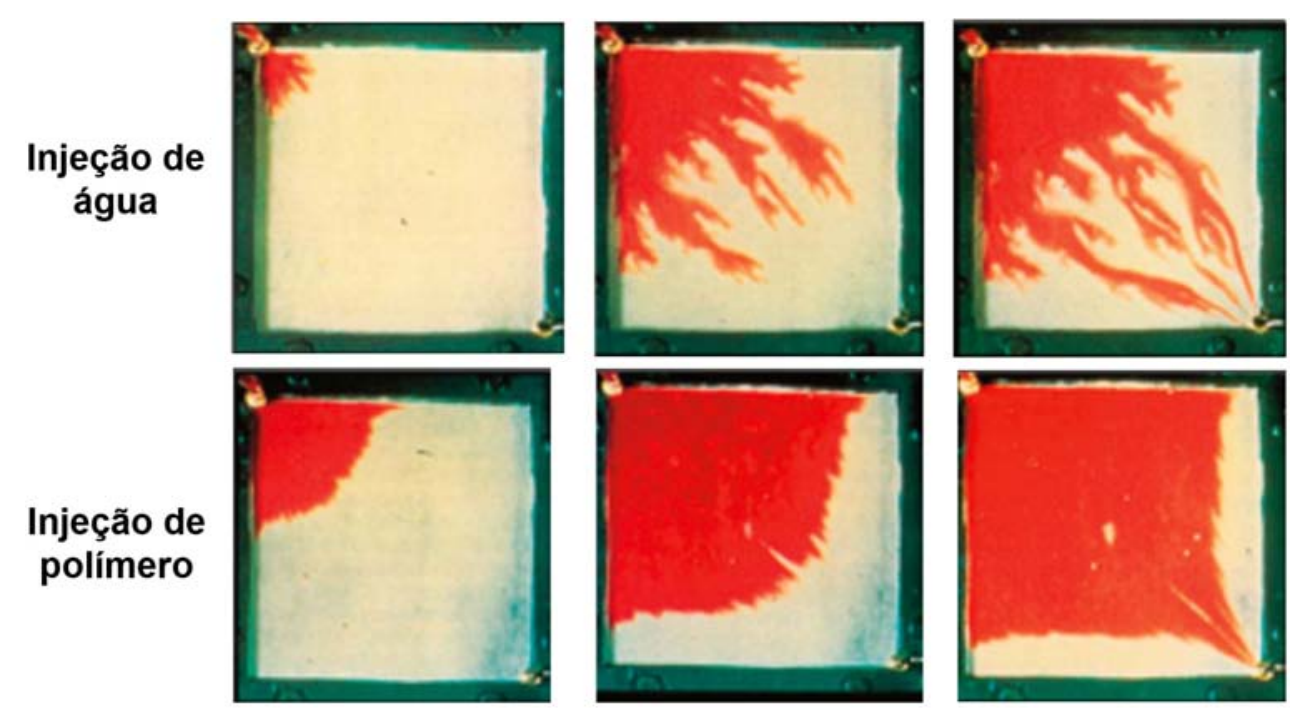

Figura 2 - Frente de deslocamento de água e polímero realizado por Sheng (2012) 
$\mathrm{O}$ aumento da viscosidade da fase aquosa leva a maiores diferenças de pressão, contribuindo para mobilização de gânglios de óleo presos por forças capilares dentro dos poros dos reservatórios. Um gânglio de óleo retido pode ser deslocado caso a diferença de pressão $\Delta P$ nas extremidades do gânglio de óleo definida pelo escoamento da fase aquosa, seja maior do que a pressão capilar $P c$, conforme apresentado no esquema da figura 3.
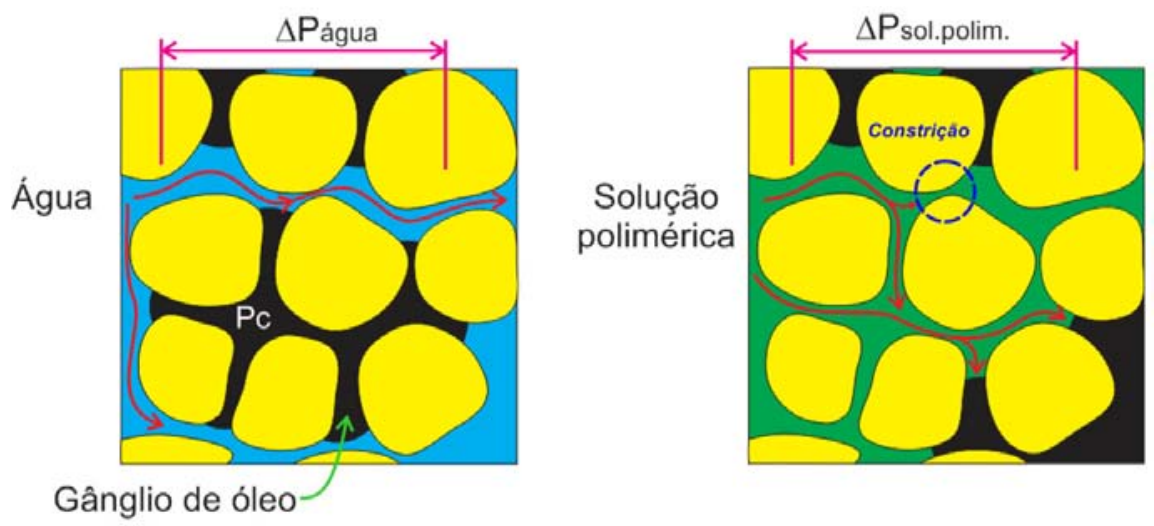

Figura 3 - a) Gânglio de óleo preso por forças capilares na injeção de água. b) Gânglio de óleo deslocado pela injeção da solução polimérica (Miranda, 2015)

No Brasil, a injeção de soluções poliméricas iniciou-se nos campos de Carmópolis (1969-1972 e 1997), Buracica (1999) e Canto do Amaro (2001) no nordeste do Brasil, com a finalidade de aumentar a produção de petróleo e reduzir os grandes volumes de produção de água. Maiores detalhes quanto aos resultados da produção são encontrados no trabalho de Melo et al. (2017), que discute aplicações de injeção do polímero no Brasil. Todos os projetos pilotos apresentaram um ganho de óleo e redução da produção de água, embora os ganhos de óleo foram inversamente proporcionais à quantidade de polímero injetado. $\mathrm{O}$ escoamento de soluções poliméricas através de um meio poroso é complexo, já que as moléculas experimentam ambas as deformações extensional e cisalhamento. Portanto, os mecanismos que governam a dinâmica dos fluidos dentro do reservatório ainda não são bem entendidos e as propriedades viscoelásticas das soluções poliméricas podem alterar o regime de escoamento na escala de poros.

Para o entendimento dos fenômenos envolvidos na injeção de soluções de polímero dentro das formações rochosas de geometria complexa nos reservatórios, 
investigações experimentais são realizadas em laboratórios utilizando estruturas 3D (rochas de arenito, estruturas não consolidadas de esferas de vidro, etc.) e dispositivos microfluídicos 2D (rede de poros e microcanais) com dimensões comparáveis ao tamanho dos poros nas rochas naturais. O desenvolvimento tecnológico da microfluídica tornou-se uma ferramenta importante nas investigações de escoamento em meios porosos e recuperação de petróleo.

\section{1.}

\section{Microfluídica}

A microfluídica é uma área da mecânica dos fluidos e fenômenos de transporte focada nos estudos dos fenômenos físicos em pequenas escalas (micro ou nanolitro). A técnica de microfluídica é empregada em várias aplicações tais como análises químicas (lab-on-a-chip, microrreação), operações biológicas, farmacêutica (processos de controle de qualidade, descoberta de drogas), biotecnologia (chips de DNA e de proteínas), tecnologia ambiental (solo, medições de qualidade de água e ar), indústria de alimentos (diagnóstico de alimentos), indústria eletrônica (impressão por jato de tinta, resfriamento de componentes eletrônicos), indústria de automóveis (injeção de combustível, monitoramento da qualidade do óleo, análises de gases de escape), na indústria de óleo e gás, entre outras. A análise e estudo dos fluidos é realizado através de dispositivos microfluídicos que transportam os fluidos por microcanais de diferentes geometrias e tamanhos. Nos últimos anos, a demanda dos dispositivos microfluídicos cresceu rapidamente na indústria e nas investigações cientificas, como esquematizada na figura 4. 


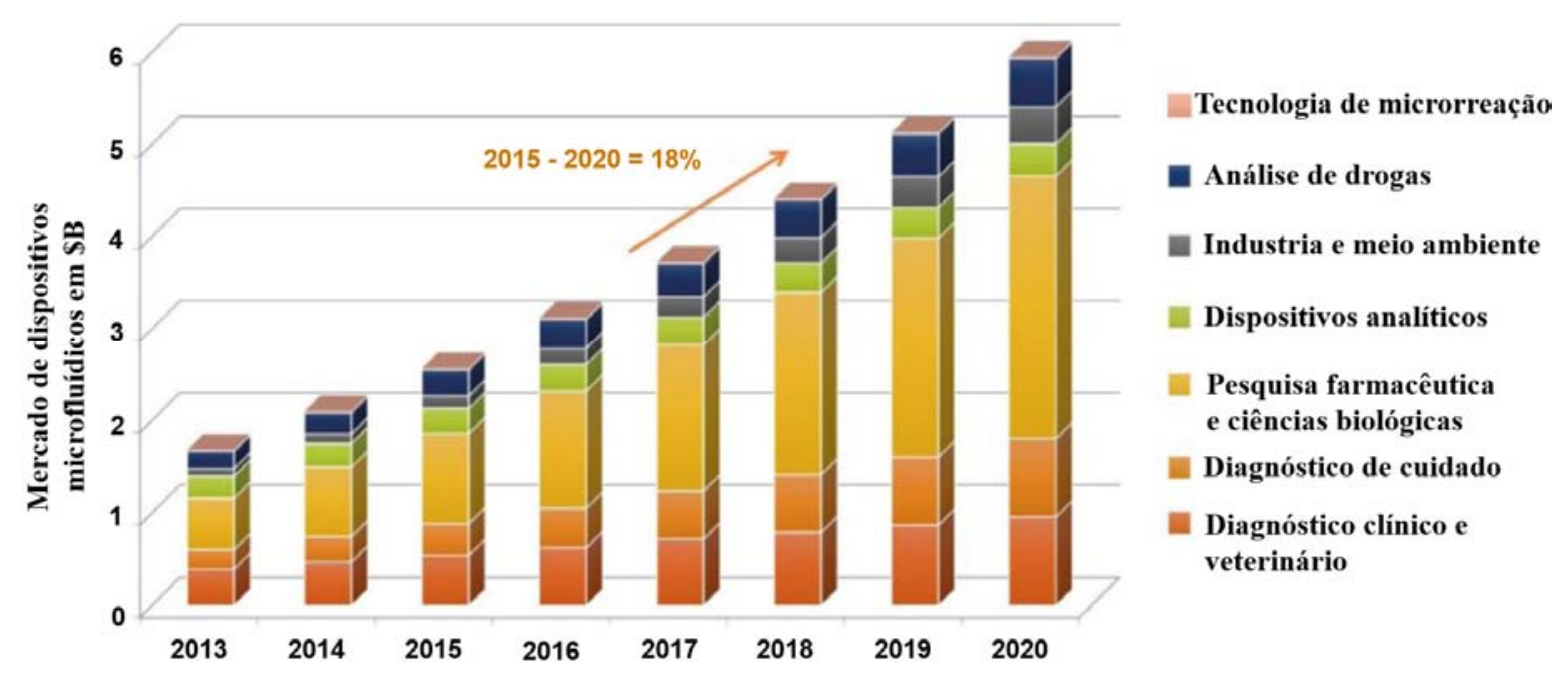

Figura 4 - Demanda de dispositivos microfluídicos. Fonte: Yole (2015)

Os dispositivos microfluídicos para o controle e a análise dos fluidos oferecem vários benefícios tais como:

Capacidade de trabalhar com pequena quantidade de volume de fluidos, reagentes, pequeno tamanho de partículas e um rápido tempo de reação.

Capacidade de trabalhar com diferentes propriedades de superfície do microcanal tais como hidrofílico, hidrofóbico, entre outros.

$>$ Dispositivos microfluídicos com diferentes geometrias do microcanal (reto, constrição abrupta, assimétrico, entre outros).

Maiores relações de superfície/volume tornam mais eficiente a transferência de calor, massa e quantidade de movimento nos microcanais (Peng e Peterson 1996).

Nos sistemas microfluídicos, o escoamento é tipicamente laminar devido às pequenas dimensões dos microcanais e às baixas velocidades do fluxo, reproduzindo uma excelente reprodutibilidade e consistência de resultados.

Integração de diferentes etapas de processos como: reações, separações, detecção e mistura de fluidos. 
Diferentes materiais são utilizados na fabricação de dispositivos microfluídicos, tais como silicone, vidro, polímeros (PDMS), metais e cerâmicas. O material utilizado nos microcanais é importante no estudo dos fluidos, por exemplo, materiais mais rígidos (vidro) permitem estudar fluidos de maior viscosidade sem deformação da geometria e maiores faixas de taxa de deformação. As técnicas utilizadas para a fabricação de dispositivos incluem micro mecanização, litografia, gravação em relevo, construção in situ e moldagem por injeção e depende da aplicação do dispositivo. Maiores detalhes sobre as técnicas são encontrados nos trabalhos de Beebe et al. (2002), Nguyen e Wereley (2006) e Tian e Finehout (2008).

A seguinte seção apresenta como a microfluídica é utilizada no estudo da dinâmica de fluidos complexos.

\subsection{1. \\ Escoamentos em microcanais com constrição}

Os escoamentos secundários (vórtices) foram observados em escoamentos de fluidos viscosos e fluidos viscoelásticos através de constrições, dependendo do fenômeno que originou essas formações. A figura 5 representa um esquema dos efeitos inerciais e efeitos elásticos na formação de vórtices para um escoamento de água e um escoamento de solução viscoelástica de óxido de polietileno (PEO) através de um canal com constrição, com o utilizado neste trabalho. 


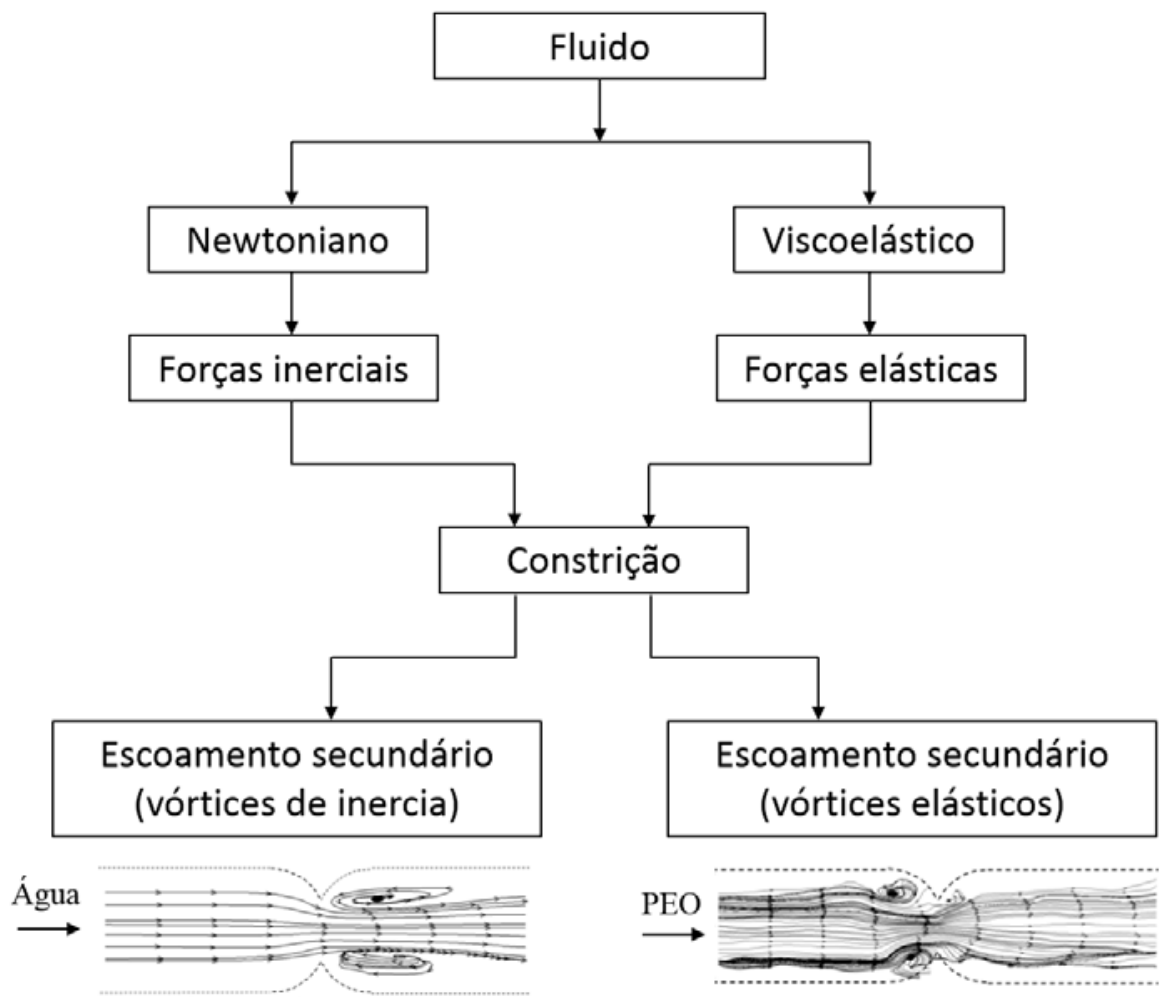

Figura 5 - Representação esquemática da formação de vórtices em fluxos Newtonianos e não Newtonianos escoando por uma constrição em particular

Nos escoamentos Newtonianos, a formação de vórtices é originada quando as forças inerciais se tornam fortes o suficiente. A saída do escoamento da garganta apresenta características de um jato. Nos escoamentos viscoelásticos, o aumento da viscosidade extensional leva a formação de vórtices à montante da garganta. As moléculas do polímero são esticadas no escoamento de cisalhamento principal, tornando-o instável e causando um escoamento secundário irregular. A densidade da energia elástica das cadeias poliméricas esticadas é aumentada no fluxo turbulento elástico, enquanto, a energia cinética permanece pequena.

A presença, o crescimento e supressão dos vórtices são uma característica importante do escoamento de fluidos viscoelásticos que depende da geometria do microcanal e das propriedades reológicas dos fluidos viscoelásticos.

As figuras 6 e 7 ilustram a constrição abrupta planar utilizada na maioria dos experimentos em escoamento de soluções viscoelásticas através de uma constrição (contração-expansão) e a geometria utilizada em nossos experimentos, com contração e expansão mais gradual, mostrando as dimensões características de ambas as geometrias. As eq. (1-8) representam os parâmetros geométricos adimensionais. 
Tipo de constrição

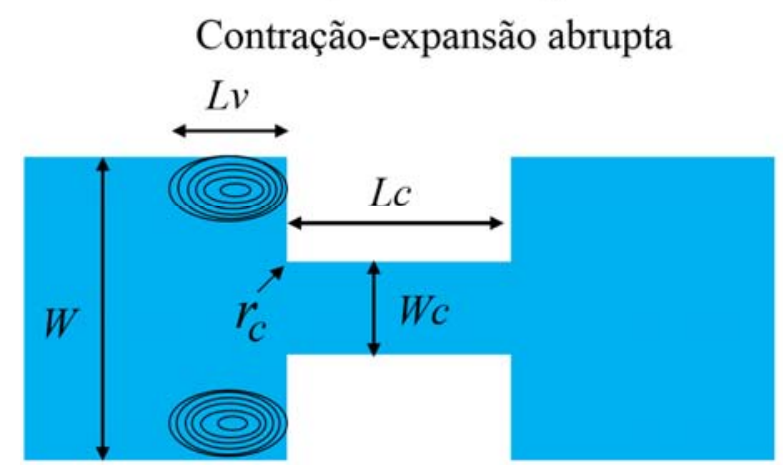

Seção transversal

(constrição)

Planar

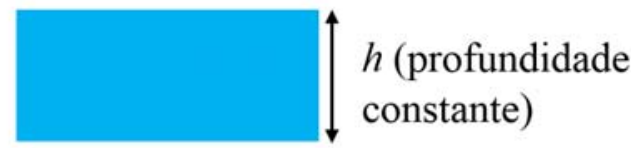

Figura 6 - Representação esquemática de uma constrição abrupta planar

$$
\begin{aligned}
& R c=\frac{\text { larg ura da entrada }}{l \arg \text { ura da constrição }}=\frac{W}{W c}, \\
& R a=\frac{\text { profundidade da constrição }}{\text { larg ura da constrição }}=\frac{h}{W c},
\end{aligned}
$$

$\frac{\text { Comprimento da constrição }}{\text { larg ura da constrição }}=\frac{L c}{W c}$,

$$
\chi=\frac{\text { comprimento do vórtice }}{\text { larg ura da entrada }}=\frac{L v}{W},
$$

Tipo de constrição

Contração-expansão gradual

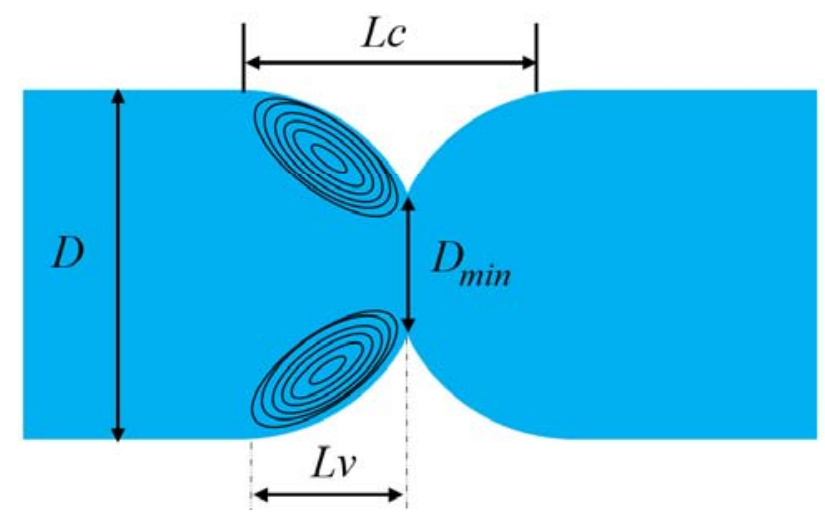

Seção transversal (constrição)

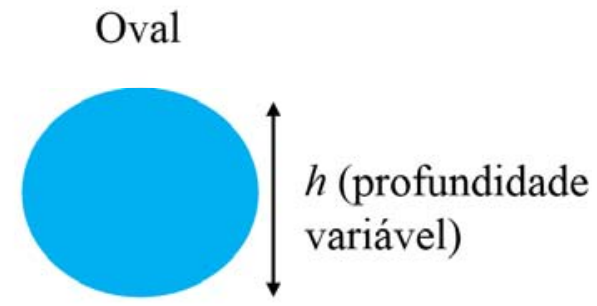

Figura 7 - Representação esquemática da constrição utilizada em nossos experimentos 


$$
\begin{aligned}
& R c=\frac{\text { Diâmetro da entrada }}{\text { Diâmetro mínimo da constrição }}=\frac{D}{D_{\text {min }}}, \\
& R a=\frac{\text { profundidade da constrição }}{l \text { arg ura da constrição }}=\frac{h(\text { variável })}{D(\text { var iável })}, \\
& \frac{\text { Comprimento da constrição }}{\text { larg ura da constrição }}=\frac{L c}{D(\text { var iável })}, \\
& \chi=\frac{\text { comprimento do vórtice }}{\text { Diâmetro da entrada }}=\frac{L v}{D} .
\end{aligned}
$$

Onde, $R c$ é a relação de contração, $R a$ é a relação de aspecto, $\chi$ é o comprimento adimensional do vórtice e $r_{c}$ é o raio de curvatura dos cantos reentrantes.

Para estudar os efeitos elásticos das soluções viscoelásticas geralmente variam os parâmetros geométricos da constrição, as propriedades das soluções e as condições do escoamento. Todas essas condições impostas no escoamento são embutidas em três parâmetros adimensionais: o número de Reynolds $R e$, o número de Weissenberg Wi e o número de elasticidade $E l$ que são as variáveis de entrada. As variáveis de saída são utilizadas para avaliar e quantificar os efeitos elásticos em escoamentos através de constrições, como apresentada no esquema da figura 8.

\section{Parâmetros geométricos}

Relação de contração: $R c$

Relação de aspecto: $R a$

Comprimento/largura da constrição

Propriedades do fluido viscoelástico

$>$ Tipo de polímero

$>$ Peso molecular do polímero: $P M$

Concentração do polímero: $C$

Concentração do solvente: $C$

\section{Condições do escoamento}

Velocidade ou vazão de injeção $Q$

$$
\begin{array}{cc}
\text { Variáveis de } & \text { Variáveis de } \\
\text { entrada } & \text { saída }
\end{array}
$$

Padrões de escoamento.

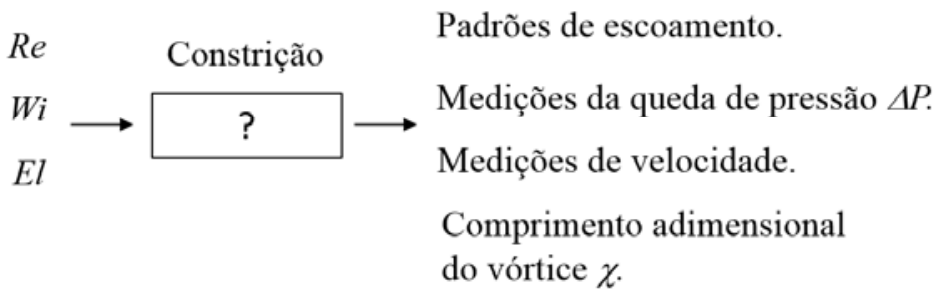

Figura 8 - Variáveis utilizadas geralmente no estudo de escoamentos viscoelásticos 
Devido aos diferentes parâmetros geométricos, diferentes propriedades do fluido viscoelástico e diferentes condições de escoamento existem uma grande variedade de padrões do escoamento viscoelástico passando através de contrições, desde um escoamento tipo Newtoniano para um escoamento com flutuações de velocidade (instabilidade) devido à elasticidade do fluido.

Como sabido na escala macro, quando um fluido Newtoniano escoa através de um tubo circular a altas velocidades (altos números de Reynolds) apresenta um comportamento turbulento, caracterizado por flutuações de pressão e velocidade do escoamento no tempo devido à inercia do fluido (Landau e Lifshitz 1987), que tem sua origem na tensão de Reynolds, na qual está associado com uma alta energia cinética do movimento turbulento e levando um papel importante na transferência de momento no fluxo. Na escala micro, as soluções poliméricas apresentam similar comportamento de instabilidade a partir de um número de Weissenberg crítico Wi $i_{c r i t}$ ou número de Deborah crítico De crit. Esta instabilidade do escoamento ocorre a baixos números de Reynolds Re, sendo manifestado também através de oscilação de velocidade e pressão. Alguns investigadores chamam este fenômeno de turbulência elástica (Groisman e Steinberg 2000), que vai acompanhado de um alongamento significativo das moléculas do polímero, resultando em um aumento nas tensões elásticas.

\section{2.}

\section{Revisão da literatura}

O conteúdo da revisão bibliográfica refere-se ao estudo de escoamentos de fluidos complexos através de diferentes geometrias e tamanhos de canais e é resumido na figura 9. 


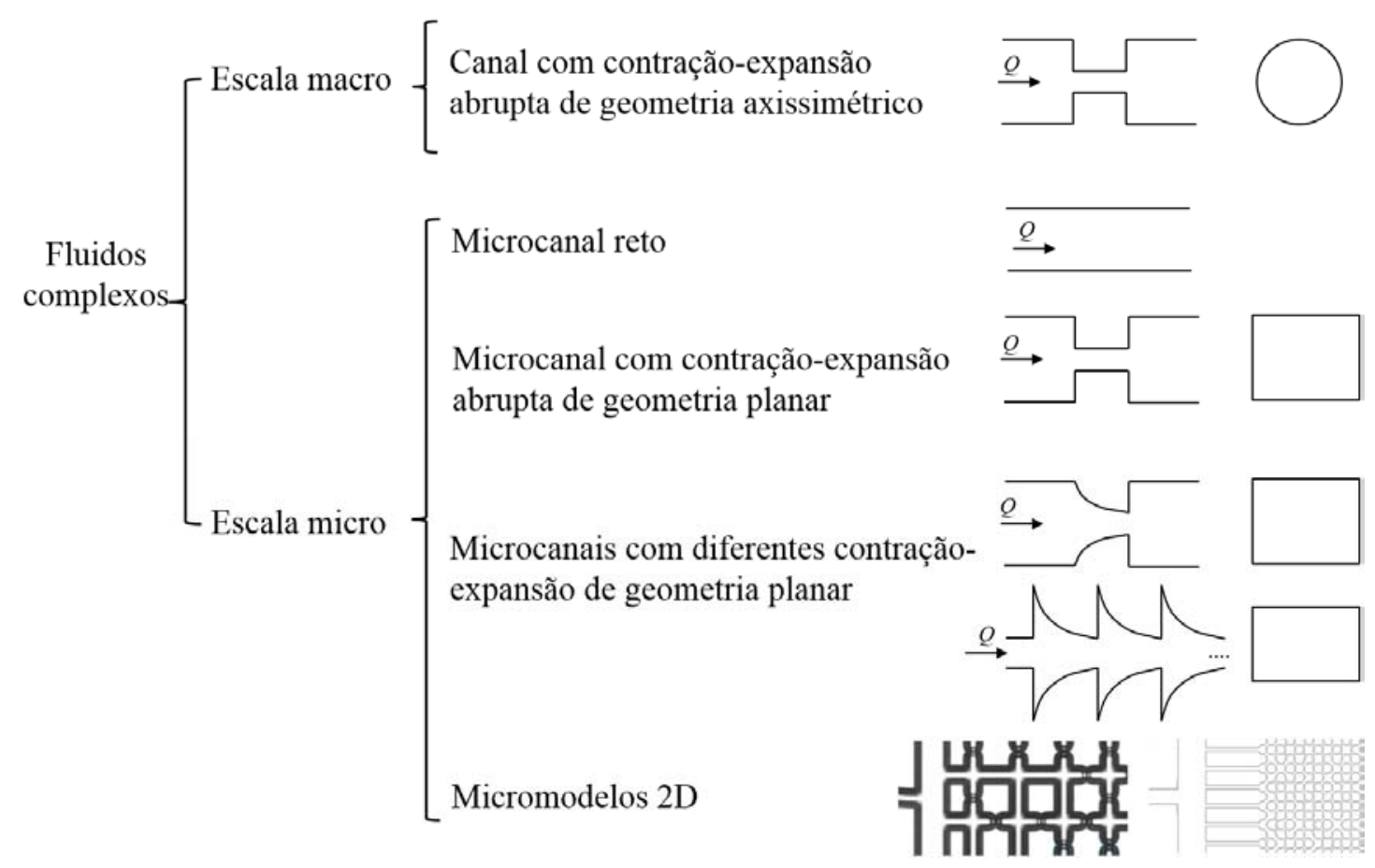

Figura 9 - Esquema com um resumo dos temas discutidos na revisão bibliográfica

Antes de iniciar a revisão bibliográfica, um microcanal de contraçãoexpansão abrupta é mostrado novamente com as variáveis utilizadas para expressar suas dimensões principais, como ilustrado na figura 10. Além disso, um sumário das investigações citadas na literatura é resumido na tabela 1, ressaltando as principais características reológicas do fluido viscoelástico, os parâmetros geométricos da constrição ou micromodelo, os parâmetros adimensionais que caracterizam a dinâmica do escoamento, as técnicas de medição e comentários.
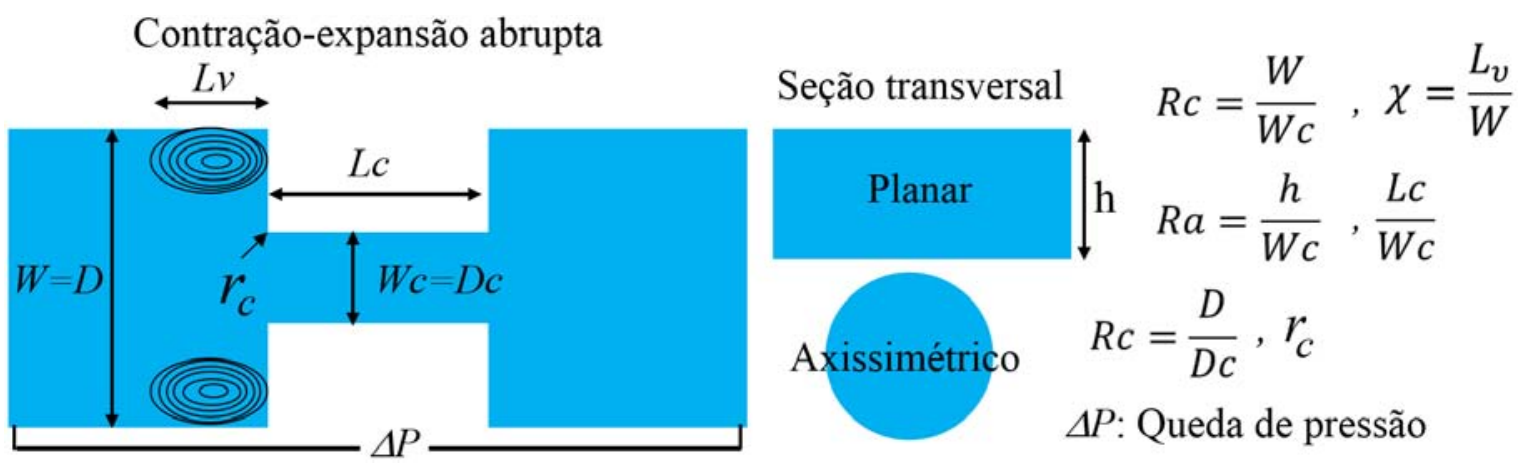

Figura 10 - Microcanal com contração-expansão abrupta 
PUC-Rio - Certificação Digital No 1313509/CA

\begin{tabular}{|c|c|c|c|c|c|}
\hline \multicolumn{6}{|c|}{ Investigações experimentais realizadas em constrição abrupta axissimétrica na escala macro } \\
\hline Autor (ano) & $\begin{array}{l}\text { Material e geometria da } \\
\text { constrição }\end{array}$ & $\begin{array}{c}\text { Características do fluido } \\
\text { viscoelástico }\end{array}$ & $\begin{array}{c}\text { Parâmetros } \\
\text { adimensionais }\end{array}$ & $\begin{array}{l}\text { Técnica de } \\
\text { medição }\end{array}$ & Comentários \\
\hline $\begin{array}{l}\text { Rothstein et } \\
\text { al. (1999) }\end{array}$ & $\begin{array}{c}\text { Acrílico, axissimétrico } \\
R c=1,4 \mathrm{~cm} / 0,35 \mathrm{~cm}=4: 1, \\
L c=0,6 \mathrm{~cm}\end{array}$ & $\begin{array}{c}\text { Boger PE }(C=0,025 \%, \\
P M=2,25 \times 10^{6} \mathrm{~g} / \mathrm{mol}, \\
\mu_{c(\dot{\gamma}=0)} \approx 22 \text { Pa.s }\end{array}$ & $\begin{array}{c}\operatorname{Re}<0,1(Q<1620 \mathrm{ml} / \mathrm{h}) \\
0,06<D e<7,5\end{array}$ & $\begin{array}{c}\text { DPIV } \\
\text { Linhas de tinta } \\
\Delta P<40 \mathrm{kPa}\end{array}$ & $\begin{array}{l}\text { Queda de pressão extra não } \\
\text { coincide com o início da } \\
\text { instabilidade elástica global. }\end{array}$ \\
\hline $\begin{array}{l}\text { Rothstein et } \\
\text { al. (2001) }\end{array}$ & $\begin{array}{c}\text { Acrílico, } 2: 1<R c<8: 1, \\
0<r_{c}<0,5, W=1,27 \mathrm{~cm}, \\
\text { axissimétrico }\end{array}$ & $\begin{array}{c}\text { Boger PE }(C=0,025 \%, \\
P M=2,25 \times 10^{6} \mathrm{~g} / \mathrm{mol}, \\
\left.\mu_{c(\dot{\gamma}=0)} \approx 22 \text { Pa.s }\right)\end{array}$ & $\begin{array}{l}R e<0,1 \\
D e \leq 11\end{array}$ & $\begin{array}{c}\text { DPIV, LDV, } \\
\text { Linhas de tinta } \\
\Delta P<26,4 \mathrm{kPa}\end{array}$ & $\begin{array}{c}\text { Efeito da variação da } R c \text { e } r_{c} \\
\text { no escoamento de entrada. }\end{array}$ \\
\hline \multicolumn{6}{|c|}{ Investigações experimentais realizadas em canais retos na escala micro } \\
\hline $\begin{array}{l}\text { Degré et al. } \\
\text { (2006) }\end{array}$ & $\begin{array}{c}\text { Vidro-PDMS, } R c=0, W=18 \\
\mu \mathrm{m}, h=100 \mu \mathrm{m}, \text { planar }\end{array}$ & $\begin{array}{c}\text { PEO, } 7,1<C<50 \mathrm{~g} / \mathrm{L}, \\
0,3 \times 10^{6}<P M<5 \times 10^{6} \mathrm{~g} / \mathrm{mol}\end{array}$ & - & micro-PIV & $\begin{array}{l}\text { Quantificação reológica } \\
\text { utilizando micro-PIV. }\end{array}$ \\
\hline $\begin{array}{l}\text { Fu et al. } \\
(2015)\end{array}$ & $\begin{array}{c}\text { Vidro, planar, } R c=0, \\
400 \times 400<W \cdot h<800 \times 800 \mu \mathrm{m}^{2}\end{array}$ & $\begin{array}{c}\text { PAAm, } 0,10 \%<C<1,25 \% \\
1000<\mu_{c(\dot{\gamma}=0)}<60000 \mathrm{cP}\end{array}$ & $0,01<\operatorname{Re}<0,04$ & micro-PIV & $\begin{array}{l}\text { Quantificação reológica } \\
\text { utilizando micro-PIV. }\end{array}$ \\
\hline \multicolumn{6}{|c|}{ Investigações experimentais realizadas em constrição abrupta planar na escala micro } \\
\hline $\begin{array}{l}\text { Rodd et al. } \\
\qquad(2005)\end{array}$ & $\begin{array}{c}\text { PDMS, planar } \\
R c=400 \mu \mathrm{m} / 25 \mu \mathrm{m}=16: 1, \\
L c=100 \mu \mathrm{m}, h=50 \mu \mathrm{m}\end{array}$ & $\begin{array}{c}\text { PEO, } 0,05 \%<C<0,3 \%, \\
P M=2 \times 10^{6} \mathrm{~g} / \mathrm{mol}, \\
1,84<\mu_{C(\dot{\gamma}=0)}<8,31 \mathrm{cP}\end{array}$ & $\begin{array}{c}0,44<R e<64(Q<14 \mathrm{ml} / \mathrm{h}) \\
W i<548 \\
3,8<E l<89\end{array}$ & $\begin{array}{l}\text { Linhas de tinta } \\
\qquad P P<140 \mathrm{kPa}\end{array}$ & $\begin{array}{l}\text { Efeito da variação da } C \text { no } \\
\text { escoamento de entrada. } \\
\text { Queda de pressão coincide } \\
\text { com instabilidade elástica. }\end{array}$ \\
\hline $\begin{array}{l}\text { Rodd et al. } \\
\qquad(2007)\end{array}$ & $\begin{array}{c}\text { PDMS, planar } \\
R c=400 \mu \mathrm{m} / 25 \mu \mathrm{m}=16: 1, \\
L c=100 \mu \mathrm{m}, h=55 \mu \mathrm{m}\end{array}$ & $\begin{array}{c}\text { PEO }(C=0,075 \%), \\
15 \%<C(\text { solvente })<60 \%, \\
P M=2 \times 10^{6}, \mu_{c(\dot{\gamma}=0)}<17,3\end{array}$ & $\begin{array}{c}0,03<R e<12(Q<4 \mathrm{ml} / \mathrm{h}) \\
0,4<W i<42,2 \\
8<E l<68\end{array}$ & $\begin{array}{l}\text { Linhas de tinta } \\
\text { micro-PIV } \\
\Delta P<60 \mathrm{kPa}\end{array}$ & $\begin{array}{c}\text { Efeito da variação da } C \text { do } \\
\text { solvente (glicerina) no } \\
\text { escoamento de entrada. }\end{array}$ \\
\hline
\end{tabular}


PUC-Rio - Certificação Digital No 1313509/CA

\begin{tabular}{|c|c|c|c|c|c|}
\hline Autor (ano) & $\begin{array}{c}\text { Material e geometria da } \\
\text { constrição }\end{array}$ & $\begin{array}{c}\text { Características do fluido } \\
\text { viscoelástico }\end{array}$ & $\begin{array}{c}\text { Parâmetros } \\
\text { adimensionais }\end{array}$ & $\begin{array}{l}\text { Técnica de } \\
\text { medição }\end{array}$ & Comentários \\
\hline $\begin{array}{l}\text { Rodd et al. } \\
\qquad(2010)\end{array}$ & $\begin{array}{c}\text { PDMS, planar } \\
R c=400 \mu \mathrm{m} / 25 \mu \mathrm{m}=16: 1, \\
50 \mu \mathrm{m}<L c<400 \mu \mathrm{m}, h=57 \mu \mathrm{m}\end{array}$ & $\begin{array}{c}\text { PEO }(0,1 \text { e } C=0,3 \%), \\
C(\text { solvente })=15 \% \text { e } 26 \%, \\
P M=2 \times 10^{6}, \mu_{c(\dot{\gamma}=0)}<5,58\end{array}$ & $\begin{array}{c}\operatorname{Re}<45(Q<14 \mathrm{ml} / \mathrm{h}) \\
W i<373 \\
6,8<E l<41\end{array}$ & $\begin{array}{l}\text { Linhas de tinta } \\
\qquad \Delta P<131 \mathrm{kPa}\end{array}$ & $\begin{array}{l}\text { Efeito da variação } L c \text { no } \\
\text { escoamento de entrada. }\end{array}$ \\
\hline $\begin{array}{l}\text { Haward et } \\
\text { al. (2010) }\end{array}$ & $\begin{array}{l}\text { Vidro, } R c=1600 / 200 \mu \mathrm{m}=8: 1, \\
\qquad \begin{array}{c}R a=16: 1, L c=2000 \mu \mathrm{m}, \\
h=3200 \mu \mathrm{m}, \text { planar }\end{array}\end{array}$ & $\begin{array}{c}\text { Poliestireno, } 0,03 \%<C<0,6 \% \\
P M=6,9 \times 10^{6} \mathrm{~g} / \mathrm{mol}, \\
27 \mathrm{cP}<\mu_{c(\dot{\gamma}=0)}<120 \mathrm{cP}\end{array}$ & $\begin{array}{c}0,07<\operatorname{Re}<11,2 \\
(50<Q<4000 \mathrm{ml} / \mathrm{h}) \\
W i<1562,31<E l<295\end{array}$ & $\begin{array}{l}\text { micro-PIV } \\
\Delta P<700 \mathrm{kPa}\end{array}$ & $\begin{array}{c}\text { Efeito da variação da } C \text { no } \\
\text { escoamento de entrada a } \\
\text { menor } R c=8: 1\end{array}$ \\
\hline $\begin{array}{l}\text { Li et al. } \\
\text { (2011) }\end{array}$ & $\begin{array}{c}\text { PMMA, planar } \\
R c=800 \mu \mathrm{m} / 102 \mu \mathrm{m}=8: 1 \\
L c=20000 \mu \mathrm{m}, h=45 \mu \mathrm{m}\end{array}$ & $\begin{array}{c}\text { PEO, } 0,3 \%<C<0,45 \%, \\
P M=4,82 \times 10^{6} \mathrm{~g} / \mathrm{mol}, \\
10,5 \mathrm{cP}<\mu_{c(\dot{\gamma}=0)}<22,5 \mathrm{cP}\end{array}$ & $\begin{array}{c}0,08<\operatorname{Re}<4,5 \\
7<W i<121 \\
3<E l<120\end{array}$ & $\begin{array}{c}\text { micro-PIV } \\
\Delta P<4000 \text { mbar }\end{array}$ & $\begin{array}{l}\text { Efeito da variação da } C \text { no } \\
\text { escoamento de entrada, com } \\
\text { alto valor de } L c=20000 \mu \mathrm{m} \text {. }\end{array}$ \\
\hline $\begin{array}{l}\text { Li et al. } \\
\text { (2011) }\end{array}$ & $\begin{array}{c}\text { PMMA, 4:1<Rc<16:1 } \\
400<L c<20000 \mu \mathrm{m}, \text { planar }\end{array}$ & $\begin{array}{c}\text { PEO, } C=0,3 \%, P M=4,8 \times 10^{6} \\
\mu_{c(\dot{\gamma}=0)}=10,5 \mathrm{cP}\end{array}$ & $\begin{array}{c}\operatorname{Re}<5,4,(Q<15 \mathrm{ml} / \mathrm{h}) \\
3<W i<120,8,6<E l<158\end{array}$ & $\begin{array}{c}\text { micro-PIV } \\
\Delta P<4000 \text { mbar }\end{array}$ & $\begin{array}{c}\text { Efeito da variação da } C \text { e } L c \\
\text { no escoamento de entrada. }\end{array}$ \\
\hline $\begin{array}{l}\text { Li et al. } \\
\text { (2015) }\end{array}$ & $\begin{array}{c}\text { PMMA, planar } \\
R c=800 \mu \mathrm{m} / 100 \mu \mathrm{m}=8: 1 \\
100<L c<20000 \mu \mathrm{m}, h=45 \mu \mathrm{m}\end{array}$ & $\begin{array}{c}\text { PEO }(C=0,3 \%, \\
\left.P M=4,8 \times 10^{6} \mathrm{~g} / \mathrm{mol}\right) \\
\mu_{c(\dot{\gamma}=0)}=10,7 \mathrm{cP}\end{array}$ & $\begin{array}{c}\operatorname{Re}<11,5(0,5<Q<12 \mathrm{ml} / \mathrm{h}) \\
10,8<W i<256,2 \\
22,3<E l<36\end{array}$ & $\begin{array}{l}\text { micro-PIV } \\
\qquad \Delta P\end{array}$ & $\begin{array}{c}\text { Efeito da cinemática da } \\
\text { entrada sobre o escoamento } \\
\text { dentro da constrição. }\end{array}$ \\
\hline $\begin{array}{l}\text { Lee et al. } \\
\text { (2014) }\end{array}$ & $\begin{array}{c}\text { PDMS, } R c=4: 1 \\
0,068 \mu \mathrm{m}<R a<0,438 \mu \mathrm{m}, \\
L c=3 \mathrm{~cm}, h=70 \mu \mathrm{m}, \text { planar }\end{array}$ & $\begin{array}{c}\text { PEO, } 0,3 \%<C<1,0 \% \\
P M=2 \times 10^{6} \mathrm{~g} / \mathrm{mol}, \\
9 \mathrm{cP}<\mu_{c(\dot{\gamma}=0)}<200 \mathrm{cP}\end{array}$ & $\begin{array}{c}\operatorname{Re}<0,1(Q<15 \mathrm{ml} / \mathrm{h}) \\
3,4<W i<208,3 \\
30<E l<900\end{array}$ & Linhas de tinta & $\begin{array}{l}\text { Efeito da variação } R a \text { no } \\
\text { escoamento de entrada. }\end{array}$ \\
\hline $\begin{array}{l}\text { Lee et al. } \\
\text { (2015) }\end{array}$ & $\begin{array}{c}\text { PDMS, } R c=4: 1, L c=3 \mathrm{~cm}, \\
h=70 \mu \mathrm{m}, \text { planar }\end{array}$ & $\begin{array}{c}\text { PEO, } 0,4 \%<C<1,0 \% \\
P M=2 \text { e } 5 \times 10^{6} \mathrm{~g} / \mathrm{mol}, \\
70 \mathrm{cP}<\mu_{c(\dot{\gamma}=0)}<39000 \mathrm{cP}\end{array}$ & $\begin{array}{c}\operatorname{Re}<0,1(Q<15 \mathrm{ml} / \mathrm{h}) \\
3,4<W i<130, \\
5100<E l<2,2 \times 10^{6}\end{array}$ & Linhas de tinta & $\begin{array}{l}\text { Efeito da variação da } C \text { no } \\
\text { escoamento de entrada para } \\
\text { altos números de } E l\end{array}$ \\
\hline
\end{tabular}


PUC-Rio - Certificação Digital No 1313509/CA

\begin{tabular}{|c|c|c|c|c|c|}
\hline Autor (ano) & $\begin{array}{c}\text { Material e geometria da } \\
\text { constrição }\end{array}$ & $\begin{array}{c}\text { Características do fluido } \\
\text { viscoelástico }\end{array}$ & $\begin{array}{c}\text { Parâmetros } \\
\text { adimensionais }\end{array}$ & $\begin{array}{l}\text { Técnica de } \\
\text { medição }\end{array}$ & Comentários \\
\hline $\begin{array}{l}\text { Gulati et al. } \\
\text { (2008) }\end{array}$ & $\begin{array}{c}\text { Silício, planar } \\
R c=200 \mu \mathrm{m} / 100 \mu \mathrm{m}=2: 1, \\
L c=7500 \mu \mathrm{m}, h=180 \mu \mathrm{m}\end{array}$ & $\begin{array}{c}\lambda \text {-DNA }(400 \mu \mathrm{g} / \mathrm{ml}) \\
P M=31,5 \times 10^{6} \mathrm{Da}\end{array}$ & $\begin{array}{c}R e<0,098\left(5 \times 10^{-4}<Q<0,30\right. \\
\mathrm{ml} / \mathrm{h}), W i<629, \\
6,4 \times 10^{3}<E l<1,4 \times 10^{6}\end{array}$ & $\begin{array}{c}\text { DPIV } \\
\text { Linhas de tinta } \\
\Delta P<1 \mathrm{psi}\end{array}$ & $\begin{array}{l}\text { Efeito da variação da } C \text { no } \\
\text { escoamento para } R c=2: 1\end{array}$ \\
\hline \multicolumn{6}{|c|}{ Investigações experimentais realizadas em diferentes constrições planar na escala micro } \\
\hline $\begin{array}{l}\text { Groisman et } \\
\text { al. (2003) e } \\
\text { (2004) }\end{array}$ & $\begin{array}{c}\text { PDMS, canais em série, } \\
h=100 \mu \mathrm{m}, W c=30 \mu \mathrm{m} \\
\text { (elipsoidal) } W c=5 / 35 / 450 \\
\mu \mathrm{m} \text { (cruzada) } W c=37 \mu \mathrm{m} \\
\text { (triangular). }\end{array}$ & $\begin{array}{c}\text { PPAm } \\
P M=1,8 \times 10^{7} \mathrm{~g} / \mathrm{mol} \\
\mu_{c(\dot{\gamma}=0)}=1,92 \mathrm{cP}\end{array}$ & - & $\begin{array}{l}\text { Linhas de tinta } \\
\qquad \Delta P<200 \mathrm{~Pa}\end{array}$ & $\begin{array}{l}\text { Avaliação da resistência ao } \\
\text { escoamento, anisotropia e } \\
\text { metaestabilidade em } \\
\text { microcanais em série. }\end{array}$ \\
\hline $\begin{array}{l}\text { Boek et al. } \\
\text { (2006) }\end{array}$ & $\begin{array}{l}\text { Vidro, canais em série, } \\
R c=160 \mu \mathrm{m} / 40 \mu \mathrm{m}=4: 1, \\
h=40 \mu \mathrm{m}, \text { planar }\end{array}$ & $\begin{array}{c}\text { EHAC } \\
\mu_{c(\dot{\gamma}=0)}=600 \text { Pa.s }\end{array}$ & $Q=3 \mu \mathrm{l} / \mathrm{min}$ & micro-PIV & $\begin{array}{l}\text { Avaliação do escoamento } \\
\text { em microcanais em série } \\
\text { utilizando micro-PIV. }\end{array}$ \\
\hline $\begin{array}{l}\text { Neves et al. } \\
\text { (2006) }\end{array}$ & $\begin{array}{c}\text { PDMS, } L c=128 \mu \mathrm{m}, h=46 \mu \mathrm{m} \\
R c=400 \mu \mathrm{m} / 54,1 \mu \mathrm{m}=37: 5, \\
\text { Contração hiperbólica- } \\
\text { expansão abrupta planar }\end{array}$ & $\begin{array}{c}\text { PEO } \\
C=0,1 \%, M=2 \times 10^{6} \mathrm{~g} / \mathrm{mol} \\
\mu_{c(\dot{\gamma}=0)}=2,3 \mathrm{cP}\end{array}$ & $\begin{array}{c}\operatorname{Re}<145(Q<13 \mathrm{ml} / \mathrm{h}) \\
D e<12,5 \\
E l=0,087\end{array}$ & $\begin{array}{l}\text { Linhas de tinta } \\
\Delta P<25000 \mathrm{~Pa}\end{array}$ & $\begin{array}{c}\text { Avaliação do escoamento de } \\
\text { entrada para uma contração } \\
\text { hiperbólica. }\end{array}$ \\
\hline $\begin{array}{l}\text { McKinley et } \\
\text { al. (2007) }\end{array}$ & $\begin{array}{c}\text { PDMS, } L c=129 \mu \mathrm{m}, h=50 \mu \mathrm{m} \\
R c=400 \mu \mathrm{m} / 55 \mu \mathrm{m}=37: 5, \\
\text { Contração hiperbólica- } \\
\text { expansão abrupta planar }\end{array}$ & $\begin{array}{c}\text { PEO }, 0,05 \%<C<0,3 \%, \\
P M=2 \times 10^{6} \mathrm{~g} / \mathrm{mol} .\end{array}$ & $\begin{array}{c}R e<5,2, \\
D e<24,4 \\
E l=4,7\end{array}$ & $\begin{array}{l}\text { Linhas de tinta } \\
\qquad \Delta P\end{array}$ & $\begin{array}{c}\text { Avaliação do escoamento de } \\
\text { entrada para uma contração } \\
\text { hiperbólica variando a } C \text {. }\end{array}$ \\
\hline
\end{tabular}


PUC-Rio - Certificação Digital No 1313509/CA

\begin{tabular}{|c|c|c|c|c|c|}
\hline Autor (ano) & $\begin{array}{c}\text { Material e geometria da } \\
\text { constrição }\end{array}$ & $\begin{array}{c}\text { Características do fluido } \\
\text { viscoelástico }\end{array}$ & $\begin{array}{c}\text { Parâmetros } \\
\text { adimensionais }\end{array}$ & $\begin{array}{l}\text { Técnica de } \\
\text { medição }\end{array}$ & Comentários \\
\hline $\begin{array}{l}\text { Neves et al. } \\
\text { (2011) }\end{array}$ & $\begin{array}{c}\text { PDMS, } L c=123 \mu \mathrm{m}, h=45 \mu \mathrm{m} \\
R c=400 \mu \mathrm{m} / 62,5 \mu \mathrm{m}=6,4: 1, \\
\text { Contração abrupta-expansão } \\
\text { hiperbólica planar }\end{array}$ & $\begin{array}{c}\text { PEO }(C=0,4 \%, \\
\left.P M=8 \times 10^{6} \mathrm{~g} / \mathrm{mol}\right) \text { diluída } \\
\text { em água/glicerina } \\
\mu_{c(\dot{\gamma}=0)}=2,3 \mathrm{cP}\end{array}$ & $\begin{array}{c}\operatorname{Re}<0,1 \\
0,02 \mathrm{ml} / \mathrm{h}<Q<1,0 \mathrm{ml} / \mathrm{h} \\
D e<30\end{array}$ & Linhas de tinta & $\begin{array}{c}\text { Avaliação do escoamento de } \\
\text { entrada para uma expansão } \\
\text { hiperbólica. }\end{array}$ \\
\hline $\begin{array}{l}\text { Sousa et al. } \\
\text { (2011) }\end{array}$ & $\begin{array}{c}\text { PDMS, } L c=128 \mu \mathrm{m}, \\
46 \mu \mathrm{m}<h<120 \mu \mathrm{m}, \\
R c=4,65: 1 \text { e } 5: 17, \\
\text { Canais hiperbólicos em serie }\end{array}$ & $\begin{array}{c}\text { PEO }(C=0,1 \%, \\
\left.P M=8 \times 10^{6} \mathrm{~g} / \mathrm{mol}\right) \\
\mu_{C(\dot{\gamma}=0)}=0,1 \mathrm{~Pa} . \mathrm{s}\end{array}$ & $\begin{array}{c}R e<0,8 \\
0,02 \mathrm{ml} / \mathrm{h}<Q<2,5 \mathrm{ml} / \mathrm{h} \\
D e<171\end{array}$ & $\begin{array}{l}\text { Linhas de tinta } \\
\qquad \Delta P\end{array}$ & $\begin{array}{c}\text { Avaliação da anisotropia do } \\
\text { escoamento para canais } \\
\text { hiperbólicos em série. }\end{array}$ \\
\hline $\begin{array}{l}\text { Gulati et al. } \\
\text { (2015) }\end{array}$ & $\begin{array}{c}\text { PDMS, } L c=3500 \mu \mathrm{m}, \\
h=50 \mu \mathrm{m}, W c=130 \mu \mathrm{m}, \\
\text { Contração convexa-saída } \\
\text { gradual }\end{array}$ & $\begin{array}{l}\lambda \text {-DNA }(400 \mu \mathrm{g} / \mathrm{ml}), \\
P M=31,5 \times 10^{6} \mathrm{~g} / \mathrm{mol}\end{array}$ & $\begin{array}{c}\operatorname{Re}<0,31 \\
0,5 \mu \mathrm{l} / \mathrm{h}<Q<40 \mu \mathrm{l} / \mathrm{h} \\
0,4<W i<446 \\
7,9 \times 10^{3}<E l<6 \times 10^{5}\end{array}$ & $\begin{array}{l}\text { Linhas de tinta } \\
\qquad \Delta P<1 \mathrm{psi}\end{array}$ & $\begin{array}{c}\text { Avaliação do escoamento de } \\
\text { entrada para uma contração } \\
\text { convexa. }\end{array}$ \\
\hline \multicolumn{6}{|c|}{ Investigações experimentais realizadas em micromodelos $2 \mathrm{D}$} \\
\hline $\begin{array}{l}\text { Miranda } \\
\text { (2015) }\end{array}$ & $\begin{array}{l}\text { Vidro, } h=50 \mu \mathrm{m}, W=110 \mu \mathrm{m}, \\
63<W c<110 \mu \mathrm{m}, \text { rede canais }\end{array}$ & $\begin{array}{c}\text { PEO }\left(C=0,1 \%, P M=8 \times 10^{6}\right. \\
\mathrm{g} / \mathrm{mol}), \mu_{c(\dot{\gamma}=0)}=8 \mathrm{cP}\end{array}$ & $\begin{array}{l}0,039 \mathrm{ml} / \mathrm{h}<Q<2,08 \mathrm{ml} / \mathrm{h} \\
5 \times 10^{-5}<\text { Capilaridade }<10^{-4}\end{array}$ & $\begin{array}{c}\text { Processamento de } \\
\text { imagens }\end{array}$ & $\begin{array}{c}\text { Avaliação saturação de óleo } \\
\text { residual }\end{array}$ \\
\hline $\begin{array}{l}\text { Clarke et al. } \\
\text { (2015) }\end{array}$ & $\begin{array}{c}\text { PMMA, } \\
\text { Área do poro }=200 \mu \mathrm{m}^{2}\end{array}$ & $\begin{array}{c}0,13 \%<\text { Xanthan }<0,24 \% \\
0,12 \%<\text { HPAM }<0,24 \%\end{array}$ & $\begin{array}{l}R e \approx 10^{-4}, Q_{\text {crit }} \approx 9 \mu \mathrm{l} / \mathrm{min} \\
10^{-4}<\text { Capilaridade }<10^{-2}\end{array}$ & PTV & $\begin{array}{l}\text { Avaliação saturação de óleo } \\
\text { residual e instabilidade. }\end{array}$ \\
\hline $\begin{array}{l}\text { Hincapie et } \\
\text { al. (2017) }\end{array}$ & Vidro-silício & $\begin{array}{c}3350<\mathrm{PEO}<9000 \mathrm{PPM} \\
500<\mathrm{HAPM}<1000 \mathrm{PPM}\end{array}$ & $10 \mu \mathrm{l} / \min <Q<100 \mu \mathrm{l} / \mathrm{min}$ & $\begin{array}{c}\text { Linhas de tinta } \\
\Delta P / \mathrm{X}<11000 \mathrm{kpa} / \mathrm{m}\end{array}$ & $\begin{array}{l}\text { Avaliação saturação de óleo } \\
\text { residual, } D P \text { e instabilidade. }\end{array}$ \\
\hline
\end{tabular}

Tabela 1 - Sumário das principais referências bibliográficas 


\subsection{1.}

\section{Investigações experimentais realizadas em canais na escala macro}

No século XIX é iniciado o estudo de escoamentos com uma contração abrupta, quando Hagenback, Boussinesqe e Couette investigaram medidas da queda de pressão em escoamentos de entrada circulares, com a finalidade de desenvolver um reômetro capilar capaz de medir a viscosidade de fluidos Newtonianos. No início dos 1900s, o problema da região de entrada hidrodinâmica para escoamentos de fluidos Newtonianos foi abordado, embora a cinemática detalhada dos fluxos de entrada foi pouco estudada. Um sumário de trabalhos investigando este fenômeno é encontrado no artigo de Fan e Hwang (1966).

As investigações de escoamento de entrada na escala macro foram estendidas para soluções de polímeros, polímeros fundidos, fluidos viscoelásticos (viscosidade extensional dependente da taxa de extensão), fluidos Boger (líquidos elásticos de viscosidade constante), entre outros, devido à importância em operações de processamento industrial. Existe um grande número de investigações experimentais e numéricas sobre a cinemática do fluxo através de constrições de diferentes geometrias. A finalidade é estudar o fenômeno do escoamento não linear associado com a elasticidade do fluido em fluxos convergentes, a interação entre inercia e elasticidade, o mecanismo de evolução de vórtices, o aumento da queda de pressão, os padrões do escoamento a diferentes regimes de escoamento sobre uma ampla faixa de números de Weissenberg ou Deborah, diferentes relações de contração e curvaturas no canto reentrante. As principais investigações foram resumidas e documentadas nos trabalhos de Bird et al. (1977), Boger (1982), Boger et al. (1986) e White et al. (1987).

\subsubsection{1.}

\section{Investigações experimentais realizadas em canais com constrição abrupta axissimétrica na escala macro}

Como nossa investigação está dirigida a escoamentos de fluidos vicoelásticos através de constrições de tamanho micro, citaremos apenas os trabalhos recentes realizados por Rothstein e McKinley sobre o estudo do escoamento de entrada em geometrias axissimétrica em escala macro, para conhecer os diferentes fenômenos envolvidos nessa escala, antes de mencionar as investigações realizadas na escala micro. 
Rothstein e McKinley (1999) investigaram o comportamento dinâmico na entrada da constrição de um líquido Boger (solução de poliestireno, $C=0,025 \% \mathrm{em}$ peso e $P M=2,25 \times 10^{6} \mathrm{~g} / \mathrm{mol}$ ) escoando através de uma contração-expansão abrupta de geometria axissimétrica $(R c=1,4 \mathrm{~cm} / 0,35 \mathrm{~cm}=4: 1$ e $L c=0,635 \mathrm{~cm})$ para uma ampla faixa de números de Deborah e baixos números de Reynolds. A visualização e quantificação do efeito elástico sobre o escoamento foram realizadas através de linhas de tinta, medidas da queda de pressão e a técnica de velocimetria por imagem de partículas digital (DPIV).

Para a solução viscoelástica de Boger foi visualizada uma queda de pressão extra acima do escoamento Newtoniano a partir do número de Deborah critico de 0,4 (figura 11). A diferença de pressão foi normalizada utilizando as medidas da queda de pressão para um fluido Newtoniano (óleo de poliestireno oligomérico) com mesma viscosidade. Estudos prévios utilizando outros fluidos viscoelásticos escoando através de uma constrição de $R c=4: 1$ mostraram também o mesmo comportamento (Cartalos e Piau 1992).

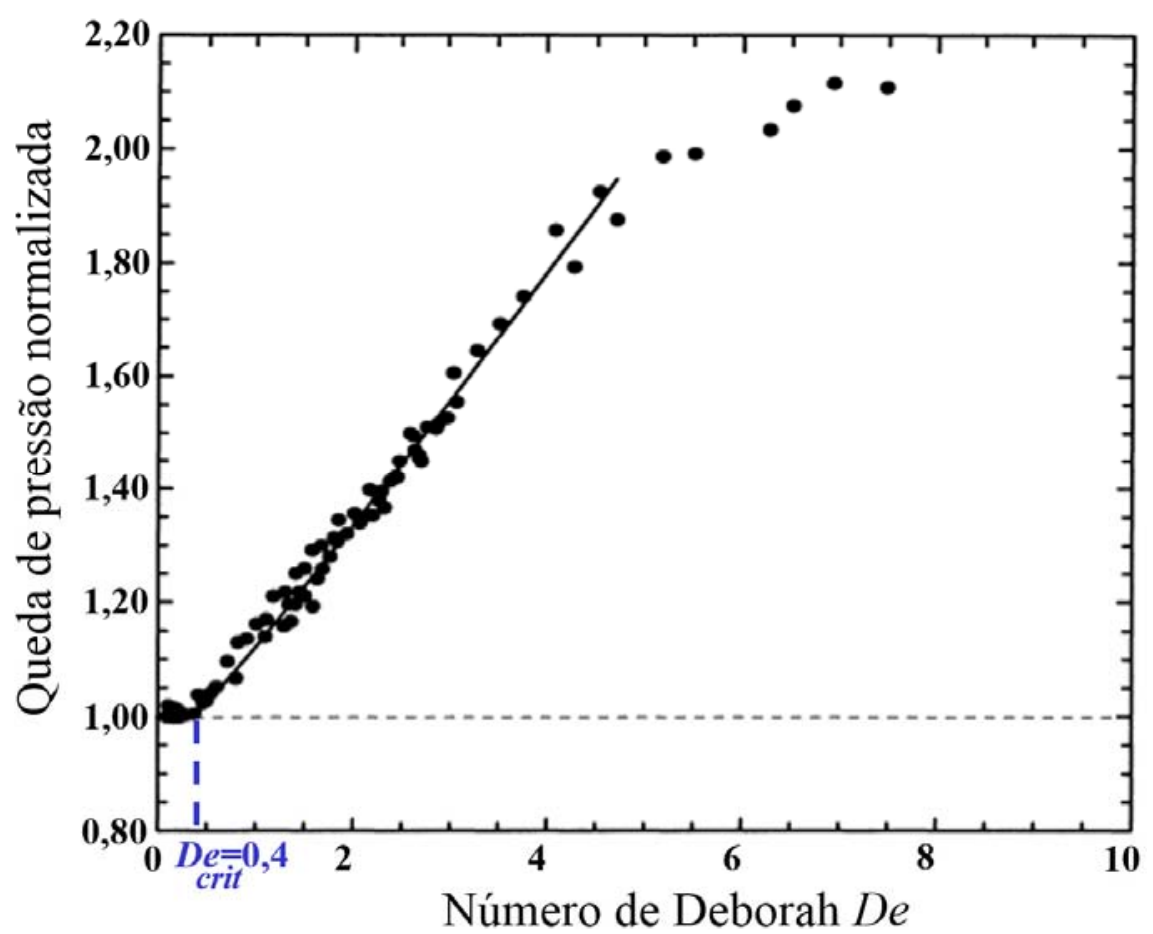

Figura 11 - Medidas da queda de pressão normalizada em função do número de Deborah para um fluido Boger $(C=0,025 \%$ em peso $)$ através da constrição axissimétrica de $R c=4: 1$ realizado por Rothstein e McKinley (1999) 
As linhas de tinta do escoamento mostraram que para baixas vazões de injeção, o escoamento apresenta um padrão semelhante ao escoamento Newtoniano, com pequenas recirculações à montante da constrição. Quando o valor do número de Deborah $D e=2,6$ foi atingido, as linhas de tinta do escoamento mostraram os vórtices formados à montante da constrição variando de tamanho no tempo. Esta evidência mostrou o início da instabilidade global no escoamento pela assimetria dos vórtices nos cantos. A figura 12 mostra a oscilação dos vórtices de canto no tempo para o número de Deborah de $D e=4,7$.

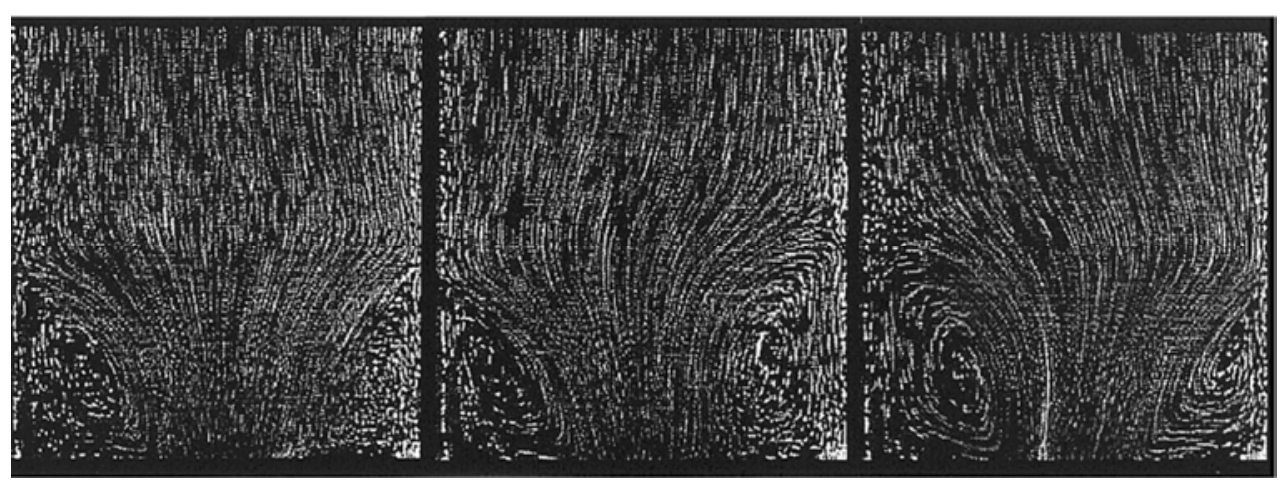

Figura 12 - Linhas de tinta do escoamento da solução de Boger à montante da constrição mostrando a oscilação dos vórtices no tempo para o número de Deborah $D e=4,7$ realizado por Rothstein e McKinley (1999)

As medidas da queda de pressão mostraram um incremento correspondente com o crescimento de vórtices, sugerindo que o desenvolvimento do vórtice está diretamente ligado ao aumento da queda de pressão. O aparecimento dos vórtices é causado pelas tensões elásticas perto da garganta da constrição (incremento da viscosidade extensional do polímero). Entretanto, as medições da queda de pressão extra $(D e=0,4)$ não coincidiram com o início da instabilidade elástica global no escoamento $(D e=2,6)$.

Rothstein e McKinley (2001) utilizaram o mesmo fluido viscoelástico de Boger do trabalho anterior para investigar os efeitos produzidos na cinemática do escoamento ao variar a relação de contração $(R c=2: 1,4: 1$ e 8:1) e o grau de curvatura dos cantos reentrantes $r_{c}$ para uma ampla faixa de números de Deborah $(D e \leq 11)$. As técnicas experimentais de velocimetria laser doppler (LDV), de velocimetria por imagem de partículas digital (DPIV) e de visualização através de 
linhas de tinta foram utilizadas para investigar os diferentes padrões do escoamento à montante da constrição, além das medições da queda de pressão.

A maiores relações de contração (figura 13a), um aumento da queda de pressão foi observado e o início do incremento da queda de pressão para os diferentes $R c$ variou pouco $(0,3 \leq D e \leq 0,8)$.

Foi observado, que o efeito da curvatura do canto reentrante causou uma mudança das condições de início para os diferentes regimes do escoamento. $\mathrm{Na}$ figura $13 \mathrm{~b}$ mostra como a presença da curvatura reentrante arredondado atrasou o início da instabilidade elástica do escoamento.
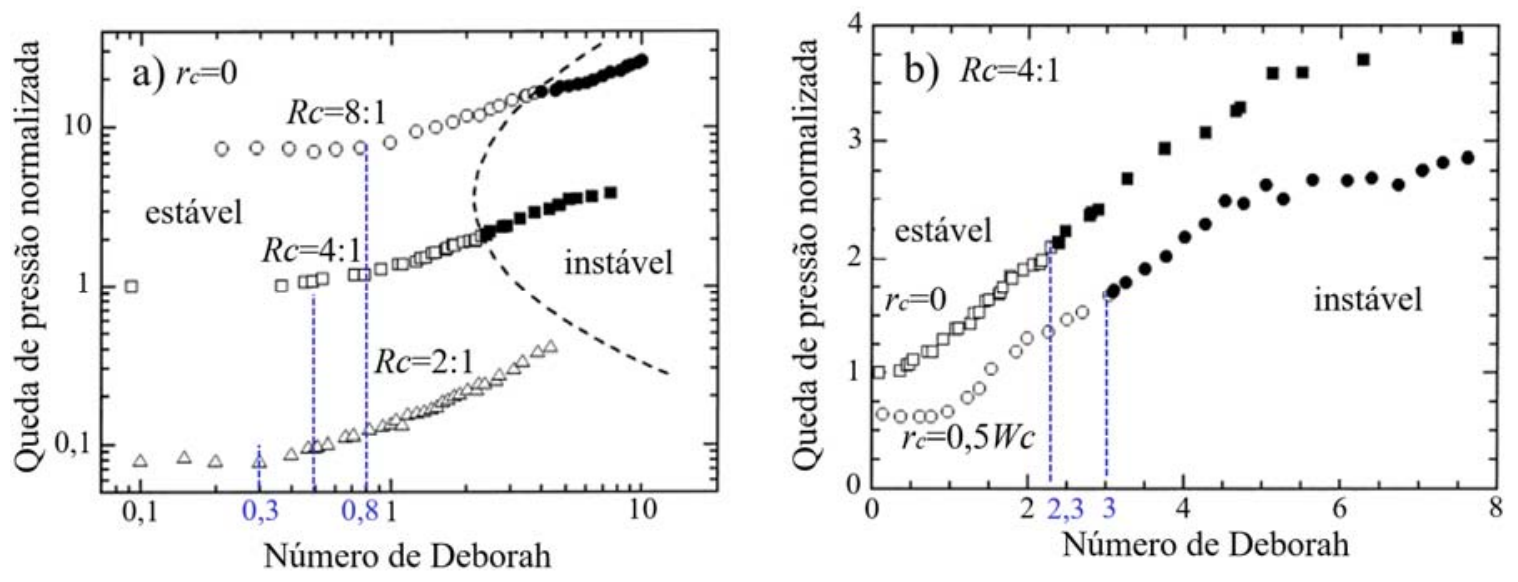

Figura 13 - Queda de pressão normalizada em função do número de Deborah. a) Efeito da $R c$

b) Efeito da curvatura do canto reentrante à $R c=4: 1$ realizado por Rothstein e McKinley (2001)

As imagens mostraram um crescimento de vórtices de canto a medida que a $R c$ foi aumentada. Embora, para a relação de $R c=2: 1$ foi observada para baixos números de Deborah $(D e=0,6)$ a formação de um vórtice de lábio. Conforme a vazão foi aumentada, o vórtice de lábio cresceu para um vórtice de canto (figura 14). Para a $R c=2: 1$, o escoamento foi estável (vórtices simétricos) no tempo na faixa de valores de números de Deborah estudados. Entretanto, instabilidades foram encontradas para as outras relações de contração (figura 13a). 

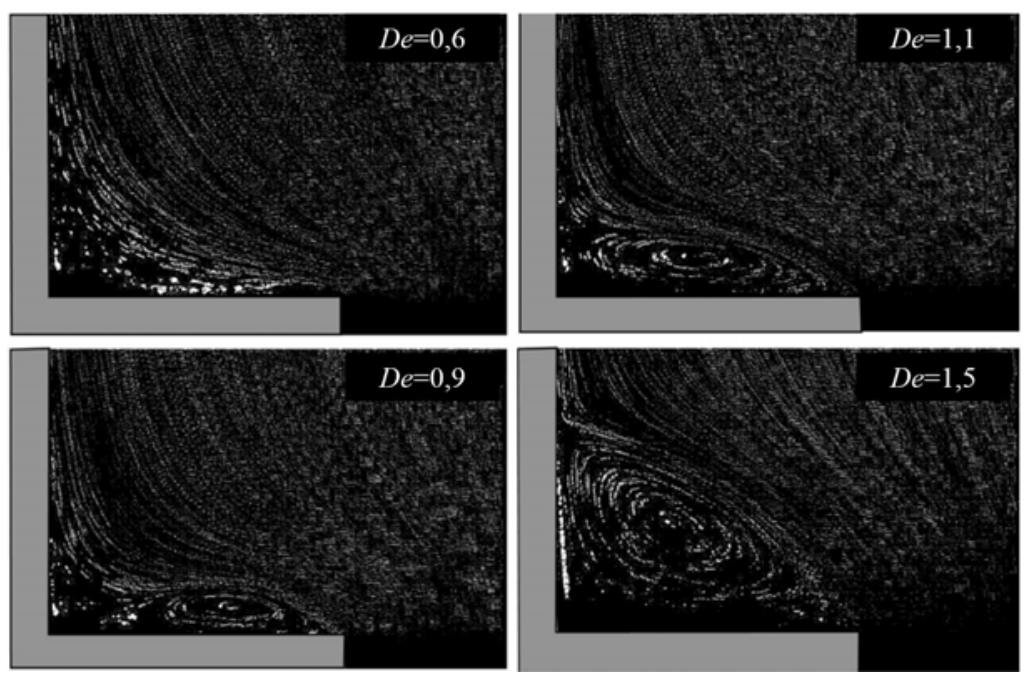

Figura 14 - Imagens com linhas de tinta mostrando o início e crescimento do vórtice de lábio à montante da constrição para diferentes números de Deborah à $R c=2: 1$ realizado por Rothstein e McKinley (2001)

$\mathrm{O}$ arredondamento do canto reentrante causou um atraso nas condições de início dos regimes do escoamento a maiores números de Deborah, como representado nas imagens da figura 15 através de linhas de tinta.

$$
R c=4: 1
$$

a) Canto reentrante
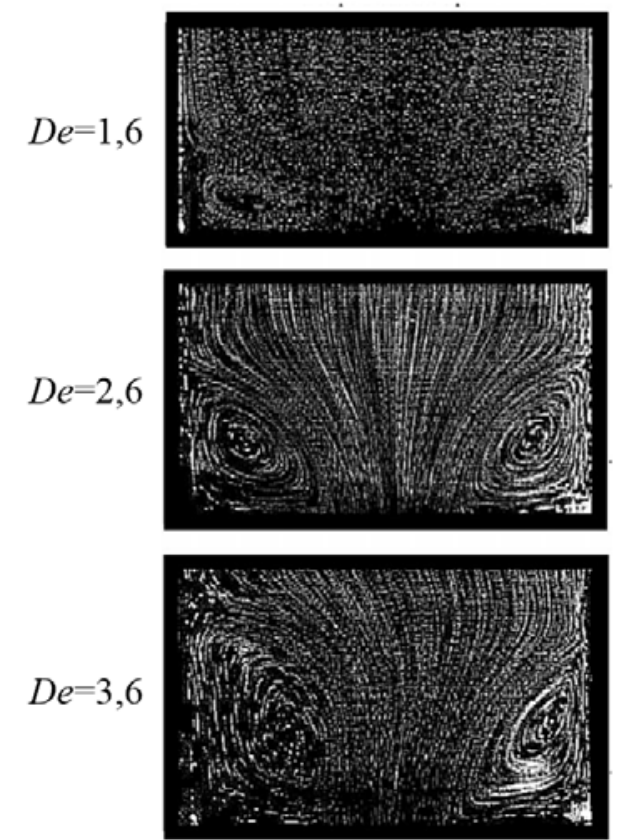

$R c=4: 1$

b) canto reentrante
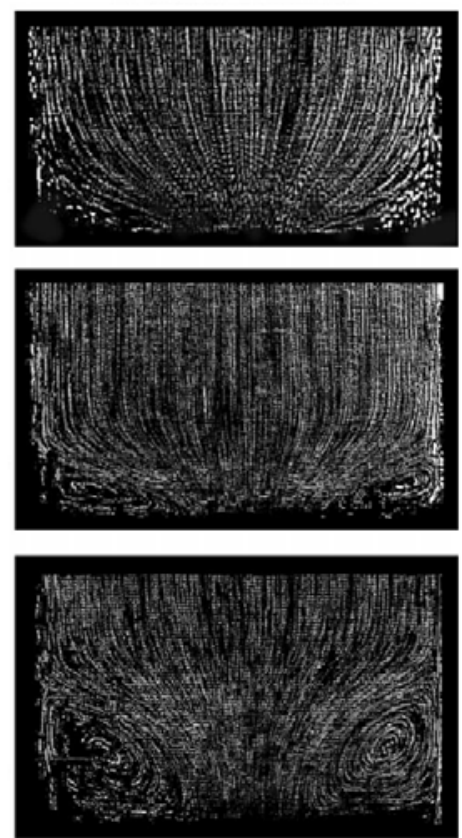

Figura 15 - O escoamento mostrando linhas de tinta para altos números de Deborah e para a $R c=4: 1$ a) Canto reentrante afiado b) Canto reentrante arredondado realizado por Rothstein e McKinley (2001) 
Finalmente para todas as geometrias avaliadas, a queda de pressão extra foi associada com o escoamento extensional do fluido viscoelástico, porém não foi relacionada com o início da instabilidade elástica no escoamento.

\subsection{2.}

Investigações experimentais realizadas em contrições na escala micro

Na seção anterior, as investigações foram referidas a caracterizar e quantificar o comportamento de fluidos não Newtonianos escoando através de diferentes geometrias de expansão-contração abrupta na escala macro por meio de diversas técnicas de medição como PIV, LDV, linhas de tinta, entre outros. A faixa de diâmetro explorado nesses trabalhos foi de 0,3 a $2,8 \mathrm{~cm}$.

Devido aos avanços das técnicas de microfabricação foi possível estudar escoamentos de fluidos complexos na escala micro através de dispositivos microfluídicos. Uma das principais vantagens de reduzir a geometria do escoamento foi alcançar altas taxas de deformação com efeitos inerciais desprezíveis (altos números de elasticidade), condições tipicamente não acessíveis em experimentos equivalentes na escala macro.

Fluidos complexos na escala micro é o centro de nossa investigação, em particular, soluções viscoelásticas escoando através de constrições utilizando a técnica de micro-PIV. Existe uma vasta literatura tanto experimental como numérica tentando explicar os diferentes fenômenos envolvidos nos escoamentos de fluidos complexos quando são submetidos a diversas condições cinemáticas. A maioria dessas investigações são orientadas para aplicações de impressão por jato de tinta, farmacêutica e ciências biológicas, e algumas na indústria do petróleo.

$\mathrm{Na}$ próxima seção citaremos as pesquisas desenvolvidas utilizando microcanais tanto de geometria simples como geometrias de maior complexidade (rede de poros e canais). 


\subsubsection{1. Investigações experimentais realizadas em canais retos na escala micro}

Degré et al. (2006) mediu as propriedades reológicas de várias soluções de óxido de polietileno PEO ( $\left.P M=0,3-5,0 \times 10^{6} \mathrm{~g} / \mathrm{mol}, C=7,5-50 \mathrm{~g} / \mathrm{L}\right)$ utilizando os perfis de velocidade e medidas da queda de pressão (imposta) do escoamento passando por um microcanal de vidro reto e de seção quadrada $(18 \times 100 \mu \mathrm{m})$. Os perfis de velocidade foram obtidos utilizando a técnica experimental de microvelocimetria por imagem de partículas (micro-PIV).

Um perfil de velocidade foi medido no centro do canal para diferentes diferenças de pressão impostas para uma solução de PEO $\left(P M=5,0 \times 10^{6} \mathrm{~g} / \mathrm{mol} \mathrm{e}\right.$ $C=7,5 \mathrm{~g} / \mathrm{L})$, como mostram as figuras $16 \mathrm{a}$ e $16 \mathrm{~b}$.

O perfil se desvia do comportamento de um escoamento Newtoniano acima de uma taxa de cisalhamento crítico, mostrando também uma condição de deslizamento do líquido na parede. A partir dos dados de pressão e velocidade foi mapeada a curva de tensão cisalhante versus taxa de cisalhamento sendo comparado com os valores obtidos de um reômetro Couette (figura 16c). Ambos os resultados mostraram boa concordância, portanto, através da técnica de velocimetria em microcanais é possível obter à reologia não linear dos fluidos com bastante precisão.

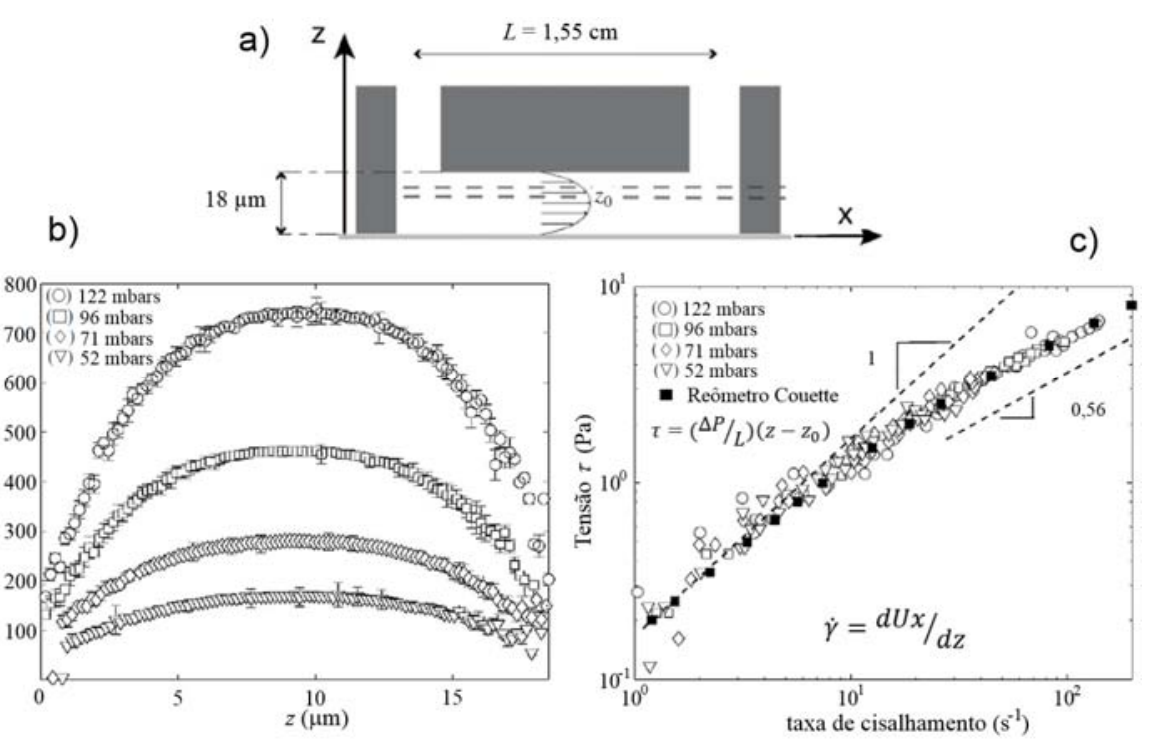

Figura 16 - a) Microcanal reto b) Perfil de velocidade para diferentes diferenças de pressão impostas c) Propriedades reológicas da solução de PEO $\left(P M=5 \times 10^{6} \mathrm{~g} / \mathrm{mol}, C=7,5 \mathrm{~g} / \mathrm{L}\right)$ utilizando os resultados da velocimetria do escoamento e do reômetro Couette realizado por Degré et al. (2006) 
Fu et al. (2015) quantificou a caracterização reológica de escoamentos de fluidos Newtonianos e não Newtonianos fluindo através de vários microcanais retos de seção quadrada $\left(400 \mu \mathrm{m}^{2}, 600 \mu \mathrm{m}^{2}\right.$ e $\left.800 \mu \mathrm{m}^{2}\right)$. Soluções de poliacrilamida (PPAm) para diferentes concentrações foram utilizadas como fluidos não Newtonianos e foram injetadas dentro dos microcanais através de uma bomba de seringa. Perfis de velocidade do escoamento foram obtidos através da técnica experimental de micro-PIV.

Como esperado, o escoamento das soluções de PAAm mostraram um perfil de velocidade achatado na parte central do microcanal, como mostrado na figura 17a, apenas para a solução de PAAm à maior concentração $(C=1,25 \%$ em peso), sendo comparado com os resultados obtidos através da simulação de Lattice Boltzmann. A figura 17b apresenta os índices de escoamento $n$ para 6 soluções de PPAm obtidos através do reômetro e das medidas do perfil de velocidade do escoamento. Os valores são bastante próximos entre si, portanto, a quantificação do índice de escoamento que caracteriza a reologia dos fluidos é possível utilizando a técnica de micro-PIV.
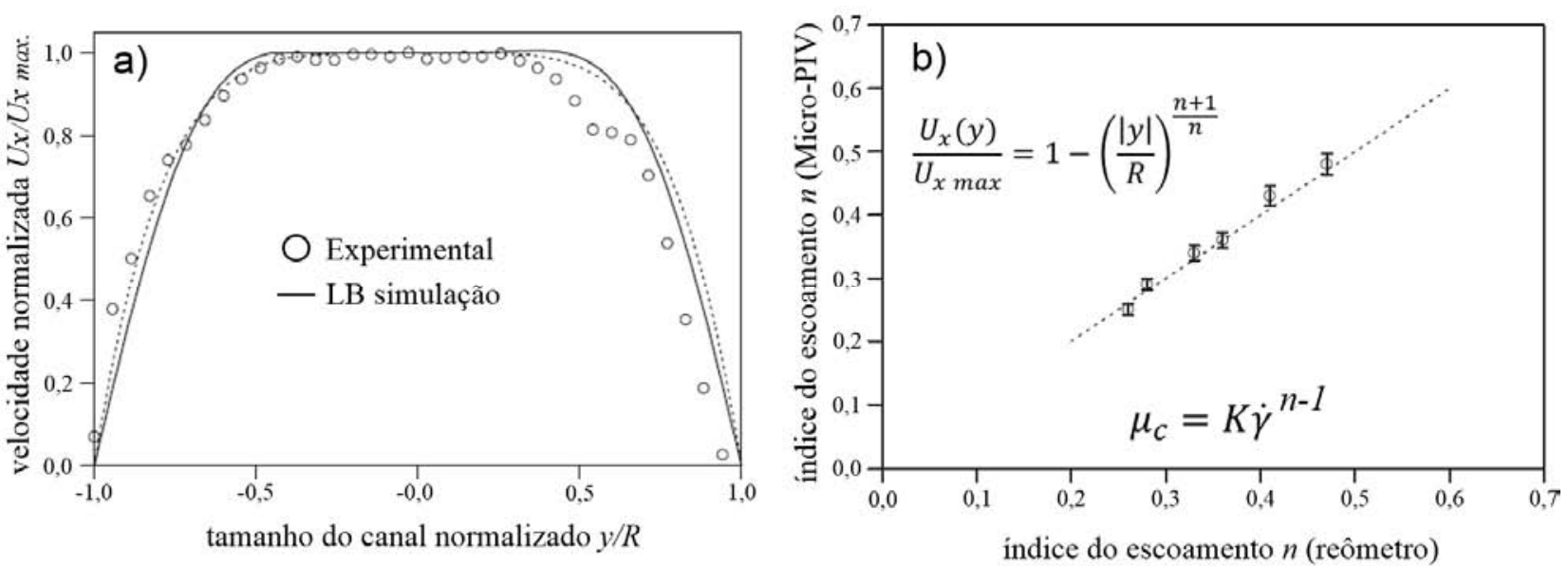

Figura 17 - a) Comparação do perfil de velocidade experimental e de simulação LB do escoamento da solução de PPAm ( $C=1,25 \%$ em peso). b) Comparação do índice de escoamento $n$ obtido através da técnica de micro-PIV e do rêometro para 6 soluções de PPAm realizado por Fu et al. (2015) 


\subsubsection{2. \\ Investigações experimentais realizadas em canais com constrição abrupta planar na escala micro}

O maior número de investigações tanto experimental como numérica foram realizadas no microcanal com contração-expansão abrupta de geometria planar, com a finalidade de entender e quantificar os efeitos elásticos de soluções poliméricas sobre os escoamentos para diferentes geometrias do microcanal, diferentes propriedades do fluido e diferentes condições do fluxo, como foram resumidos na figura 8. O escoamento pode apresentar diversos regimes de escoamento, desde simples a complexos no espaço e tempo e, portanto, existe uma grande necessidade de entender esses fenômenos.

A primeira pesquisa estudada no microcanal padrão de contração-expansão abrupta com geometria planar foi realizada por Rodd et al. (2005), a fim de investigar os efeitos de inercia e de elasticidade no crescimento de vórtices e a instabilidade elástica do escoamento em uma constrição por meio de medidas da queda de pressão e a técnica de visualização através de linhas de tinta. Para gerar essas condições, soluções poliméricas de PEO foram utilizadas variando a concentração em peso de PEO $(0,05 \%, 0,1 \%$ e $0,3 \%)$ e mantendo a mesma geometria da constrição $(R c=400 \mu \mathrm{m} / 25 \mu \mathrm{m}=16 / 1, L c=100 \mu \mathrm{m}$ e $h=50 \mu \mathrm{m})$.

Os resultados das medidas da queda de pressão para as três soluções de PEO divergiram do comportamento Newtoniano para um número de Weissenberg acima de $W i_{c r i t} \approx 50$, representado na figura 18 . A queda de pressão extra foi associada com a resistência à extensão das moléculas do polímero. 


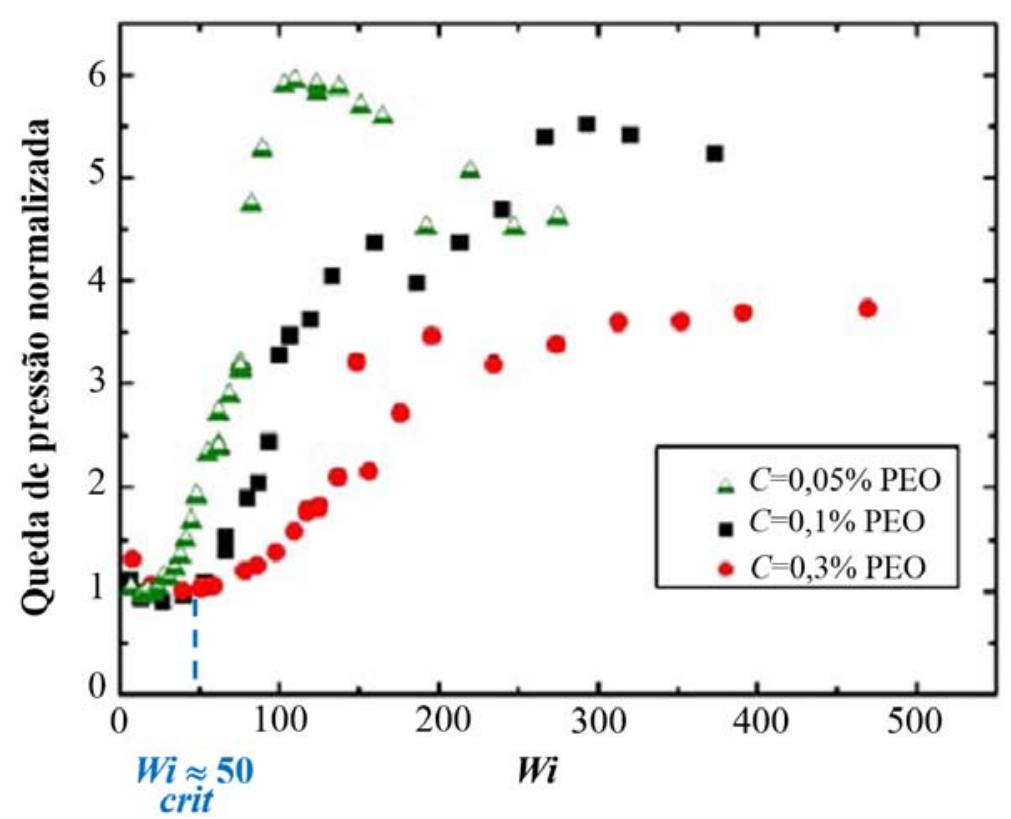

Figura 18 - Queda de pressão normalizada em função de Weissenberg para três soluções de PEO $\left(P M=2 \times 10^{6} \mathrm{~g} / \mathrm{mol}\right)$ realizado por Rodd et al. (2005)

As linhas de tinta do escoamento das soluções poliméricas de PEO mostraram vários regimes, como ilustrado na figura 19 . O crescimento de vórtices à montante da constrição apresentou diferentes configurações causadas pela elasticidade da solução polimérica à medida que o número de Weissenberg foi aumentado. O início da instabilidade elástica no escoamento correspondeu com o início de incremento da queda de pressão em $W i_{c r i t} \approx 50$. Para os números de elasticidade $E l=3,8$ ( $C=0,05 \%$ em peso de PEO) e $E l=8,4$ ( $C=0,1 \%$ em peso de $\mathrm{PEO}$ ) na condição crítica, as linhas de tinta parecem se cruzando no escoamento. Enquanto, para o número de elasticidade $E l=89$ ( $C=0,3 \%$ em peso de $\mathrm{PEO})$ é visualizado a formação de vórtices de lábio.

É importante ressaltar que o número de $W i_{c r i t} \approx 50$ onde inicia a instabilidade global do escoamento é muito maior do que os resultados apresentados por Rothstein e McKinley (1998) para o número de Deborah de valor De $e_{c r i} \approx 2,6$. A discrepância é o método utilizado para calcular o tempo de relaxação, na qual Rodd utilizou o reômetro CaBER, enquanto Rothstein utilizou o modelo de Zimm. 


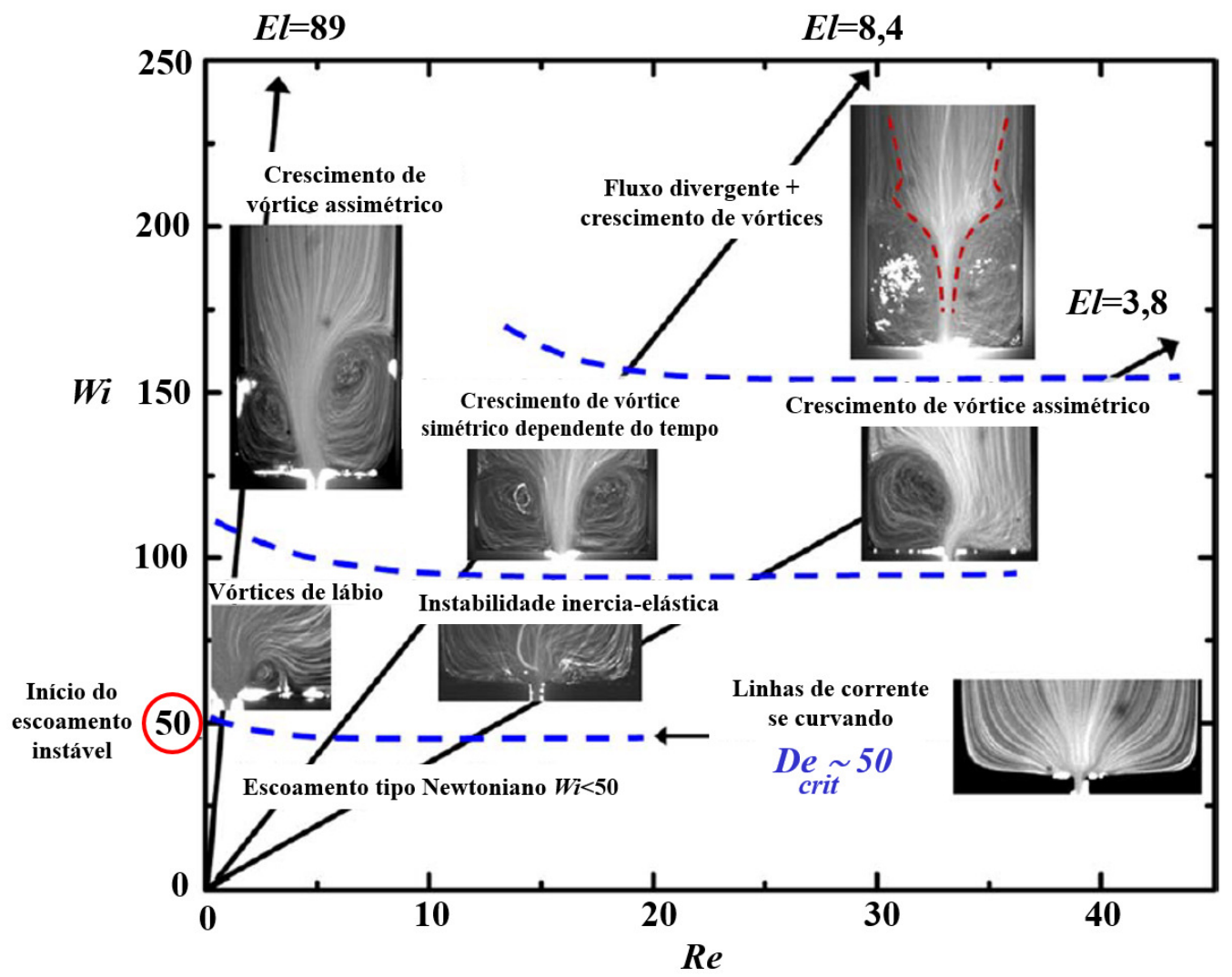

Figura 19 - O diagrama $R e$ vs. Wi mostra um resumo dos diferentes regimes de escoamento para três soluções de PEO $(E l=3,8, E l=8,4$ e $E l=89)$ realizado por Rodd et al. (2005)

No trabalho anterior, Rodd et al. (2005) mostrou o efeito principal da elasticidade do fluido viscoelástico em escoamentos através de contrações, gerando estruturas dinâmica de fluxo complexos à montante do plano da contração para baixos e altos números de $W i$.

Rodd et al. (2007) ampliou suas investigações caracterizando a dinâmica do escoamento na entrada de uma constrição planar utilizando quatro soluções de PEO ( $C=0,075 \%$ em peso), variando apenas a concentração em peso do solvente glicerol/água $(15 \%, 30 \%, 45 \%$ e $60 \%)$. Eles utilizaram a mesma geometria da constrição do trabalho anterior. Para quantificar o efeito da elasticidade da solução de PEO foram realizadas medidas da queda de pressão, medições de velocidade utilizando a técnica de micro-PIV e a visualização do escoamento através de linhas de tinta das imagens.

Todas as soluções exibiram evolução similar da queda de pressão, embora a solução de $\mathrm{PEO}$ de maior elasticidade $E l=68$ mostrou menor queda de pressão extra, como mostrado na figura 20 a seguir: 

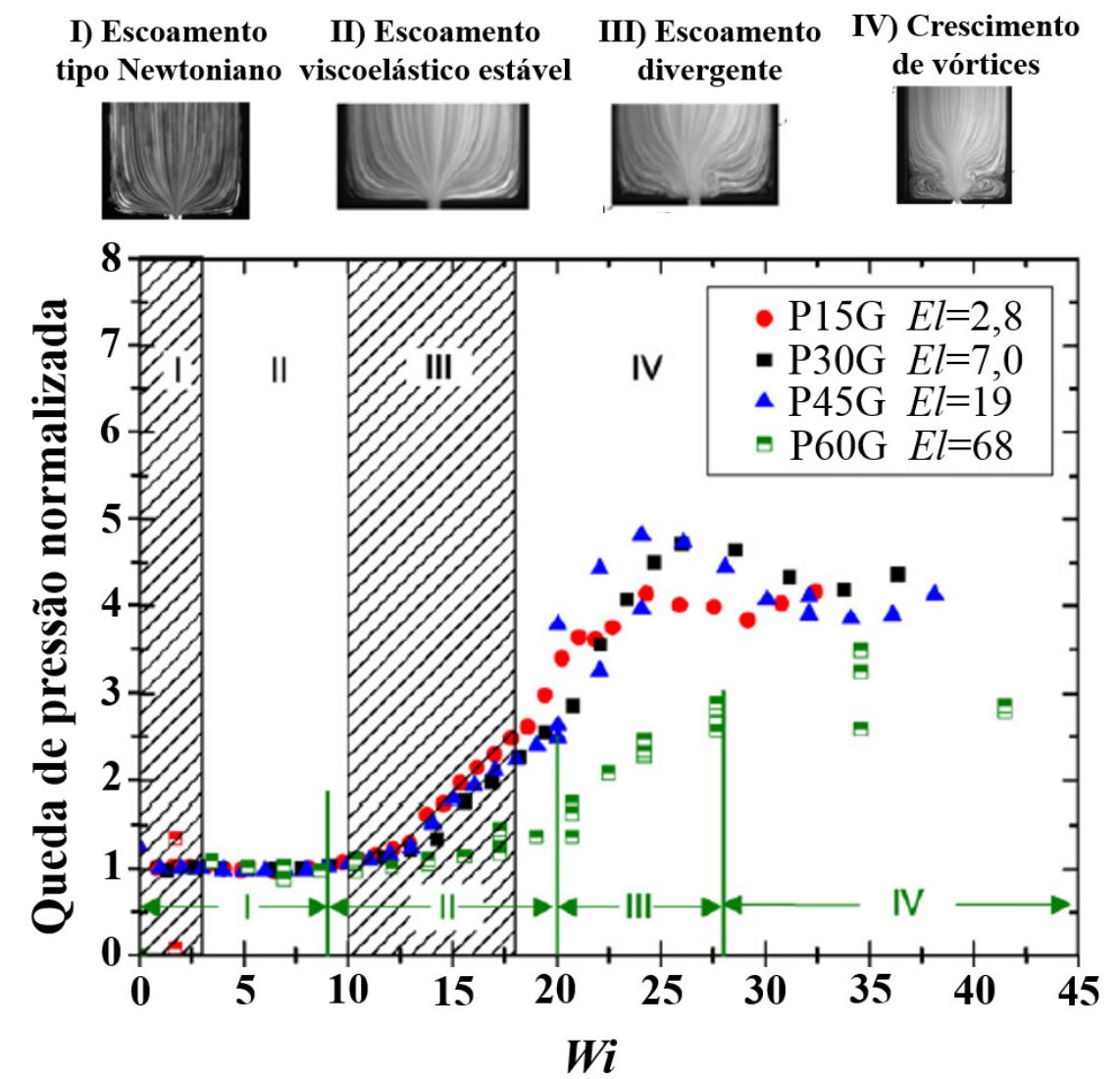

Figura 20 - Queda de pressão normalizada em função de Weissenberg para quatro soluções de PEO ( $C=0,075 \%$ em peso) realizado por Rodd et al. (2007)

As imagens capturadas do escoamento e a técnica de micro-PIV mostraram a presença de quatro tipos de regimes, ilustrados na figura 20. Os regimes III e IV foram atribuídos às tensões elásticas geradas durante o fluxo extensional à montante da constrição e aos efeitos inerciais. Enquanto, os regimes I e II foram atribuídos às forças inerciais ainda dominantes no escoamento. De acordo às observações e medições, a transição entre os regimes de fluxo é uma função fraca para os menores números de elasticidade $(E l=2,8, E l=7$ e $E l=19)$.

A figura 21 representa a imagem do escoamento na entrada da constrição por meio de linhas de tinta (figura 21a) e linhas de corrente (figura 21b) calculadas a partir do campo de velocidade medido utilizando a técnica de micro-PIV para $\mathrm{Wi}=2$ e $R e=0,11$. 
a)

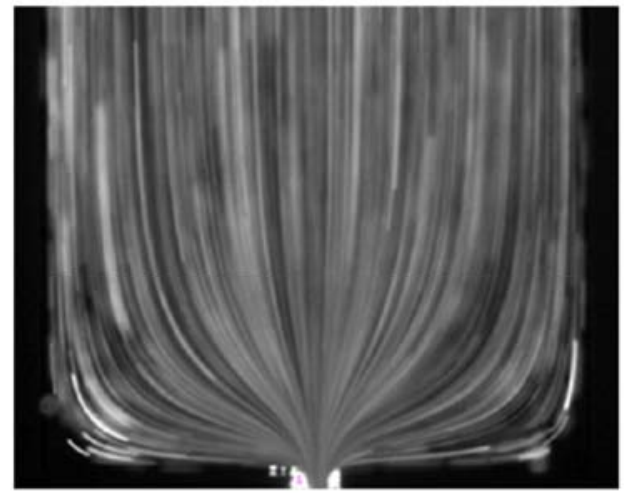

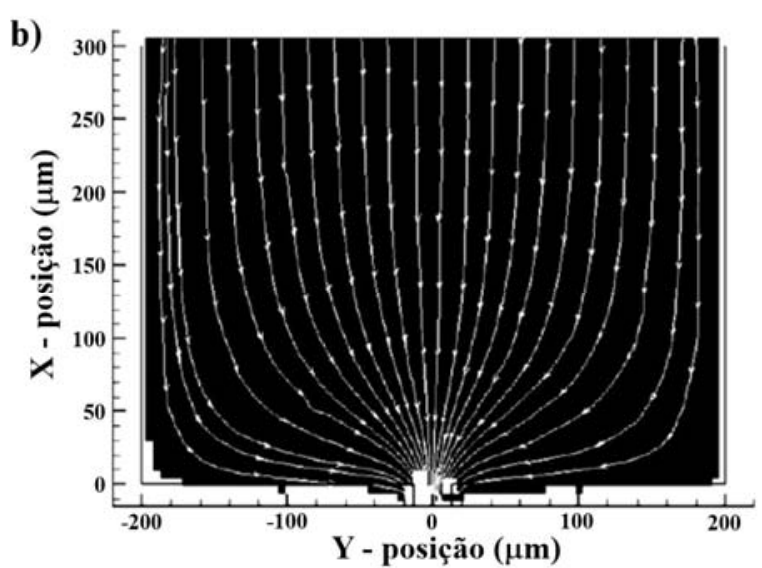

Figura 21 - Visualização do escoamento da solução de PEO (concentração em peso de glicerina/água $C=45 \%$ ) na entrada da constrição. a) Linhas de tinta. b) Linhas de correntes medidos através da técnica de micro-PIV realizado por Rodd et al. (2007)

Os trabalhos anteriores de Rodd e colaboradores estudaram a caracterização do escoamento na entrada de uma constrição variando as propriedades das soluções (porcentagem da concentração do polímero e da concentração do solvente).

Rodd et al. (2010) estudou o efeito da variação do comprimento da constrição $(50 \mu \mathrm{m}<L c<400 \mu \mathrm{m})$ nas medidas da queda de pressão e na cinemática do escoamento à montante da contração-expansão abrupta planar. Soluções aquosas de PEO a diferentes concentrações em peso $(C=0,1 \%$ e $0,3 \%)$ foram utilizadas, e a cinemática do escoamento foi caracterizada através de imagens com linhas de tintas.

A figura 22 mostra as medidas da queda de pressão apenas à concentração de $C=0,1 \%$ em peso de PEO para diferentes comprimentos de constrição $L c$.

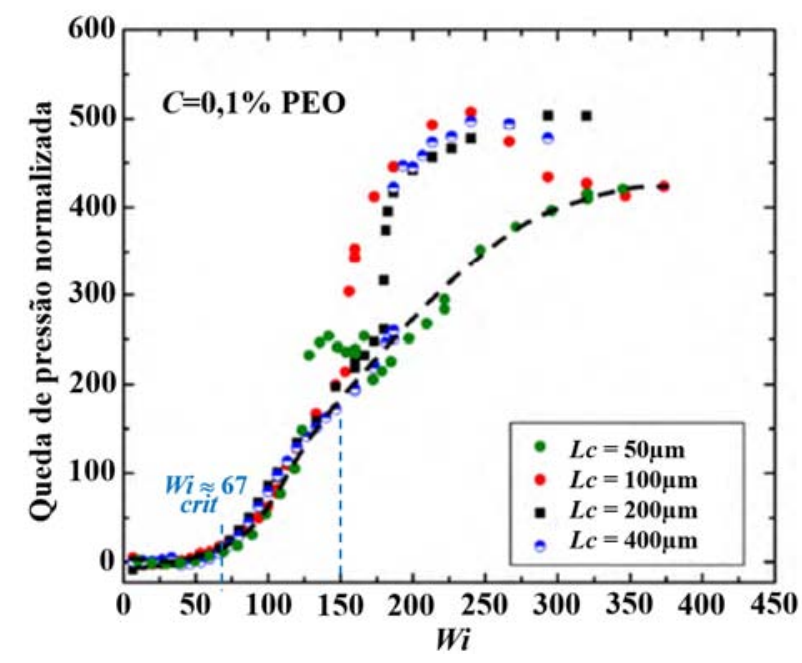

Figura 22 - Medidas da queda de pressão normalizada no escoamento da solução de PEO ( $C=0,1 \%$ em peso) em função de $W i$ para diferentes $L c$ realizado por Rodd et al. (2010) 
As medidas da queda de pressão normalizada apresentaram comportamento similar com exceção do comprimento de $L c=50 \mu \mathrm{m}$. O início da instabilidade em todos os escoamentos ocorreu em $W_{\text {crit }} \approx 67$, e o rápido aumento da queda de pressão em torno de $W i \approx 150$ foi devido à formação e crescimento de um único vórtice de canto à entrada da constrição.

A figura 23 representa os diferentes padrões do escoamento em função do comprimento da constrição $L c$, mostrando apenas os resultados para a concentração de $C=0,3 \%$ em peso de PEO. Vale ressaltar que as imagens com linhas de tinta para $L c=100 \mu \mathrm{m}$ são os mesmos do trabalho de Rodd et al. (2005), e que as imagens não mostram o comprimento total da constrição.

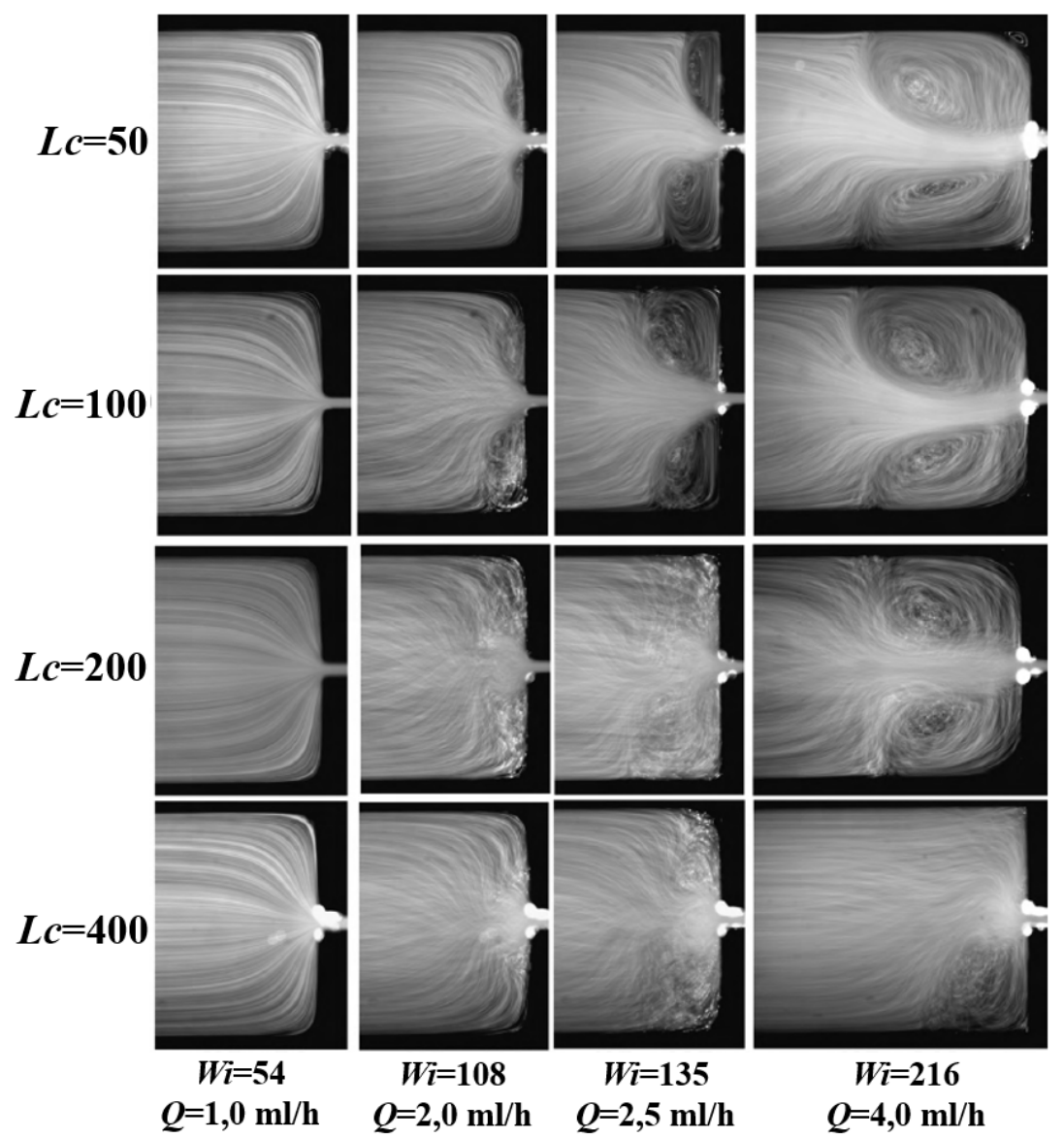

Figura 23 - Imagens com linhas de tinta do escoamento da solução de PEO ( $C=0,3 \%$ em peso) para diferentes $L c$ realizado por Rodd et al. (2010)

Para condições de vazão constante (Wi=constante), ao aumentar o comprimento da constrição, a dinâmica dos vórtices elásticos vai sendo diminuído, como resultado da aparição de estruturas de escoamento inerciais-elásticas. 
É importante ressaltar, que todas as investigações realizadas por Rodd et al. (2005, 2007 e 2010) mostraram um aumento da queda de pressão associado com o início da instabilidade elástica do escoamento na escala micro. Caso contrário, nos trabalhos de Rothstein e McKinley (1998 e 2001) na escala macro, a queda de pressão extra não foi relacionada com o início da instabilidade elástica global do escoamento para as geometrias axissimétricas utilizadas.

No trabalho a seguir, é importante ressaltar que a profundidade do canal planar $h$ foi muito maior do que os trabalhos realizados por Rodd para fornecer uma boa aproximação de um escoamento bidimensional.

Haward et al. (2010) ampliou o estudo do escoamento à montante da constrição planar utilizando soluções de poliestireno de alto peso molecular $\left(P M=6,9 \times 10^{6} \mathrm{~g} / \mathrm{mol}\right)$, variando apenas a concentração em peso do polímero $(0,03 \%<C<\% 0,6)$. As dimensões principais da constrição são $R c=1600 \mu \mathrm{m} / 200 \mu \mathrm{m}=8: 1, L c=2000 \mu \mathrm{m}$ e $h=3200 \mu \mathrm{m}$ (profundidade). Medidas de velocidade do campo de escoamento utilizando micro-PIV e medidas da queda de pressão foram realizadas para caracterizar e quantificar os padrões do escoamento na região de entrada da constrição.

As linhas de corrente mostraram três regimes de escoamento (escoamento tipo Newtoniano, escoamento instável e escoamento de crescimento de vórtices) à montante da constrição, sendo confirmado as transições através das medições da queda de pressão. Os regimes de escoamento foram similares a aqueles reportados por Rodd et al. (2007) utilizando soluções poliméricas de PEO.

Haward et al. (2010) não observou vórtices de lábios em nenhum regime do escoamento, uma possível causa pode ser a baixa resolução (janela de interrogação) utilizada no presente estudo. É importante ressaltar que Rodd et al. (2005) observou esse fenômeno.

As transições entre a escala de regimes de fluxo com o número de Weissenberg, indicaram o domínio dos efeitos elásticos sobre os efeitos inerciais em todas as soluções de poliestireno.

A figura 24 apresenta os campos instantâneos do escoamento da solução de poliestireno ( $C=0,1 \%$ em peso) capturados em diferentes tempos para $W i=417 \mathrm{e}$ 
$E l=53$. É possível observar a mudança de direção do escoamento no tempo através do campo de vetores de velocidade e das linhas de corrente.

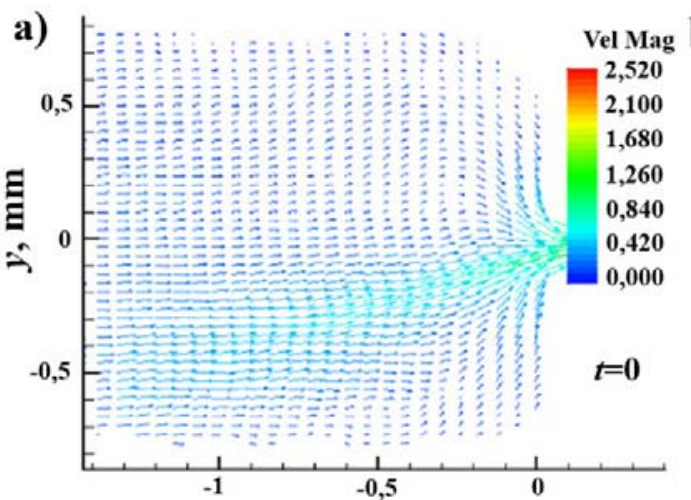

$\mathbf{x}, \mathbf{m m}$

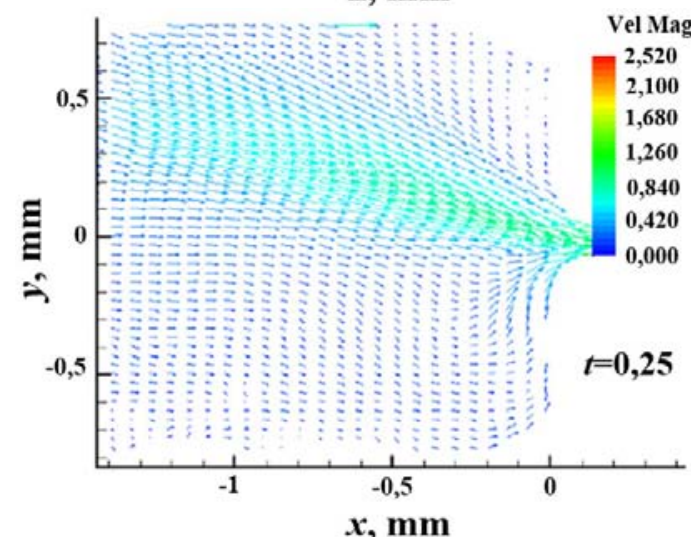

b)
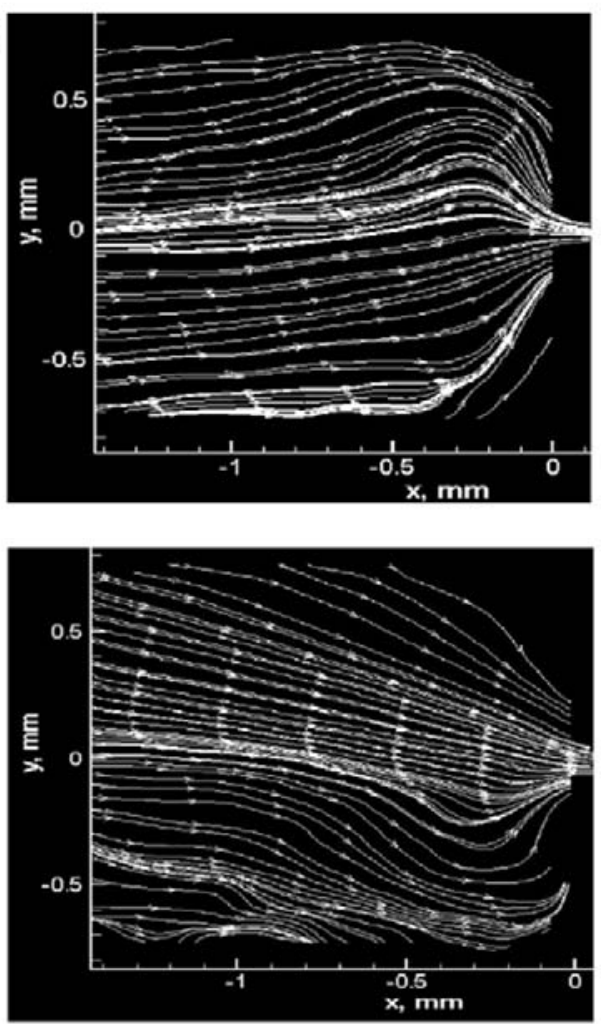

Figura 24 - Campos instantâneos de velocidade capturados no intervalo de tempo de 0,25 s por meio da técnica de micro-PIV a) Campo vetorial de velocidade. b) Linhas de corrente realizado por Haward et al. (2010)

Li et al. (2011) estudou o comportamento dinâmico não-linear do escoamento à montante da constrição variando a concentração do polímero em peso $(0,3 \%$, $0,35 \%, 0,4 \%$ e $0,45 \%$ ) da solução aquosa semidiluída de óxido de polietileno PEO $\left(P M=4,8 \times 10^{6} \mathrm{~g} / \mathrm{mol}\right)$ através de uma geometria planar com uma relação de contração-expansão de $R c=800 \mu \mathrm{m} / 102 \mu \mathrm{m}=8: 1$. O comprimento da constrição de $L c=20 \mathrm{~mm}$ permitiu o escoamento dentro da constrição seja totalmente desenvolvido e, portanto, minimize as interações transientes produzido pelo escoamento à jusante da constrição (zona de expansão) sobre a dinâmica dos vórtices à montante da constrição. A evolução da formação e dinâmica do vórtice foi caracterizada utilizando a técnica de micro-PIV sobre uma ampla faixa de números de elasticidade; $20 \leq E l \leq 120$. 
Os regimes da dinâmica do escoamento foram identificados com presença de vórtices de lábio e de canto, como mostrado na figura 25.
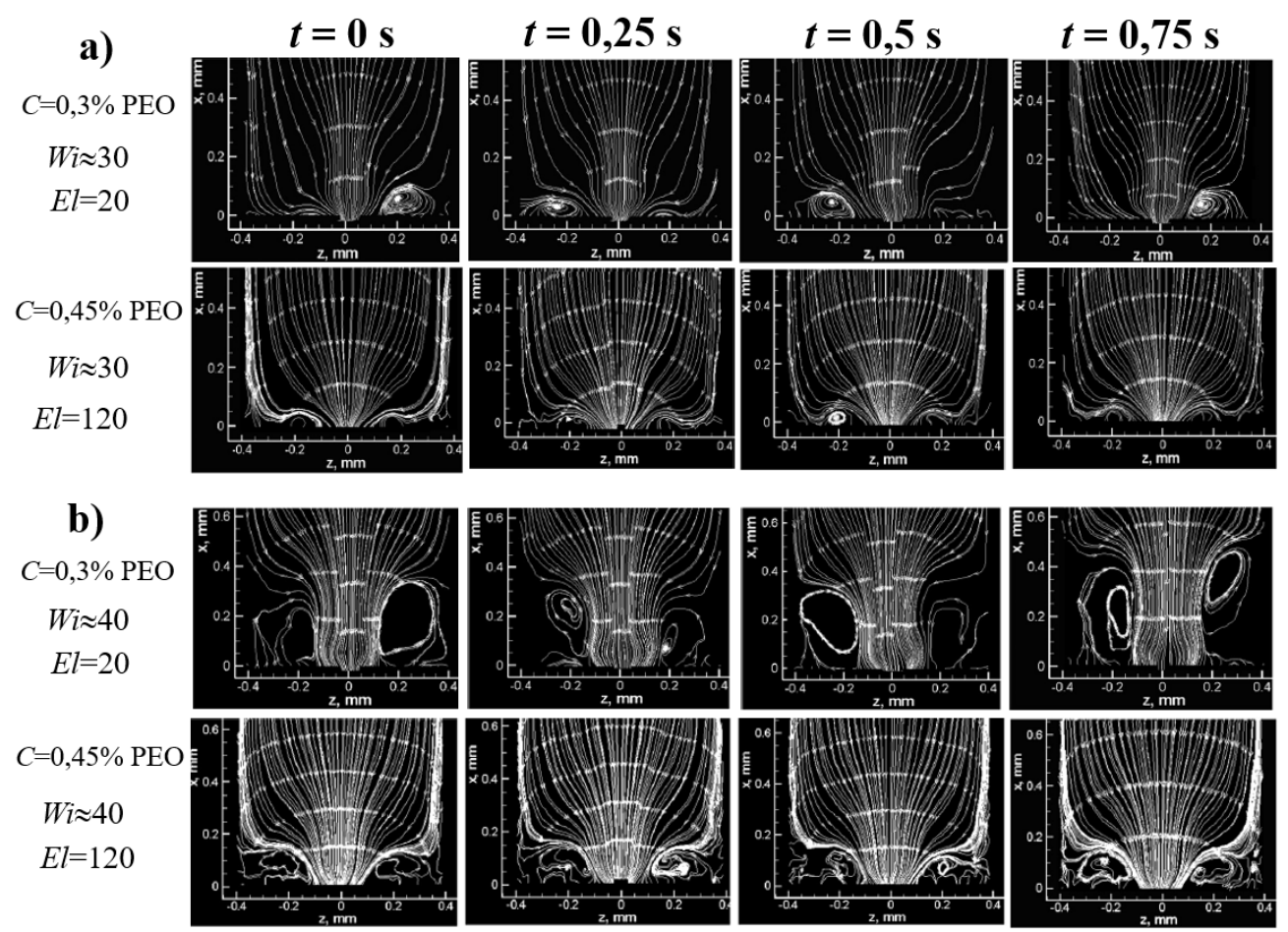

Figura 25 - Imagens com linhas de corrente capturados a cada intervalo de 0,25 s para duas concentrações de solução de PEO. a) $E l=20$ e $E l=120$ ambos a $W i \approx 30$. b) $E l=20$ e $E l=120$ ambos a $W i \approx 40$ realizado por $L i$ et al. (2011)

Para o caso do regime de vórtice de lábio ( $W i \approx 30)$, o vórtice apresenta um comportamento assimétrico para o $E l=20$ e $C=0,3 \%$ em peso da solução de PEO. Enquanto, o vórtice é estável e simétrico para o $E l=120$ e $C=0,45 \%$ em peso. Portanto, o vórtice de lábio é mais simétrico a altos números de elasticidade.

Para o caso do regime de vórtice de canto $(W i \approx 40)$, o escoamento é instável no tempo. Os vórtices de canto são mais simétricos a maior número de elasticidade $E l=120$ devido a que os efeitos elásticos são mais dominantes.

Li et al. (2011) estudou o comportamento dinâmico não-linear do escoamento à montante da constrição variando a geometria do escoamento através da $R c$ (4:1:4, 8:1:8 e 16:1:16) e o $L c(400$ e $4000 \mu \mathrm{m})$. A solução semidiluída de óxido de polietileno $\mathrm{PEO}\left(P M=4,8 \times 10^{6} \mathrm{~g} / \mathrm{mol}\right)$ à concentração de $0,3 \%$ em peso foi utilizada nos experimentos. A dinâmica não linear da solução de PEO foi investigada através 
da técnica de micro-PIV e de medidas da queda de pressão em uma ampla faixa de números de Weissenberg $(3<W i<120)$.

Os efeitos da relação de contração $R c$ mostraram qualitativamente diferentes vórtices dinâmicos à montante da constrição, como mostrado na figura 26.

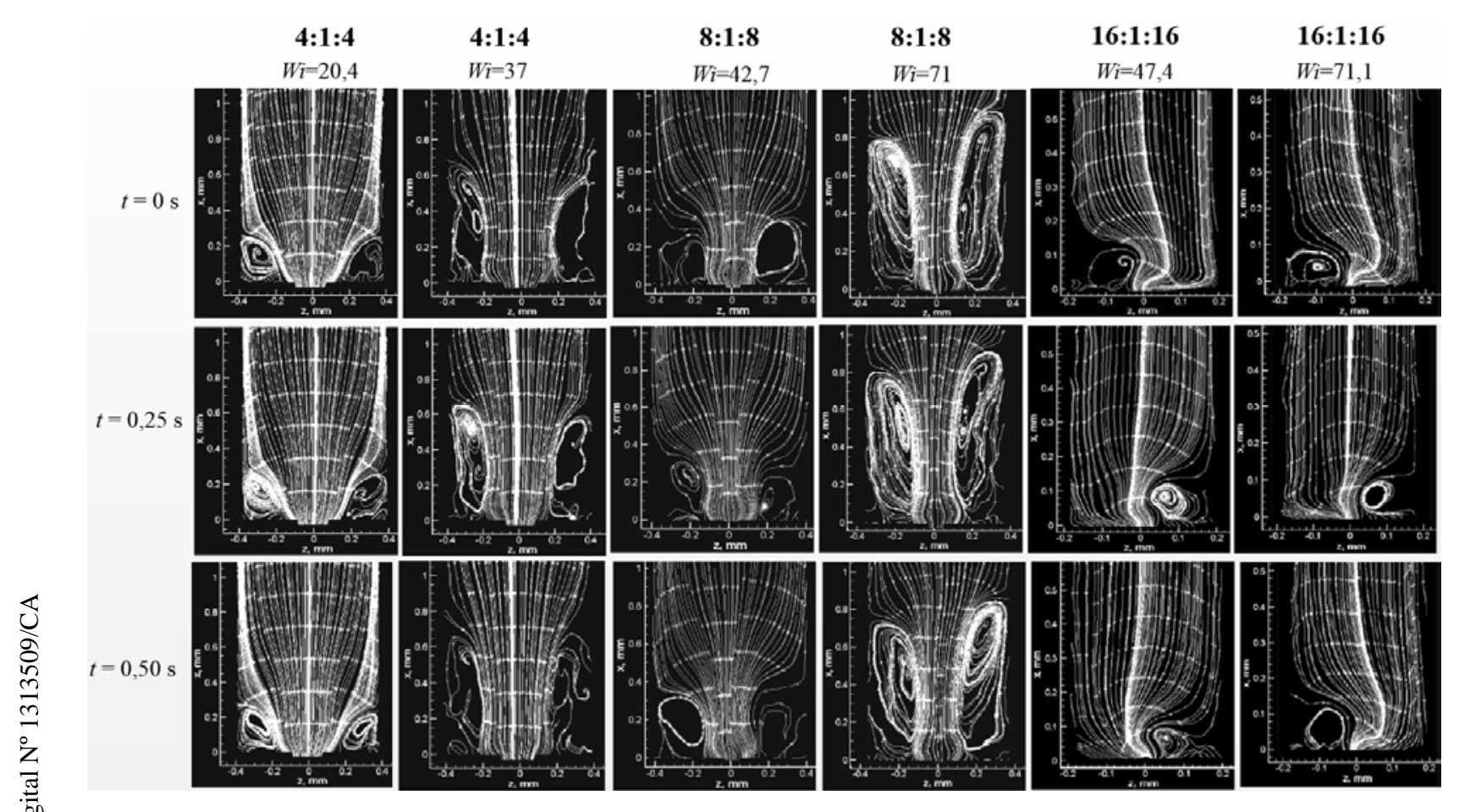

Figura 26 - Dinâmica temporal do escoamento da solução de $\operatorname{PEO}(C=0,3 \%$ em peso) à montante da constrição para diferentes $R c$ realizado por $L i$ et al. (2011)

A menor relação de contração $R c=4: 1$ mostrou apenas a presença de vórtices de canto estáveis e simétricos no tempo. Entretanto, para maiores relações de contração foi visualizada a formação de vórtices de lábio, seguido de vórtices de canto menos estáveis e menos simétricos conforme o número de Weissenberg foi aumentado. Portanto, a relação de contração é um parâmetro geométrico importante na classificação do regime do escoamento.

O efeito de variação de $R c$ e $L c$ na caracterização do tamanho do vórtice são representados nas figuras 27 e e 27 p para a solução de PEO à concentração de $0,3 \%$ em peso. 

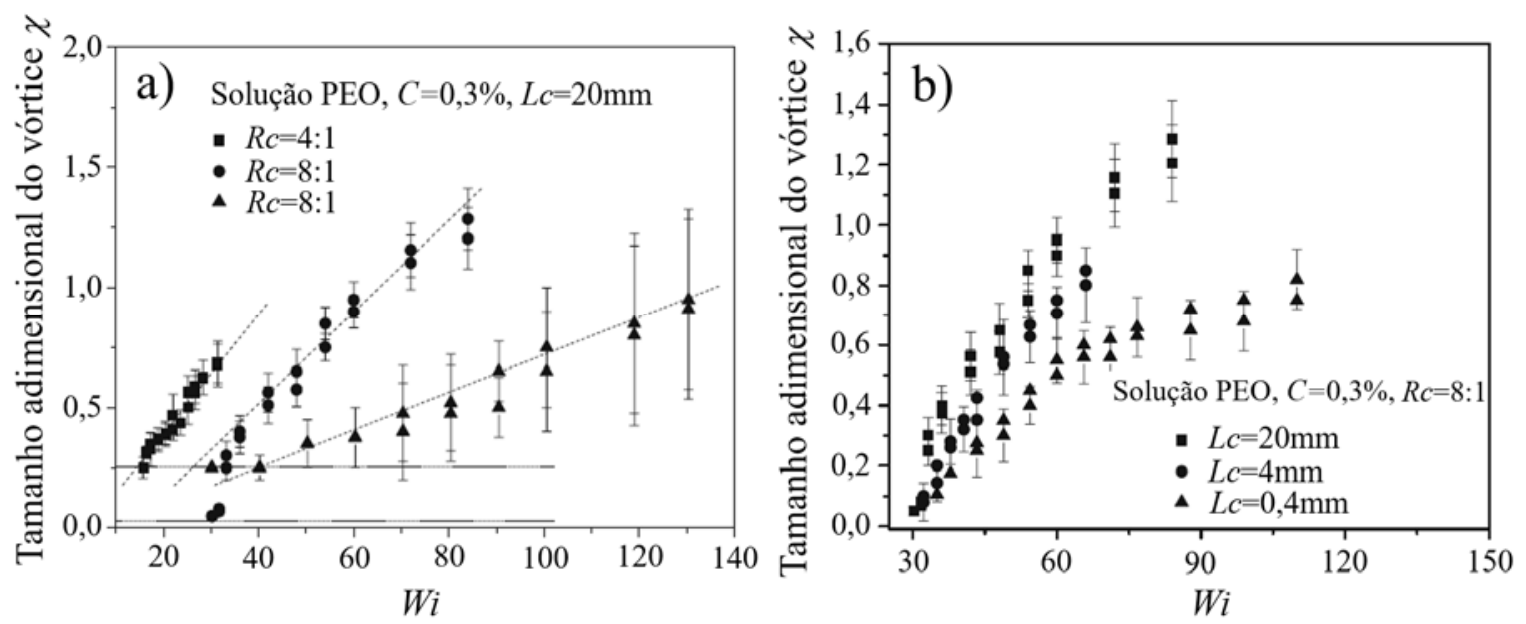

Figura 27 - Comprimento adimensional do vórtice em função do número de Wi. a) Para diferentes $R c$ e b) Para diferentes $L c$ realizado por $L i$ et al. (2011)

Para todos os valores da razão de contração $R c$ é observada uma relação quase linear entre o tamanho adimensional do vórtice de canto e o número de Wi. O aumento da barra de erro é devido a que o vórtice de canto se torna assimétrico e instável a maiores taxas de deformação.

Quando é incrementado o $L c$, a mudança entre um regime de escoamento a outro ocorre a um maior valor de Wi. Um maior $L c$ assegura a formação de um escoamento totalmente desenvolvido dentro da constrição, desacoplando os efeitos dinâmicos não linear à jusante da constrição sobre a dinâmica dos vórtices à montante da constrição e, consequentemente, aumentando o tamanho dos vórtices.

Os trabalhos citados anteriormente foram realizados com a finalidade de entender a instabilidade do escoamento viscoelástico à montante da constrição.

Entretanto, Li et al. (2015) estudou os efeitos da cinemática do escoamento à montante da constrição sobre o escoamento dentro da constrição utilizando uma solução de $\mathrm{PEO}\left(C=0,3 \%\right.$ em peso, $\left.P M=4,8 \times 10^{6} \mathrm{~g} / \mathrm{mol}\right)$ diluída em água deionizada escoando através de uma contração abrupta planar $(R c=8: 1=800 \mu \mathrm{m} / 100 \mu \mathrm{m}$, $L c=20 \mathrm{~mm}, h=45 \mu \mathrm{m})$. A cinemática do escoamento da solução viscoelástica de ambas as regiões foram investigadas utilizando a técnica de micro-PIV e medidas da queda de pressão em uma faixa de Weissenberg de $10,8<W i<256,2$. 
A figura 28 apresenta as linhas de corrente à montante da constrição e os campos de velocidade do escoamento na constrição (média amostral de 50 pares de imagens) medidos no plano central do canal para três regimes de escoamento.

a)

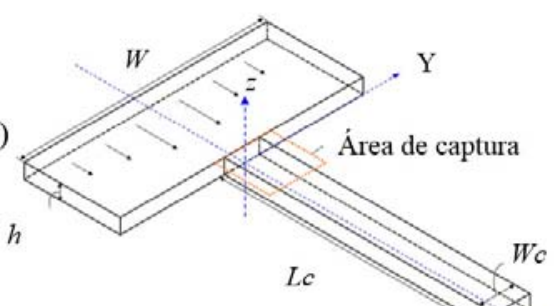

b) $W i=42,6(Q=2,0 \mathrm{ml} / \mathrm{h})$
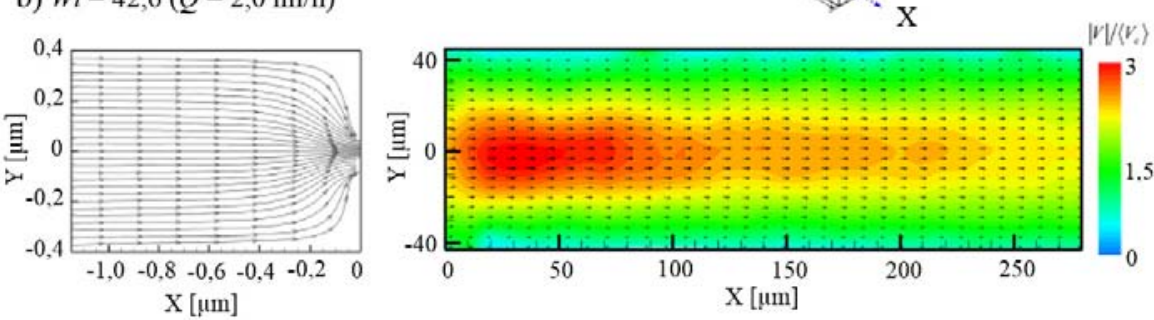

c) $W_{i}=85,5(Q=4,0 \mathrm{ml} / \mathrm{h})$
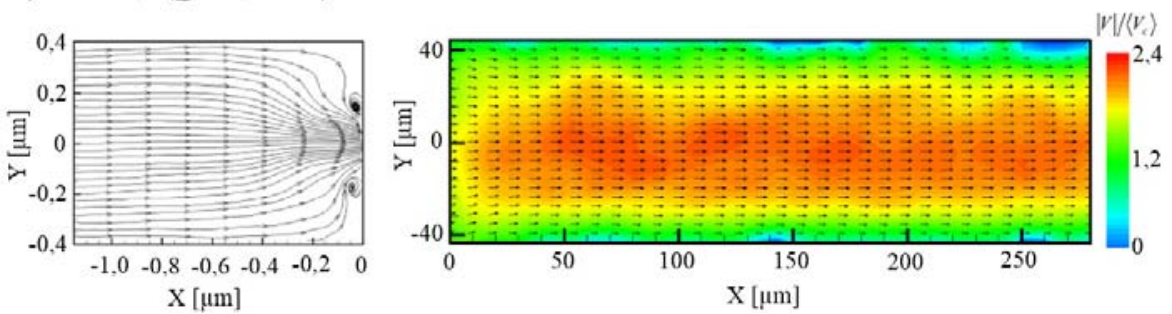

d) $W i=128,1(Q=6,0 \mathrm{ml} / \mathrm{h})$
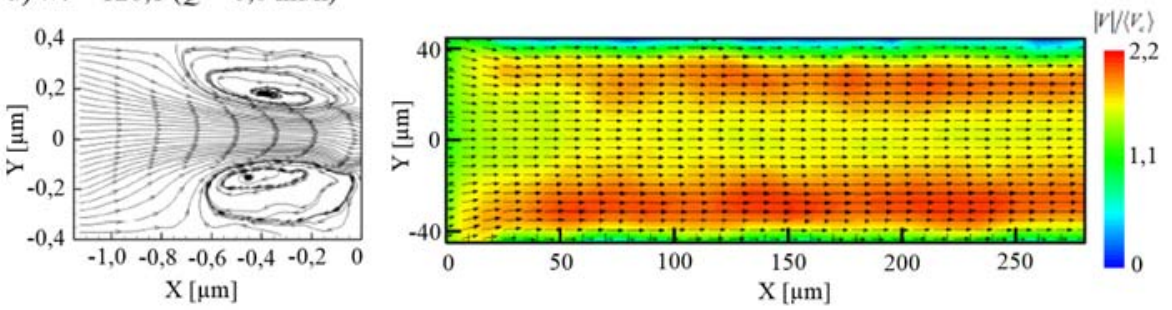

$W i=170,1(Q=8,0 \mathrm{ml} / \mathrm{h})$
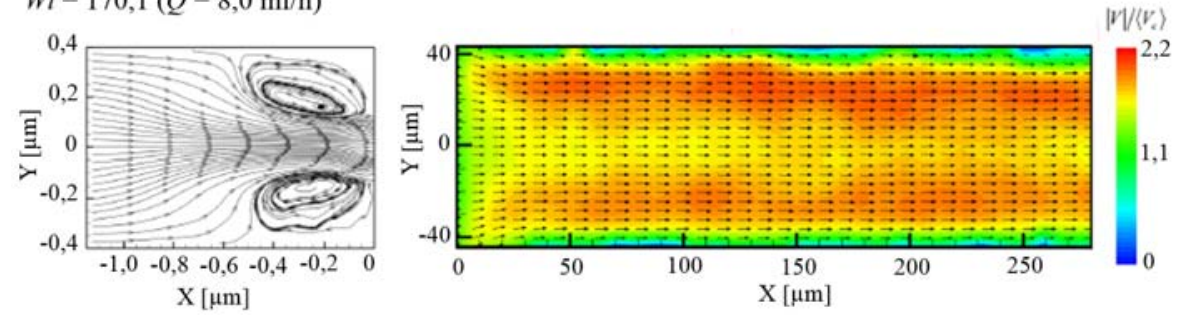

Figura 28 - a) Geometria do dispositivo microfluídico. b-d) Linhas de corrente à montante da constrição (esquerda) e campos de velocidade do escoamento dentro da constrição (direita) para quatro valores de Weissenberg realizado por Li et al. (2015) 
Para o primeiro regime de escoamento $(W i \leq 65)$, as linhas de corrente são simétricas e o campo vetorial de velocidade exibiu um aumento de velocidade na entrada da constrição, porém foi diminuindo à medida que passava pela constrição até atingir a região totalmente desenvolvida. Neste regime, as medidas da queda de pressão indicaram uma dependência fraca com o número de Weissenberg.

Para o regime de escoamento entre $65<W i<108$, a formação de vórtices de lábio foi visualizada, e um fluxo mais uniforme dentro da constrição foi observado.

Para a faixa de Weissenberg de $108 \leq W i \leq 171$, as linhas de corrente mostraram a etapa de formação e crescimento de vórtices de canto causado pelo aumento da viscosidade extensional na região central do escoamento à montante da constrição. A queda de pressão aumentara rapidamente conforme os vórtices de canto crescem. Entretanto, os campos de velocidade mostraram uma aparente redução de velocidade do escoamento na região central ao longo da constrição (perfis de velocidade em forma côncava). Este fenômeno foi explicado pelo aumento da viscosidade extensional local na região central da constrição induzido pelo escoamento extensional de entrada à montante da constrição, revelando a dependência com as condições do escoamento de entrada.

Um trabalho em paralelo foi realizado por Lee et al. (2014) e colaboradores para investigar o efeito da variação da relação de aspecto $R a$ sobre a dinâmica dos vórtices. Soluções poliméricas de PEO $\left(P M=2 \times 10^{6} \mathrm{~g} / \mathrm{mol}\right)$ para diferentes concentrações em peso $(0,3 \%, 0,4 \%, 0,5 \%, 0,6 \%, 0,7 \%$ e $1,0 \%)$ foram utilizadas e imagens com linhas de tinta permitiram visualizar os regimes de escoamento.

Em geral todos os padrões de escoamento mostraram a mesma sequência de evolução desde um padrão semelhante ao escoamento Newtoniano para um escoamento com crescimento de vórtices. De acordo às condições impostas no fluxo, alguns padrões não foram observados, como representado no resumo da figura 29. 


\begin{tabular}{|c|c|c|c|c|c|}
\hline a) & $\begin{array}{c}\text { Escoamento tipo } \\
\text { Newtoniano }\end{array}$ & $\begin{array}{l}\text { Vórtice } \\
\text { de lábio }\end{array}$ & $\begin{array}{l}\text { Vórtice } \\
\text { de canto }\end{array}$ & $\begin{array}{c}\text { Fluxo } \\
\text { divergente }\end{array}$ & $\begin{array}{l}\text { Crescimento } \\
\text { de vórtice }\end{array}$ \\
\hline \multicolumn{6}{|l|}{$\begin{array}{l}\text { Baixas relações } \\
\text { de aspecto }\end{array}$} \\
\hline & $Q=0,5$ Wi $=6,9$ & $Q=4,0 \mathrm{Wi}=55,6$ & & $Q=8,0 \quad W i=111,1$ & $Q=15 \quad W i=208,3$ \\
\hline \multicolumn{6}{|l|}{$\begin{array}{c}\text { Altas relações } \\
\text { de aspecto }\end{array}$} \\
\hline$R a \geq 0,25$ & $Q=0,1 \quad W i=7,4$ & $Q=0,8 \mathrm{Wi}=59,2$ & $Q=1,4 \quad W i=103,5$ & $Q=2,2 \quad W i=162,7$ & $Q=1,4 W i=124,1$ \\
\hline
\end{tabular}

\begin{tabular}{|c|c|c|c|c|c|}
\hline b) & $\begin{array}{c}\text { Escoamento tipo } \\
\text { Newtoniano }\end{array}$ & $\begin{array}{l}\text { Vórtice } \\
\text { de lábio }\end{array}$ & $\begin{array}{c}\text { Vórtice } \\
\text { de canto }\end{array}$ & $\begin{array}{c}\text { Fluxo } \\
\text { divergente }\end{array}$ & $\begin{array}{c}\text { Crescimento } \\
\text { de vórtice }\end{array}$ \\
\hline \multirow{2}{*}{$\begin{array}{l}\text { Baixo número de } \\
\text { elasticidade } \\
E l=\mathbf{3 0}\end{array}$} & & & & & \\
\hline & $Q=0,5$ Wi $=6,9$ & $Q=4,0 \quad W i=55,6$ & & $Q=8,0 \quad W i=111$, & $Q=15 \quad W i=208,3$ \\
\hline \multirow{2}{*}{$\begin{array}{l}\text { Alto número de } \\
\text { elasticidade } \\
E l=\mathbf{8 0 0}\end{array}$} & & & & & \\
\hline & $Q=0,3$ Wi $=3,4$ & $Q=1,0 \mathrm{Wi}=11,3$ & & & $Q=3,0 W i=34,0$ \\
\hline
\end{tabular}

Figura 29 - Padrões de escoamento. a) Para diferentes relações de aspecto $R \boldsymbol{a}$ b) Para diferentes números de elasticidade $E l$ realizado por Lee et al. (2014)

Lee et al. (2015) expandiu a investigação para soluções de PEO analisando o efeito da variação do peso molecular do polímero $\left(P M=2 \times 10^{6}\right.$ e $\left.5 \times 10^{6} \mathrm{~g} / \mathrm{mol}\right)$ sobre o escoamento passando pelo microcanal de contração abrupta de $R c=200 \mu \mathrm{m} / 50 \mu \mathrm{m}=4: 1$ e $h=70 \mu \mathrm{m}$. Soluções de PEO para diferentes concentrações em peso $(0,4 \%, 0,6 \%, 0,7 \%, 0,8 \%$ e $1,0 \%)$ foram utilizadas, e por meio de imagens com linhas de tinta foi determinado os diferentes regimes de escoamento.

A figura 30a apresenta dois tipos de estado do escoamento (estável e instável) para a concentração de 1,0\% em peso de PEO. A solução polimérica de menor peso molecular mostrou apenas os regimes de escoamento estáveis $\left(E l \sim 10^{3}\right)$. Enquanto, para a solução polimérica de maior peso molecular foram observados unicamente os regimes de escoamento instáveis $\left(E l \sim 10^{6}\right)$. A figura $30 \mathrm{~b}$ representa o regime de flutuação aperiódica do escoamento onde o tamanho dos vórtices varia rapidamente no tempo de forma caótica.

Esta investigação atingiu números de elasticidade $E l$ mais altos do que comparados com os trabalhos citados anteriormente, devido ao alto peso molecular, a alta concentração do polímero e as pequenas dimensões da constrição utilizada. O regime de flutuação aperiódica do vórtice foi citado pela primeira vez. 

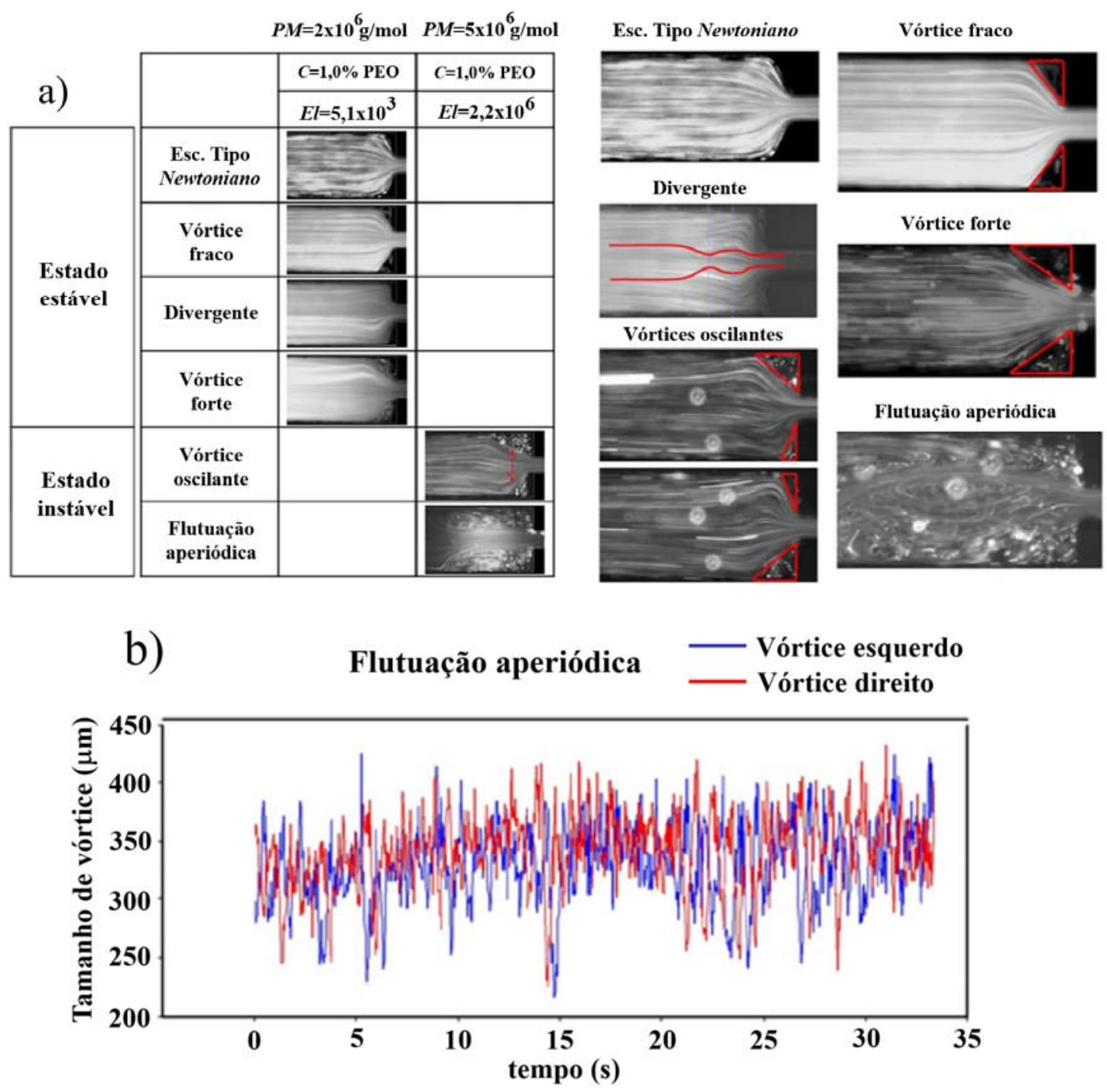

Figura 30 - a) Regimes de escoamento da solução de PEO ( $C=1,0 \%$ em peso). b) Tamanho dos vórtices no regime de flutuação aperiódica variando no tempo realizado por Lee et al. (2015)

Gulati et al. (2008) utilizou o microcanal de contração abrupta planar de $R c=200 \mu \mathrm{m} / 100 \mu \mathrm{m}=2: 1$ e $h=180 \mu \mathrm{m}$ para estudar o escoamento de soluções semidiluída de $\lambda$-DNA ( $P M=31,5 \times 10^{6}$ Da e forte comportamento shear thinning) a altos números de elasticidade $6,4 \times 10^{3}<E l<1,4 \times 10^{6}$ utilizando imagens com linhas de tinta, medições da queda de pressão e a técnica de velocimetria de imagem de partículas digital (DPIV).

As linhas de tinta mostraram o início de crescimento de vórtices de canto a um baixo número de Weissenberg $(W i \approx 4,2)$. À medida que a vazão foi incrementada, o crescimento dos vórtices de canto foi simétrico e estável. A figura 31 mostra os regimes observados através das imagens com linhas de tinta na faixa de elasticidade estudada. 

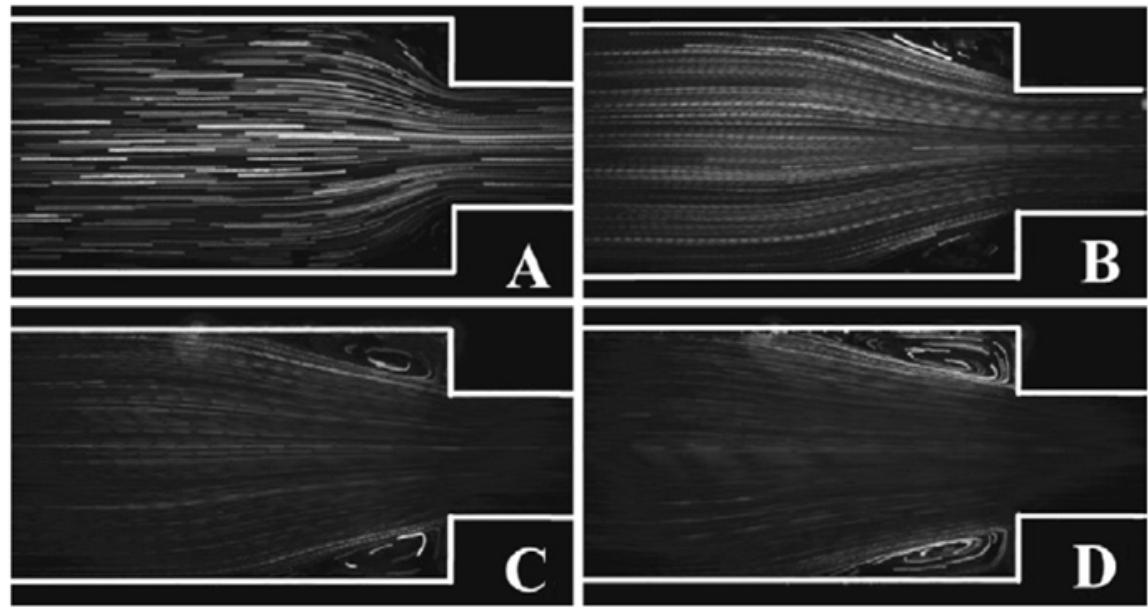

Figura 31 - Imagens com linhas de tinta à montante da constrição para o escoamento de $\lambda$-DNA e $R c=2: 1$ a) $W i=10,5$ e $E l=1,6 \times 10^{4}$. b) $W i=41,9$ e $E l=2,7 \times 10^{4}$. c) $W i=104,8$ e $E l=5,8 \times 10^{4}$. d) $W i=209,6$ e $E l=1,8 \times 10^{5}$ realizado por Gulati et al. (2008)

Em contraste, o trabalho de Rodd et al. (2005) apresentou diferentes regimes de escoamento (vórtice de lábio e fluxo divergente) não encontrados no trabalho de Gulati e colaboradores (2008). A discrepância foi atribuída devido ao comportamento shear thinning e a rigidez da molécula de $\lambda$-DNA, além da diferente relação de contração $R c=16: 1$ utilizada por Rodd.

As vazões de injeção e medidas da queda de pressão utilizada por Gulati et al. (2008) foram próximas ao nosso trabalho pelas dimensões da constrição, embora o tipo de geometria e o fluido viscoelástico utilizados foram diferentes.

Vale mencionar também investigações realizadas na geometria de contraçãoexpansão abrupta utilizando soluções aquosas de poliacrilamida (PPAm) para diferentes pesos moleculares, concentrações, relação de contração e são encontradas em detalhe nos trabalhos de Lanzaro et al. (2011) e (2014).

\subsubsection{3. Investigações experimentais realizadas em canais com diferentes constrições planar na escala micro}

O estudo do comportamento viscoelástico de soluções poliméricas na escala micro foram realizadas também para outros tipos de geometria. A seguir citaremos algumas investigações desenvolvidas nesta área de estudo. 
Os primeiros trabalhos em microfluídica utilizando soluções aquosas viscoelásticas foram realizados por Groisman et al. (2003) e (2004). Eles fabricaram microcanais de geometrias especiais com a finalidade de demonstrar que os diferentes fenômenos não lineares do escoamento de soluções viscoelásticas (resistência ao escoamento, anisotropia e metaestabilidade) gerados ao escoar por contrições possam ser utilizados como elementos de memória, lógica e de controle em circuitos eletrônicos, em circuitos microfluídicos integrados complexos, em aplicações médicas, entre outros.

Medidas da queda de pressão foram utilizadas para determinar a dependência com a vazão de operação, e a visualização do escoamento através das imagens com linhas de tintas permitiu observar os diferentes padrões do escoamento da solução de poliacrilamida PPAm $\left(P M=1,8 \times 10^{7} \mathrm{~g} / \mathrm{mol}\right)$.

A caracterização reológica e a quantificação do crescimento de vórtices não foram mostradas em detalhe. A medição da resistência, a anisotropia e a metaestabilidade do escoamento foram realizadas utilizando microcanais planar simples e em série mostrados na figura 32 .

a)
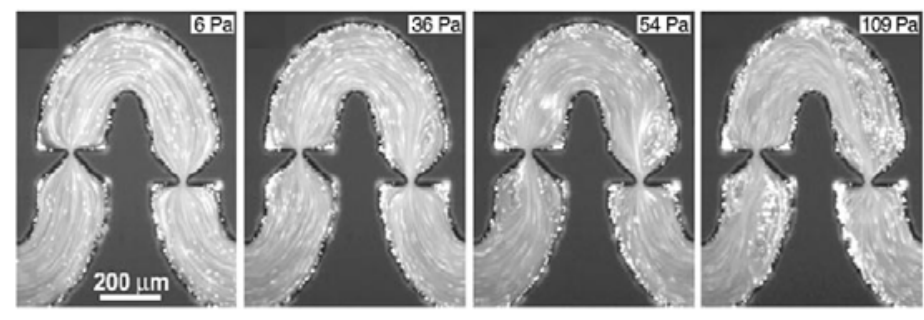

b)
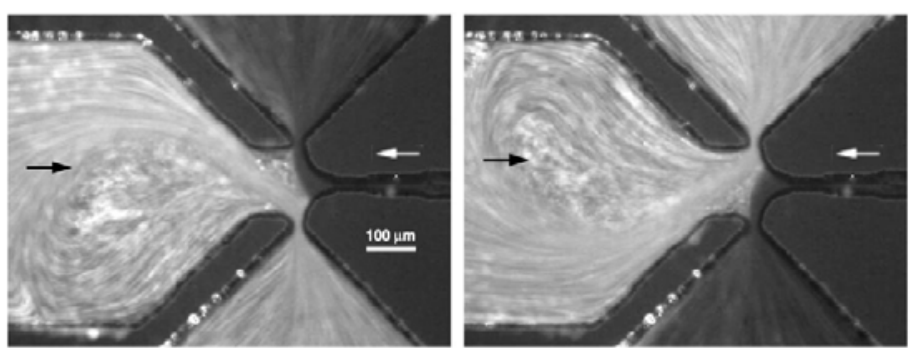

c)
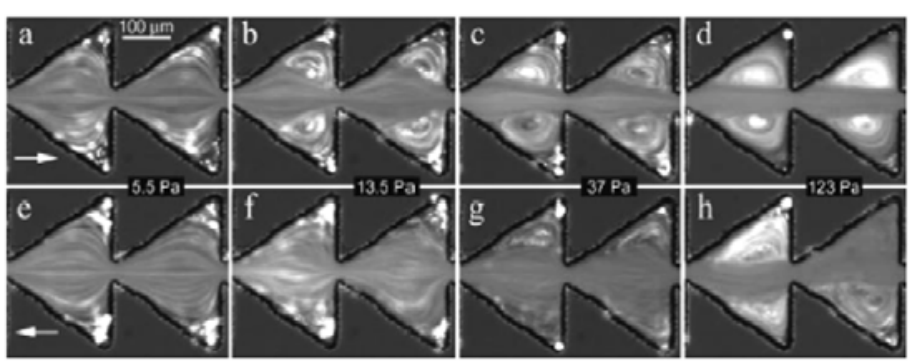

Figura 32 - a) Microcanais conectados em série (46 segmentos idênticos) de geometria elipsoidal planar. b) Microcanal de constrição cruzada. c) Microcanais conectados em série (43 segmentos idênticos) de geometria triangular planar realizados por Groisman et al. (2003) e (2004) 
Boek et al. (2006) apresentou resultados experimentais para o escoamento de fluidos micelares de EHAC (mistura de surfactante, isopropanol e $\mathrm{KCl}$ ) escoando através de microcanais conectados em série com geometria expansão-contração de $R c=160 \mu \mathrm{m} / 40 \mu \mathrm{m}=4: 1$. Campos de velocidade do escoamento foram medidos utilizando a técnica de micro-velocimetria por imagem de partículas para demonstrar a resposta complexa do fluido ao passar por constrições.

A figura 33 representa o campo vetorial de velocidade média determinado a partir da media amostral (ensemble average) de 20 pares de imagens consecutivas. No caso da água (figura 33a), o campo vetorial de velocidade foi bastante simétrico (comportamento semelhante de um escoamento Newtoniano). Para a solução viscoelástica de EHAC (figura 33b), o campo vetorial mostrou um escoamento tipo jato e nas esquinas salientes do microcanal a presença de vórtices (Moffatt, 1963).
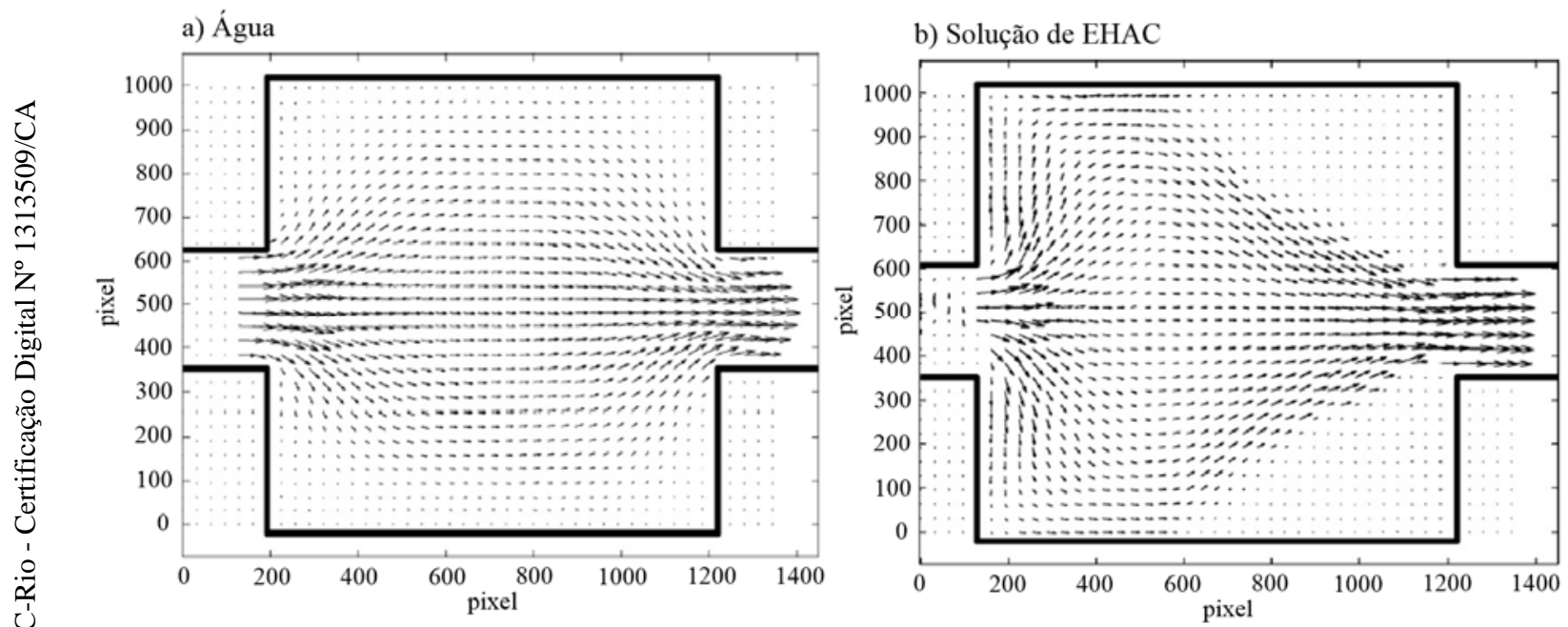

Figura 33 - Campo vetorial de velocidade média a) Escoamento de água b) Escoamento da solução de EHAC realizado por Boek et al. (2006)

Quando o campo vetorial de velocidade foi analisado a partir de um par de imagens (campo instantâneo), o escoamento de água foi encontrado estável no tempo (figura 34a), porém o escoamento da solução de EHAC apresentou flutuações de velocidade na região da constrição (figura 34b). Essas flutuações foram visualizadas também nas soluções poliméricas escoando em constrições na escala macro (Larson, 1992) e foram chamadas de turbulência elástica por alguns investigadores (Groisman et al., 2000). 
a) Água
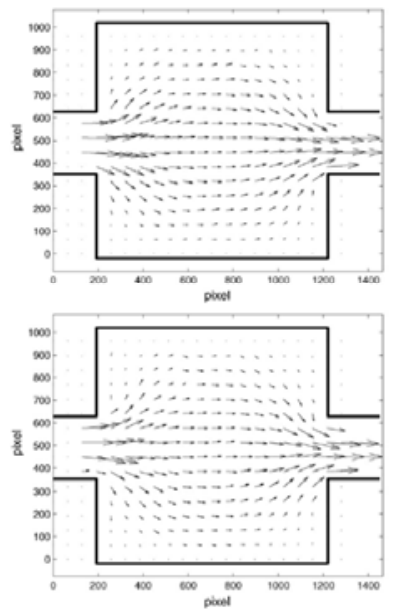

b) Solução de EHAC
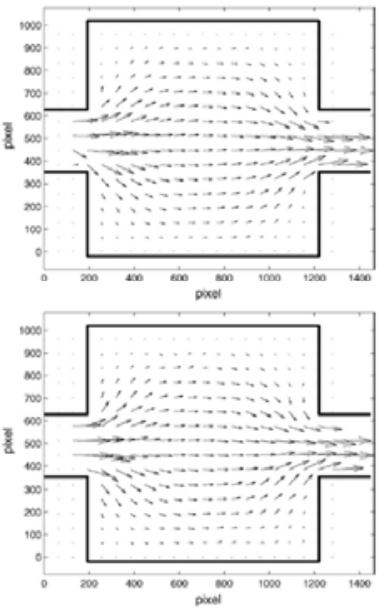
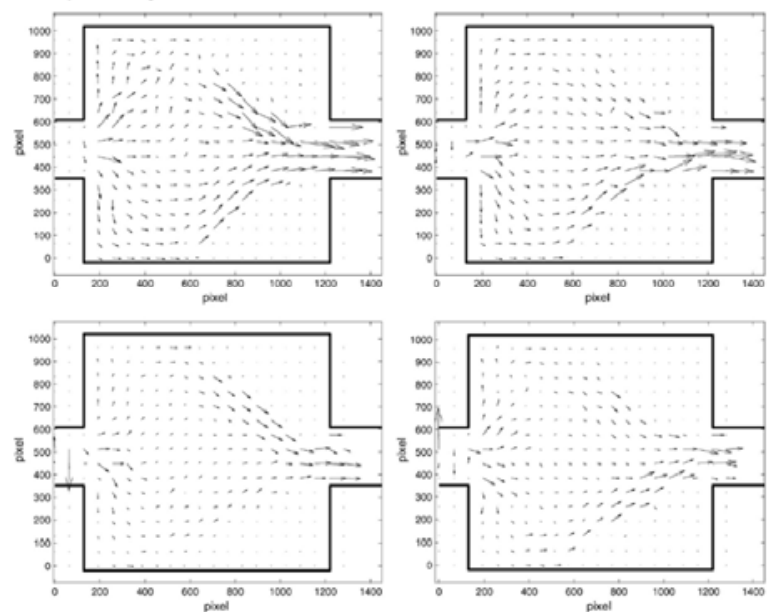

Figura 34 - Campos de velocidade instantâneos consecutivos a) Escoamento de água b) Escoamento de solução de EHAC realizado por Boek et al. (2006)

Neves et al. (2006) investigou o comportamento extensional do escoamento de uma solução aquosa de PEO $\left(C=0,1 \%\right.$ em peso e $\left.P M=2 \times 10^{6} \mathrm{~g} / \mathrm{mol}\right)$ através de um microcanal de geometria planar de contração hiperbólica e expansão abrupta $(R c=400 \mu \mathrm{m} / 54,1 \mu \mathrm{m}=37: 5, h=46 \mu \mathrm{m}$ e $L c=128 \mu \mathrm{m})$. A cinemática do escoamento foi visualizada por meio de linhas de tinta e quantificada através de medidas da queda de pressão.

A figura 35 apresenta a geometria da constrição, as medidas da queda de pressão e os diferentes regimes de escoamento para o número de elasticidade $E l=0,087$.
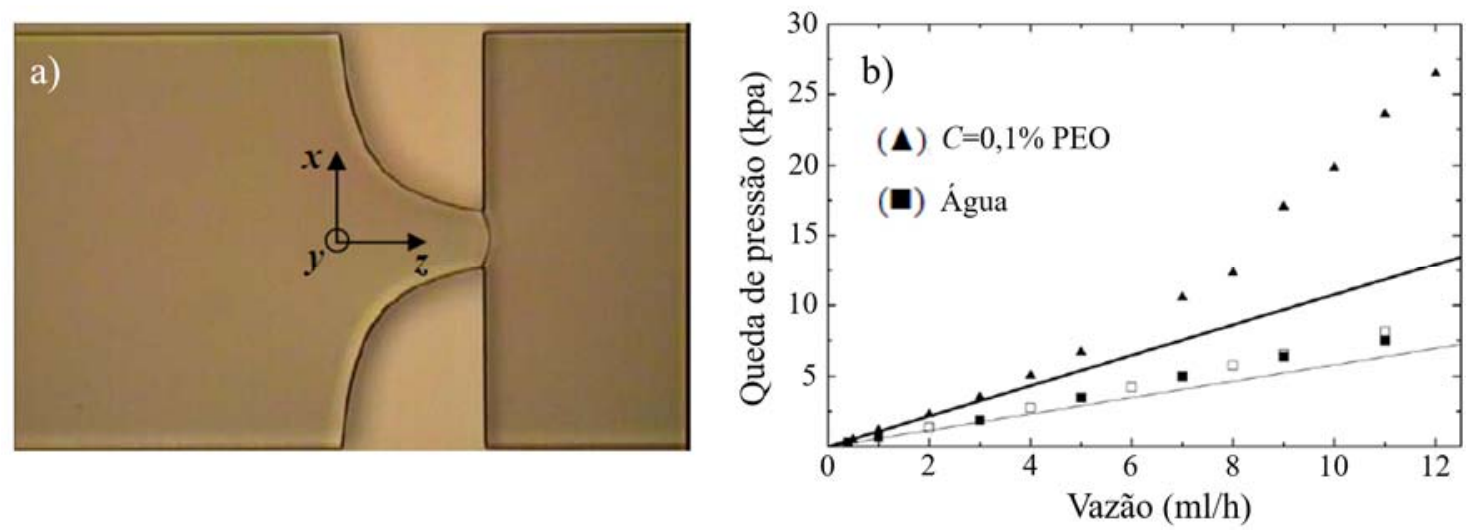


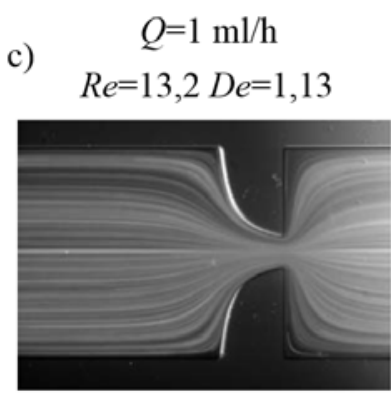

$$
Q=7 \mathrm{ml} / \mathrm{h}
$$

$R e=92,3 \quad D e=7,93$

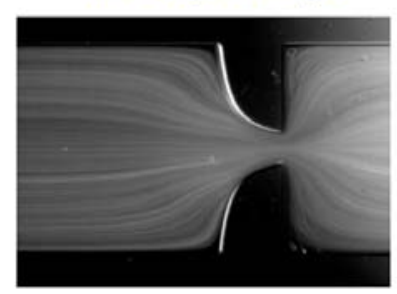

$Q=3 \mathrm{ml} / \mathrm{h}$

$$
R e=39,6 D e=3,40
$$

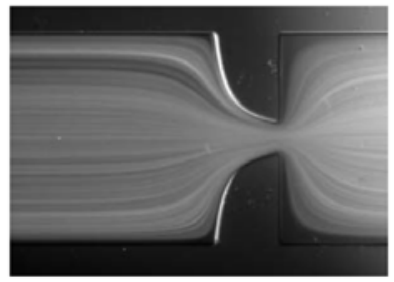

$Q=9 \mathrm{ml} / \mathrm{h}$

$$
R e=119,0 D e=10,2
$$

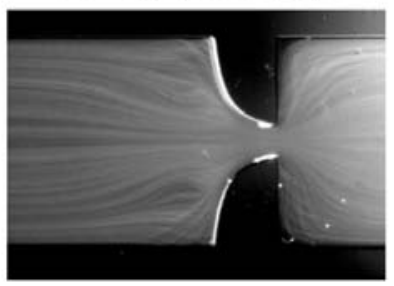

$Q=5 \mathrm{ml} / \mathrm{h}$

$R e=66,0 D e=5,66$

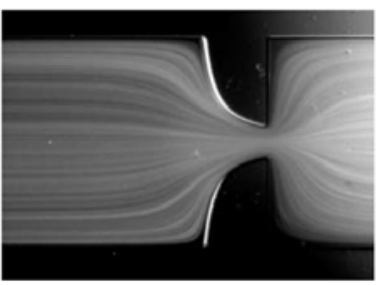

$Q=11 \mathrm{ml} / \mathrm{h}$

$R e=145,0 D e=12,5$

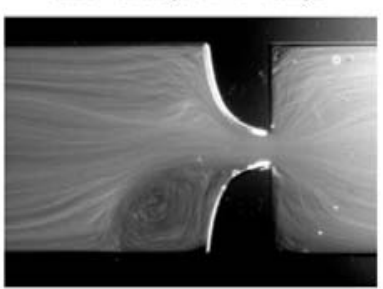

Figura 35 - a) Microcanal com contração hiperbólica e expansão abrupta planar b) Queda de pressão vs. vazão c) Imagens com linhas de tinta do escoamento da solução de PEO $(C=0,1 \%$ em peso) para diferentes vazões de injeção realizado por Neves et al. (2006)

À vazão crítica $Q_{c r i t} \approx 7 \mathrm{ml} / \mathrm{h}$, uma resposta não linear da queda de pressão em relação à vazão é observada para a solução de PEO, e coincide com o início dos efeitos elásticos através da formação de linhas de corrente divergente no escoamento $\left(Q_{c r i t}=7 \mathrm{ml} / \mathrm{h}\right.$ e $\left.D e=7,93\right)$ seguido da presença e crescimento de vórtices. O aumento da queda de pressão está associado com o incremento da viscosidade extensional a altas taxas de deformação (Rodd et al., 2005).

Na figura 36 é mostrado os efeitos ao variar a relação $L c / W c$ sobre o início da instabilidade elástica global na cinemática do escoamento visualizado através das imagens com linhas de tinta.

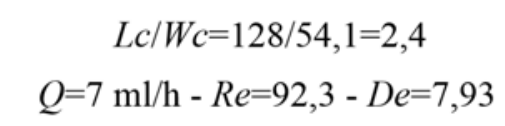

a)

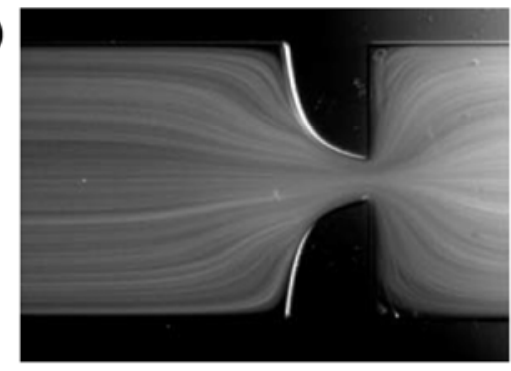

$L c / W c=382 / 19,9=19,2$

$Q=3 \mathrm{ml} / \mathrm{h}-R e=39,6-D e=2,26$

b)

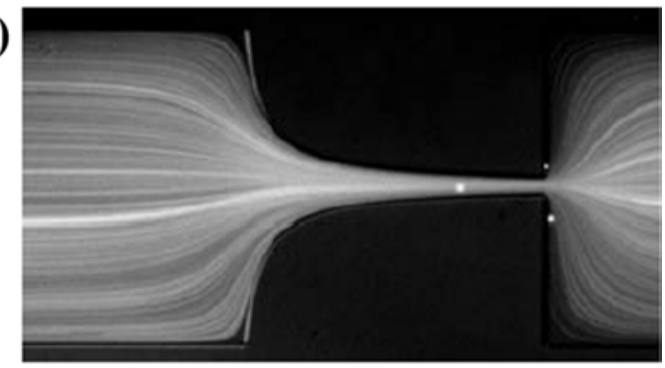

Figura 36 - Imagens com linhas de tinta mostrando o início dos efeitos elásticos para a relação a) $L c / W c=2,4$ e b) $L c / W c=19,2$ realizado por Neves et al. (2006) 
É observado que os efeitos elásticos para ambos os casos iniciam no regime de escoamento de linhas divergentes, porém o ponto crítico foi deslocado para um menor número de Deborah à medida que a relação $L c / W c$ foi maior. Os efeitos elásticos da solução polimérica foram ativados antecipadamente para maiores relações de $L c / W c$.

McKinley et al. (2007) continuou as investigações do comportamento extensional do escoamento de uma solução aquosa de PEO através da mesma geometria hiperbólica utilizando diferentes concentrações em peso de PEO $(0,05 \%$, $0,1 \%$ e $0,3 \%$ ) e $P M=2 \times 10^{6} \mathrm{~g} / \mathrm{mol}$. A cinemática do escoamento foi visualizada através de linhas de tinta, e a quantificação do escoamento por meio de medidas da queda de pressão.

A figura 37 representa a viscosidade extensional aparente para cada solução de PEO em função da taxa de extensão.

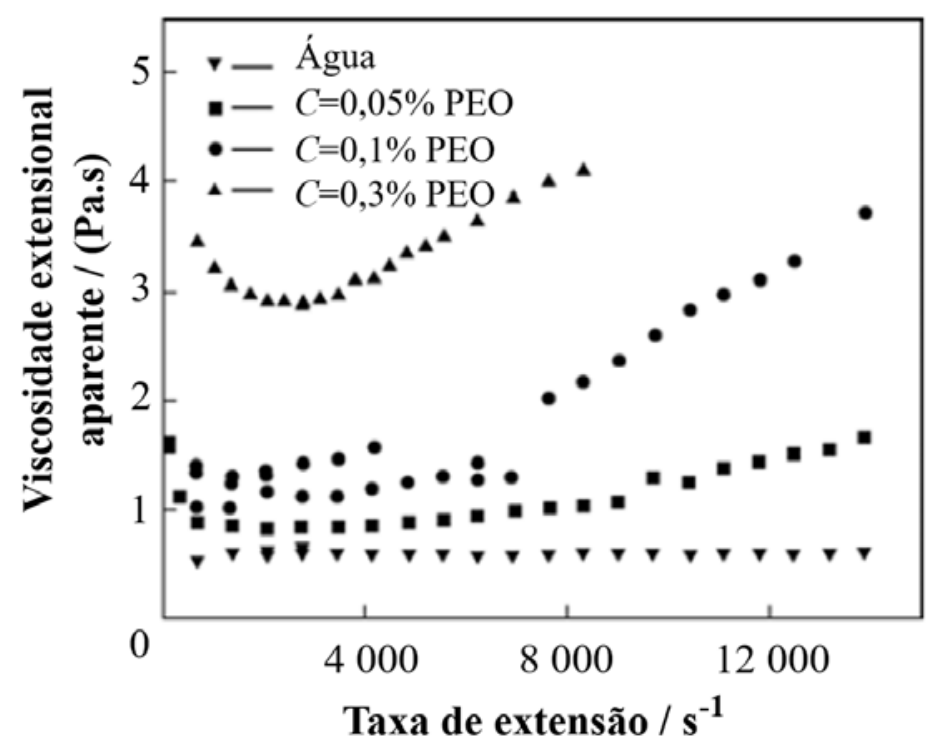

Figura 37 - Medidas da queda de pressão através da constrição reportados como viscosidade extensional aparente realizado por McKinley et al. (2007)

Os resultados revelaram que à medida que a concentração do polímero foi aumentada (maiores tempos de relaxação), a taxa de extensão crítica foi menor (diretamente relacionada com o número de Deborah) e a magnitude da viscosidade extensional aumentou. As imagens com linhas de tinta mostraram os mesmos regimes de escoamento observado por Neves et al. (2006). 
Os fenômenos observados nos escoamentos de fluidos viscoelásticos através de geometrias de contração hiperbólica são qualitativamente similares aos de geometria de contração abrupta planar.

Outras investigações em constrições hiperbólicas avaliando os efeitos da variação do peso molecular e a concentração do polímero sobre o comportamento não linear de escoamentos viscoelásticos de soluções de poliacrilamida PPAm podem ser encontrados nos trabalhos de Deano et al. (2011) e Lanzaro et al. (2014).

Neves et al. (2011) investigou a dinâmica do escoamento à montante da geometria de contração abrupta-expansão hiperbólica utilizando uma solução aquosa de PEO ( $C=0,4 \%$ em peso e $\left.P M=8 \times 10^{6} \mathrm{~g} / \mathrm{mol}\right)$ diluída em uma mistura de água/glicerina em peso $(66,6 \% / 33,4 \%)$. A geometria utilizada apresentou as seguintes dimensões: $R c=400 \mu \mathrm{m} / 62,5 \mu \mathrm{m}=6,4: 1, L c=123 \mu \mathrm{m}$ e $h=45 \mu \mathrm{m}$. A técnica de visualização através de imagens com linhas de tinta ajudaram a identificar os diferentes regimes do escoamento.

A figura 38a ilustra a geometria utilizada. As figuras $38 \mathrm{~b}$ e $38 \mathrm{c}$ mostram o efeito da variação da vazão sobre a natureza do escoamento determinados experimentalmente e numericamente.

A sequência de transições de regime de escoamento inicia-se com um fluxo tipo Newtoniano (estável), finalizando com um escoamento instável onde o tamanho dos vórtices varia aleatoriamente no tempo e é acompanhado de escoamentos secundários. Simulações numéricas em 2D realizadas por Alves et al. (2005) mostraram qualitativamente os mesmos padrões de escoamento utilizando o modelo constitutivo Oldroyd-B (figura 38c). 


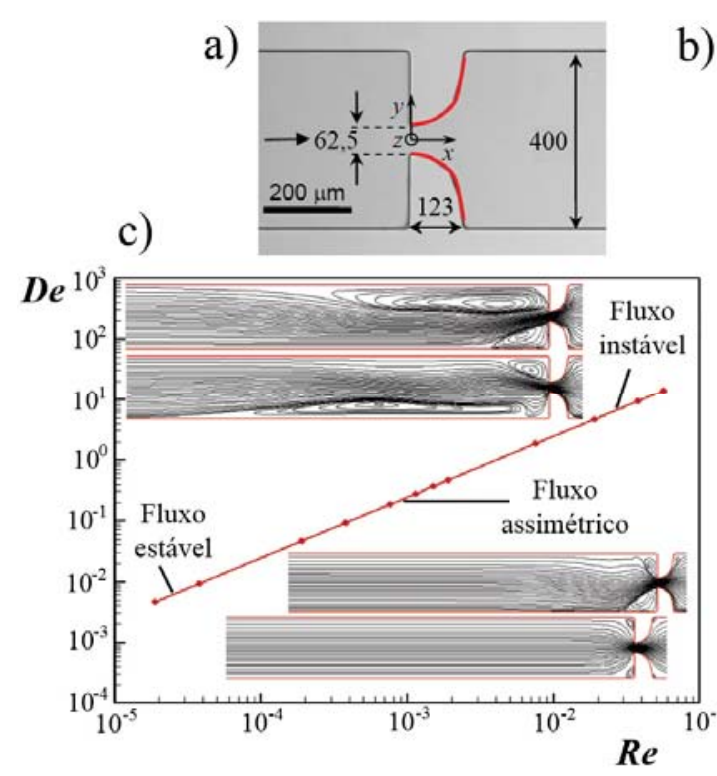

b)

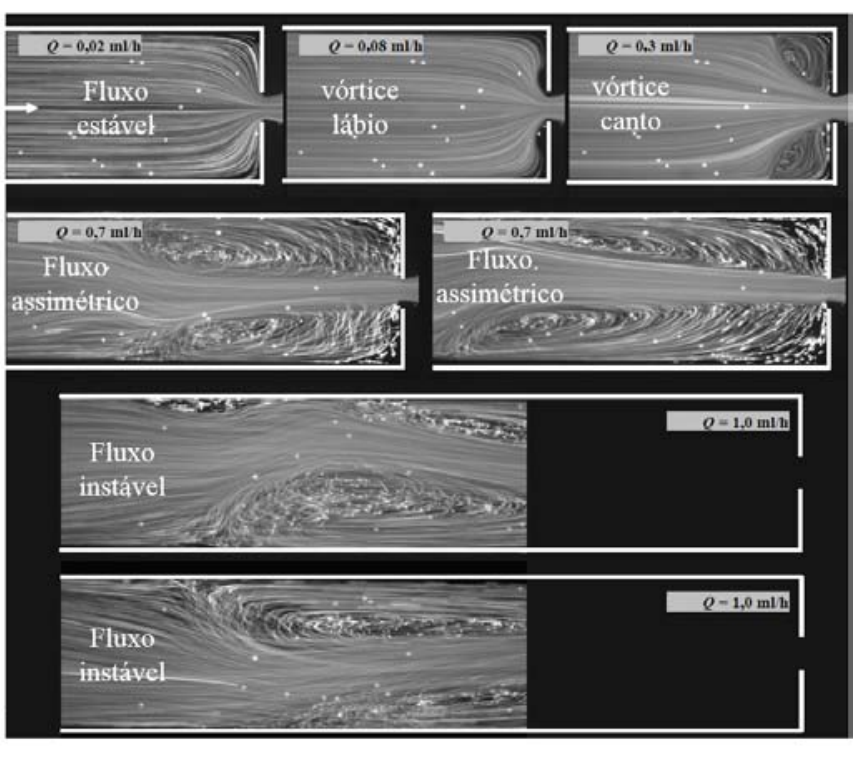

Figura 38 - a) Constrição de geometria contração abrupta-expansão hiperbólica. b) Regimes de escoamento realizados experimentalmente por Neves et al. (2011). c) Regimes de escoamento determinados numericamente por Alves et al. (2005)

Sousa et al. (2011) estudou o escoamento viscoelástico de uma solução de PEO $\left(C=0,1 \%\right.$ em peso e $\left.P M=8 \times 10^{6} \mathrm{~g} / \mathrm{mol}\right)$ sendo injetado em ambas as direções através de microcanais de forma hiperbólica conectadas em série $(W=326 \mu \mathrm{m}$, $W c=70 \mu \mathrm{m}$ e $L c=128 \mu \mathrm{m})$. A visualização do escoamento foi realizada através de linhas de tinta, e o campo de velocidade foi investigado por meio da técnica de micro-PIV.

A figura 39a apresenta as linhas de tinta para as duas direções de fluxo. A velocidade axial ao longo da linha central do microcanal (5 elementos) medido por meio da técnica experimental de micro-PIV é representada na figura $39 \mathrm{~b}$. 
$1^{\circ}$ Condição: $R e=0,070-D e=12,9$

a)

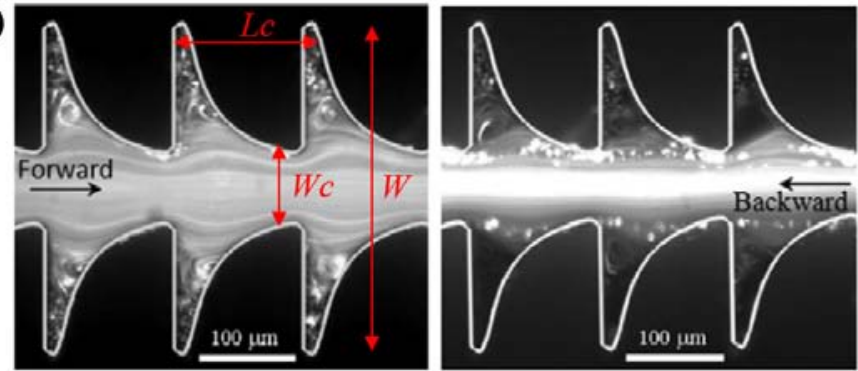

$2^{\circ}$ Condição: $R e=0,23-D e=43,1$
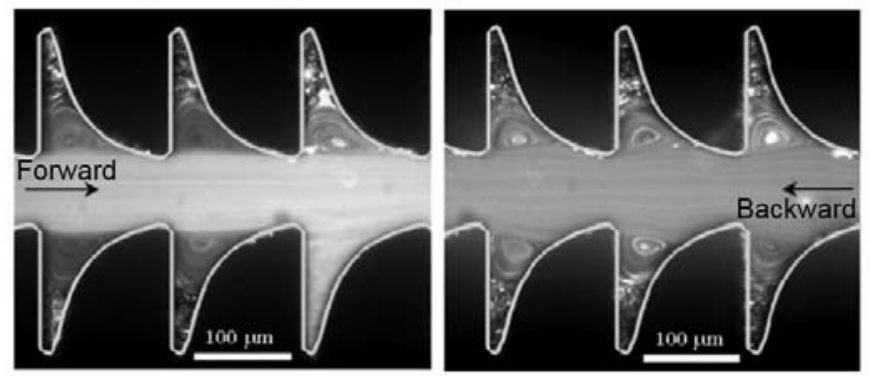

Velocidade axial normalizada ao longo do centro da linha
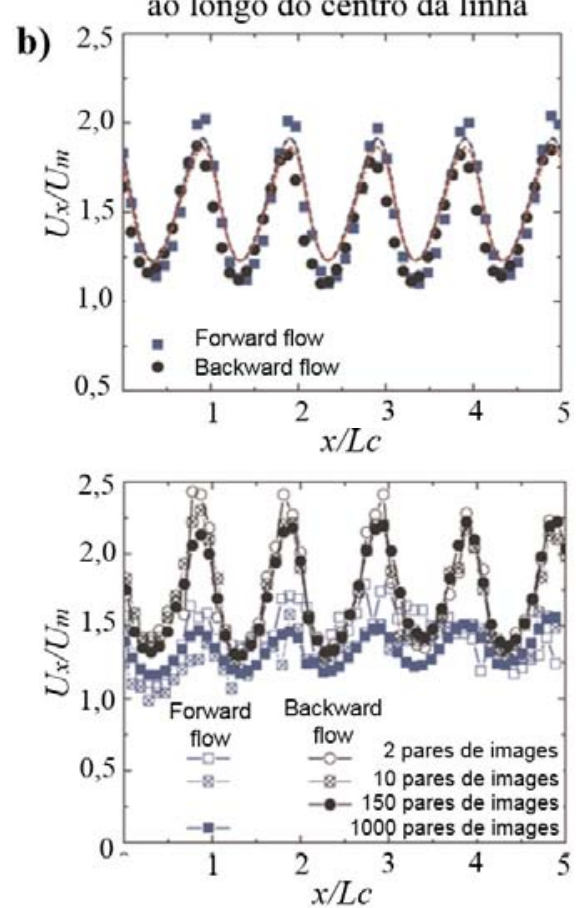

Figura 39 - a) Microcanais conectados em série (42 segmentos idênticos) de geometria elipsoidal planar para duas condições de escoamento injetadas em ambas as direções. b)

Perfil de velocidade axial normalizada ao longo da linha central do microcanal (5 segmentos) realizado por Sousa et al. (2011)

Para a primeira condição de escoamento $(D e=12,9)$, recirculações estáveis dentro dos cantos hiperbólicos foram observadas, e a velocidade axial na linha central do microcanal mostrou o mesmo perfil sinusoidal para ambas as direções (forward and backward).

Para a segunda condição de escoamento $(D e=43,1)$, as recirculações dentro dos cantos se tornaram assimétricas e instáveis na direção do escoamento (forward). Enquanto na direção oposta (backward), as recirculações continuaram estáveis. A velocidade axial na linha central determinada a partir da media amostral de vários pares de imagens mostra a diferença de amplitudes de oscilação entre ambas as direções, confirmando que o início da instabilidade elástica ocorre a um menor número de Deborah na direção do escoamento do que na direção oposta.

No trabalho de Sousa et al. (2010) é encontrado resultados para soluções de PAAm utilizando geometrias hiperbólica e triangular, mostrando comportamentos similares. 
Gulati et al. (2015) estudou experimentalmente o escoamento de soluções de $\lambda$-DNA $\left(P M=31,5 \times 10^{6} \mathrm{~g} / \mathrm{mol}\right)$ através de uma contração gradual convexa e de saída gradual a altos números de $E l\left(\sim 10^{4}\right.$ e $\left.10^{5}\right)$, como ilustrado na figura 40.

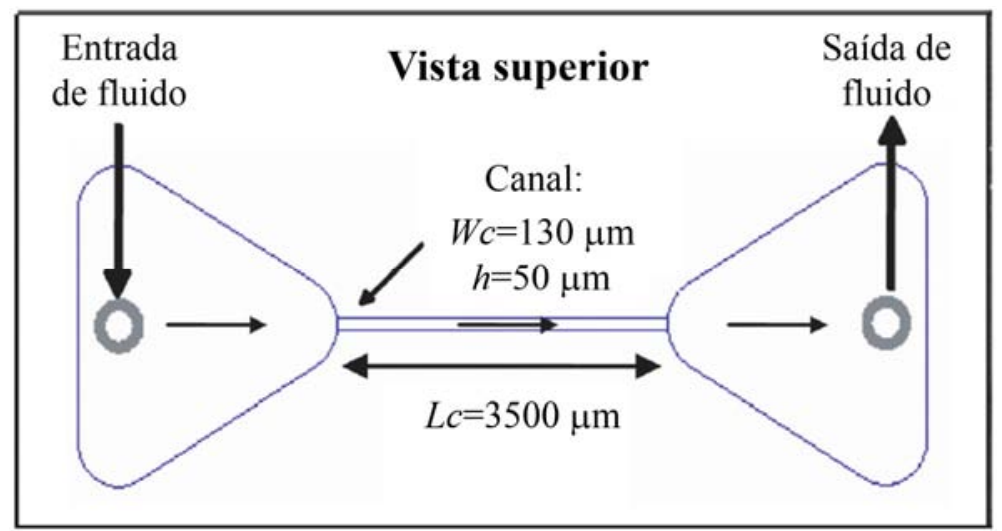

Figura 40 - Dispositivo microfluídico planar de entrada convexa utilizado por Gulati et al. (2015)

O objetivo da investigação foi estudar a cinemática dentro da região do vórtice para esta geometria em particular. A figura 41 exibe as partículas nas imagens capturadas por micro-PIV e os campos vetoriais de velocidade para dois regimes de escoamento.

a) Regime sem vórtices

b) Regime com vórtices
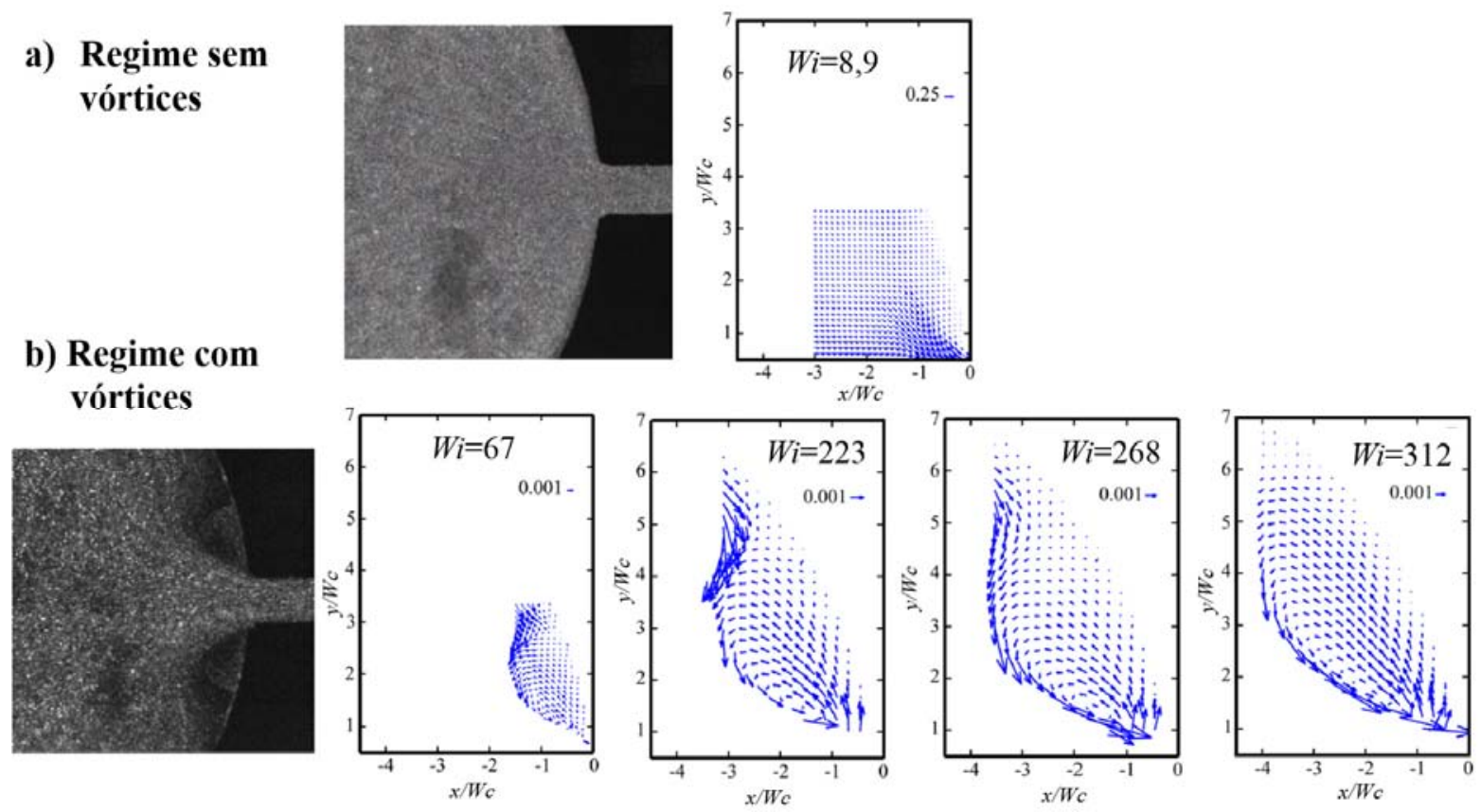

Figura 41 - Imagens do escoamento da solução de $\lambda$-DNA com partículas traçadoras e campos de velocidade à montante da constrição. a) Regime sem presença de vórtices. b) Regime com presença de vórtices realizado por Gulati et al. (2015) 
Os campos de velocidade revelaram um regime de escoamento sem presença de vórtices a baixos números de Weissenberg Wi $\leq 8,9$ (figura 41a). Entretanto para $W i>8,9$ (figura 41b), o início e crescimento de vórtices ocorreu de forma simétrica e estável, coincidindo com o incremento da queda de pressão no escoamento. Além disso, o campo vetorial de velocidade dentro do vórtice, determinado a partir da media amostral de 300 pares de imagens, mostrou um rápido crescimento do centro do vórtice na direção axial em comparação com a direção perpendicular.

\subsubsection{4.}

\section{Investigações experimentais realizadas em micromodelos}

A maioria de resultados apresentados na seção anterior para microcanais simples e conectados em serie são utilizados para aplicações de impressão por jato de tinta, desenho e operação de sistemas de análises, para o desenvolvimento de bombas microfluídicas, dispositivos integrados, reômetros microfluídicos, aplicações biológicas (DNA), entre outros.

Para investigações na indústria de petróleo, dispositivos microfluídicos formado por redes de canais de geometria complexa são utilizados para simular escoamentos em meios porosos, permitindo a visualização do escoamento na escala de poros e determinação da saturação de óleo residual.

A seguir, citaremos alguns trabalhos estudando o efeito da viscoelasticidade de soluções poliméricas sobre a distribuição dos fluidos em meios porosos utilizando dispositivos microfluídicos.

Miranda (2015) injetou uma solução polimérica de PEO ( $C=0,1 \%$ em peso) dentro de um dispositivo microfluídico (figura 42), com a finalidade de entender o efeito da viscoelasticidade da solução polimérica na redução da saturação de óleo remanescente no meio poroso. Os resultados de saturação foram comparados com as injeções de líquidos Newtonianos, água e uma solução de glicerina em água ( $C=51 \%$ em peso), e quantificados através do processamento de imagens em várias regiões do micromodelo, a diferentes vazões. É importante mencionar que as soluções de glicerina em água e PEO foram preparadas à mesma viscosidade e foram maiores do que a viscosidade da água. 

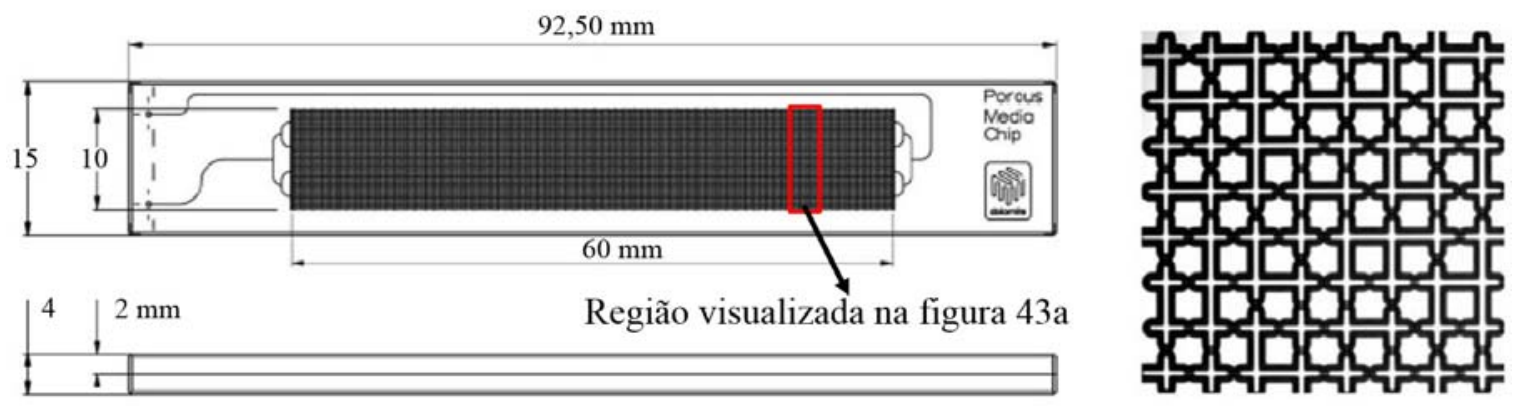

Figura 42 - Dispositivo microfluídico de vidro utilizado por Miranda (2015)

As imagens da região do escoamento da figura 43a mostra a saturação ao final da injeção dos líquidos para a vazão de $Q=4,16 \mathrm{ml} / \mathrm{h}$. Foi observado que a injeção da solução de PEO produz um maior deslocamento de gânglios de óleo do que comparado com a solução de glicerina e água, levando uma menor saturação de óleo residual para altos números de capilaridade, como visualizada na figura 43b.

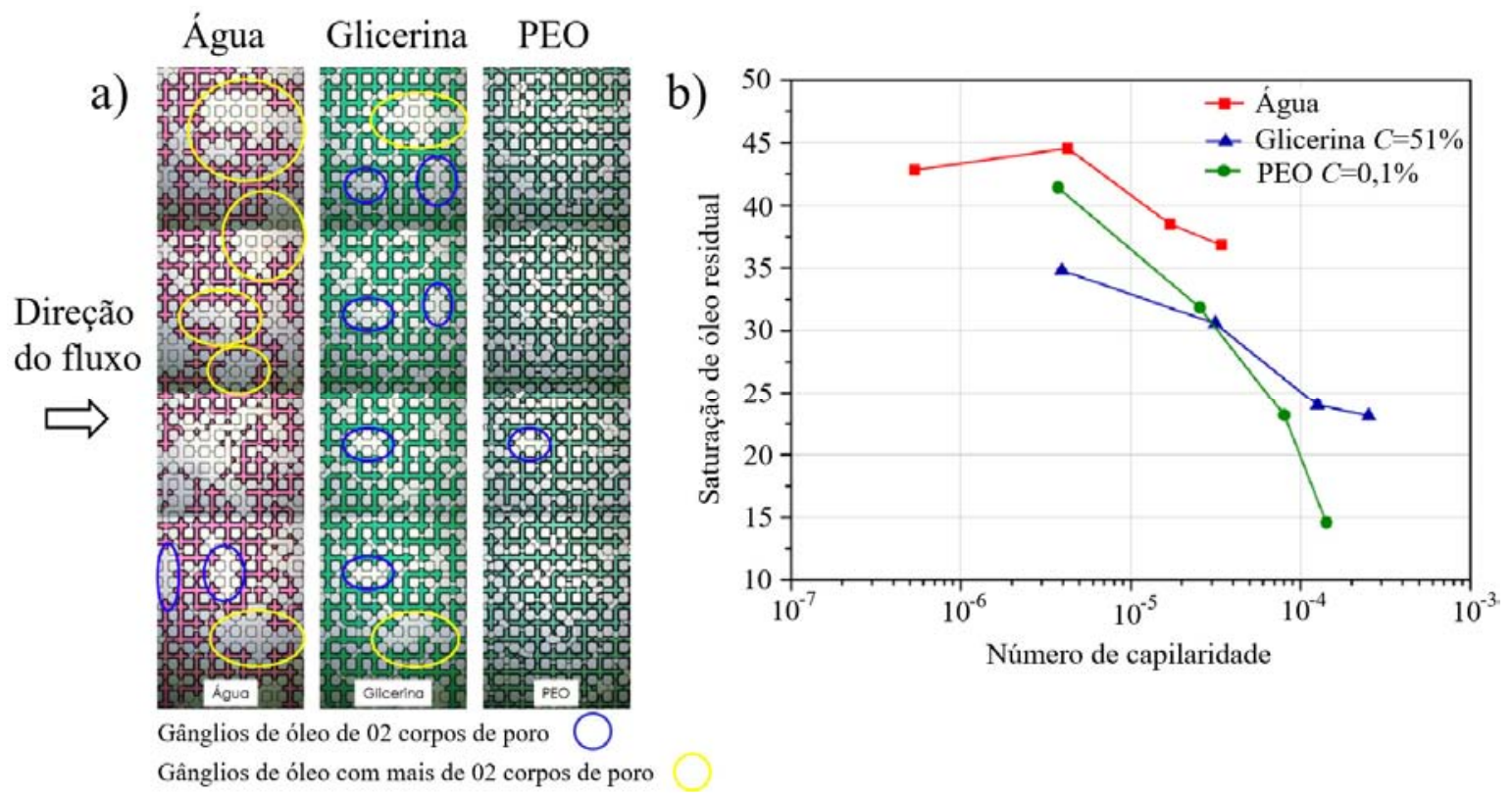

Figura 43 - a) Saturação ao final da injeção dos líquidos $(Q=4,16 \mathrm{ml} / \mathrm{h})$. b) Saturação de óleo residual em função do número de capilaridade realizado por Miranda (2015)

Os efeitos elásticos da solução polimérica aumentaram a viscosidade extensional da fase aquosa levando a um aumento da queda de pressão no meio poroso e, consequentemente, uma maior quantidade de gânglios de óleo são deslocados dos poros (menor saturação de óleo). 
As seguintes investigações em micromodelo bidimensional utilizaram técnicas de visualização e medição para acompanhar o movimento do fluido e identificar possíveis mudanças no padrão do escoamento relacionado com a instabilidade elástica, além de quantificar a saturação de óleo residual.

Clarke et al. (2015) observou um aumento no gradiente de pressão ao injetar soluções poliméricas viscoelásticas de HPAM 3630S para diferentes concentrações em peso tanto em um dispositivo microfluídico (rede de poros e canais) como em uma rocha cilíndrica de arenito Bentheimer (tamanho médio de poros de $39 \mu \mathrm{m}$ ).

$\mathrm{Na}$ rocha cilíndrica, uma rápida queda de saturação de óleo residual na amostra com o aumento do número de capilaridade foi observada ao injetar soluções poliméricas. A redução de saturação foi associada à relação de viscosidade entre a solução injetada e o óleo, como mostrada na figura 44.

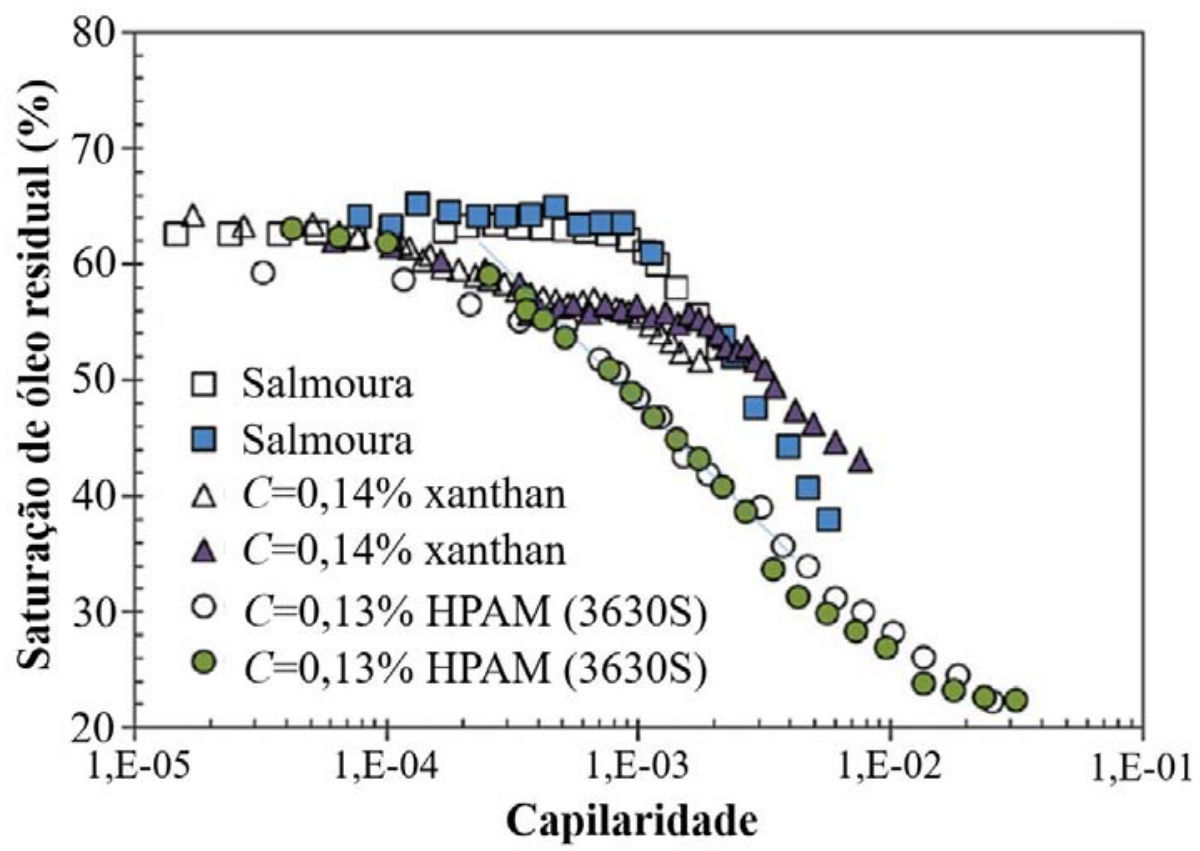

Figura 44 - Saturação de óleo residual em função do número de capilaridade (símbolos abertos: repetitividade do teste) realizado por Clarke et al. (2015)

O dispositivo microfluídico feito em PMMA é formado por uma rede de canais de $200 \mu \mathrm{m}^{2}$ de área de poro (figura $45 \mathrm{a}$ ). A visualização do escoamento foi realizada utilizando a técnica de velocimetria de rastreamento de partículas (PTV).

Nos experimentos de injeção monofásica, a solução viscosa de glicerol apresentou um escoamento laminar (linhas de tinta não se cruzam). Entretanto, nas 
soluções viscoelásticas de HPAM é observado um escoamento com flutuações induzidas pela elasticidade do polímero e linhas de tinta se atravessando nos poros, acompanhado de um aumento de gradiente de pressão no dispositivo microfluídico, como revelado na figura $45 \mathrm{~b}$.

Nos experimentos de escoamento bifásico (figura 45c), quando a solução viscosa foi injetada, os meniscos dos gânglios de óleo bloqueados nos poros permaneceram estacionários (sem flutuação). Enquanto, a injeção da solução viscoelástica de HPAM gerou flutuações nos meniscos dos gânglios de óleo. A flutuação dos gânglios foi relacionada com as flutuações presentes na fase aquosa, da mesma forma que aconteceu para o caso da injeção monofásica.

a)
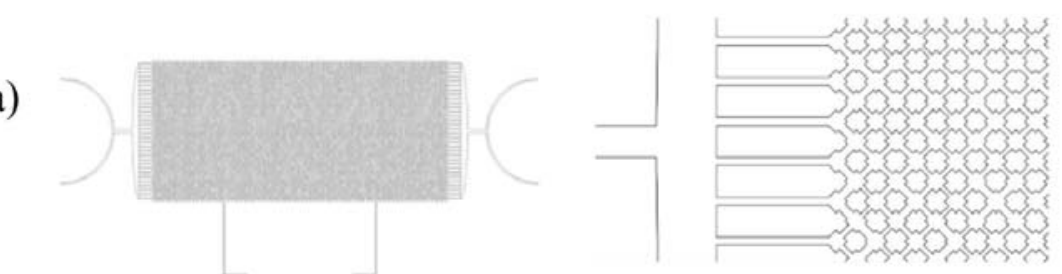

b) Glicerol $84 \% \mathrm{em}$ peso HPAM 3630 S $0,24 \%$ em peso

HPAM 6040 S $0,12 \%$ em peso
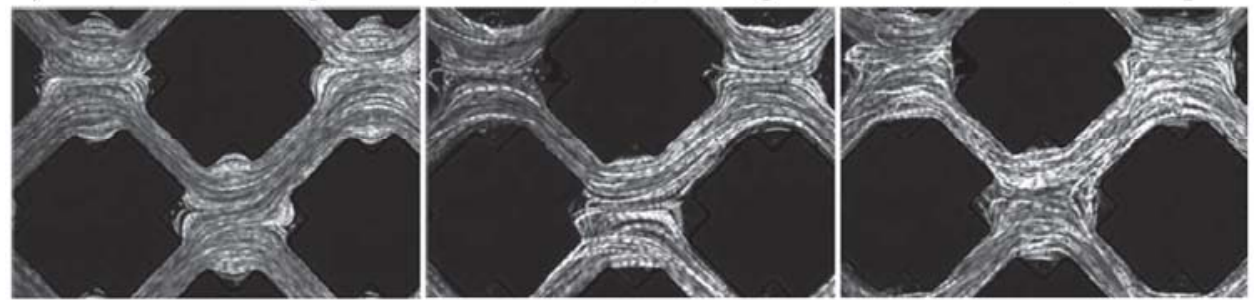

c)

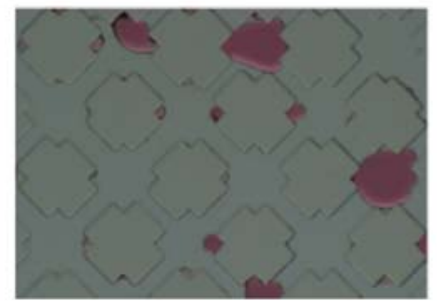

Figura 45 - a) Dispositivo microfluídico 2D. b) Imagens com linhas de tinta dos escoamentos das soluções de glicerol e HPAM. c) Imagem com gânglios de óleo remanescente realizado por Clarke et al. (2015)

Deve ser esperado que as forças elásticas das soluções poliméricas viscoelásticas de alto peso molecular possam gerar flutuações no escoamento e um incremento no gradiente de pressão, assim dando origem ao deslocamento da fase imiscível presa nos poros (gânglios de óleo) através das contrições e, consequentemente, melhorar a recuperação de óleo (desaturação do meio poroso) a menor números de capilaridade. 
Hincapie et al. (2017) estudou a recuperação adicional de óleo em um micromodelo de vidro-silício 2D, figura 46a, através da injeção de soluções poliméricas de PEO e HPAM 6035S conduzidos em escoamentos monofásico e bifásico. As soluções poliméricas foram preparadas para diferentes concentrações e diferentes pesos moleculares, e o deslocamento do fluido nos poros foi visualizado por meio de linhas de corrente.

Para a condição monofásica, o comportamento da solução de PEO de alta concentração (5000 PPM) mostrou um gradiente de pressão linear em relação ao número de Reynolds $(0<\operatorname{Re}<0,025)$. As linhas de corrente não mostraram flutuações, nem mudanças na direção do escoamento nem linhas de corrente se cruzando, como visualizado na figura $46 \mathrm{~b}$ para três poros diferentes à vazão de $100 \mu \mathrm{l} / \mathrm{min}$.

No caso da solução de HPAM foram analisados para dois valores de concentração. A concentração de 500 PPM, as linhas de corrente mostraram um escoamento laminar apenas a baixas vazões de injeção $(Q=10 \mu 1 / \mathrm{min})$. A concentração de 1000 PPM, o escoamento mostrou características de fluxo de transição (mudança de direção, formação de vórtices e linhas de corrente se cruzando) e um aumento da queda de pressão, como visualizado na figura 46c. O grau de instabilidade elástica é altamente dependente da concentração do polímero.

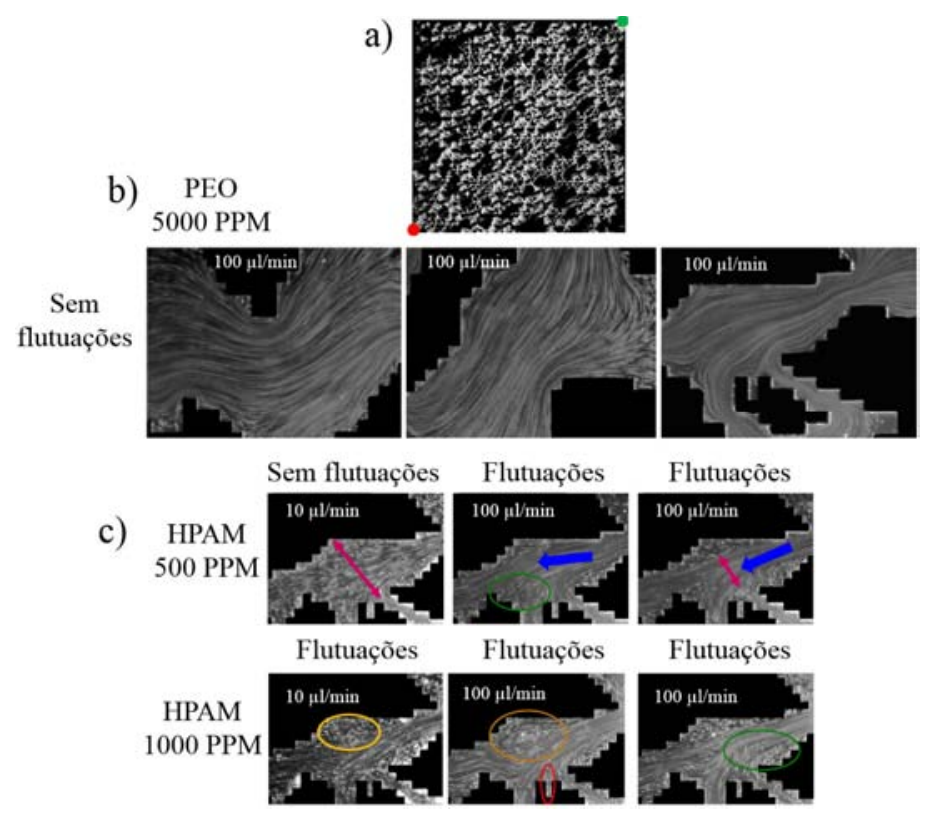

Figura 46 - a) Dispositivo microfluídico 2D. b) Imagens com linhas de tinta do escoamento da solução de PEO. c) Imagens com linhas de tinta do escoamento de 2 soluções de HPAM realizado por Hincapie et al. (2017) 
Para o escoamento bifásico, é importante mencionar que o deslocamento do óleo foi realizado primeiro injetando a solução de PEO seguido da solução de HPAM. A mobilização do óleo foi quantificada em cinco regiões de poros (figura 47) à vazão de injeção de $30 \mu 1 / \mathrm{min}$.

Após a injeção da solução de PEO à vazão de $Q=30 \mu \mathrm{l} / \mathrm{min}$ no regime de escoamento laminar, o volume de óleo mobilizado foi 6,85\% maior em comparação com a condição de escoamento laminar à vazão de $Q=0,5 \mu 1 / \mathrm{min}$, devido a que uma vazão de injeção alta leva maior velocidade intersticial gerando maiores forças nas gotas de óleo. A seguir, a solução de HPAM foi injetada, e o volume de óleo recuperado foi aproximadamente 5 vezes maior do que a solução de PEO. A mobilização adicional foi associada a instabilidade elástica presente no escoamento (vórtices e mudança de direção do escoamento principal), sendo mais afetados os poros $\mathrm{N}^{\circ} 2$ e $\mathrm{N}^{\circ} 5$.

Os resultados mostraram que a taxa de mobilização de óleo aumenta para um incremento da concentração de PEO/HPAM.

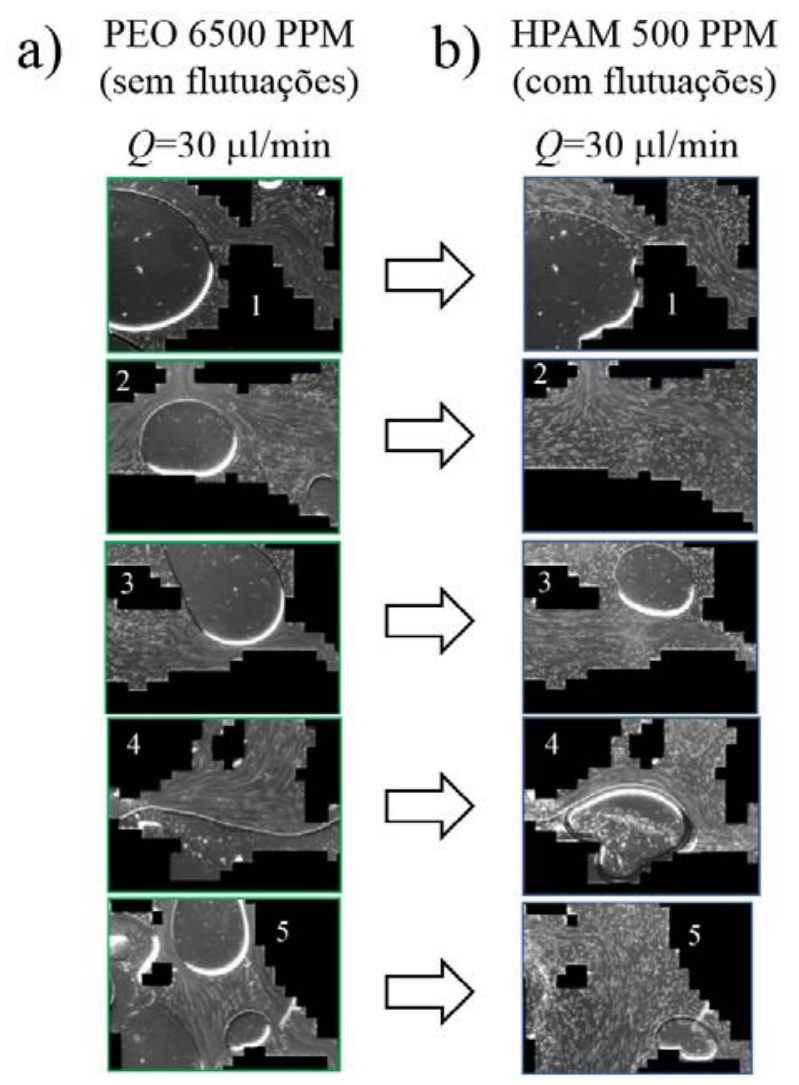

Figura 47 - Visualização das linhas de corrente em cinco poros diferentes à vazão de $30 \mu \mathrm{l} / \mathrm{min}$. a) Durante a injeção de PEO (6500 PPM) sem presença de flutuações. b) Durante a injeção de HPAM (500 PPM) com presença de flutuações realizado por Hincapie et al. (2017) 
Projetos pilotos em campos de produção de petróleo no Brasil (Melo et al., 2017) mostraram que a injeção de polímeros levou a um aumento na recuperação de óleo, embora os mecanismos que governaram a dinâmica complexa do escoamento dentro do reservatório não foram bem compreendidos.

Investigações recentes com relação a escoamentos em meios porosos através de micromodelos (dispositivos microfluídicos) mostraram um aumento do fator de recuperação de óleo com a injeção de polímeros (Miranda, 2015 e Hincapie et al., 2017). Para o entendimento dos fenômenos que envolvem esse processo é essencial compreender em detalhe o estudo do escoamento na escala de poros.

\section{3 .}

Investigação experimental realizada neste trabalho

A presente investigação estuda o comportamento dinâmico não linear de uma solução viscoelástica de PEO a uma concentração de $0,1 \%$ em peso através de um capilar com garganta. Medidas da queda de pressão e campos de velocidade foram realizadas. A constrição utilizada apresenta uma forma especial de contraçãoexpansão gradual de geometria aproximadamente axissimétrica, apenas encontrada nos trabalhos de Gutiérrez (2013) para injeção de gotas de óleo e de Miranda (2015) dentro de um micromodelo de meio poroso.

Medidas da queda de pressão do escoamento da solução de PEO através da constrição foram realizadas com a finalidade de quantificar o efeito elástico do polímero quando for comparado com uma solução Newtoniana de glicerina em água escoando pela mesma constrição. A solução de glicerina em água foi preparada à mesma viscosidade da solução polimérica de PEO.

Medidas de campo de velocidade do escoamento da solução de PEO perto da região da constrição foram realizadas por meio da técnica de micro-PIV, para determinar os diferentes padrões do escoamento quando for submetido a diferentes condições de fluxo e detectar o início da instabilidade elástica no escoamento associado à queda de pressão extra. A quantificação foi determinada ao ser comparado com os campos de velocidade da solução viscosa de glicerina às mesmas condições de fluxo. 


\section{4 . \\ Diferenças entre a literatura e nossa investigação}

Como citado nas referências bibliográficas para a escala micro, as investigações experimentais sobre injeções de fluidos viscoelásticos utilizaram constrições de geometria planar e profundidade constante. Essas investigações foram focadas no estudo do comportamento dinâmico do escoamento à montante e dentro da constrição para aplicações de jato de tinta, ciências biológicas, entre outros. Também não foram encontrados na literatura investigações em microcanais com constrições de geometria axissimétrica, apenas realizado no trabalho de simulação numérica de Pareto (2015). Em nossa investigação foi utilizada uma garganta de geometria quase axissimétrica e de profundidade variável tornando o estudo da cinemática do escoamento viscoelástico através da garganta mais complexo quando comparado com a geometria padrão de constrição planar, sendo importante para a aplicação dirigida ao estudo de escoamentos em meios porosos.

As investigações realizadas em microcanais com garganta na literatura mostraram apenas a caracterização quantitativa do escoamento na entrada e dentro da constrição utilizando apenas campos de velocidade, não foi encontrado detalhes do escoamento na saída da constrição. Neste trabalho foi apresentado em detalhe a quantificação em toda a região do escoamento (entrada, dentro e na saída da constrição) através dos campos de velocidade, desvios padrões e taxa de deformação em todo o escoamento por meio da técnica de micro-PIV.

Em nosso trabalho, os resultados das medidas da queda de pressão acompanhado com as medições de campo de velocidade, desvio padrão e taxa de deformação do escoamento da solução polimérica viscoelástica de PEO foram comparados com os resultados de uma solução viscosa de glicerina em água (preparada à mesma viscosidade da solução polimérica). Essa metodologia nos permitiu ter certeza de separar e quantificar os efeitos elásticos do polímero no escoamento. Na literatura os resultados de medidas da queda de pressão e campos de velocidade do escoamento dos fluidos viscoelásticos não são 
comparados com outro fluido, apenas utilizam os resultados obtidos da região do escoamento tipo Newtoniano do mesmo fluido viscoelástico para efeito de comparação.

É importante citar também que nossa transição, onde inicia a instabilidade do escoamento, ocorreu a uma vazão muito menor do que as encontradas na literatura, além das medições da queda de pressão. A dimensão e a geometria da constrição jogam um papel importante para que as condições do fluxo estudadas sejam similares ao escoamento nas gargantas de poros dos reservatórios. Um esquema das diferenças é ilustrado através da figura 48.

\section{Revisão da literatura}

$>$ Geometria

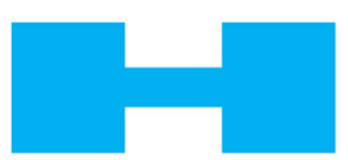

Constrição:

seção planar

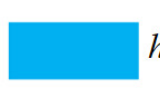

Profundidade constante

\section{Presente investigação}

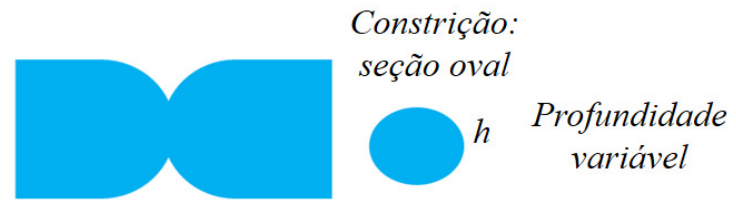

- Escoamento em meios porosos

\section{Aplicação}

- Jato de tinta

- Ciências biológicas

- Outros.

\section{Quantificação do escoamento}

- Campo de velocidade média

- Campo de velocidade instantâneo

- Campo de velocidade média

- Campo de velocidade instantâneo

- Campo de desvio padrão

Método para separar os efeitos elásticos

- Campo de taxa de deformação
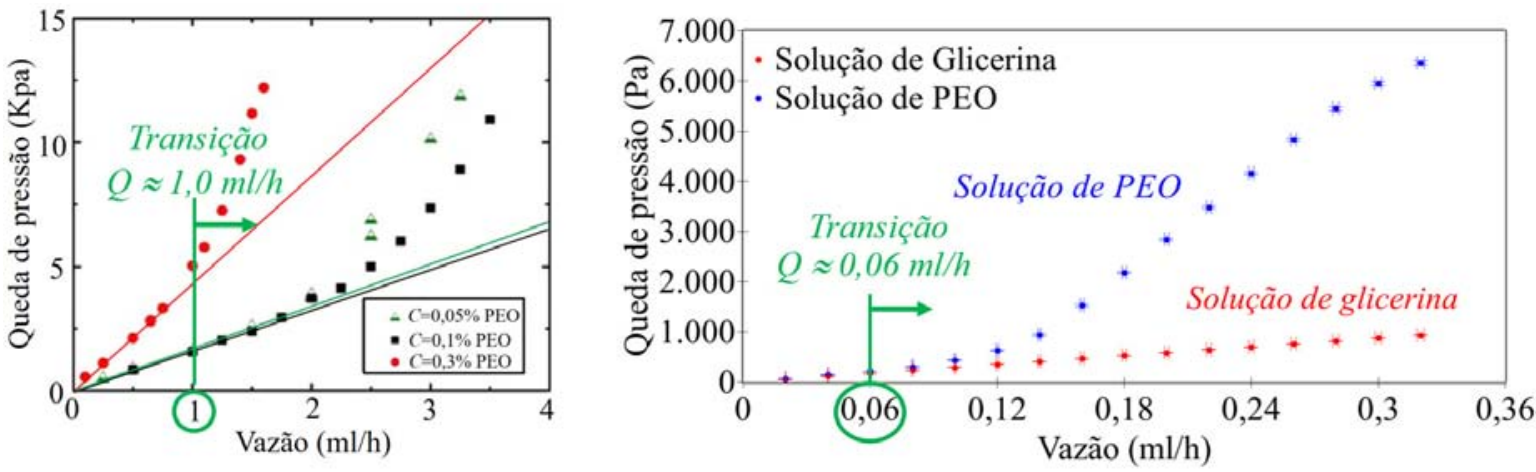

Figura 48 - Resumo das diferenças entre a literatura e nossa investigação

Finalmente, tanto as condições de fluxo como as dimensões da constrição utilizadas nesta investigação são similares à escala real do escoamento nos 
poros dentro de um reservatório, e forneceram informações importantes de como soluções poliméricas viscoelásticas se comportam em um meio poroso, o que poderá ter impacto na sua utilização na recuperação de óleo melhorada em reservatórios.

\section{5 .}

\section{Objetivo da tese}

A presente investigação tem como objetivo analisar o escoamento viscoelástico de uma solução polimérica de PEO escoando através de um canal com uma garganta em escala micrométrica, representando de forma simplificada o escoamento de soluções poliméricas através de uma garganta de poro.

Para quantificar os efeitos elásticos do polímero no escoamento foi realizada experimentalmente medidas da queda de pressão e medidas de campo de velocidade próximo à região da constrição utilizando a técnica de micro-PIV. Os resultados obtidos ajudaram a explicar e entender os fenômenos envolvidos neste processo e ser utilizados para validar modelos numéricos desenvolvidos na escala de poros.

\section{6.}

\section{Estrutura da tese}

A presente investigação foi estruturada em sete capítulos:

Capítulo 1 "Introdução": Nesta seção foi apresentado um breve resumo do método de recuperação de injeção de polímeros em reservatórios e a importância da microfluídica no estudo de fluidos complexos através de microcanais. Além disso, uma revisão bibliográfica em detalhe das principais investigações sobre o estudo de escoamento de fluidos viscoelásticos através de canais e micromodelos, as principais diferenças de nossa investigação com a literatura e o objetivo da tese.

Capítulo 2 "Fluidos complexos em microcanais": Nesta seção é apresentada as principais propriedades e parâmetros adimensionais utilizados para caracterizar o escoamento de fluidos complexos.

Capítulo 3 "Técnica de medição do escoamento": Nesta seção é descrita a técnica experimental de micro-velocimetria por imagem de partículas utilizada nesta investigação para determinar os campos de velocidade do escoamento. 
Capítulo 4 "Metodologia": É apresentada uma descrição dos equipamentos e procedimentos experimentais utilizados nesta investigação.

Capítulo 5 "Resultados": Neste capítulo são mostrados os resultados de medidas da queda de pressão e os resultados dos campos de velocidade do escoamento.

Capítulo 6 "Comentários finais": Neste capítulo é apresentado as conclusões e sugestões para futuros trabalhos.

Capítulo 7 "Referências bibliográficas": É apresentado um listado dos principais artigos, teses e informações utilizadas para o desenvolvimento da tese. 


\section{2 \\ Fluidos complexos em microcanais}

Este capítulo apresenta as propriedades e parâmetros que são utilizados para caracterizar fluidos complexos e assim estudar o comportamento da dinâmica do escoamento viscoelástico através de microcanais para diferentes tamanhos e geometrias.

\section{1.}

\section{Reologia dos fluidos complexos}

Esta seção apresenta as principais propriedades reológicas dos fluidos complexos e são citadas a seguir.

\subsection{1. \\ Viscosidade extensional e cisalhamento}

Nos fluidos Newtonianos, a tensão é proporcional à taxa de deformação. A constante de proporcionalidade é uma propriedade do fluido, viscosidade, que não varia com a taxa de deformação, porém varia com a temperatura e a pressão. Entretanto, nos fluidos complexos (não Newtonianos), a tensão é uma função complexa da cinemática e história de deformação do fluido, levando a vários fenômenos não observados no escoamento de fluidos Newtonianos. As figuras 49a e 49b representam as curvas de tensão e viscosidade em função da taxa de deformação sob cisalhamento, mostrando os diferentes comportamentos reológicos dos fluidos. 


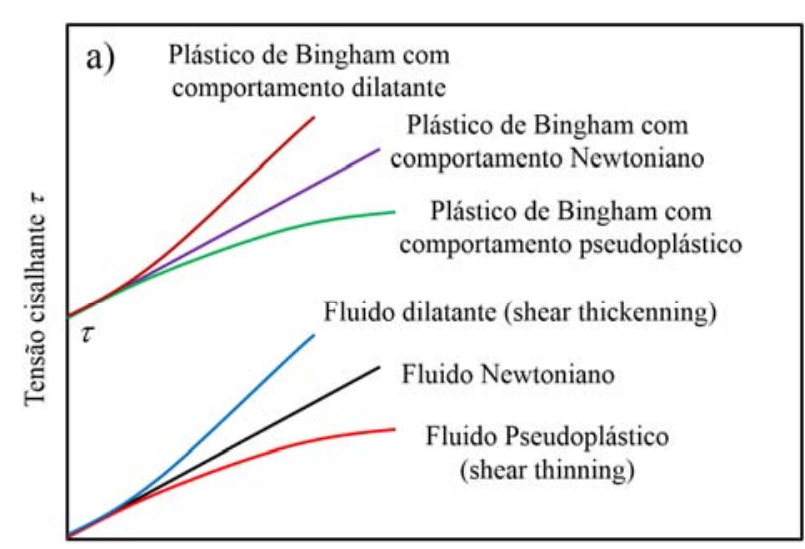

Taxa de cisalhamento $\dot{\gamma}$

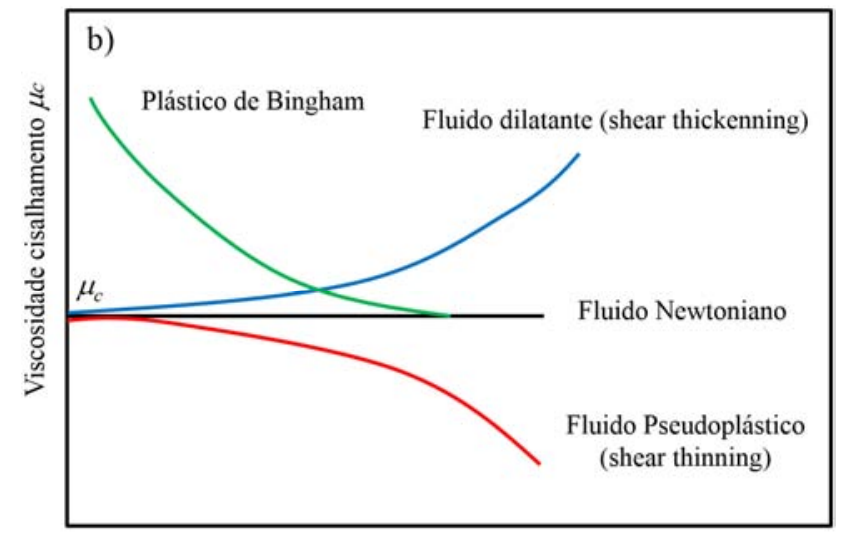

Taxa de cisalhamento $\dot{\gamma}$

Figura 49 - Comportamentos reológicos dos fluidos sob cisalhamento. a) Tensão cisalhante. b) Viscosidade de cisalhamento

Os fluidos complexos apresentam também diferentes comportamentos reológicos quando sofrem taxa de deformação extensional, como mostrado na figura 50 .

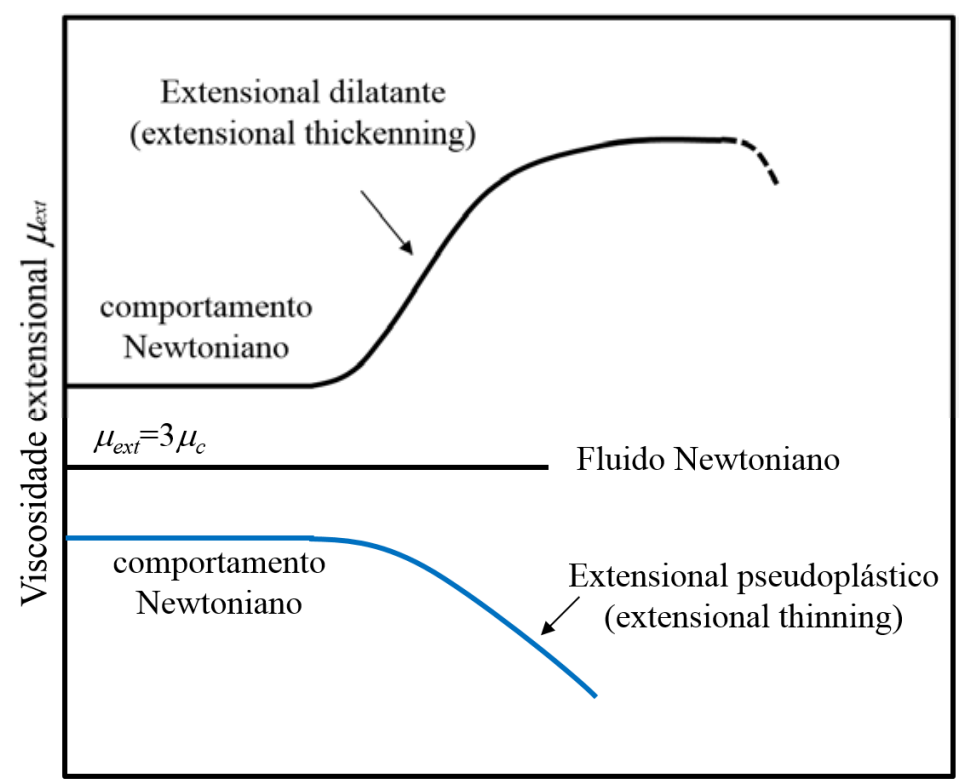

Taxa de extensão $\dot{\varepsilon}$

Figura 50 - Comportamentos reológicos dos fluidos sob taxa de deformação extensional

É importante ressaltar que os fluidos Newtonianos e não Newtonianos inelásticos apresentam uma viscosidade extensional constante de três vezes o valor da sua viscosidade de cisalhamento $\mu_{e x t}=3 \mu_{c}$ (Trouton, 1906). No caso dos fluidos viscoelásticos, para baixas taxas de extensão, a viscosidade extensional é constante (comportamento Newtoniano) e igual a três vezes sua viscosidade de cisalhamento. Acima de um determinado valor de taxa de extensão, a viscosidade extensional 
varia com a taxa de extensão $\mu_{\text {ext }}=\mu_{\text {ext }(\dot{\varepsilon})}$. O número de Trouton $T r$, variável adimensional, relaciona a viscosidade extensional e de cisalhamento segundo a eq. (9).

$$
T_{r}=\frac{\mu_{e x t(\dot{\varepsilon})}}{\mu_{c(\dot{\lambda})}} .
$$

A caracterização das propriedades reológicas dos fluidos complexos (figuras 49 e 50) é usualmente realizada em laboratórios através de reômetros. O reômetro rotacional é utilizado para determinar a viscosidade cisalhante e os coeficientes de diferença de tensões normais do fluido. Reômetros extensionais são utilizados para determinar a viscosidade extensional.

A investigação dos fluidos complexos escoando através de microcanais dos dispositivos microfluídicos é importante para o entendimento e otimização de muitas aplicações industriais, em particular o escoamento em meios porosos. As dimensões e geometrias dos canais podem representar o espaço poroso de uma forma mais simples, permitindo um estudo sistemático dos diferentes regimes de escoamento que podem ocorrer devido ao comportamento não Newtoniano dos fluidos.

\subsection{2.}

\section{Tempo de relaxação}

Uma das características importantes das soluções poliméricas é a escala de tempo característico do fluido, chamado de tempo de relaxação $\lambda$, que fornece uma medida do grau de elasticidade das cadeias do polímero.

Para um fluido Newtoniano, qualquer deformação aplicada aumenta a energia potencial a nível molecular. No entanto, a energia adicional é dissipada e volta rapidamente a seu estado de equilíbrio na ordem de $\sim 10^{-15} \mathrm{~s}$.

Para as soluções poliméricas, as cadeias do polímero têm um maior tempo de resposta (longa memoria estrutural) em voltar a seu estado de equilíbrio depois de uma tensão aplicada. Geralmente, o tempo de resposta está na ordem de 
microssegundos até minutos, devido à competição entre as forças entrópicas das cadeias do polímero desenrolando-se e as forças hidrodinâmicas do escoamento.

O tempo de relaxação $\lambda_{\text {CaBER }}$ de uma solução polimérica pode ser determinado experimentalmente utilizando o reômetro extensional Haake CaBER da Thermo Fisher Scientific ${ }^{\circledR}$. O procedimento será explicado no capítulo de metodologia. O tempo de relaxação $\lambda_{\text {Zimm }}$ pode ser estimado também utilizando a teoria de Zimm (Tirtaatmadja et al., 2006), como representado na eq. (10) a seguir:

$$
\lambda_{\text {Zimm }}=0,463 \frac{[\eta] P M \eta_{s}}{N_{A} K_{B} T} .
$$

Onde, $[\eta]$ é a viscosidade intrínseca, $\eta_{s}$ é a viscosidade do solvente, $P M$ é o peso molecular do polímero, $N_{A}$ é o número de Avogadro, $K_{B}$ é a constante de Boltzmann e $T$ a temperatura absoluta. $O$ peso molecular afeta o comportamento do escoamento de uma solução polimérica e está diretamente relacionado com o tamanho da molécula. Soluções de alto peso molecular exibem maiores tempos de relaxação.

A viscosidade intrínseca $[\eta]$ é uma medida da contribuição de um soluto para a viscosidade de uma solução, e pode ser estimada através da equação empírica dada por Mark-Houwink-Sakurada que relaciona a viscosidade intrínseca de um polímero com seu peso molecular $P M$, e sendo aplicada para pesos moleculares acima de 10.000, segundo mostrada na eq. (11).

$$
[\eta]=a P M^{b}
$$

Onde $a$ e $b$ são constantes que dependem do polímero, o solvente e a temperatura. A viscosidade intrínseca das soluções de PEO para vários pesos moleculares foram medidas experimentalmente através de um viscosímetro capilar (Ubbelohde) por Tirtaatmadja et al. (2006). Os dados foram ajustados a uma análise de regressão linear dando a equação composta de Mark-Houwink, como apresentada na eq. (12).

$$
[\eta]=0,072 P M^{0,65} .
$$




\subsection{3.}

\section{Concentração da solução}

A dinâmica do escoamento das soluções viscoelásticas é bastante influenciada pela concentração do polímero $C$. Diferentes regimes de comportamento são observados em função da razão da concentração do polímero pela concentração crítica de sobreposição $C^{*}$. Se a concentração da solução é $C \leq C^{*}$, o fluido é considerado diluído e as cadeias do polímero não interagem entre elas. Se a concentração é $C \approx C^{*}$, o fluido é considerado semidiluído e as cadeias começam a interagir entre si. Se a concentração é $C \geq C^{*}$, o fluido é considerado concentrada e as cadeias do polímero influenciam fortemente no comportamento do escoamento. A concentração crítica é calculada de acordo à eq. (13) (Graessley, 1980).

$$
C^{*}=\frac{0,77}{[\eta]}
$$

É importante mencionar, que as equações que governam o comportamento dos fluidos viscoelásticos são as equações básicas de conservação da massa e de conservação do momento linear. Porém, na equação do movimento tem que aparecer o tensor das tensões que é determinado por uma equação constitutiva reológica que descreve o comportamento do fluido viscoelástico, em que aparecem o tempo de relaxação do polímero, a viscosidade do fluido entre outros. Diferentes modelos constitutivos são utilizados como o modelo de Maxwell, Oldroyd-B, modelo PPT (Phan-Thien-Tanner) e o modelo FENE.

\section{2.}

\section{Parâmetros que caracterizam a dinâmica do escoamento}

Esta seção apresenta os principais parâmetros adimensionais utilizados nesta investigação.

\subsection{1.}

\section{Número de Weissenberg}

O número de Weissenberg Wi é uma variável adimensional que caracteriza a relação entre as forças elásticas e as forças viscosas e é utilizado principalmente 
quando existe uma importante componente elongacional no escoamento de fluidos viscoelásticos passando através de constrições. No presente trabalho é utilizado este parâmetro, definido através da eq. (14).

$$
W i=\frac{\text { forças elásticas }}{\text { forças viscosas }}=\lambda \dot{\varepsilon} \text {. }
$$

Onde, $\dot{\varepsilon}$ é a taxa de extensão no escoamento e $\lambda$ é o tempo de relaxação. Devido à geometria do microcanal utilizada nos experimentos, a taxa de extensão (gradiente de velocidade) é estimada utilizando a diferença de velocidades médias entre o menor diâmetro $U_{r}$ e a entrada $U_{e}$ da constrição, separado pela metade do comprimento da constrição $L c / 2$, como mostrada na eq. (15) e figura 51.

$$
\dot{\varepsilon}=\frac{U_{r}-U_{e}}{L_{c} / 2}
$$

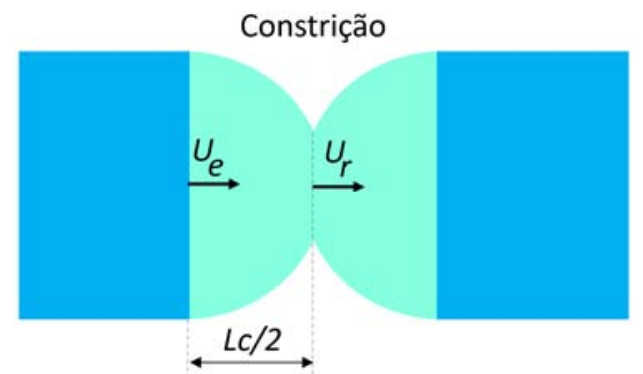

Figura 51 - Representação esquemática da constrição utilizada

Outro parâmetro utilizado na literatura é o número de Deborah De, que relaciona o tempo de relaxação do polímero $\lambda$ e o tempo característico para o processo de deformação ou tempo de residência do fluido $t_{c}$, como apresentada na eq. (16).

$$
D e=\lambda / t_{c}
$$

Para escoamentos essencialmente estáveis, o tempo característico para o processo de deformação é infinito e o número de Deborah é, portanto, zero para tais fluxos, independentemente do tempo de relaxação. O número de Deborah é insuficiente para caracterizar completamente os efeitos devido à viscoelasticidade. 
O fato é que o número de Weissenberg e o número de Deborah quantificam efeitos diferentes.

\subsection{2.}

\section{Número de Reynolds}

É importante caracterizar o regime do escoamento dos experimentos realizados para os diferentes fluidos. O número de Reynolds Re é um parâmetro adimensional que quantifica a importância relativa entre as forças inerciais e as forças viscosas, como definido na eq. (17) a seguir:

$$
R e=\frac{\text { forças inerciais }}{\text { forças vis cos as }}=\frac{\rho U m D_{e q}}{\mu} .
$$

Onde $\rho$ é a massa específica do fluido, $U m$ é a velocidade média do escoamento, $D_{e q}$ é o diâmetro equivalente e $\mu$ é a viscosidade dinâmica do fluido. Neste trabalho, o canal considerado não possui diâmetro constante, o diâmetro equivalente $D_{e q}$ foi determinado utilizando a expressão de Poiseuille, eq. (18), e os dados experimentais das medidas da queda de pressão $\Delta P$ em função da vazão de injeção $Q$ do escoamento de água através do comprimento do microcanal com constrição $L$, como mostrado na figura 52.

$$
D_{e q}=\left(\frac{128 \mu L Q}{\pi \Delta P}\right)^{1 / 4}
$$

a)

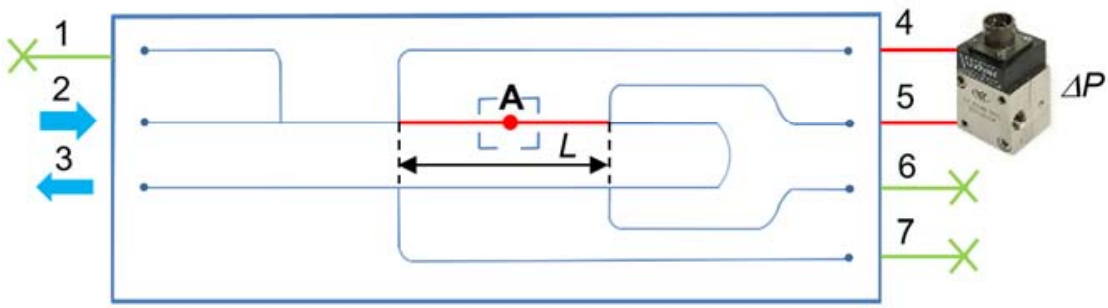



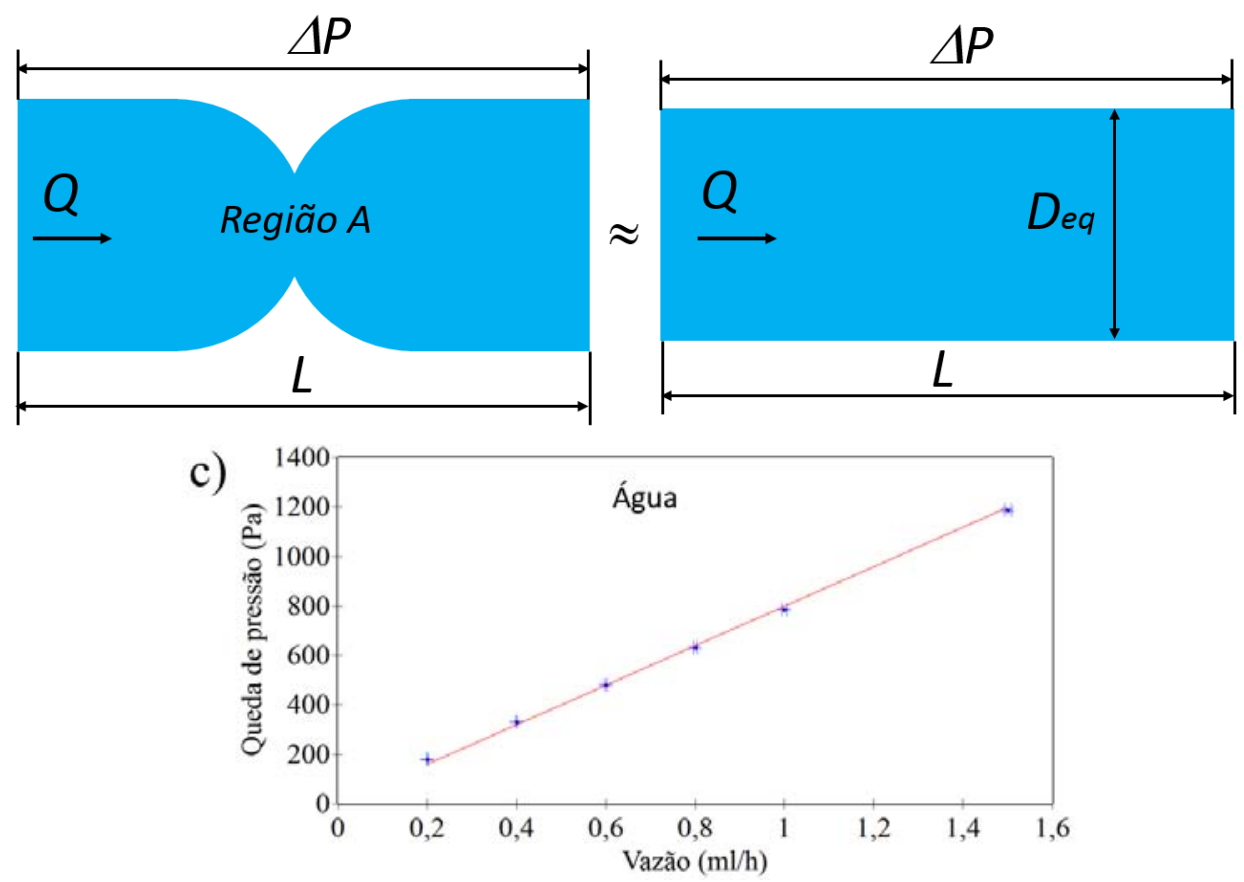

Figura 52 - a) Dispositivo microfluídico utilizado neste trabalho. b) Microcanal com constrição utilizado para as medidas da queda de pressão. c) Microcanal com diâmetro equivalente. c) Gráfico das medidas da queda de pressão em função da vazão do escoamento de água

O escoamento de fluidos não Newtonianos em microcanais apresentam tipicamente baixos números de Reynolds onde o fluxo é em regime laminar e dominado pelas forças viscosas $(\operatorname{Re}<<1)$.

\subsection{3.}

\section{Número de elasticidade}

O número de elasticidade $E l$ mede a importância relativa entre os efeitos elásticos e os efeitos inerciais de um fluido viscoelástico. O número de elasticidade depende apenas da reologia do fluido e a geometria do microcanal e não é afetado pela cinemática do escoamento (velocidade ou vazão de injeção). Portanto, para um único fluido e uma única geometria dada, o número de $E l$ é constante e definido através da eq. (19).

$$
E l=\frac{\text { forças elásticas }}{\text { forças inerciais }}=\frac{W i}{R e} .
$$


Devido às pequenas dimensões dos microcanais dos dispositivos microfluídicos, é possível obter escoamentos com altos valores de $E l$, várias ordens de grandeza maior do que obtidos em experimentos equivalentes na escala macro. 


\section{3 \\ Técnica de medição do Escoamento}

Para determinar o campo de velocidade do escoamento dos fluidos em escala micrométrica foi utilizada a técnica experimental de micro-PIV e é descrita a seguir.

\section{1.}

\section{Técnica de Micro-PIV}

A técnica de velocimetria por imagem de partículas (PIV) foi desenvolvida pelos investigadores Pickering et al. (1984) e Adrian (1984) para medir campos de velocidade em escoamentos em escala macro. A técnica PIV foi adaptada por Santiago et al. (1998) para medir campos de velocidade de escoamentos em dispositivos microfluídicos e incorporando microscopia epifluorescente. A nova técnica foi chamada de micro-velocimetria por imagem de partículas (micro-PIV).

As principais diferenças entre ambas as técnicas são: a iluminação do escoamento, o tamanho das partículas utilizadas e as lentes do microscópio acopladas à câmera digital (Santiago et al., 1998), além dos métodos de processamento de imagem.

\subsection{1.}

\section{Princípio de funcionamento}

O sistema micro-PIV é composto basicamente de um sistema ótico de visualização (microscópio de epi-fluorescência e um cubo filtro), um sistema de iluminação (lasers e lâmpada), um sistema de controle programável (software), uma câmera, um sincronizador e um sistema de injeção no qual o fluido é misturado com micropartículas com fluorescência escoando através de dispositivos microfluídicos. A figura 53 representa um esquema básico do sistema de micro-PIV. 


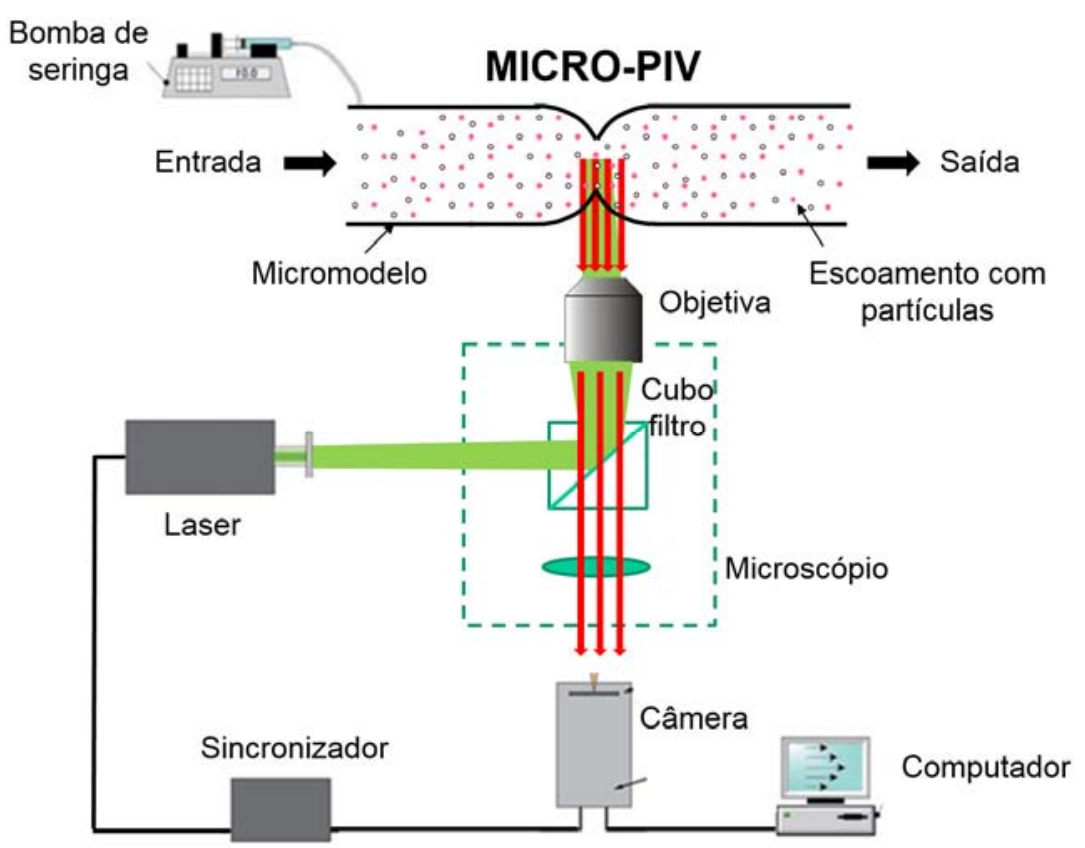

Figura 53 - Imagem ilustrativa dos componentes de um sistema de micro-PIV

Nas diversas aplicações de microfluídica utilizando a técnica de micro-PIV, o fluido é misturado com partículas traçadoras com fluorescência para visualizar e caracterizar o movimento dos fluidos dentro das diferentes geometrias dos microcanais.

O volume do fluido localizado na região de interesse do dispositivo microfluídico é iluminado por uma fonte de luz pulsada. Quando um pulso de luz do laser atinge o escoamento, todas as partículas traçadoras emitem uma luz de fluorescência passando através de um sistema de filtros até atingir à câmera. Uma imagem da posição das partículas no escoamento de interesse em um instante de tempo é gravada pela câmera. A unidade do sincronizador torna possível o ajuste de sincronização entre o pulso de luz do laser e a aquisição da imagem realizada pela câmera no computador.

Para determinar o deslocamento das partículas no escoamento é necessário a aquisição de duas imagens consecutivas separadas por um período de tempo conhecido $\Delta t$ (frame straddling). Cada imagem é dividida em pequenas regiões denominadas janelas de interrogação que terão uma quantidade de partículas traçadoras. O deslocamento médio, ou pico de correlação da posição das partículas contidas em cada janela de interrogação com relação a janela consecutiva em tempo, é determinado por meio de algoritmos estatísticos (Meinhart et al., 2000) durante o processamento das imagens. Finalmente um vetor de velocidade é 
tipicamente representado em cada janela e em todo o plano de medição bidimensional (campo de vetores).

\subsection{2.}

\section{Iluminação no sistema Micro-PIV}

No sistema PIV, o escoamento localizado no plano focal é iluminado por um plano de luz do laser. A profundidade de medição onde as partículas contribuem à formação do pico de correlação é determinada pela espessura do plano de luz do laser, já que a mesma é menor do que a profundidade de campo da lente $\delta z$ (profundidade de campo onde as partículas se encontram focadas com níveis de ruído mínimos).

Entretanto, o sistema de micro-PIV associado às pequenas escalas é difícil obter planos de luz de espessuras de 1-10 $\mu \mathrm{m}$ (Lee e Kim 2009), devido a isto, é necessário iluminar todo o volume do escoamento. A profundidade de medição é expressa como profundidade de correlação $2 Z_{\text {corr }}$ (depth of correlation) onde as partículas dentro e fora do foco contribuem na imagem capturada. As partículas localizadas na região fora do foco reduzem a relação sinal/ruído (SNR) do campo da imagem. Meinhart et al. (2000) identificaram que tanto a concentração de partículas como a profundidade do canal avaliado podem influenciar na SNR. A figura 54a representa um esquema da iluminação do sistema de micro-PIV, e a figura 54b mostra as profundidades de medição.

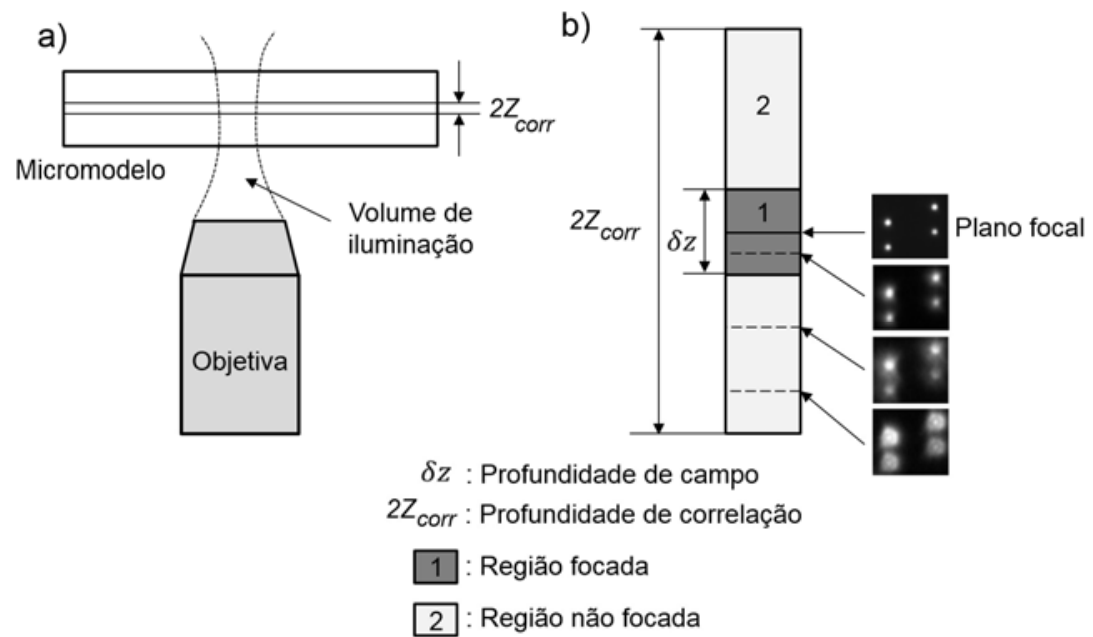

Figura 54 - a) Volume de iluminação da técnica de micro-PIV. b) Profundidade de campo e profundidade de correlação 
Segundo Inoué e Spring (1997), a profundidade de campo de uma lente de objetiva padrão $\delta z$ é estimada através do somatório da profundidade de campo devido à difração e aos efeitos geométricos, como indicado na eq. (20).

$$
\delta z=\frac{n_{r} \lambda_{0}}{N A^{2}}+\frac{n_{r} e}{N A M}
$$

Onde, $n_{r}$ é o índice de refração do meio entre o dispositivo microfluídico e a lente da objetiva, $\lambda_{0}$ é o comprimento de onda da luz no vácuo, $N A$ é a abertura numérica da lente da objetiva, $e$ é o menor tamanho característico no plano da imagem do microscópio e $M$ é a magnificação total da lente. Para nosso sistema com $n_{r}=1,33$ (meio ar), $\lambda_{0}=560 \mathrm{~nm}, N A=0,3, e=6,45 \mu \mathrm{m}, M=20 \times$ encontrarmos o valor da profundidade de campo ótico de $\delta z=9,7 \mu \mathrm{m}$.

Os diâmetros das partículas são visualizados nas imagens utilizando uma alta magnificação, embora a resolução espacial de um sistema ótico é limitada devida à difração da luz. Devido ao volume de iluminação utilizada na técnica de micro-PIV, as partículas localizadas na região focada e não focada contribuem nas medições de velocidade. Olsen e Adrian (2000a, b) incorporaram uma expressão para estimar o diâmetro efetivo da partícula $d_{e}$ considerando o espalhamento geométrico da partícula (distância $z$ do plano focal) e o efeito do movimento Browniano da partícula, como definida na eq. (21).

$$
d_{e}=\left[M^{2} d_{p}^{2}+\frac{1,49(M+1)^{2} \lambda_{0}{ }^{2}}{N A^{2}}+4 M^{2} N A^{2} z^{2}+8 M^{2} \beta^{2} D_{v} t_{c}\right]^{1 / 2} .
$$

Onde, $d_{p}$ é o diâmetro da partícula, $\beta$ é uma constante de distribuição de probabilidade, $D_{v}$ é a difusividade das partículas e $t_{c}$ é o tempo característico do escoamento. Finalmente, a profundidade de correlação $2 Z_{\text {corr }}$ para o sistema de micro-PIV é calculada através da eq. (23), utilizando a contribuição relativa do diâmetro efetivo da partícula $\varepsilon_{r}$ definida através da eq. (22). A profundidade de correlação foi estimada em $2 Z_{\text {corr }}=26 \mu \mathrm{m}$. 
$\varepsilon_{r}=\frac{d_{e}^{4}(z=0)}{d_{e}^{4}\left(z=Z_{\text {corr }}\right)}$

$Z_{\text {corr }}=\frac{1}{2}\left[\frac{1-\sqrt{\varepsilon_{r}}}{\sqrt{\varepsilon_{r}}}\left(\frac{d_{p}^{2}}{4 N A^{2}}+\frac{1,49(M+1)^{2} \lambda_{0}^{2}}{4 M^{2} N A^{4}}\right)\left(1+\frac{8 M^{2} \beta^{2} D_{v} t_{c}}{M^{2} d_{p}^{2}+\frac{1,49(M+1)^{2} \lambda_{0}^{2}}{N A^{2}}}\right)\right]^{1 / 2}$

É importante ressaltar que a profundidade de campo ótico $\delta z$ é referida ao objeto ainda focado em termos de qualidade de imagem. Enquanto, a profundidade de correlação $2 Z_{\text {corr }}$ no sistema de micro-PIV é atribuído às partículas que contribuem com as medições de velocidade do escoamento. A estimativa da profundidade de correlação $2 Z_{\text {corr }}$ segundo a eq. (23), não leva em conta alguns efeitos, como mostra Bryant et al. (2014). Um exemplo é o desalinhamento entre a câmera e o microcanal do dispositivo microfluídico que pode levar a medidas de velocidade menores do que esperado, devido ao volume de amostragem desalinhado. Além disso, seria possível calibrar o $2 Z_{c o r r}$, ao invés de estimá-lo.

\subsection{3.}

\section{Etapas de processamento de imagens}

As imagens capturadas do escoamento por meio da câmera passam através de diferentes etapas de processamento para obter o campo vetorial de velocidade do escoamento.

\subsubsection{1.}

\section{Pré-processamento de imagens}

Esta etapa é utilizada para detectar as partículas aderidas à parede, contornos da parede e manchas produzidas nas imagens com a finalidade de aumentar a relação sinal/ruído do campo da imagem. As partículas localizadas na região não focada da profundidade de correlação contribuem de maneira diferente para o ruído de fundo nas imagens, e diversas técnicas são utilizadas para remover o ruído.

As imagens de fundo são apropriadas para remover o ruído e são calculados a partir de uma sequência de pares de imagens. Nesta investigação, a primeira 
imagem de fundo (ruído de fundo A) foi gerada a partir do pixel de menor intensidade localizado na mesma posição das imagens capturadas no tempo $t$. A segunda imagem de fundo (ruído de fundo B) foi gerada a partir do pixel de menor intensidade localizado na mesma posição das imagens capturadas no tempo $t+\Delta t$. Finalmente, cada imagem processada é obtida subtraindo a intensidade de fundo (imagem de fundo) de cada imagem original para o tempo de captura respectivo, como mostrada na figura 55. Esta técnica fornecida pelo software Insight $4 G$ da TSI captura a maior quantidade de partículas para melhorar a sinal/ruído nos campos instantâneos devido à falta de partículas nelas, embora permita algum ruído nas imagens.

b)

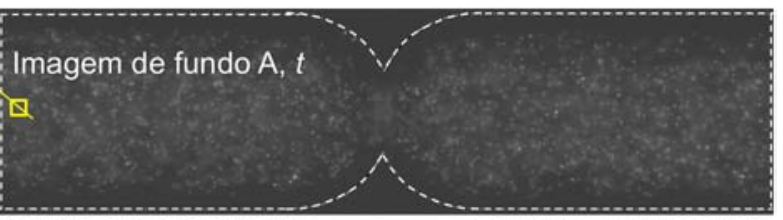

Imagem de fundo $\mathrm{B}, t+\Delta t$

c)
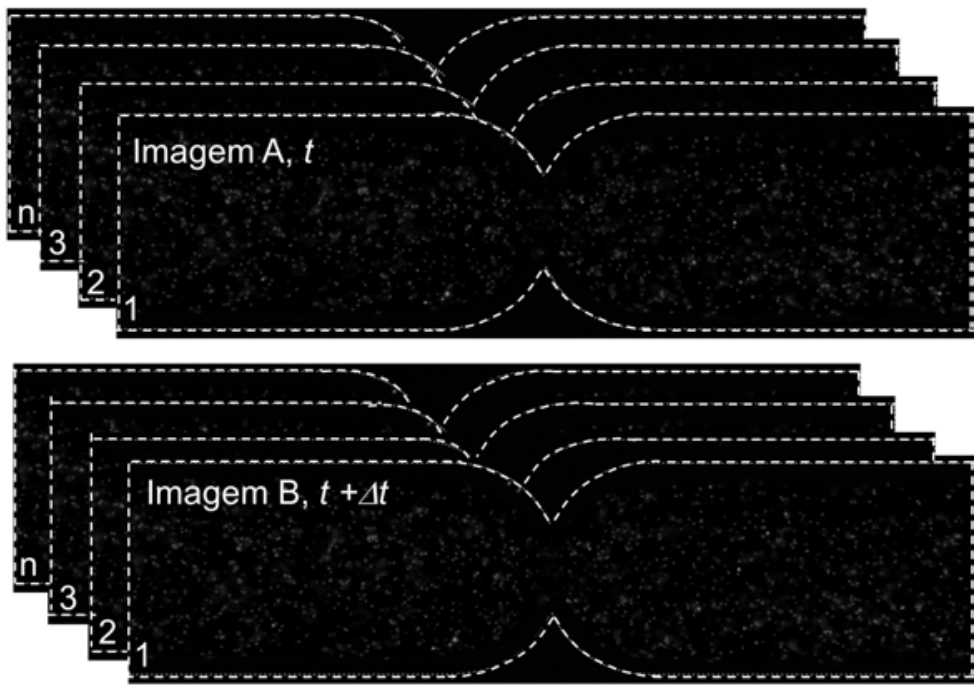

Figura 55 - a) Imagens sem pré-processamento. b) Imagem de fundo (ruído).

c) Imagens com pré-processamento 


\subsubsection{2. Processamento de imagens}

Como explicado anteriormente, as imagens capturadas do escoamento são divididas em pequenas áreas chamadas janelas de interrogação que contêm uma quantidade de partículas traçadoras.

A técnica de correlação cruzada correlaciona cada janela de interrogação da primeira imagem com sua correspondente na segunda imagem separada por um intervalo de tempo $\Delta t$, para obter o mapa de correlação e a localização do pico utilizando a função da transformada rápida de Fourier (FFT) e Gaussiana, como mostrada na figura 56 a seguir.

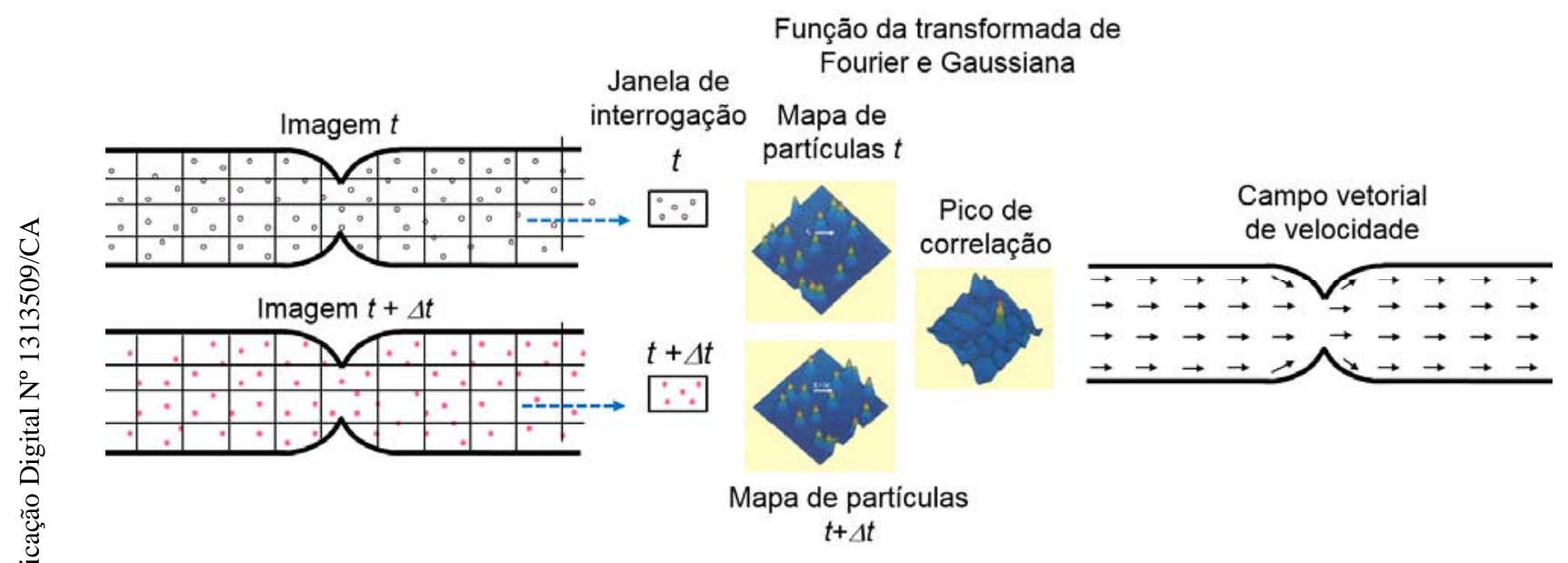

Figura 56 - Método de correlação cruzada (Prasad, 2000)

Quando as janelas de interrogação contêm poucas partículas ou a relação sinal/ruído é baixo, o pico de sinal de correlação principal pode ser menor do que outros sub picos de sinal (ruído) gerando um vetor de velocidade incorreto. Devido a isto, o método de correlação média ou média amostral (ensemble average) é utilizada para melhorar a relação sinal/ruído em escoamentos de regime permanente desenvolvido por Meinhart et al. (2000). Esta técnica calcula as funções de correlação instantânea de vários pares de imagens consecutivas e a partir delas calcula a função de correlação média para determinar a localização do pico do sinal. Este método é representando na figura 57 para a média amostral de 5 e 15 pares de imagens consecutivas, mostrando apenas o processo para uma janela de interrogação. 
a) 5 pares de imagens

I)

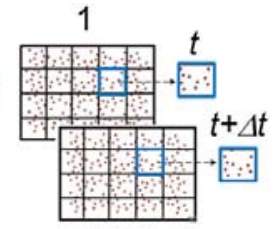

II)

III)

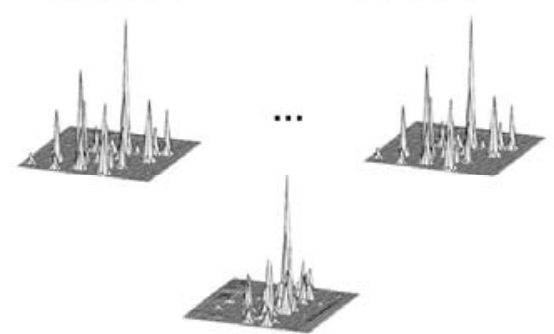

IV)

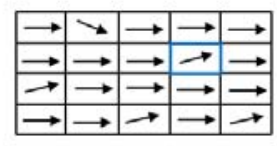

I) Sequência de pares de imagens

II) Mapas de correlação cruzada instantâneos b) 15 pares de imagens
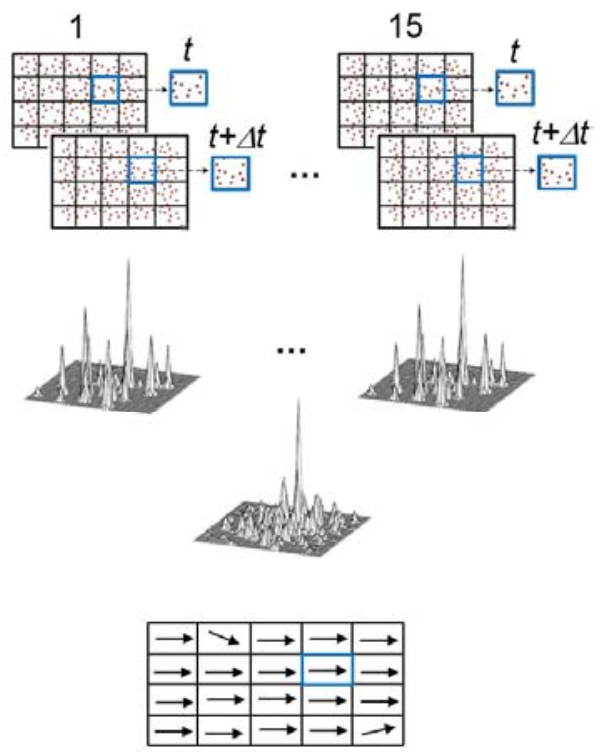

III) Mapas de correlação média

IV) Campo vetorial de velocidade média

Figura 57 - Método de correlação média. a) 5 pares de imagens consecutivas. b) 15 pares de imagens consecutivas

Para nossa investigação, a técnica de correlação cruzada foi utilizada para determinar os campos de velocidade instantâneos, e a técnica de correlação média foi utilizada para determinar os campos de velocidade média dos escoamentos em estudo. As técnicas são fornecidas pelo software Insight $4 G$ da TSI.

\subsubsection{3. Pós-processamento de imagens}

Depois do processamento, alguns vetores exibem um maior desvio em magnitude e direção em relação a seus vetores vizinhos e são chamados de vetores espúrios. Eles são encontrados no campo vetorial devido ao número insuficiente de partículas nas janelas de interrogação ou pares perdidos de partículas durante o processamento causando um baixo sinal de correlação. $\mathrm{Na}$ etapa de pós-processamento, métodos estatísticos discutidos a seguir são utilizados para detectar, eliminar e de ser necessário substituir os vetores espúrios por novos vetores.

A validação dos vetores pode ser local ou global dependendo das condições dinâmicas do escoamento analisado. Devido aos diferentes gradientes de 
velocidade encontrados nos escoamentos da solução polimérica de PEO, a validação do vetor local para a análise dos campos de velocidade foi utilizada.

Os métodos estatísticos de validação mais utilizados são a mediana local, a média local e a mediana universal. O método da mediana local compara a diferença entre cada vetor de velocidade e sua velocidade mediana local dos vetores vizinhos com a velocidade de tolerância dada pelo usuário. $\mathrm{O}$ método da média local é similar à mediana local exceto que utiliza a velocidade média local dos vetores vizinhos. Enquanto, o método da mediana universal normaliza a mediana local pela mediana das diferenças entre todos os vetores vizinhos e sua velocidade mediana deles, e logo é comparado com a tolerância normalizada dado pelo usuário. É um método de validação mais robusto porque a tolerância é menos sensível ao campo de fluxo. A figura 58 representa o método do cálculo da mediana universal para uma dimensão de $3 \times 3$.

Dimensão 3x3

\begin{tabular}{|c|c|c|}
\hline $\mathrm{V}_{1}$ & $\mathrm{~V}_{2}$ & $\mathrm{~V}_{3}$ \\
\hline $\mathrm{V}_{4}$ & $\mathrm{~V}$ & $\mathrm{~V}_{5}$ \\
\hline $\mathrm{V}_{6}$ & $\mathrm{~V}_{7}$ & $\mathrm{~V}_{8}$ \\
\hline
\end{tabular}

V: Vetor velocidade

$\begin{array}{llllllllllll}\text { Vetores vizinhos: } & V_{1} & V_{2} & V_{3} & V_{4} & V_{5} & V_{6} & V_{7} & V_{8}\end{array}$

Mediana local vetores vizinhos: $\mathrm{V}_{\mathrm{MV}}=\frac{\mathrm{V}_{4}+\mathrm{V}_{5}}{2}$

Método da mediana local do vetor: $\mathrm{V}_{\mathrm{ML}}=\mathrm{V}-\mathrm{VMV}$

Diferença entre todos vetores vizinhos e sua velocidade mediana deles:

$\left|\mathrm{V}_{1}-\mathrm{V}_{M V}\left\|\mathrm{~V}_{2}-\mathrm{V}_{M V}\right\| \mathrm{V}_{3}-\mathrm{V}_{M V}\right| \mathrm{V}_{4}-\mathrm{V}_{M V}|| \mathrm{V}_{5}-\mathrm{V}_{M V}|| \mathrm{V}_{6}-\mathrm{V}_{M V}|| \mathrm{V}_{7}-\mathrm{V}_{\mathrm{MV}}|| \mathrm{V}_{8}-\mathrm{V}_{\mathrm{MV}} \mid$

Mediana das diferenças: $\mathrm{V}_{\mathrm{MD}}=\frac{\left|\mathrm{V}_{4}-\mathrm{V}_{\mathrm{MV}}\right|+\left|\mathrm{V}_{5}-\mathrm{V}_{\mathrm{MV}}\right|}{2}$

Método da mediana universal: $\mathrm{V}_{\mathrm{MU}}=\frac{\left|\mathrm{V}_{\mathrm{ML}}\right|}{\left|\mathrm{V}_{\mathrm{MD}}\right|}$

Figura 58 - Método do cálculo da mediana universal na etapa de pós-processamento

No campo vetorial podem aparecer vetores espúrios devido a falhas nas etapas de processamento (correlação de pico) e de pós-processamento (validação dos vetores). Se necessário, os vetores espúrios podem ser substituídos utilizando a média ou mediana local dos vetores vizinhos, quando o comportamento do escoamento seja compreendido. A figura 59 representa uma área do escoamento de um campo de velocidade instantâneo de solução de glicerina utilizando as etapas de validação (mediana universal) e substituição de vetores (mediana local). 
b)
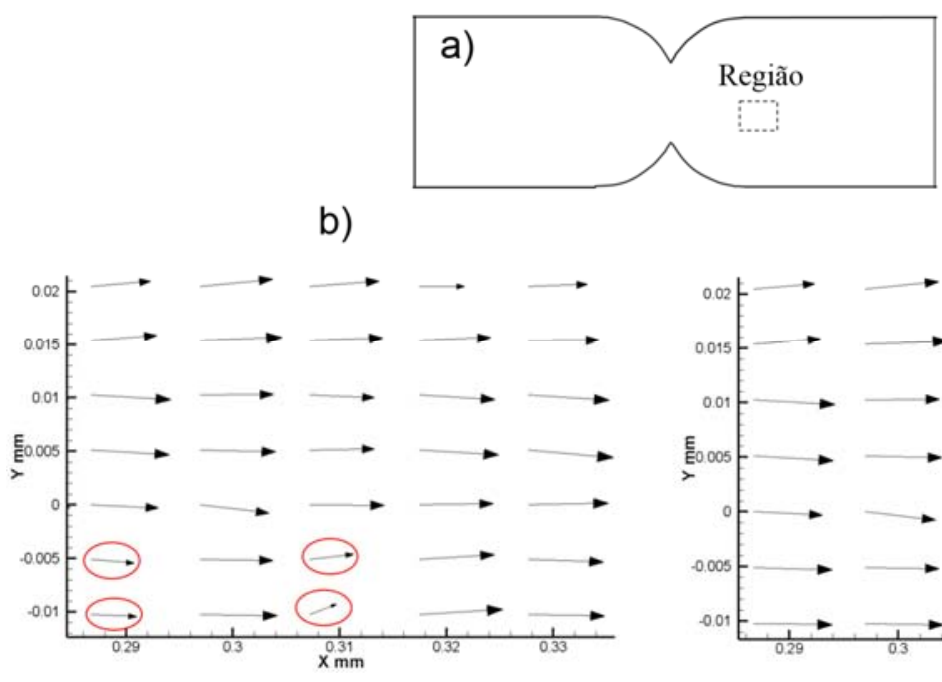

c)

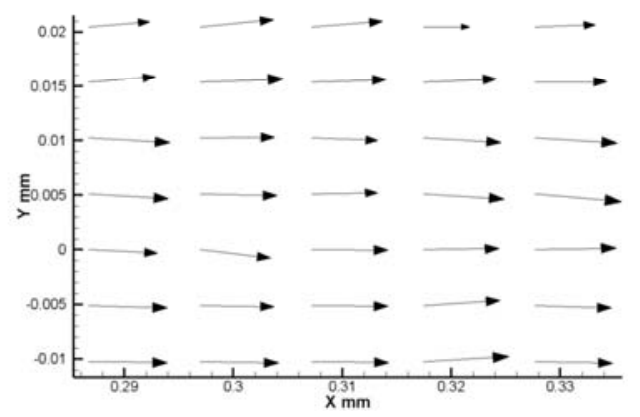

Figura 59 - a) Região do escoamento selecionado. b) Validação de vetores. c) Substituição de vetores

\section{2.}

\section{Movimento Browniano das partículas}

O movimento Browniano resulta de colisões entre as moléculas do fluido e as partículas suspendidas dando origem ao movimento aleatório das partículas. O movimento Browniano se torna importante quando são utilizadas partículas traçadoras na ordem de sub-microns e campos de velocidade na ordem de $10 \mu \mathrm{m} / \mathrm{s}$ (Santiago et al., 1998).

É importante que as partículas traçadoras acompanhem fielmente as linhas de corrente do escoamento e com um tempo de resposta rápida (Raffel et al., 2007). O número de Stokes Stk, parâmetro adimensional, avalia esta condição e é definido entre o tempo de resposta da partícula $t_{p}$ e o tempo característico do escoamento $t_{c}$, como mostrado na eq. (24).

$$
S t k=\frac{t_{p}}{t_{c}}
$$

Um modelo simples para obter o tempo de resposta de uma partícula é assumindo uma partícula esférica e uma resposta de primeira ordem quando o escoamento é submetido a uma aceleração constante. A eq. (25) define a resposta característica da partícula. 


$$
t_{p}=\frac{d_{p} \rho_{p}}{18 \mu}
$$

Onde, $d_{p}$ é o diâmetro da partícula, $\rho_{p}$ é a densidade da partícula e $\mu$ é a viscosidade dinâmica do fluido. Para o caso dos fluidos utilizados nesta investigação (água, solução de glicerina e solução polimérica de PEO), os tempos de resposta e os números de Stokes foram estimados como descrito a seguir.

Água: $t_{p}=\frac{d_{p} \rho_{p}}{18 \mu}=\frac{(1 \mu \mathrm{m})\left(1,055 \mathrm{~kg} / \mathrm{m}^{3}\right)}{18(0,001 \mathrm{~Pa} . \mathrm{s})}=59 \mathrm{ps}, \quad t_{c}=\Delta t=5-20 \mu \mathrm{s}$,

Glicerina: $t_{p}=\frac{d_{p} \rho_{p}}{18 \mu}=\frac{(1 \mu \mathrm{m})\left(1,055 \mathrm{~kg} / \mathrm{m}^{3}\right)}{18(0,004 \mathrm{~Pa} . \mathrm{s})}=15 \mathrm{ps}, t_{c}=\Delta t=9-280 \mu \mathrm{s}$,

PEO: $t_{p}=\frac{d_{p} \rho_{p}}{18 \mu}=\frac{1}{\mu} \frac{(1 \mu \mathrm{m})\left(1,055 \mathrm{~kg} / \mathrm{m}^{3}\right)}{18}=1 \mathrm{a} 10 \mathrm{ps}, t_{c}=\Delta t=4,5-250 \mu \mathrm{s}$,

Água: $S t k \approx 10^{-5}$ a $10^{-6}$, Glicerina: $S t k \approx 10^{-6}$ a $10^{-8}$, PEO: $S t k \approx 10^{-7}$ a $10^{-8}$.

Os tempos característicos do escoamento $t_{c}$ foram considerados os tempos de captura entre imagens consecutivas $\Delta t$ utilizando a técnica de micro-PIV para as diferentes condições de escoamento. Os tempos de resposta foram bastante menor do que os tempos característicos do escoamento $(S t k<<1)$, portanto, as partículas traçadoras utilizadas seguiram as linhas de corrente do escoamento dos fluidos.

O movimento Browniano limita o tamanho mínimo da partícula na escala micro. O erro relativo devido ao movimento Browniano $\mathcal{E}_{B}$ é estimado através da eq. (26) dada por Santiago et al. (1998), assumindo um escoamento estável no tempo e com pequenos gradientes de velocidade. O coeficiente de difusão $D_{f}$ para uma partícula esférica é determinado utilizando a expressão de Einsten (1905), mostrado na eq. (27). 


$$
\begin{aligned}
& \varepsilon_{B}=\frac{\text { Deslocamento devido ao mov. Browniano }}{\text { Deslocamento total da partícula }}=\frac{1}{U m} \sqrt{\frac{2 D_{f}}{\Delta t}}, \\
& D_{f}=\frac{K_{B} T}{3 \pi \mu d_{p}} .
\end{aligned}
$$

Onde, $K_{B}$ é a constante de Boltzmann, $T$ é a temperatura absoluta do fluido, $\mu$ é a viscosidade dinâmica do fluido, $d_{p}$ é o diâmetro da partícula, $\Delta t$ é o intervalo de tempo entre imagens consecutivas e $U m$ é a velocidade característica do fluido determinado a partir da vazão de injeção $Q$. Os resultados dos coeficientes de difusão e dos erros relativos na direção dos escoamentos em estudo são mostrados a seguir:

Água: $D_{f}=\frac{K_{B} T}{3 \pi \mu d_{p}}=\frac{\left(1,38 \times 10^{-23} \mathrm{~J} / \mathrm{K}\right)(296,15 \mathrm{~K})}{3 \pi(0,001 \mathrm{~Pa} . \mathrm{s})(1 \mu \mathrm{m})}=4,3 \times 10^{-13} \mathrm{~m}^{2} / \mathrm{s}$, $\Delta t=5-20 \mu \mathrm{s}, Q=0,2-5,0 \mathrm{ml} / \mathrm{h}$,

Glicerina: $D_{f}=\frac{K_{B} T}{3 \pi \mu d_{p}}=\frac{\left(1,38 \times 10^{-23} \mathrm{~J} / \mathrm{K}\right)(296,15 \mathrm{~K})}{3 \pi(0,004 \mathrm{~Pa} . \mathrm{s})(1 \mu \mathrm{m})}=1,1 \times 10^{-13} \mathrm{~m}^{2} / \mathrm{s}$, $\Delta t=9-280 \mu \mathrm{s}, Q=0,02-0,32 \mathrm{ml} / \mathrm{h}$, PEO: $D_{f}=\frac{K_{B} T}{3 \pi \mu d_{p}}=\frac{1}{\mu} \frac{\left(1,38 \times 10^{-23} \mathrm{~J} / \mathrm{K}\right)(296,15 \mathrm{~K})}{3 \pi(1 \mu \mathrm{m})} \approx 10^{-13} \mathrm{a} 10^{-14} \mathrm{~m}^{2} / \mathrm{s}$, $\Delta t=4,5-250 \mu \mathrm{s}, Q=0,02-0,32 \mathrm{ml} / \mathrm{h}$, Água: $\varepsilon_{B} \approx 0,2 \%$ a $3,5 \%$, Glicerina: $\varepsilon_{B} \approx 1,7 \%$ a $4,7 \%$, PEO: $\varepsilon_{B} \approx 1 \%$ a $4,7 \%$.

Vale mencionar que a viscosidade dinâmica do fluido viscoelástico de PEO varia com a taxa de cisalhamento, e para diferentes condições de escoamento apresenta instabilidade no tempo acompanhado de altos gradientes de velocidade. O erro Browniano pode ser reduzido através da média amostral das partículas localizadas na mesma janela de interrogação de várias imagens consecutivas $\varepsilon_{B} / \sqrt{N}$, sendo $N$ ó número total de partículas na média amostral (Werelet e Meinhart 2002). 


\section{4 \\ Metodologia}

Este capítulo descreve os equipamentos, o procedimento experimental, a preparação e caracterização das soluções aquosas utilizados nos experimentos. Os experimentos foram realizados no Laboratório de Microhidrodinâmica e Escoamento em Meios Porosos (LMMP) do Departamento de Engenharia Mecânica da PUC - Rio.

\section{1.}

\section{Bancada experimental}

A figura 60 representa um esquema da bancada experimental utilizada nas medições da queda de pressão e campo de velocidade no escoamento, com a finalidade de estudar o comportamento viscoelástico da solução polimérica de óxido de polietileno (PEO) escoando através de uma constrição (garganta de poro).

Os componentes da bancada experimental são os seguintes: o micromodelo, o sistema de injeção dos fluidos, o sistema de medição de pressão e o sistema de micro-PIV.

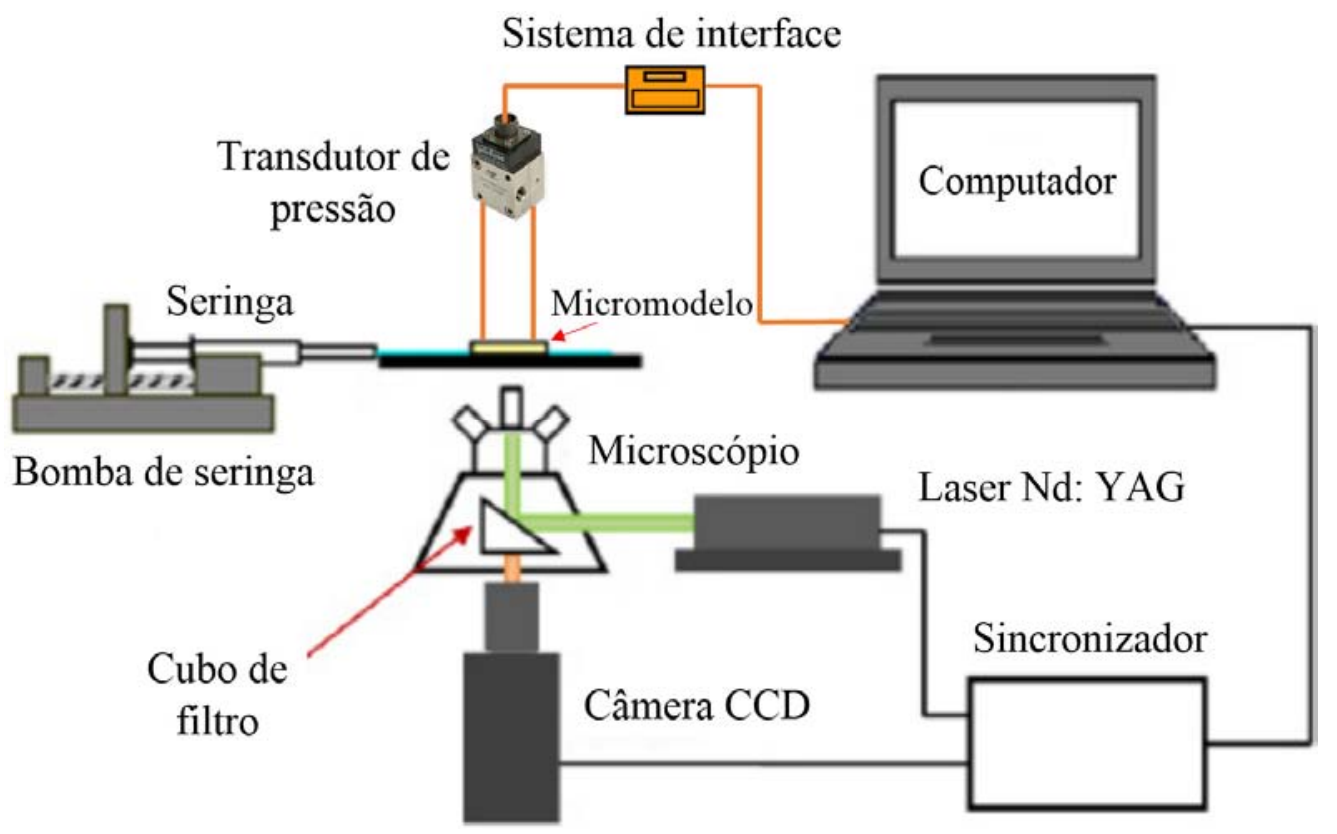

Figura 60 - Esquema da bancada experimental 


\subsection{1. Micromodelo}

A geometria dos poros e gargantas de poros são importantes a fim de compreender o comportamento dinâmico dos fluidos nas rochas dos reservatórios e uma classificação deles é apresentada na tabela 2 (Borbas, 1994).

Tabela 2 - Classificação da geometria de um poro

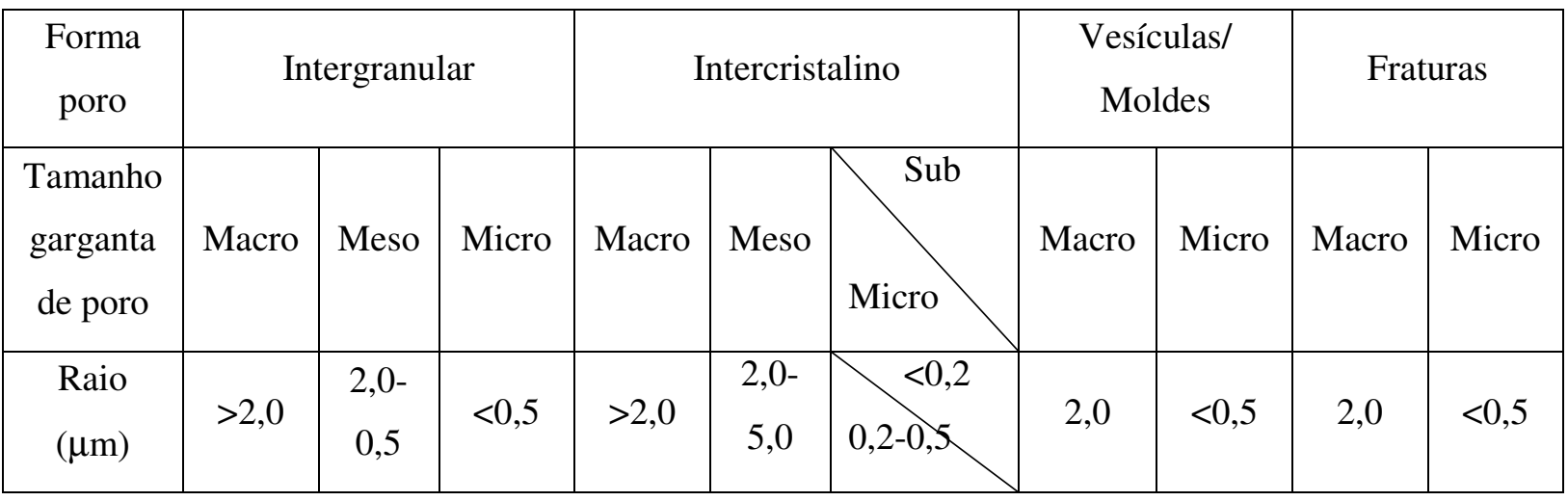

O poro intergranular é formado por espaços intersticiais entre os grãos da estrutura e o poro intercristalino é formado pelos cristais da rocha. As vesículas e moldes são grandes poros formados pela dissolução de grão do cimento, e as fraturas são poros formados pela ruptura ao longo de planos de rocha.

O micromodelo (dispositivo microfluídico) foi utilizado como modelo de uma garganta de poro em escala micrométrica e possui sete orifícios. Estes orifícios são conectados às mangueiras de tomadas de pressão, de injeção e saída dos fluidos por meio de conectores lineares; todos comercializados pela Dolomite Microfluidics LTD.

A geometria do micromodelo apresenta uma seção transversal oval constante ao longo dos microcanais e uma constrição. A figura 61 mostra o micromodelo e suas dimensões principais. 
a)

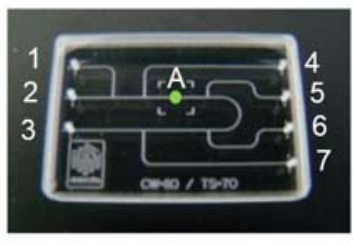

b)

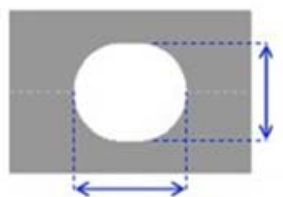

Largura do canal: $110 \mu \mathrm{m}$
Constrição: Região A

Profundidade do canal: $100 \mu \mathrm{m}$

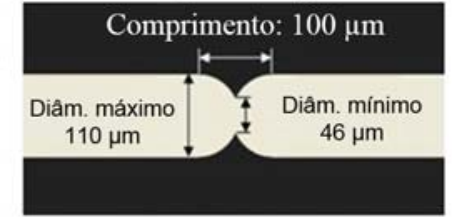

Figura 61 - a) Micromodelo b) Geometria da seção transversal e da constrição

O micromodelo fabricado em vidro permite a injeção de fluidos sem deformação da geometria. Além disso, possui excelente transparência ótica, boa compatibilidade química e pode trabalhar em uma ampla faixa de pressões e temperaturas.

A técnica de litografia foi utilizada pela Dolomite Microfluidics LTD para a fabricação do dispositivo microfluídico utilizado neste trabalho, e um breve resumo do procedimento de fabricação é descrito na figura 62 a seguir:

1. Aplicar uma camada de cromo e de fotorresistente ao vidro

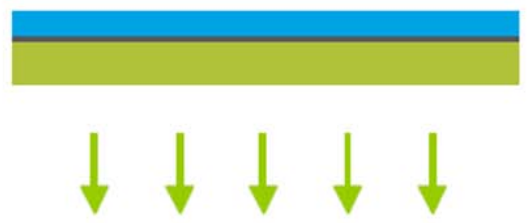

2. Expor o fotorresistente à luz UV através da máscara

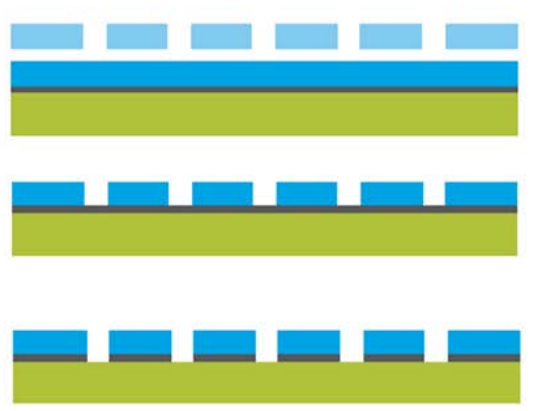

4. Gravar camada de cromo

5. Molhar o vidro gravado com solução de ácido HF

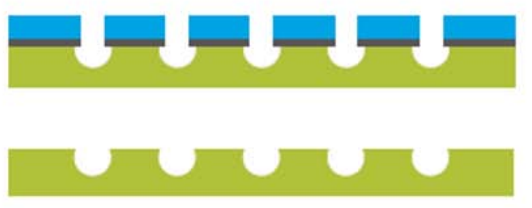

6. Remover o cromo e o fotorresistente, logo limpar

7. Micro perfuração

8. Camada de cobertura de vidro de ligação térmica

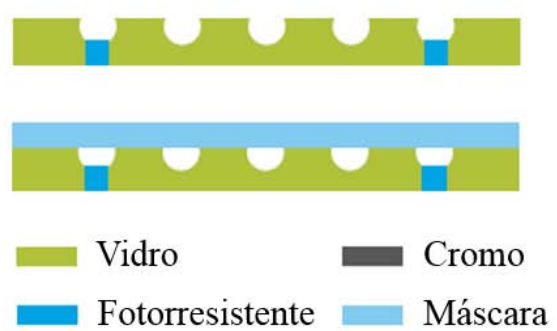

Figura 62 - Representação esquemática do processo litográfico. Fonte: Dolomite (2012) 


\subsection{2.}

\section{Sistema de injeção}

Os fluidos são inseridos em seringas de vidro Hamilton Gastight ${ }^{\circledR}$ da série 1000 e são injetados no interior do micromodelo por meio de uma bomba de seringa de infusão continua (Modelo Harvard Apparatus Elite 11, exatidão $\pm 0,5 \%$ ).

Válvulas plásticas de três vias, conectores e mangueiras de plástico são utilizadas na montagem do circuito. O sistema de injeção experimental real é apresentado na figura 63 e um esquema da montagem do sistema injeção junto ao dispositivo microfluídico e transdutor de pressão ilustrado na figura 64 .

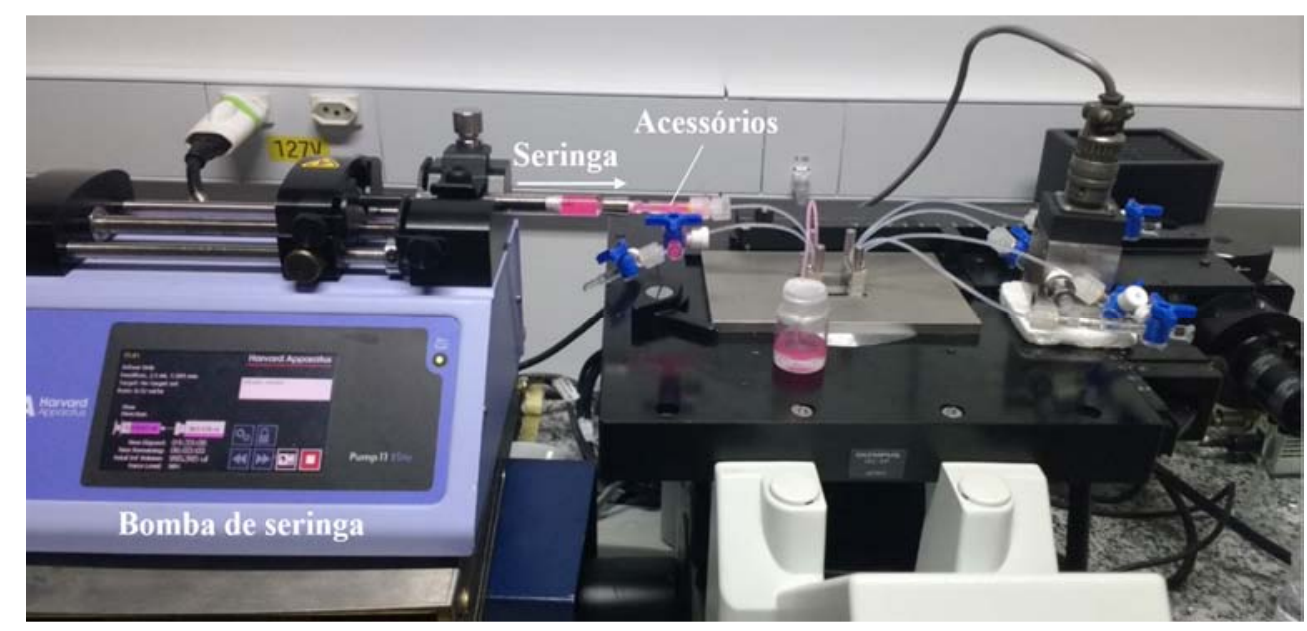

Figura 63 - Montagem experimental do sistema de injeção dos fluidos

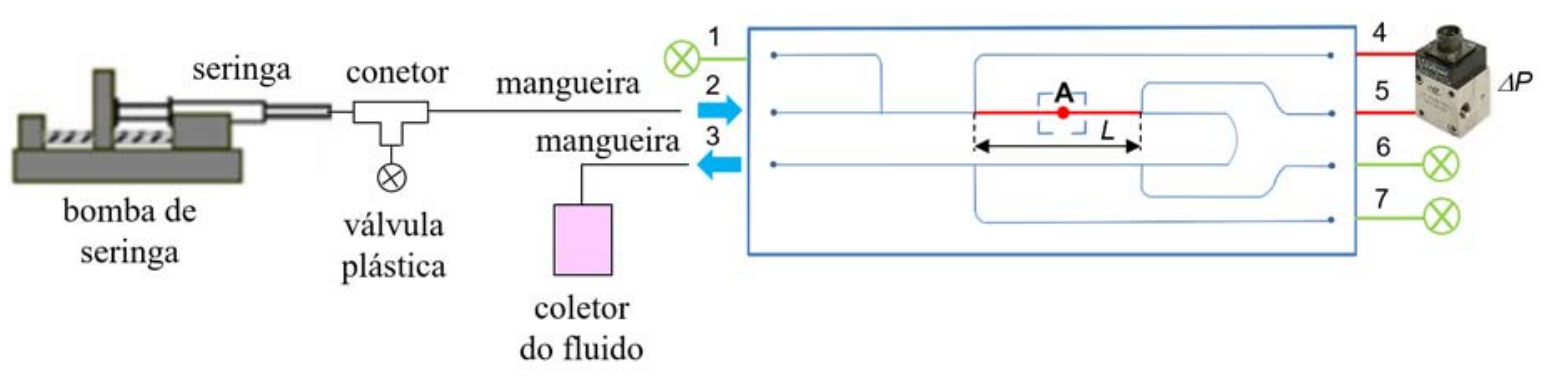

Figura 64 - Esquema da montagem do sistema de injeção com o dispositivo microfluídico e o transdutor de pressão

O fluido foi injetado pela abertura $\mathrm{N}^{\circ} 2$ e a saída do fluido foi pela abertura $\mathrm{N}^{\circ} 3$. As aberturas $\mathrm{N}^{\circ} 1, \mathrm{~N}^{\circ} 6$ e $\mathrm{N}^{\circ} 7$ foram fechadas durante o experimento utilizando válvulas de plástico. As aberturas $\mathrm{N}^{\circ} 4$ e $\mathrm{N}^{\circ} 5$ foram conectadas ao transdutor de pressão para medir a queda de pressão no microcanal com constrição de 
comprimento L. A constrição está localizada na posição A do dispositivo microfluídico, como mostrado no esquema da figura 64.

\subsection{3.}

\section{Sistema de medição de pressão}

A medição da queda de pressão dos fluidos no microcanal com constrição foi realizada por meio de um transdutor de pressão diferencial de relutância variável (Modelo DP15, exatidão $\pm 0,25 \% \mathrm{FS}$ ), fabricado pela Validyne Engineering Corporation.

O transdutor possui duas câmaras. A câmara positiva (+) é conectada à tomada localizada antes da constrição (abertura $\mathrm{N}^{\circ} 4$ da figura 64) e a câmara negativa (-) à tomada localizada depois da constrição (abertura $\mathrm{N}^{\circ} 5$ da figura 64). As câmaras são separadas por um diafragma plano em aço inoxidável (sensor de pressão).

A variação de deflexão do diafragma é transmitida em valor de sinal de voltagem ao computador por meio de circuitos eletrônicos. Este sinal é convertido em pressão mediante o processo de calibração (Apêndice A). O diafragma utilizado nos experimentos possui a faixa de medição de pressão entre 0 e 1,25 psi $(0-8,6 \mathrm{kPa})$.

A aquisição de dados em tempo real é efetuada utilizando o software Easy Sense 2100 fornecida pela Validyne. A figura 65 apresenta a montagem do transdutor de pressão diferencial no micromodelo.

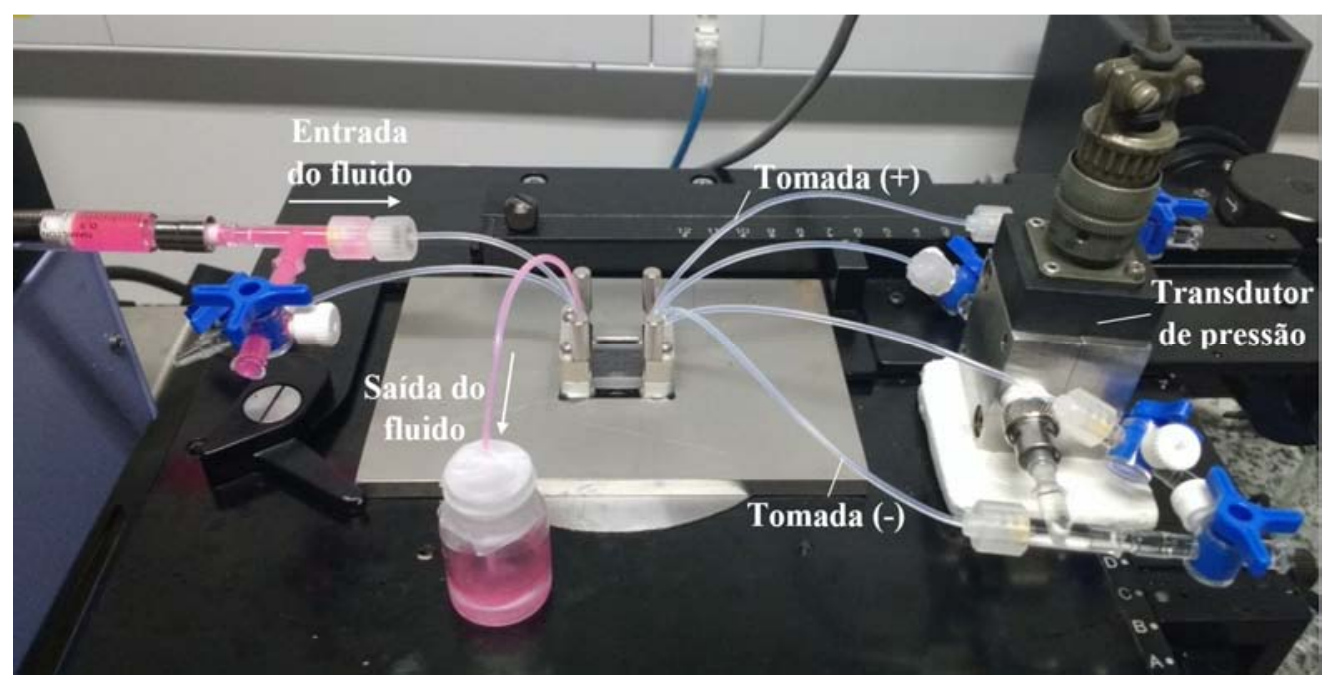

Figura 65 - Montagem do transdutor de pressão diferencial 


\subsection{4. \\ Sistema de micro-PIV}

O sistema de micro-PIV foi utilizado para obter o campo de velocidade do escoamento próximo à região da constrição e é composto de um sistema ótico, um sistema de iluminação epifluorescência, entre outros, desenvolvido pela TSI $^{\circledR}$ (Trust Science Innovation).

\subsubsection{1. Microesferas com fluorescência}

Para determinar o campo de velocidade do escoamento, os fluidos foram misturados com uma suspensão de microesferas de poliestireno (suspensão em água destilada) à proporção de 1:0,14 (volume da mistura/volume da suspensão de microesferas), fornecida pela Invitrogen ${ }^{\circledR}$.

A densidade das microesferas e a massa específica dos fluidos devem ser próximas (flutuação neutra). As microesferas devem ser pequenas (na ordem de microns) para que seu movimento relativo ao fluido seja insignificante e que se desloquem ao longo das linhas de corrente do escoamento. A seguir são dadas as características principais das microesferas:

$>\mathrm{O}$ diâmetro das microesferas é de $1 \mu \mathrm{m}$;

$>$ A densidade das microesferas é de $1,055 \mathrm{~g} / \mathrm{cm}^{3}$;

$>$ A concentração de microesferas na suspensão é de 1,0x $10^{10}$ microesferas $/ \mathrm{ml}$;

$>$ O comprimento de onda de excitação/emissão das microesferas é de 540/560 nm (fluorescência de cor laranja).

\subsubsection{2.}

\section{Laser Nd:YAG}

O laser de duplo pulso Mod. SOLO III-Nd:YAG da New Wave $e^{T M}$ emite uma luz verde para iluminar o escoamento (fluido misturado com as microesferas em suspensão) localizado perto da região da constrição.

O laser é composto por uma fonte de energia e uma cabeça dupla (figura 66). A fonte de energia fornece um sistema eletrônico de controle/potência e um sistema de resfriamento para ambas as cabeças do laser. 
O feixe de luz verde saindo da cabeça dupla do laser é transportado e guiado por meio de um cabo de fibra ótica conectada à porta ótica inferior do microscópio. O laser Nd:YAG apresenta as seguintes características:

Energia por pulso de $50 \mathrm{~mJ}$

Comprimento de onda de $532 \mathrm{~nm}$;

Frequência máxima ou taxa de repetição de $15 \mathrm{~Hz}$.
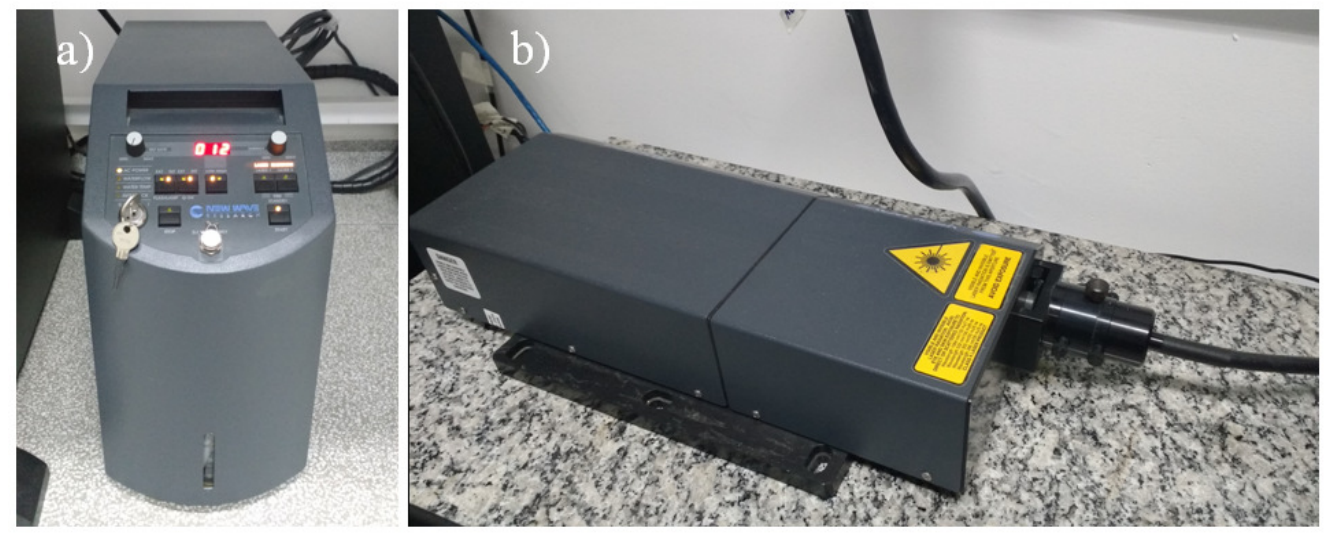

Figura 66 - a) Fonte b) Cabeça do laser Mod. SOLO III - Nd:YAG

\subsubsection{3. \\ Microscópio}

O microscópio de epi-fluorescência Mod. IX71S1F-3 da Olympus ${ }^{\circledR}$ permitiu observar o escoamento localizado próximo à região da constrição por meio dos sistemas de ampliação (ocular e objetiva) e focalização (macrométrico e micrométrico). A objetiva Mod. UplanFLN 10x/0,30 da Olympus $^{\circledR}$ foi utilizada nas visualizações.

O microscópio utiliza uma lâmpada de halogênio Mod. TH4-100 da Olympus $^{\circledR}$ para iluminar o escoamento (luz ultravioleta). O microscópio e a lâmpada de halogênio são apresentados na figura 67. 


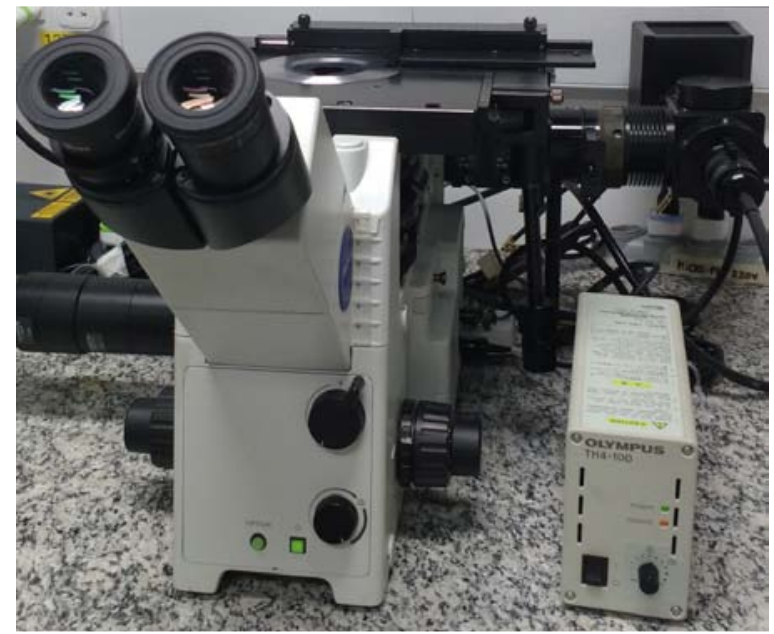

Figura 67 - Microscópio de fluorescência e lâmpada de halogênio da Olympus®

Ambas as luzes das fontes do laser e da lâmpada incidem sobre um cubo de filtro contendo três filtros óticos (espelho dicroico, o filtro de barreira e o filtro de excitação) inseridos no microscópio. O cubo de filtro separa a luz de fluorescência emitida pelas microesferas $(560 \mathrm{~nm})$ da luz de excitação das fontes $(532 \mathrm{~nm})$, devido aos diferentes comprimentos de onda. A luz de fluorescência atinge à câmera formando as imagens do escoamento, como ilustrada na figura 68 .

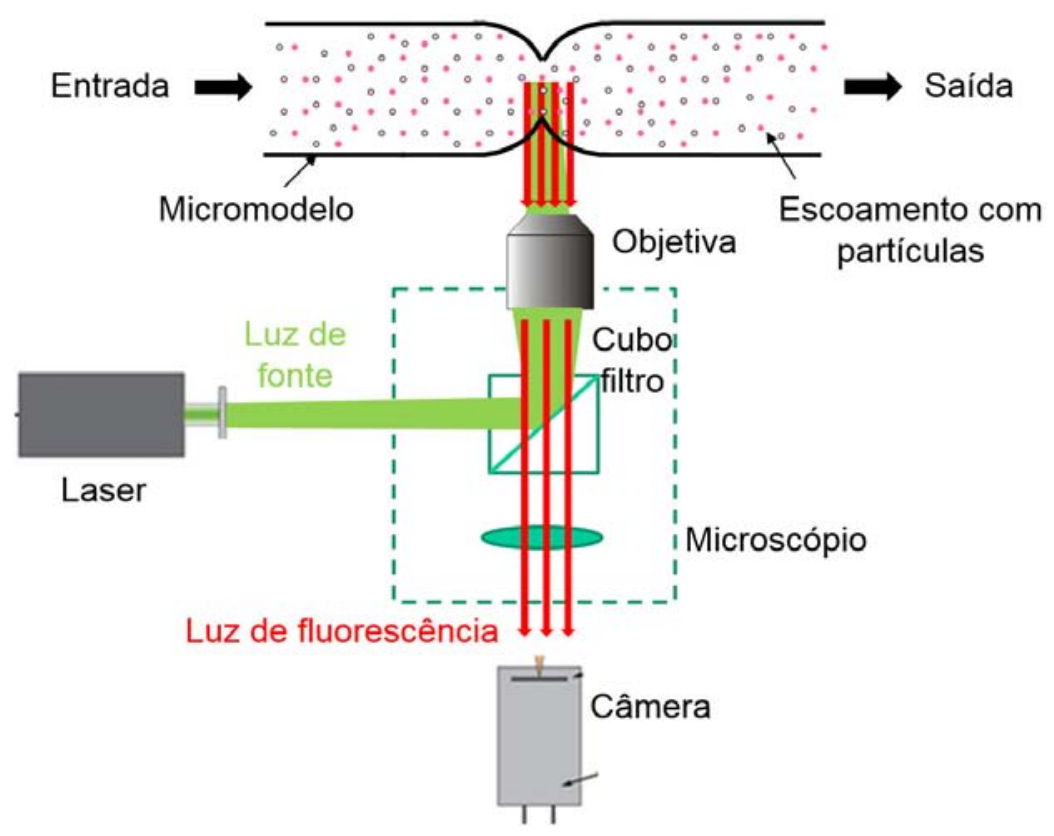

Figura 68 - Esquema de iluminação do microscópio de fluorescência 


\subsubsection{4.}

\section{Câmera digital}

A câmera Mod. 630066 PowerView $^{T M}$ da $T_{S I}^{\circledR}$ captura as imagens do escoamento (fluido com as microesferas em suspensão) perto da constrição e fica acoplada ao eixo horizontal do microscópio, como ilustrada na figura 69.

A câmera possui uma lente de magnificação $2 x$ para retransmitir a imagem sobre sua superfície. Entretanto, a magnificação total utilizada nos experimentos foi de 20x (magnificação da objetiva 10x e da lente 2x) e a calibração de resolução espacial foi de $0,32 \mu \mathrm{m} /$ pixel (TSI User's Guide, 2011). As características principais da câmera são citadas a seguir:

Frequência de $10 \mathrm{~Hz}$;

Resolução espacial de 1,4 megapixels;

Tamanho do pixel de 6,45 x 6,45 $\mu \mathrm{m}$;

Formato da imagem de 1376 x 1024 pixels (8,8 x 6,6 mm).



Figura 69 - Câmera Mod. 630066 PowerView $^{\mathrm{TM}}$ da TSI ${ }^{\circledR}$

\subsubsection{5.}

\section{Sincronizador}

O sincronizador Mod. 610034 LaserPulse da $T S I^{\circledR}$ foi utilizado para que os disparos de pulso do laser sejam sincronizados com a captura de imagens da câmera. O sincronizador é mostrado na figura 70. 


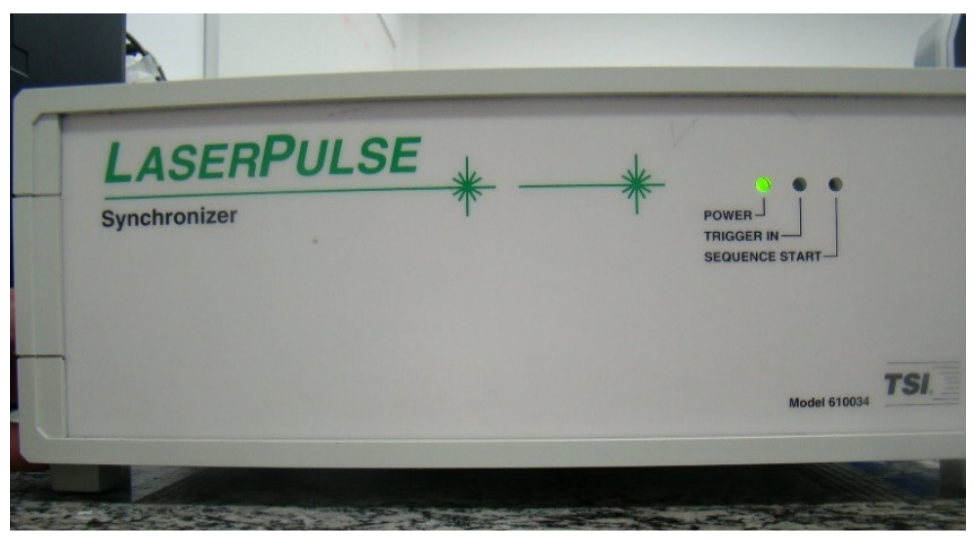

Figura 70 - Sincronizador Mod. 610034 LaserPulse da TSI ${ }^{\circledR}$

A configuração de sincronização dos equipamentos e a aquisição de imagens foram realizadas usando o software Insight $4 G^{T M}$ da $T S I^{\circledR}$. A seguir, citamos as funções principais realizadas pelo software:

> Configurar o tempo de exposição da câmera e o disparo de pulso do laser;

$>$ Configurar a energia do laser (Q-Switch delay);

> Calibrar a resolução espacial da câmera;

> Analisar as imagens capturadas utilizando as etapas de pré-processamento, processamento e pós-processamento;

$>$ Visualizar o campo de velocidade do escoamento utilizando o software Tecplot Focus 2009.

\section{2.}

Soluções aquosas

\subsection{1.}

\section{Preparação das soluções aquosas}

A água do sistema de purificação Mod. Milli- $Q^{\circledR}$ da Millipore Corporation (figura 71) foi utilizada para preparar a solução polimérica e a solução de glicerina. 


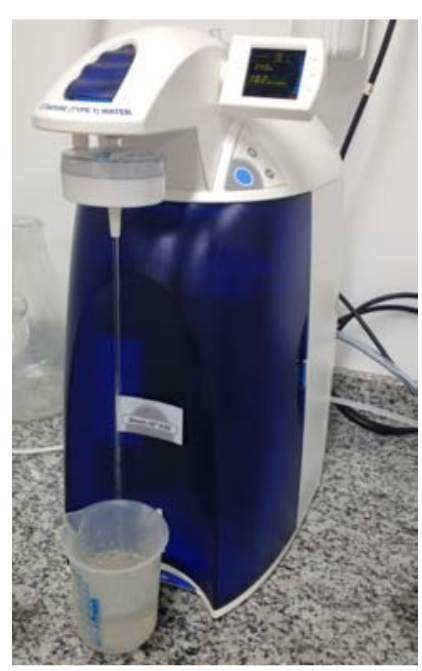

Figura 71 - Purificador de água Milli-Q ${ }^{\circledR}$

As propriedades da água deionizada purificada do sistema Milli-Q ${ }^{\circledR}$ são apresentadas na tabela 3, a seguir:

Tabela 3 - Propriedades da água deionizada Milli-Q a $23^{\circ} \mathrm{C}$

\begin{tabular}{|c|c|c|}
\hline Tipo & $\begin{array}{c}\rho \\
\mathbf{g} / \mathbf{m l}]\end{array}$ & $\begin{array}{c}\boldsymbol{\mu} \\
{[\mathbf{c P}]}\end{array}$ \\
\hline Água deionizada & 0,99 & 0,93 \\
\hline
\end{tabular}

Onde $\rho$ é a massa específica e $\mu$ é a viscosidade dinâmica.

\subsubsection{1. \\ Solução polimérica}

O óxido de polietileno (PEO) de peso molecular $8 \times 10^{6} \mathrm{~g} / \mathrm{mol}$ da Sigma Aldrich $^{\circledR}$ foi utilizado na preparação da solução polimérica à concentração de $0,1 \%$ em peso. Este polímero flexível e solúvel em água possui um comportamento extensional forte a baixas concentrações, motivo principal do uso deste polímero em nossos experimentos (Dontula et al., 1998).

O procedimento de preparação da solução polimérica foi realizado sob condições bem controladas para garantir a sua repetitividade, conforme explicado a seguir: 
Processo de pesagem em peso: A solução polimérica de 600,6 g à concentração de 0,1\% em peso de PEO foi obtida usando $600 \mathrm{~g}(606,06 \mathrm{ml})$ de água deionizada e $0,6 \mathrm{~g}$ de polímero. O polímero e a água deionizada foram pesados utilizando uma balança analítica eletrônica Quimis (Modelo Q500L210C, precisão de $\pm 0,1 \mathrm{mg}$ ) e uma balança de precisão Ohaus ${ }^{\circledR}$ (Modelo Adventurer Pro AV2101 e precisão de 0,1g).

Processo de mistura: Um agitador mecânico digital Mod. $R W-20$ da $I K A^{\circledR}$ foi utilizado durante o período de mistura a uma rotação de 200 RPM. O polímero foi vertido aos poucos na água deionizada para evitar aglomerados na solução. Em seguida, um filme de parafina plástica foi colocado para evitar poeira e evaporação da solução, como mostrada na figura 72. O tempo de mistura foi de 24 horas para assegurar uma completa dissolução do polímero na solução. Finalmente, a solução polimérica foi deixada em repouso durante 24 horas antes de ser utilizada nos experimentos, para assegurar a completa relaxação das cadeias poliméricas esticadas durante o processo de mistura.
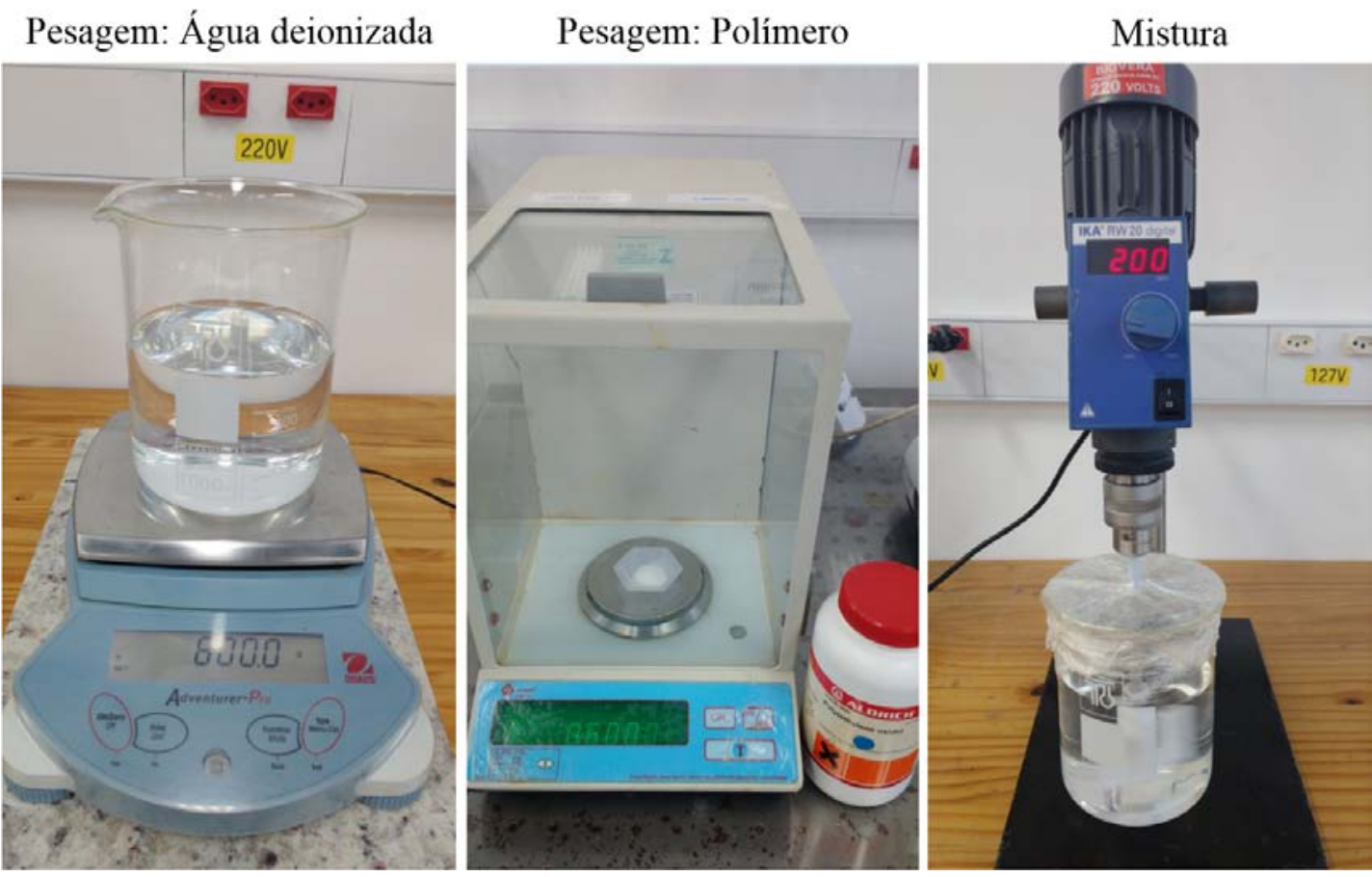

Figura 72 - Processo de preparação da solução polimérica 


\subsubsection{2. \\ Solução de glicerina}

A glicerina $\left(\mathrm{C}_{3} \mathrm{H}_{8} \mathrm{O}_{3}\right)$ de peso molecular 92,09 g/mol (Vetec Química Fina LTDA) e de massa específica $1,26 \mathrm{~g} / \mathrm{ml}$ foi utilizada na preparação da solução água/glicerina.

A solução de glicerina (solução viscosa) foi utilizada nos experimentos como um fluido Newtoniano com a mesma viscosidade da solução polimérica. Desta forma, qualquer diferença no comportamento do escoamento entre as duas soluções pode ser relacionada às forças viscoelásticas presentes na solução de PEO. O procedimento de preparação é descrito a seguir:

$>$ Processo de seleção da solução: Inicialmente soluções de glicerina em água de $50 \mathrm{ml}$ foram preparadas para diferentes concentrações, com a finalidade de encontrar uma solução cuja viscosidade seja próxima à viscosidade de cisalhamento da solução polimérica de PEO (será explicado com maior detalhe na caracterização das soluções aquosas). Finalmente, a solução utilizada nos experimentos foi de $45 \%$ em peso de glicerina.

Processo de pesagem em peso: A solução de água/glicerina de 603,69ml à concentração de $45 \%$ em peso de glicerina foi obtida usando $366 \mathrm{~g}$ $(\approx 369,69 \mathrm{ml})$ de água deionizada e $294,84 \mathrm{~g}(\approx 234 \mathrm{ml})$ de glicerina. Glicerina e água deionizada foram pesadas utilizando a balança analítica eletrônica Quimis (Modelo Q500L210C e precisão de $\pm 0,1 \mathrm{mg}$ ).

Processo de mistura: Um agitador magnético digital Mod. Corning PC-240 da $I K A^{\circledR}$ e uma barra de agitação magnética foram utilizadas durante o período de mistura a uma rotação de 500 RPM. A glicerina foi vertida lentamente na água deionizada. Finalmente, um filme de parafina plástica foi colocado para evitar poeira e evaporação da solução durante o tempo de mistura (2 horas), como mostrada na figura 73 . 


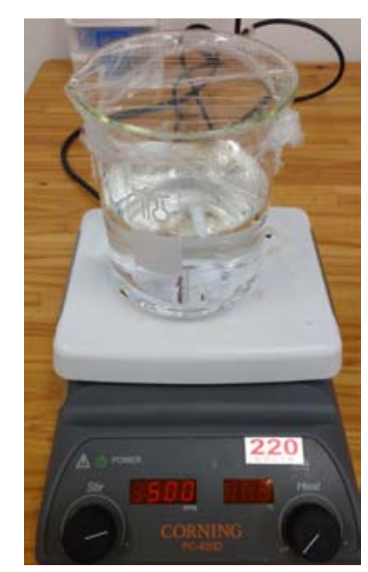

Figura 73 - Processo de preparação da solução de glicerina

\subsection{2.}

\section{Caracterização das soluções aquosas}

O picnômetro é um instrumento de medição que permitiu medir a massa específica das soluções aquosas. O picnômetro fabricado em vidro possui um volume constante de $10,6 \mathrm{ml}$.

O procedimento de medição foi repetido três vezes para cada solução às mesmas condições $\left(T=23^{\circ} \mathrm{C}\right)$ para garantir a sua repetitividade, conforme explicado a seguir:

Processo de pesagem seco: O picnômetro foi pesado vazio utilizando uma balança analítica eletrônica Quimis (Modelo Q500L210C e precisão de $\pm 0,1 \mathrm{mg})$.

Processo de pesagem cheio: A solução foi vertida no interior do picnômetro e logo foi pesado utilizando a mesma balança analítica, como mostrada na figura 74 .

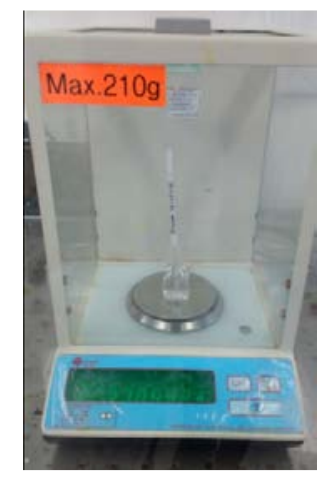

Figura 74 - Pesagem da solução utilizando um picnômetro 
A massa especifica $\rho$ foi obtida dividindo a diferença de massa dos processos de pesagem e o volume do picnômetro. Os resultados são mostrados na tabela 4, a seguir:

Tabela 4 - Massa especifica das soluções aquosas

\begin{tabular}{|c|c|}
\hline Soluções aquosas & $\begin{array}{c}\boldsymbol{\rho} \\
{[\mathbf{g} / \mathbf{m l}]}\end{array}$ \\
\hline Solução de glicerina & 1,11 \\
\hline Solução polimérica de PEO & 0,99 \\
\hline
\end{tabular}

As propriedades reológicas das soluções foram determinadas usando um reômetro rotacional e extensional sob as mesmas condições de operação $\left(T=23^{\circ} \mathrm{C}\right)$ para garantir a sua repetitividade.

O reômetro rotacional Physica MCR 301 da Anton Paar foi utilizado para medir a viscosidade de cisalhamento das soluções em função da taxa de cisalhamento (figura 75).

A geometria cone/placa de diâmetro de $60 \mathrm{~mm}$ e ângulo de $1^{\circ}$ foi utilizada nas medições.

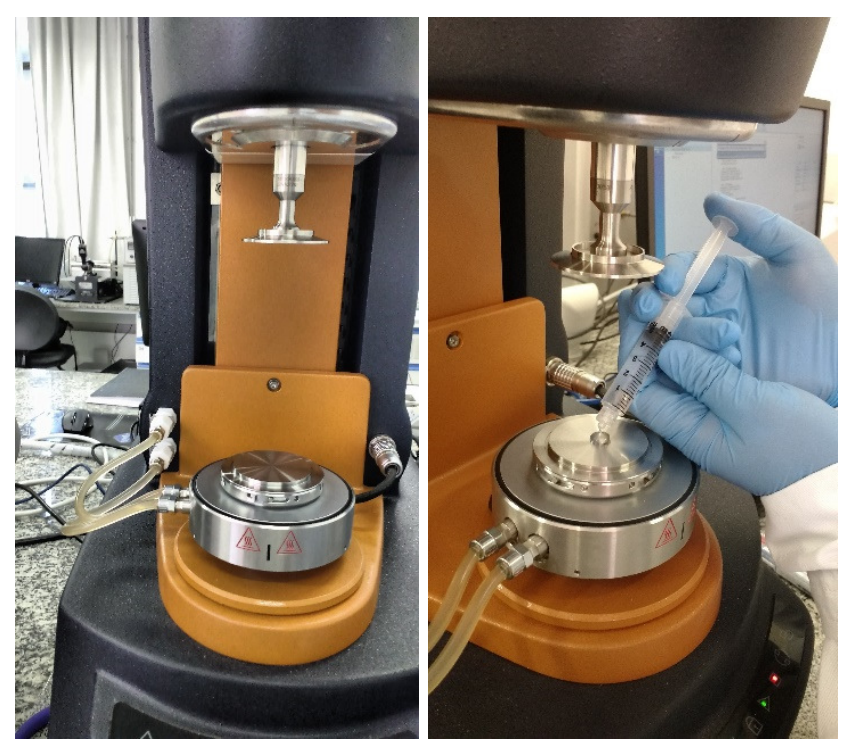

Figura 75 - Reômetro rotacional Physica MCR 301 da Anton Paar 
A figura 76 apresenta a viscosidade de cisalhamento da solução de glicerina e PEO em função da taxa de cisalhamento.

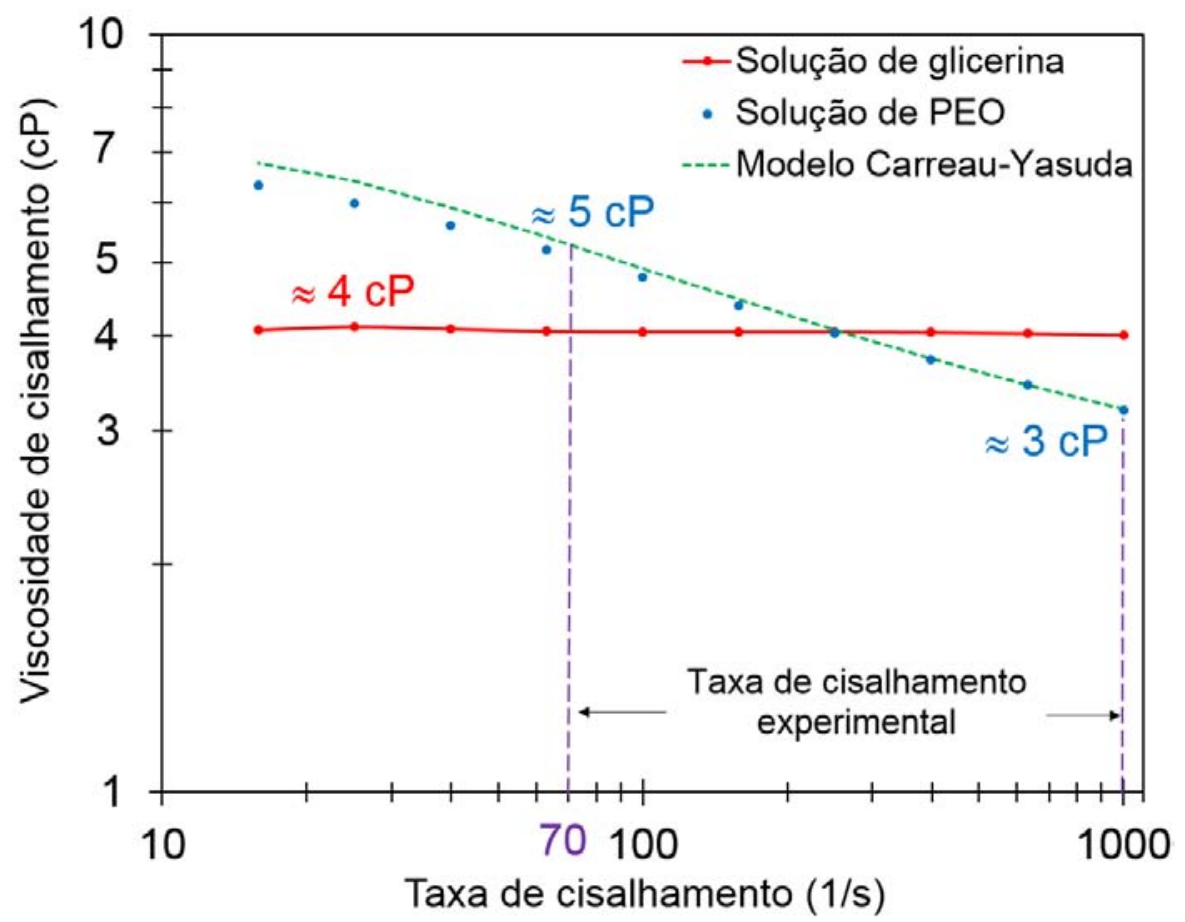

Figura 76 - Viscosidade de cisalhamento da solução polimérica de PEO e glicerina em função da taxa de cisalhamento

A viscosidade da solução polimérica de PEO decresce com o incremento da taxa de cisalhamento apresentando um comportamento pseudo-plástico (shear thinning). A solução de glicerina apresenta um comportamento Newtoniano (viscosidade constante com a taxa de cisalhamento) com um valor de viscosidade de aproximadamente $4 \mathrm{cP}$. A viscosidade de cisalhamento da solução de PEO ajustado ao modelo de Carreau-Yasuda é representada por uma linha descontínua. Este modelo é definido através da eq. (28) a seguir:

$$
\mu_{c}=\mu_{c(\dot{\gamma}=\infty)}+\left(\mu_{c(\dot{\gamma}=0)}-\mu_{c(\dot{\gamma}=\infty)}\right)\left(1+\left(\lambda_{C Y s} \dot{\gamma}\right)^{2}\right)^{\frac{n-1}{2}} .
$$

Onde, $\mu_{c(\dot{\gamma}=0)}$ é a viscosidade à taxa de cisalhamento zero, $\mu_{c(\dot{\gamma}=\infty)}$ é a viscosidade à taxa de cisalhamento infinito, $\lambda_{C Y s}$ é o tempo de relaxação do modelo Carreau-Yasuda, $\dot{\gamma}$ é a taxa de cisalhamento e $n$ é o índice do escoamento. Os 
valores dos coeficientes do modelo Carreau-Yasuda obtidos a partir dos dados reológicos da solução polimérica de PEO é mostrado na tabela 5.

Tabela 5 - Coeficientes do modelo Carreau-Yasuda para a solução polimérica de PEO

\begin{tabular}{|c|c|}
\hline & $\boldsymbol{C = 0 , 1 \%}$ PEO \\
\hline$\mu_{c(\dot{\gamma}=0)}(\mathrm{cP})$ & 7,17 \\
\hline$\mu_{c(\dot{\gamma}=\infty)}(\mathrm{cP})$ & 1,66 \\
\hline$\lambda_{C Y S}(\mathrm{~s})$ & 0,049 \\
\hline$n$ & 0,67 \\
\hline
\end{tabular}

Os valores característicos da taxa de cisalhamento dos experimentos realizados foram estimados através da eq. (29) para escoamentos em tubos, também utilizados para microcanais.

$$
\dot{\gamma}=\frac{8 U m}{D_{e q}}\left(\frac{3 n+1}{4 n}\right)
$$

Onde, $n=0,67$ obtido do modelo de Carreau-Yasuda, $U m$ é a velocidade média do escoamento (injeção da bomba de seringa) e $D_{e q}=92,8 \mu \mathrm{m}$ é o diâmetro equivalente determinado através da fórmula da equação de Hagen-Poiseuille, citado na eq. (18) do capítulo 2. Os valores característicos da taxa de cisalhamento variam de 70 a 1000 1/s, que correspondem aos valores de viscosidade de 5,0 a 3,0 cP, como mostrado na figura 76.

É importante que a solução de PEO e glicerina tenham similar viscosidade de cisalhamento, a fim de separar o efeito extensional produzido pelas cadeias do polímero durante sua passagem pela constrição através das medições da queda de pressão e campo de velocidade no escoamento.

* O reômetro extensional Haake CaBER 1 da Thermo Fisher Scientific ${ }^{\circledR}$ foi utilizado para medir a viscosidade extensional da solução polimérica de PEO (figura 77). 

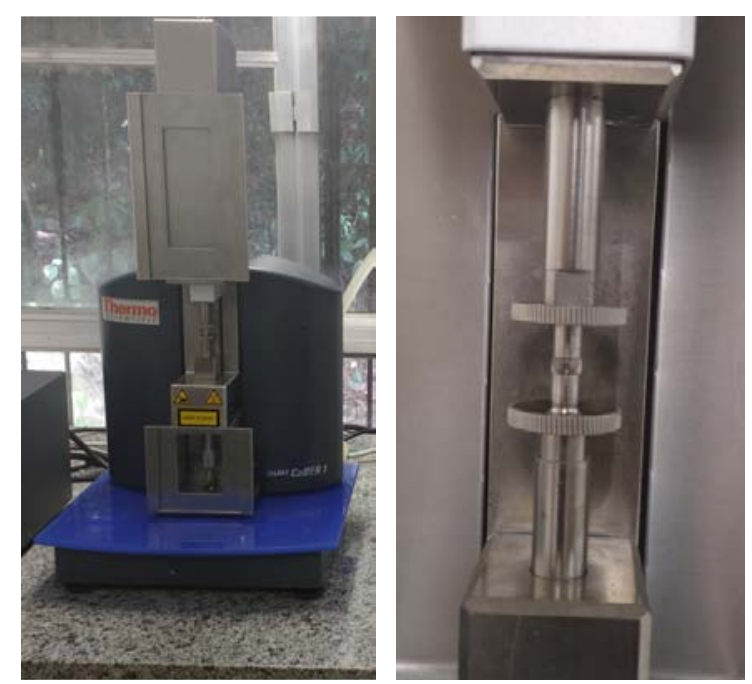

Figura 77 - Reômetro extensional Haake CaBER 1 da Thermo Fisher Scientific ${ }^{\circledast}$

O princípio de funcionamento da técnica de afinamento de uma coluna de fluido consiste em colocar uma pequena quantidade da amostra entre duas placas circulares seguido de uma tensão axial aplicada sobre a amostra (placa superior é separado rapidamente da placa inferior), formando-se um filamento alongado. A variação do diâmetro do filamento ocorre sob a ação da força capilar e resistido pela ação combinada de tensões viscosas e elásticas. Um micrometro laser monitora o diâmetro do ponto médio do filamento do fluido em função do tempo. A figura 78a mostra uma sequência de imagens da evolução do filamento no tempo até sua ruptura para uma solução polimérica de $\mathrm{PEO}$ à concentração de $C=0,1 \%$ em peso e $P M=2 \times 10^{6} \mathrm{~g} / \mathrm{mol}$.

O rêometro extensional CaBER permite determinar a viscosidade extensional das soluções poliméricas (Bhardwaj et al., 2007). A reologia extensional de fluidos menos viscosos e menos concentrados foram realizados por Bazilevsky et al. (1990,1997), Entov et al. (1997), McKinley et al. (2000), Anna et al. (2001), Stelter et al. (2000), Rodd et al. (2004), Tirtaatmadja et al. (2006), embora algumas dificuldades foram encontradas nas medições de soluções de baixa viscosidade quando a relação de aspecto da amostra foi bastante pequena ou os efeitos de inercia do fluido se tornaram importantes (Stelter et al. 2000, Rodd et al. 2004, Scott (2004), Arnolds et al, 2010). A formação de pequenas gotículas (figura 78b) e a presença de oscilações (figura 78c) interrompem a evolução de um filamento uniforme. 
a)

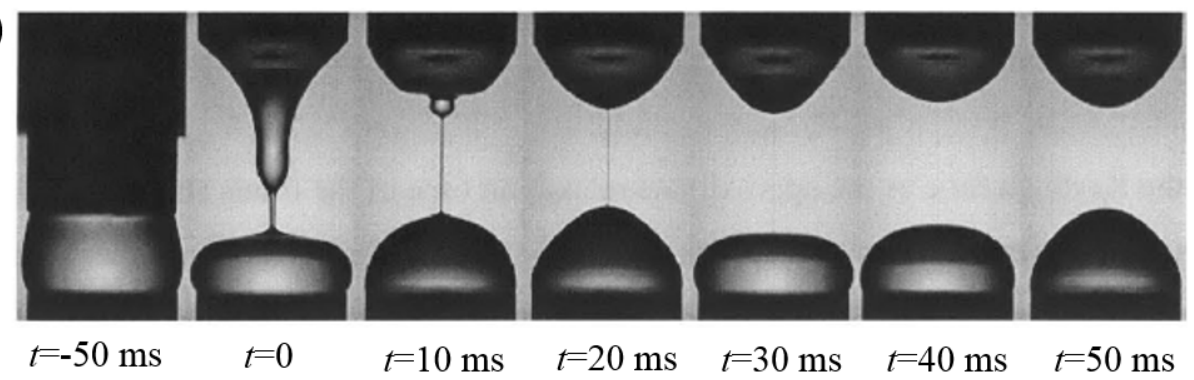

b)

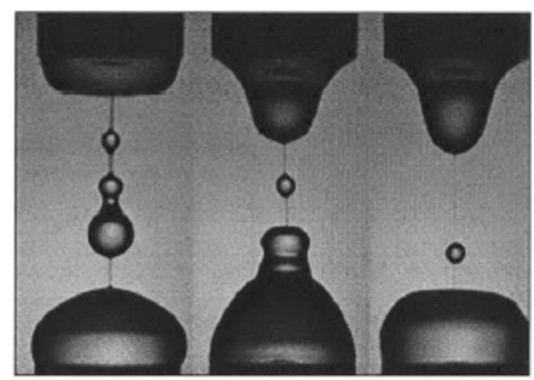

c)

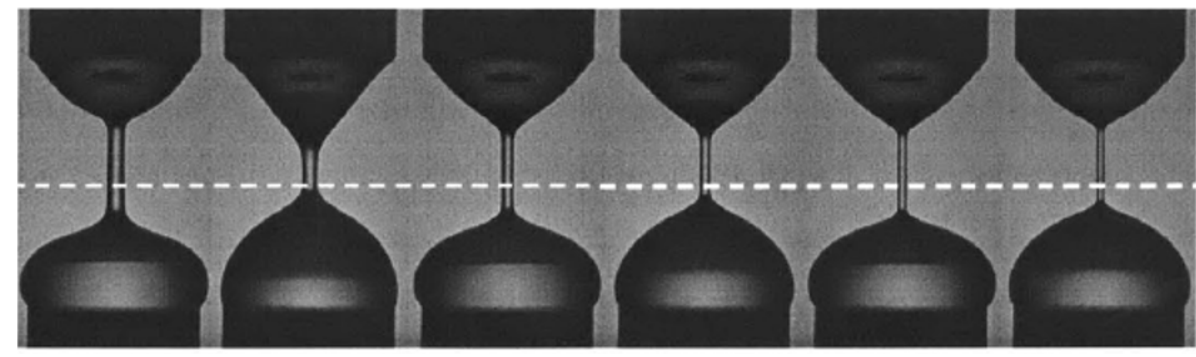

Figura 78 - a) Evolução do filamento de uma amostra de PEO $(C=0,1 \%)$ utilizando o reômetro extensional CaBER. b) Formação de gotas no filamento de uma amostra de PEO $(C=0,1 \%)$.

c) Oscilações no filamento de uma amostra de PEO $(C=0,1 \%)$ realizado por Scott (2004).

Para selecionar a geometria adequada é preciso calcular o número de Bond $B_{o}$, parâmetro adimensional, que compara as forças de corpo com as forças de tensão superficial. $\mathrm{O}$ número de Bond deve ser $B_{o} \leq 1$ para minimizar as forças gravitacionais, como definido na eq. (30). A geometria utilizada foi placas circulares de raio $r_{0}=2 \mathrm{~mm}$.

$$
B_{0}=\frac{\rho g r_{0}^{2}}{\sigma_{\text {sup }}}=\frac{\left(998 \mathrm{~kg} / \mathrm{m}^{3}\right)\left(9,81 \mathrm{~m} / \mathrm{s}^{2}\right)(0,002 \mathrm{~m})^{2}}{0,0575 \mathrm{~N} / \mathrm{m}}=0,68
$$

Onde, $\rho$ é a massa específica da solução polimérica de $\mathrm{PEO}, g$ é a gravidade e $\sigma_{s u p}$ é a tensão superficial da solução polimérica. O número de Bond é $B_{o}=0,68$, portanto, a gravidade pode ser desprezada. 
A evolução do diâmetro do filamento em função do tempo $D_{f i l}(t)$ obtido através do reômetro extensional CaBER com placas circulares de $r_{0}=2 \mathrm{~mm}$ é representado na figura 79 .

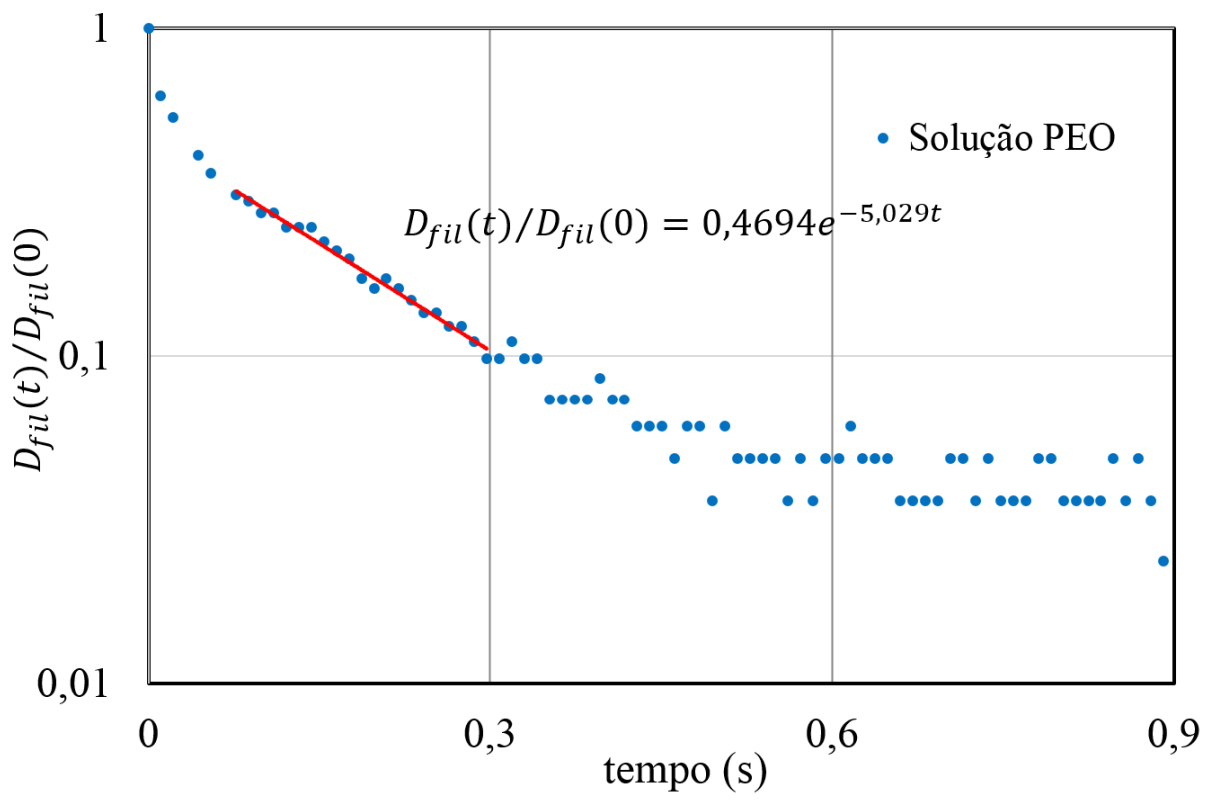

Figura 79 - Relação da variação do diâmetro do filamento da solução de PEO no tempo

A diminuição do diâmetro do filamento $D_{f i l}(t)$ em relação ao diâmetro inicial $D_{f i l}(0)$ é exponencial no tempo, como mostrado no gráfico semi-logarítmico da figura 79 e pode ser definida pela expressão da eq. (31).

$$
\frac{D_{f i l}(t)}{D_{f i l}(0)}=(0,4694) \cdot \exp (-5,029 t)
$$

O tempo de relaxação característico $\lambda_{\text {CaBER }}$ da solução polimérica de PEO pode ser estimado utilizando o modelo de Maxwell Convectado Superior (UCM), segundo mostrado na eq. (32).

$$
\frac{D_{f i l}(t)}{D_{f i l}(0)}=\left(\frac{G D_{f i l}(0)}{2 \sigma_{\text {sup }}}\right)^{1 / 3} \cdot \exp \left(-\frac{t}{3 \lambda_{\text {CaBER }}}\right)
$$

Onde, $G$ é o módulo elástico do filamento. O tempo de relaxação característico é calculado comparando as equações (31) e (32), sendo o valor de $\lambda_{\text {CaBER }}=66 \mathrm{~ms}$. 
Entretanto, o tempo de relaxação da solução de glicerina (fluido Newtoniano) é $\lambda_{\text {glicerina }} \approx 0$.

Para estimar o tempo de relaxação através da teoria de Zimm $\lambda_{\text {Zimm }}$, é necessário calcular a viscosidade intrínseca $[\eta]$ da solução de PEO.

- Cálculo da viscosidade intrínseca da solução de PEO: O peso molecular do polímero de PEO utilizado é de $P M=8 \times 10^{6} \mathrm{~g} / \mathrm{mol}$, utilizando a eq. (12) do capítulo 2 temos:

$[\eta]=0,072 P M^{0,65}=0,072\left(8 \times 10^{6}\right)^{0,65}=2210 \mathrm{ml} / \mathrm{g}$

- Cálculo da concentração crítica da solução de PEO: Utilizando a eq. (13) do capítulo 2 temos:

$$
C^{*}=\frac{0,77}{[\eta]}=\frac{0,77}{2210}=349 P P M
$$

É importante citar que a concentração da solução de PEO utilizada é de $0,1 \%$ em peso ( $C=1000 \mathrm{PPM})$, portanto a razão de concentração do polímero e concentração crítica é de $C / C^{*}=2,87$. A solução polimérica de PEO utilizada em nossos experimentos é uma solução semidiluída $\left(C \approx C^{*}\right)$.

- Cálculo do tempo de relaxação da teórica de Zimm para a solução de PEO: Utilizando a eq. (10) do capítulo 2 temos:

$$
\lambda_{\text {Zimm }}=0,463 \frac{[\eta] P M \eta_{s}}{N_{A} K_{B} T}=\frac{0,463\left(2210 \frac{\mathrm{ml}}{\mathrm{g}}\right)\left(8 \times 10^{6} \frac{\mathrm{g}}{\mathrm{mol}}\right)(0,93 \mathrm{cP})}{\left(6,022 \times 10^{23} \mathrm{~mol}^{-1}\right)\left(1,3806 \times 10^{-23} \frac{\mathrm{Kg} \mathrm{m}^{2}}{\mathrm{~s}^{2} \mathrm{~K}}\right)(296,15 \mathrm{~K})}=3,32 \mathrm{~ms}
$$

O tempo de relaxação estimado através da teoria de Zimm foi menor do que o valor obtido através do CaBER $\left(\lambda_{C a B E R}=66 \mathrm{~ms}\right)$. Esta discrepância foi reportada também em outras investigações (Rodd et al., 2007 e 2010), sendo 
possíveis causas a polidispersidade do polímero na amostra e a concentração não diluída do polímero na solução (Li et al., 2015). Nas investigações de Sousa et al. (2011) utilizaram o mesmo polímero de PEO $(C=0,1 \%$ e $P M=8 \times 10^{6} \mathrm{~g} / \mathrm{mol}$ ) diluída em água deionizada obtendo os tempos de relaxação de $\lambda_{\text {CaBER }}=73,9 \mathrm{~ms}$ e $\lambda_{\text {Zimm }}=10,1 \mathrm{~ms}$, sendo bastante próximos de nossos resultados.

Para um fluxo extensional axial, um elemento de fluido inicialmente cilíndrico é separado exponencialmente no tempo (Bird et al., 1987a). Na prática, as regiões centrais do filamento do fluido experimentam uma taxa de deformação extensional variando com o tempo $\dot{\varepsilon}(t)$, e pode ser estimada a partir da variação do diâmetro do filamento (Anna e McKinley 2001), como mostrado na eq. (33). As medições de viscosidade extensional $\mu_{\text {ext }}(t)$ pode ser quantificada através de um balanço de forças entre as tensões capilares e as tensões elásticas no filamento do fluido (Schümmer e Tebel 1983), segundo a eq. (34).

$$
\begin{gathered}
\dot{\varepsilon}(t)=-\frac{2}{D_{f i l}(t)}\left(\frac{d D_{f i l}(t)}{d t}\right), \\
\mu_{e x t}(t) \approx-\frac{\sigma_{\text {sup }}}{d D_{f i l}(t) / d t} .
\end{gathered}
$$

A figura 80 mostra a viscosidade extensional da solução polimérica de PEO em função da taxa de deformação extensional. 


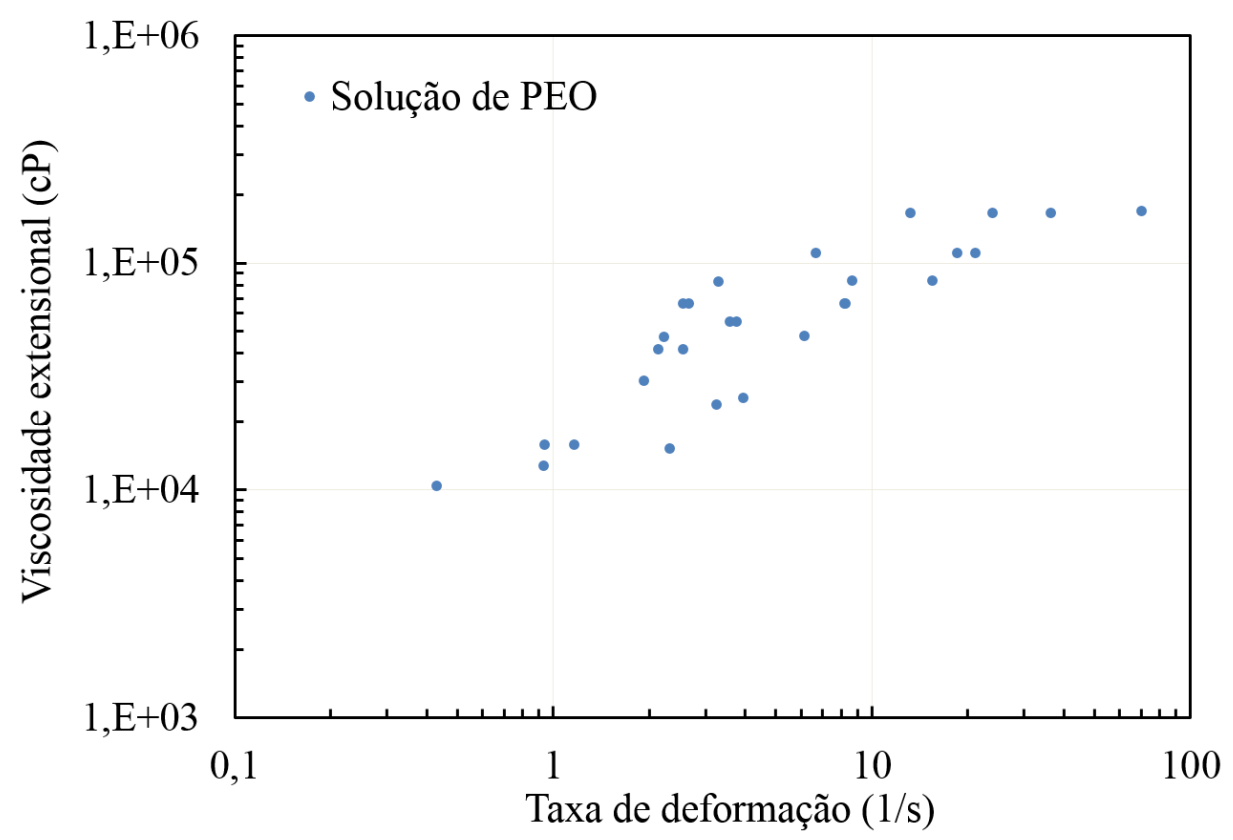

Figura 80 - Viscosidade extensional da solução polimérica de PEO à $C=0,1 \%$

A viscosidade extensional da solução polimérica de PEO cresce com o incremento da taxa de deformação extensional. Este comportamento dilatante por extensão (extensional thickening) é característico de soluções viscoelásticas (Bailey e Koleske 1976, Gauri e Koelling 1997, Dinic et al. 2015 e Sousa et al. 2017).

Este aumento de viscosidade extensional passa a ser importante quando soluções poliméricas de PEO escoam através de gargantas de poros, gerando um aumento da queda de pressão e instabilidade no escoamento (Rodd et al. 2005, McKinley et al. 2007 e Lee et al. 2014). Essa mudança no comportamento do escoamento pode explicar a redução da saturação de óleo residual com injeção de soluções viscoelásticas (Miranda 2015, Clarke et al. 2015 e Hincapie et al. 2017).

O Hencky strain $\varepsilon(t)$ do elemento do fluido no plano médio do filamento pode ser obtido integrando a eq. (33) e resultando na eq. (35). A figura 81 representa a relação de Trouton $\operatorname{Tr}$ como função do Hencky strain para a solução de PEO.

$$
\mathcal{E}(t)=-2 \ln \left(\frac{D_{f i l}(0)}{D_{f i l}(t)}\right) .
$$




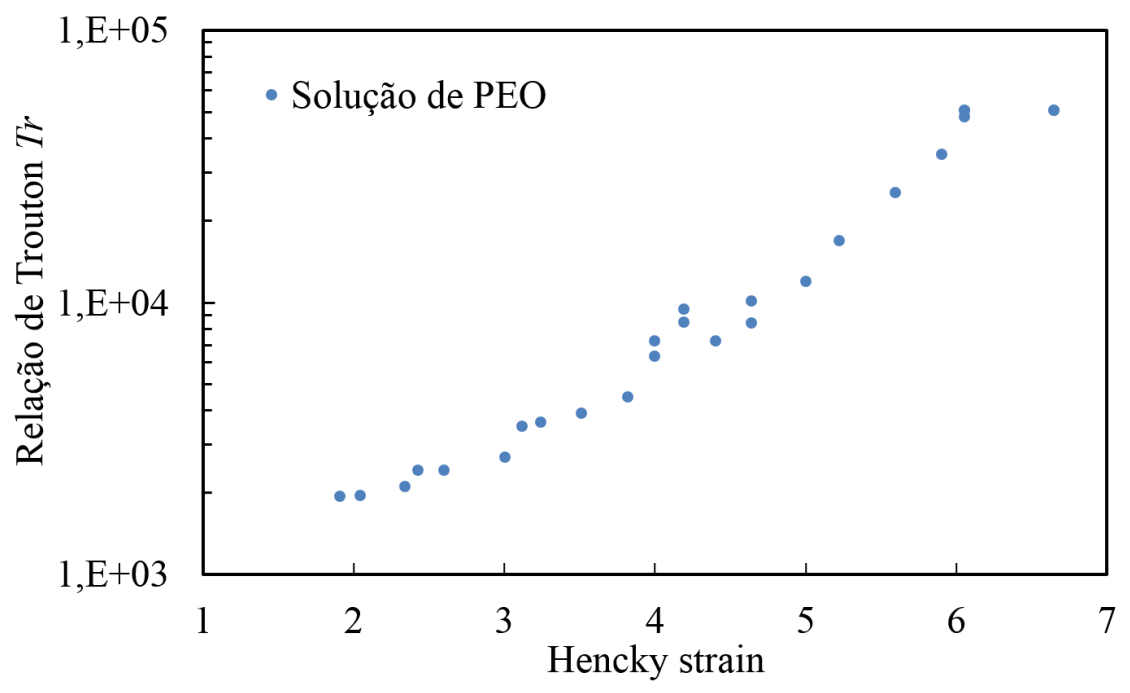

Figura 81 - Relação de Trouton em função do Hencky strain para a solução polimérica de $\mathrm{PEO}$ à $C=0,1 \%$

É observado que a relação de Trouton é alta $(T r>1000)$ inclusive no início da região elasto-capilar e aumentou aproximadamente em duas ordens de magnitude à medida que o Hencky strain foi aumentado, indicando um forte comportamento dilatante por extensão. Li e Haward (2015) e Mohammad et al. (2018) reportaram similar comportamento para soluções poliméricas de PEO $(C=0,3 \%$ e $C=0,1 \%)$ com relações de Trouton na ordem de $10^{4}$ e $10^{5}$. A figura 82 mostra os resultados reportados por Li e Haward (2015).

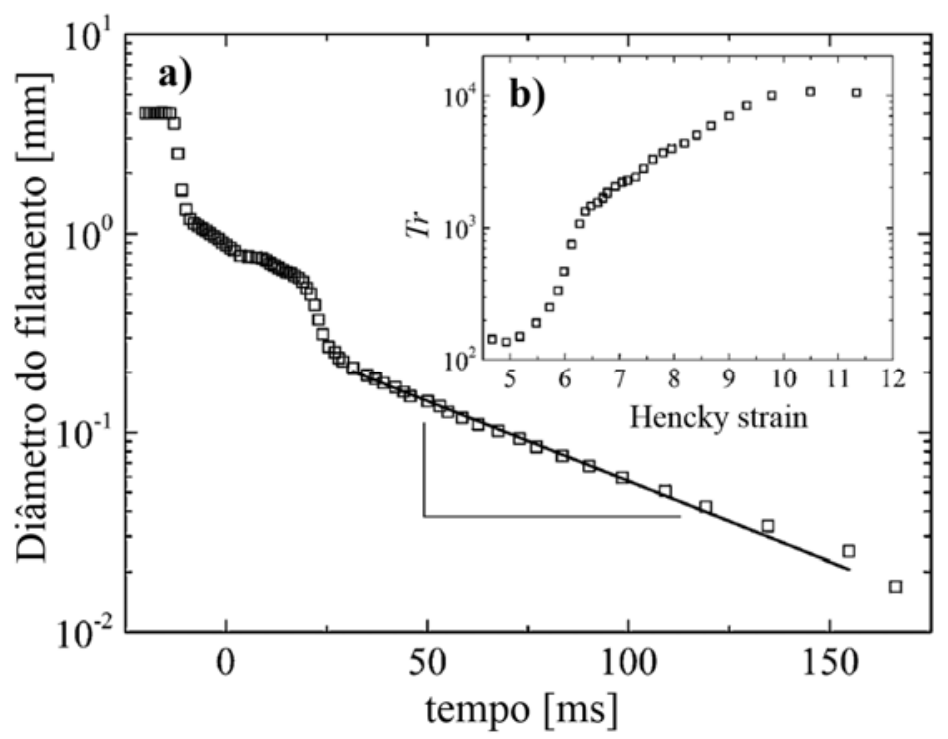

Figura 82 - Reologia da solução polimérica de PEO $\left(C=0,3 \%\right.$ e $\left.P M=4,8 \times 10^{6} \mathrm{~g} / \mathrm{mol}\right)$ diluída em água. a) Medições do diâmetro do filamento versus tempo utilizando o reômetro extensional CaBER. b) Relação de Trouton versus Hencky strain realizado por Li e Haward (2015) 
Espera-se para um fluido Newtoniano sob um escoamento extensional uniaxial, a sua viscosidade extensional seja igual a 3 vezes sua viscosidade de cisalhamento $(\operatorname{Tr}=3)$.

\section{3. \\ Procedimento experimental}

O procedimento experimental foi dividido em duas partes: Medição da queda de pressão e medição do campo de velocidade no escoamento. Os fluidos injetados no interior do micromodelo foram água, solução de glicerina e solução polimérica de PEO. Todos os experimentos foram realizados à temperatura de $T=23^{\circ} \mathrm{C}$.

\subsection{1.}

\section{Medição da queda de pressão $\Delta P$}

A figura 83 representa um esquema da geometria dos microcanais no micromodelo de vidro. A câmera positiva (+) do transdutor foi conectada à tomada $\mathrm{N}^{\circ} 4$ localizada antes da constrição e a câmera negativa (-) foi conectada à tomada $\mathrm{N}^{\circ} 5$ localizada depois da constrição. O procedimento é descrito a seguir:

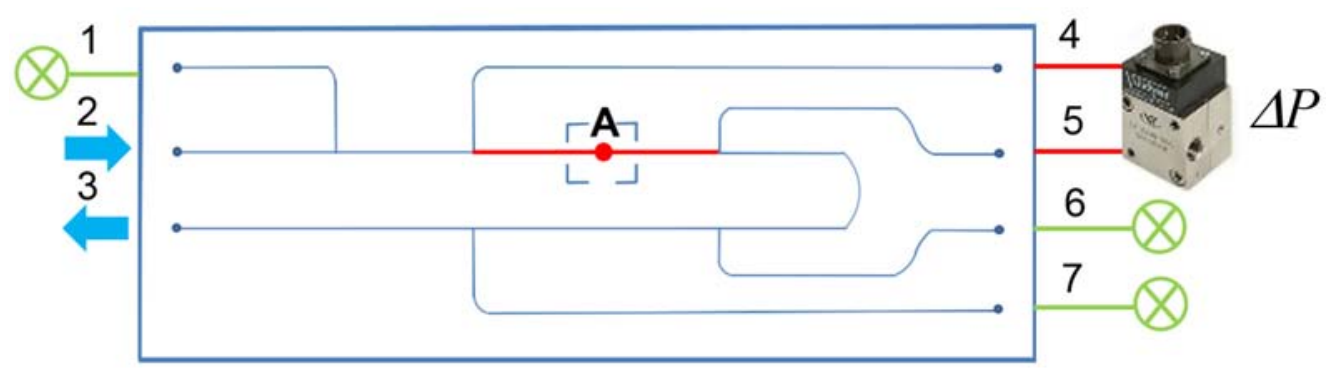

Figura 83 - Esquema da distribuição dos microcanais no micromodelo junto com as tomadas de medição da queda de pressão no microcanal com constrição

Saturação do micromodelo: Antes de iniciar os experimentos, o micromodelo e todas as tomadas foram preenchidos com o fluido a ser injetado. Foi necessário expulsar as bolhas de ar do sistema, a fim de evitar que as medições de pressão fossem afetadas.

Preparação do sistema de injeção: O fluido a ser injetado foi inserido na seringa de vidro Hamilton Gastight ${ }^{\circledR}$. Seringas de $10 \mathrm{ml}$ e $2,5 \mathrm{ml}$ foram 
utilizadas para injetar a água e as soluções de glicerina e PEO no micromodelo.

Injeção do fluido: $\mathrm{O}$ fluido foi injetado pela abertura $\mathrm{N}^{\circ} 2$ utilizando uma bomba de seringa Harvard Elite 11, e a saída do fluido foi pela abertura $\mathrm{N}^{\circ} 3$. As aberturas $\mathrm{N}^{\circ} 4$ e $\mathrm{N}^{\circ} 5$ foram conectadas as tomadas do transdutor para medir a queda de pressão, e as aberturas $\mathrm{N}^{\circ} 1, \mathrm{~N}^{\circ} 6$ e $\mathrm{N}^{\circ} 7$ foram fechadas durante o experimento por meio de válvulas de plástico.

Aquisição de dados: Os valores da queda de pressão foram capturados a cada 0,25 segundos no intervalo de 10 minutos utilizando o software Easy Sense 2100 .

Determinação da curva diferença de pressão em função da vazão: Finalmente, a relação entre a queda de pressão e a vazão foi obtida usando o software Qtiplot.

\subsection{2. \\ Determinação do campo de velocidade}

A figura 84 representa a região perto da constrição onde foi determinado o campo de velocidade do escoamento dos fluidos. O procedimento é descrito a seguir:

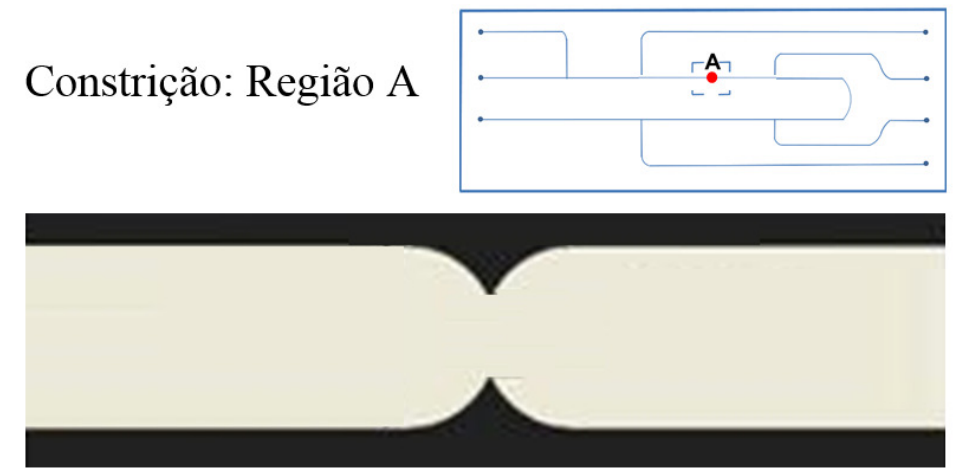

Figura 84 - Região de medição do campo de velocidade 
Ligar os equipamentos de micro-PIV: Os equipamentos foram ligados na seguinte sequência: lasers, câmera, sincronizador e o software Insight $4 G^{T M}$. O tempo de aquecimento dos lasers (energia máxima) é de 30 minutos.

Saturação do micromodelo: O micromodelo foi saturado com o fluido a ser injetado. Foi necessário retirar as bolhas de ar presente no sistema, para evitar que a medição do campo de velocidade fosse afetada.

Focalização do micromodelo: O microscópio foi utilizado para localizar o plano central do microcanal com constrição onde foi medido o campo de velocidade no escoamento, como mostrado na figura 85 .

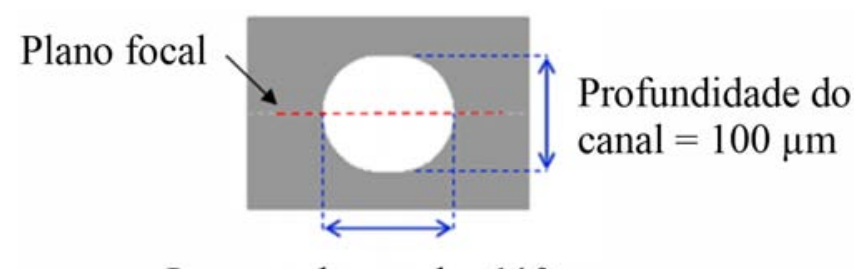

Largura do canal $=110 \mu \mathrm{m}$

Figura 85 - Plano focal para a captura de imagens

Configuração de captura de imagens: Foi configurado o número de pares de imagens consecutivas a serem capturados, o tempo de exposição da câmera e o tempo de disparo dos lasers mediante o software Insight $4 G^{T M}$.

$>$ Preparação do sistema de injeção: O fluido a ser injetado foi misturado com a suspensão de microesferas de poliestireno à proporção de 1:0,14 (volume da mistura/volume da suspensão de microesferas) e logo a mistura foi inserida na seringa de vidro Hamilton Gastight ${ }^{\circledR}$ de 2,5 ml.

Injeção do fluido com as microesferas: $\mathrm{O}$ caminho percorrido do fluido misturado com as microesferas no interior do micromodelo foi idêntico ao sistema de medição da queda de pressão, como mostrada na figura 83 .

Captura de imagens: Antes de iniciar a captura de imagens, o microcanal com constrição deve estar totalmente preenchido de microesferas e o valor da 
queda de pressão correspondente à vazão injetada seja atingido (achado das medições da queda de pressão). Foram capturados 500 pares de imagens consecutivas. A captura de imagens e da queda de pressão eram realizados também simultaneamente.

Configuração do processamento de imagens: Os pares de imagens capturados foram analisados utilizando as etapas de pré-processamento, processamento e pós-processamento de imagens do software Insight $4 G^{T M}$.

Análise do campo de velocidade: Os pares de imagens processados foram analisados no software Tecplot Focus 2009. 


\section{Resultados}

Os resultados experimentais foram separados em duas partes: Medições da queda de pressão no microcanal com constrição em função das propriedades do fluido injetado e vazão, e medições de campo de velocidade na região da constrição utilizando a técnica de micro-velocimetria por imagem de partículas (micro-PIV). Todas as medições foram realizadas à temperatura de $T=23^{\circ} \mathrm{C}$.

\section{1.}

\section{Medição da queda de pressão}

Nesta primeira parte são apresentadas as medições da queda de pressão dos fluidos escoando através de um microcanal com constrição. As medições experimentais da água foram comparadas com resultados de simulação e analítico para avaliar a precisão das medidas. Os resultados de simulação foram obtidos através do software computacional Comsol utilizando a geometria da constrição, enquanto, para os resultados analíticos foi utilizado a expressão de Poiseuille ajustado para um diâmetro equivalente circular. As medições experimentais das soluções de glicerina e PEO que apresentaram aproximadamente a mesma viscosidade, foram comparadas entre si para estimar a queda de pressão extra devido aos efeitos elásticos do polímero.

A figura 86 representa o esquema com um resumo dos experimentos da queda de pressão realizados.

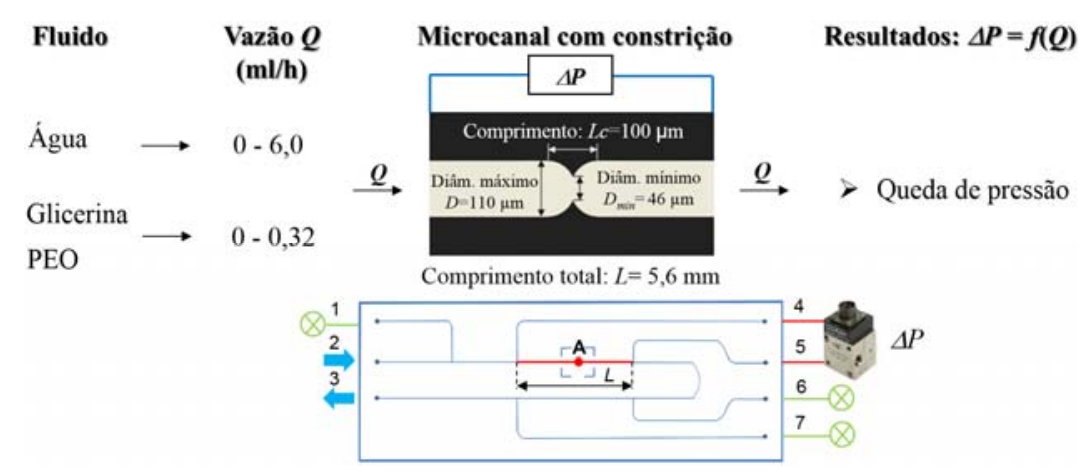

Figura 86 - Esquema dos experimentos da queda de pressão realizados 


\subsection{1.}

\section{Tempo de aquisição das medições da queda de pressão}

Para cada vazão de injeção imposta pela bomba de seringa, os dados da queda de pressão eram adquiridos quando o escoamento atingia regime permanente, e a diferença de pressão tornava-se constante.

O tempo de estabilização do sistema variou para as diferentes vazões e os diferentes fluidos injetados. No caso da água, o tempo foi em torno de 1 minuto, e para a solução de glicerina foi em torno de 3 minutos. No caso da solução de PEO, o tempo variou de 5 a 15 minutos devido aos diferentes incrementos da queda de pressão na faixa de vazões estudada.

Depois de atingir o regime permanente do escoamento, a aquisição dos dados da queda de pressão foi realizada cada 0,25 segundos no intervalo de 10 minutos (2400 dados) para todos os fluidos e as vazões de injeção.

Vale ressaltar que os tempos de estabilização e aquisição foram algumas vezes maiores devido a perturbações que afetavam a estabilidade do escoamento. As perturbações se originavam por causa de bolhas de ar no interior do transdutor de pressão, variação na injeção mecânica (bomba de seringa), sujeira presa na constrição, variação de temperatura, entre outros. Quando o escoamento não retornava a sua condição estável devido aos motivos citados anteriormente, a injeção era parada e reiniciada novamente.

As figuras 87 e 88 mostram os valores experimentais da queda de pressão da água e das soluções de glicerina e PEO capturados em tempo real após o escoamento atingir o regime permanente para diferentes vazões de injeção. 


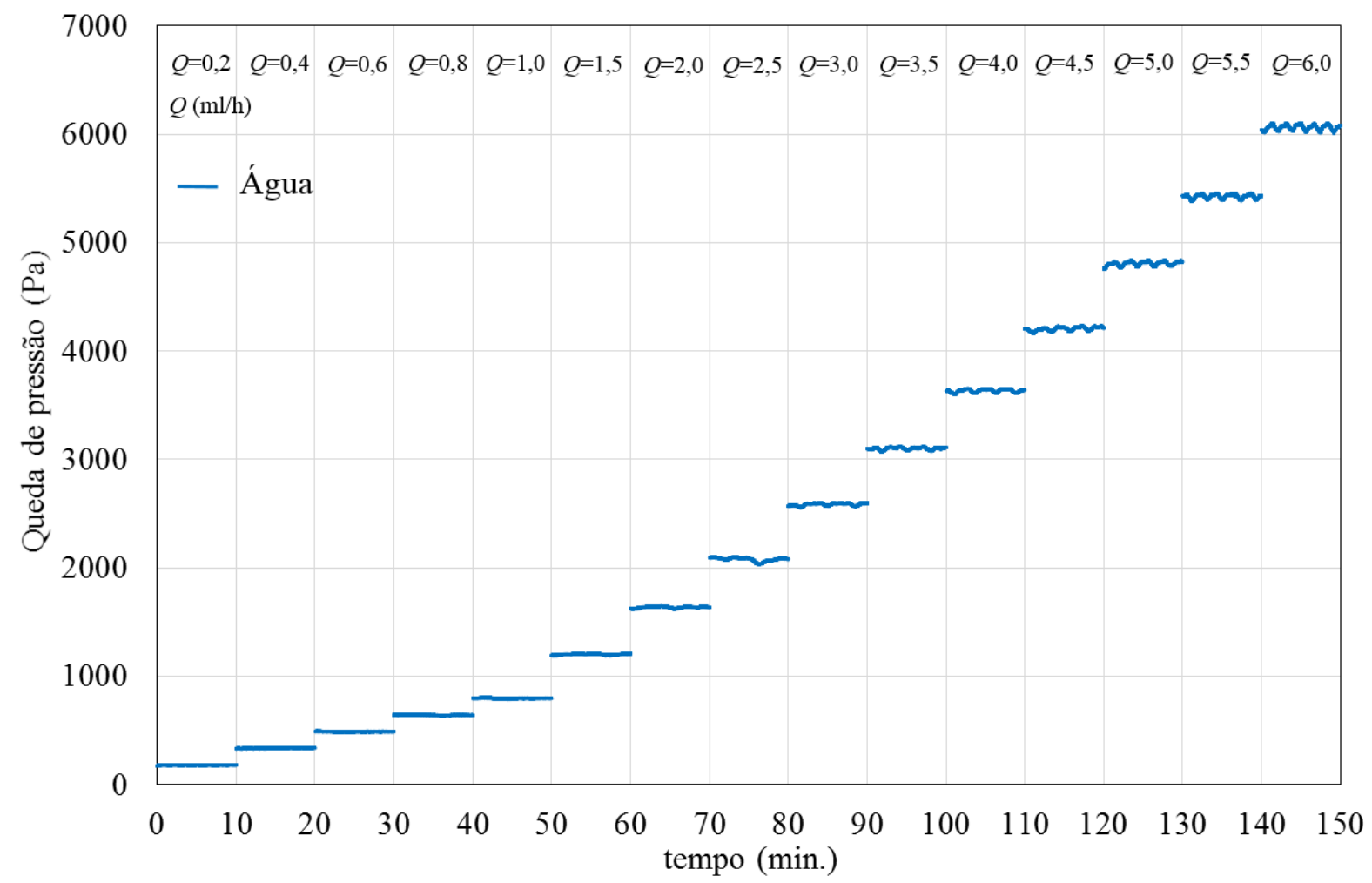

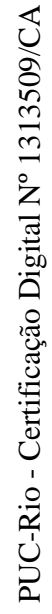

Figura 87 - Valores da queda de pressão para o escoamento de água medidos em tempo real para diferentes vazões de injeção

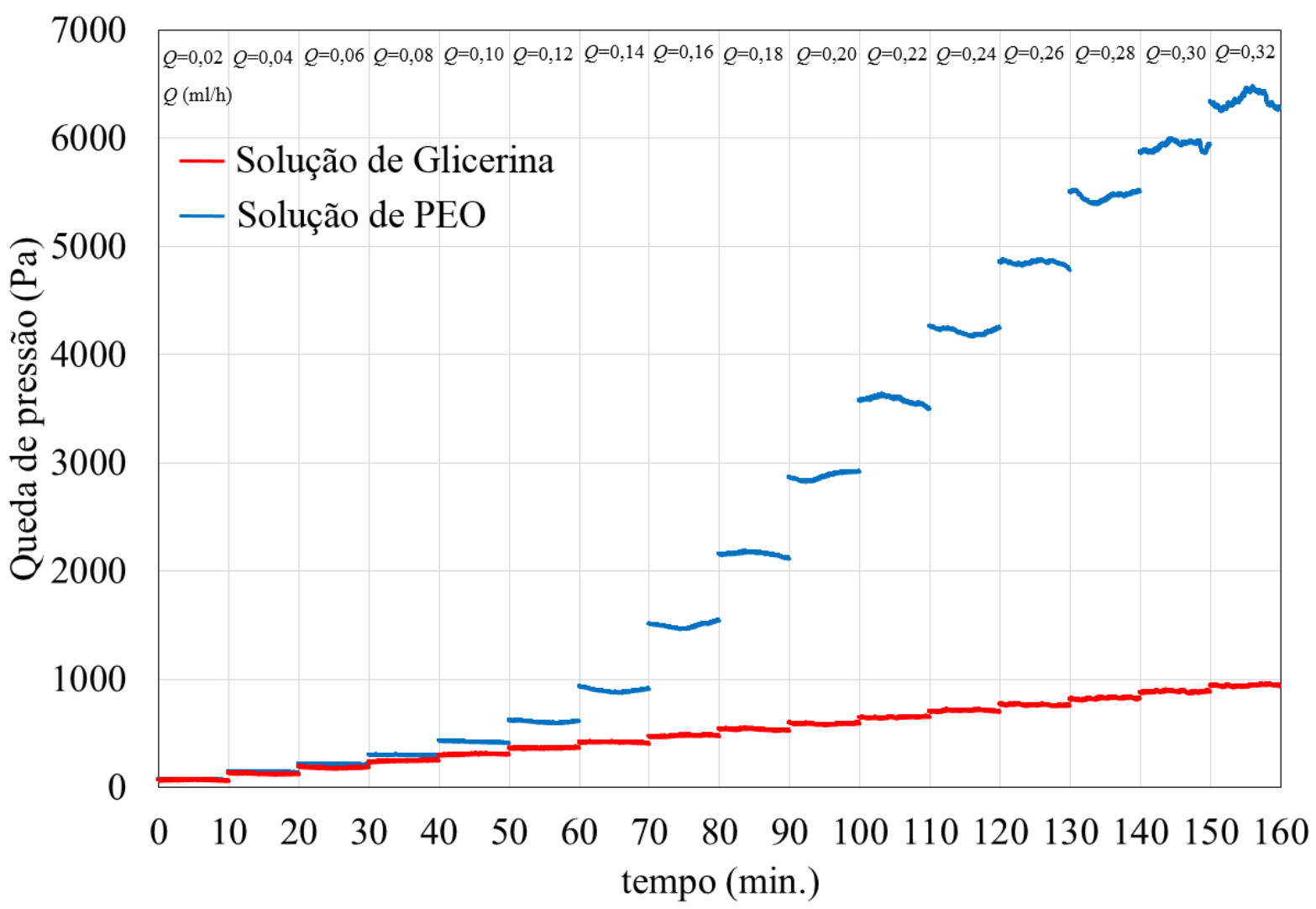

Figura 88 - Valores da queda de pressão da solução de glicerina e PEO medidos em tempo real para diferentes vazões de injeção 


\subsection{2.}

\section{Repetibilidade das medições da queda de pressão}

As medições da queda de pressão foram repetidas três vezes para cada fluido e realizadas em dias diferentes, com o objetivo de determinar a repetibilidade dos valores medidos. Por essa razão, os experimentos foram sempre realizados em condições de laboratório idênticas.

Devido à degradação da solução polimérica de PEO com o tempo, várias soluções foram preparadas para a realização dos experimentos. Cada nova solução era preparada seguindo rigorosamente o procedimento descrito no capítulo 4 . Depois, as propriedades reológicas da solução eram medidas no reômetro para ter certeza que todas as diferentes soluções preparadas possuíam as mesmas propriedades reológicas. Finalmente, a solução era injetada no sistema para continuar com os testes.

Vale ressaltar que os equipamentos (seringa, bomba de seringa e transdutor de pressão) utilizados durante toda a abordagem experimental foram os mesmos, para minimizar variações nas medidas.

As figuras 89, 90, 91 mostram os valores médios da queda de pressão (a média de 2400 dados) em função da vazão capturados em regime permanente para os diferentes fluidos e testes realizados, acompanhado com as barras de erro.

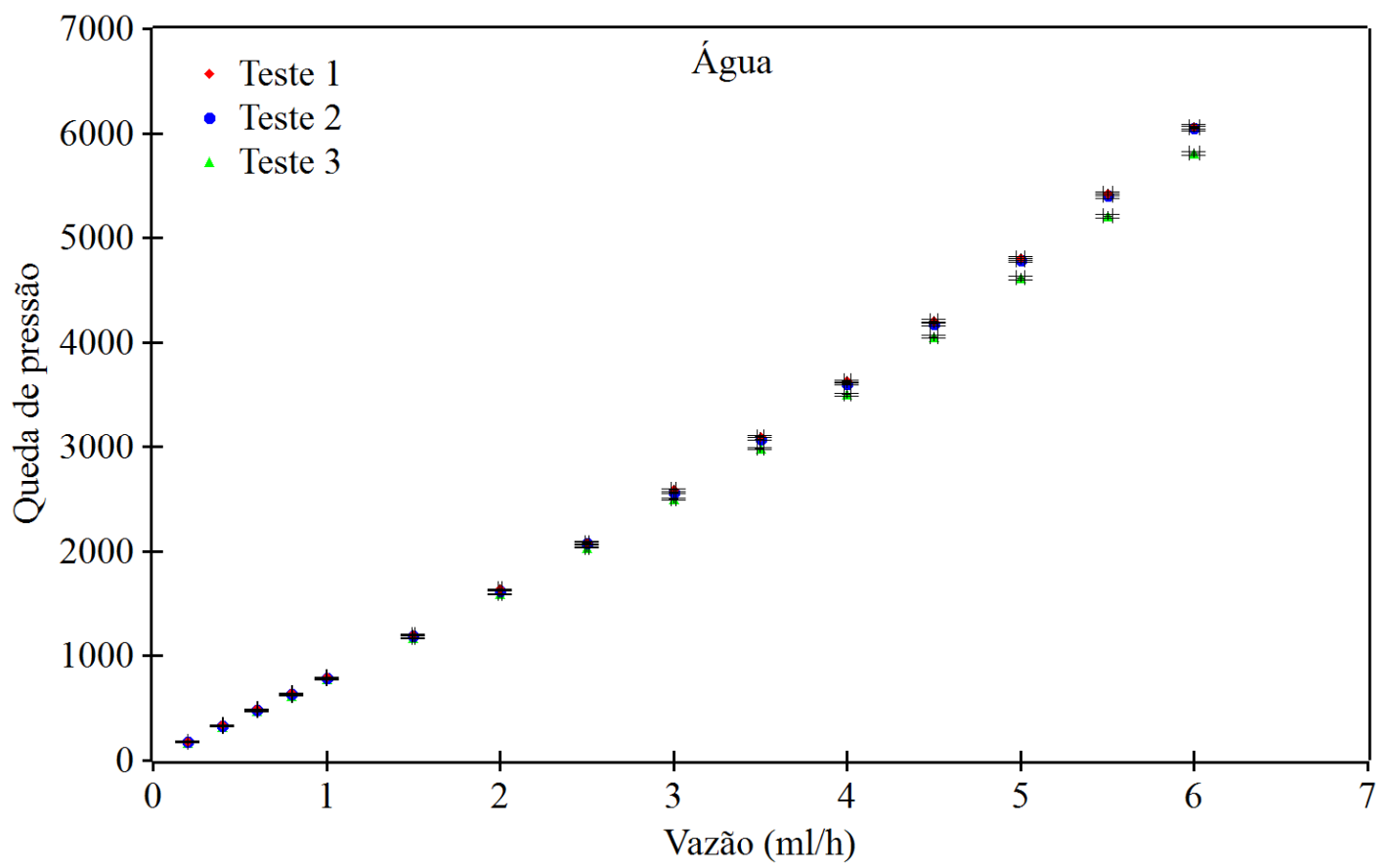

Figura 89 - Repetibilidade das medições da queda de pressão para o escoamento de água 


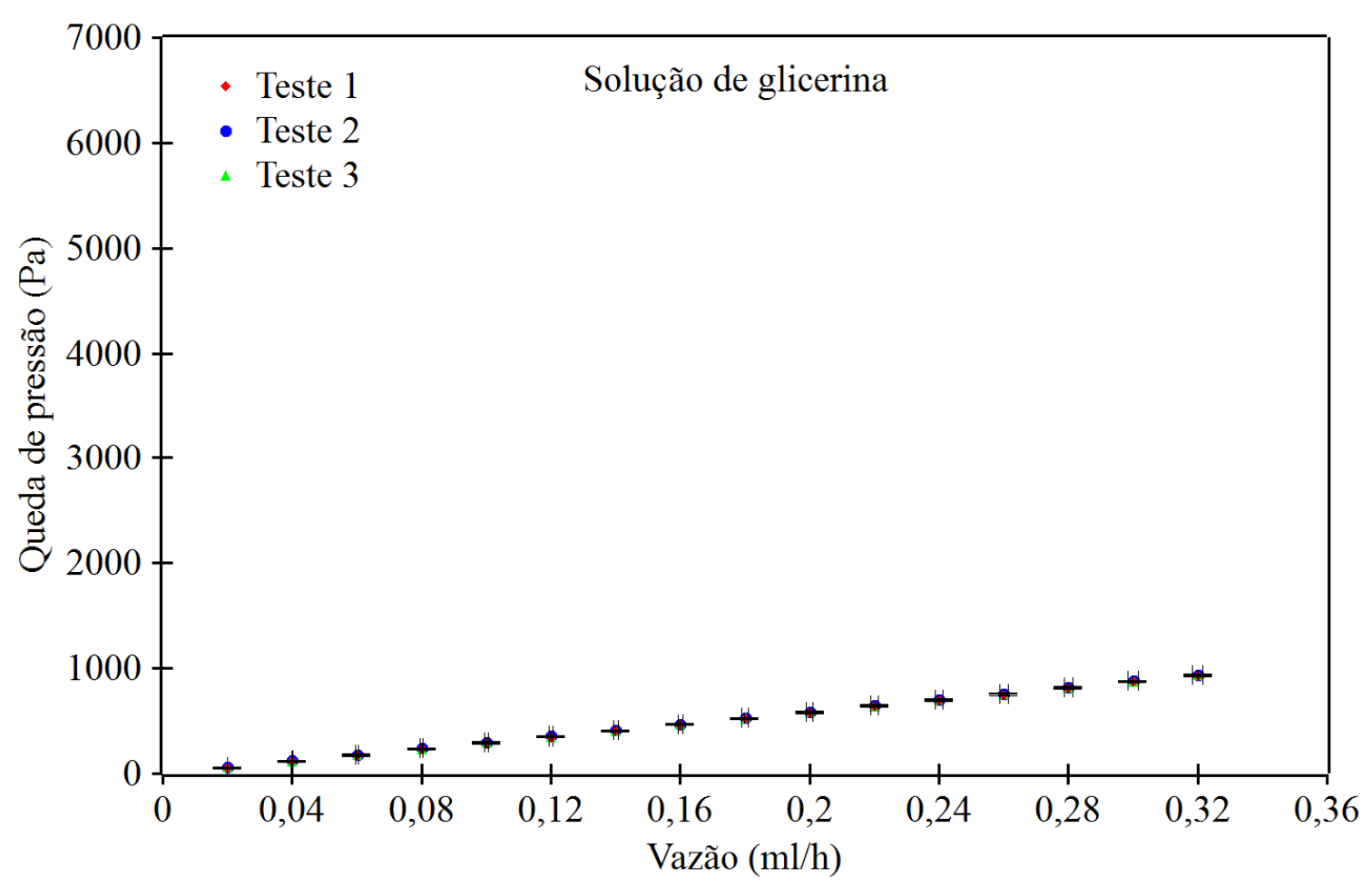

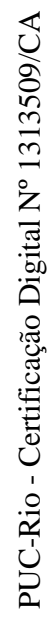

Figura 90 - Repetibilidade das medições da queda de pressão para a solução de glicerina

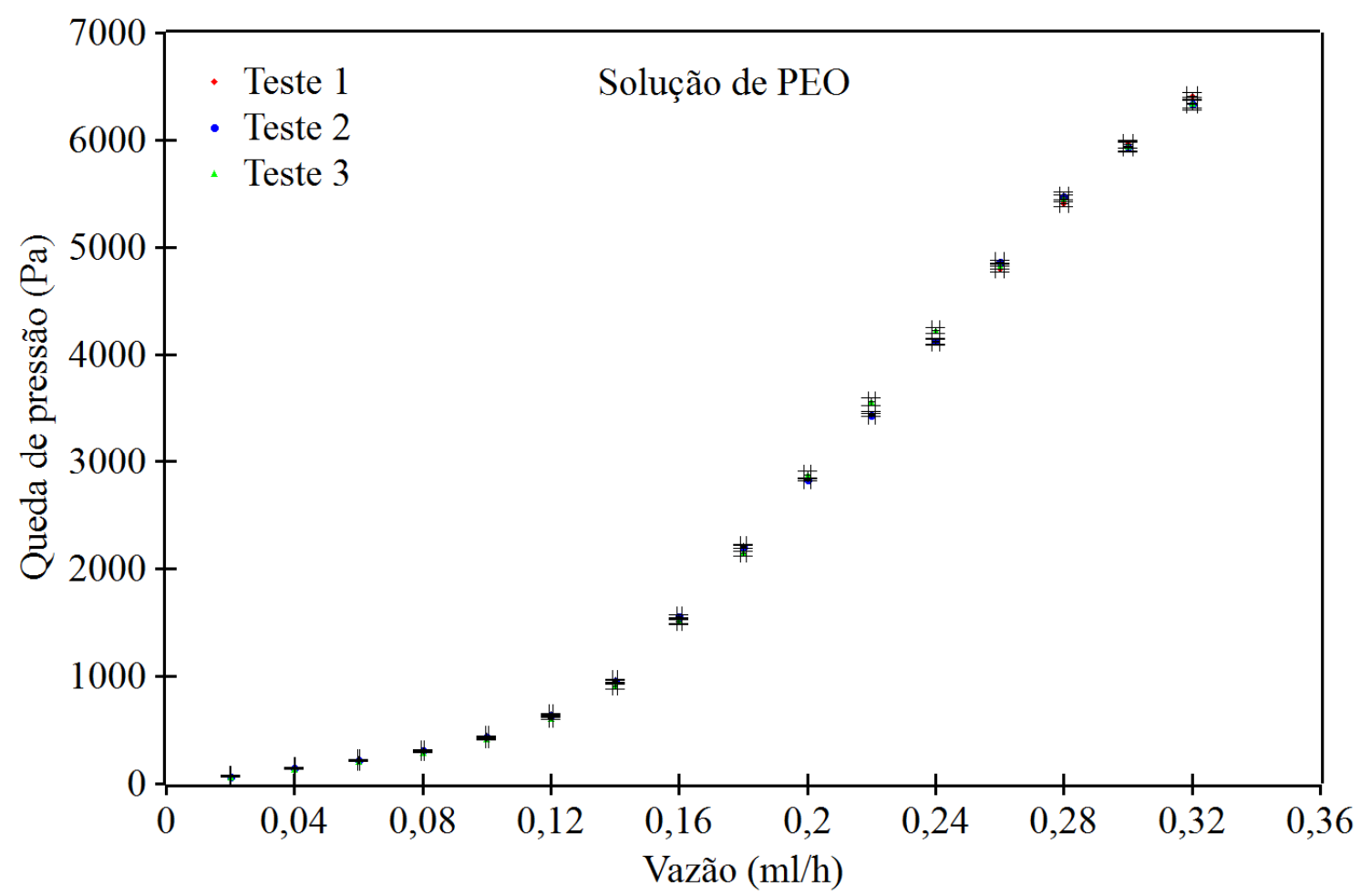

Figura 91 - Repetibilidade das medições da queda de pressão para a solução de PEO 
No caso da água, os valores da queda de pressão em cada teste (2400 dados) apresentam uma baixa dispersão em torno ao seu valor médio, na qual o coeficiente de variação foi menor que $C V<1,5 \%$ como mostra as barras de erro. Enquanto, pode-se observar uma excelente repetitividade dos dados, sendo a variação máxima abaixo de $3 \%$.

No caso das soluções de glicerina e PEO, os valores da queda de pressão em cada teste (2400 dados) apresentam uma dispersão bastante aceitável em torno ao seu valor médio, na qual o coeficiente de variação foi menor que $C V<5 \%$, confirmando que não existe um grande desvio padrão para a solução de PEO a altas vazões de injeção, como mostrado na figura 88. A maior dispersão dos dados foi observada para as menores vazões de injeção por causa da faixa limite inferior de medição do transdutor de pressão. Enquanto, uma excelente repetitividade dos dados foi observada, sendo a variação máxima abaixo de $4 \%$.

\subsection{3.}

\section{Análises das medições da queda de pressão}

\subsubsection{1. Queda de pressão no escoamento de água}

Medições experimentais da queda de pressão no escoamento de água passando através do microcanal com constrição foram realizadas com a finalidade de validar o procedimento experimental, já que as medidas de diferencial de pressão podem ser comparadas com os resultados de simulação do Comsol utilizando a geometria da constrição. Enquanto, os dados experimentais foram comparados também com os dados analíticos obtidos através da fórmula da equação de HagenPoiseuille (citada na equação 18 do capítulo 2) para avaliar o comportamento do escoamento na faixa de vazões estudada. Para obter o diâmetro equivalente circular através da expressão de Hagen-Poiseuille foram utilizados apenas os dados experimentais menor que $Q<2 \mathrm{ml} / \mathrm{h}$ onde apresentou uma resposta linear, como mostrada na figura 92 . 
a)

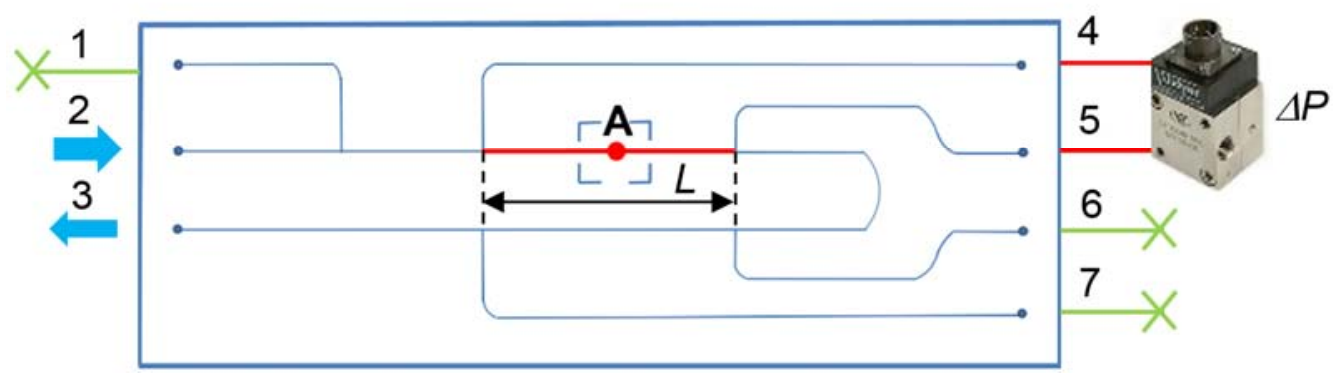

b)
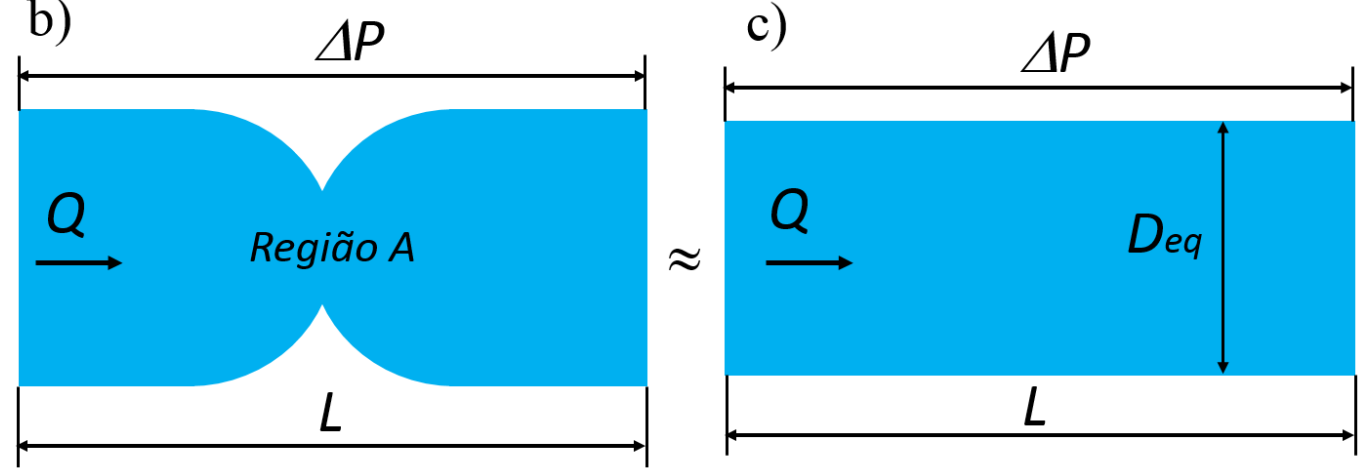

d)

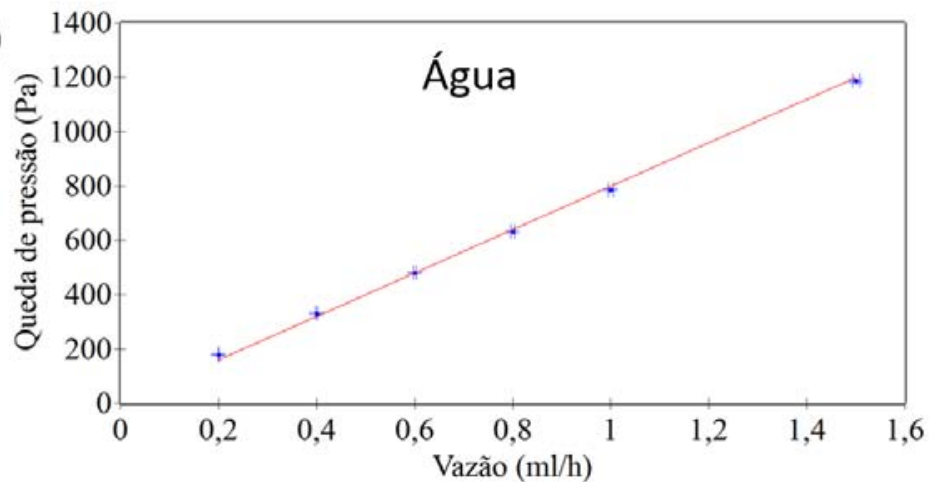

Figura 92 - Esquema do dispositivo microfluídico utilizado neste trabalho b) Microcanal com constrição c) Microcanal com diâmetro equivalente circular. d) Gráfico das medidas da queda de pressão em função da vazão do escoamento de água na região da resposta linear $(Q<2 \mathrm{ml} / \mathrm{h})$

Na figura 93, os dados experimentais (a média dos três testes) e dados do Comsol são representados por pontos discretos, e os dados analíticos obtidos da expressão de Hagen-Poiseuille são representados por uma linha contínua. 


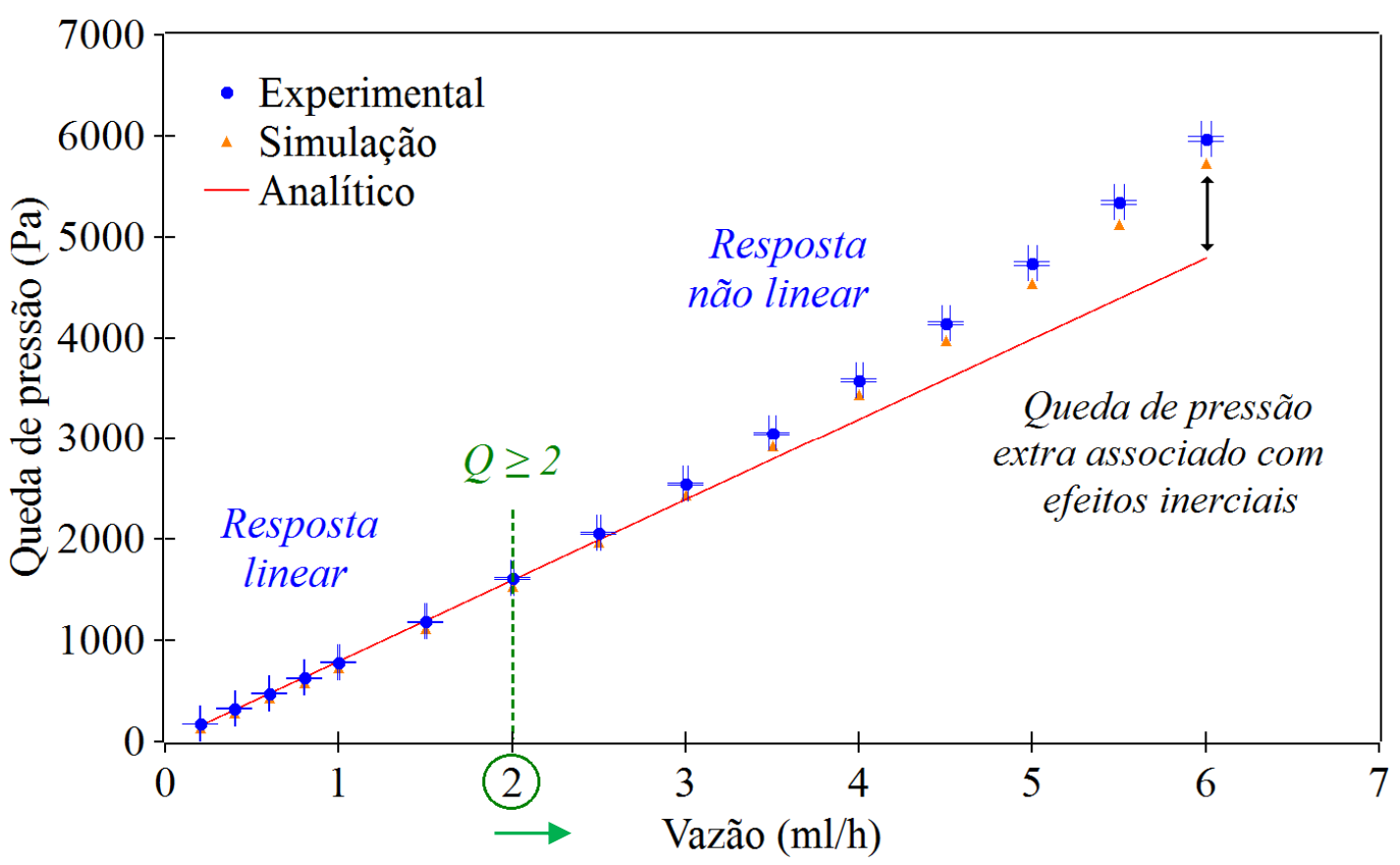

Figura 93 - Comparação dos valores médios experimentais da queda de pressão e os valores analíticos em função da vazão para o escoamento de água

A resposta dos resultados experimental e simulação foram bastante próximos entre si, sendo a variação máxima abaixo de $10 \%$ para vazões menor que $Q<1 \mathrm{ml} / \mathrm{h}$, e a variação máxima abaixo de $5 \%$ para vazões maior que $Q>1 \mathrm{ml} / \mathrm{h}$.

O resultado analítico da expressão de Hagen-Poiseuille descreve uma resposta linear da diferença de pressão em função da vazão imposta. Entretanto, ambos os resultados simulação e experimental foi possível observar dois tipos de resposta à medida que a vazão foi aumentada.

Para vazões menor que $Q<2 \mathrm{ml} / \mathrm{h}(\operatorname{Re}<8,2)$, os dados experimentais e simulação exibiram uma resposta linear, característico de um escoamento Newtoniano com efeitos inerciais desprezíveis. Para vazões $Q \geq 2 \mathrm{ml} / \mathrm{h}(R e \geq 8,2)$, os dados experimentais e simulação começaram a afastar-se da resposta linear analítica.

A hipótese feita inicialmente para este desvio do comportamento linear foi que efeitos inerciais tornavam-se importantes para as vazões mais altas. Isto foi confirmado pelas medições de campo de velocidade perto da região da constrição. Para vazões $Q \geq 2 \mathrm{ml} / \mathrm{h}$, os campos de velocidade mostraram a presença de vórtices à jusante da constrição, perto da parede do microcanal. Portanto, a resposta não linear foi associada aos efeitos inerciais do escoamento ao passar pela constrição. 
$\mathrm{Na}$ abordagem de medição de campo de velocidade serão mostradas as imagens onde aparece a formação de vórtices no escoamento.

\subsubsection{2.}

\section{Queda de pressão nas soluções de glicerina e PEO}

Uma solução polimérica de óxido de polietileno (PEO) à concentração de $0,1 \%$ em peso foi injetada no microcanal com constrição, com o propósito de medir os efeitos do aumento da viscosidade extensional no escoamento através das medidas da queda de pressão.

Para determinar o efeito do comportamento elástico da solução polimérica, foram realizados experimentos com um fluido Newtoniano (comportamento puramente viscoso) com a mesma viscosidade de cisalhamento da solução de PEO: solução de glicerina em água à concentração de $45 \%$ em peso.

Para as soluções de glicerina e PEO, as medições da queda de pressão foram realizadas na faixa de vazões de $0<Q \leq 0,32 \mathrm{ml} / \mathrm{h}(0<R e \leq 0,34)$. A figura 94 apresenta os valores experimentais (a média dos três testes) da queda de pressão da solução de PEO e da solução de glicerina em função da vazão de injeção.

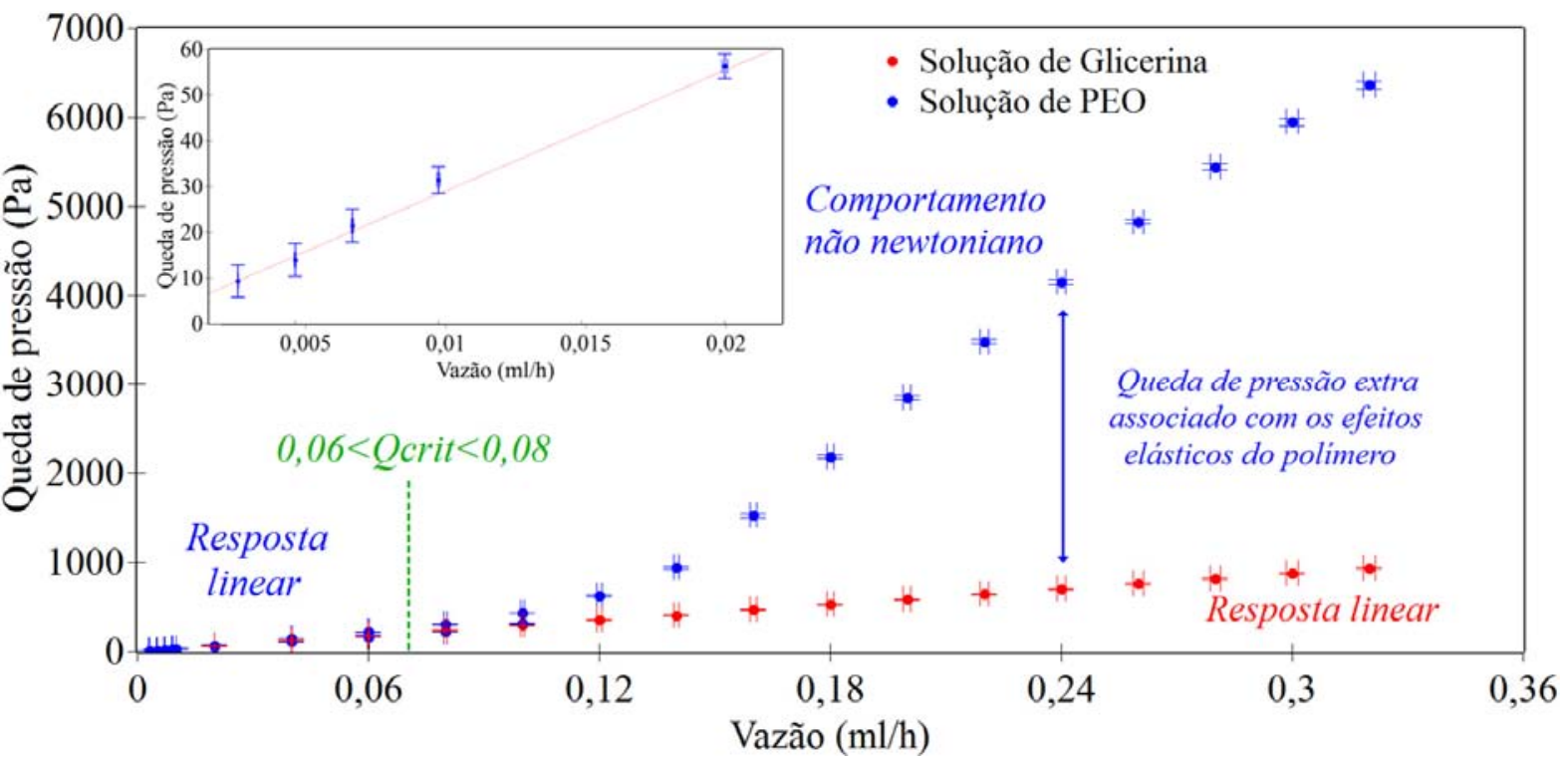

Figura 94 - Comparação dos valores médios da queda de pressão da solução de PEO e da solução de glicerina em função da vazão

O resultado experimental da queda de pressão da solução de glicerina (solução viscosa) apresentou uma resposta linear em toda a faixa de vazões 
estudada, descrevendo o comportamento de um escoamento Newtoniano com efeitos inerciais desprezíveis. É importante mencionar que medidas da queda de pressão do escoamento da solução de glicerina foram realizadas até a vazão $Q=2 \mathrm{ml} / \mathrm{h}$ e foi observado também uma resposta linear. Devido ao limite superior de medição do transdutor de pressão de 1,25 psi (8618 Pa) não foi possível medir para vazões maior que $Q>2 \mathrm{ml} / \mathrm{h}$, para determinar em que vazão os efeitos inerciais se tornam importantes no escoamento (resposta não linear). Enquanto, o resultado experimental da queda de pressão da solução polimérica de PEO (solução viscoelástica) mostrou um comportamento linear a baixas vazões e um comportamento não Newtoniano acima de uma determinada vazão crítica $Q_{c r i t}$.

Abaixo de uma vazão crítica $0,06 \mathrm{ml} / \mathrm{h}<Q_{\text {crit }}<0,08 \mathrm{ml} / \mathrm{h}$ foi observada a resposta linear da solução polimérica de PEO. Nesta região de vazões muito baixa, a solução de PEO se comporta como um fluido Newtoniano. A taxa de extensão no escoamento através da garganta é baixa o suficiente tal que a viscosidade extensional do fluido apresenta um comportamento Newtoniano $\mu_{\text {ext }} \approx 3 \mu_{c(\dot{\gamma}=0)}$. Efeitos elásticos que levam a um aumento da viscosidade extensional só são observados a altas taxas de extensão. Os valores da queda de pressão da solução de PEO e da solução de glicerina foram bastante próximos nesta região linear, confirmando o fato que a queda de pressão é devida a efeitos viscosos. Os dois fluidos possuem viscosidade de cisalhamento aproximadamente iguais. Para a faixa de vazões $0,003 \mathrm{ml} / \mathrm{h}<Q_{\text {crit }}<0,02 \mathrm{ml} / \mathrm{h}$, a incerteza foi alta já que os valores se encontram no limite inferior de medição do transdutor de pressão, apesar disso os valores foram aceitáveis, como mostra o gráfico inserido da figura 94.

Acima da vazão crítica $Q_{c r i t}$ é observado um comportamento não Newtoniano que pode ser relacionado a efeitos elásticos da solução de PEO. A taxa de extensão do escoamento através da garganta do capilar aumenta com a vazão. Como apresentado na figura 80, a viscosidade extensional da solução de PEO é alta para altas taxas de extensão. Essa elevada resistência a extensão leva a um aumento considerável na queda de pressão no escoamento. Os valores da queda de pressão da solução de PEO foram maiores do que os valores da solução de glicerina nesta região de comportamento não Newtoniano, confirmando o efeito produzido apenas pela elasticidade do polímero. 
Números adimensionais são usados em engenharia para facilitar a correlação e a interpretação de dados experimentais. No estudo de escoamentos de fluidos viscoelásticos, a intensidade relativa das forças elásticas pode ser caracterizada pelo número de Weissenberg Wi. Primeiro é necessário determinar as taxas de extensão característico $\dot{\varepsilon}$ do escoamento de PEO submetido ao passar pela constrição para diferentes condições de fluxo (calculado através da equação 15) e o tempo de relaxação característico da solução de PEO $\lambda_{C a B E R}=66 \mathrm{~ms}$ (determinado no capítulo de metodologia). Os valores calculados são resumidos na tabela 6 a seguir:

Tabela 6 - Valores das taxas de extensão e números de Weissenberg para a solução viscoelástica de PEO a diferentes condições de fluxo

\begin{tabular}{|c|c|c|c|c|c|c|c|}
\hline$Q(\mathrm{ml} / \mathrm{h})$ & 0,003 & 0,005 & 0,007 & 0,009 & 0,01 & 0,02 & 0,04 \\
\hline$\dot{\varepsilon}(1 / \mathrm{s})$ & 8,3 & 13,8 & 19,3 & 24,8 & 27,6 & 55,2 & 110,3 \\
\hline$W i$ & 0,5 & 0,9 & 1,3 & 1,6 & 1,8 & 3,6 & 7,2 \\
\hline
\end{tabular}

\begin{tabular}{|c|c|c|c|c|c|c|c|}
\hline$Q(\mathrm{ml} / \mathrm{h})$ & 0,06 & 0,08 & 0,10 & 0,12 & 0,14 & 0,16 & 0,18 \\
\hline$\dot{\varepsilon}(1 / \mathrm{s})$ & 165,5 & 220,7 & 275,8 & 331 & 386,2 & 441,3 & 496,5 \\
\hline$W i$ & 10,8 & 14,3 & 17,9 & 21,5 & 25,1 & 28,7 & 32,3 \\
\hline
\end{tabular}

\begin{tabular}{|c|c|c|c|c|c|c|c|}
\hline$Q(\mathrm{ml} / \mathrm{h})$ & 0,20 & 0,22 & 0,24 & 0,26 & 0,28 & 0,30 & 0,32 \\
\hline$\dot{\varepsilon}(1 / \mathrm{s})$ & 551,7 & 606,8 & 662,0 & 717,2 & 772,3 & 827,5 & 882,7 \\
\hline$W i$ & 35,9 & 39,4 & 43 & 46,6 & 50,2 & 53,8 & 57,4 \\
\hline
\end{tabular}

O resultado da queda de pressão da solução de PEO foi normalizado com o resultado da queda de pressão da solução de glicerina para a mesma vazão de injeção, para estimar a queda de pressão extra devido aos efeitos elásticos do polímero em função do número de Weissenberg, como mostrado na figura 95. 


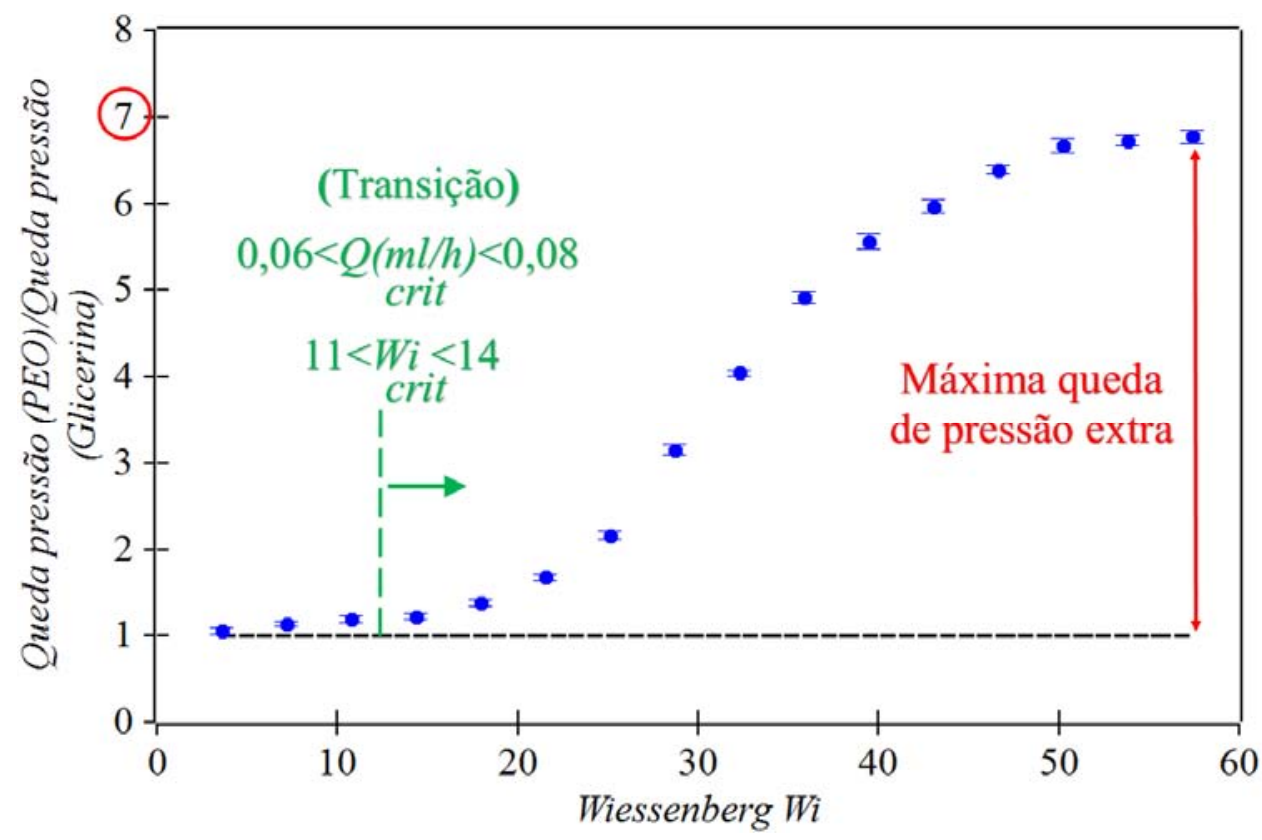

Figura 95 - Queda de pressão extra normalizada em função do número de Weissenberg

O incremento da queda de pressão é observado acima do número de Weissenberg crítico $11<W i_{c r i t}<14$. Como discutido anteriormente, esse aumento da queda de pressão pode ser associado aos efeitos elásticos do escoamento através da garganta, que tornam-se importantes acima de um $W i_{c r i t}$.

Para $W i=57$, o valor da queda de pressão da solução de PEO foi o máximo na faixa de vazões estudada, cujo valor foi aproximadamente 7 vezes maior do valor da queda de pressão da solução de glicerina (maior efeito elástico do polímero).

Em números de Weissenberg menor que Wicrit não foi observada uma substancial queda de pressão extra; o escoamento é dominado pelas forças viscosas.

Usualmente a velocidade de injeção para um reservatório de óleo está em torno de 1 pé/dia. A condição do escoamento nas gargantas dos poros dos reservatórios é complexa, dependendo da porosidade e permeabilidade das rochas, e a geometria e tamanho das gargantas dos poros. Para um caso particular de rocha de carbonato com baixa porosidade de $5 \%$ e com um diâmetro das gargantas de poros aproximadamente de $110 \mu \mathrm{m}$ semelhante ao diâmetro do microcanal com constrição utilizado neste trabalho, a vazão de injeção dentro da garganta seria em torno da ordem de $10^{-3} \mathrm{ml} / \mathrm{h}$. Esta vazão de injeção é próxima as vazões de injeção utilizadas em nosso trabalho, para injetar a solução polimérica de PEO dentro do microcanal com constrição, como mostrada na tabela 6 . 


\subsection{4.}

\section{Regime do escoamento}

É importante caracterizar o regime do escoamento dos experimentos realizados para os diferentes fluidos. O número de Reynolds Re é um parâmetro adimensional que representa a relação entre as forças inerciais e as forças viscosas, como definido na eq. (17) do capítulo 2.

Outro parâmetro adimensional importante avaliado é o fator de Fanning $f$. O fator de Fanning está relacionado diretamente com a queda de pressão do fluido, como mostrado na eq. (36) a seguir:

$$
f=\frac{\Delta P D_{e q}}{2 L \rho U m^{2}},
$$

onde $\Delta P$ é a queda de pressão, $D_{e q}=92,8 \mu \mathrm{m}$ e o diâmetro equivalente, $L=5,6 \mathrm{~mm}$ é o comprimento do microcanal com constrição, $U m$ é a velocidade média do escoamento (vazão de injeção) e $\rho$ é a massa específica do fluido. Como mencionado antes, neste trabalho a geometria do canal não possui diâmetro constante, devido a isto, o diâmetro equivalente foi determinado utilizando a expressão de Poiseuille a partir dos dados experimentais das medidas da queda de pressão do escoamento de água apenas na região da resposta linear $(Q<2 \mathrm{ml} / \mathrm{h})$.

Segundo a definição para um escoamento laminar de um fluido Newtoniano em um tubo reto circular, o fator de Fanning é representado por meio da expressão $f=16 / R e$.

As figuras 96, 97 e 98 apresentam o fator de Fanning em função do número de Reynolds para os diferentes fluidos testados: água, solução de glicerina e solução de PEO. O valor teórico de $f=16 / R e$ é representado nas figuras por uma linha contínua. 


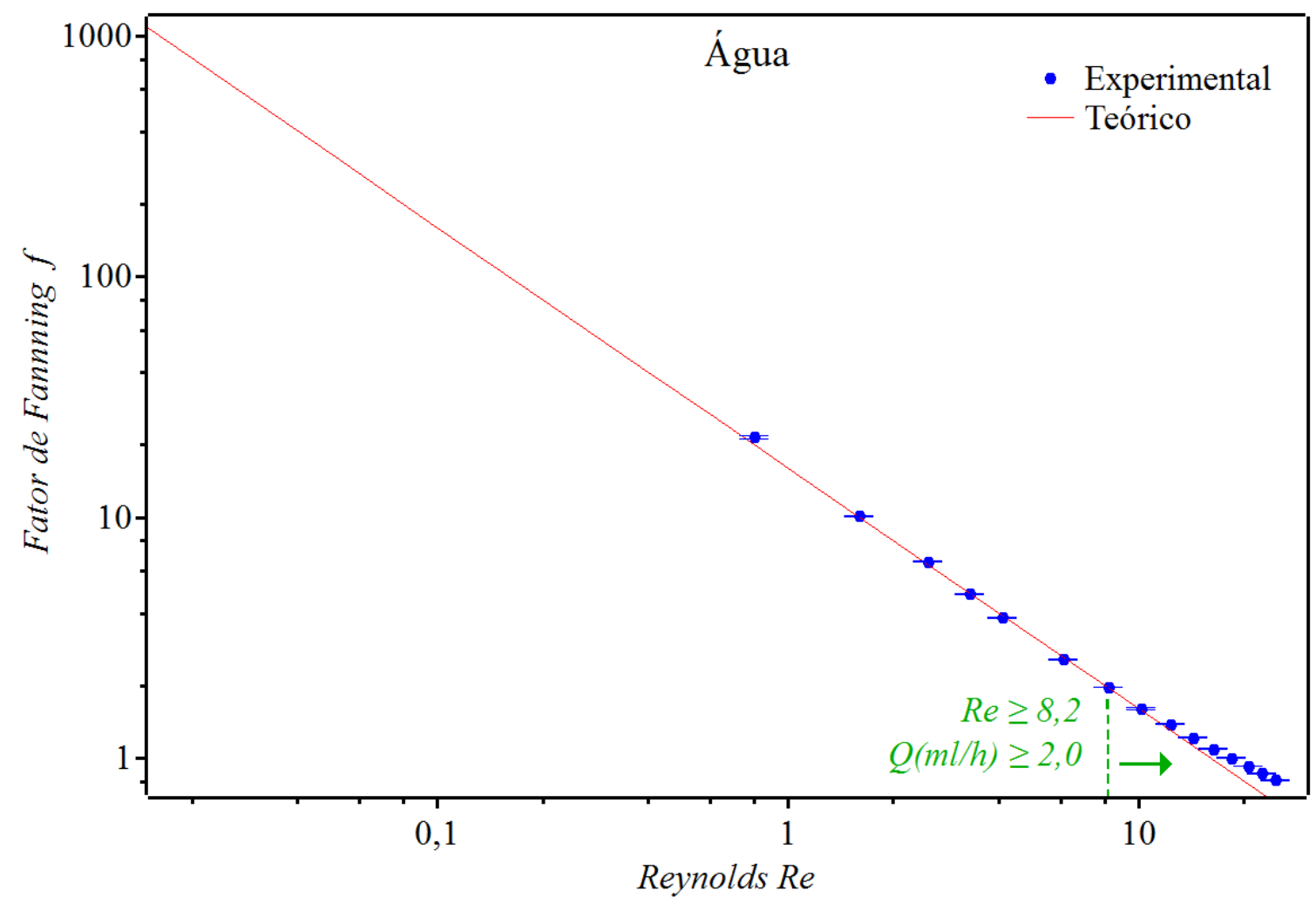

Figura 96 - Comparação dos valores de fator de Fanning experimental e teórico em função do número de Reynolds para o caso do fluido de água

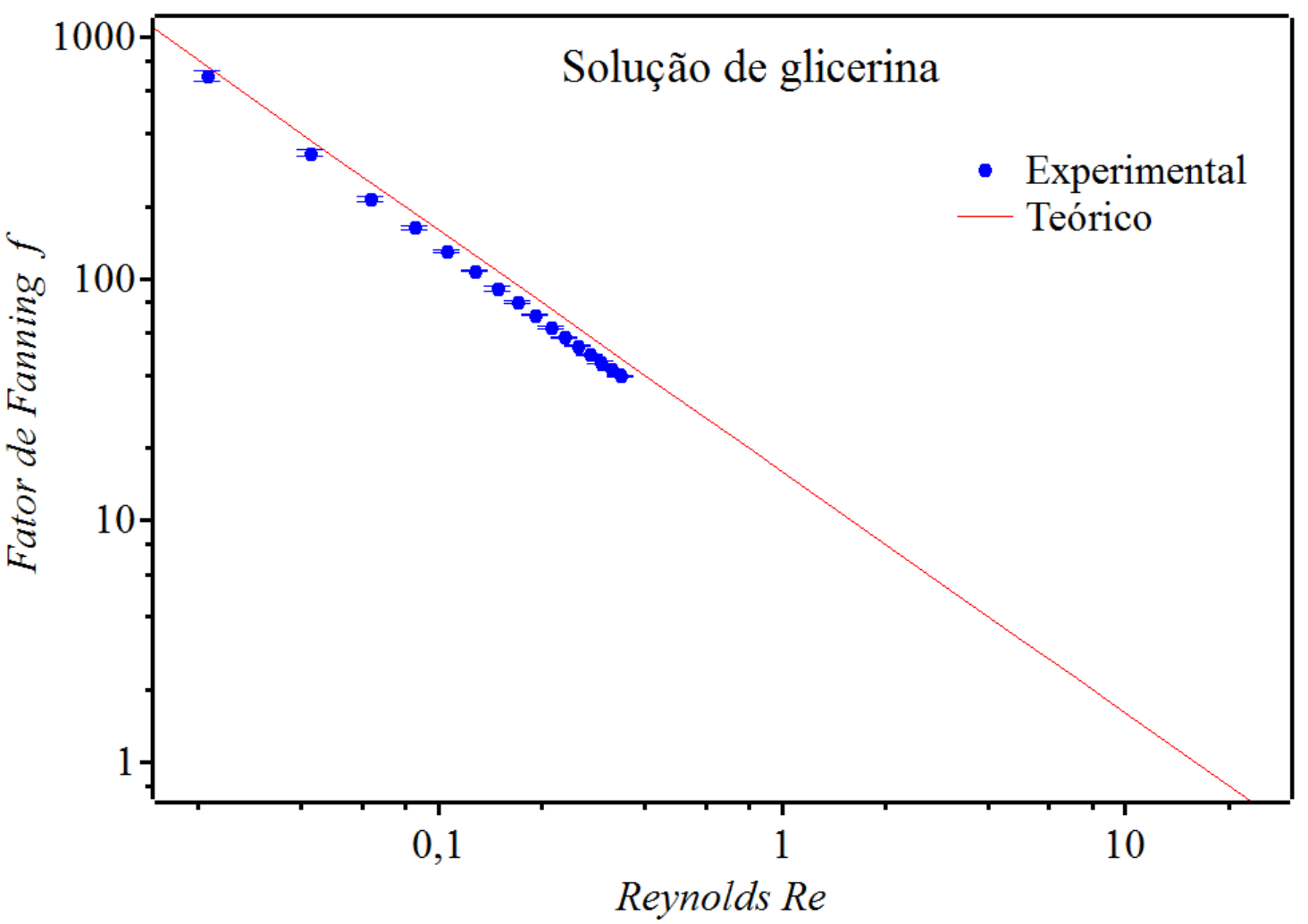

Figura 97 - Comparação dos valores de fator de Fanning experimental e teórico em função do número de Reynolds para o caso da solução de glicerina 


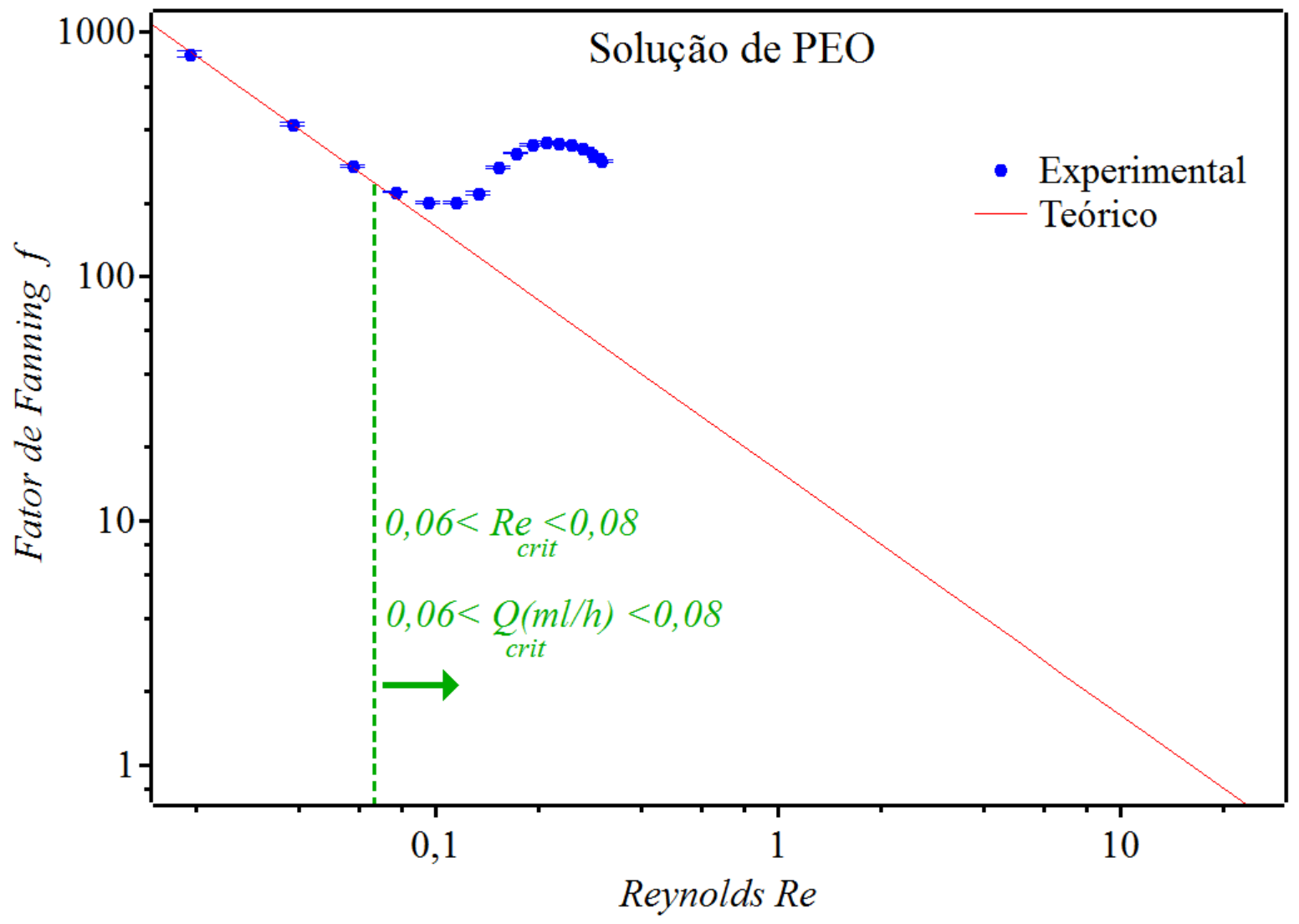

Figura 98 - Comparação dos valores de fator de Fanning experimental e teórico em função do número de Reynolds para o caso da solução polimérica de PEO

No caso da água (fluido Newtoniano), os valores experimentais de número de Reynolds variaram entre $0,8 \leq \operatorname{Re} \leq 24,5$, correspondendo ao regime de escoamento laminar. Os valores de fator de Fanning medidos são bem próximos da expressão teórica. Para valores de $R e \geq 8,2$ ocorre um ligeiro aumento do fator de atrito. Como mencionado anteriormente, a presença de vórtices no escoamento observado a partir da vazão de $Q \geq 2 \mathrm{ml} / \mathrm{h}(\operatorname{Re} \geq 8,2)$ leva a um ligeiro aumento da queda de pressão.

No caso da solução de glicerina (fluido Newtoniano), os valores experimentais de número de Reynolds variaram entre $0,02 \leq R e \leq 0,34$, característico de um escoamento laminar. Os valores experimentais de fator de Fanning foram bastante similares à resposta teórica.

No caso da solução de PEO (fluido viscoelástico), os valores experimentais de número de Reynolds variaram entre $0,02 \leq R e \leq 0,30$. De fato, as duas soluções apresentam propriedades similares (massa específica e viscosidade dinâmica) e o mesmo regime laminar. Os valores experimentais concordam com os valores 
teóricos até o número de Reynolds crítico $\left(0,06<R e_{c r i t}<0,08\right)$. Nesta região os efeitos viscosos foram dominantes levando a um comportamento tipo Newtoniano.

Acima do número de $R e_{c r i t}$ foi observado um aumento do fator de Fanning devido ao aumento da queda de pressão no escoamento. Portanto, este comportamento não pode ser relacionado com os efeitos inerciais porque o número de Reynolds é muito baixo nesta região estudada.

A figura 99 apresenta o fator de Fanning em função do número de Weissenberg para a solução de PEO. Fica claro que acima do número de Weissenberg crítico $\left(11<W i_{c r i t}<14\right)$, os efeitos elásticos começam a ser mais importantes do que os efeitos viscosos, levando a um aumento da queda de pressão e consequentemente um aumento de fator de Fanning.

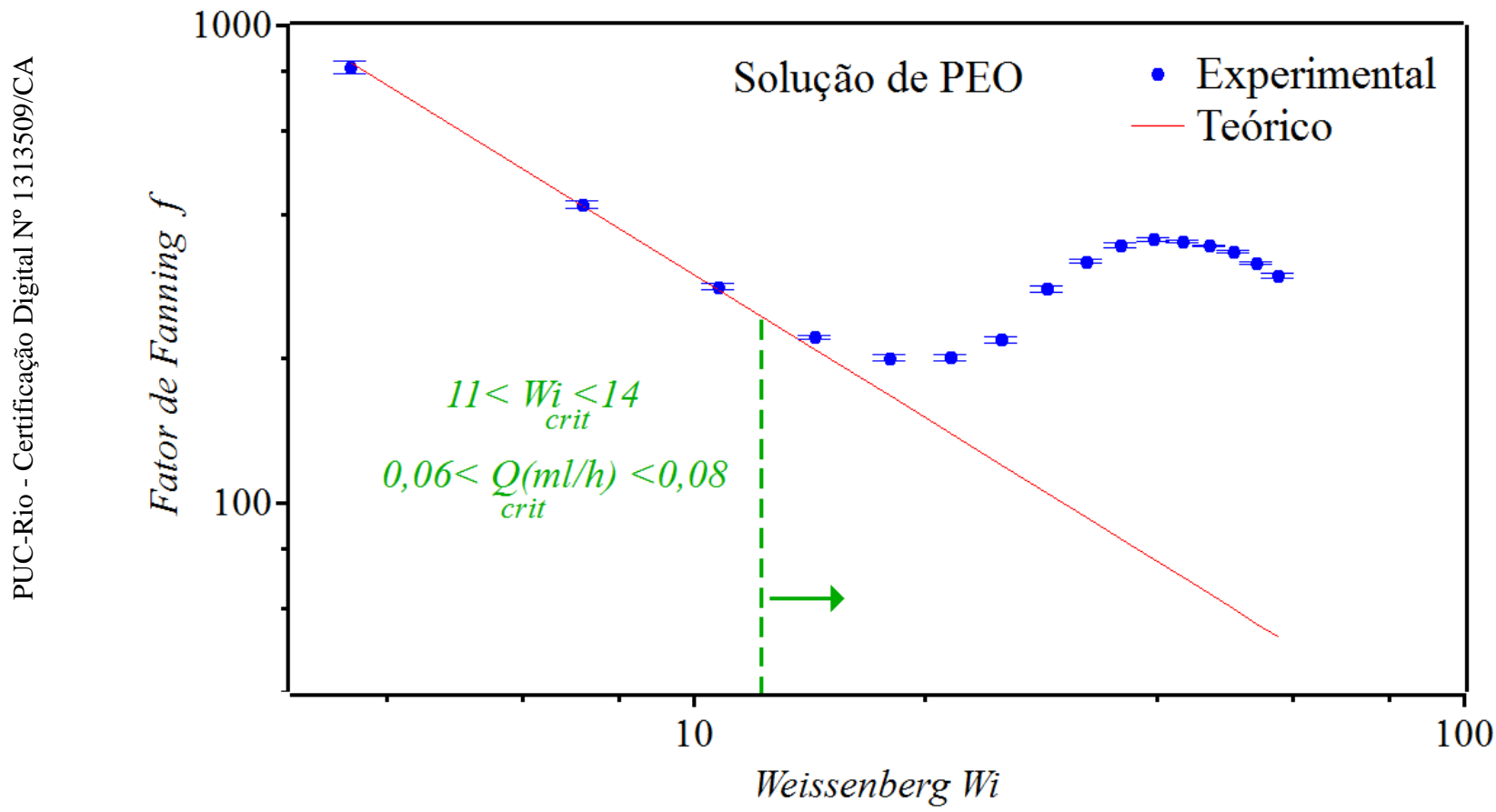

Figura 99 - Fator de Fanning experimental em função do número de Weissenberg para a solução de PEO 


\section{2. \\ Medição de campo de velocidade}

Esta segunda parte dos resultados experimentais apresenta a quantificação do escoamento de água e das soluções de glicerina e PEO na região da garganta (contração e expansão) através das medições de campo de velocidade utilizando a técnica de micro-PIV.

As medições de campo de velocidade do escoamento de água foram realizadas para explicar a resposta não linear observada nas medições da queda de pressão.

A finalidade das medições de campo de velocidade no escoamento da solução de PEO foi quantificar o efeito da elasticidade do polímero no escoamento e determinar os diferentes regimes de escoamento através da constrição, comparando-os com os campos de velocidade da solução de glicerina (líquido puramente viscoso com viscosidade semelhante à solução polimérica). Além disso, determinar a relação entre as medições da queda de pressão associado ao escoamento da solução de PEO e glicerina.

A figura 100 representa o esquema com um resumo dos experimentos dos campos de velocidade realizados.

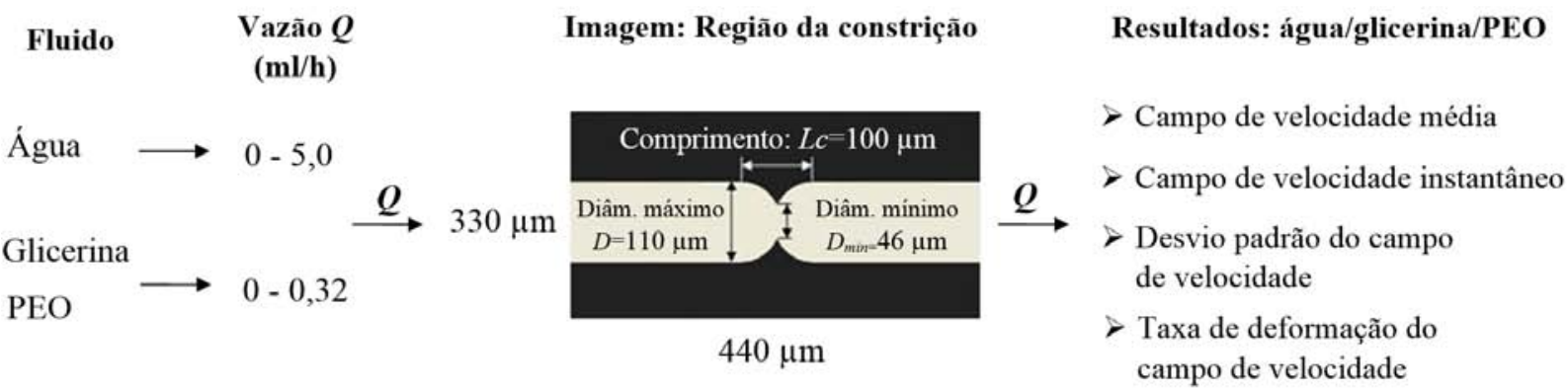

Figura 100 - Esquema dos experimentos dos campos de velocidade realizados

\subsection{1. \\ Determinação dos parâmetros experimentais para as medições dos campos de velocidade}

Antes de obter os campos de velocidade do escoamento localizado na região da constrição, foi necessário determinar importantes parâmetros para conseguir melhores resultados nas medições com o micro-PIV e são descritos a seguir: 


\subsubsection{1.}

\section{Calibração da resolução espacial}

Segundo o manual de operação da TSI (2011), a câmera de Mod. 630066 PowerView $^{T M}$ da TSI $^{\circledR}$ que possui uma lente de magnificação $2 \mathrm{x}$ e utiliza uma objetiva de 10x, apresenta uma resolução espacial de $0,32 \mu \mathrm{m} /$ pixel. A medição foi conferida também utilizando uma régua graduada padrão.

\subsubsection{2.}

\section{Seleção da máscara}

Uma máscara ajustada à geometria da região da constrição foi desenhada utilizando símbolos geométricos disponíveis no software Insight $4 G^{T M}$, com a finalidade de processar as imagens apenas na área do escoamento de interesse, cujas dimensões foram mostradas na figura 100.

\subsubsection{3.}

Determinação da concentração de microesferas (partículas traçadoras) no escoamento e o tamanho da janela de interrogação

O fluxograma da figura 101 mostra o procedimento realizado para determinar a concentração de microesferas e o tamanho da janela de interrogação utilizada nos experimentos.

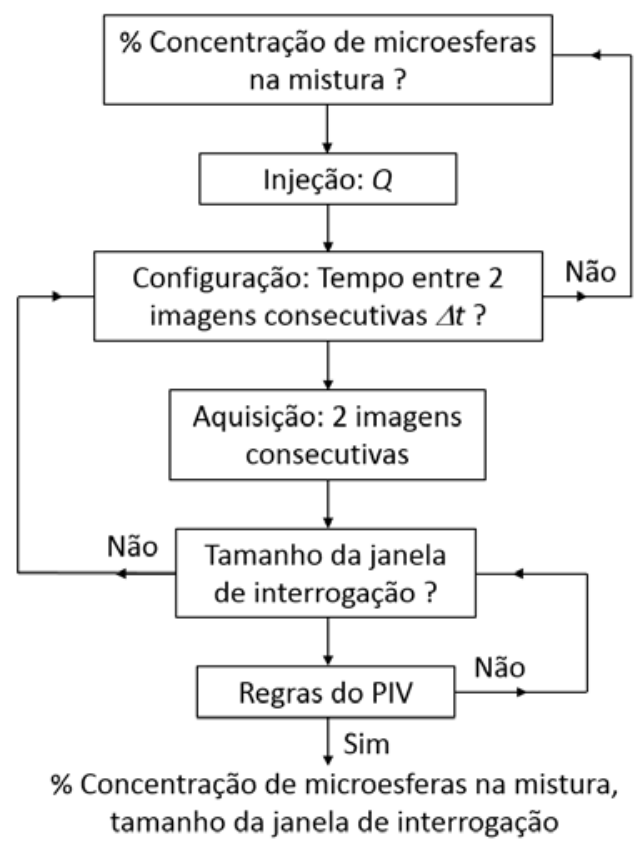

Figura 101 - Sequência de passos para determinar a concentração de microesferas e o tamanho da janela de interrogação 
As microesferas de poliestireno são fornecidas como suspensão aquosa com 2\% de concentração de sólidos. Segundo o critério recomendado pela TSI (2011), um bom ponto de partida para diluir essa concentração é de 1:0,10 (volume total/volume da suspensão de microesferas). $\mathrm{O}$ volume de mistura recomendada pela TSI foi preparado e injetado ao micromodelo a uma vazão de injeção conhecida $Q$. No software foi anotado um valor assumido inicial de tempo $\Delta t$ e um par de imagens foi capturado. Depois, as duas imagens são divididas em janelas de interrogação. Finalmente, as regras de PIV discutidas a seguir devem ser cumpridas, caso contrário, um novo valor do tamanho da janela de interrogação ou o tempo entre duas imagens $\Delta t$ ou a concentração de microesferas deve ser alterada.

As regras de PIV desenvolvidas por Keane e Adrian (1990) para otimizar a medição da velocidade das partículas nas imagens são citadas a seguir:

Diâmetro da partícula na imagem: A variação do diâmetro da partícula sobre a imagem afeta a precisão do algoritmo de processamento de imagens para estimar o deslocamento do pico de correlação na resolução sub-pixel. Em geral, o diâmetro recomendado deve ser de 2 a 4 pixels (Prasad et al., 1992). No presente trabalho, o diâmetro médio das microesferas utilizado nos experimentos foi de $1 \mu \mathrm{m}$ e a resolução espacial foi de $0,32 \mu \mathrm{m} /$ pixel, portanto, o diâmetro médio das microesferas nas imagens foi em torno de 3 pixels.

Número de pares de partículas na janela de interrogação: Os resultados de Keane e Adrian (1990) mostraram que a porcentagem de vetores válidos correlaciona fortemente com o número de pares de partículas por janela de interrogação. Eles recomendaram utilizar mais de 10 pares de partículas por janela de interrogação. Para satisfazer essa necessidade nos experimentos, a concentração de microesferas encontrada na mistura foi de 1:0,14 (volume da mistura /volume da suspensão de microesferas).

Deslocamento máximo das partículas: O deslocamento máximo das partículas está limitado a 1/4 do tamanho original da janela de interrogação para minimizar os pares perdidos de partículas. Além disso, o tempo de captura entre duas imagens consecutivas deve ser pequeno suficiente para que as partículas nas 
regiões de alta velocidade (maiores gradientes de velocidade) não excedam o deslocamento máximo permitido. O tamanho da janela de interrogação selecionado foi de $32 \times 16$ pixels $(10,24 \times 5,12 \mu \mathrm{m})$, sendo o deslocamento máximo das microesferas na direção do escoamento de 8 pixels e na direção perpendicular de 4 pixels.

\subsubsection{4. \\ Determinação do tempo entre duas imagens consecutivas}

Depois de determinar a concentração de microesferas no escoamento e o tamanho da janela de interrogação, o tempo de intervalo $\Delta t$ entre duas imagens foi otimizado para diferentes condições de escoamento e obter o campo de velocidade. O fluxograma da figura 102 apresenta o procedimento a seguir:

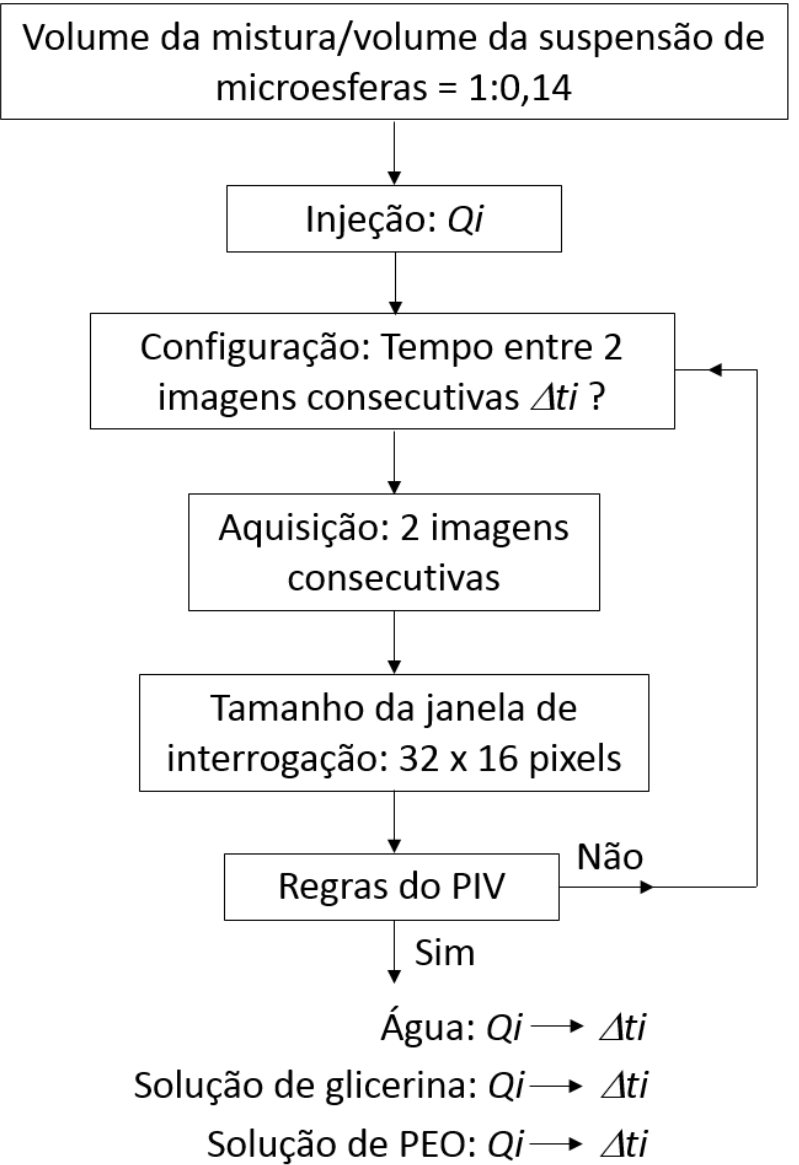

Figura 102 - Sequência de passos para determinar o tempo $\Delta t$ entre dois imagens consecutivas 
A faixa de valores do tempo $\Delta t$ entre duas imagens consecutivas é mostrada na tabela 7 a seguir:

Tabela 7 - Faixa de valores do tempo $\Delta t$ entre duas imagens consecutivas

\begin{tabular}{|c|c|c|}
\cline { 2 - 3 } \multicolumn{1}{c|}{} & $Q(\mathrm{ml} / \mathrm{h})$ & $\Delta t(\mu \mathrm{s})$ \\
\hline Água & $0,2-5,0$ & $5-20$ \\
\hline Solução de glicerina & $0,02-0,32$ & $9-280$ \\
\hline Solução de PEO & $0,02-0,32$ & $4,5-250$ \\
\hline
\end{tabular}

\subsubsection{5.}

\section{Determinação do número de pares de imagens}

O procedimento realizado para estimar o número de pares de imagens

utilizados nos experimentos é mostrado no fluxograma da figura 103.

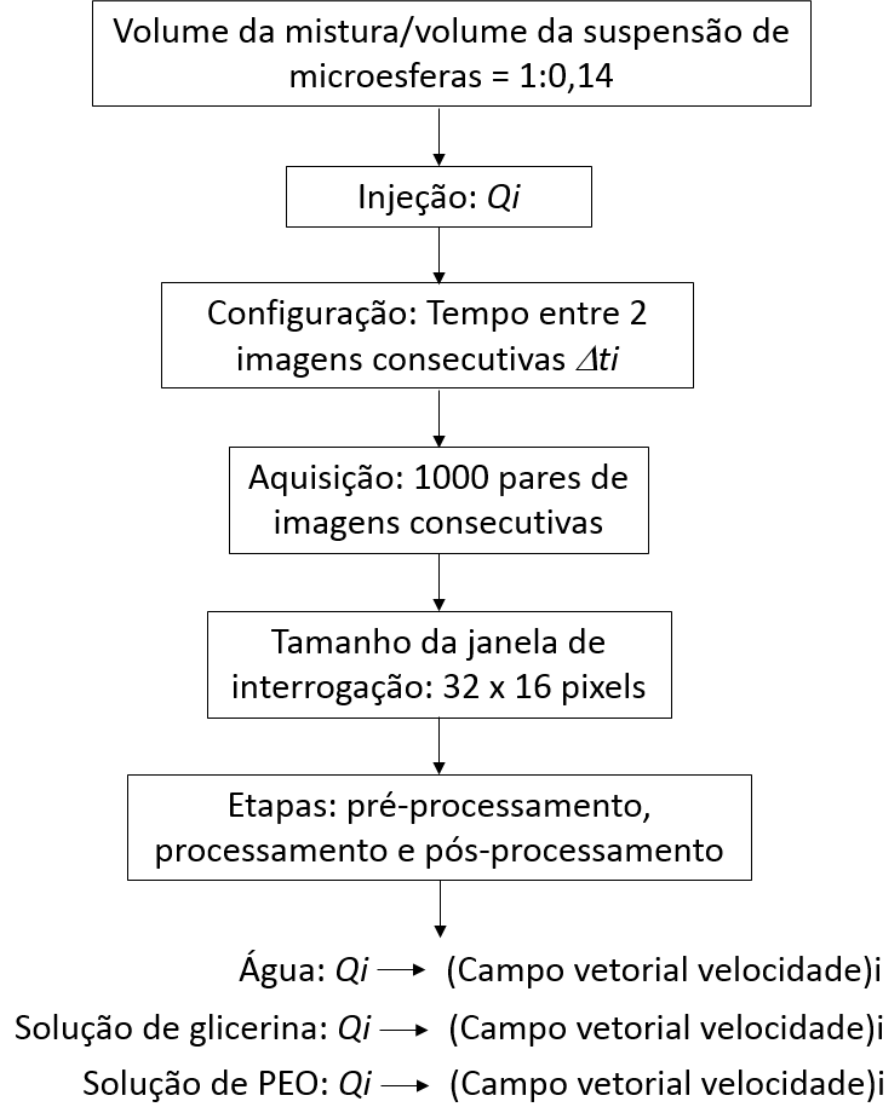

imagens consecutivas $\Delta t i$

Aquisição: 1000 pares de imagens consecutivas

Tamanho da janela de interrogação: 32 × 16 pixels

Etapas: pré-processamento, processamento e pós-processamento

Água: $Q i \rightarrow$ (Campo vetorial velocidade)i Solução de glicerina: $Q i \longrightarrow$ (Campo vetorial velocidade)i Solução de PEO: $Q i \rightarrow$ (Campo vetorial velocidade)i

Figura 103 - Sequência de passos para determinar o número de pares de imagens utilizados 
Para cada vazão de injeção dos fluidos foi capturado 1000 pares de imagens consecutivas do escoamento na região da constrição. Depois da captura, as imagens passaram por diferentes etapas de processamento, como mencionado no capítulo 3 .

A etapa de pré-processamento foi utilizada para detectar partículas fixas, paredes e manchas nas imagens (ruído de fundo). A técnica de subtração consistiu em criar apenas um par de imagens (ruído de fundo) a partir do pixel de intensidade mínima localizada na mesma posição da sequência de pares de imagens originais. Finalmente, a cada par de imagem original foi removida a intensidade do ruído de fundo.

A etapa de processamento foi utilizada para determinar o campo vetorial de velocidade do escoamento. Um simples passo de processamento com $50 \%$ de sobreposição da janela foi utilizado, e as janelas de interrogação inicial e final foram iguais (Nyquist Grid). A correlação do mapeamento foi determinada utilizando o método clássico da transformada de Fourier, e a localização do pico mediante a função Gaussiana.

A etapa de pós-processamento foi realizada para remover vetores falsos do campo vetorial de velocidade. Para validar a veracidade dos vetores foi utilizado o critério da mediana universal adimensional, descrito no capítulo 3.

Finalmente, uma área do escoamento perto da constrição (onde as flutuações foram maiores) foi selecionada para observar a variação da velocidade média instantânea no tempo (direção axial). No esquema da figura 104 é visualizado a posição e o tamanho da área de interesse selecionada.

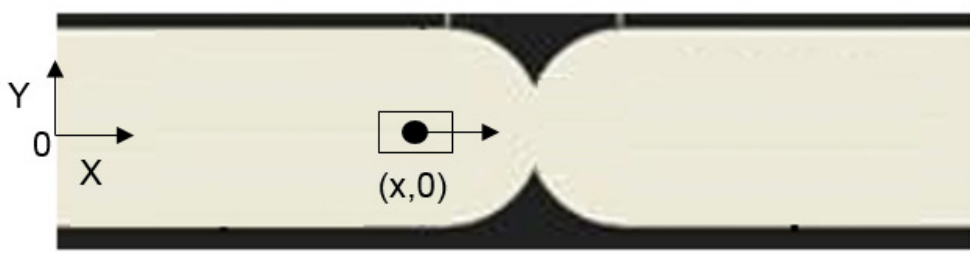

Janela de interrogação

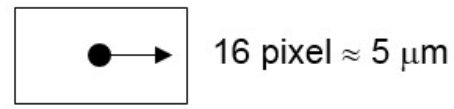

$32 \mathrm{pixel} \approx 10 \mu \mathrm{m}$

Figura 104 - Região do escoamento onde foi medido a velocidade média instantânea na direção axial com o tempo

As figuras 105, 106 e 107 apresentam a variação temporal da velocidade média instantânea para todas as vazões de injeção dos fluidos. 

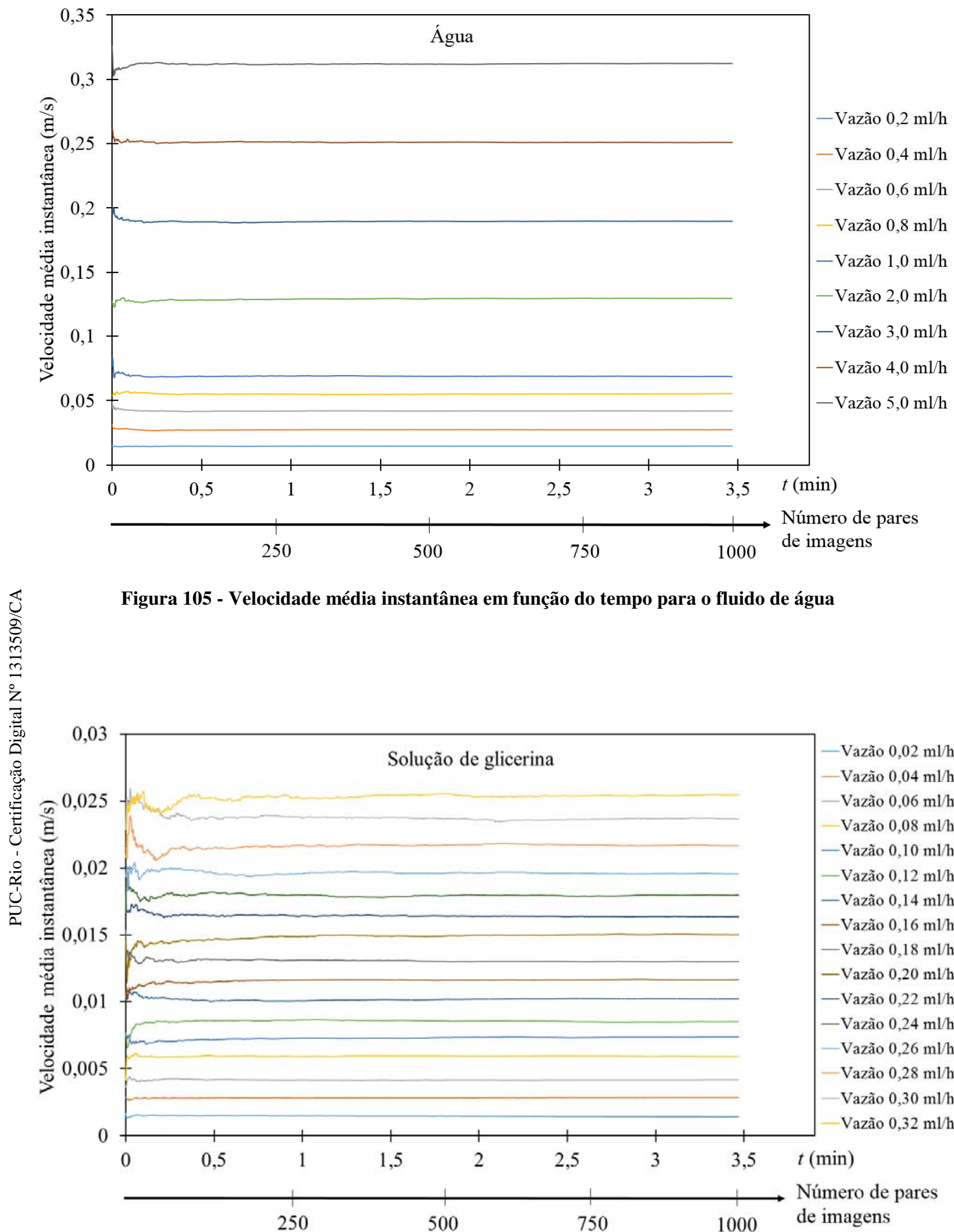

Figura 106 - Velocidade média instantânea em função do tempo para a solução de glicerina 


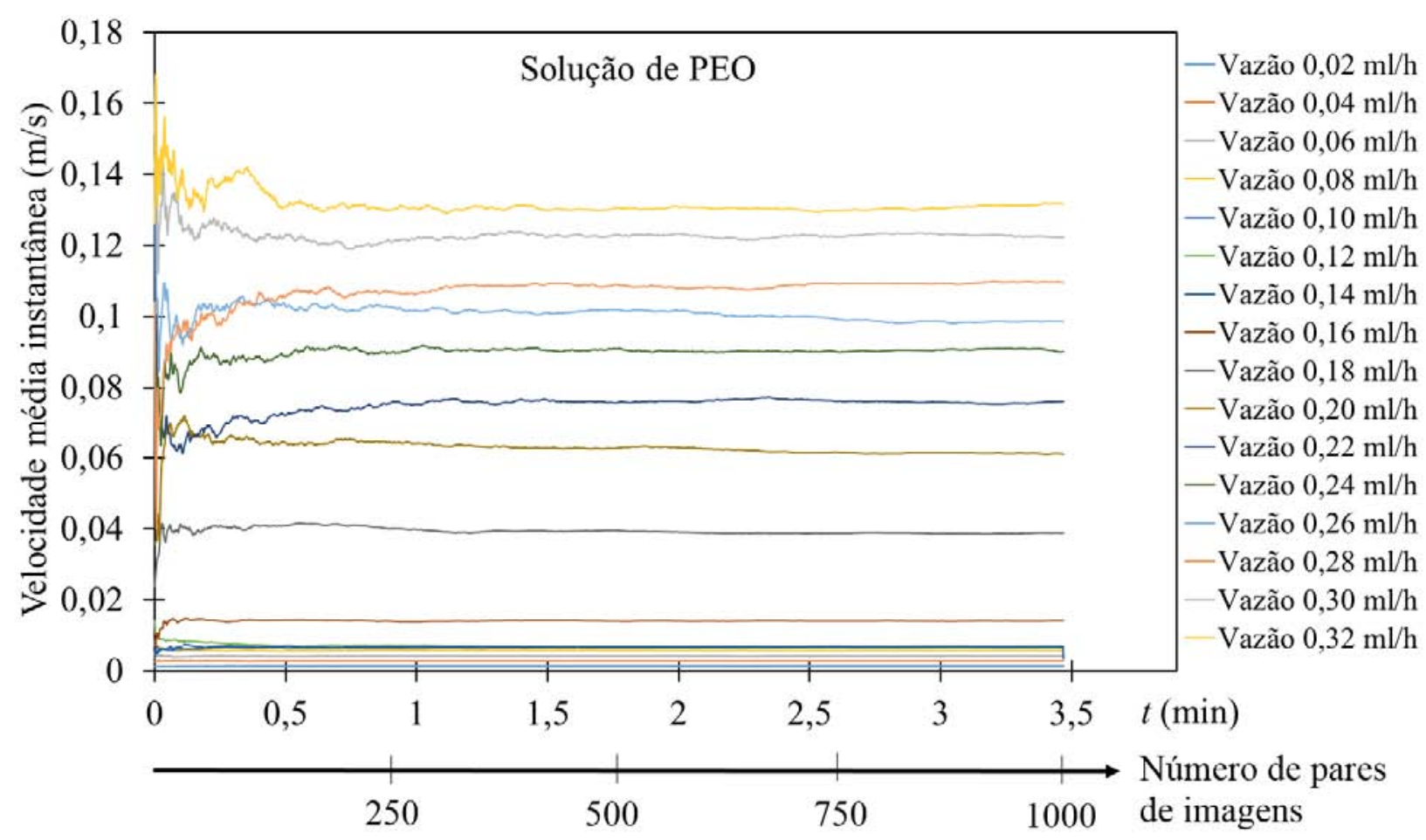

Figura 107 - Velocidade média instantânea em função do tempo para a solução de PEO

Segundo os gráficos, o valor representativo da velocidade média instantânea para o escoamento de água pode ser determinado a partir de 100 pares de imagens consecutivas, e para a solução de glicerina foi apenas um pouco maior do que o caso do escoamento de água. Para o escoamento da solução de PEO foi observado maiores flutuações nas medições e, portanto, um maior número de pares de imagens foi necessário para que seu valor fosse representativo. Tendo em conta essa consideração, 500 pares de imagens foram selecionados para determinar os campos de velocidade.

\subsection{2.}

\section{Determinação dos campos de velocidade}

Determinado os parâmetros experimentais como descrito na seção anterior (concentração de microesferas, o tamanho da janela de interrogação, o número de pares de imagens e o tempo entre duas imagens consecutivas), os pares de imagens foram capturados em sequência à taxa de repetição de $4,8 \mathrm{~Hz}$ na região da garganta após a queda de pressão atingir o regime permanente para uma condição de vazão constante. Citando que a janela de interrogação utilizada para determinar os campos de velocidade foi de $32 \times 16$ pixels, porém alguns casos foram processados com 
outro tamanho de janela de interrogação e esta alteração é ressaltada para cada caso. Vale mencionar que as medições de velocidade do escoamento utilizando a técnica de micro-PIV levam em conta tanto as partículas focadas no plano focal como as partículas focadas nos planos adjacentes em toda a profundidade de correlação (Meinhart, 2000).

Para evitar os efeitos de entrada e das tomadas de pressão sobre a condição do escoamento totalmente desenvolvido à montante da garganta, as imagens da garganta foram capturadas a uma distância de 2,8 mm em relação às tomadas de pressão e de $10 \mathrm{~mm}$ em relação ao plano de entrada do fluido, como mostrada no esquema da figura 108.

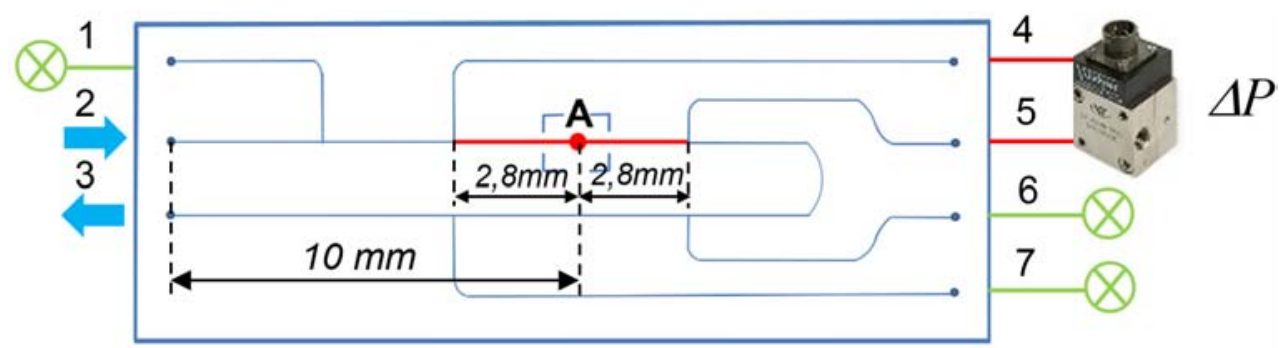

Figura 108 - Esquema do dispositivo microfluídico mostrando a posição da constrição (região A), e a distância em relação às tomadas de pressão e à entrada do fluido

Langhaar (1942) propôs uma correlação para o cálculo do comprimento de desenvolvimento hidrodinâmico $L_{e}$ para um escoamento laminar em dutos circulares, como mostrado na eq. (37):

$$
L_{e}=0,0575 D R e
$$

Onde, $D$ representa o diâmetro interno do tubo circular e $R e$ é o número de Reynolds. O diâmetro interno do microcanal (aproximadamente circular) é de 0,11 mm. Os valores de números de Reynolds para o caso da água e as soluções de glicerina e PEO são menores que $R e \leq 24,5, R e \leq 0,34$ e $R e \leq 0,30$ respectivamente. Isto leva a um comprimento de desenvolvimento menor que $L e \leq 0,15 \mathrm{~mm}$, que garante um escoamento completamente desenvolvido à montante da garganta. 
Finalmente, na região de menor diâmetro da garganta foi observada uma menor velocidade do que esperado nos campos de velocidade, devido a que as partículas ficaram grudadas na parede do canal (ruído de fundo). Isto levou a um aumento da incerteza em torno de $5 \%$ nessa pequena região do escoamento, porém esse valor mudava por causa da quantidade de partículas aderidas na parede acontecendo em todos os casos, como mostrado na imagem da figura 109.

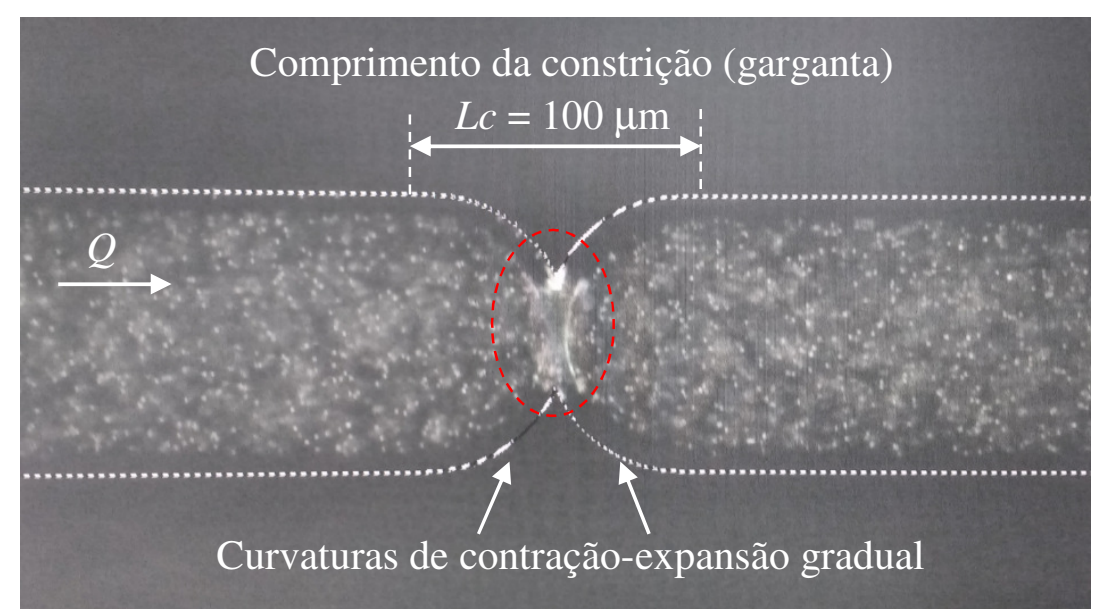

Figura 109 - Imagem de partículas grudadas no centro da garganta

\subsubsection{1. Campos de velocidade média}

Na técnica de micro-PIV, a baixa densidade de partículas e o alto ruído nas imagens são geralmente observados mesmo para escoamentos em regime permanente. A fim de melhorar a precisão das medições, uma função de correlação baseado na média amostral de pares de imagens (Meinhart et al., 2000) foi utilizada para determinar o campo de velocidade média dos escoamentos.

A seguir mostrarmos como a técnica da media amostral (ensemble average) melhora a relação sinal/ruído em escoamentos de regime permanente (Meinhart et al., 2000). A figura 110 apresenta os campos vetoriais de velocidade obtidos a partir da media amostral de diferentes números de pares de imagens consecutivas para o caso da solução de glicerina (fluido Newtoniano) à vazão de $Q=0,32 \mathrm{ml} / \mathrm{h}$.

A escala do tamanho dos vetores é igual para todos os campos vetoriais de velocidade. 

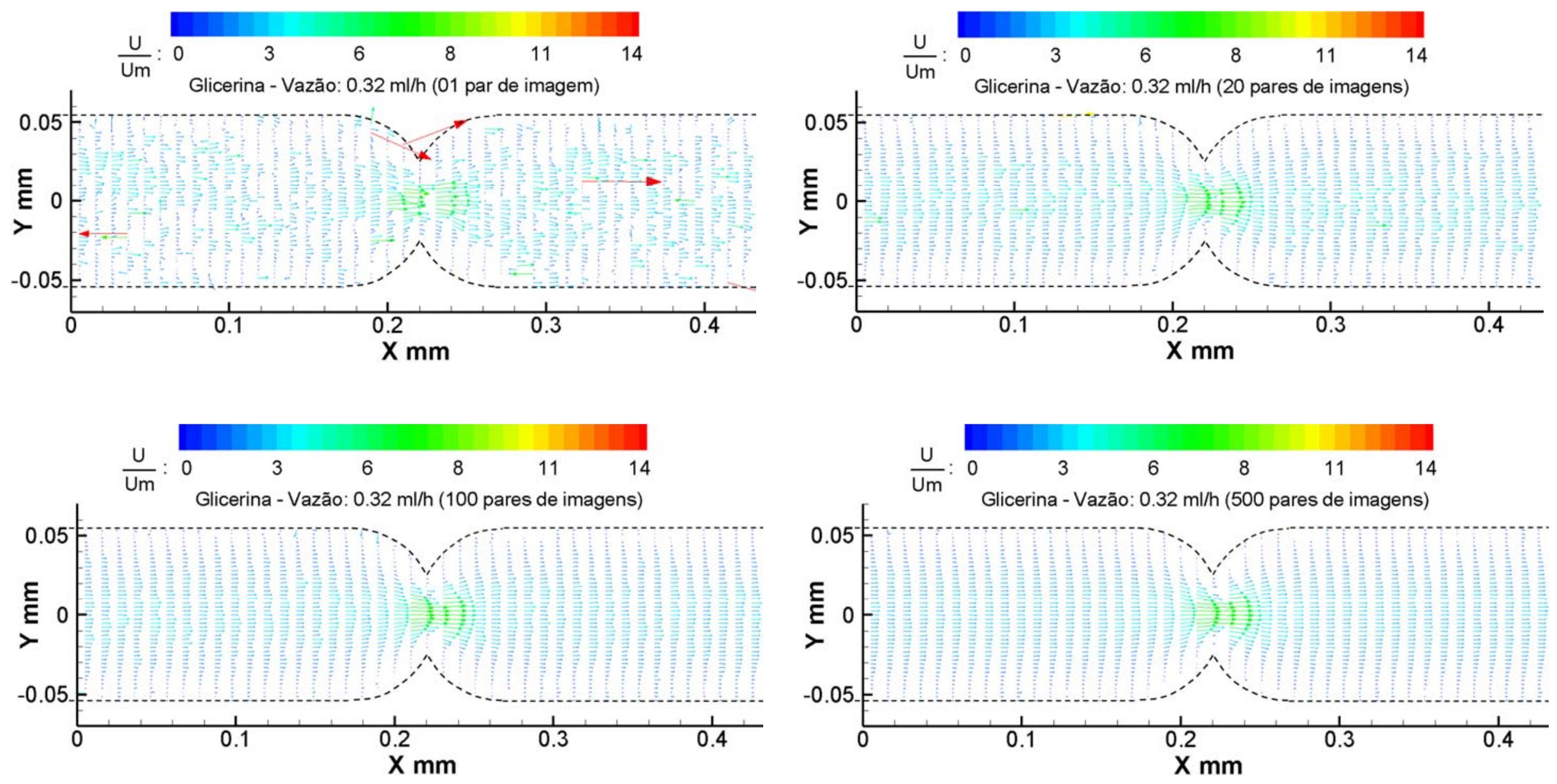

Figura 110 - Efeito do número de pares de imagens na relação sinal/ruído do escoamento utilizando a técnica da média amostral (ensemble average) 
O campo de velocidade média dos escoamentos foi determinado a partir da média amostral de 500 pares de imagens consecutivos e foi normalizado em relação à velocidade média do escoamento $U m$ (injeção da bomba de seringa). Os perfis de velocidade e as linhas de corrente do escoamento são mostrados. Para a maioria dos casos foi utilizado a janela de interrogação de 32x16 pixel (calibração da resolução espacial de $0,32 \mu \mathrm{m} /$ pixel para as duas direções), e a resolução das medidas foi um vetor para cada $5,12 \mu \mathrm{m}$ na direção axial do escoamento e um vetor para cada 2,56 $\mu \mathrm{m}$ na direção perpendicular ao escoamento.

Campos de velocidade média para o escoamento de água: Os campos de velocidade média do escoamento de água passando através da constrição foram determinados com a finalidade de entender a não linearidade visualizada nas medições da queda de pressão.

Nas figuras 111, 112 e 113 são apresentados os campos de velocidade média normalizado do escoamento de água para diferentes vazões de injeção. O lado esquerdo e direito das figuras mostram os perfis de velocidade e as linhas de corrente do escoamento na região da constrição.

A fim de facilitar a visualização dos perfis de velocidade no campo vetorial (lado esquerdo), apenas a metade dos perfis na direção axial $\mathrm{X}$ e perpendicular $\mathrm{Y}$ foram mostrados. É importante ressaltar que a escala de tamanho dos vetores foi diferente para cada vazão de injeção, para mostrar em detalhe os perfis na região de maior velocidade do escoamento. 
PUC-Rio - Certificação Digital No 1313509/CA
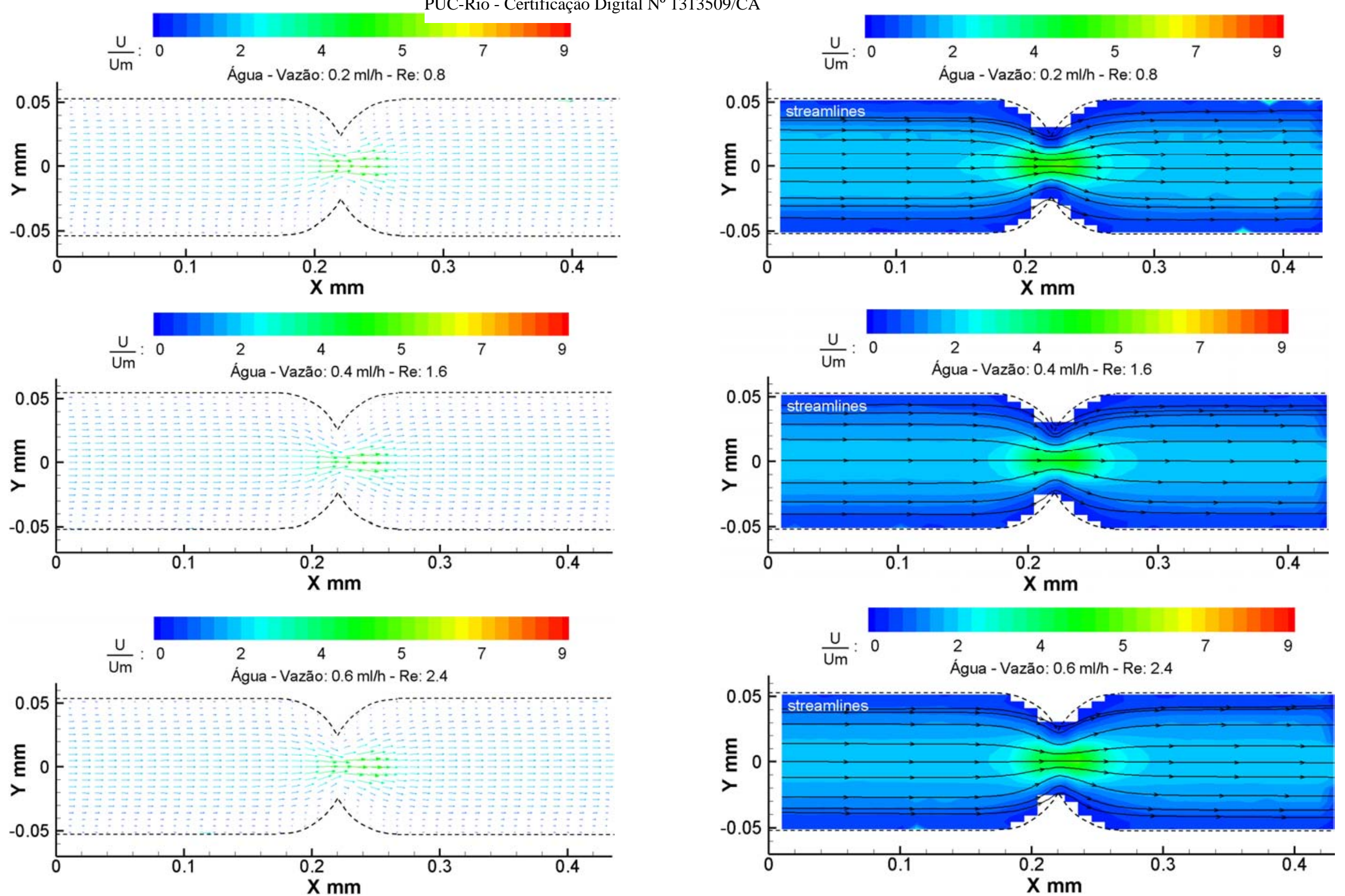

Figura 111 - Campo vetorial de velocidade média normalizado (lado esquerdo) e linhas de corrente (lado direito) do escoamento de água para as vazões de injeção de $Q=0,2 \mathrm{ml} / \mathrm{h}, Q=0,4 \mathrm{ml} / \mathrm{h}$ e $Q=0,6 \mathrm{ml} / \mathrm{h}$ 
PUC-Rio - Certificação Digital Nº 1313509/CA
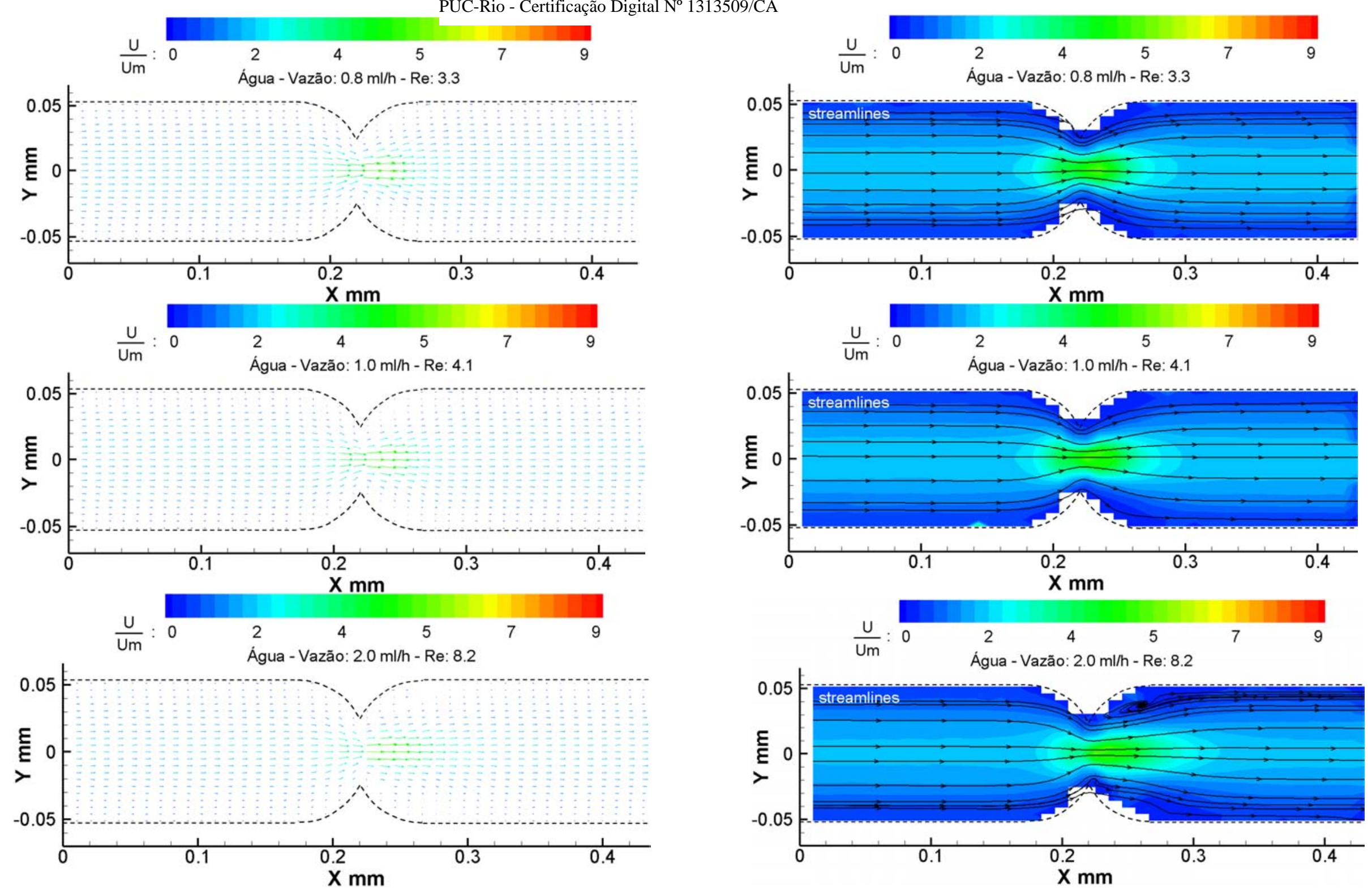

Figura 112 - Campo vetorial de velocidade média normalizado (lado esquerdo) e linhas de corrente (lado direito) do escoamento de água para as vazões de injeção de $Q=0,8 \mathrm{ml} / \mathrm{h}, Q=1,0 \mathrm{ml} / \mathrm{h}$ e $Q=2,0 \mathrm{ml} / \mathrm{h}$ 
PUC-Rio - Certificação Digital N 1313509/CA
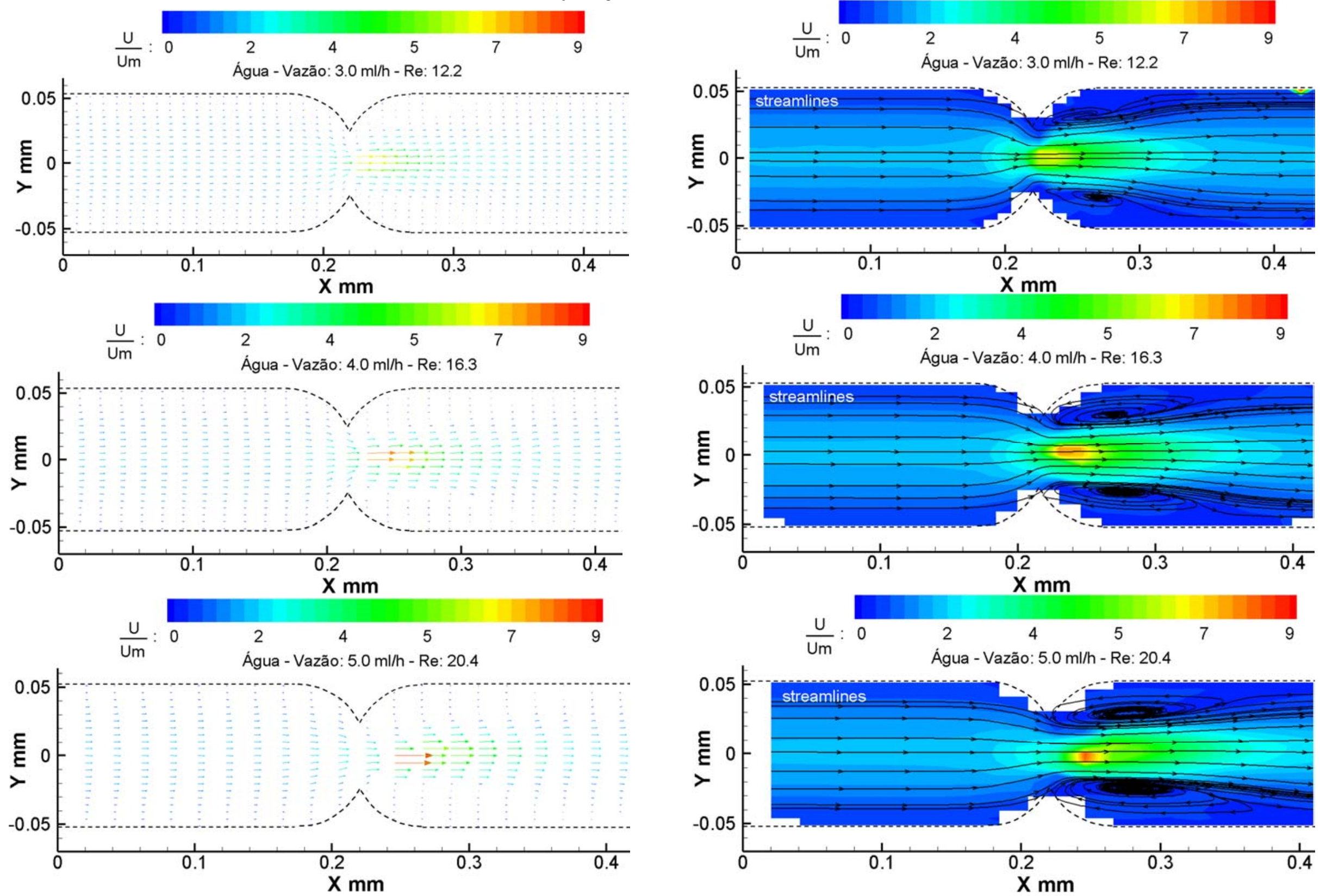

Figura 113 - Campo vetorial de velocidade média normalizado (lado esquerdo) e linhas de corrente (lado direito) do escoamento de água para as vazões de injeção de $Q=3,0 \mathrm{ml} / \mathrm{h}, Q=4,0 \mathrm{ml} / \mathrm{h}$ e $Q=5,0 \mathrm{ml} / \mathrm{h}$ 
Para vazões $Q<1,0 \mathrm{ml} / \mathrm{h}(\operatorname{Re}<4,1)$, pode-se observar que as linhas de corrente e o campo do módulo de velocidade são simétricos em relação ao plano da garganta. Esta simetria é característica de um escoamento a baixo número de Reynolds (escoamento de Stokes). As linhas de corrente não mostraram nenhuma presença de recirculações na região de visualização do escoamento, já que as forças inerciais são desprezíveis.

Para vazões $Q \geq 1,0 \mathrm{ml} / \mathrm{h}(R e \geq 4,1)$, a simetria do escoamento é quebrada, indicando que as forças inercias passaram a ser relevantes. Inicialmente mostrando linhas divergentes à saída da constrição, seguido da presença de recirculação (vórtices) simétrico em relação ao eixo do capilar à jusante da garganta para a vazão de injeção de $Q=2,0 \mathrm{ml} / \mathrm{h}(\operatorname{Re}=8,2)$. Isso levou uma redução do tamanho do escoamento principal e maiores gradientes de velocidade conforme a vazão foi aumentada $(U / U m \approx 9)$. Devido à presença da constrição, os efeitos de inercia se tornaram importantes afetando a dinâmica do escoamento à jusante da garganta e a queda de pressão no escoamento. O tamanho da recirculação cresce com o aumento da vazão, conforme mostrado na figura 113. Rodd et al. (2005) visualizou também o início da formação de recirculação no escoamento de água à saída de uma constrição abruta planar $(R c=400 \mu \mathrm{m} / 25 \mu \mathrm{m})$ para baixo número de Reynolds $(\operatorname{Re}=3,7)$.

Vale mencionar que os campos vetoriais para vazões $Q \geq 1,0 \mathrm{ml} / \mathrm{h}$ foram determinados utilizando um maior tamanho da janela de interrogação $(64 \times 32$, 96x32 e 128x32 pixels) devido às altas velocidades encontradas na região central à jusante da garganta.

O software comercial computacional Comsol foi utilizado para ilustrar a presença de vórtices à jusante da garganta. A figura 114 mostra a mudança no padrão de linhas de corrente em função da vazão de injeção. Pode-se observar um escoamento simétrico para $R e=0,8$ e a presença de vórtices para $R e \geq 8,2$ $(Q \geq 2,0 \mathrm{ml} / \mathrm{h})$. Vale ressaltar que a resposta não linear da queda de pressão em função da vazão imposta é observada para $R e \geq 8,2$ o que mostra que este comportamento está associado ao aparecimento dos vórtices à jusante da garganta. 


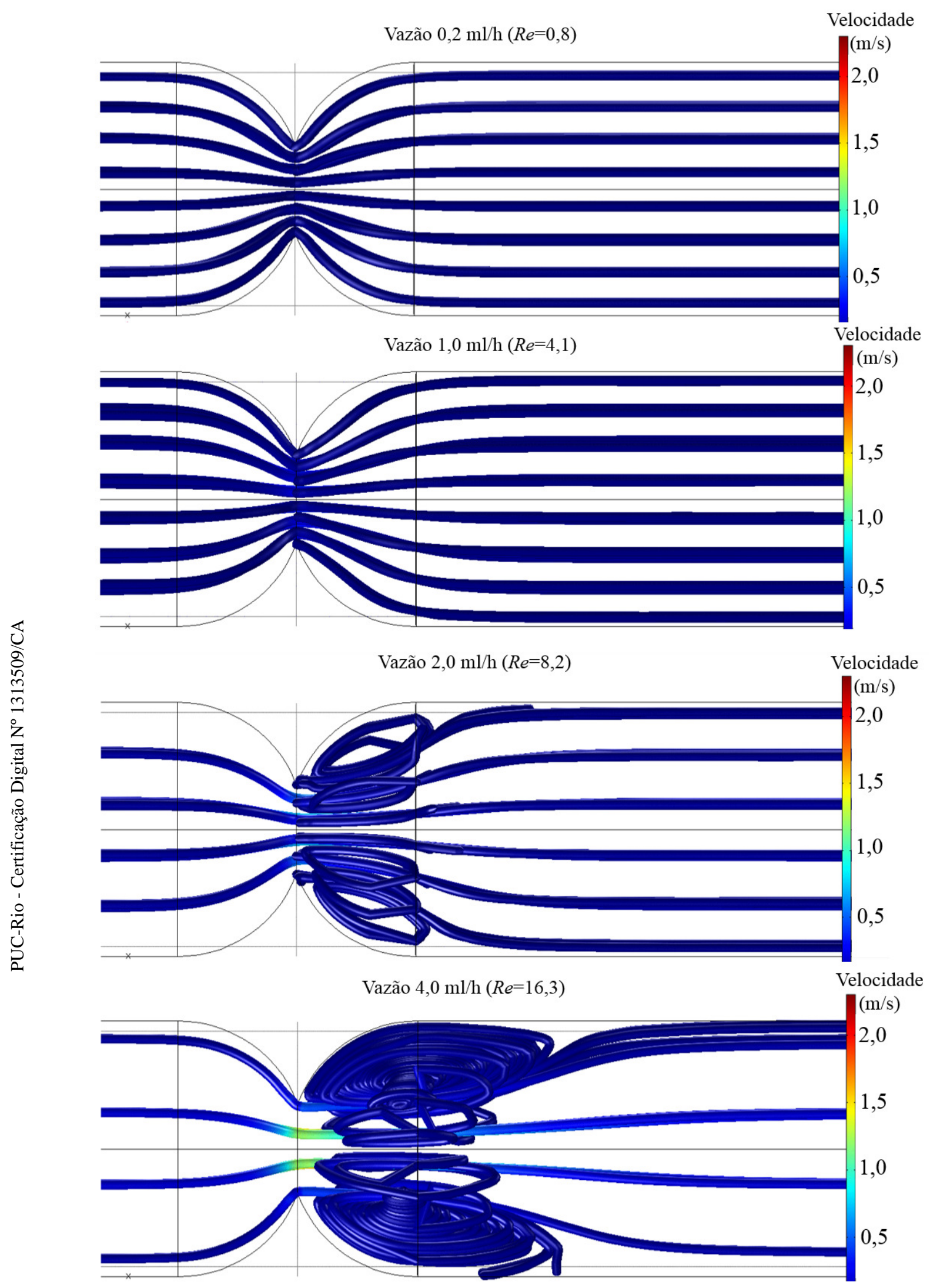

Figura 114 - Linhas de corrente do escoamento de água utilizando o software computacional Comsol 
Campos de velocidade média da solução de PEO e glicerina: Os campos de velocidade média do escoamento da solução polimérica de PEO foram determinados com a finalidade de visualizar a evolução do escoamento da solução de PEO na região da constrição à medida que o número de Weissenberg foi incrementado (efeitos elásticos do polímero). Os campos de velocidade da solução polimérica são comparados com o campo de velocidade de um fluido Newtoniano com viscosidade semelhante (solução de agua-glicerina) com o objetivo de quantificar o efeito da elasticidade no padrão do escoamento.

As medições adquiridas ao longo do tempo são importantes para determinar o campo do escoamento global médio mesmo quando os efeitos elásticos tornam o escoamento instável, pois as flutuações de velocidade são suavizadas. Sousa et al. (2011) utilizou os campos de velocidade média para estudar o comportamento dinâmico do escoamento da solução polimérica de PEO $\left(C=0,1 \%\right.$ em peso e $P M=8 \times 10^{6} \mathrm{~g} / \mathrm{mol}$ ) passando através de microcanais com contrição (conectados em série) em ambas as direções tanto para o regime estável como instável do escoamento.

Nas figuras 115, 116, 117, 118, 119 e 120 são apresentados os campos de velocidade média normalizado dos escoamentos da solução de PEO e glicerina para diferentes vazões de injeção $(0,02 \mathrm{ml} / \mathrm{h} \leq Q \leq 0,32 \mathrm{ml} / \mathrm{h})$, mostrando os perfis de velocidade na região da constrição.

A fim de facilitar a visualização dos perfis de velocidade no campo vetorial normalizado, apenas a metade dos perfis na direção axial $\mathrm{X}$ foi mostrada. É importante ressaltar, que a comparação é realizada apenas entre o escoamento da solução de glicerina e PEO para a mesma vazão de injeção, porque apresentam a mesma escala de tamanho de vetores e assim poder mostrar em detalhe os perfis na região de maior velocidade do escoamento da solução de PEO. A comparação não é realizada entre os mesmos campos de velocidade de glicerina e entre os mesmos campos de velocidade de PEO. 
PUC-Rio - Certificação Digital No 1313509/CA
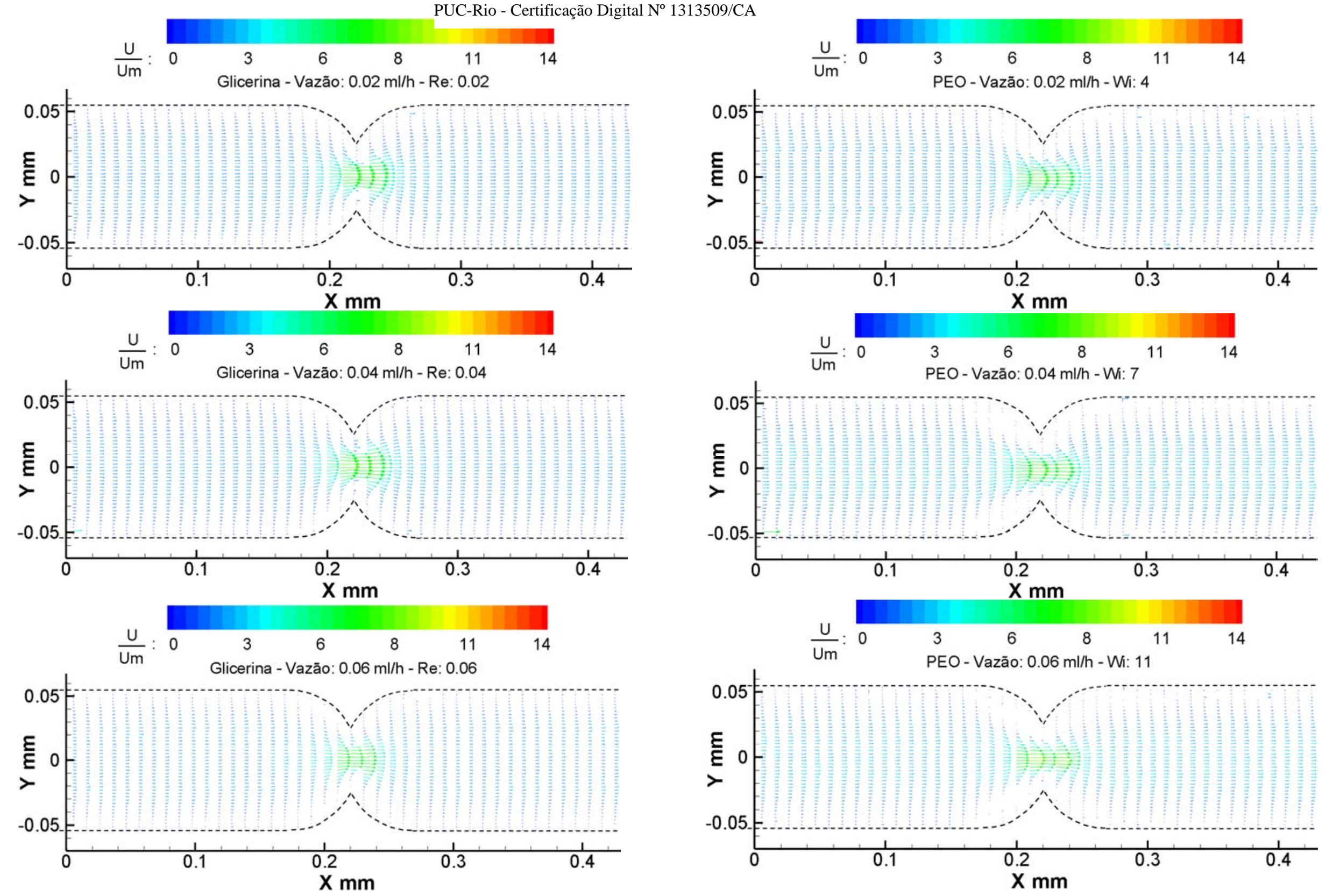

Figura 115 - Campo vetorial de velocidade média normalizado para a solução de glicerina e $P E O$ às vazões de injeção de $Q=0,02 \mathrm{ml} / \mathrm{h}, Q=0,04 \mathrm{ml} / \mathrm{h}$ e $Q=0,06 \mathrm{ml} / \mathrm{h}$ 
PUC-Rio - Certificação Digital No 1313509/CA
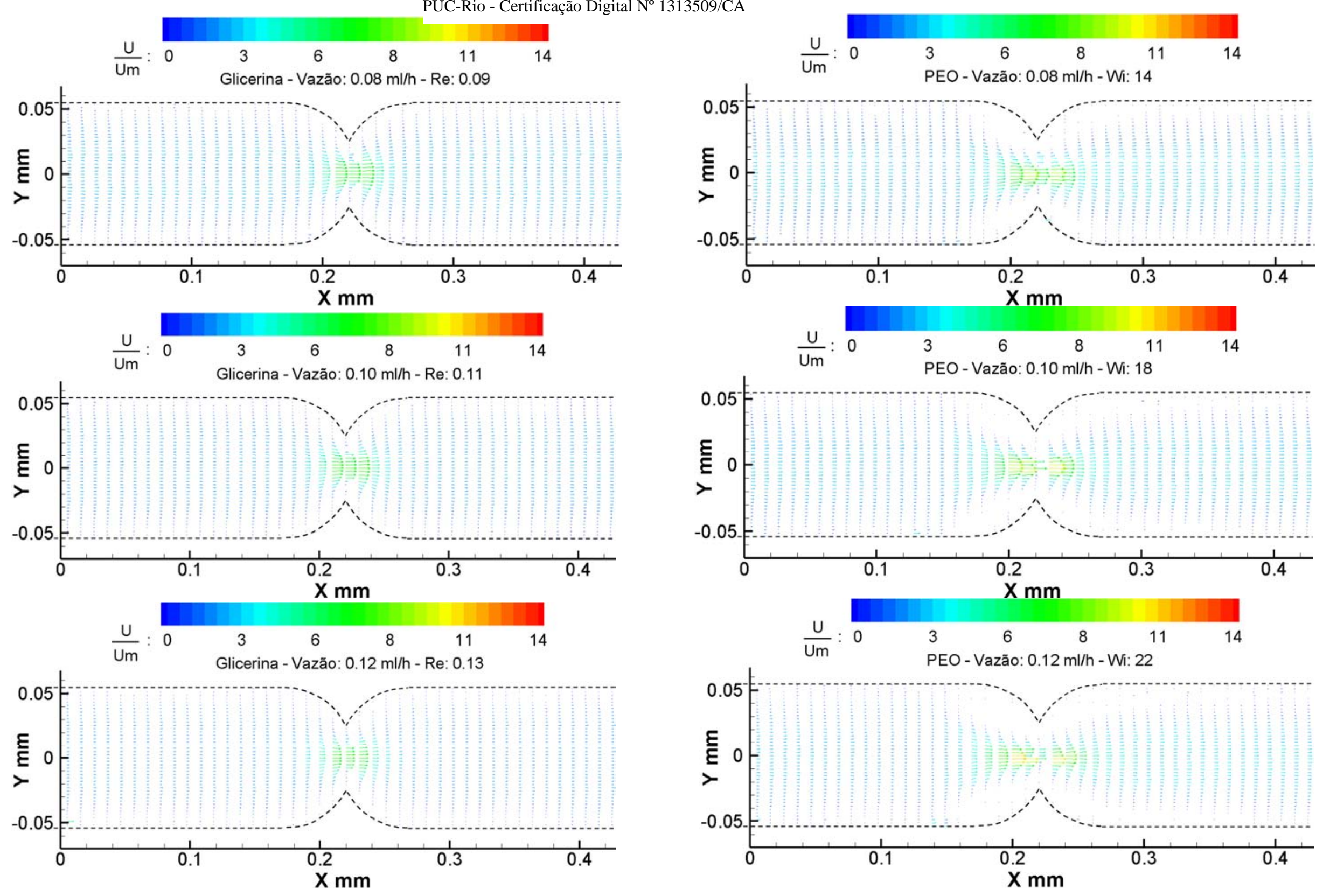

Figura 116 - Campo vetorial de velocidade média normalizado para a solução de glicerina e $P E O$ às vazões de injeção de $Q=0,08 \mathrm{ml} / \mathrm{h}, Q=0,10 \mathrm{ml} / \mathrm{h}$ e $Q=0,12 \mathrm{ml} / \mathrm{h}$ 
PUC-Rio - Certificação Digital N 1313509/CA
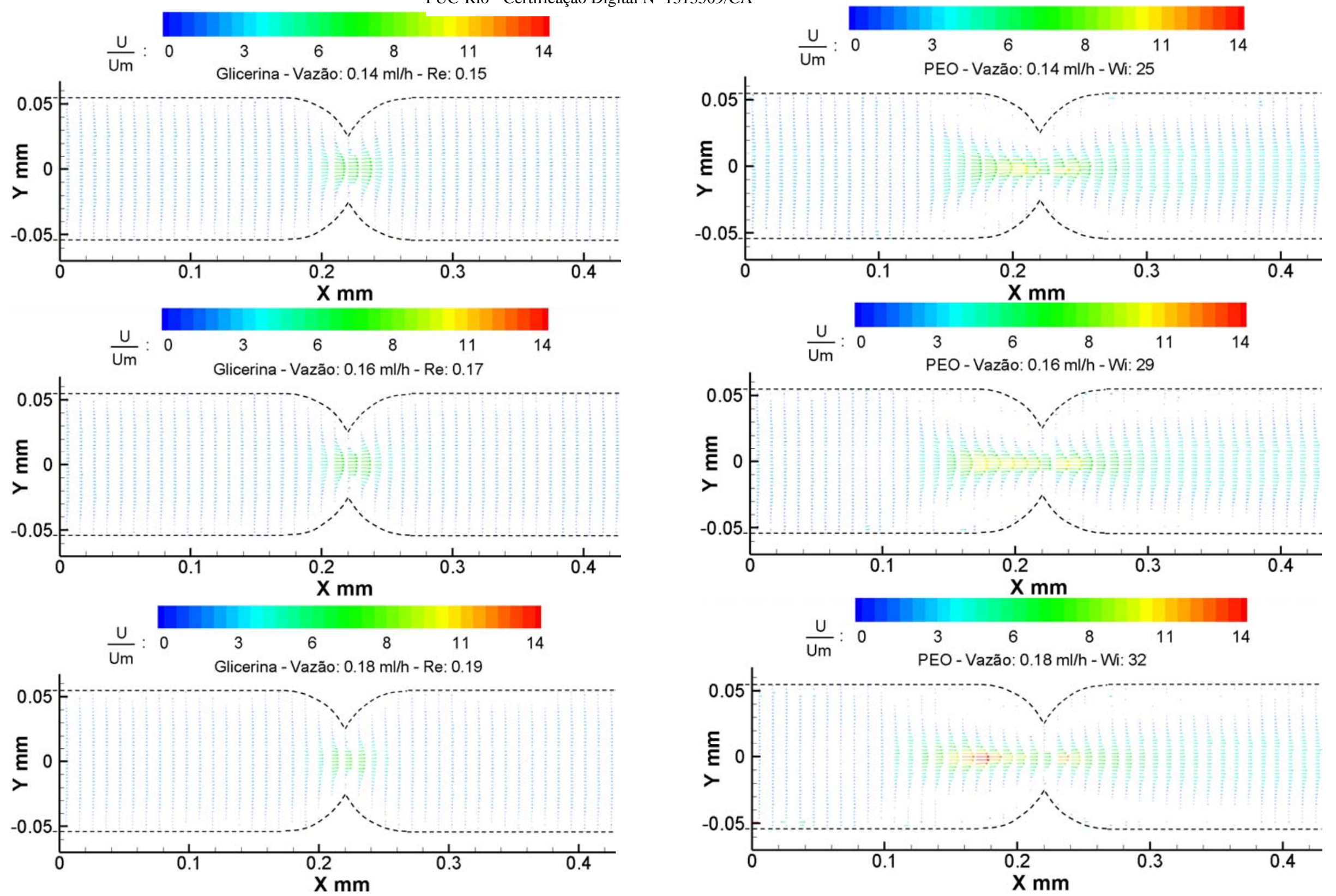

Figura 117 - Campo vetorial de velocidade média normalizado para a solução de glicerina e $P E O$ às vazões de injeção de $Q=0,14 \mathrm{ml} / \mathrm{h}, Q=0,16 \mathrm{ml} / \mathrm{h}$ e $Q=0,18 \mathrm{ml} / \mathrm{h}$ 
PUC-Rio - Certificação Digital No 1313509/CA
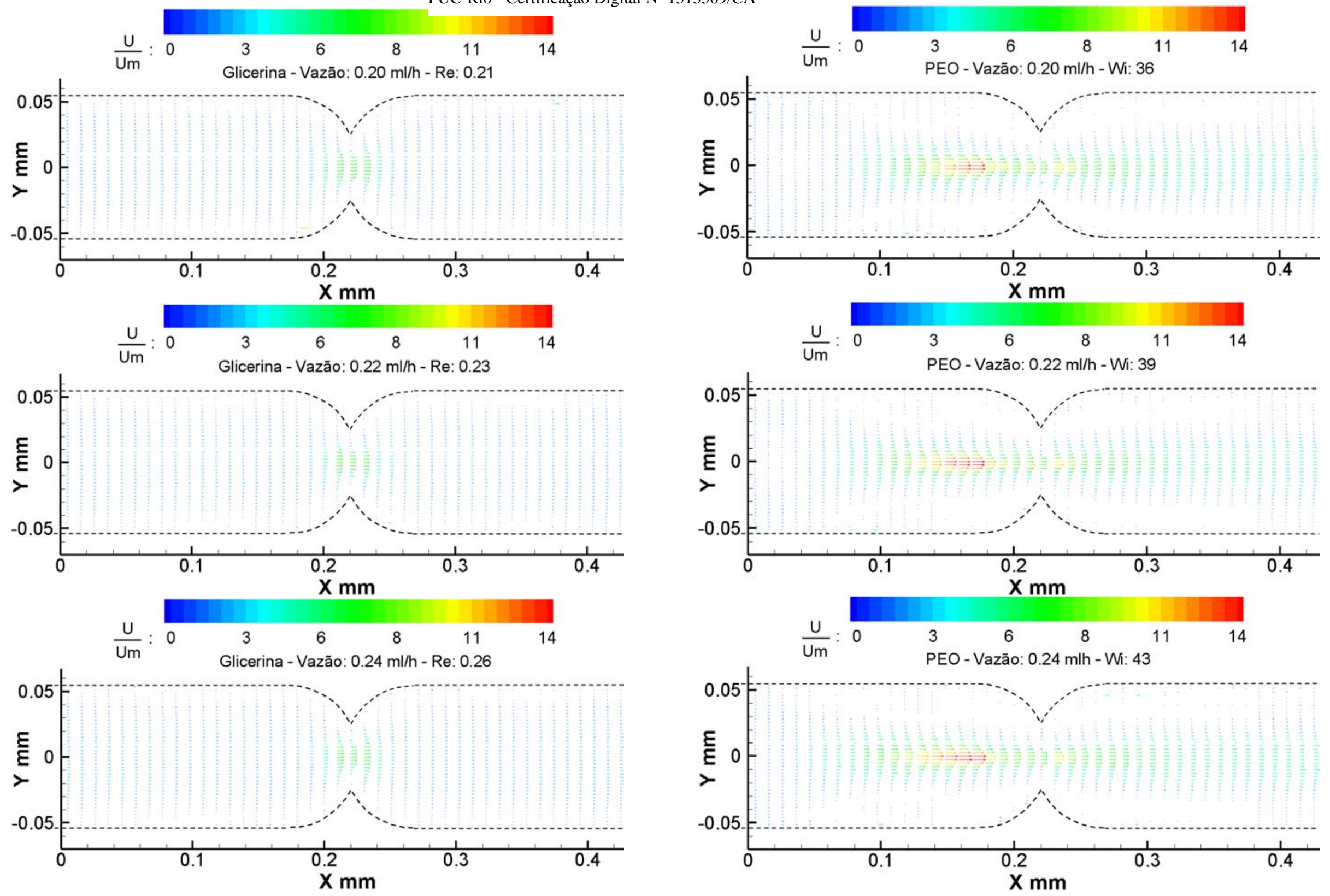

Figura 118 - Campo vetorial de velocidade média normalizado para a solução de glicerina e $P E O$ às vazões de injeção de $Q=0,20 \mathrm{ml} / \mathrm{h}, Q=0,22 \mathrm{ml} / \mathrm{h}$ e $Q=0,24 \mathrm{ml} / \mathrm{h}$ 

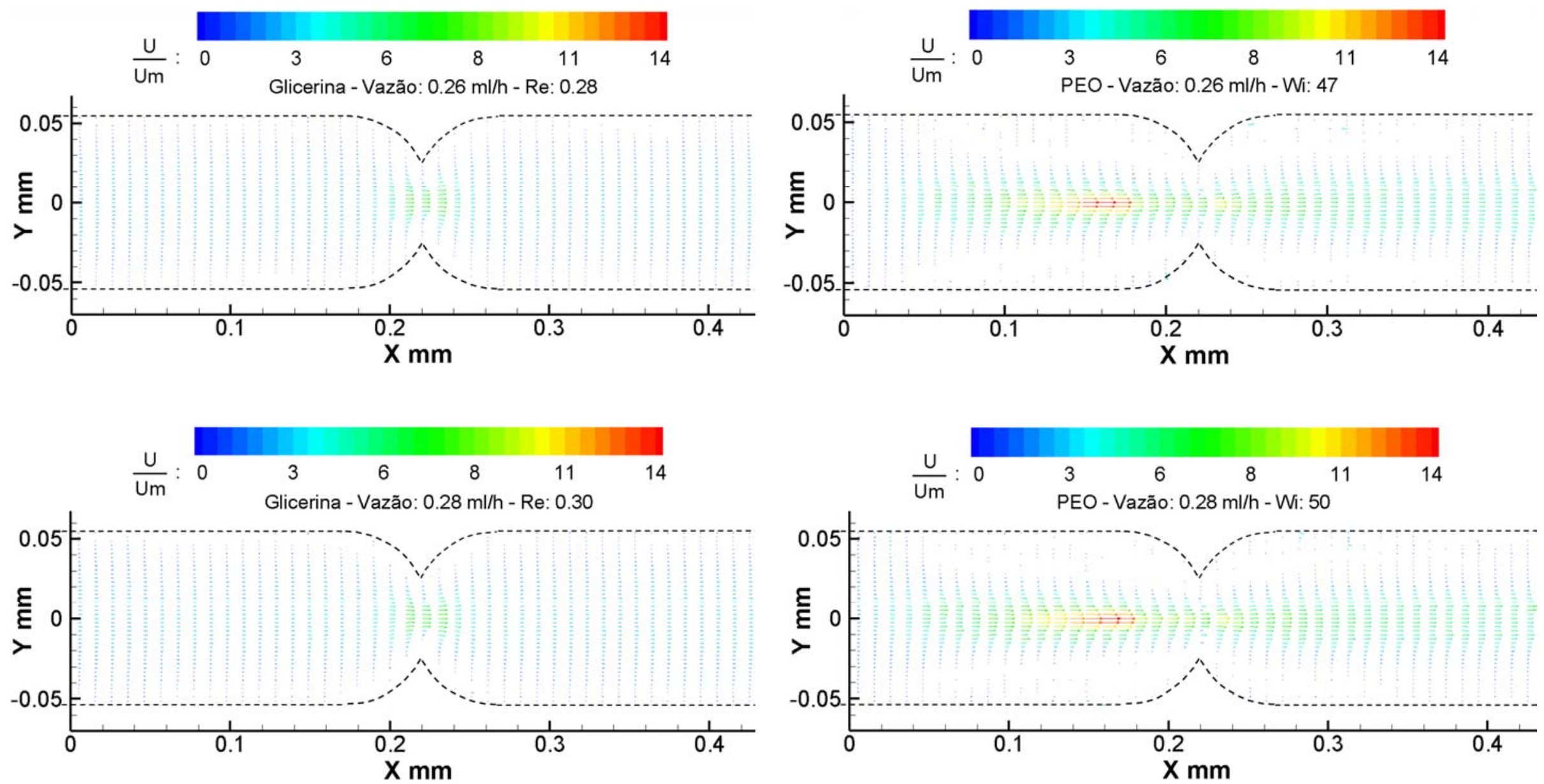

Figura 119 - Campo vetorial de velocidade média normalizado para a solução de glicerina e $P E O$ às vazões de injeção de $Q=0,26 \mathrm{ml} / \mathrm{h}$ e $Q=0,28 \mathrm{ml} / \mathrm{h}$ 

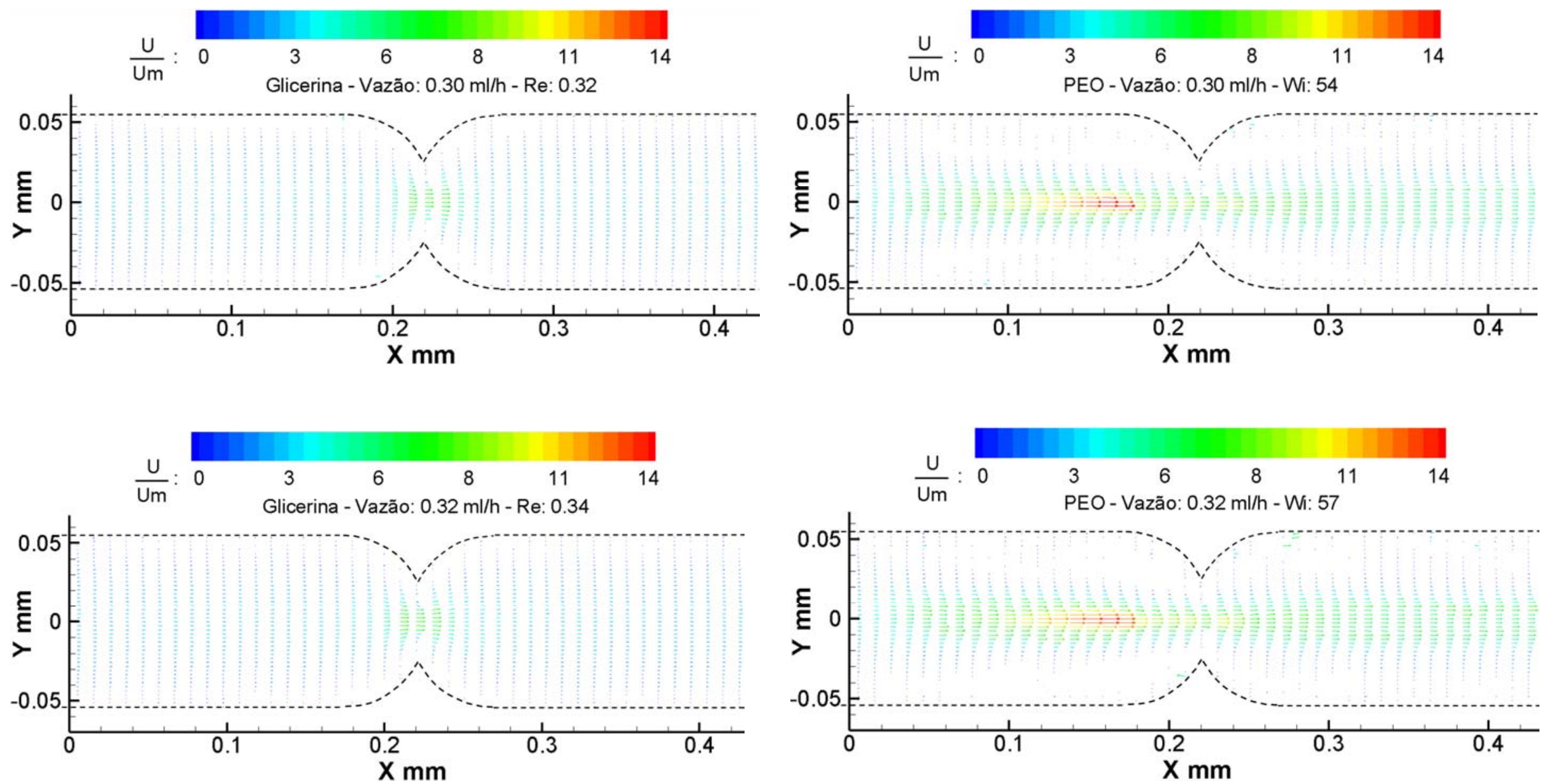

Figura 120 - Campo vetorial de velocidade média normalizado para a solução de glicerina e $P E O$ às vazões de injeção de $Q=0,30 \mathrm{ml} / \mathrm{h}$ e $Q=0,32 \mathrm{ml} / \mathrm{h}$ 
O escoamento da solução de glicerina é simétrico em relação ao plano da garganta, sem a presença de recirculações. Como discutido anteriormente, o escoamento Newtoniano para baixos número de Reynolds é simétrico, com efeitos inerciais desprezíveis. O valor do número de Reynolds máximo foi de $R e=0,34$.

Para vazões $Q>0,06 \mathrm{ml} / \mathrm{h}$, os campos vetoriais de velocidade média normalizados dos escoamentos à mesma vazão começaram a ter diferencias significativas entre eles.

Inicialmente em condições de fluxo crítico $0,06<Q_{c r i t}<0,08$, o campo de velocidade média normalizado da solução de PEO mostrou um incremento de velocidade na região central da constrição maior do que observado com a solução de glicerina, mostrando que o escoamento da solução de PEO começa a ser transiente.

À medida que a vazão foi aumentada, o escoamento da solução de PEO apresentou vórtices à montante e à jusante da garganta. Maiores gradientes de velocidade no escoamento da solução de PEO foram encontrados quando comparado com o escoamento da solução de glicerina. Essas evidências mostraram que o escoamento de PEO resultou transiente. À vazão máxima de $Q=0,32 \mathrm{ml} / \mathrm{h}$, a velocidade média máxima adimensional encontrada no escoamento da solução de PEO foi aproximadamente 5 vezes do que obtida no escoamento da glicerina. Essas evidências confirmaram que as forças elásticas se tornaram dominantes sobre as forças viscosas no escoamento da solução de PEO (comportamento não Newtoniano) acima de um valor crítico do número de Weissenberg $\left(11<W i_{c r i t}<14\right)$.

A figura 121 apresenta dois perfis de velocidade localizados antes e depois da constrição (separados à mesma distância) para diferentes vazões de injeção para a solução de glicerina e PEO. 

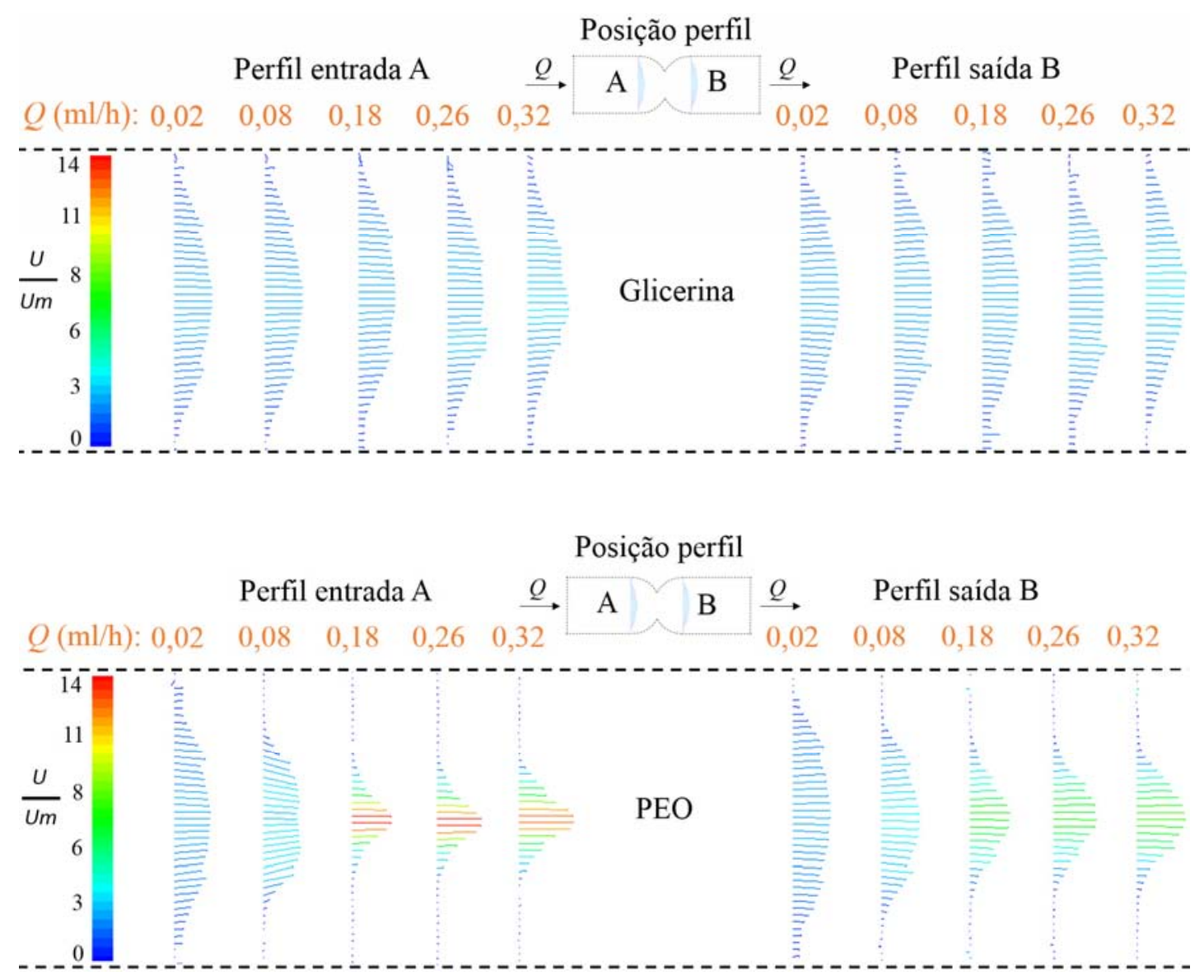

Figura 121 - Perfil de velocidade média adimensional do escoamento da solução de glicerina e PEO em duas posições para diferentes vazões de injeção

Para a solução de glicerina, os perfis de velocidade antes e depois da garganta a uma mesma vazão de injeção foram similares, indicando a simetria do escoamento. Todos os perfis de velocidade apresentaram uma forma parabólica, evidência que os efeitos inercias são desprezíveis na faixa de vazão estudada. $\mathrm{O}$ número de Reynolds máximo do escoamento da solução de glicerina foi de $R e=0,34$.

Entretanto, para a solução de PEO, os perfis de velocidade mostraram uma mudança significativa na sua forma, conforme a vazão foi aumentada.

Na vazão $Q=0,02 \mathrm{ml} / \mathrm{h}(W i=4)$, os perfis de velocidade são similares aos mostrados no escoamento da solução de glicerina, indicação que os efeitos viscosos ainda são dominantes no escoamento.

Para vazões $Q>0,6 \mathrm{ml} / \mathrm{h}(W i>11)$, o escoamento começa a sofrer os efeitos devido à elasticidade do polímero e a presença de regiões de recirculação. O perfil 
de entrada apresenta uma forma de jato com a presença de vórtices próximo às paredes. O perfil de saída mostra uma clara evidência que as cadeias poliméricas não recuperaram ainda sua configuração original.

Devido à presença de vórtices encontrados em todos os campos de velocidade média da solução de PEO avaliados, campos de velocidade média para menor vazões de injeção foram determinados com a finalidade de encontrar o início de formação de vórtices no escoamento da solução polimérica de PEO.

Nas figuras 122, 123, 124 e 125 (campo vetorial superior) são apresentados os campos de velocidade média normalizados do escoamento da solução de PEO para a faixa de vazões $0,003 \mathrm{ml} / \mathrm{h} \leq Q \leq 0,01 \mathrm{ml} / \mathrm{h}$ mostrando os perfis de velocidade. As figuras 122, 123, 124 e 125 (campo vetorial inferior) são apresentados os campos de velocidade média apenas na região do escoamento localizado na parte inferior da constrição, com uma resolução espacial de 8x8 pixels para ter uma melhor visualização do início de formação de vórtices em sacrifício do escoamento principal. 

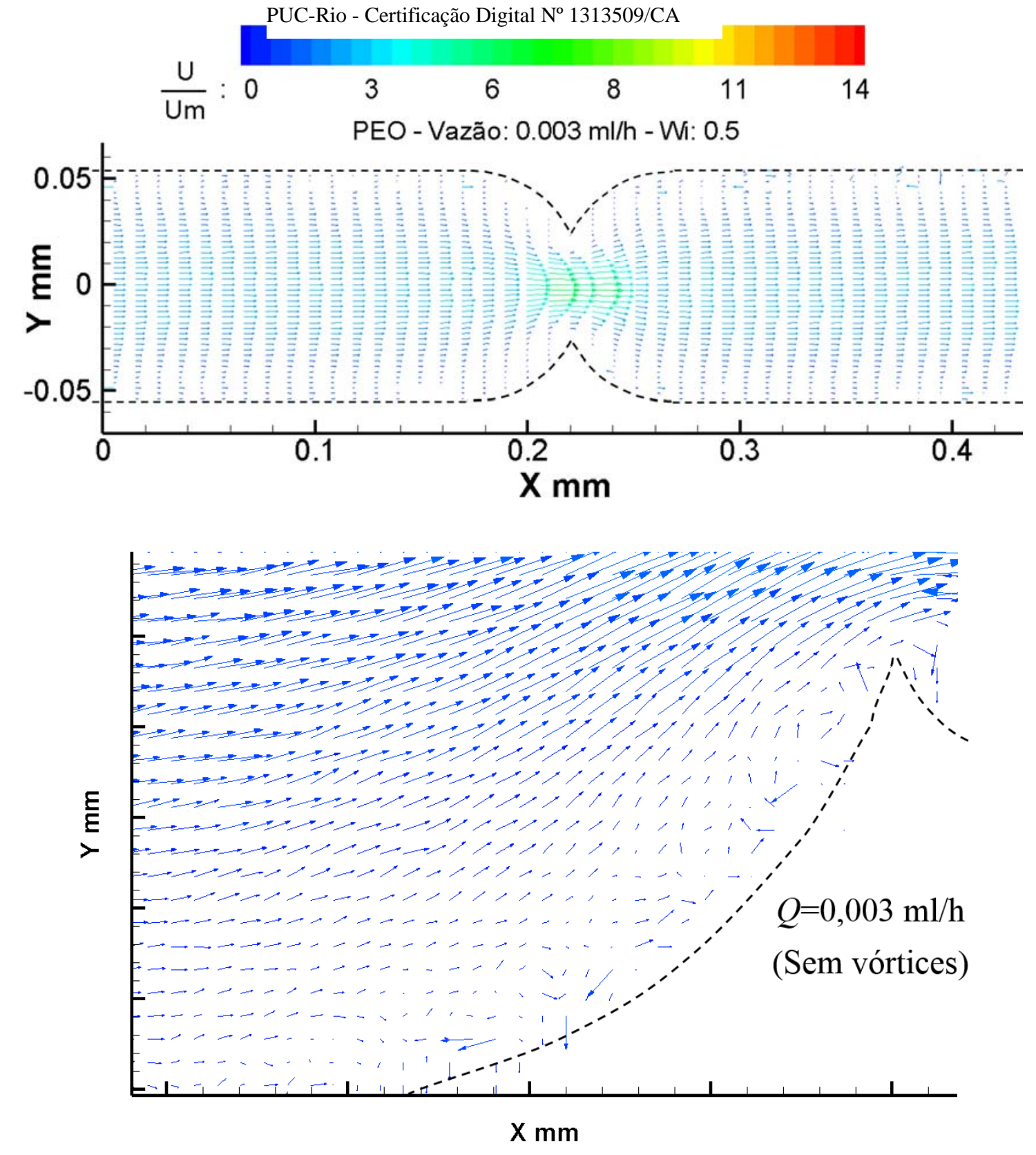

Figura 122 - Campo vetorial de velocidade da região total (imagem superior) e da região inferior da constrição (imagem inferior) do escoamento da solução de PEO para a vazão de $Q=0,003 \mathrm{ml} / \mathrm{h}$ 


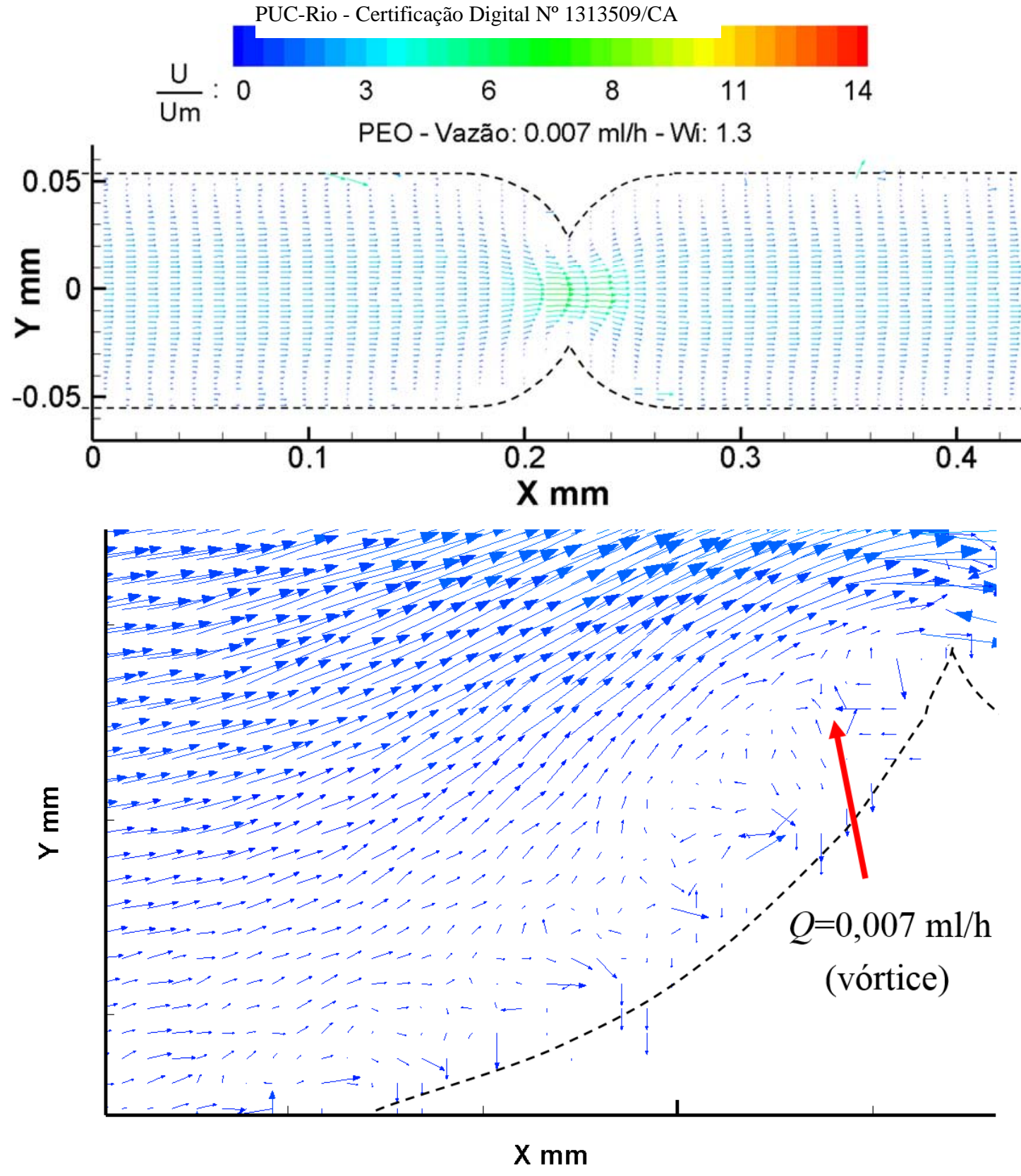

Figura 123 - Campo vetorial de velocidade da região total (imagem superior) e da região inferior da constrição (imagem inferior) do escoamento da solução de PEO para a vazão de $Q=0,007 \mathrm{ml} / \mathrm{h}$ 

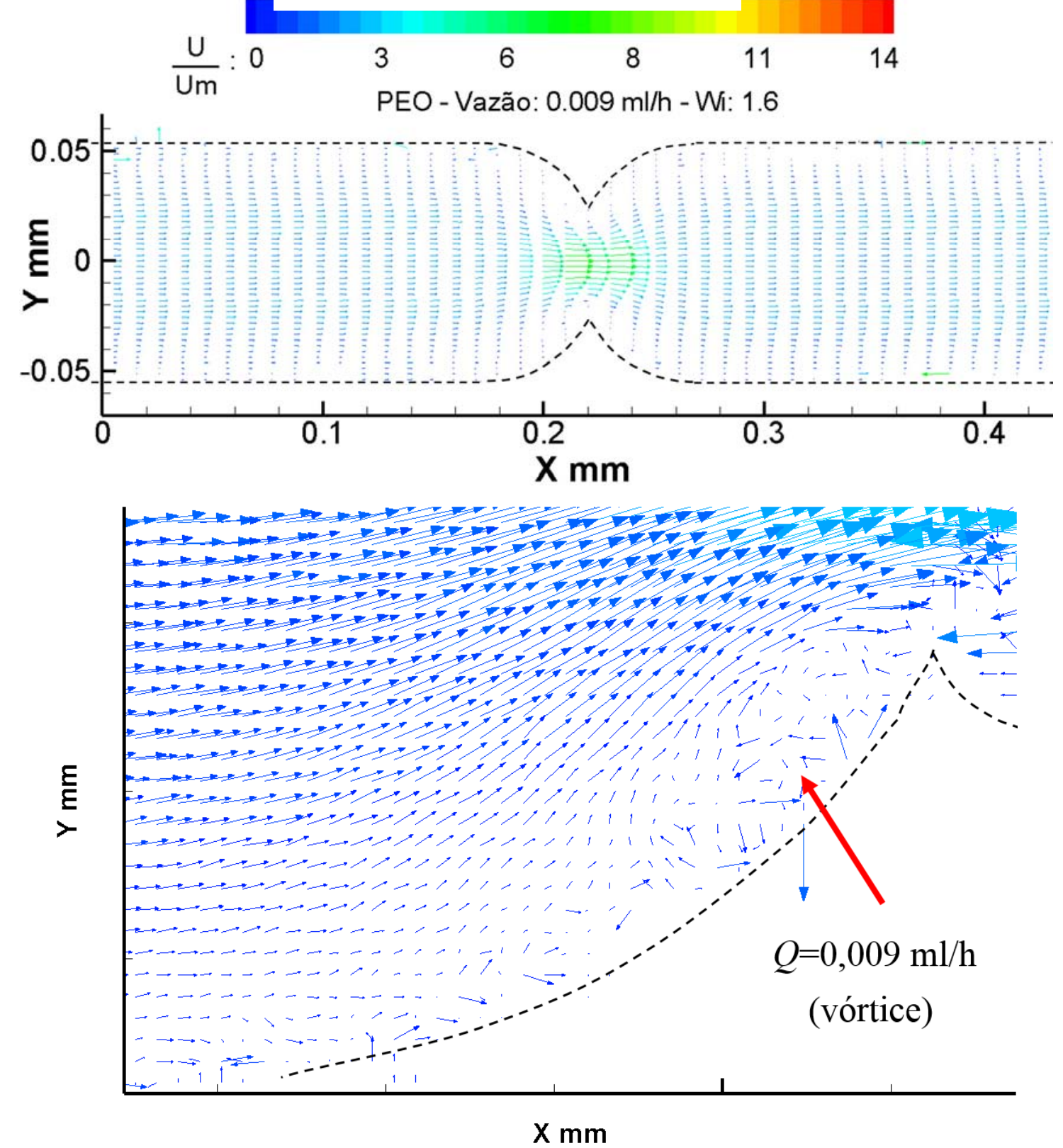

Figura 124 - Campo vetorial de velocidade da região total (imagem superior) e da região inferior da constrição (imagem inferior) do escoamento da solução de PEO para a vazão de $Q=0,009 \mathrm{ml} / \mathrm{h}$ 

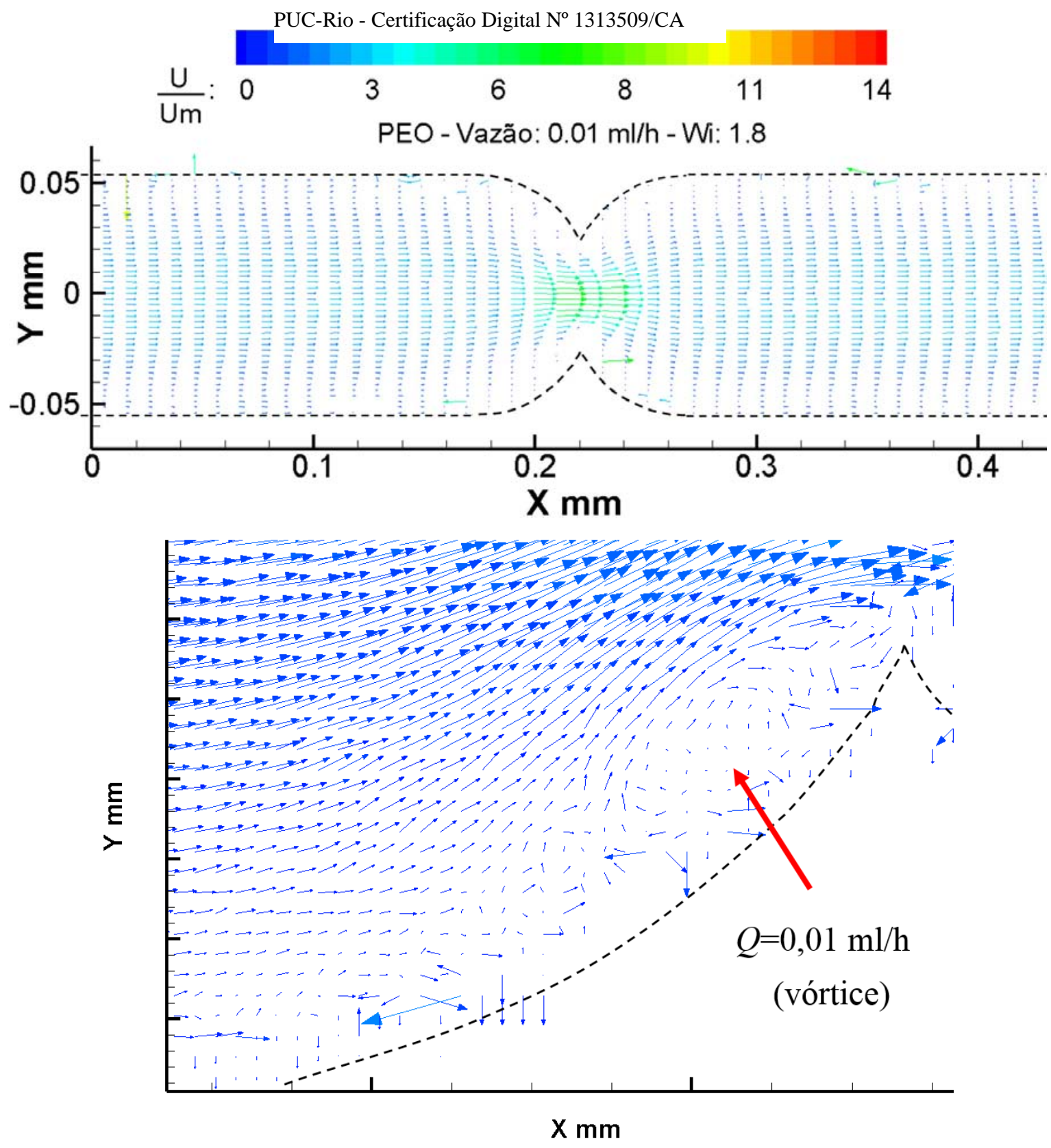

Figura 125 - Campo vetorial de velocidade da região total (imagem superior) e da região inferior da constrição (imagem inferior) do escoamento da solução de $P E O$ para a vazão de $Q=0,01 \mathrm{ml} / \mathrm{h}$ 
Todos os campos vetoriais de velocidade média foram bastante similares, nenhuma evidência de instabilidade no escoamento global. É possível observar a formação de vórtices na contração a partir da vazão $Q=0,007 \mathrm{ml} / \mathrm{h}$. $\mathrm{O}$ início dos efeitos elásticos no escoamento é apenas local através de formação de recirculações, porque as medidas da queda de pressão global ainda não são afetadas. É importante ressaltar que os vetores espúrios perto das paredes são devido à falta de precisão da localização das paredes do canal na imagem e a baixa densidade de partículas.

As figuras 126, 127, 128, 129, 130 e 131 apresentam o módulo de velocidade com linhas de corrente do escoamento da solução de glicerina e solução de PEO para a faixa de vazões $0,02 \mathrm{ml} / \mathrm{h} \leq Q \leq 0,32 \mathrm{ml} / \mathrm{h}$. 
PUC-Rio - Certificação Digital N 1313509/CA
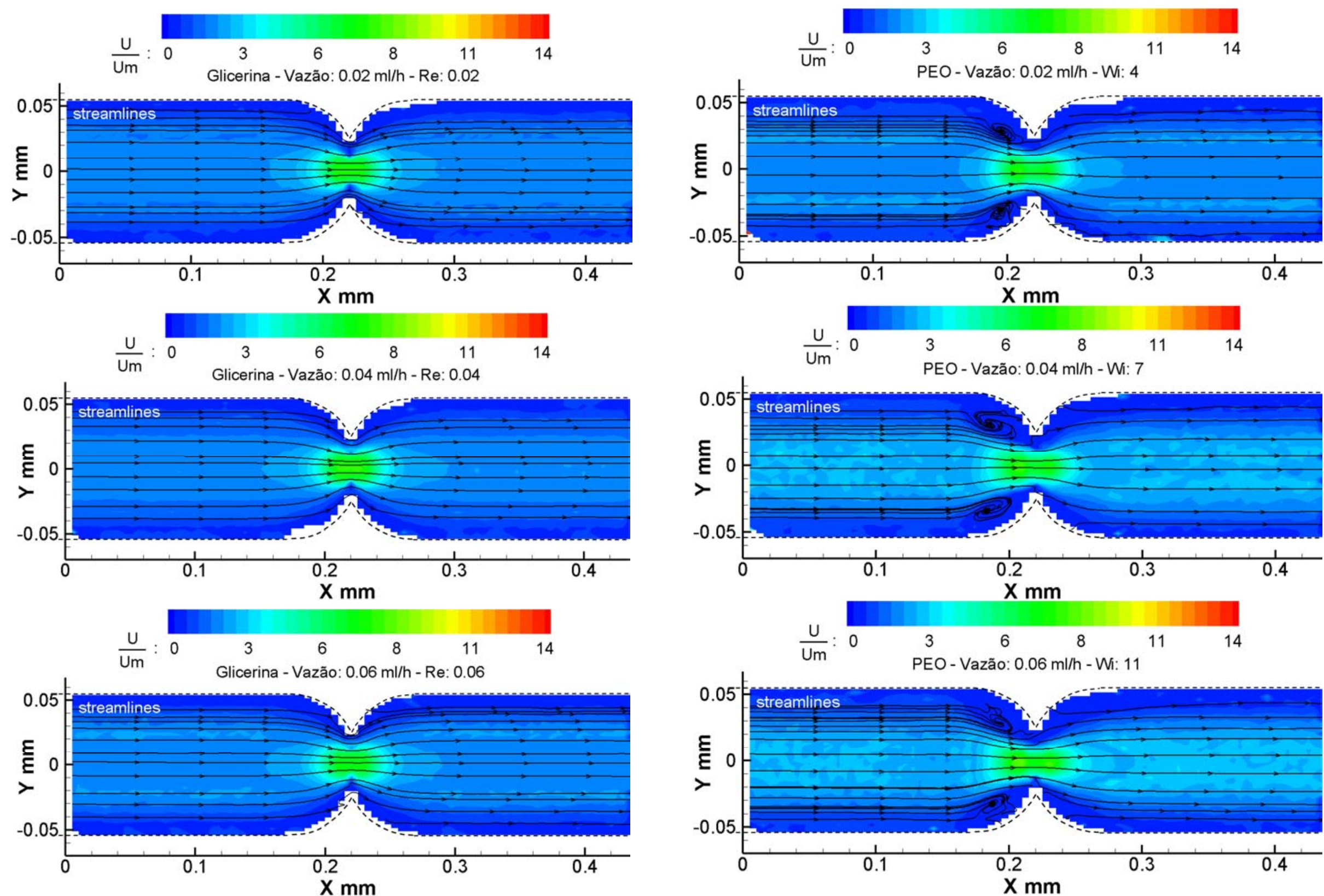

Figura 126 - Campo do módulo de velocidade média com linhas de corrente para a solução de glicerina e PEO às vazões de injeção $Q=0,02 \mathrm{ml} / \mathrm{h}, Q=0,04 \mathrm{ml} / \mathrm{h}$ e $Q=0,06 \mathrm{ml} / \mathrm{h}$ 
PUC-Rio - Certificação Digital No 1313509/CA
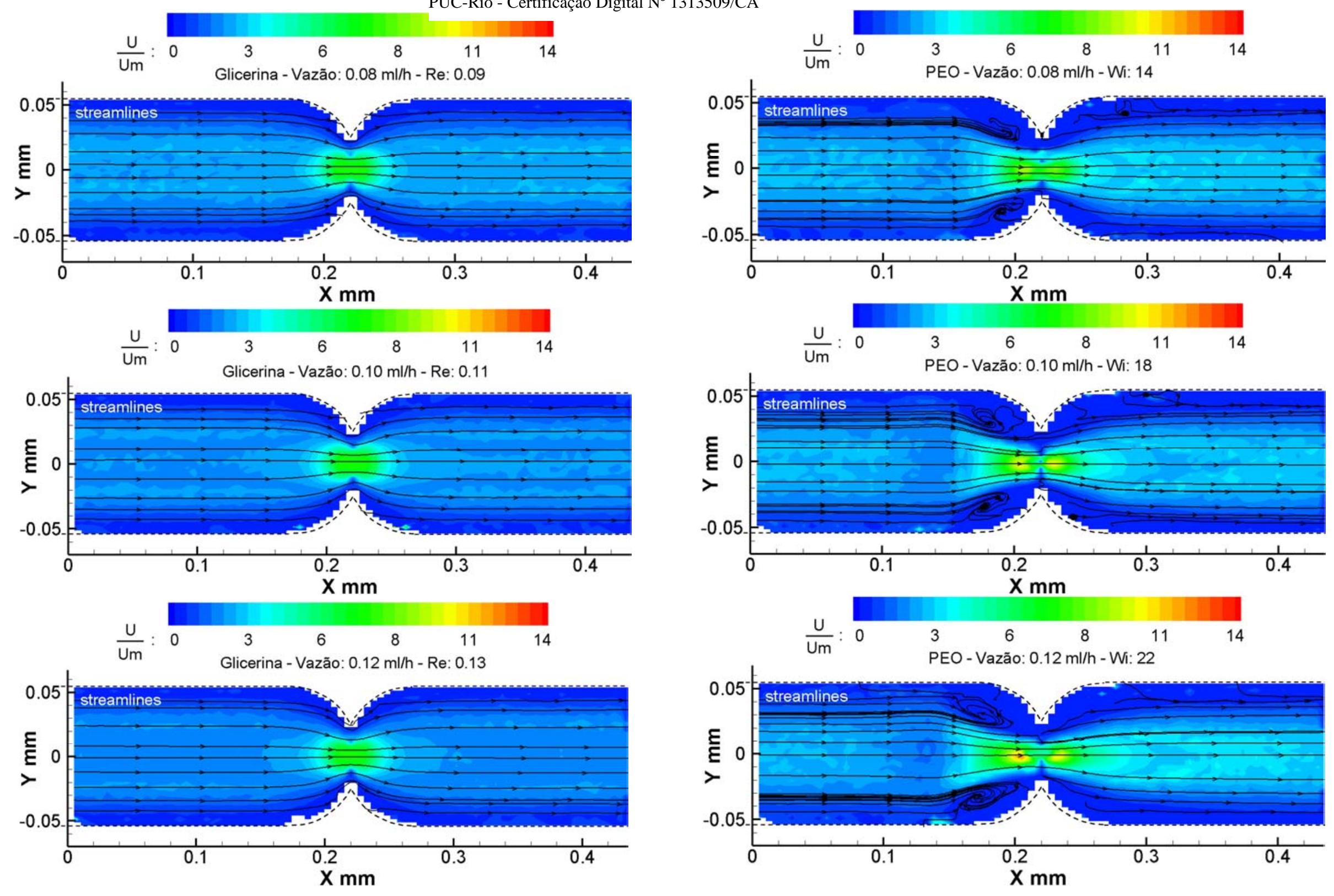

Figura 127 - Campo do módulo de velocidade média com linhas de corrente para a solução de glicerina e PEO às vazões de injeção $Q=0,08 \mathrm{ml} / \mathrm{h}, Q=0,10 \mathrm{ml} / \mathrm{h}$ e $Q=0,12 \mathrm{ml} / \mathrm{h}$ 
PUC-Rio - Certificação Digital No 1313509/CA
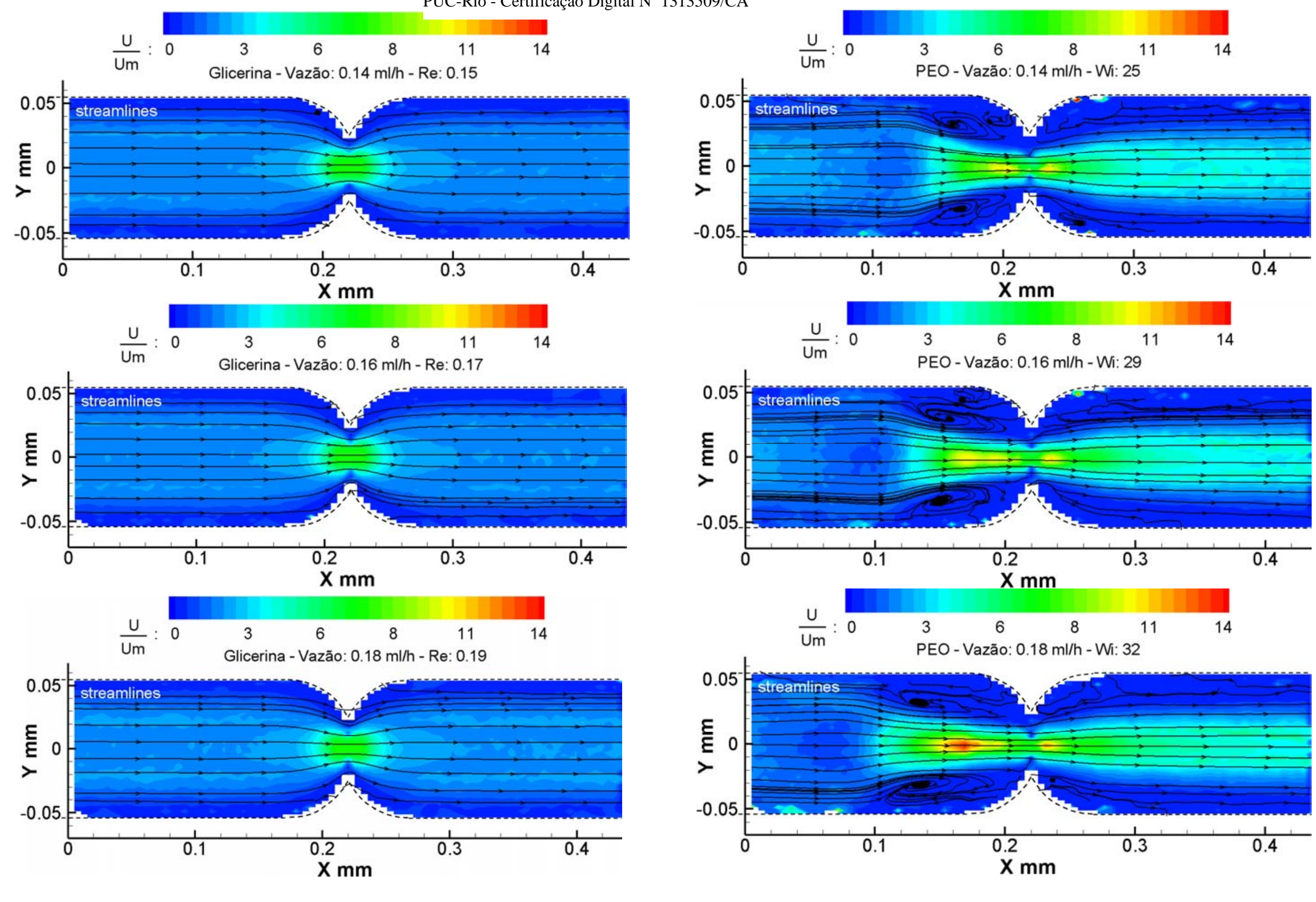

Figura 128 - Campo do módulo de velocidade média com linhas de corrente para a solução de glicerina e PEO às vazões de injeção $Q=0,14 \mathrm{ml} / \mathrm{h}, Q=0,16 \mathrm{ml} / \mathrm{h}$ e $Q=0,18 \mathrm{ml} / \mathrm{h}$ 
PUC-Rio - Certificação Digital No 1313509/CA

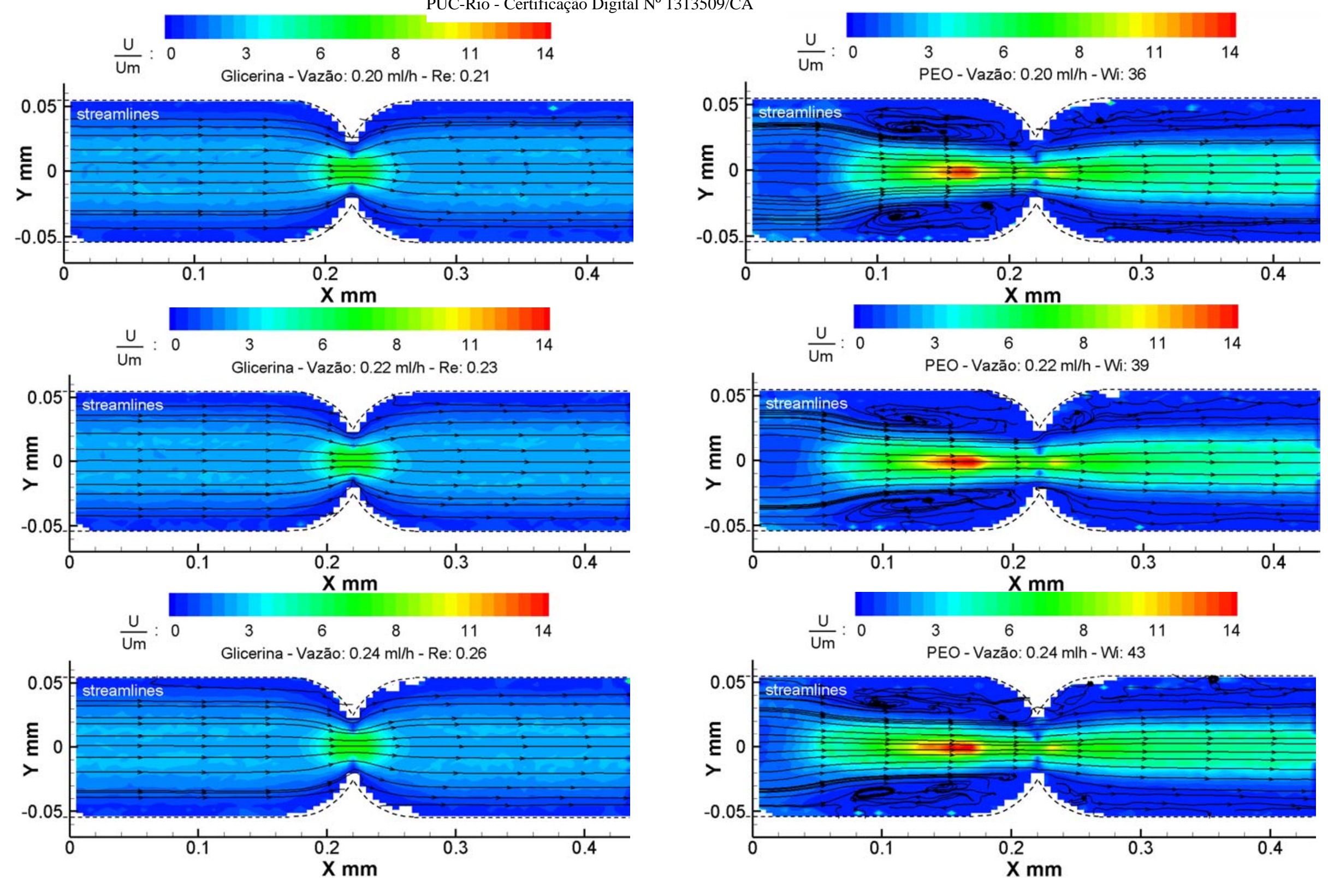

Figura 129 - Campo do módulo de velocidade média com linhas de corrente para a solução de glicerina e PEO às vazões de injeção $Q=0,20 \mathrm{ml} / \mathrm{h}, Q=0,22 \mathrm{ml} / \mathrm{h}$ e $Q=0,24 \mathrm{ml} / \mathrm{h}$ 

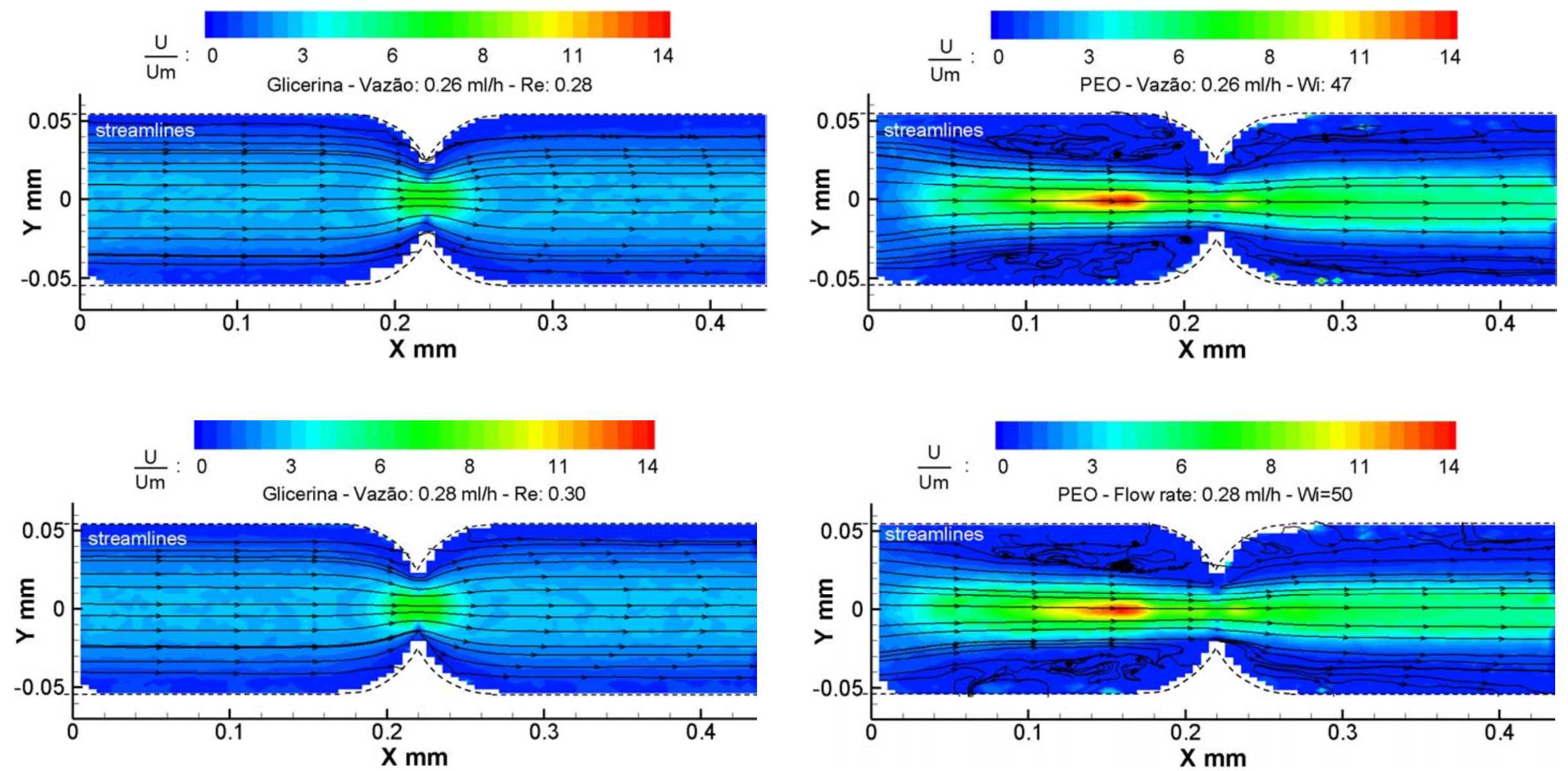

Figura 130 - Campo do módulo de velocidade média com linhas de corrente para a solução de glicerina e PEO às vazões de injeção $Q=0,26 \mathrm{ml} / \mathrm{h}$ e $Q=0,28 \mathrm{ml} / \mathrm{h}$ 

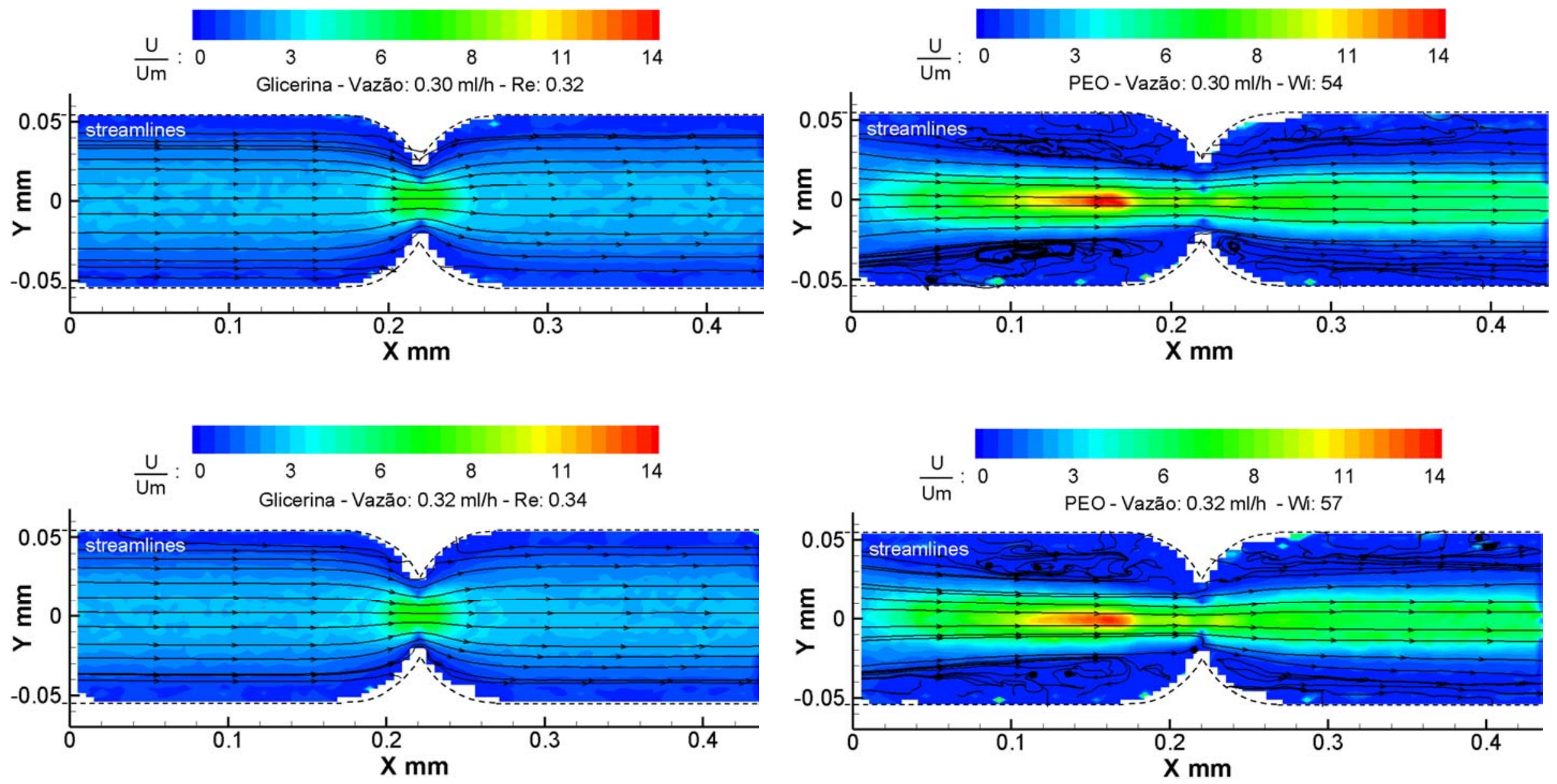

Figura 131 - Campo do módulo de velocidade média com linhas de corrente para a solução de glicerina e $P E O$ às vazões de injeção $Q=0,30 \mathrm{ml} / \mathrm{h}$ e $Q=0,32 \mathrm{ml} / \mathrm{h}$ 
Para toda a faixa de vazão explorada, o escoamento de glicerina não apresenta vórtices ou recirculações causadas pelas forças de inércia. Além disso, o escoamento é simétrico em relação à constrição, conforme esperado para um fluido Newtoniano com efeitos inerciais desprezíveis. Entretanto, as linhas de corrente do escoamento da solução de PEO mostraram vórtices de recirculação e a simetria do escoamento é quebrada.

Para vazões entre $0,02 \mathrm{ml} / \mathrm{h} \leq Q \leq 0,06 \mathrm{ml} / \mathrm{h}$, as linhas de corrente do escoamento principal e dos vórtices da solução de PEO são bem definidas e apresentam bastante semelhança com os campos de velocidade do escoamento de glicerina, apenas a única diferença é a presença de pequenos vórtices. A presença de vórtices (escoamentos giratórios) na constrição é devido ao aumento local da viscosidade da solução de PEO na região central da constrição pela elasticidade das cadeias do polímero, embora as tensões elásticas ainda sejam pequenas nesta faixa de vazão.

Para vazões $Q>0,06 \mathrm{ml} / \mathrm{h}$, as linhas de corrente do escoamento principal e o tamanho de crescimento dos vórtices da solução de PEO não são claramente definidos, sobretudo para maiores vazões. As linhas de corrente nos vórtices e no escoamento principal perto das paredes à jusante da constrição mostraram a sobreposição de caminhos de partículas (linhas de corrente cruzando-se), evidência que a estrutura tridimensional do escoamento está sendo afetada pelas forças elásticas que passaram a ser dominantes no escoamento.

É observado também através do campo do módulo de velocidade, o escoamento extensional se deslocar em direção à montante da garganta, aumentando em magnitude, devido à extensão das cadeias do polímero. O padrão do escoamento se assemelha a um jato, apesar das forças inerciais serem desprezíveis. Esse padrão é bem diferente do padrão de um escoamento Newtoniano (campos de glicerina) e leva a um aumento da queda de pressão global no escoamento. Portanto, a elasticidade da solução do polímero torna-se importante na estrutura do escoamento e a formação com crescimento de vórtices.

Foram determinados também os campos do módulo de velocidade com as linhas de corrente do escoamento da solução de PEO na faixa de vazão de injeção $0,003 \mathrm{ml} / \mathrm{h} \leq Q \leq 0,01 \mathrm{ml} / \mathrm{h}, \quad$ representados nas figuras $132,133,134$ e 135 respectivamente. As linhas de corrente foram geradas a partir dos campos vetoriais de velocidade média determinados anteriormente. 
PUC-Rio - Certificação Digital No 1313509/CA

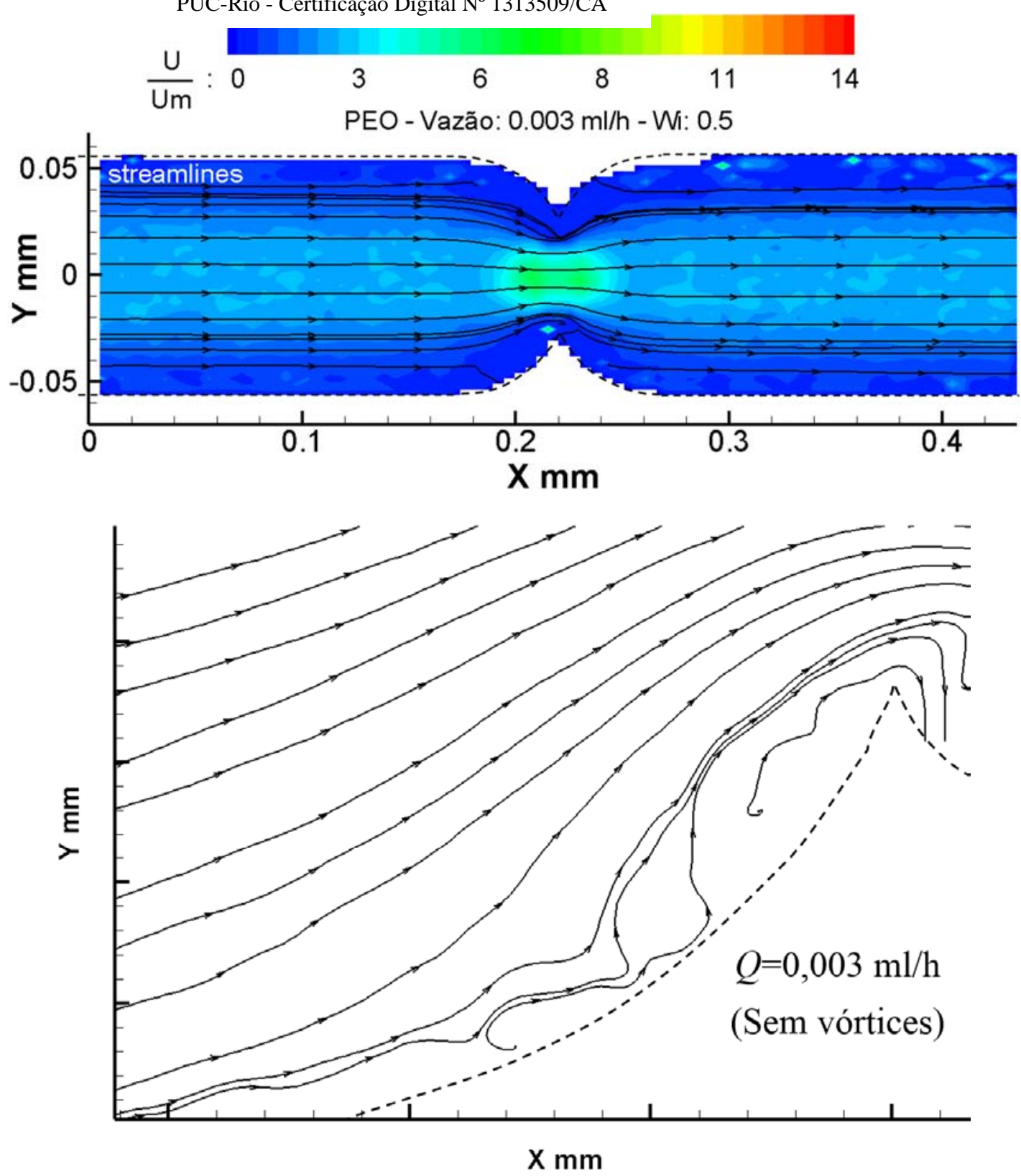

Figura 132 - Campo do módulo de velocidade média da região total (imagem superior) e linhas de corrente na região inferior da constrição (imagem inferior) para o escoamento da solução de PEO à vazão de $Q=0,003 \mathrm{ml} / \mathrm{h}$ 

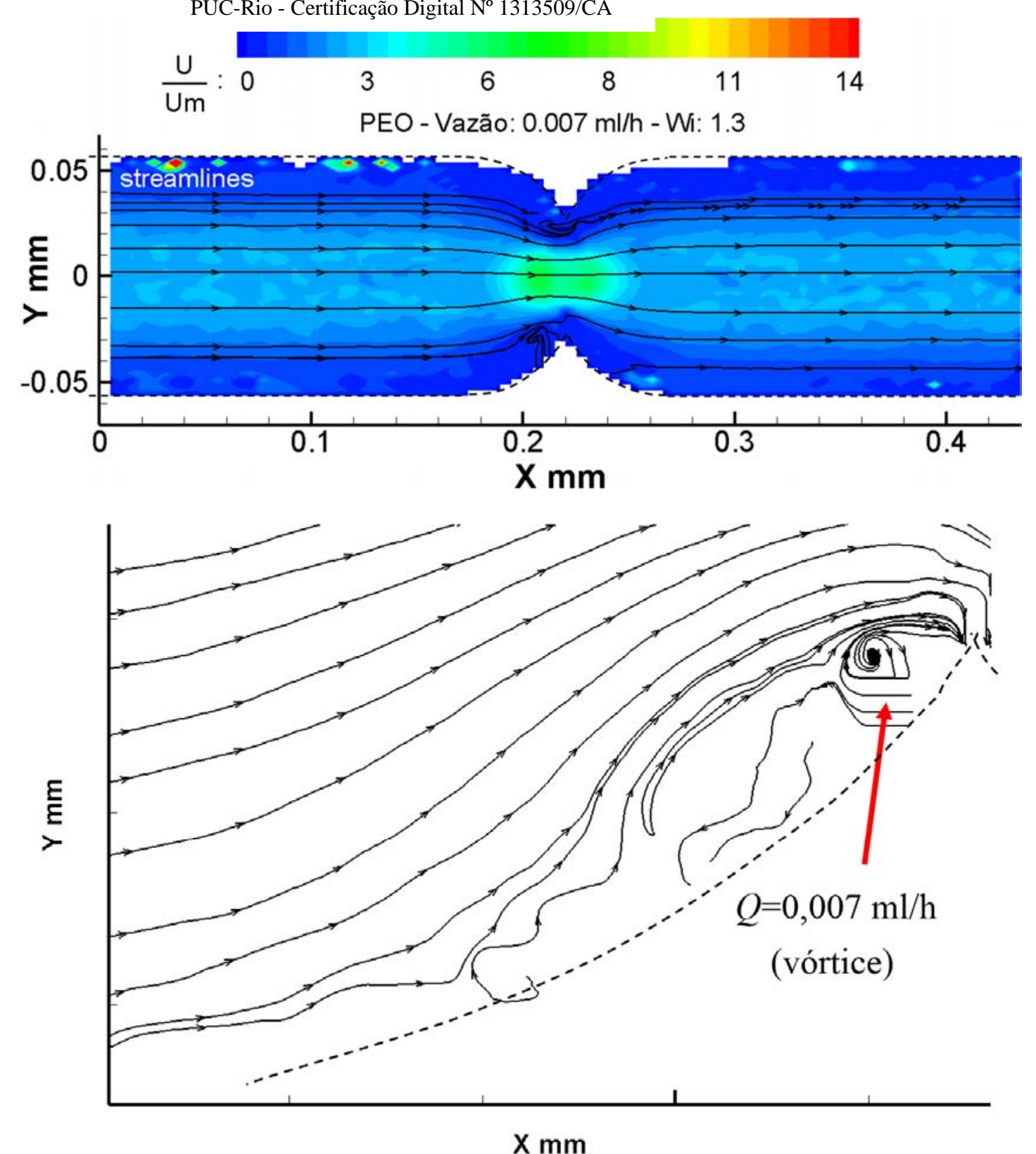

Figura 133 - Campo do modulo de velocidade média da região total (imagem superior) e linhas de corrente na região inferior da constrição (imagem inferior) para o escoamento da solução de PEO à vazão de $Q=0,007 \mathrm{ml} / \mathrm{h}$ 
PUC-Rio - Certificação Digital No 1313509/CA
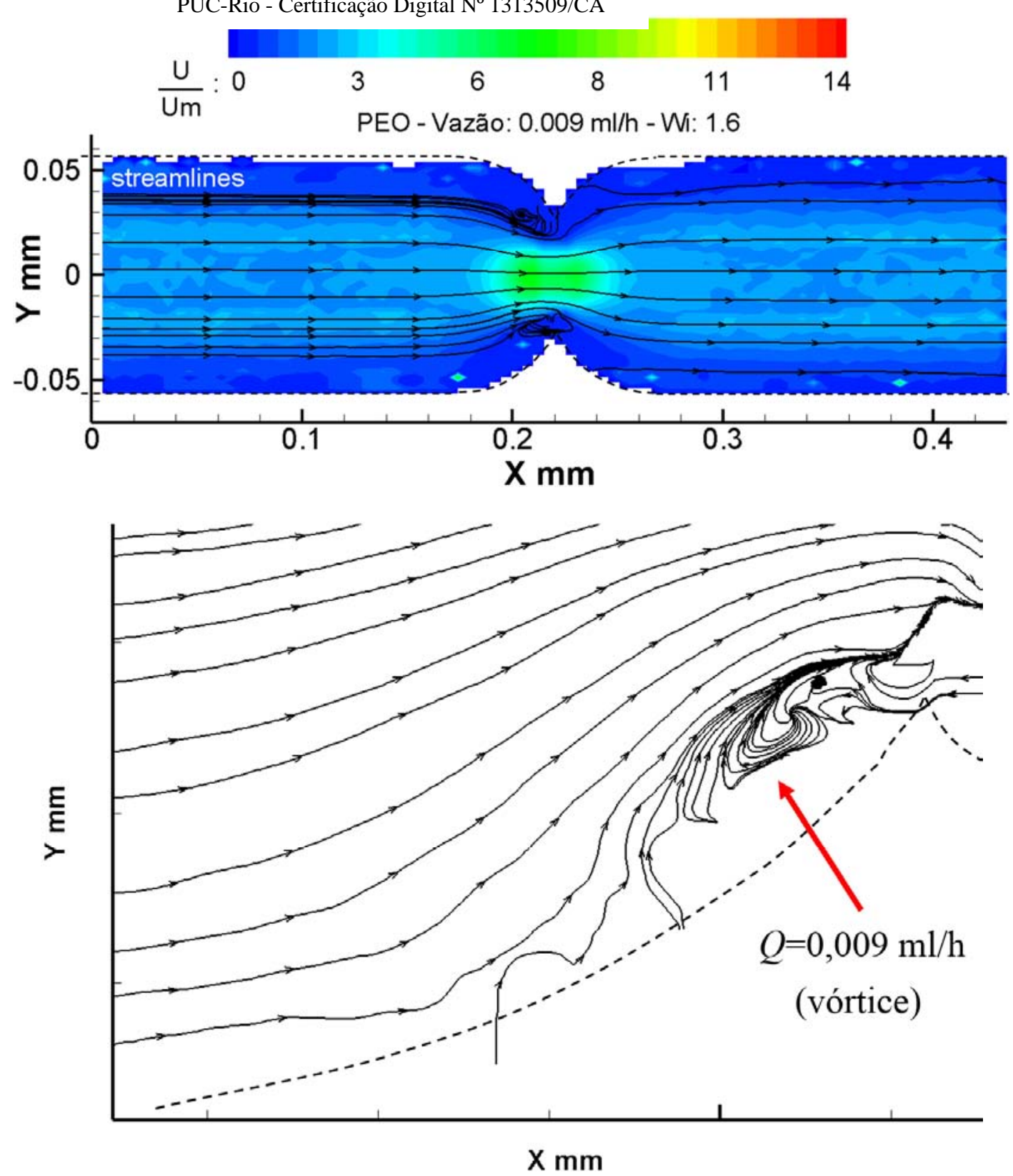

Figura 134 - Campo do módulo de velocidade média da região total (imagem superior) e linhas de corrente na região inferior da constrição (imagem inferior) para o escoamento da solução de $P E O$ à vazão de $Q=0,009 \mathrm{ml} / \mathrm{h}$ 
PUC-Rio - Certificação Digital N 1313509/CA
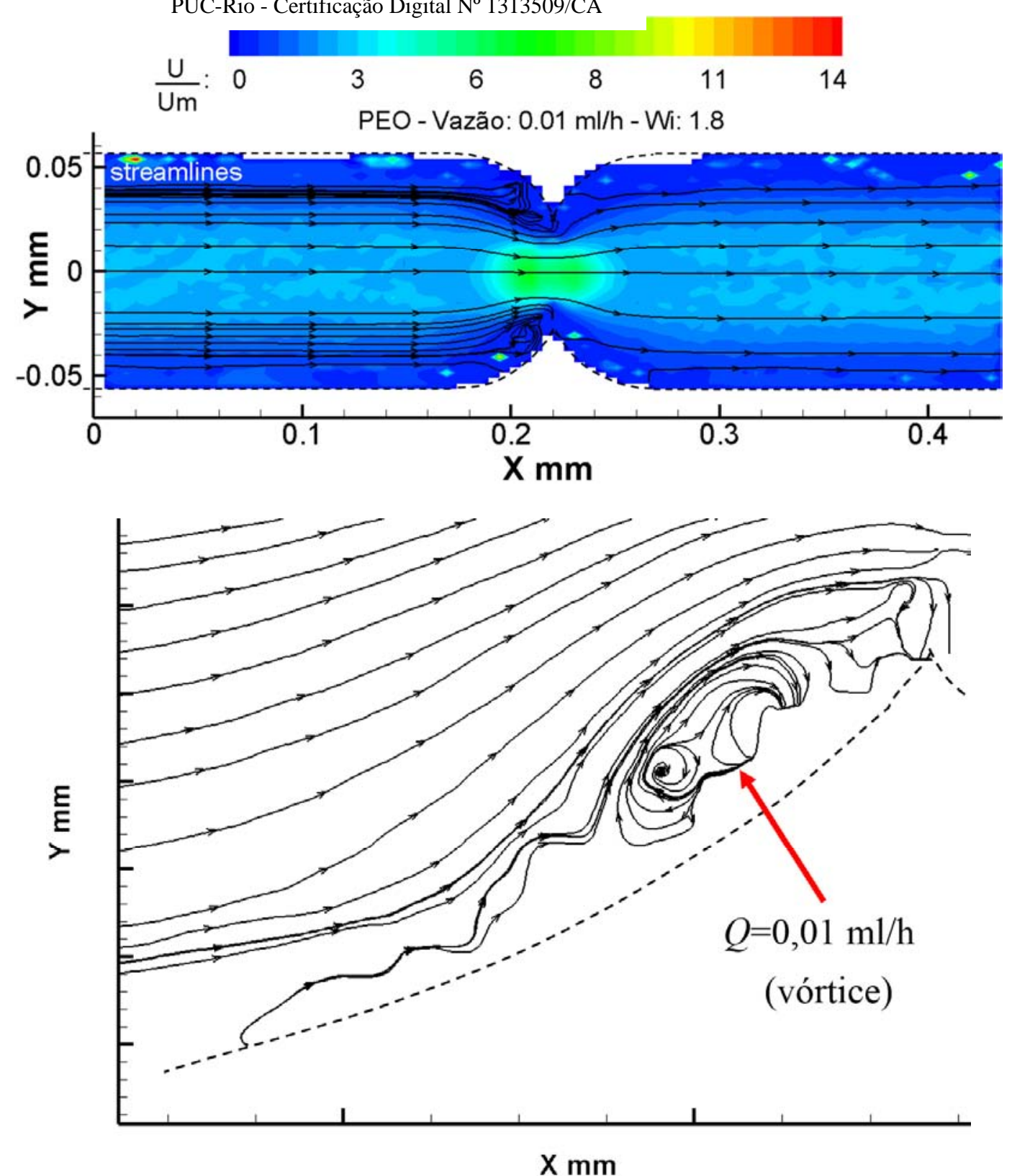

Figura 135 - Campo do modulo de velocidade média da região total (imagem superior) com linhas de corrente na região inferior da constrição (imagem inferior) para o escoamento da solução de $P E O$ à vazão de $Q=0,01 \mathrm{ml} / \mathrm{h}$ 
As linhas de corrente confirmaram a presença de vórtices na região da constrição a partir da vazão de $Q=0,007 \mathrm{ml} / \mathrm{h}$ como foi visualizado através dos campos vetoriais de velocidade, embora não são bem definidas pela baixa resolução espacial e a pouca densidade de partículas nas imagens perto das paredes.

Devido aos diferentes comportamentos do escoamento da solução de PEO observados através dos campos vetoriais de velocidade e as linhas de corrente no tempo médio, os campos de velocidades instantâneos são determinados a fim de analisar o comportamento do escoamento no tempo.

\subsubsection{2.}

\section{Campos de velocidade instantânea}

A fim de observar a evolução do escoamento no tempo, o campo de velocidade instantâneo foi determinado a partir do processamento de um par de imagem (clássico PIV). O tamanho da janela de interrogação de 64x32 pixels (dois vezes maior do que o tamanho da janela utilizado nos campos de velocidade média) foi utilizado com a finalidade de reduzir a sinal de ruído devido à falta de partículas nas imagens. A resolução das medidas foi um vetor para cada 10,24 $\mu \mathrm{m}$ na direção axial do escoamento e um vetor para cada $5,12 \mu \mathrm{m}$ na direção perpendicular do escoamento.

Para cada condição diferente do escoamento (vazão e fluido) foram determinados 500 campos de velocidade instantâneo consecutivos da região da constrição à frequência de 4,8 Hz (0,2 s). Porém, são mostrados apenas três ou quatro campos instantâneos consecutivos na sequência da frequência através de linhas de corrente.

Campos de velocidade instantânea do escoamento de água: As medições dos campos de velocidade instantânea do escoamento de água passando através da constrição foram realizadas com a finalidade de mostrar a estabilidade do escoamento no regime de estudo, mostrando apenas as linhas de corrente. A figura 136 apresenta os campos instantâneos por meio de linhas de corrente em três instantes de tempo consecutivos para a vazão de $Q=0,2 \mathrm{ml} / \mathrm{h}$ (sem presença de vórtices) e $Q=5,0 \mathrm{ml} / \mathrm{h}$ (com presença de vórtices). 

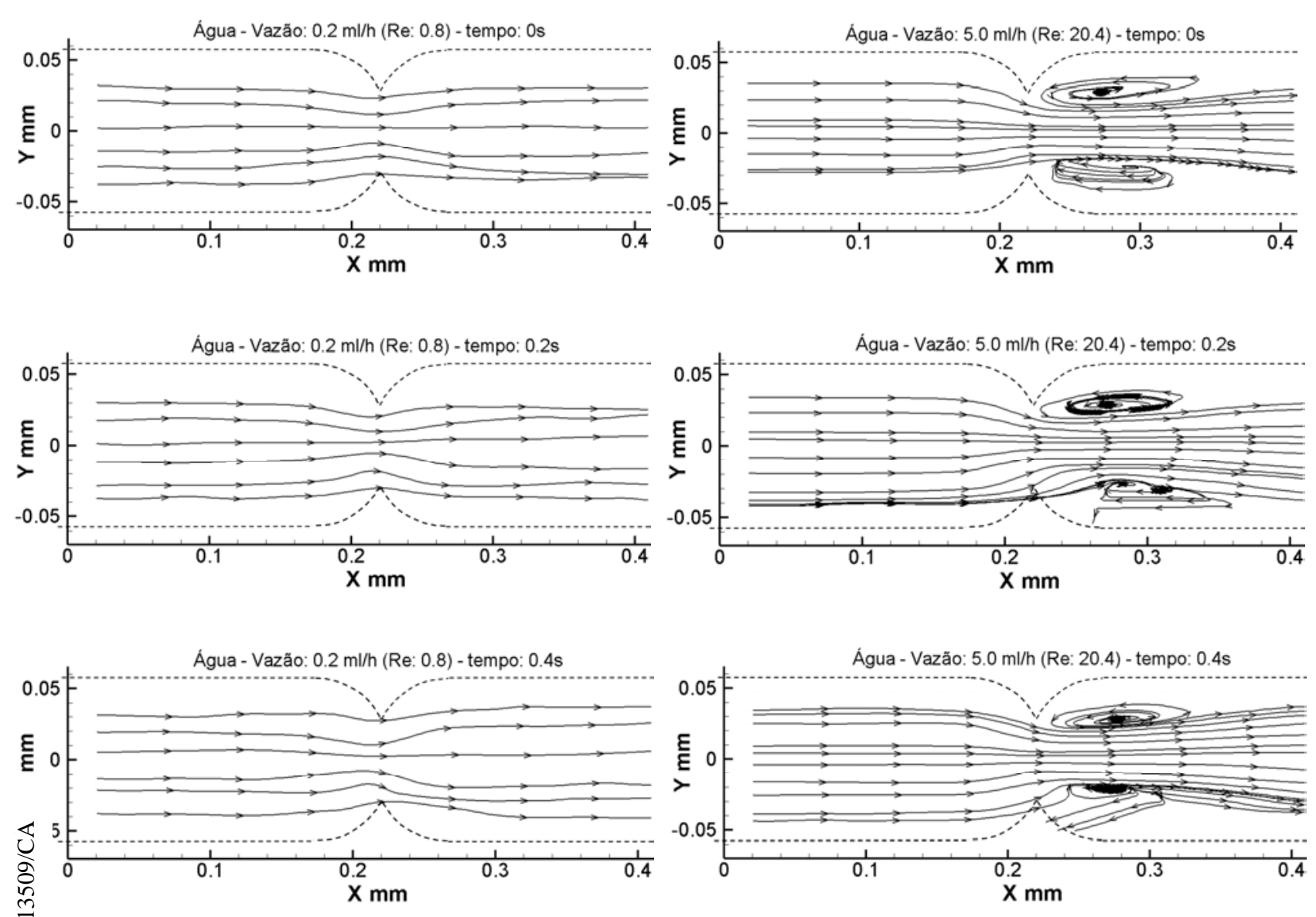

Figura 136 - Campos instantâneos consecutivos do escoamento de água capturados à frequência de 4,8 Hz (0,2 s) para as vazões de $Q=0,2 \mathrm{ml} / \mathrm{h}$ e $Q=5,0 \mathrm{ml} / \mathrm{h}$

As linhas de corrente dos campos instantâneos do escoamento mostraram que não há variação do campo de velocidade com o tempo para ambas as vazões de injeção, indicando um escoamento estável. Ambos os vórtices são bastante idênticos nos campos e com leve diferença de tamanho, talvez pelo baixo sinal de correlação nas regiões de menor velocidade (escoamentos secundários). O seguinte diagrama da figura 137 apresenta um resumo dos diferentes regimes de escoamento encontrados na faixa de número de Reynolds estudado para o escoamento de água passando através da garganta de geometria tipo contração-expansão gradual com relação de contração $R c=2,4: 1(100 \mu \mathrm{m} / 46 \mu \mathrm{m})$. É importante mencionar, que nos campos de velocidade instantâneo foi difícil detectar o padrão do escoamento de linhas divergentes pela baixa densidade de partículas perto da constrição, porém foi detectado nos campos de velocidade média e os campos determinados através do software Comsol, lembrando que o escoamento de água está em regime permanente. 


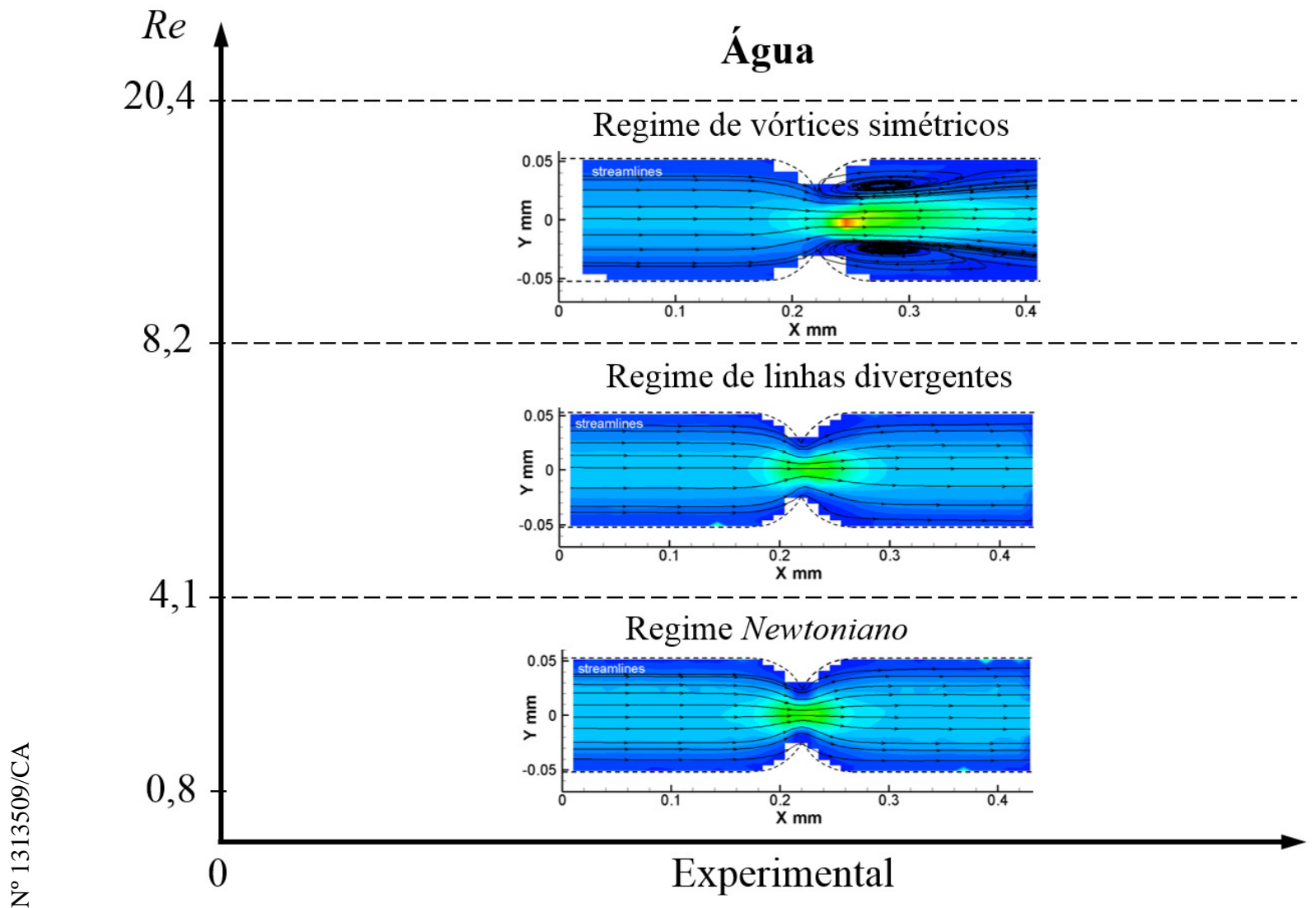

Figura 137 - Diagrama mostrando os diferentes regimes de escoamento de água na faixa de Reynolds de $0,8 \leq \operatorname{Re} \leq \mathbf{2 0 , 4}$

Campos de velocidade instantânea das soluções de glicerina e PEO: As medições dos campos de velocidade instantânea nos escoamentos das soluções de glicerina e PEO foram realizadas com o objetivo de encontrar os diferentes regimes que governam o escoamento no decorrer do tempo para diferentes condições de escoamento ao passar pela constrição. A figura 138 mostra três campos instantâneos consecutivos da solução de glicerina capturados à frequência de $4,8 \mathrm{~Hz}$ e são avaliados em quatro condições de escoamento ( $Q=0,02 \mathrm{ml} / \mathrm{h}, Q=0,08 \mathrm{ml} / \mathrm{h}, Q=0,16 \mathrm{ml} / \mathrm{h}$ e $Q=0,28 \mathrm{ml} / \mathrm{h}$ ), mostrando apenas as linhas de corrente. 
Glicerina - Vazão $0.02 \mathrm{~m} / \mathrm{h}$ (Re: 0.02) - tempo: 0s

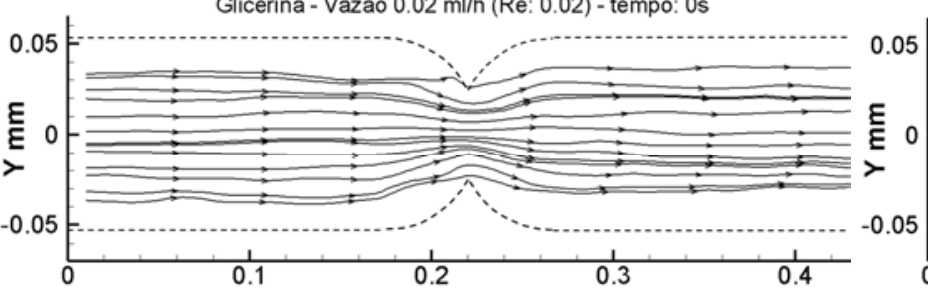

Glicerina - Vazão $0.08 \mathrm{~mm} / \mathrm{m}(\mathrm{Re}: 0.09)$ - tempo: 0s
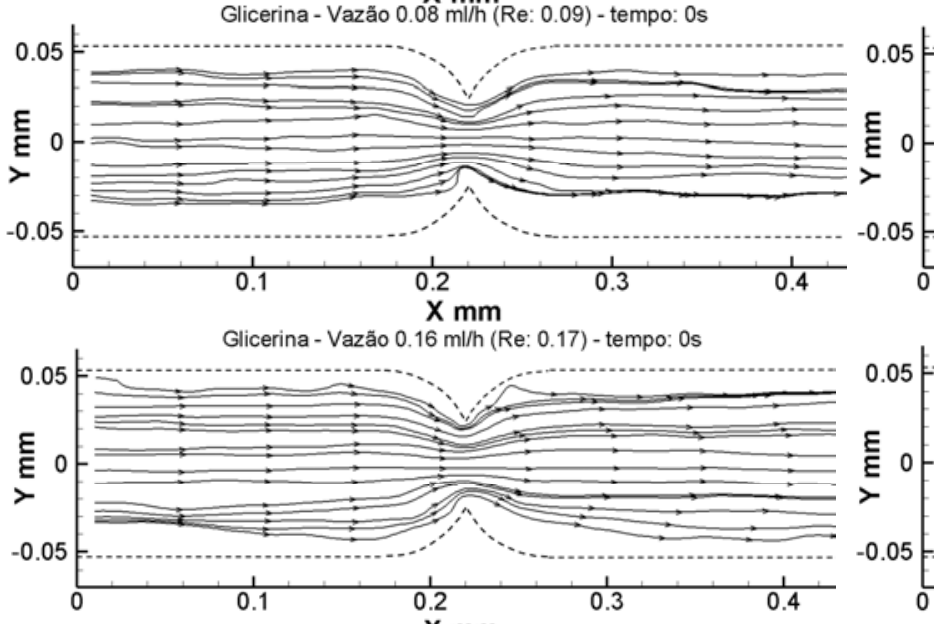

Glicerina - Vazão 0.28 $\mathrm{m} / / h$ mm (Re: 0.30) - tempo: 0s

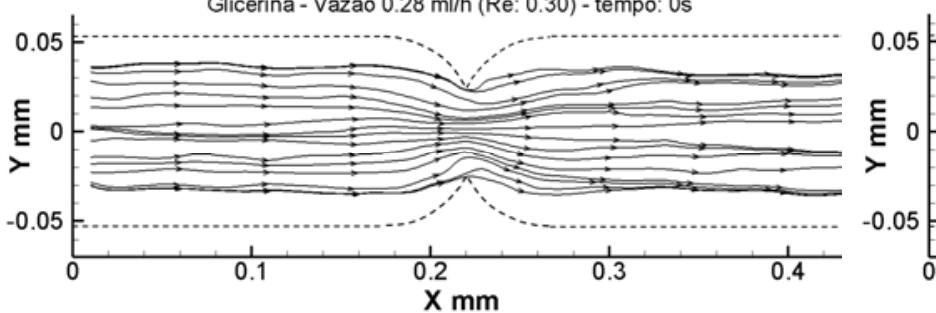

Glicerina - Vazăo $0.02 \mathrm{~m} / \mathrm{h}$ (Re: 0.02) - tempo: $0.2 \mathrm{~s}$

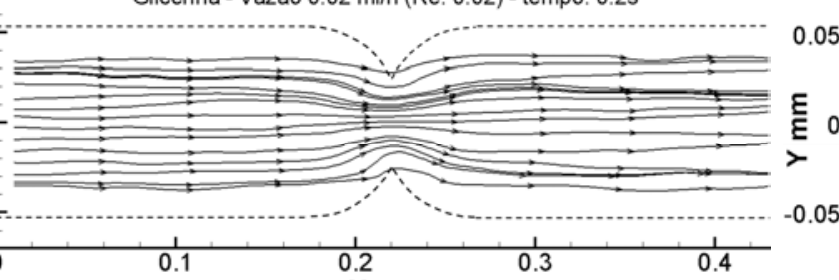

Glicerina - Vazão 0.08 ml/h (Re: 0.09) - tempo: $0.2 \mathrm{~s}$

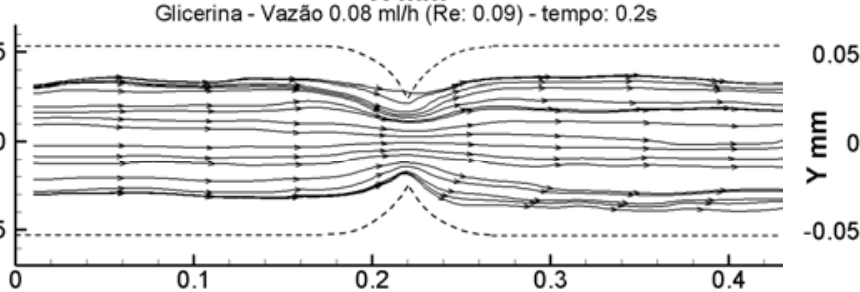

$\mathrm{X} \mathrm{mm}$
$\mathrm{ml} / \mathrm{h}(\mathrm{Re}: 0.17)$ - tempo: $0.2 \mathrm{~s}$

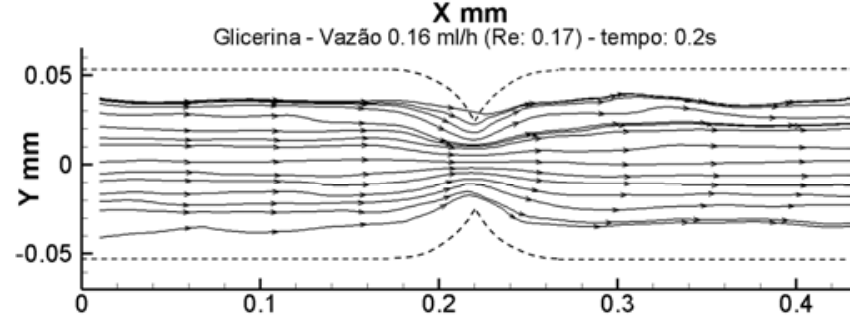

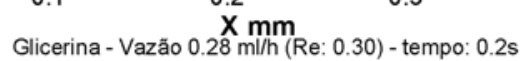

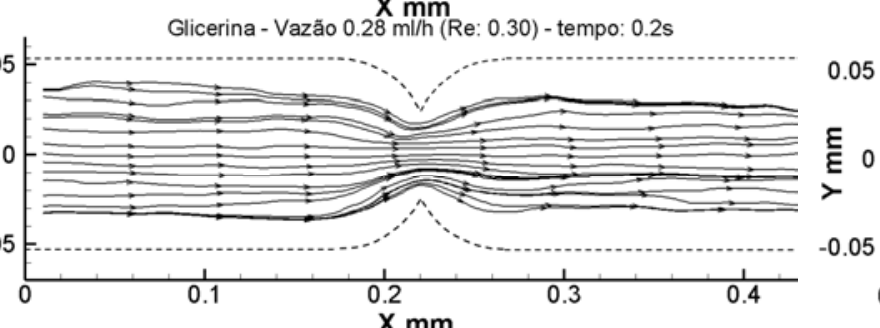

Glicerina - Vazăo: $0.02 \mathrm{~m} / \mathrm{h}$ (Re: 0.02 ) - time: $0.4 \mathrm{~s}$

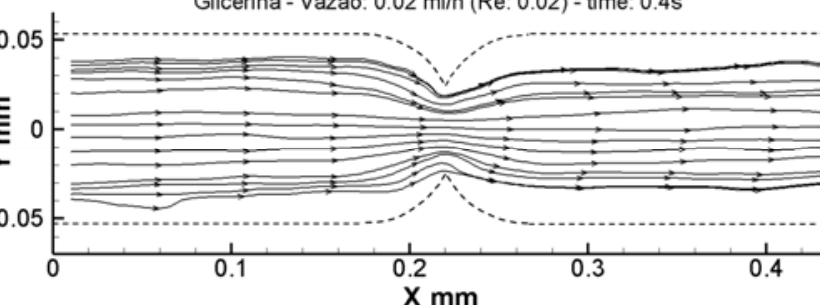

Glicerina - Vazão $0.08 \mathrm{ml} / \mathrm{h}$ (Re: 0.09) - tempo: $0.4 \mathrm{~s}$

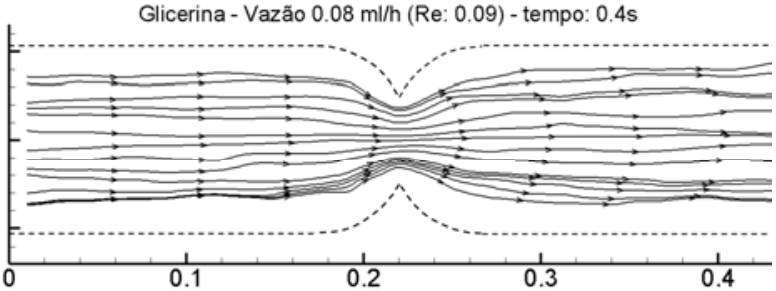

$\mathbf{X} \mathrm{mm}$
Glicerina - Vazão $0.16 \mathrm{~m} / \mathrm{h}$ (Re: 0.17 ) - tempo: $0.4 \mathrm{~s}$

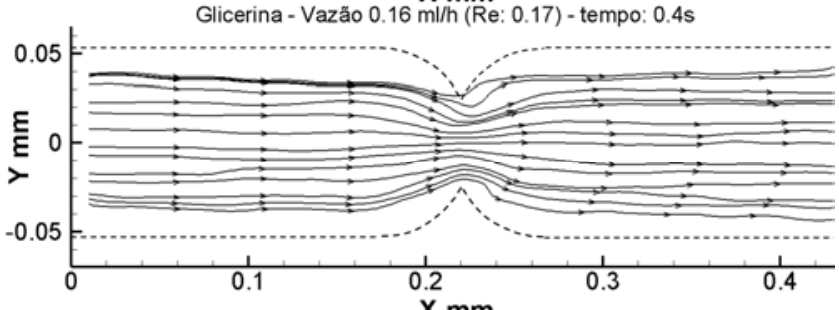

Glicerina - Vazăo $0.28 \mathrm{~m} / / \mathrm{hm}$ (Re: 0.30 ) - tempo: $0.4 \mathrm{~s}$

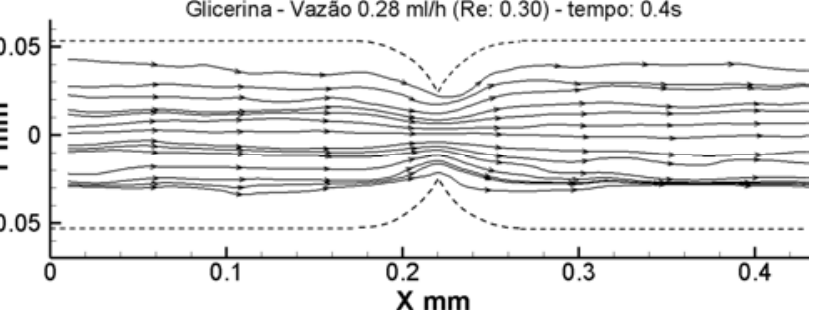

Figura 138 - Campos instantâneos consecutivos do escoamento da solução de glicerina capturados à frequência de 4,8 Hz $(0,2 \mathrm{~s})$ para as vazões de $Q=0,02 \mathrm{ml} / \mathrm{h}, Q=0,08 \mathrm{ml} / \mathrm{h}, Q=0,16 \mathrm{ml} / \mathrm{h}$ e $Q=0,28 \mathrm{ml} / \mathrm{h}$ 
Os campos de velocidade instantâneo com linhas de corrente não mostraram variação do escoamento no tempo (à maior frequência disponível de 4,8 Hz) para todos os casos avaliados, indicando um regime de escoamento Newtoniano estável no tempo. A maiores números de Reynolds $\operatorname{Re}>0,34$ de nossa faixa estudada, a presença das forças de inercia poderiam alterar o padrão do escoamento formando vórtices ou recirculações, como ocorreu no caso do escoamento de água. Finalmente, a figura 139 representa o único regime de escoamento da solução de glicerina encontrado na faixa estudada.

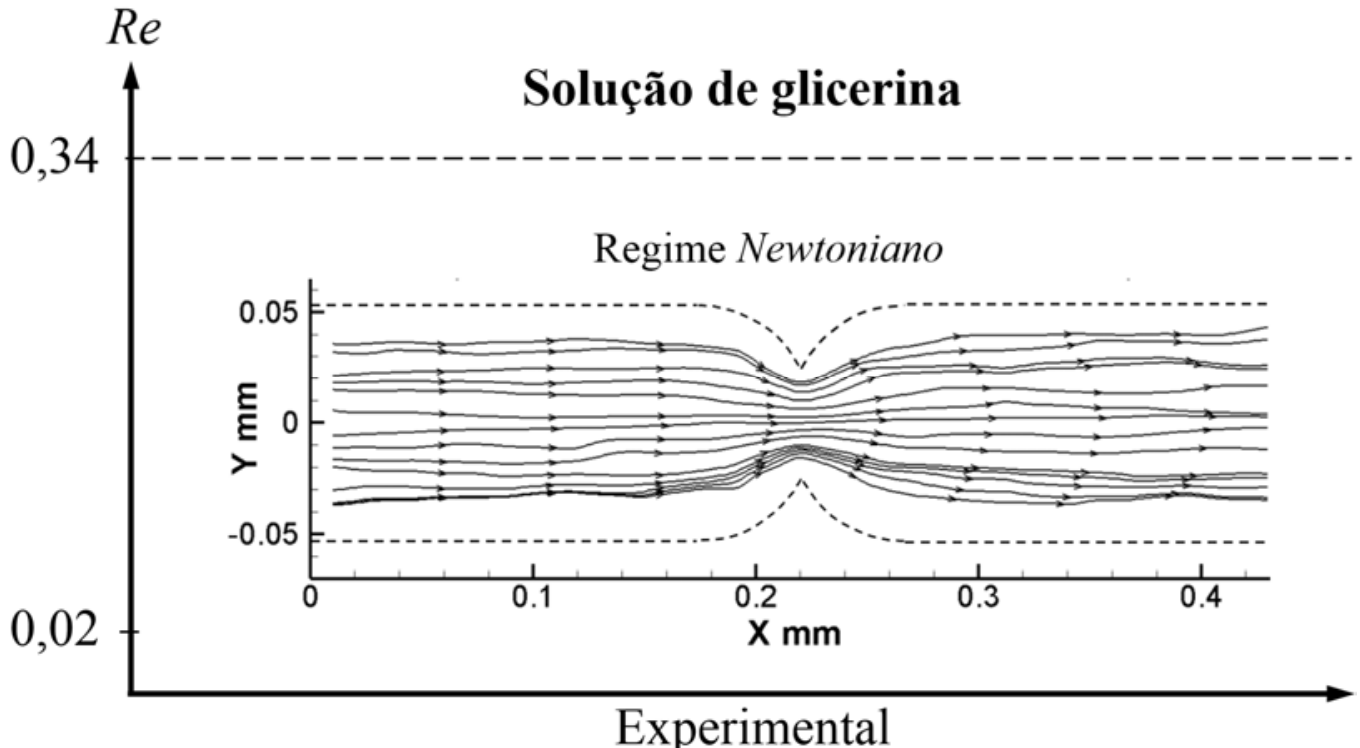

Figura 139 - Diagrama mostrando o regime de escoamento da solução de glicerina na faixa de Reynolds de $0,02 \leq \operatorname{Re} \leq 0,34$

A evolução temporal do escoamento da solução de PEO é mostrada nas figuras 140,141, 142, 143, 144 e 145 através de linhas de corrente nos campos instantâneos consecutivos capturados à frequência de 4,8 Hz. Foram avaliados em seis condições de escoamento. Para as vazões de $Q=0,003 \mathrm{ml} / \mathrm{h}$ e $Q=0,007 \mathrm{ml} / \mathrm{h}$ é mostrado uma sequência de três campos instantâneos consecutivos, enquanto, para os casos restantes é mostrado dois sequências de quatro campos instantâneos consecutivos. 


\section{1 sequência}

PEO - Vazão $0.003 \mathrm{ml} / \mathrm{h}$ (W: 0.5) - tempo: 0s

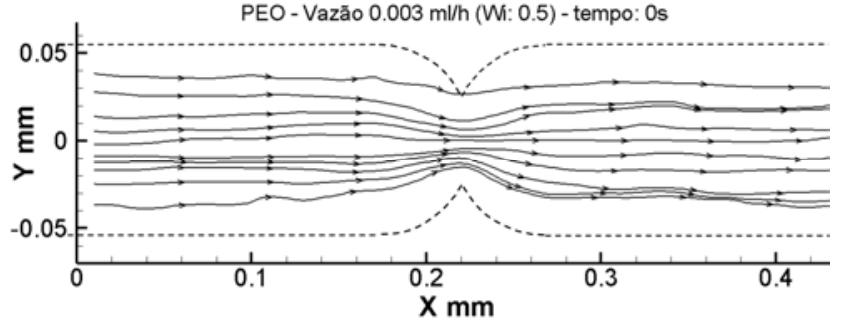

PEO - Vazão $0.003 \mathrm{~m} / \mathrm{h}$ (W: 0.5$)$ - tempo: $0.2 \mathrm{~s}$

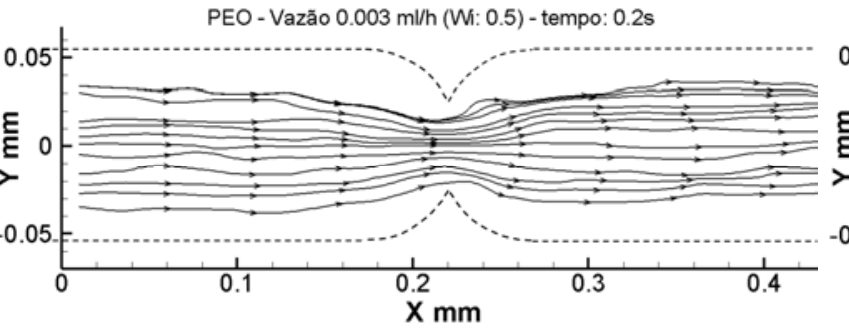

PEO - Vazão $0.003 \mathrm{~m} / \mathrm{h}$ (W: 0.5$)$ - tempo: $0.4 \mathrm{~s}$

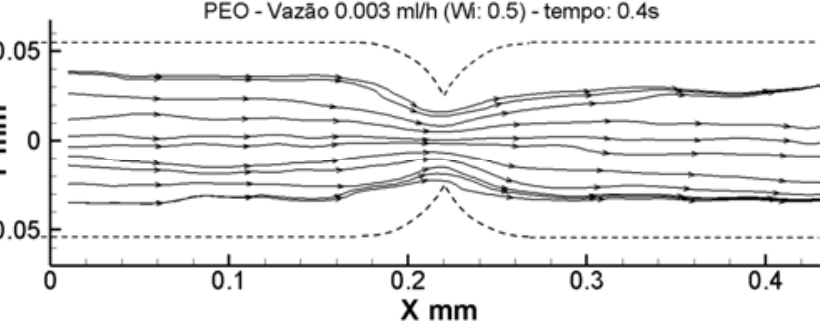

Figura 140 - Campos instantâneos consecutivos do escoamento da solução de PEO para a vazão de $Q=0,003 \mathrm{ml} / \mathrm{h}$ capturados à frequência de $4,8 \mathrm{~Hz}(0,2 \mathrm{~s})$

\section{1 sequência}
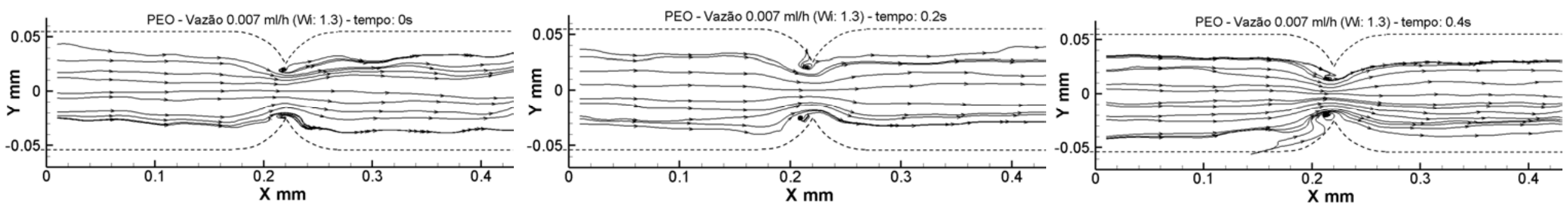

Figura 141 - Campos instantâneos consecutivos do escoamento da solução de PEO para a vazão de $Q=0,007 \mathrm{ml} / \mathrm{h}$

capturados à frequência de $4,8 \mathrm{~Hz}(0,2 \mathrm{~s})$ 


\section{1 sequência}

PEO - Vazão $0.02 \mathrm{~m} / \mathrm{h}$ (Wi: 4) - tempo: 0s

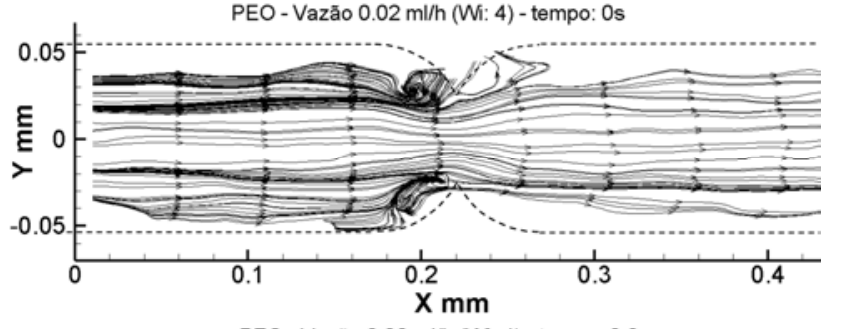

PEO - Vazão $0.02 \mathrm{~m} / \mathrm{h}$ (Wi: 4) - tempo: $0.2 \mathrm{~s}$

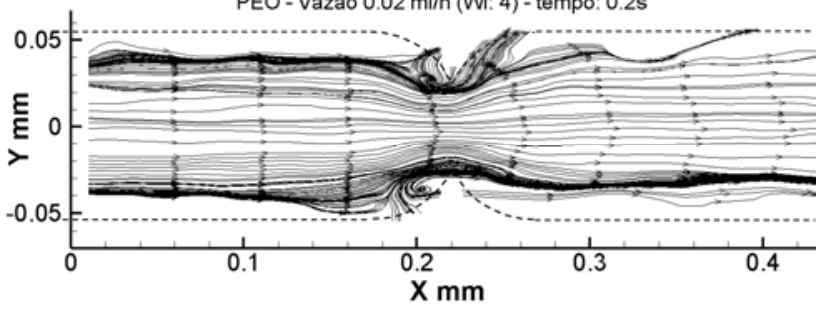

PEO - Vazão $0.02 \mathrm{~m} / \mathrm{h}$ (Wi: 4) - tempo: $0.4 \mathrm{~s}$

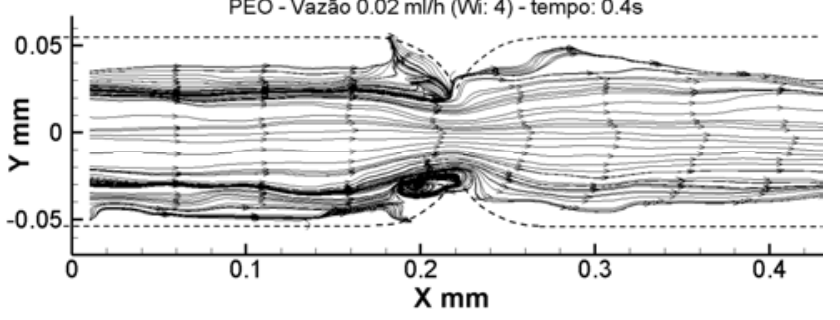

PEO - Vazão $0.02 \mathrm{~m} / \mathrm{h}$ (Wi: 4) - tempo: $0.6 \mathrm{~s}$

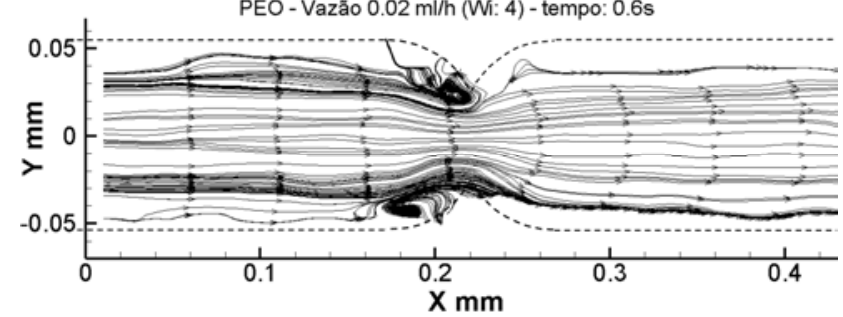

\section{2 sequência}

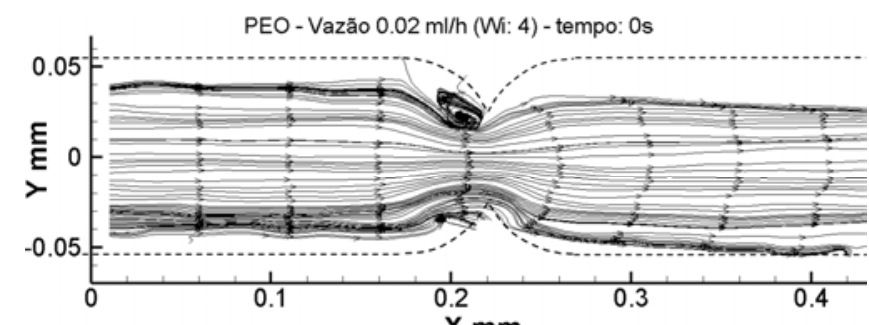

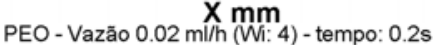

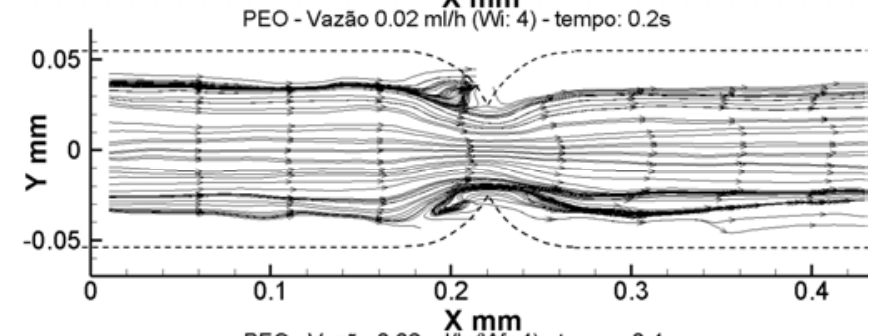

PEO - Vazão $0.02 \mathrm{ml} / \mathrm{h}$ (Wii: 4 ) - tempo: $0.4 \mathrm{~s}$

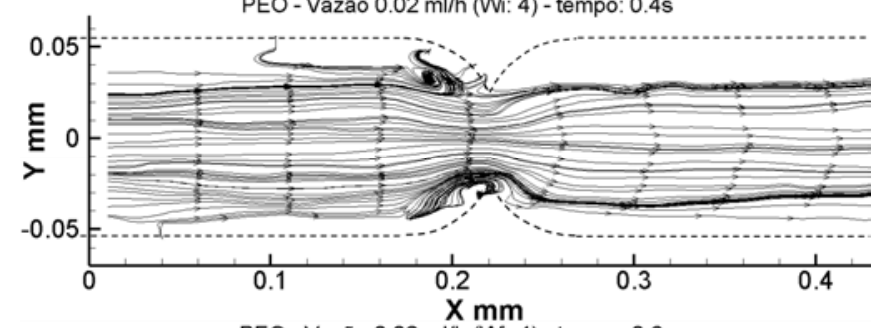

PEO - Vazão $0.02 \mathrm{~m} / \mathrm{h}$ (Wi: mi $^{-}$- tempo: $0.6 \mathrm{~s}$

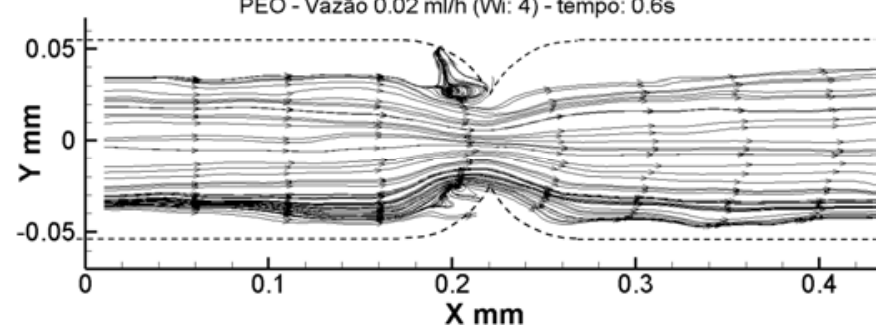

Figura 142 - Campos instantâneos consecutivos do escoamento da solução de PEO para a vazão de $Q=0,02 \mathrm{ml} / \mathrm{h}$ em duas sequências diferentes capturados à frequência de 4,8 Hz $(0,2 \mathrm{~s})$ 


\section{1 sequência}

PEO - Vazão 0.08 ml/h (Wi: 14) - tempo: 0

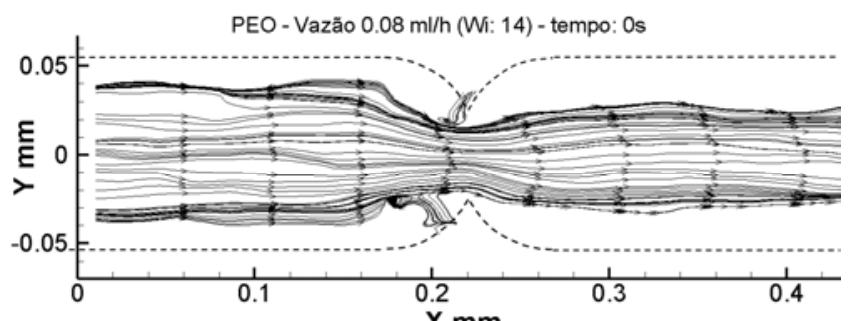

PEO - Vazão 0.08 ml/h (Wi: 14) - tempo: $0.2 \mathrm{~s}$

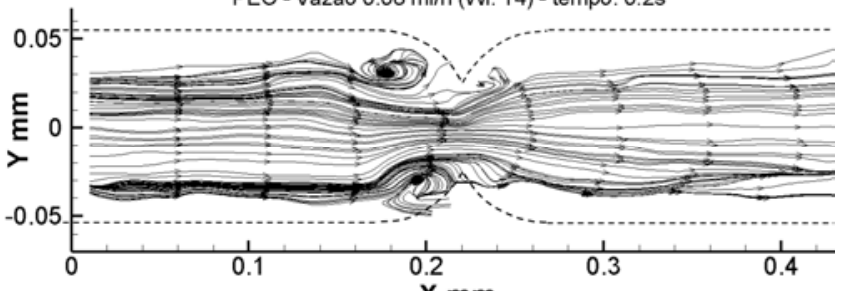

PEO - Vazão 0.08 ml/h (Wi: 14) - tempo: $0.4 \mathrm{~s}^{\text {X }}$

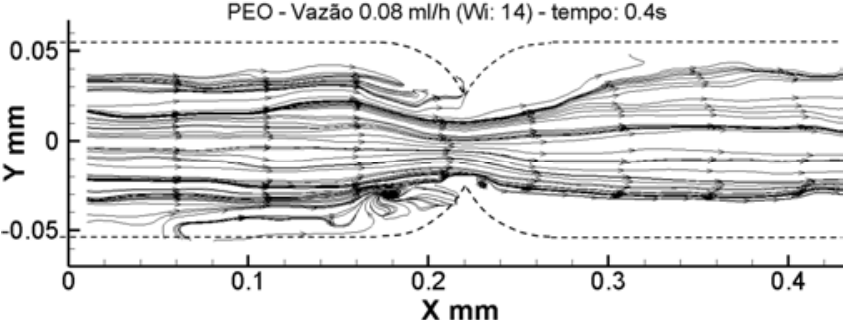

PEO - Vazão $0.08 \mathrm{ml} / \mathrm{h}$ (Wi: 14) - tempo: $0.6 \mathrm{~s}$

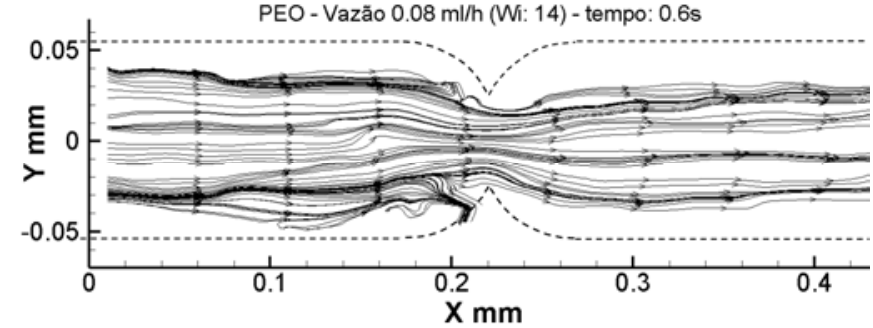

\section{2 sequência}

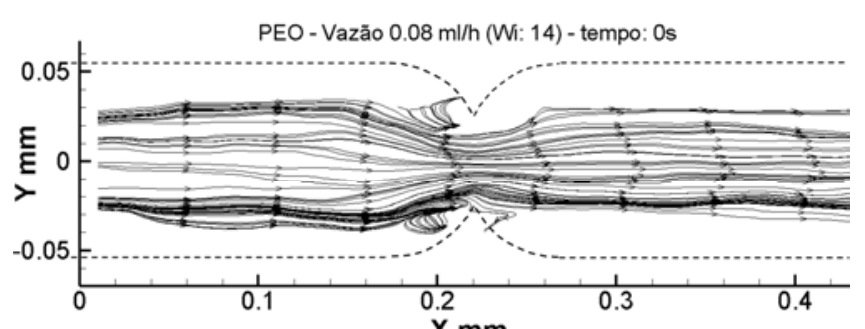

PEO - Vazão $0.08 \mathrm{~m} / \mathrm{h}$ (W: $\mathrm{Wm}_{14}$ - tempo: $0.2 \mathrm{~s}$

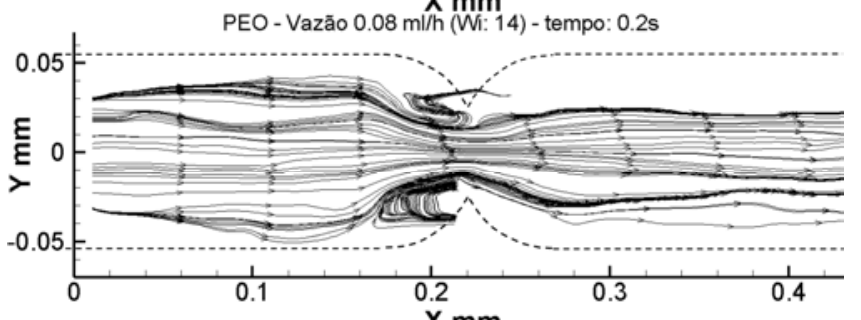

PEO - Vazão $0.08 \mathrm{~m} / \mathrm{h}$ (Wli: 14) - tempo: $0.4 \mathrm{~s}$

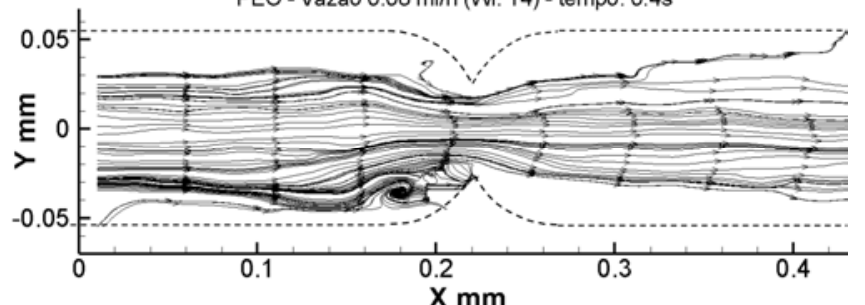

PEO - Vazão $0.08 \mathrm{~m} / / \mathrm{h}$ (Wi: 14) - tempo: $0.6 \mathrm{~s}$

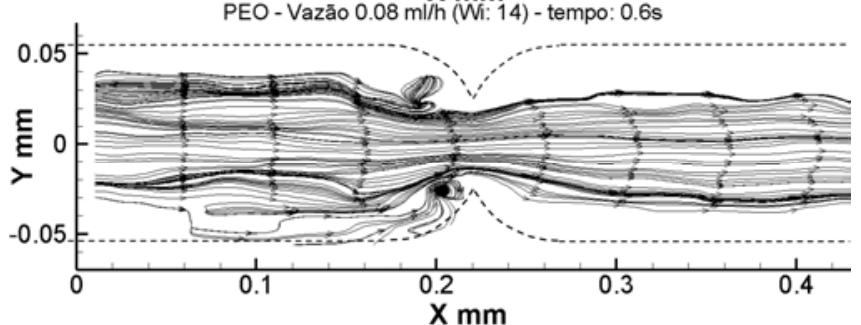

Figura 143 - Campos instantâneos consecutivos do escoamento da solução de PEO para a vazão de $Q=0,08 \mathrm{ml} / \mathrm{h}$ em duas sequências diferentes capturados à frequência de $4,8 \mathrm{~Hz}(0,2 \mathrm{~s})$ 


\section{1 sequência}

PEO - Vazão $0.16 \mathrm{ml} / \mathrm{h}$ (Wi: 29) - tempo: 0s

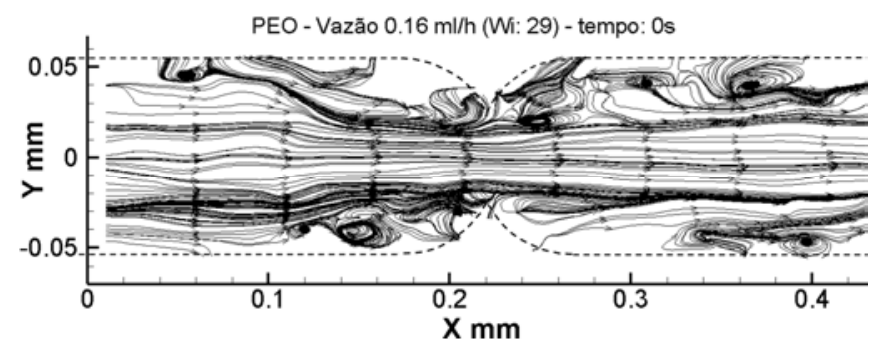

PEO - Vazão $0.16 \mathrm{~m} / \mathrm{h}$ (Wi: 29) - tempo: $0.2 \mathrm{~s}$

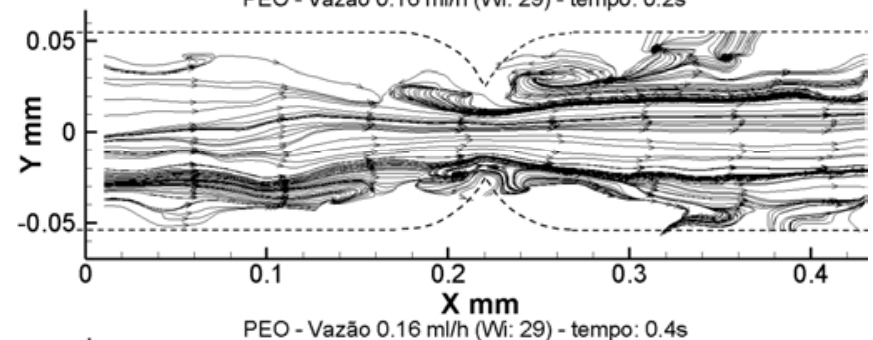

PEO - Vazão $0.16 \mathrm{ml} / \mathrm{h}$ (Wi: 29) - tempo: 0.4

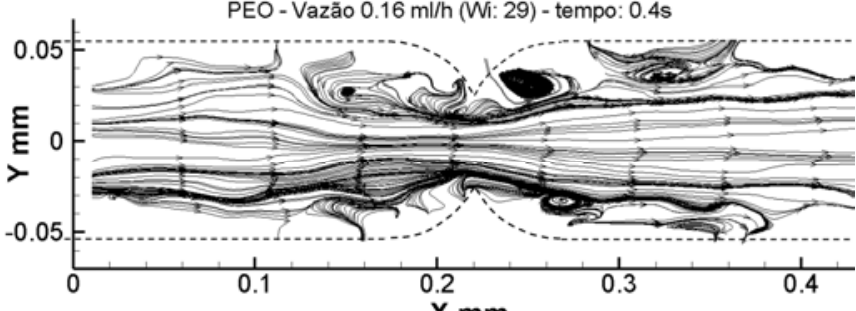

PEO - Vazão $0.16 \mathrm{ml} / \mathrm{X}$ (Wi: 29) - tempo: $0.6 \mathrm{~s}$

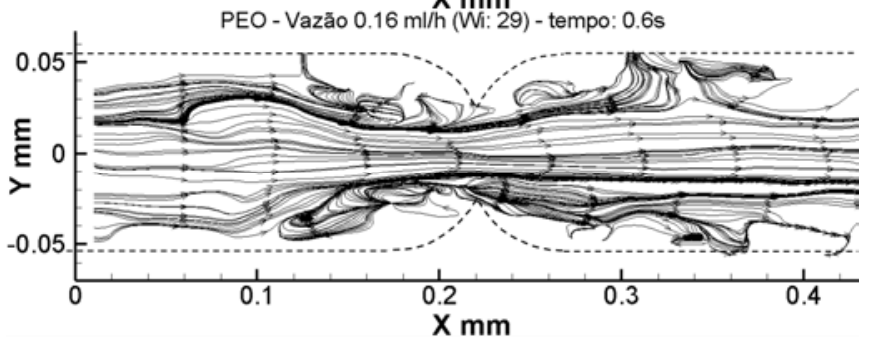

\section{2 sequência}

PEO - Vazão $0.16 \mathrm{ml} / \mathrm{h}$ (Wi: 29) - tempo: 0s
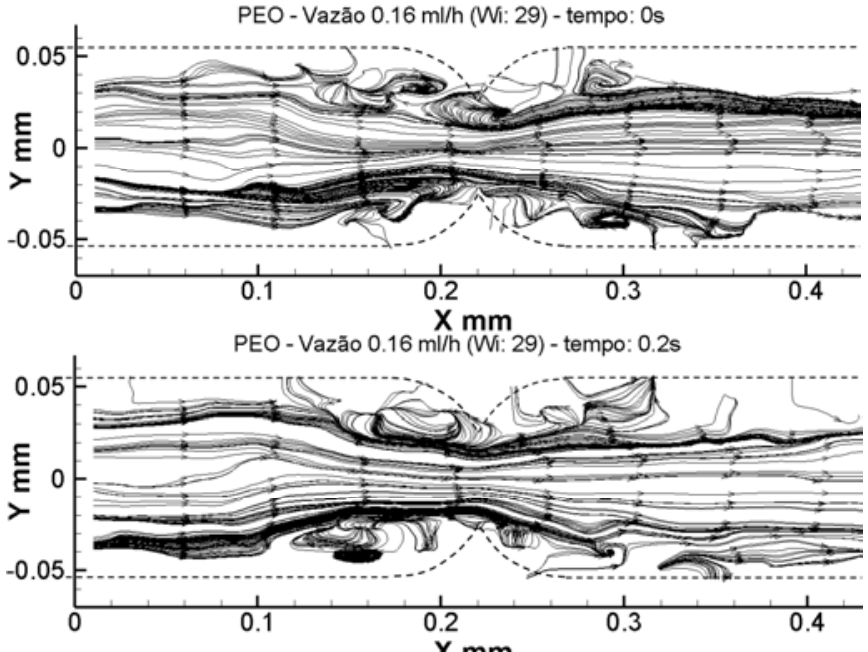

PEO - Vazão $0.16 \mathrm{ml} / \mathrm{h}$ (Wi: 29) - tempo: $0.4 \mathrm{~s}$
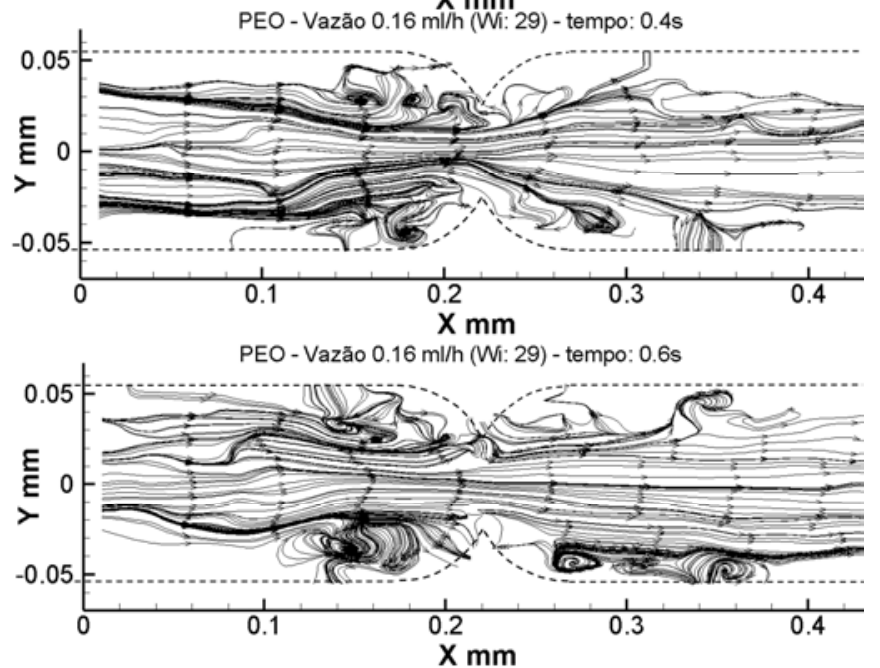

Figura 144 - Campos instantâneos consecutivos do escoamento da solução de PEO para a vazão de $Q=0,16 \mathrm{ml} / \mathrm{h}$ em duas sequências diferentes capturados à frequência de $4,8 \mathrm{~Hz}(0,2 \mathrm{~s})$ 


\section{1 sequência}

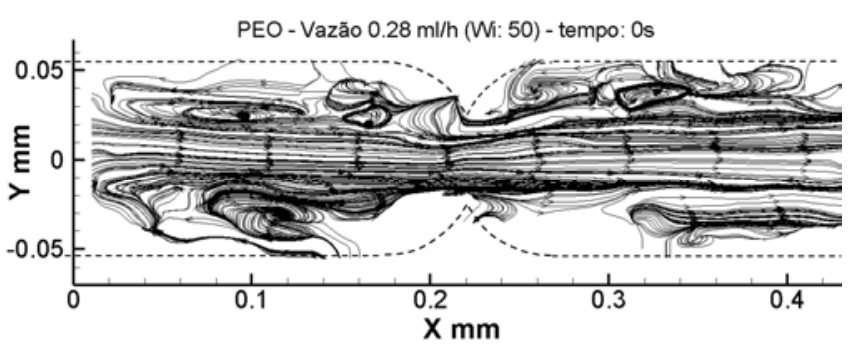

PEO - Vazão $0.28 \mathrm{ml} / \mathrm{h}$ (Wi: 50) - tempo: $0.2 \mathrm{~s}$

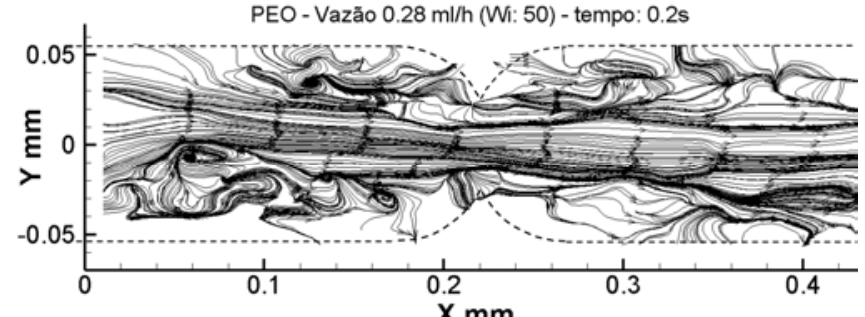

PEO - Vazão $0.28 \mathrm{ml} / \mathrm{h}$ (Wi: mo - tempo: $0.4 \mathrm{~s}$

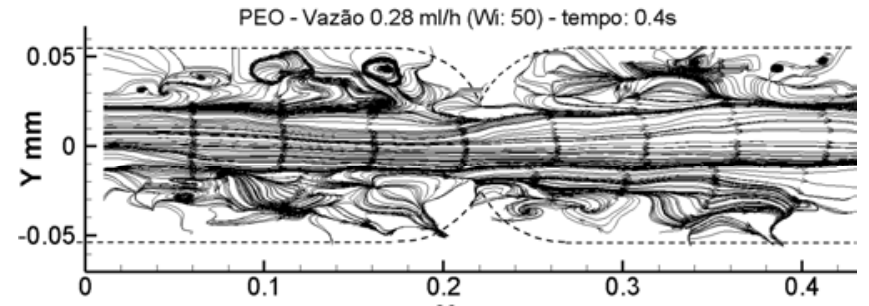

PEO - Vazão $0.28 \mathrm{ml/h}$ (Wi: ${ }^{\mathrm{X}}$ ) - tempo: $0.6 \mathrm{~s}$

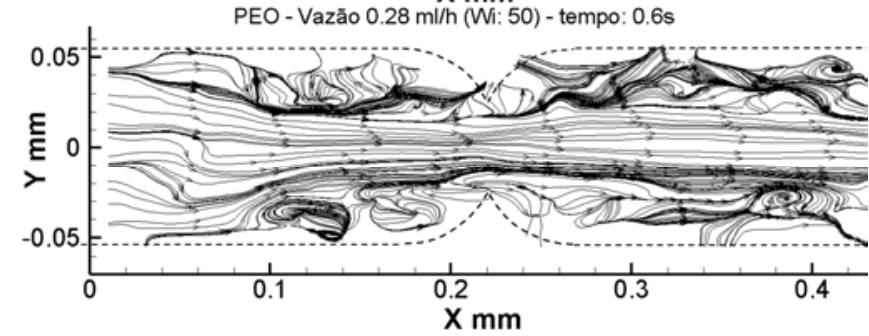

\section{2 sequência}

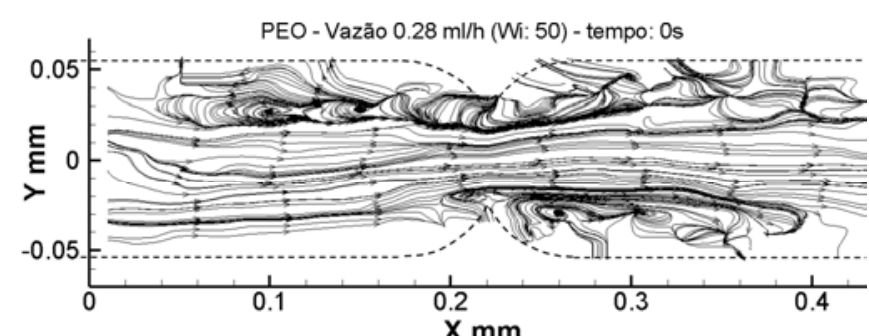

PEO - Vazão 0.28 ml/h mm (Wi: 50) - tempo: $0.2 \mathrm{~s}$

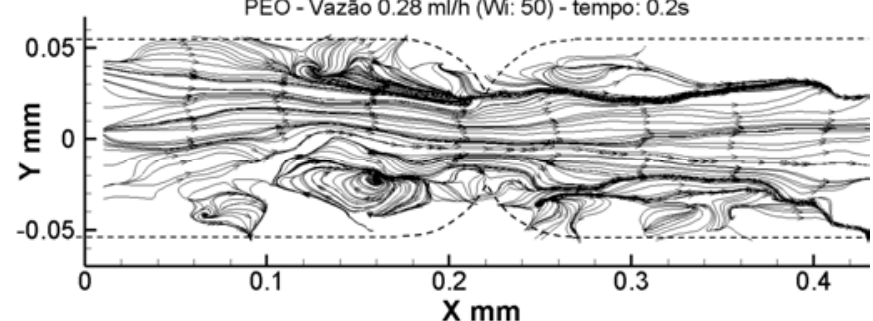

PEO - Vazão $\underset{0.28 \mathrm{ml} / \mathrm{h} \text { (Wi: }}{\mathbf{X} \text { mo) - tempo: } 0.4 \mathrm{~s}}$

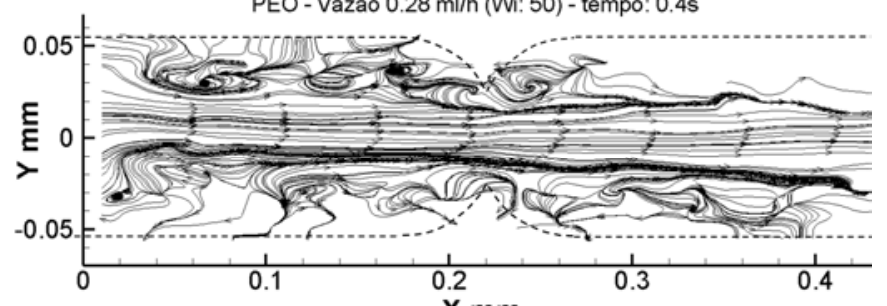

PEO - Vazão $0.28 \mathrm{~m} / \mathrm{X}$ m (Wi: 50 ) - tempo: $0.6 \mathrm{~s}$

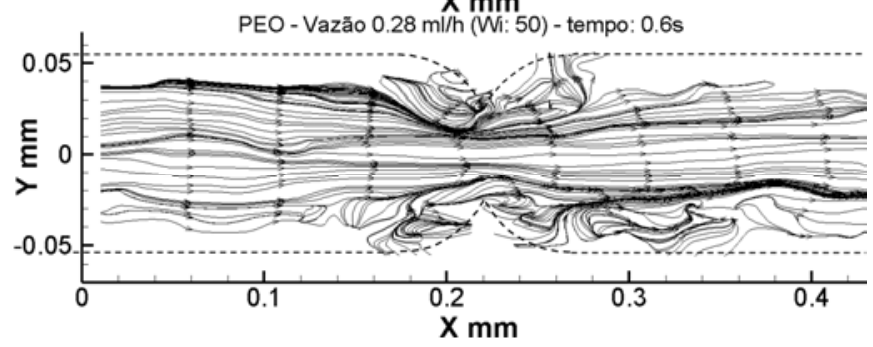

Figura 145 - Campos instantâneos consecutivos do escoamento da solução de PEO para a vazão de $Q=0,28 \mathrm{ml} / \mathrm{h}$ em duas sequências diferentes capturados à frequência de $4,8 \mathrm{~Hz}(0,2 \mathrm{~s})$ 
Para a vazão $Q=0,003 \mathrm{ml} / \mathrm{h}(W i=0,5)$, o escoamento da solução de PEO é essencialmente de comportamento Newtoniano sem zonas de recirculações e mostram um padrão similar ao escoamento da solução de glicerina.

Para a vazão $Q=0,007 \mathrm{ml} / \mathrm{h} \quad\left(W i_{\text {vort }}=1,3\right.$ e $\left.R e_{\text {vort }}=0,007\right)$, a simetria do escoamento é alterada devido ao início de formação de pequenas recirculações simétricas e estáveis na constrição (vórtices), evidência de que as forças elásticas começaram a atuar no escoamento apenas localmente. As medidas da queda de pressão global ainda não são afetadas (resposta linear). Não foi possível visualizar antes da formação de vórtices linhas de corrente divergente na constrição, devido à baixa resolução espacial.

À medida que a vazão é aumentada, a partir de $Q=0,02 \mathrm{ml} / \mathrm{h}(W i=4,0)$, o tamanho dos vórtices começa a variar no tempo (vórtices assimétricos em relação ao plano da constrição), mostrada nas duas sequências capturadas do escoamento.

Quando o escoamento foi analisado para uma vazão de $Q=0,08 \mathrm{ml} / \mathrm{h}$ ( $W i=14$ ), os vórtices à montante da constrição foram variando de tamanho, além do desaparecimento esporádico em certos instantes (instável dependente do tempo). O escoamento da solução de PEO atingiu o início da instabilidade (flutuações de velocidade no escoamento), coincidindo com o aumento da queda de pressão no escoamento (comportamento não Newtoniano). O regime crítico do escoamento é dado entre os números de Weissenberg de $11<W i_{c r i t}<14$. Finalmente, os efeitos elásticos do polímero passaram a ser dominantes no escoamento.

À vazão de injeção $Q=0,16 \mathrm{ml} / \mathrm{h}$ (Wi=29), as sequências dos campos instantâneos mostram a formação de vórtices de uma forma desordenada e o aparecimento de recirculações no escoamento localizado à jusante da constrição (perto das paredes). Um escoamento totalmente tridimensional, instável e dependente do tempo é visualizado pela presença forte da elasticidade do polímero atuando no escoamento. 
No caso da vazão de injeção $Q=0,28 \mathrm{ml} / \mathrm{h}$, a condição do escoamento na solução do PEO mostrou maiores interações transientes e uma mudança significativa na direção do escoamento principal.

Os trabalhos na escala micro realizados por Rodd et al. (2005) e (2007) utilizando uma geometria de contração-expansão abrupta planar $(R c=16: 1)$ citaram também que o inicio do incremento da queda de pressão correspondeu ao início da instabilidade elástica no escoamento.

Os padrões de escoamento também foram visualizados em diferentes geometrias de contração-expansão planar (Galindo, 2014). Apenas a região à montante da constrição foi mostrada. O regime de escoamento desordenado foi visualizado apenas por Lee at el. (2015) para uma contração-expansão abrupta planar $(R c=4: 1)$, e números de elasticidade altos na ordem de $\sim 10^{6}$, como citado nas referências bibliográficas.

Finalmente, o escoamento da solução de glicerina foi estável. O escoamento da solução de PEO foi estável para as menores vazões, onde os efeitos viscosos ainda são dominantes. Porém, conforme a vazão foi aumentada, o início da instabilidade elástica no escoamento da solução de PEO ocorreu em um número de Weissenberg crítico $\left(W i_{c r i t}\right)$, levando o escoamento para um regime instável e tridimensionalmente desordenado, coincidindo com o incremento da queda de pressão global no escoamento.

Segundo os resultados da evolução dinâmica do escoamento no tempo, cinco padrões de escoamento da solução de PEO foram visualizados e resumidos no diagrama $W i$ vs. Re para o número de elasticidade de $E l=W i / R e=188$, ilustrado na figura 146. Como comentando antes, a velocidade de injeção para um reservatório de óleo está em torno de 1 pé/dia, e para um caso particular de rocha de carbonato com porosidade de $5 \%$ e diâmetro de garganta de poro de $110 \mu$ m (diâmetro do microcanal com constrição), a vazão de injeção estaria na ordem de $10^{-3} \mathrm{ml} / \mathrm{h}$. O regime I e II estão à mesma ordem de grandeza $10^{-3} \mathrm{ml} / \mathrm{h}$, e o regime III e IV estão na ordem de grandeza $10^{-2} \mathrm{ml} / \mathrm{h}$. A partir do regime IV, a diferença de pressão no escoamento seria maior do que a pressão capilar dentro dos poros levando para mobilização de gânglios de óleo presos nos poros e, consequentemente, uma maior recuperação de óleo. 


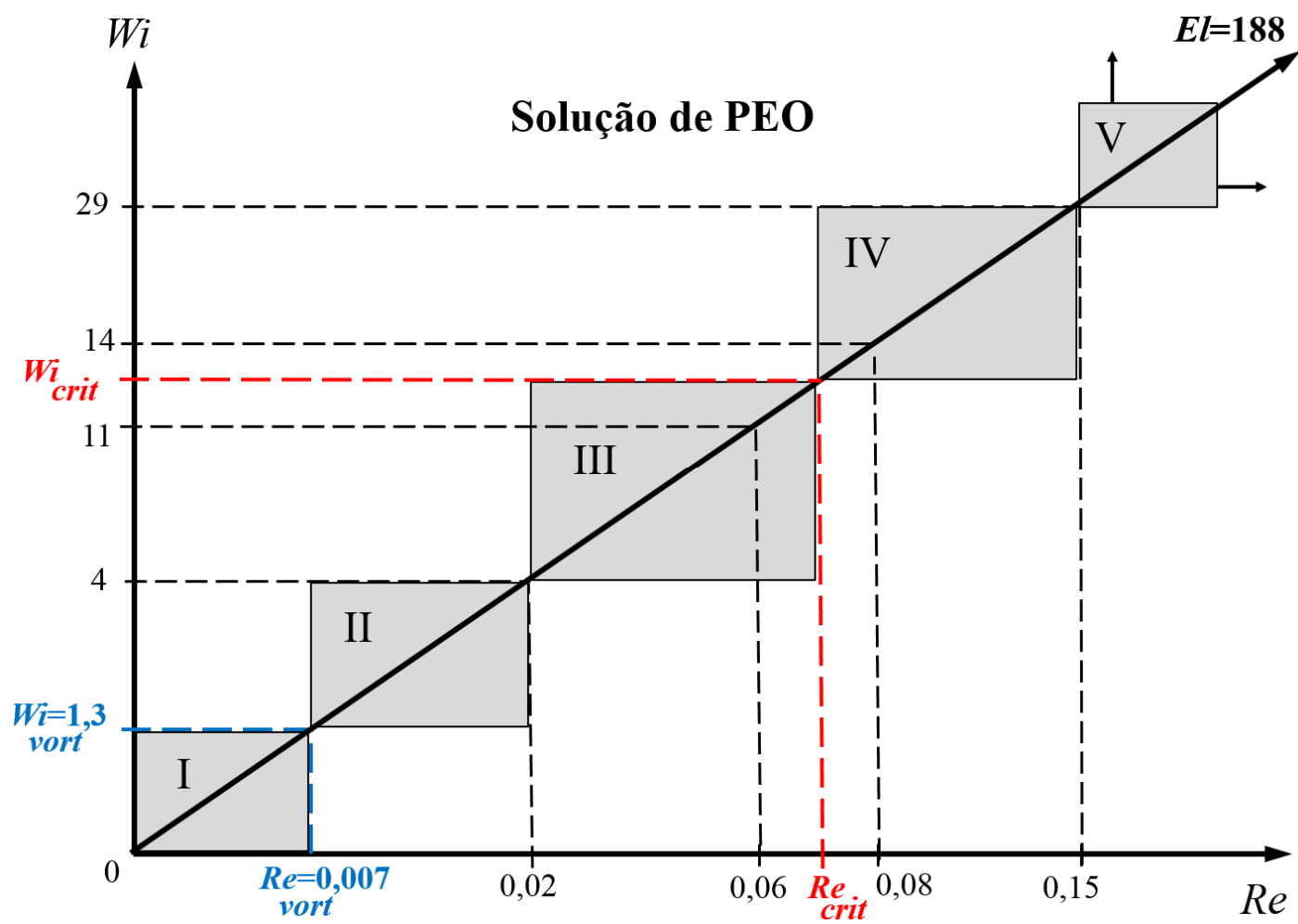

I) Régime de escoamento tipo Newtoniano $(0<W i<1,3)$

$\boldsymbol{W i}=\mathbf{1 , 3}$ Início das forças elásticas (início de vort formação de vórtices)

II) Régime de crescimento de vórtices simétrico estável $(1,3 \leq W i<4)$
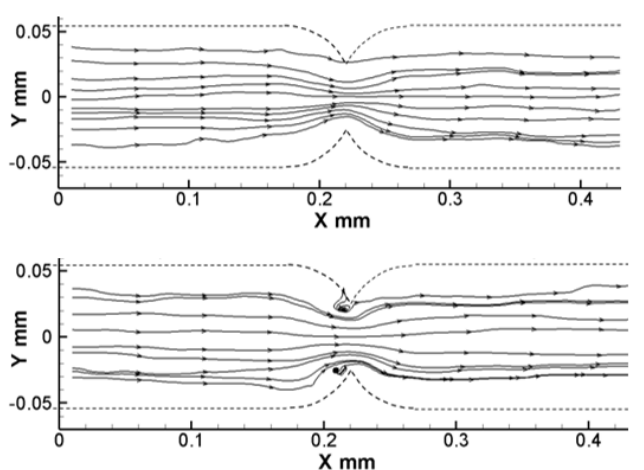

III) Régime de crescimento de vórtices assimétrico estável $(4 \leq W i<\underset{c r i t}{W i})$

\section{$\mathbf{1 1}<\boldsymbol{W i}<\mathbf{1 4}$ Início da instabilidade no crit escoamento}

IV) Régime de crescimento de vórtices assimétrico instável $(W i \leq W i<29)$
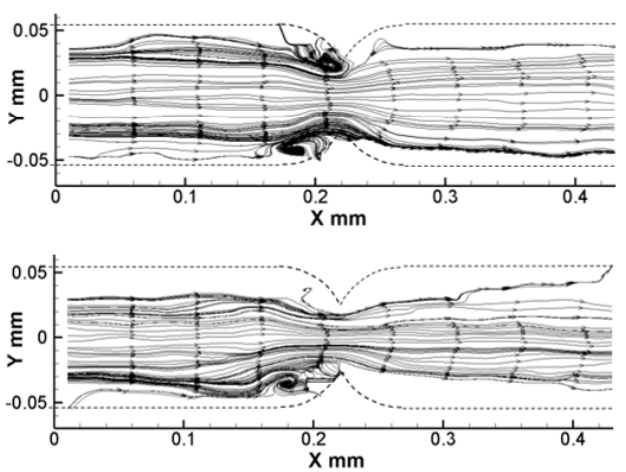

V) Régime de escoamento desordenado $(W i \geq 29)$

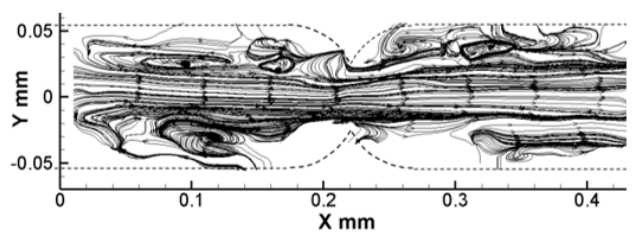

Figura 146 - Diagrama e sumário mostrando os regimes de escoamento da solução de PEO para o número de elasticidade de $E l=188$ 
O comportamento de crescimento dos vórtices observado à montante da constrição na solução viscoelástica de PEO foram caracterizados em termos quantitativos através do comprimento adimensional do vórtice. O valor extraído do tamanho do vórtice a partir do campo de velocidade média é uma aproximação de medição devido à baixa resolução das regiões de vórtices e recirculações aleatórios (sem forma definida) observadas nos campos instantâneos.

O comprimento normalizado do vórtice $\chi$ foi determinado dividindo o comprimento do vórtice $L v$ (distância ao longo da parede) pelo diâmetro $D$ do microcanal. A figura 147 representa a evolução do crescimento do vórtice superior $\chi_{s}$ e inferior $\chi_{i}$ em função do número de Weissenberg, mostrando também os regimes de escoamento.

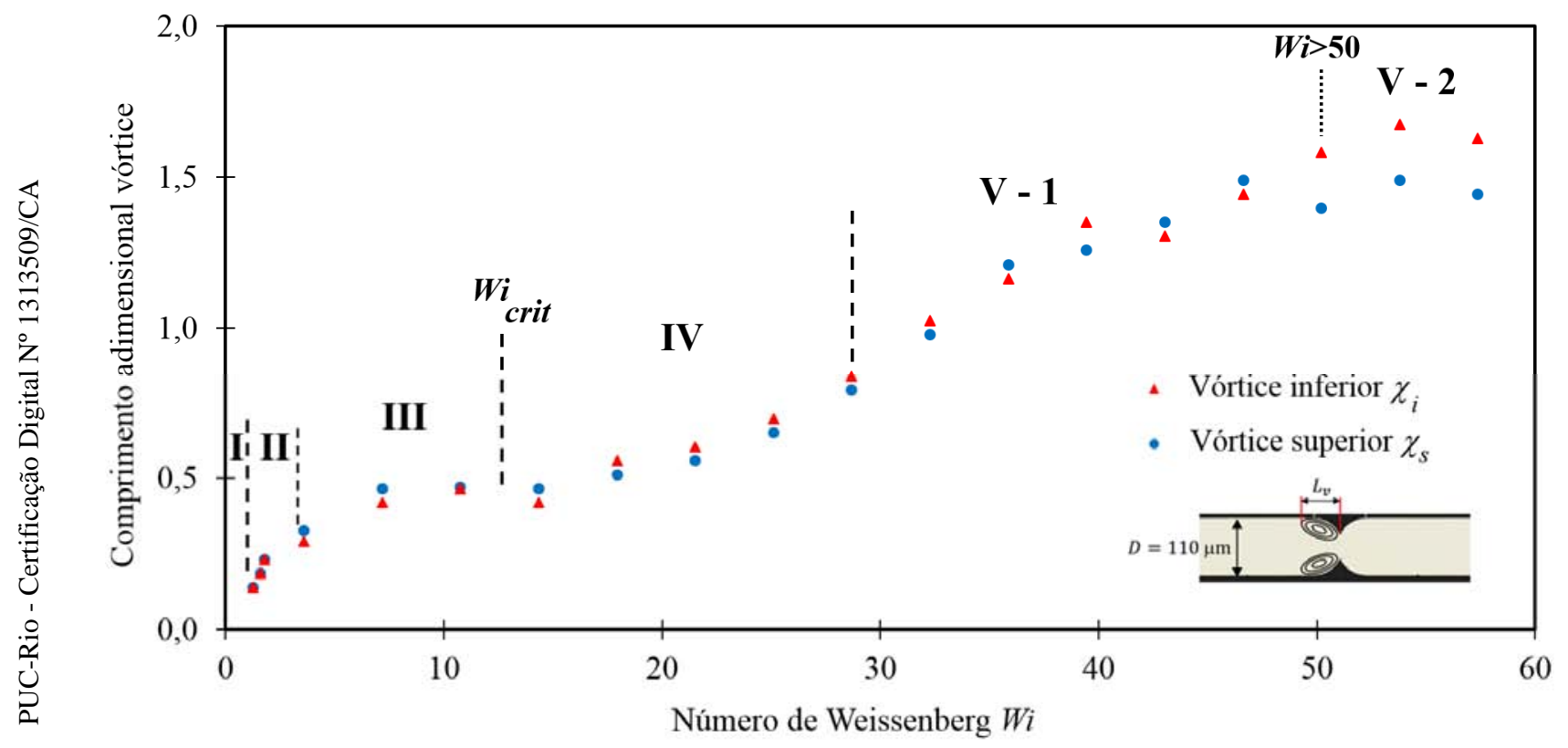

Figura 147 - Comprimento adimensional dos vórtices em função do número de Weissenberg para a solução de PEO

No regime de escoamento tipo Newtoniano (I), a presença de vórtices não foi observada. As forças viscosas no escoamento são dominantes.

No regime de crescimento de vórtices simétrico e estável (II), o escoamento é afetado localmente pelas forças elásticas, e vórtices de comprimento similar são observados. A faixa de crescimento dos vórtices foi de $0,14 \leq \chi \leq 0,24$ respectivamente. 
No regime de crescimento de vórtices assimétrico estável (III), uma pequena variação do comprimento dos vórtices é observada, sendo confirmado nos campos instantâneos.

No regime de escoamento de vórtices assimétrico instável (IV), a elasticidade das cadeias da solução polimérica ao passar pela constrição afeta globalmente o escoamento. O comprimento dos vórtices cresce rapidamente (quase linear) com o aumento do número de Weissenberg, atingindo um tamanho próximo ao diâmetro do canal de $\chi \approx 0,84$.

No regime de escoamento desordenado (V) é observado dois cenários. $\mathrm{Na}$ primeira região (V-1), o crescimento do comprimento dos vórtices continua em aumento. Enquanto, na região $\mathrm{V}-2$ (Wi>50), o crescimento dos vórtices é quase constante em torno de 1,5 vezes o diâmetro do canal.

Devido às diferentes geometrias de constrições utilizadas nos trabalhos anteriores, é difícil fazer uma comparação com nossos resultados. Apenas a geometria de contração gradual na escala micro utilizada por Gulati et al. (2015) é similar, embora seja planar, para uma comparação unicamente qualitativa. A figura 148 mostra a geometria do canal de entrada, e o comprimento adimensional do vórtice determinado a partir da média amostral de 300 pares de imagens consecutivas do escoamento de DNA estável e simétrico no tempo.
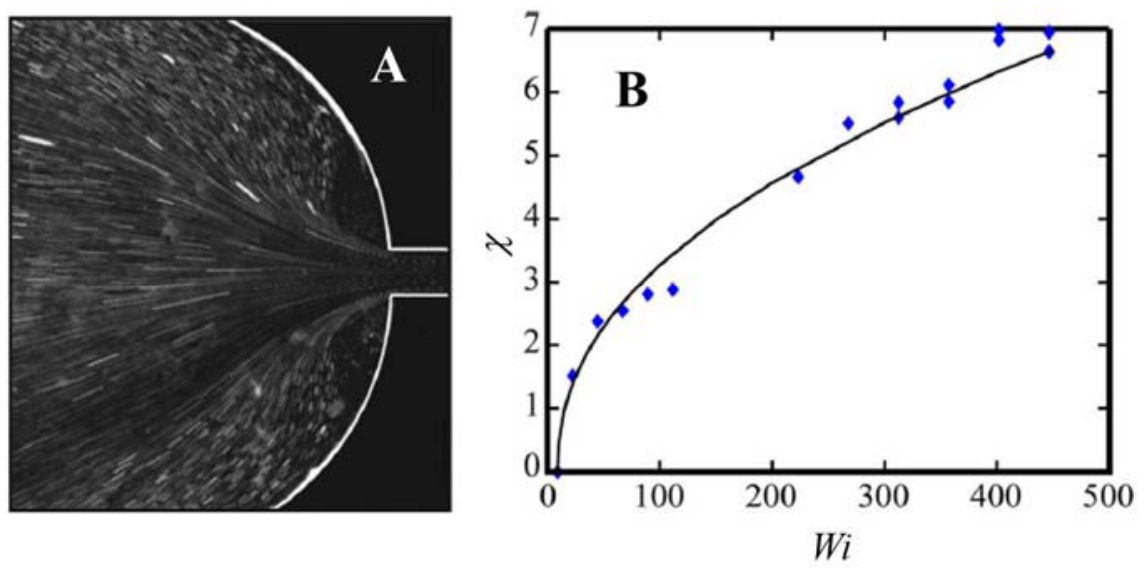

Figura 148 - A) Geometria da contração gradual. B) Comprimento adimensional do vórtice para um escoamento de DNA (entangled solution) realizado por Gulati et al. (2015) 
O crescimento dos vórtices tem correlação com as medidas da queda de pressão extra no escoamento e é avaliada na figura 149 a seguir:

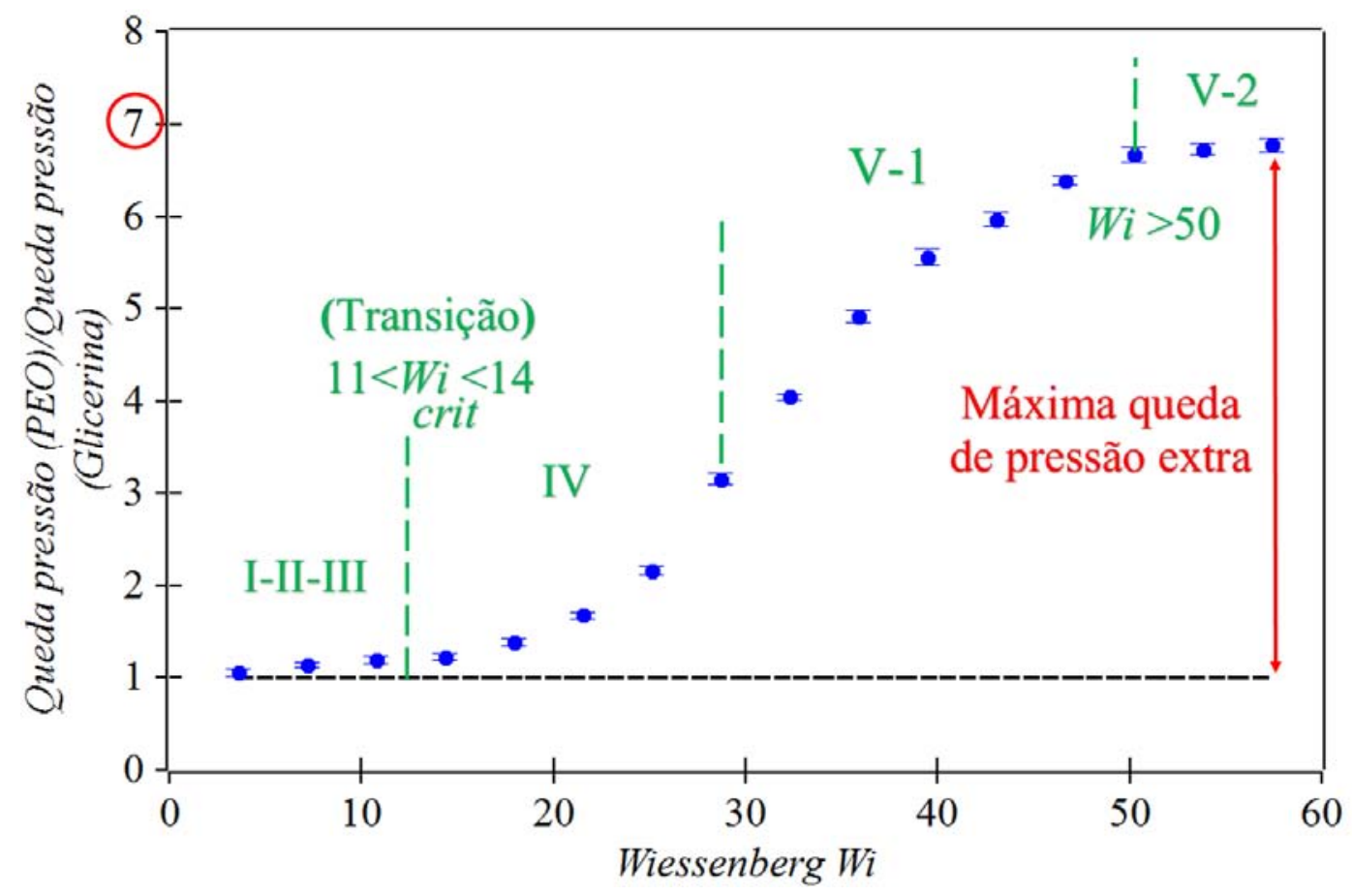

Figura 149 - Queda de pressão extra adimensional da solução de PEO em função de Wi mostrando os regimes do escoamento

Nos três primeiros regimes do escoamento (I-II-III), as medidas da queda de pressão extra devido aos efeitos elásticos do polímero no escoamento foram quase nulas. Os vórtices gerados afetaram apenas localmente o escoamento na constrição.

Nos regimes de instabilidade do escoamento (IV-V), o aumento da queda de pressão extra é acompanhado com o crescimento dos vórtices em tamanho e comprimento. Não obstante, na região V-2 (Wi>50) é observada medidas da queda de pressão extra aproximando-se a um patamar, coincidindo com o tamanho dos vórtices quase constante. De fato, as cadeias poliméricas estão chegando a sua extensão máxima ou perto dela.

A partir dos campos de velocidade instantâneos das soluções de glicerina e PEO foi avaliada a variação temporal da velocidade instantânea da região do escoamento que foi selecionada para determinar o número de pares de imagens (figura 104), com a finalidade de quantificar o incremento das flutuações de 
velocidade local devido apenas ao efeito elástico da solução viscoelástica de PEO quando for comparado com a solução de glicerina (puramente viscosa).

Para a solução de glicerina e PEO, a velocidade instantânea na direção do escoamento $U x$ foi normalizada pela velocidade média do escoamento $U m$ (vazão de injeção). As figuras 150, 151 e 152 exibem os valores de velocidade instantâneos dos primeiros 40 segundos de captura (200 pares de imagens) para a faixa de vazões $0,02 \mathrm{ml} / \mathrm{h} \leq Q \leq 0,32 \mathrm{ml} / \mathrm{h}$. 

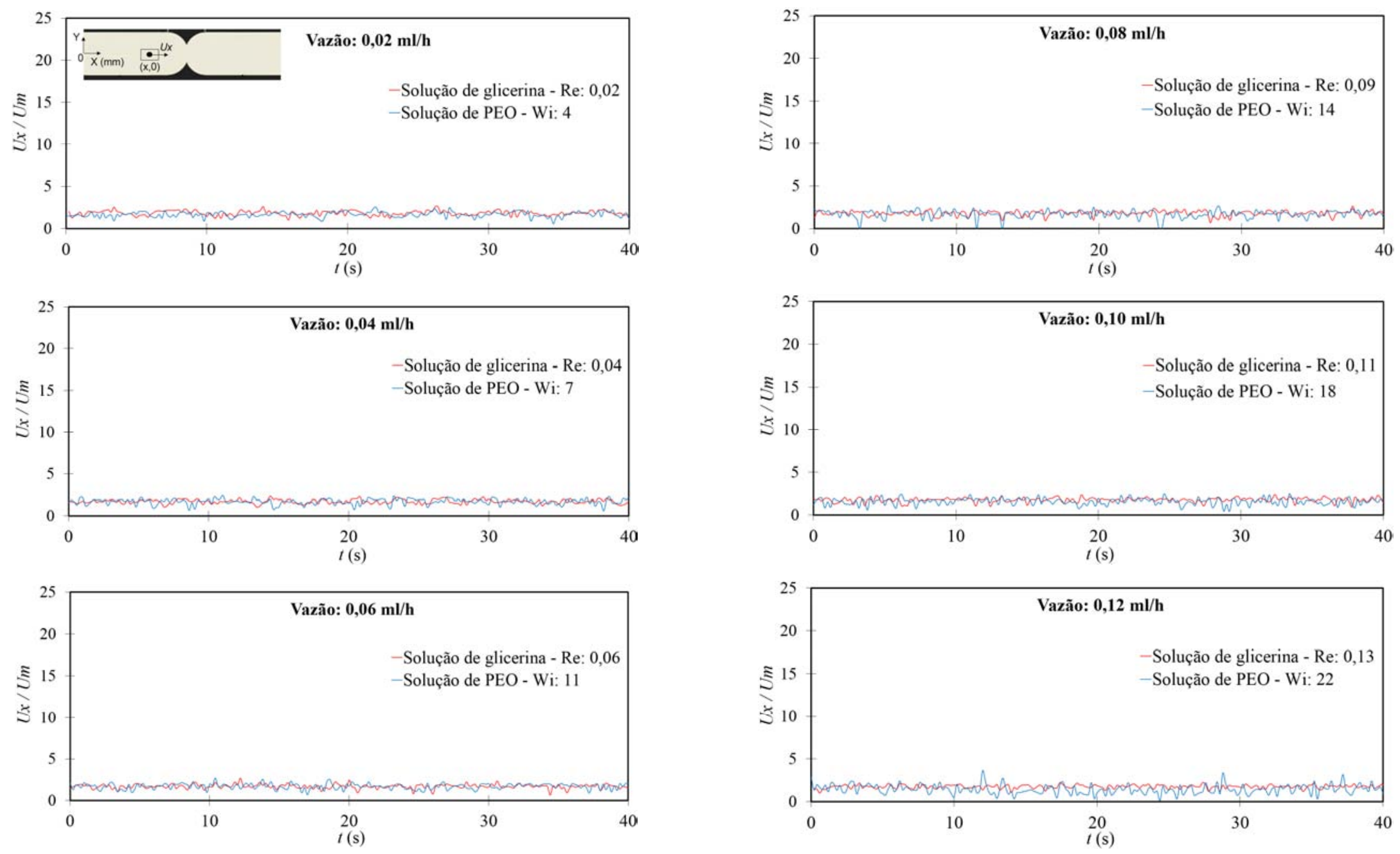

Figura 150 - Velocidade instantânea local adimensional. Para a solução de glicerina e PEO às vazões de injeção de $Q=0,02 \mathrm{ml} / \mathrm{h}, Q=0,04$ $\mathrm{ml} / \mathrm{h}, Q=0,06 \mathrm{ml} / \mathrm{h}, Q=0,08 \mathrm{ml} / \mathrm{h}, Q=0,10 \mathrm{ml} / \mathrm{h}$ e $Q=0,12 \mathrm{ml} / \mathrm{h}$ 

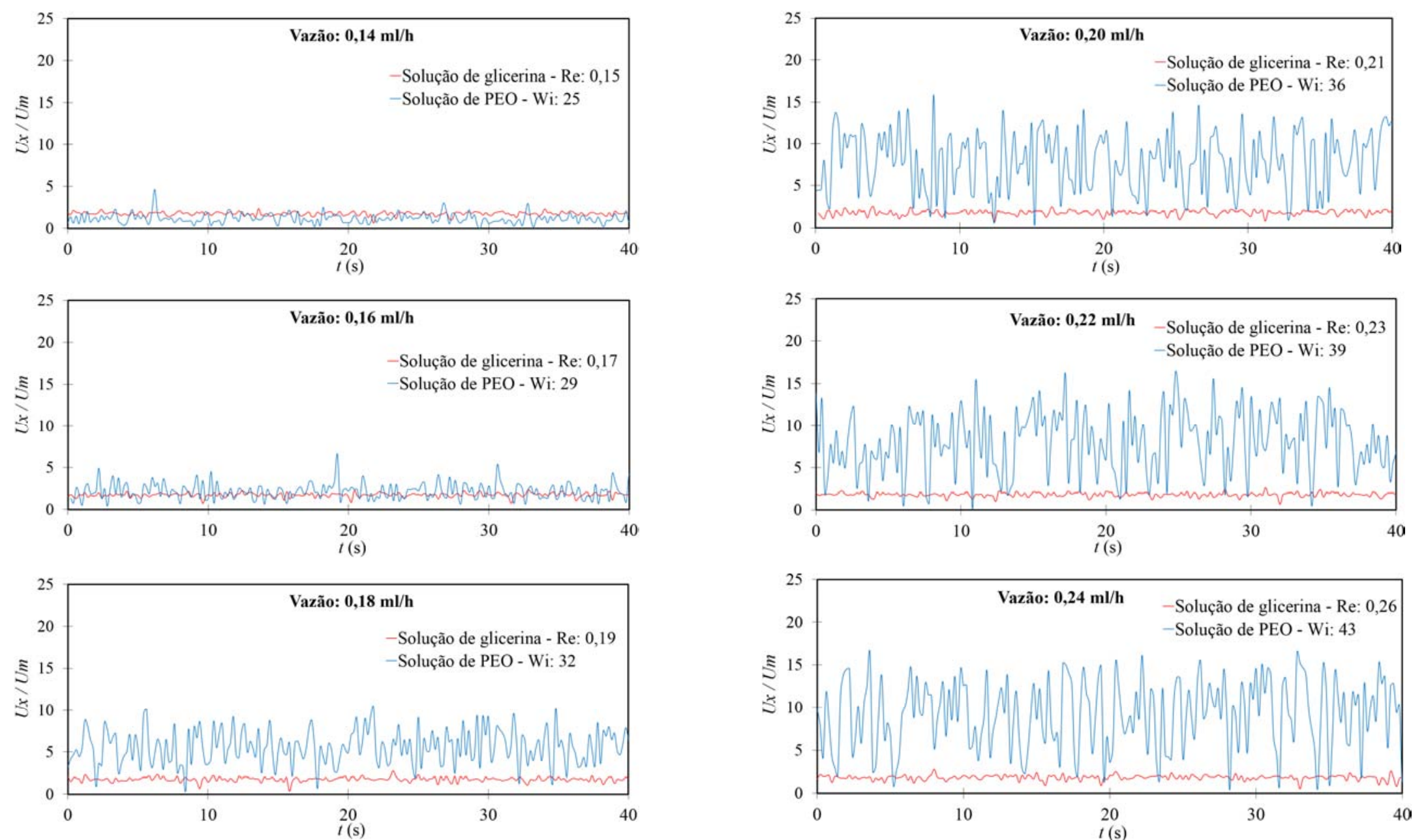

Figura 151 - Velocidade instantânea local adimensional. Para a solução de glicerina e PEO às vazões de injeção de $Q=0,14 \mathrm{ml} / \mathrm{h}, Q=0,16$ $\mathrm{ml} / \mathrm{h}, Q=0,18 \mathrm{ml} / \mathrm{h}, Q=0,20 \mathrm{ml} / \mathrm{h}, Q=0,22 \mathrm{ml} / \mathrm{h}$ e $Q=0,24 \mathrm{ml} / \mathrm{h}$ 

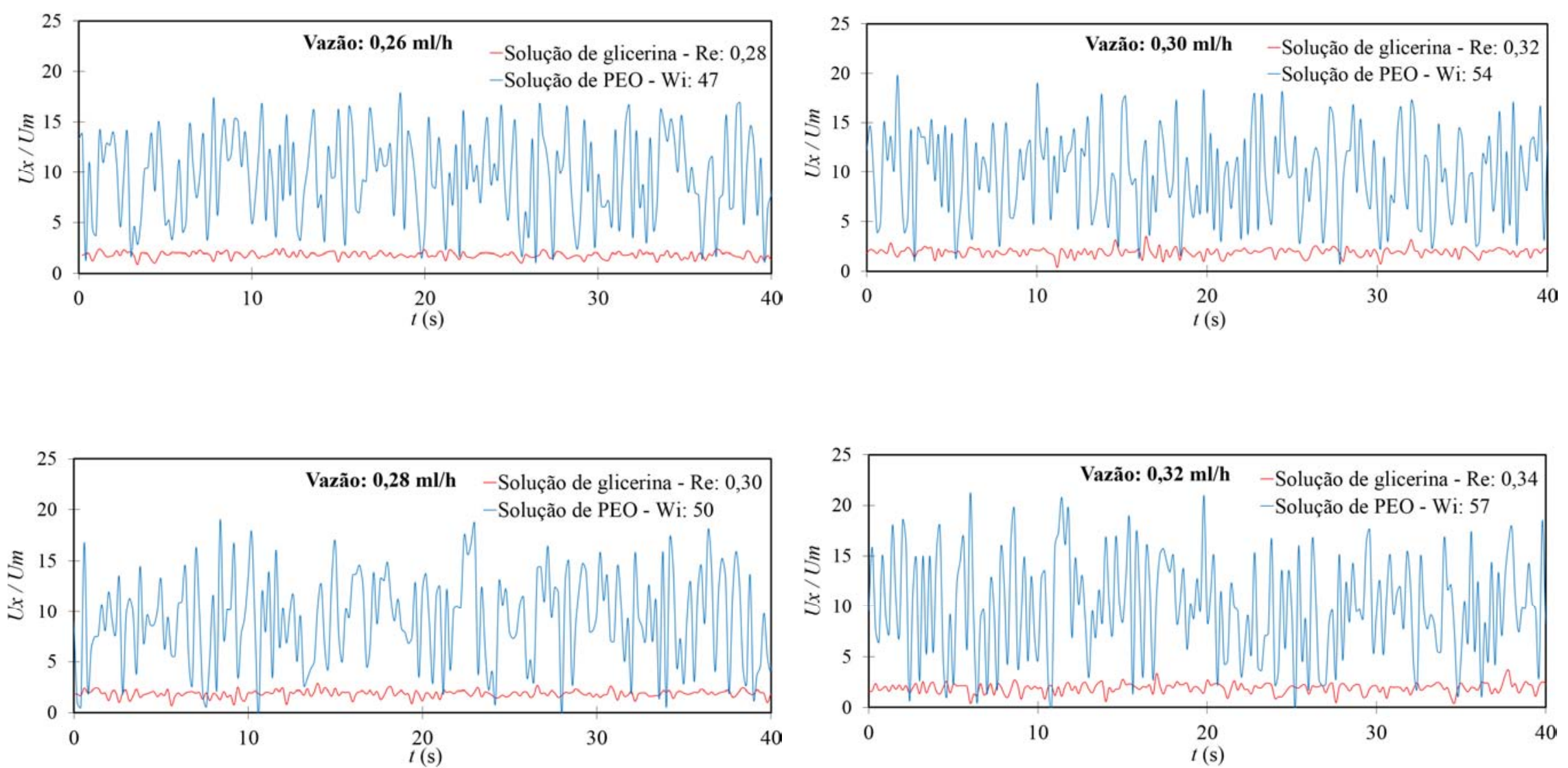

Figura 152 - Velocidade instantânea local adimensional. Para a solução de glicerina e PEO às vazões de injeção de $Q=0,26 \mathrm{ml} / \mathrm{h}, Q=0,28$ $\mathrm{ml} / \mathrm{h}, Q=0,30 \mathrm{ml} / \mathrm{h}$ e $Q=0,32 \mathrm{ml} / \mathrm{h}$ 
Às menores vazões, $Q<0,18 \mathrm{ml} / \mathrm{h}$, é possivel observar as velocidades instantâneas local da solução de PEO e glicerina variando próximos entre eles. Entretanto, para maiores vazões $Q \geq 0,18 \mathrm{ml} / \mathrm{h}$, os valores de velocidade instantâneo local da solução de PEO crescem em magnitude e flutuação.

Para quantificar a magnitude e intensidade de variação da velocidade instantânea local da solução de PEO e glicerina, a media e o desvio padrão dos 500 valores de velocidade local (campos instantâneos) foi determinado e representado na figura 153 em função da vazão de injeção.

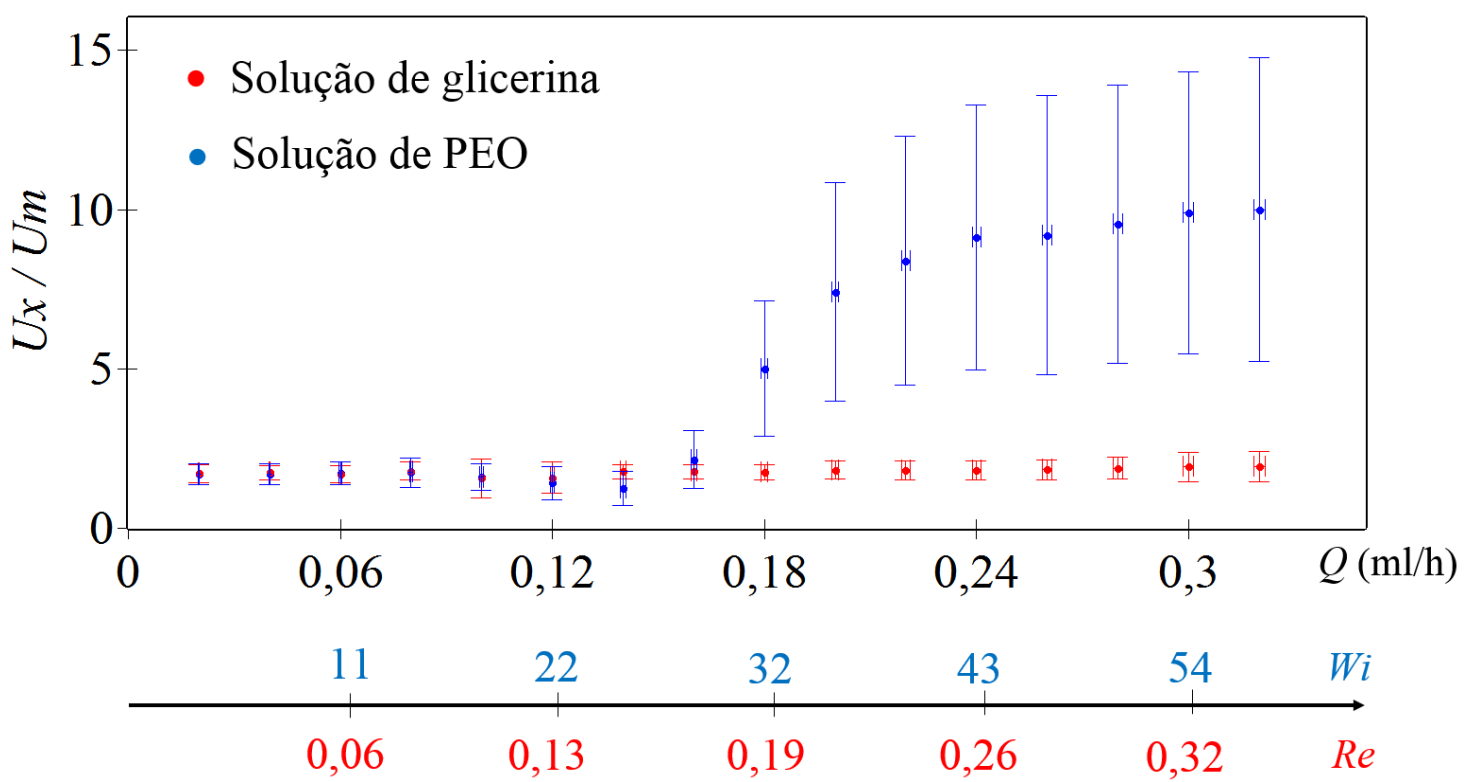

Figura 153 - Velocidade instantânea local adimensional (média de 500 valores) em função da vazão para as soluções de glicerina e PEO

No inicio é possivel observar que tanto a magnitude como as flutuações de velocidade das soluções de glicerina e PEO são muito próximos, em torno de $U x / U m \approx 1,7$. A partir da condição do escomanto de $W i>32$, a magnitude e a flutução de velocidade da solução de PEO crescem rapidamente até atingir um patamar em torno de $U x / U m \approx 10$, enquanto a solução de glicerina mantem o mesmo valor quase constante. $\mathrm{O}$ fato do crescimento é devido a que as forças elásticas do polímero chegam a ser dominantes e, consequentemente, alteram o padrão dinâmico do escoamento. As flutuações de velocidade não podem ser causados por efeitos de inercia, já que os números de Reynolds são muito baixos, na ordem de $\approx 10^{-1}$. 
Vale mencionar que o atraso do incremento da velocidade instantânea e da flutuação de velocidade na solução de PEO é devido a que a área selecionada fica a uma certa distância onde o escoamento é afetado inicialmente (diâmetro menor da garganta). Como explicado anteriormente, nessa região as partículas ficavam grudadas na parede fazendo difícil sua avaliação.

As medições da queda de pressão global e as medições de velocidade instantânea local devido apenas aos efeitos elásticos do polímero podem ser relacionadas através da figura 154 em função da vazão de injeção.

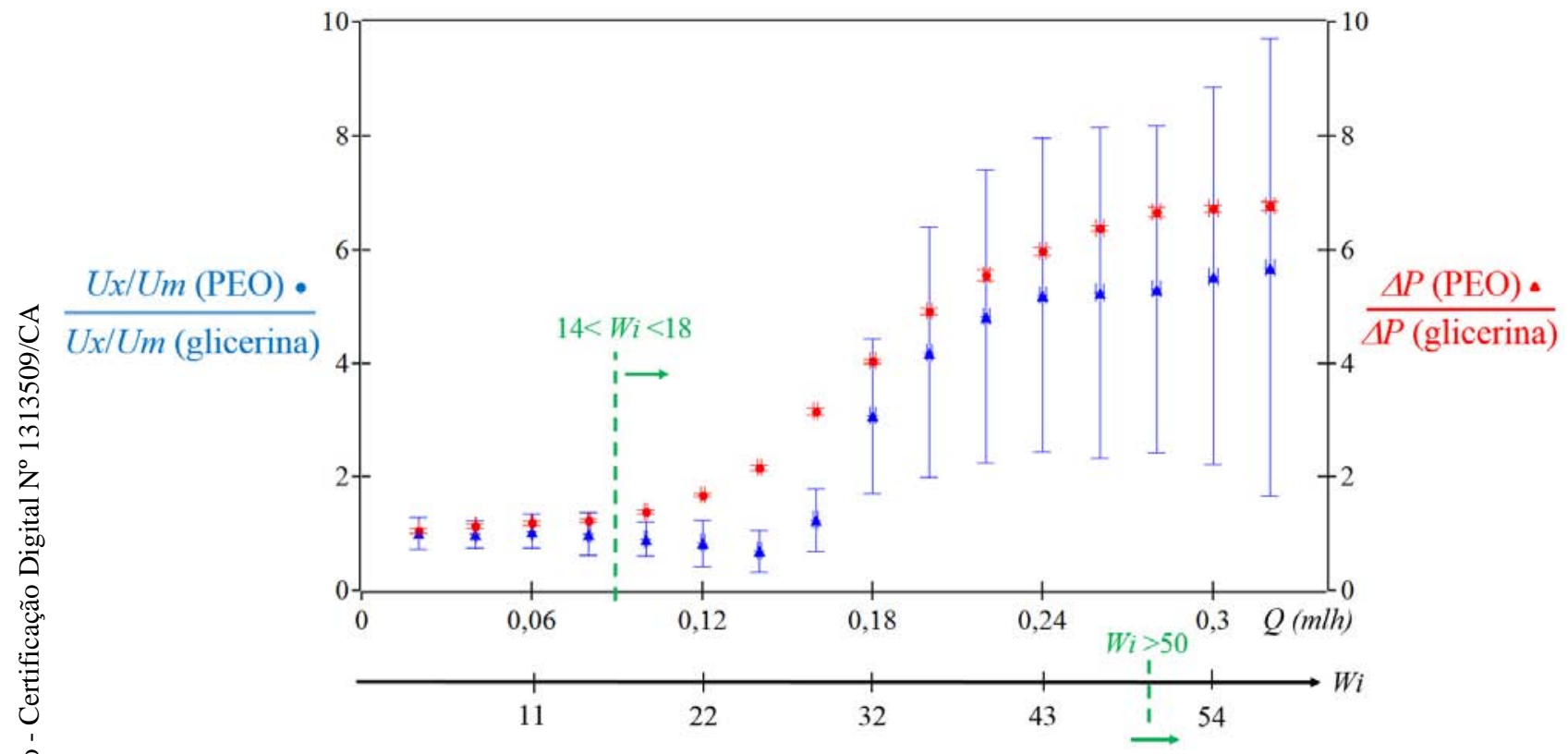

Figura 154 - Comparação da queda de pressão extra e o aumento da velocidade instantânea local em função da vazão

É possivel notar uma tendência constante para menores valores de Weissenberg, devido a que os efeitos viscosos ainda são importantes nos escoamentos.

Para Weissenberg $W i>14$, um aumento progressivo na queda de pressão extra é visualizado. Enquanto, uma pequena diminuição dos valores de velocidade instantânea local é observada talvez pelos efeitos shear thinning presente na solução semidiluida de PEO, seguido de um incremento por causa dos efeitos da elasticidade que se tornaram importantes no escoamento. Ambas as medições 
tendem a atingir um patamar, coincidendo com o tamanho constante dos vórtices a partir do número de Weissemberg Wi>50.

Uma visão global das flutuações de velocidade em todo o escoamento (na região da garganta) é representado através do desvio padrão dos campos de velocidade instantâneo e é discutido na seção a seguir.

\subsubsection{3.}

\section{Desvio padrão dos campos de velocidade}

A finalidade de determinar o desvio padrão dos 500 campos de velocidade instantâneo do escoamento na região da constrição é estudar as regiões do escoamento que sofreram um fluxo extensional, e a intensidade das flutuações de velocidade.

É importante mencionar que os campos de velocidade instantâneo foram determinados com uma janela de interrogação de 64x32 pixel a fim de melhorar a relação de sinal/ruído nas imagens. Embora, as partículas aderidas no centro da garganta, e a baixa densidade de partículas perto das paredes levaram maiores flutuações de velocidade nessas regiões nos campos de desvio padrão.

As figuras 155, 156, 157, 158, 159 e 160 representam os campos de escoamento medidos ao longo do tempo para a solução de glicerina como a solução de PEO para efeitos de comparação. Foram realizados para diferentes condições de injeção no escoamento $(0,02 \mathrm{ml} / \mathrm{h} \leq Q \leq 0,32 \mathrm{ml} / \mathrm{h})$. 

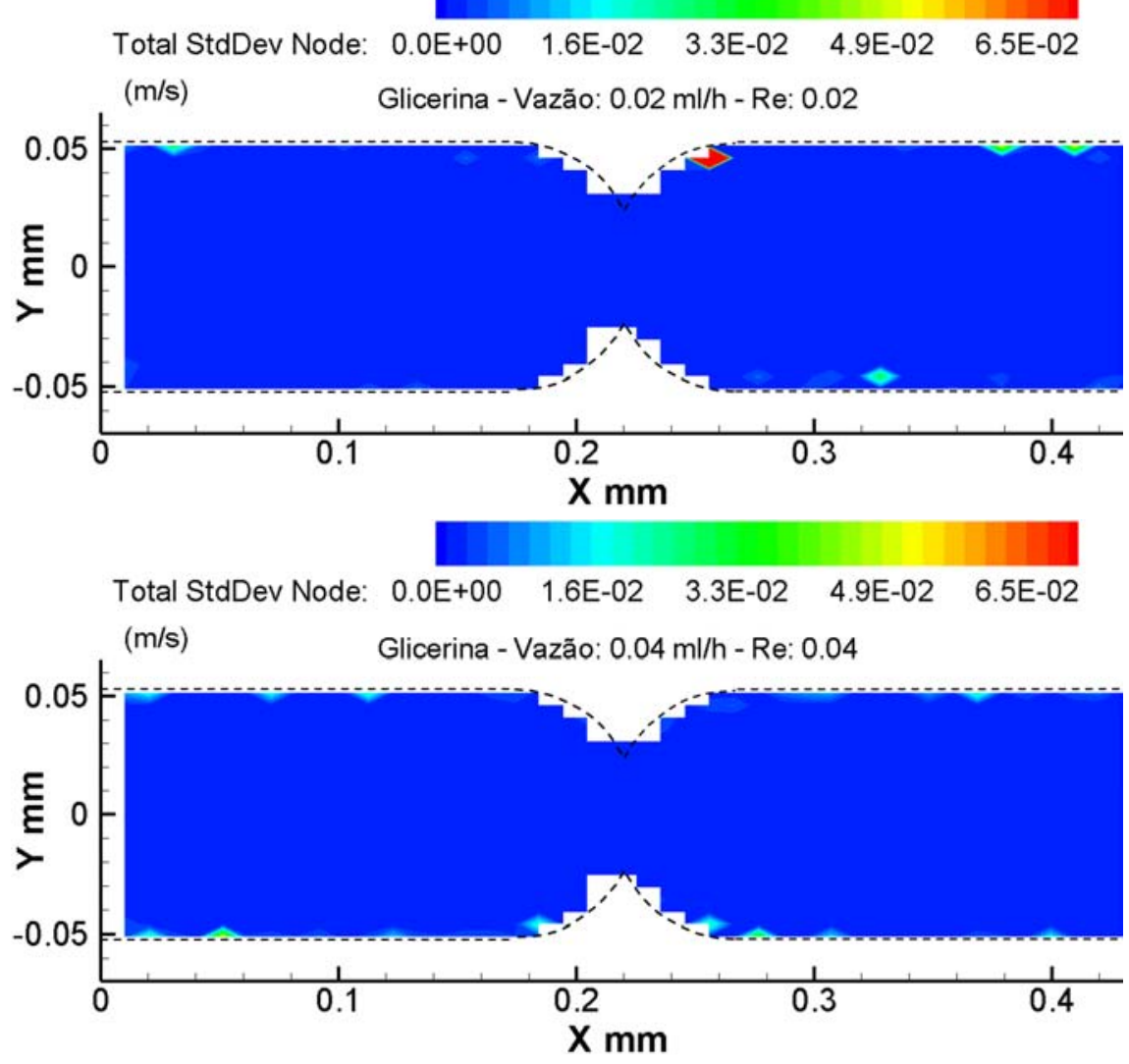

Total StdDev Node: $\quad 0.0 \mathrm{E}+00 \quad 1.6 \mathrm{E}-02 \quad 3.3 \mathrm{E}-02 \quad 4.9 \mathrm{E}-02 \quad 6.5 \mathrm{E}-02$

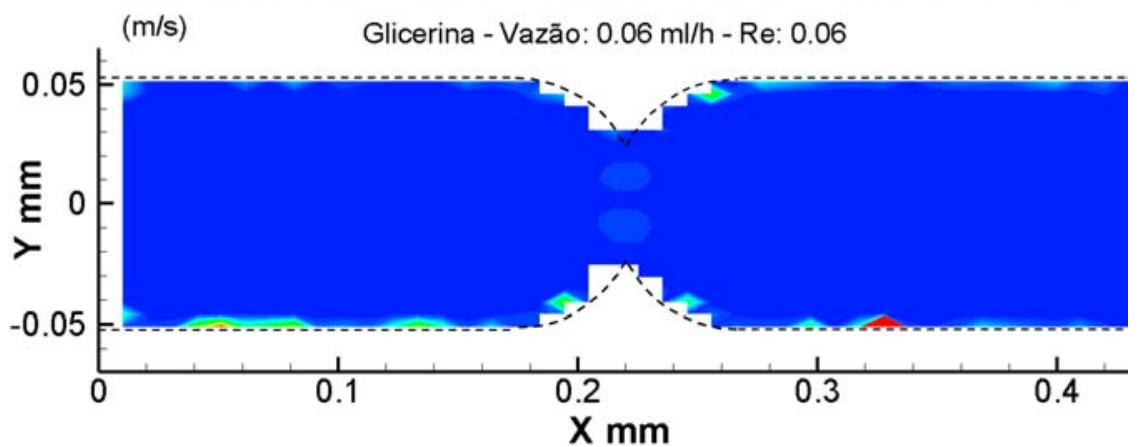

Total StdDev Node: $\quad 0.0 \mathrm{E}+00 \quad 1.6 \mathrm{E}-02 \quad 3.3 \mathrm{E}-02 \quad 4.9 \mathrm{E}-02 \quad 6.5 \mathrm{E}-02$ $(\mathrm{m} / \mathrm{s})$

PEO - Vazão: $0.02 \mathrm{ml} / \mathrm{h}$ - Wi: 4
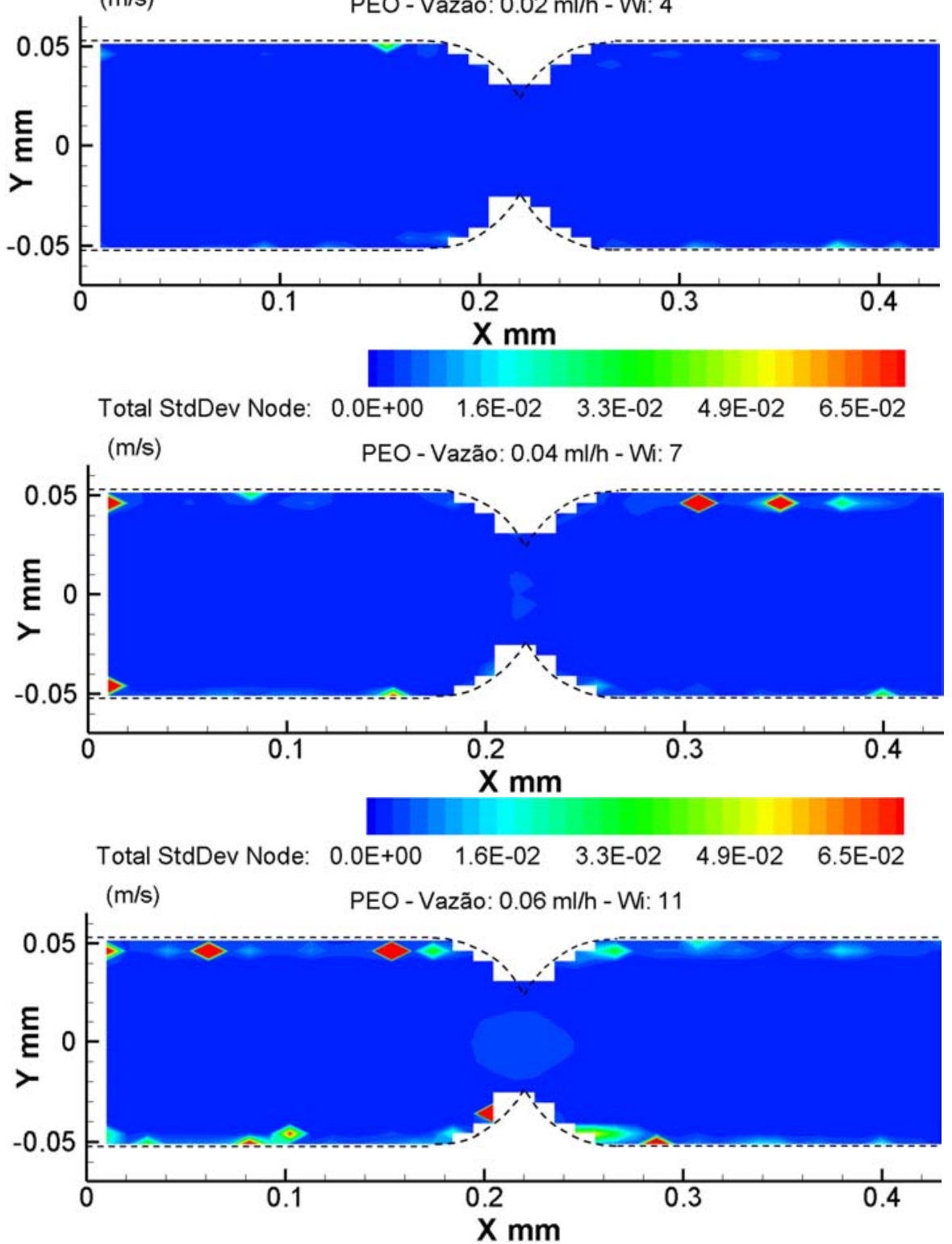

Figura 155 - Campo de desvio padrão para a solução de glicerina e PEO às vazões de injeção $Q=0,02 \mathrm{ml} / \mathrm{h}, Q=0,04 \mathrm{ml} / \mathrm{h}$ e $Q=0,06 \mathrm{ml} / \mathrm{h}$ 


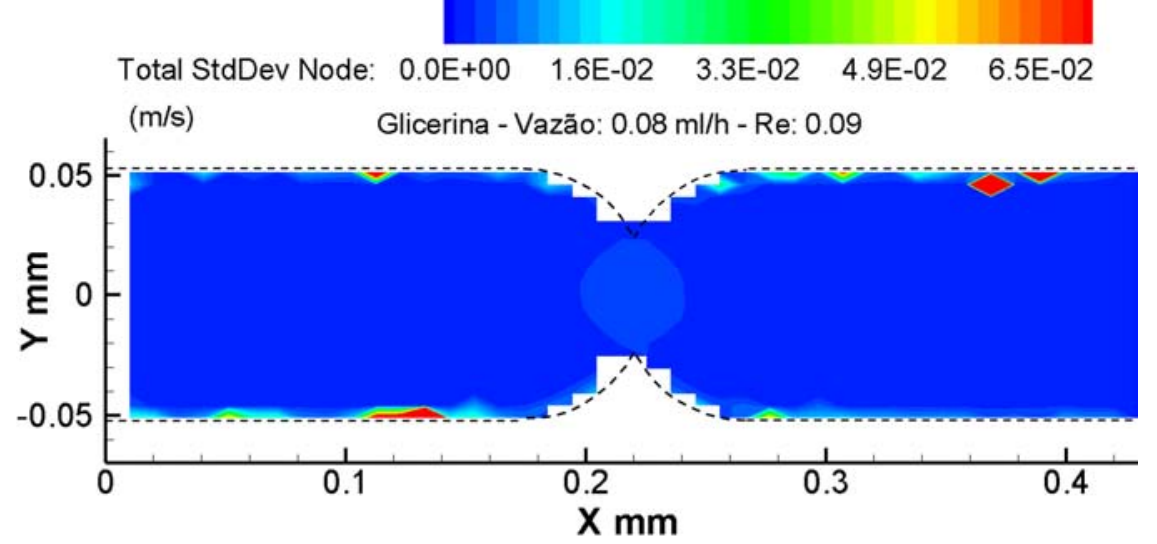

Total StdDev Node: $\quad 0.0 \mathrm{E}+00 \quad 1.6 \mathrm{E}-02 \quad 3.3 \mathrm{E}-02 \quad 4.9 \mathrm{E}-02 \quad 6.5 \mathrm{E}-02$

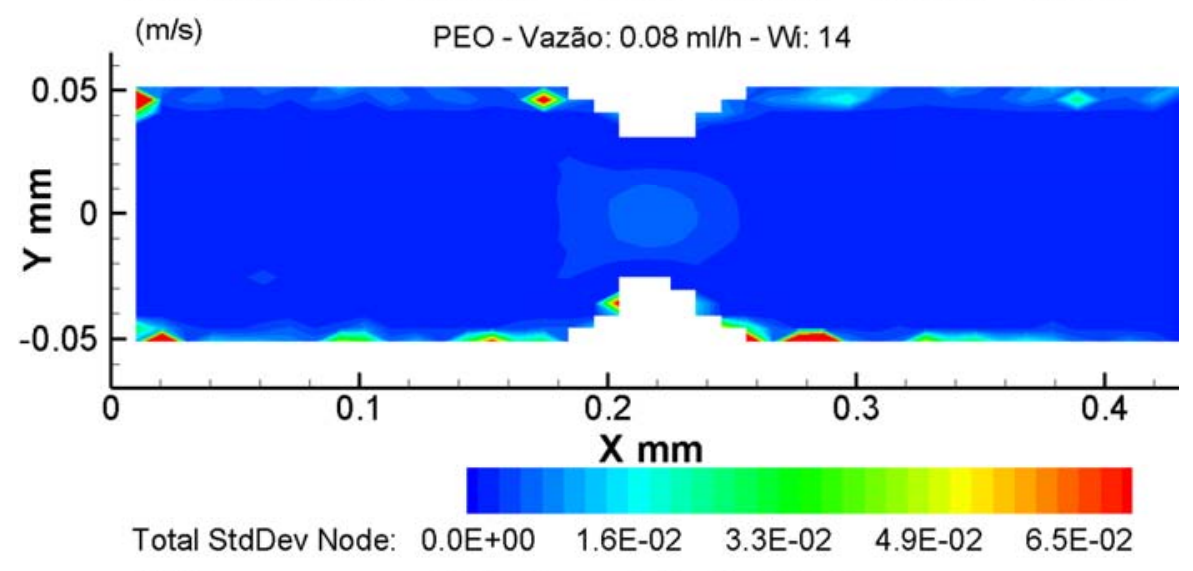

Total StdDev Node: $\quad 0.0 \mathrm{E}+00 \quad 1.6 \mathrm{E}-02 \quad 3.3 \mathrm{E}-02 \quad 4.9 \mathrm{E}-02 \quad 6.5 \mathrm{E}-02$

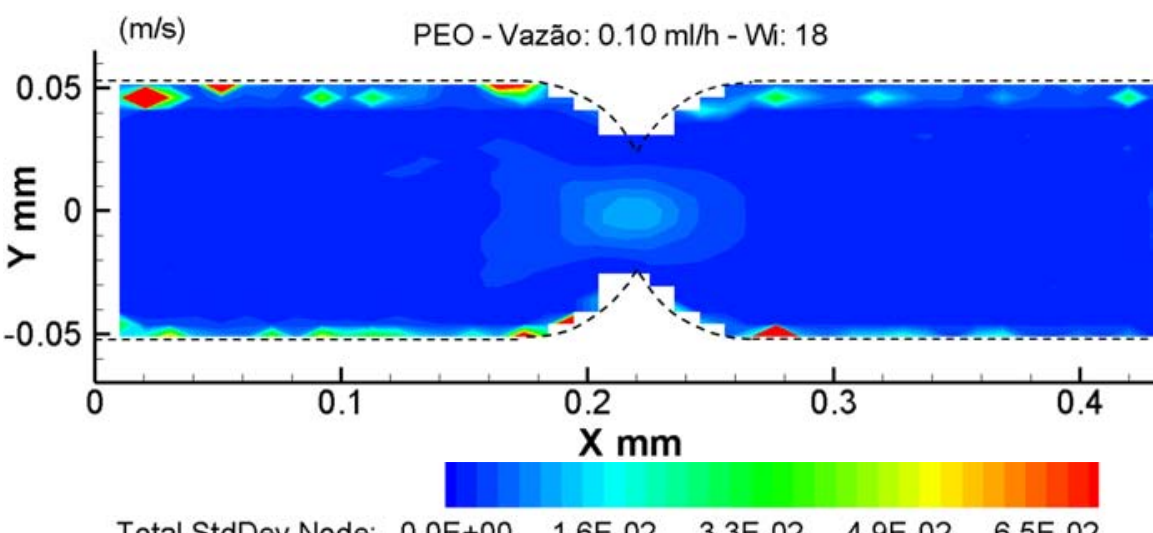

Total StdDev Node: $\quad 0.0 \mathrm{E}+00 \quad 1.6 \mathrm{E}-02 \quad 3.3 \mathrm{E}-02 \quad 4.9 \mathrm{E}-02 \quad 6.5 \mathrm{E}-02$

(m/s) Glicerina - Vazão: $0.12 \mathrm{ml} / \mathrm{h}$ - Re: 0.13
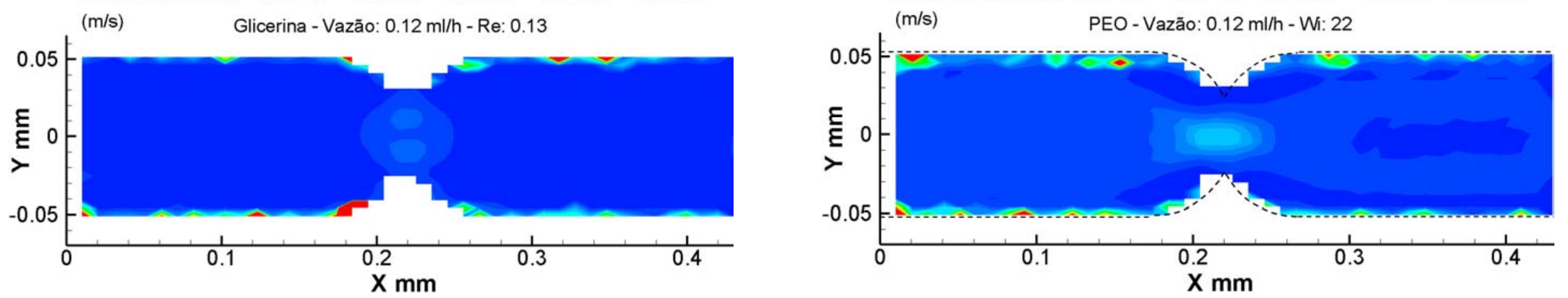

Figura 156 - Campo de desvio padrão para a solução de glicerina e $P E O$ às vazões de injeção $Q=0,08 \mathrm{ml} / \mathrm{h}, Q=0,10 \mathrm{ml} / \mathrm{h}$ e $Q=0,12 \mathrm{ml} / \mathrm{h}$ 

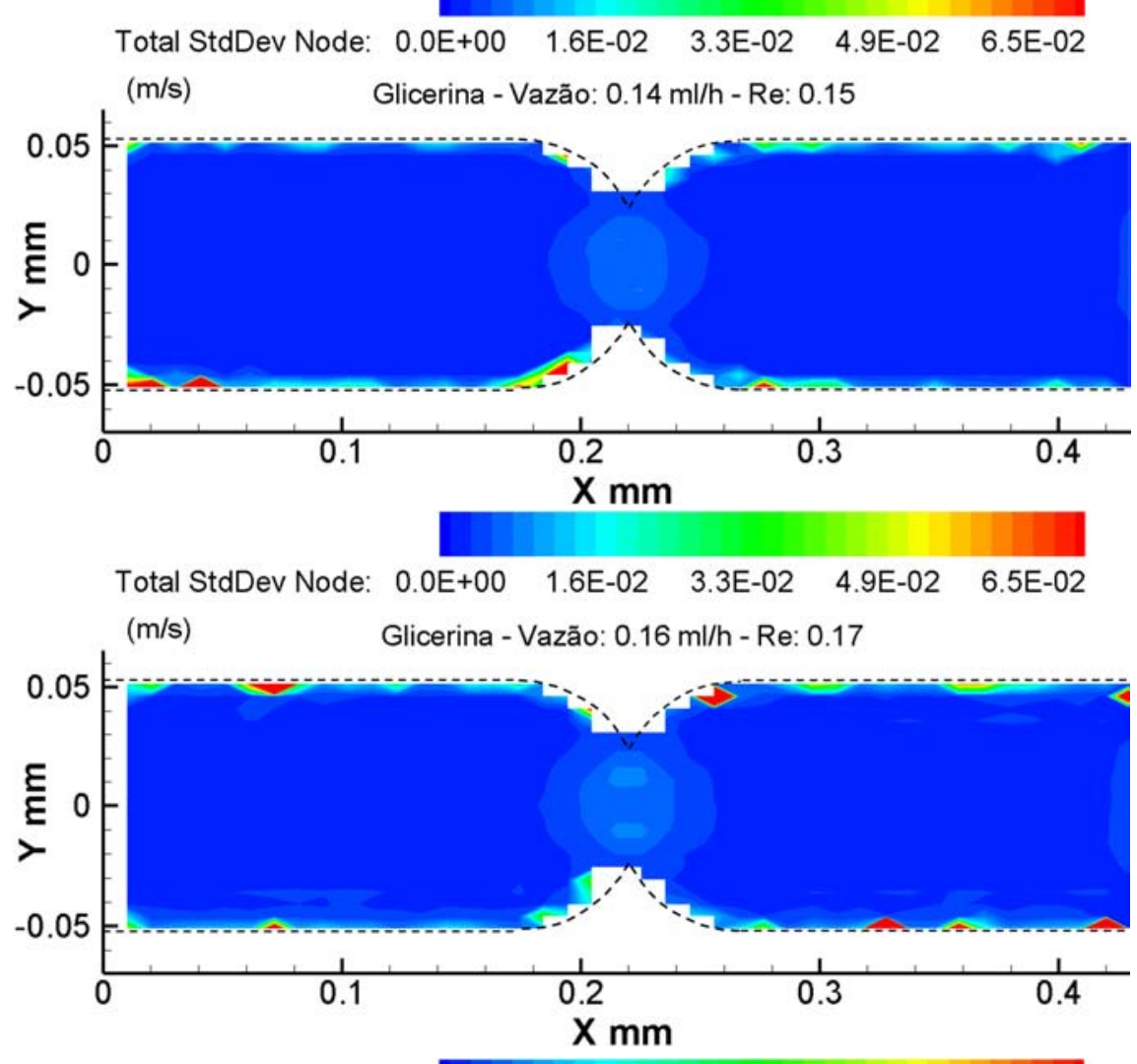

Total StdDev Node: $\quad 0.0 \mathrm{E}+00 \quad 1.6 \mathrm{E}-02 \quad 3.3 \mathrm{E}-02 \quad 4.9 \mathrm{E}-02 \quad 6.5 \mathrm{E}-02$ $(\mathrm{m} / \mathrm{s})$

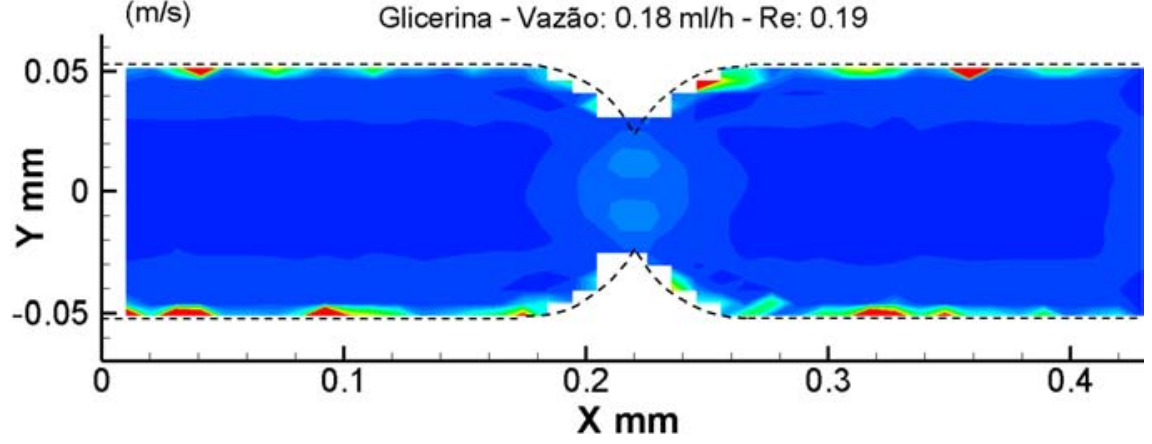

Total StdDev Node: $\quad 0.0 \mathrm{E}+00 \quad 1.6 \mathrm{E}-02 \quad 3.3 \mathrm{E}-02 \quad 4.9 \mathrm{E}-02 \quad 6.5 \mathrm{E}-02$ $(\mathrm{m} / \mathrm{s})$

PEO - Vazão: $0.14 \mathrm{ml} / \mathrm{h}$ - Wi: 25

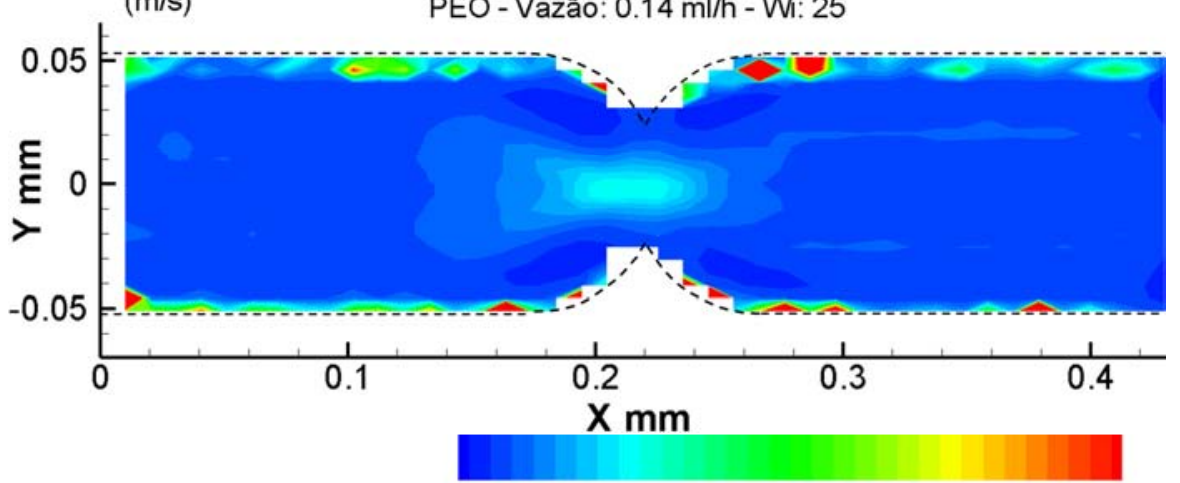

Total StdDev Node: $\quad 0.0 \mathrm{E}+00 \quad 1.6 \mathrm{E}-02 \quad 3.3 \mathrm{E}-02 \quad 4.9 \mathrm{E}-02 \quad 6.5 \mathrm{E}-02$

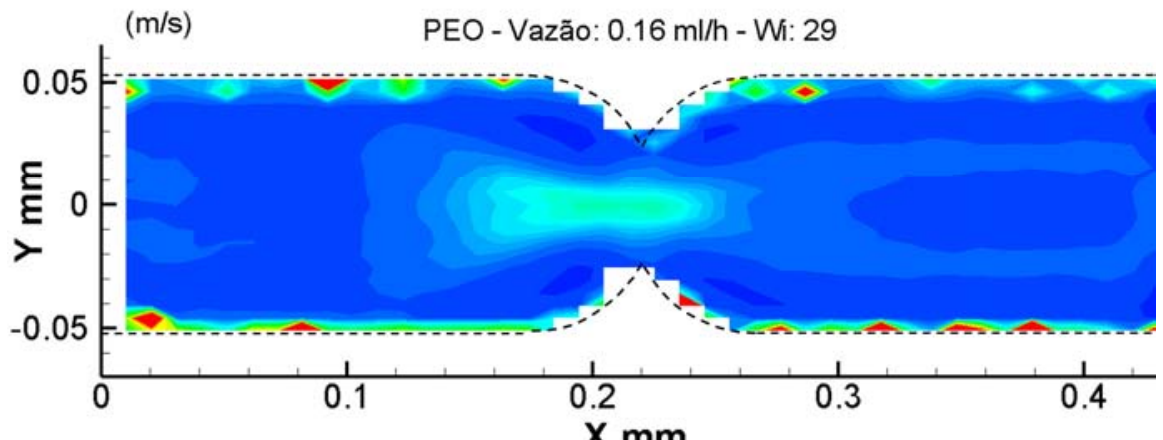

$\mathrm{X} \mathrm{mm}$

Total StdDev Node: $\quad 0.0 \mathrm{E}+00 \quad 1.6 \mathrm{E}-02 \quad 3.3 \mathrm{E}-02 \quad 4.9 \mathrm{E}-02 \quad 6.5 \mathrm{E}-02$

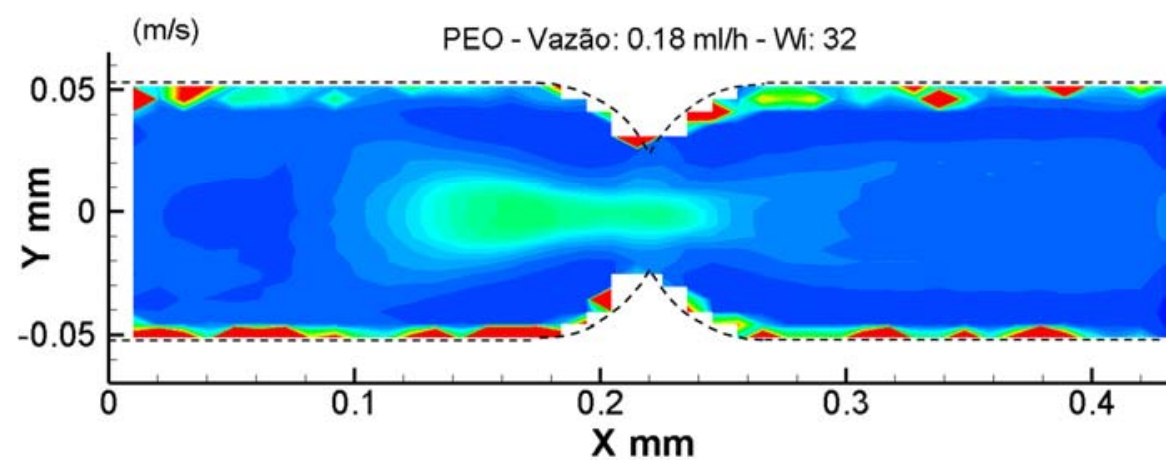

Figura 157 - Campo de desvio padrão para a solução de glicerina e $P E O$ às vazões de injeção $Q=0,14 \mathrm{ml} / \mathrm{h}, Q=0,16 \mathrm{ml} / \mathrm{h}$ e $Q=0,18 \mathrm{ml} / \mathrm{h}$ 


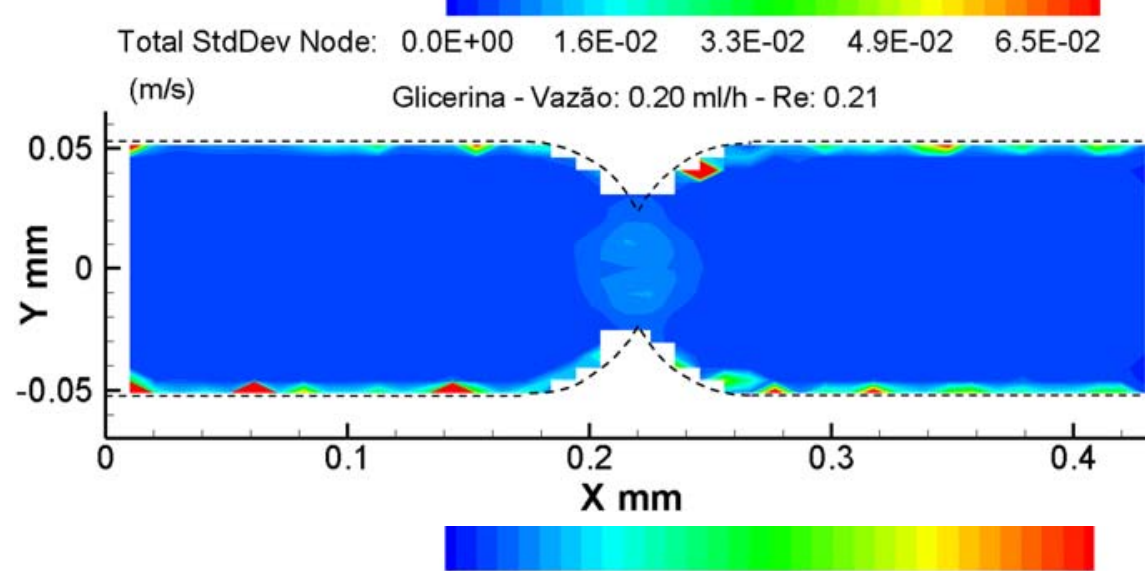

Total StdDev Node: $\quad 0.0 \mathrm{E}+00 \quad 1.6 \mathrm{E}-02 \quad 3.3 \mathrm{E}-02 \quad 4.9 \mathrm{E}-02 \quad 6.5 \mathrm{E}-02$

$(\mathrm{m} / \mathrm{s})$

PEO - Vazão: $0.20 \mathrm{ml} / \mathrm{h}$ - Wi: 36

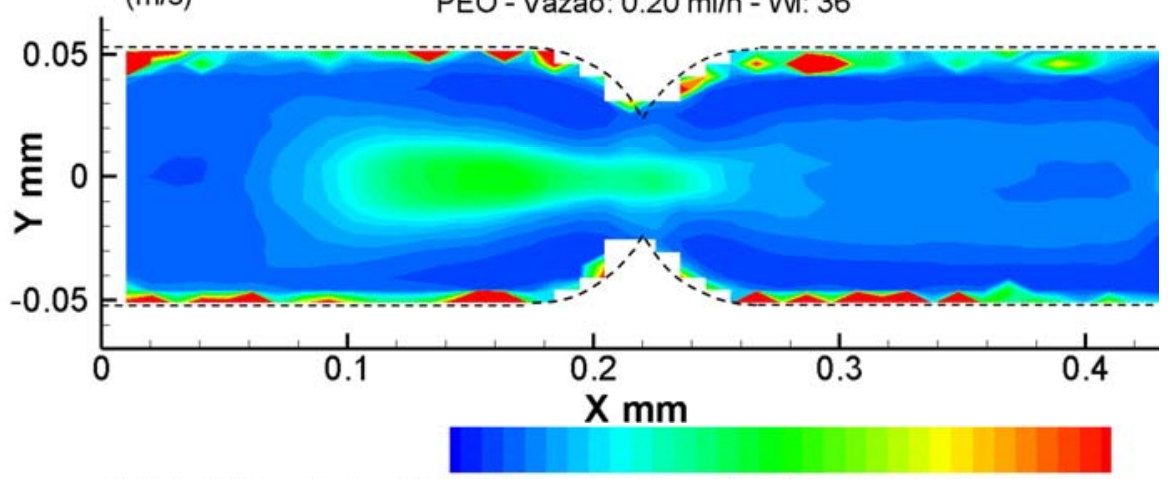

Total StdDev Node: $\quad 0.0 \mathrm{E}+00 \quad 1.6 \mathrm{E}-02 \quad 3.3 \mathrm{E}-02 \quad 4.9 \mathrm{E}-02 \quad 6.5 \mathrm{E}-02$
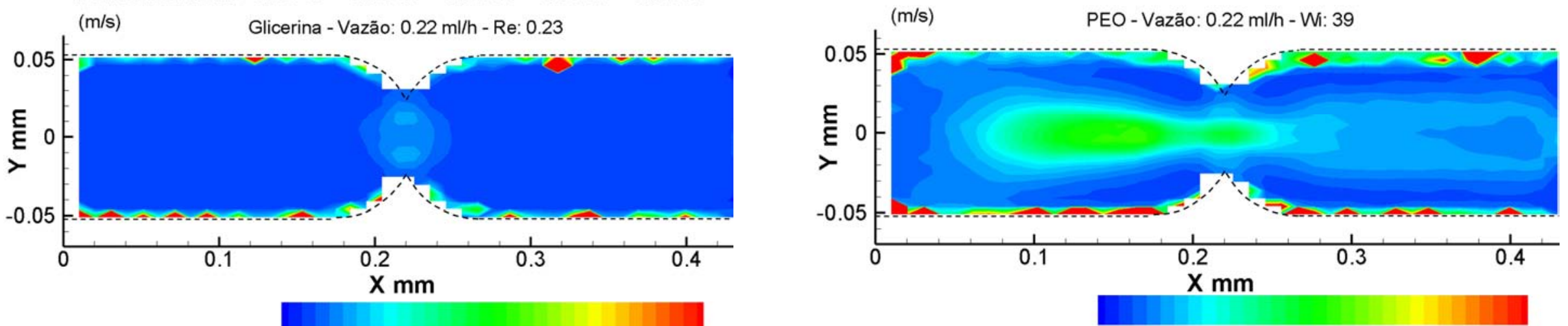

Total StdDev Node: $\quad 0.0 \mathrm{E}+00 \quad 1.6 \mathrm{E}-02 \quad 3.3 \mathrm{E}-02 \quad 4.9 \mathrm{E}-02 \quad 6.5 \mathrm{E}-02$

(m/s) Glicerina - Vazão: $0.24 \mathrm{ml} / \mathrm{h}$ - Re: 0.26
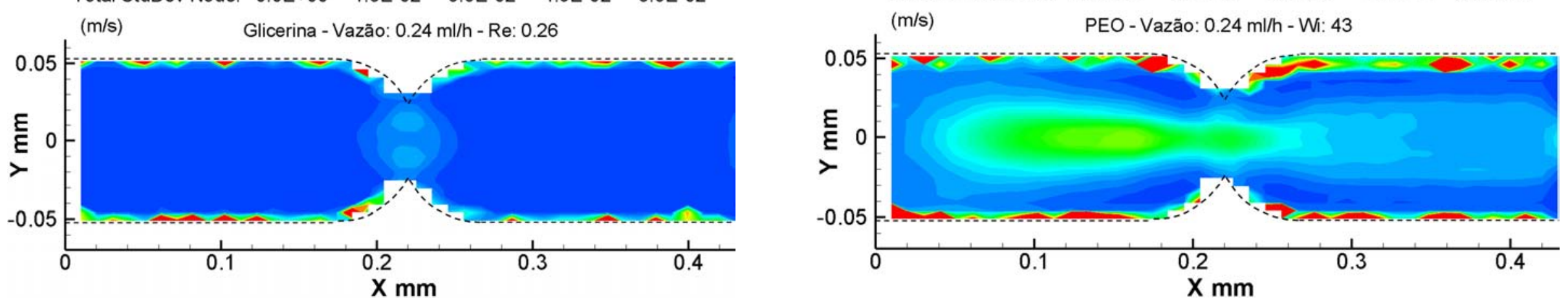

Figura 158 - Campo de desvio padrão para a solução de glicerina e $P E O$ às vazões de injeção $Q=0,20 \mathrm{ml} / \mathrm{h}, Q=0,22 \mathrm{ml} / \mathrm{h}$ e $Q=0,24 \mathrm{ml} / \mathrm{h}$ 

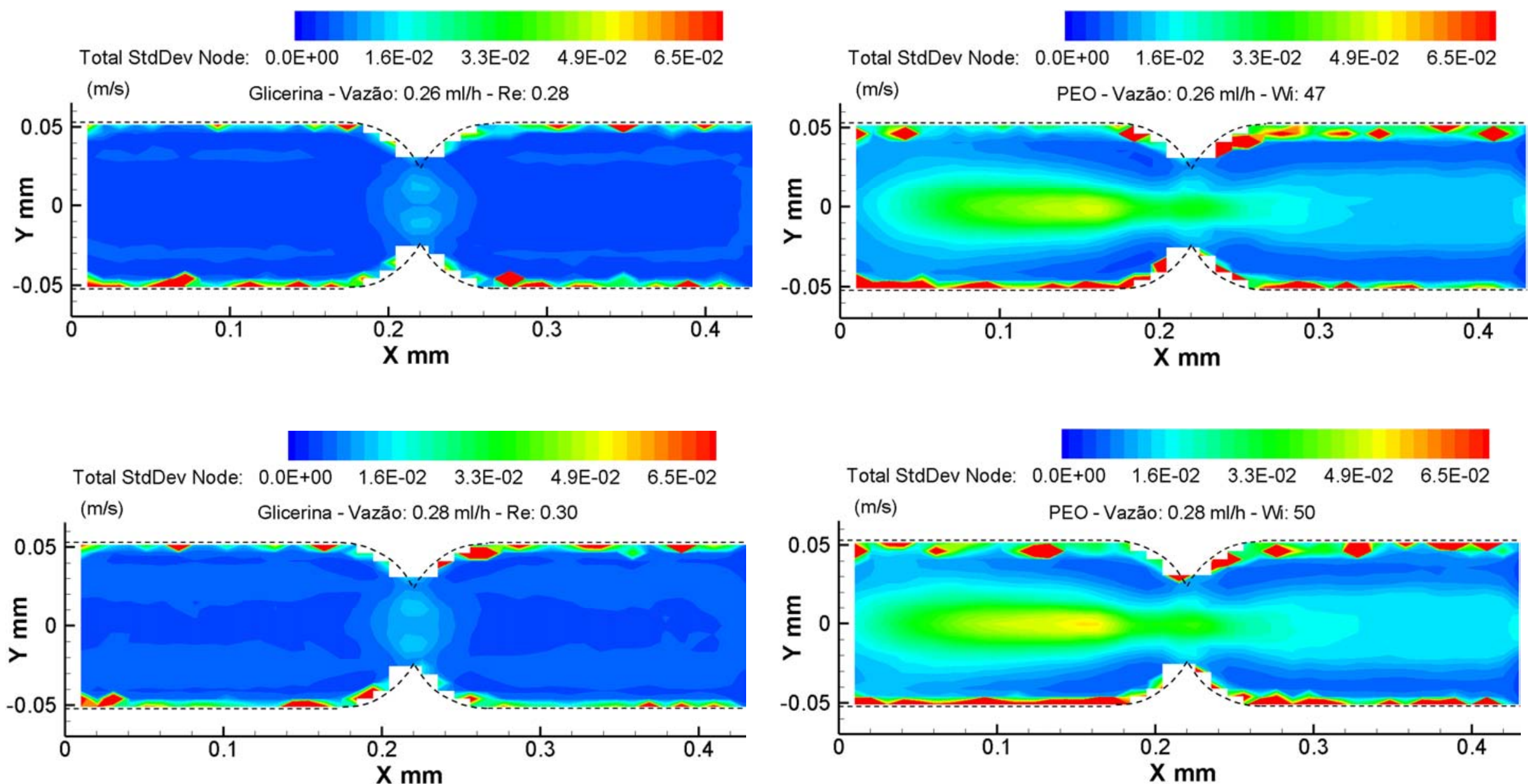

Figura 159 - Campo de desvio padrão para a solução de glicerina e $P E O$ às vazões de injeção $Q=0,26 \mathrm{ml} / \mathrm{h}$ e $Q=0,28 \mathrm{ml} / \mathrm{h}$ 

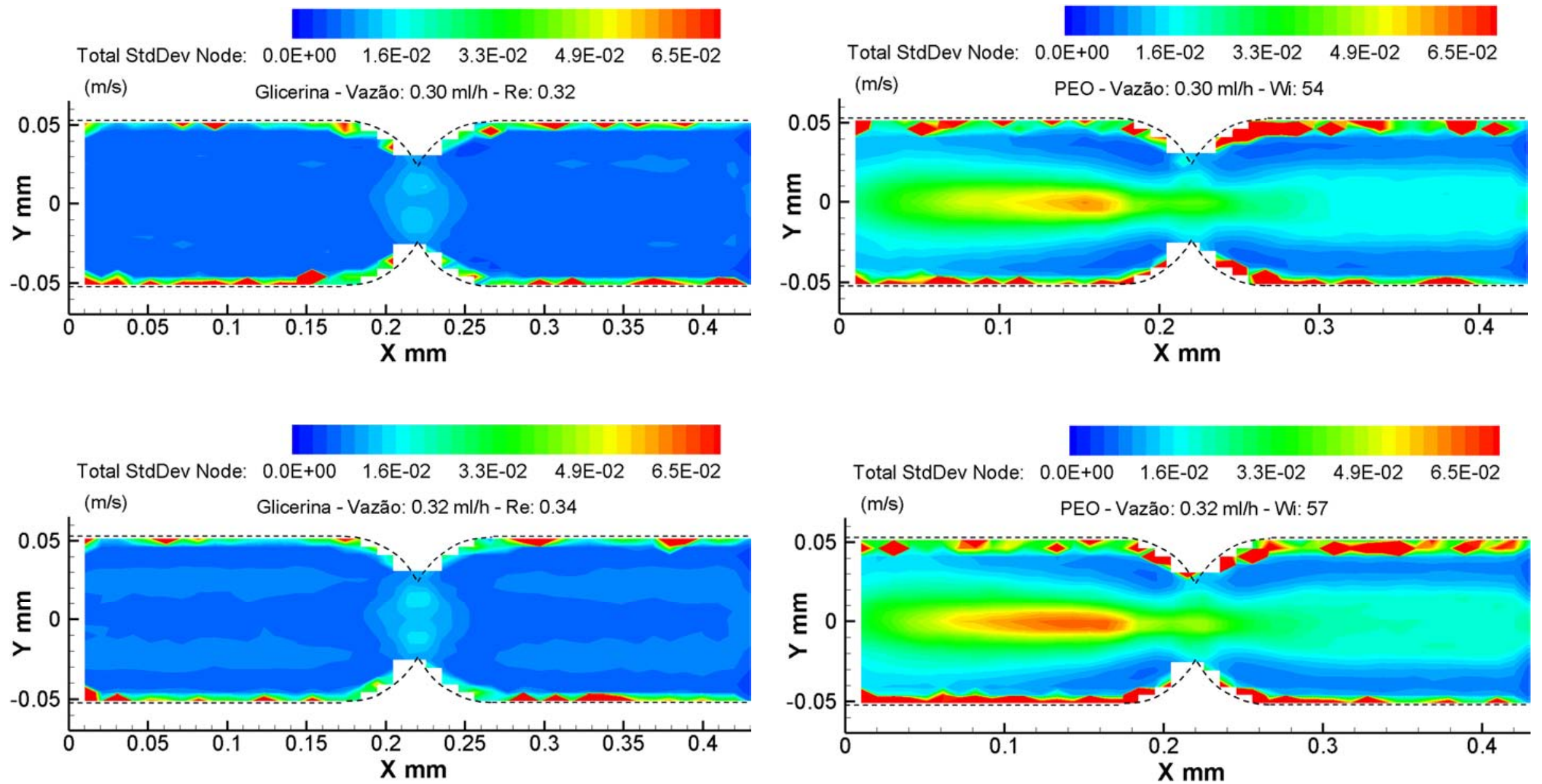

Figura 160 - Campo de desvio padrão para a solução de glicerina e PEO às vazões de injeção $Q=0,30 \mathrm{ml} / \mathrm{h}$ e $Q=0,32 \mathrm{ml} / \mathrm{h}$ 
Para maiores vazões de injeção $Q>0,06 \mathrm{ml} / \mathrm{h}$ existe uma distribuição de velocidade assimétrica no escoamento da solução de PEO. O aumento da viscosidade extensional com a taxa de extensão (componente elongacional do escoamento) coincide com o início de flutuações localizada na região central da garganta e logo vão crescendo por toda a região da garganta e sua vizinhança. Além disso, a formação e crescimento dos vórtices levaram maior intensidade de flutuações de velocidade à montante da garganta, sendo relacionada com o aumento da queda de pressão. As flutuações no escoamento de PEO são significativamente maiores do que observadas no escoamento da solução de glicerina.

Os efeitos de alongamento e contração das cadeias poliméricas da solução de PEO ao passarem pela garganta são os responsáveis pelo incremento das flutuações, sendo maiores na direção axial do escoamento. As figuras 161 e 162 mostram as flutuações de velocidade na direção axial X e perpendicular Y do escoamento Newtoniano (solução de glicerina) e viscoelástico (solução de PEO) para a vazão máxima estudada $(Q=0,32 \mathrm{ml} / \mathrm{h})$.
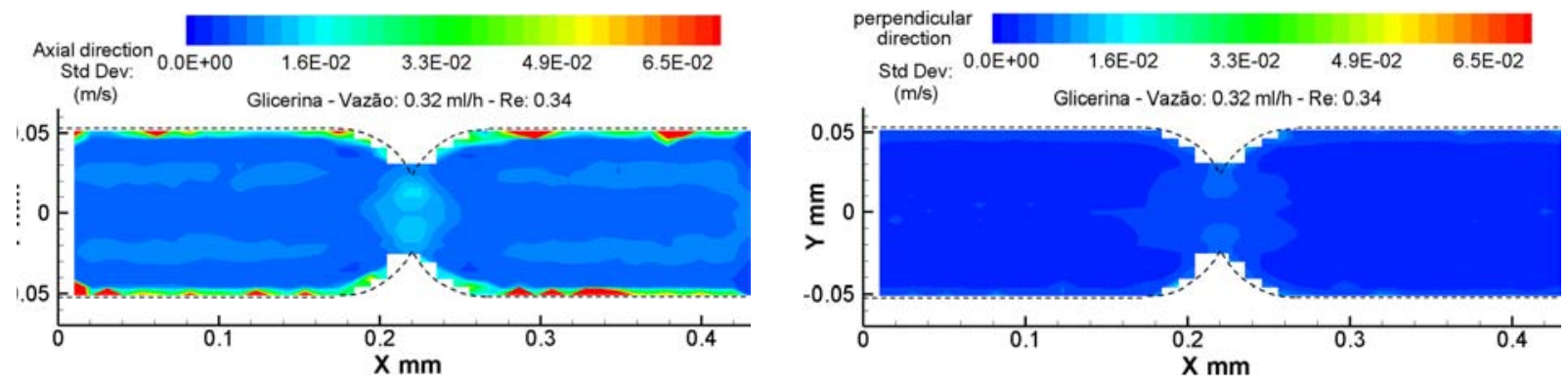

Figura 161 - Campo de desvio padrão na direção axial e perpendicular do escoamento da solução de glicerina para a vazão de injeção de $Q=0,32 \mathrm{ml} / \mathrm{h}$
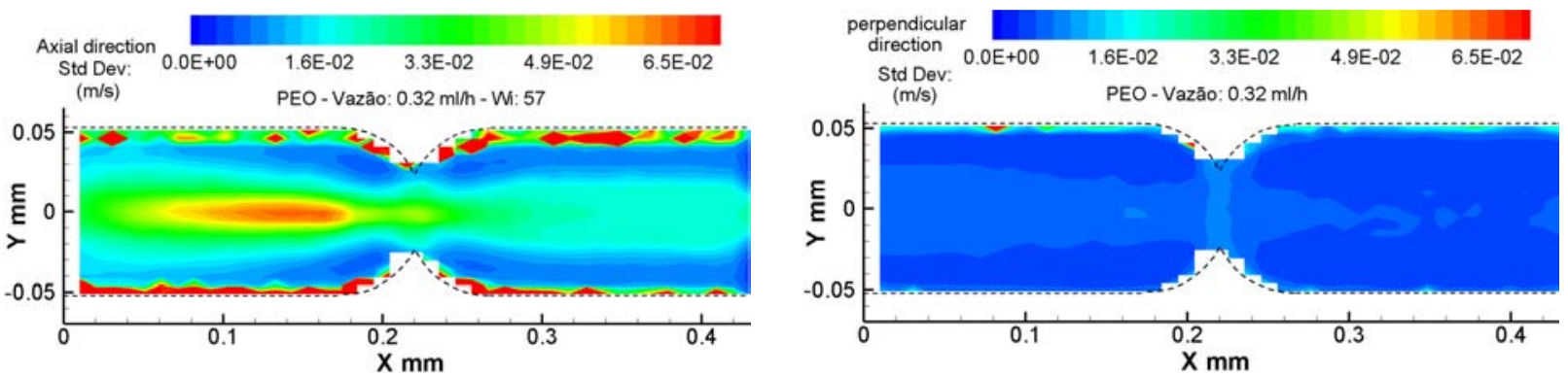

Figura 162 - Campo de desvio padrão na direção axial e perpendicular do escoamento da solução de PEO para a vazão de injeção de $Q=0,32 \mathrm{ml} / \mathrm{h}$ 
É importante ressaltar na região à saída da garganta dos campos de desvio padrão, as cadeias poliméricas da solução de PEO não conseguiram reestabelecer sua configuração original (relaxação), influenciando no escoamento de entrada. Tomando em conta esse fato e a variação de profundidade da garganta tornam um escoamento de cinemática complexa do que comparado com as geometrias padrão de contrição abrupta planar de profundidade constante e de maiores comprimentos de constrição (Li et al., 2015 e Clarke et al., 2015).

O trabalho de Clarke et al. (2015) citado anteriormente, estudou o comportamento viscoelástico da solução 3630S HPAM escoando por uma rede de poros e canais. Eles observaram fortes flutuações de velocidade no centro dos poros a partir de uma vazão crítica $Q_{c r i t}=9 \mu \mathrm{l} / \mathrm{min}\left(Q_{c r i t}=0,54 \mathrm{ml} / \mathrm{h}\right)$ quando foi comparado com uma solução viscosa de glicerol utilizando a técnica PTV (particle tracking velocimetry), como mostrada na figura 163. Embora, o poro é formado por constrições abrupta planar de profundidade constante, mostrando uma dinâmica do escoamento mais simples e sem regiões de recirculação. Vale mencionar que as flutuações ao redor das paredes são devido à falta de partículas (sinal de ruído).
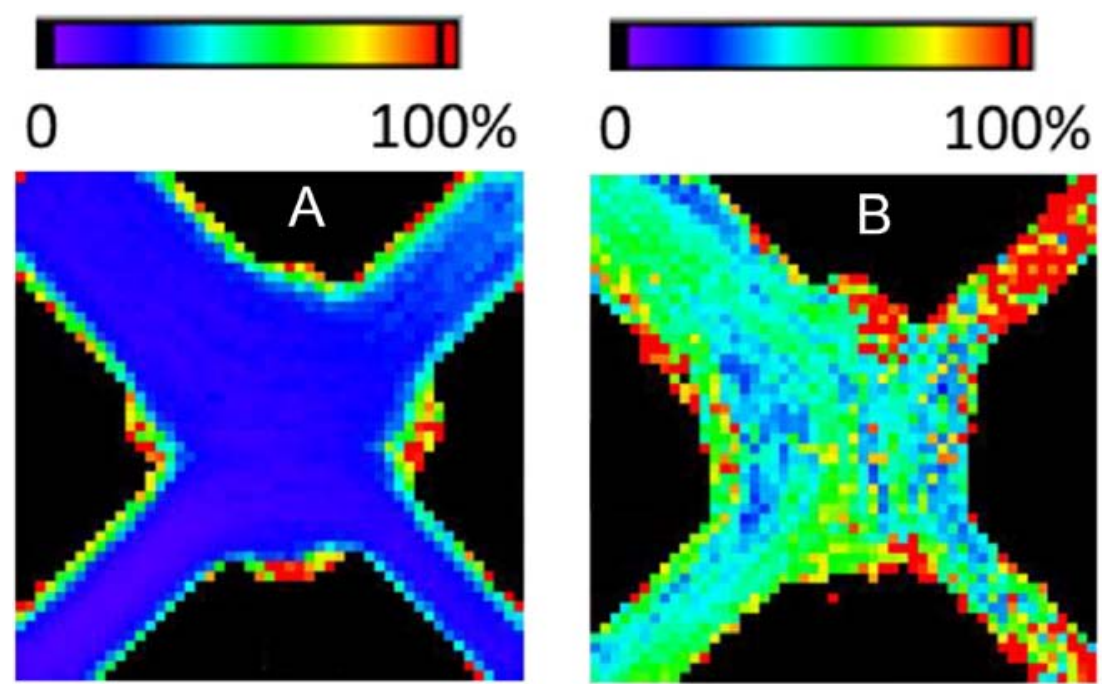

Figura 163 - Campo de desvio padrão. (a) Solução de glicerol de 84\% em peso (b) Solução de 3630S HPAM de 0,12\% em peso realizado por Clarke et al. (2015) 


\subsubsection{4.}

\section{Taxa de deformação do campo de velocidade média}

A taxa de deformação no escoamento foi determinada para revelar a dinâmica do escoamento não Newtoniano e estimar a viscosidade para diferentes condições do escoamento.

Os campos de taxa de deformação da solução de glicerina e PEO foram determinados a partir do campo de velocidade média do escoamento e foram adimensionalizados em relação à velocidade média do escoamento dividido pelo comprimento da garganta $U m / L c$.

As figuras 164, 165, 166, 167, 168 e 169 representam os campos de taxa de deformação para a solução de glicerina e a solução de PEO determinados para diferentes vazões de injeção $0,02 \mathrm{ml} / \mathrm{h} \leq Q \leq 0,32 \mathrm{ml} / \mathrm{h}$. 
PUC-Rio - Certificação Digital N 1313509/CA


Figura 164 - Taxa de deformação para a solução de glicerina e PEO às vazões de injeção $Q=0,02 \mathrm{ml} / \mathrm{h}, Q=0,04 \mathrm{ml} / \mathrm{h}$ e $Q=0,06 \mathrm{ml} / \mathrm{h}$ 
PUC-Rio - Certificação Digital N 1313509/CA
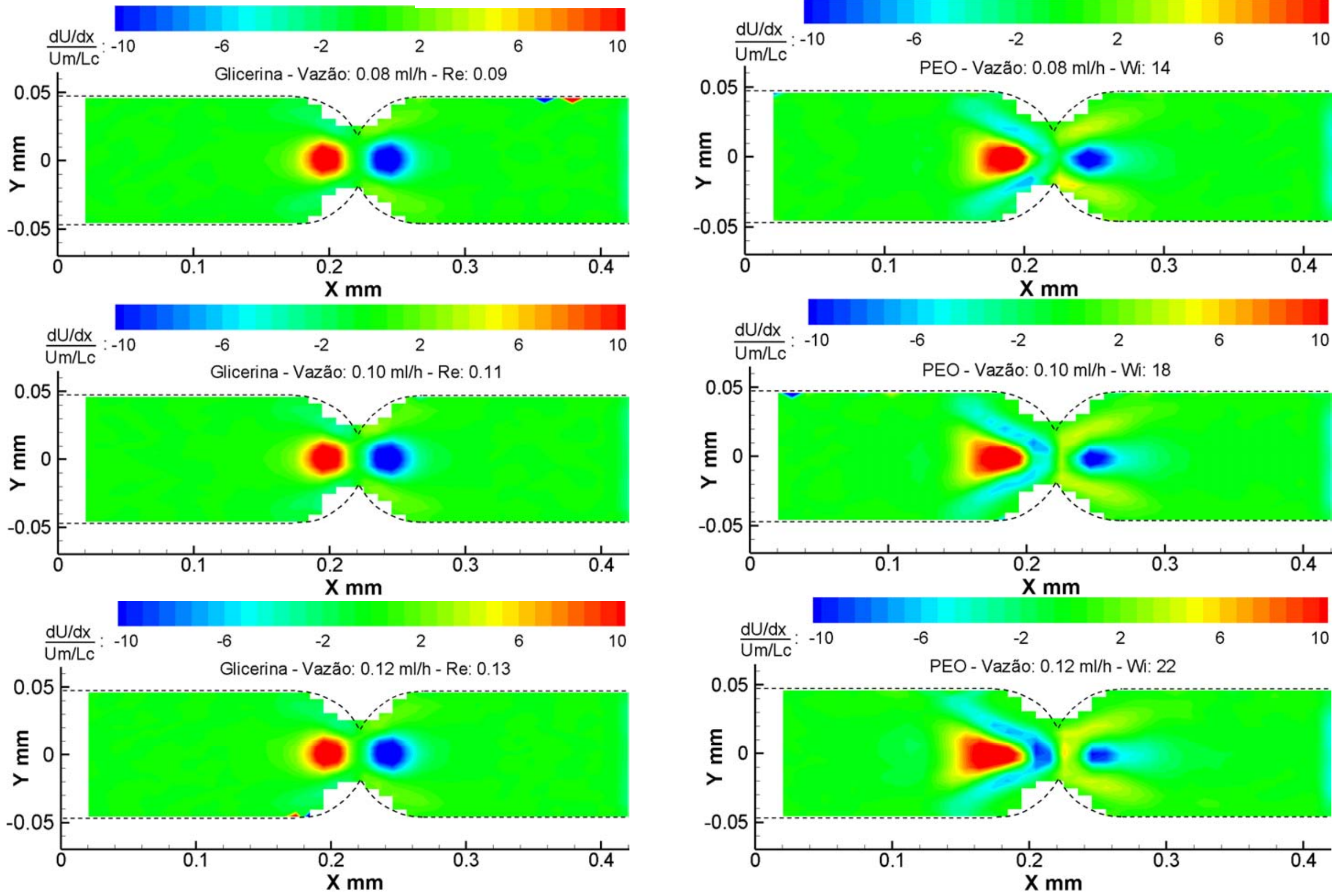

Figura 165 - Taxa de deformação para a solução de glicerina e PEO às vazões de injeção $Q=0,08 \mathrm{ml} / \mathrm{h}, Q=0,10 \mathrm{ml} / \mathrm{h}$ e $Q=0,12 \mathrm{ml} / \mathrm{h}$ 

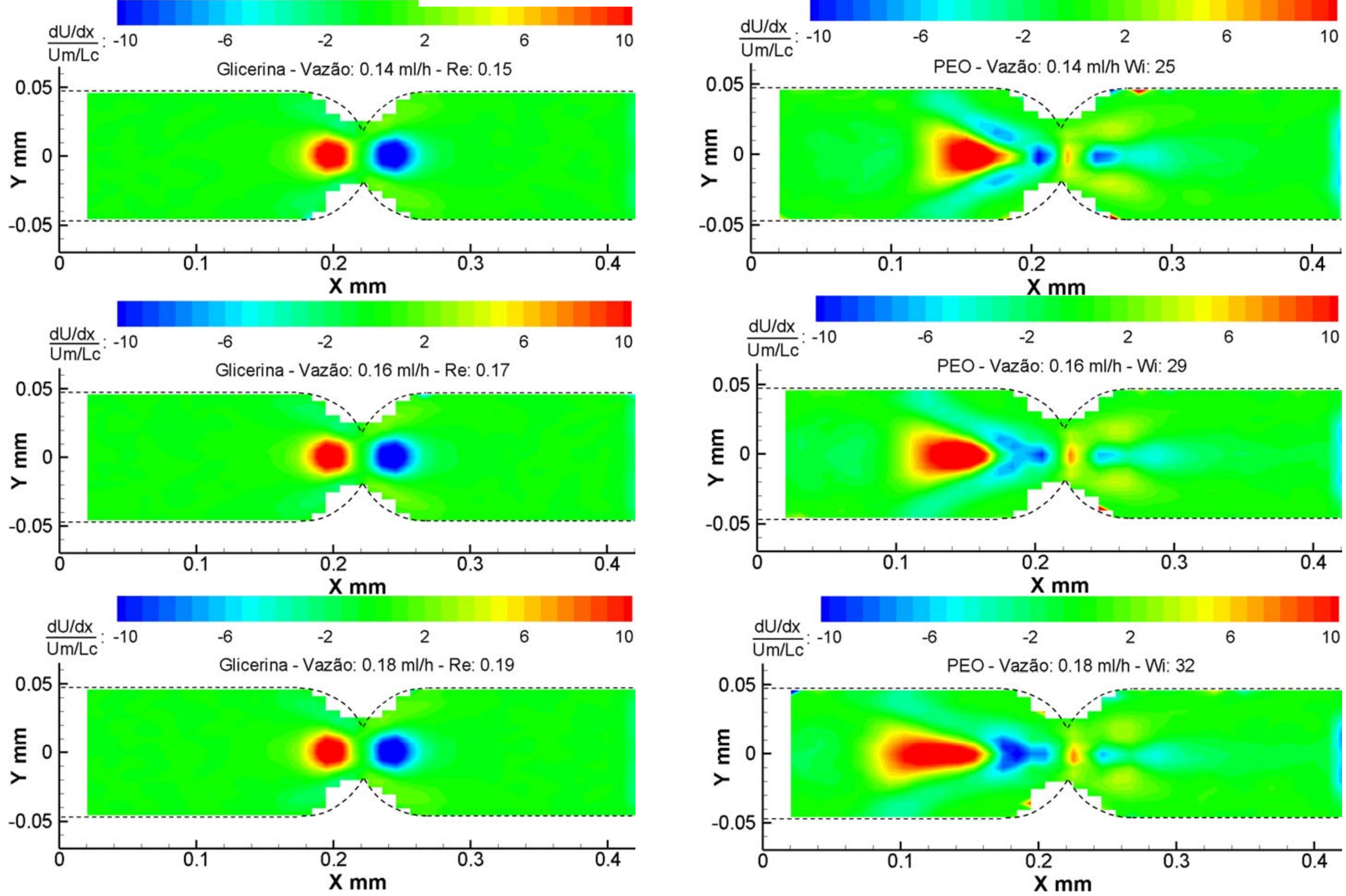

Figura 166 - Taxa de deformação para a solução de glicerina e $P E O$ às vazões de injeção $Q=0,14 \mathrm{ml} / \mathrm{h}, Q=0,16 \mathrm{ml} / \mathrm{h}$ e $Q=0,18 \mathrm{ml} / \mathrm{h}$ 
PUC-Rio - Certificação Digital N 1313509/CA
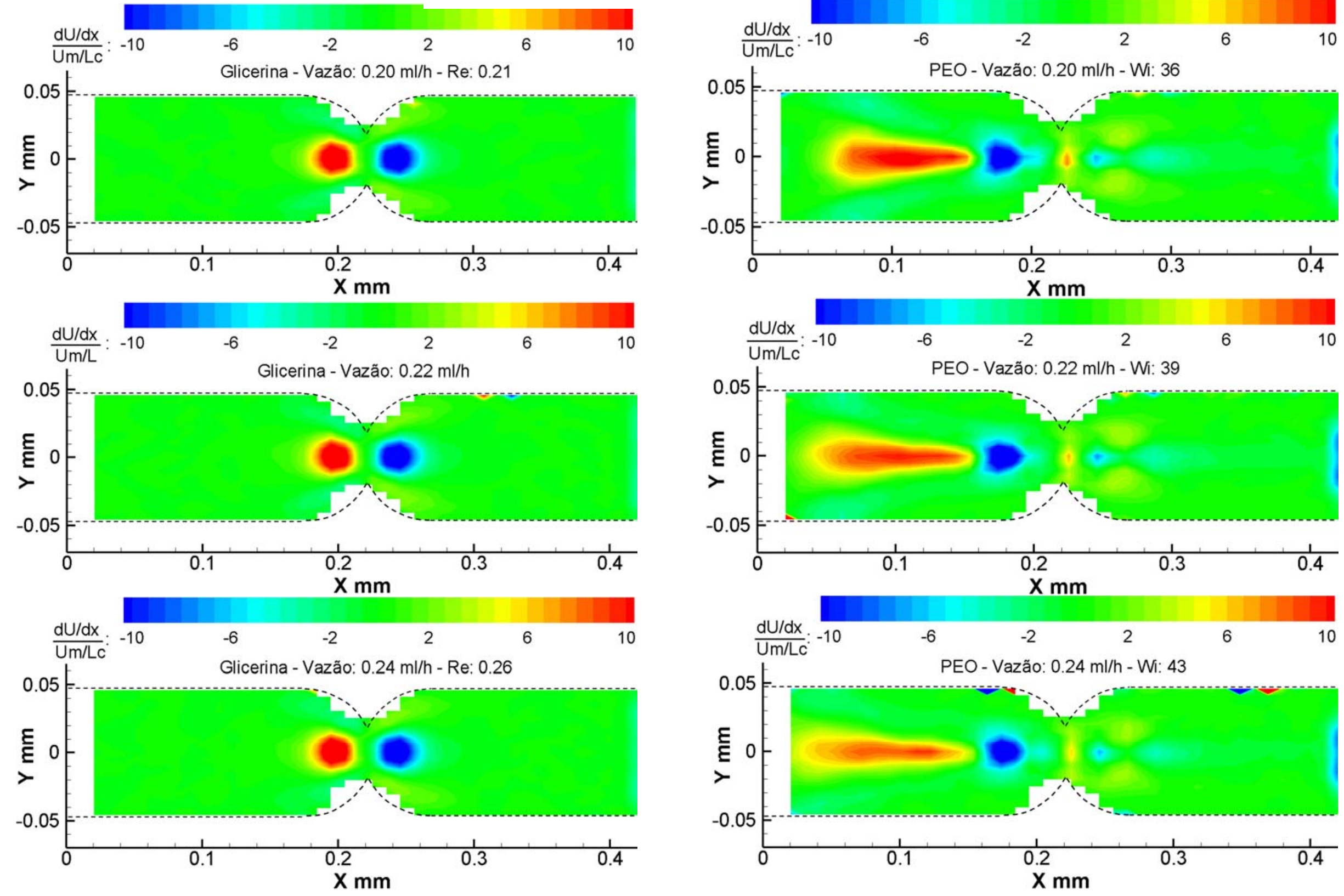

Figura 167 - Taxa de deformação para a solução de glicerina e PEO às vazões de injeção $Q=0,20 \mathrm{ml} / \mathrm{h}, Q=0,22 \mathrm{ml} / \mathrm{h}$ e $Q=0,24 \mathrm{ml} / \mathrm{h}$ 

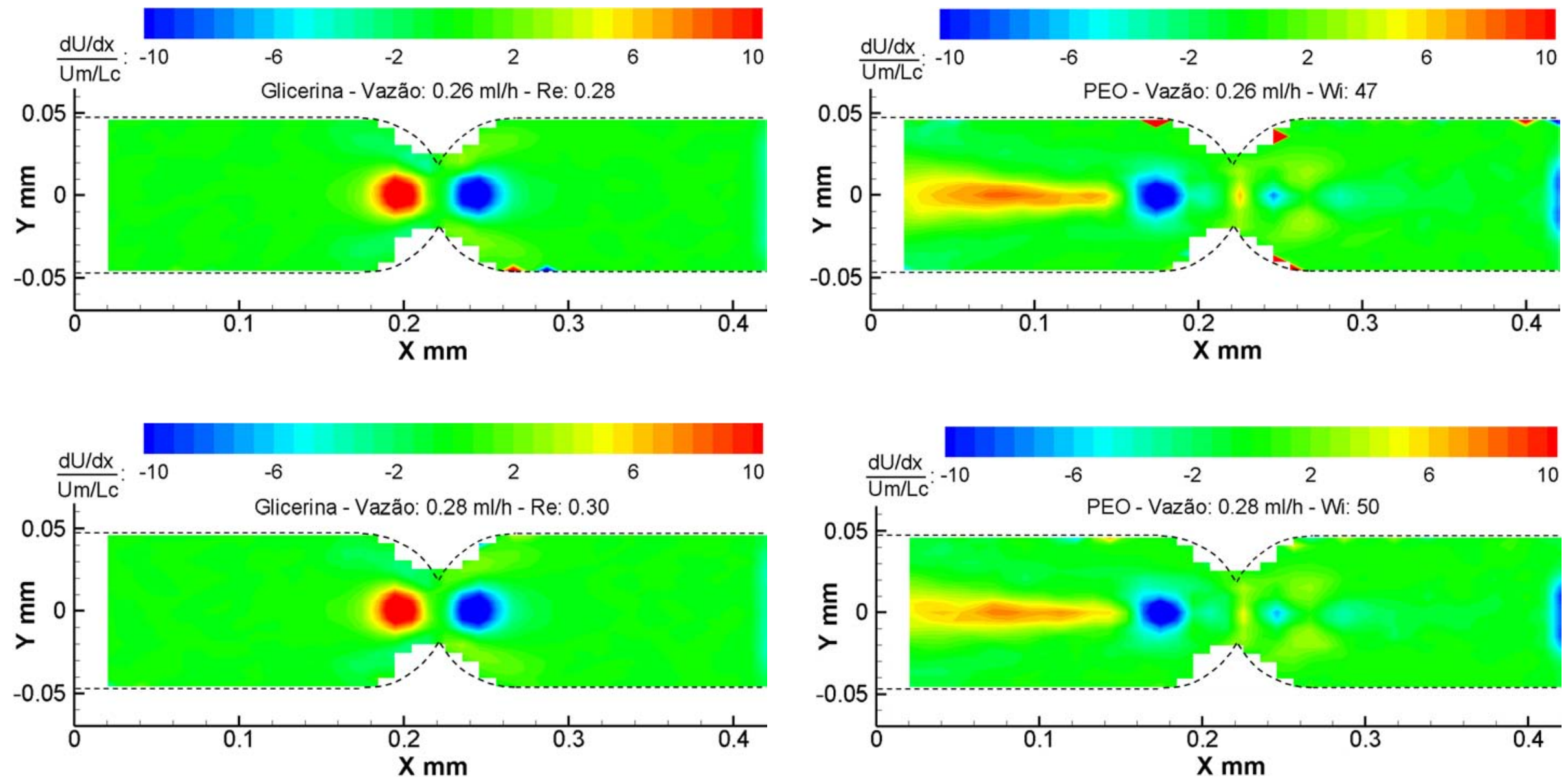

Figura 168 - Taxa de deformação para a solução de glicerina e PEO às vazões de injeção $Q=0,26 \mathrm{ml} / \mathrm{h}$ e $Q=0,28 \mathrm{ml} / \mathrm{h}$ 

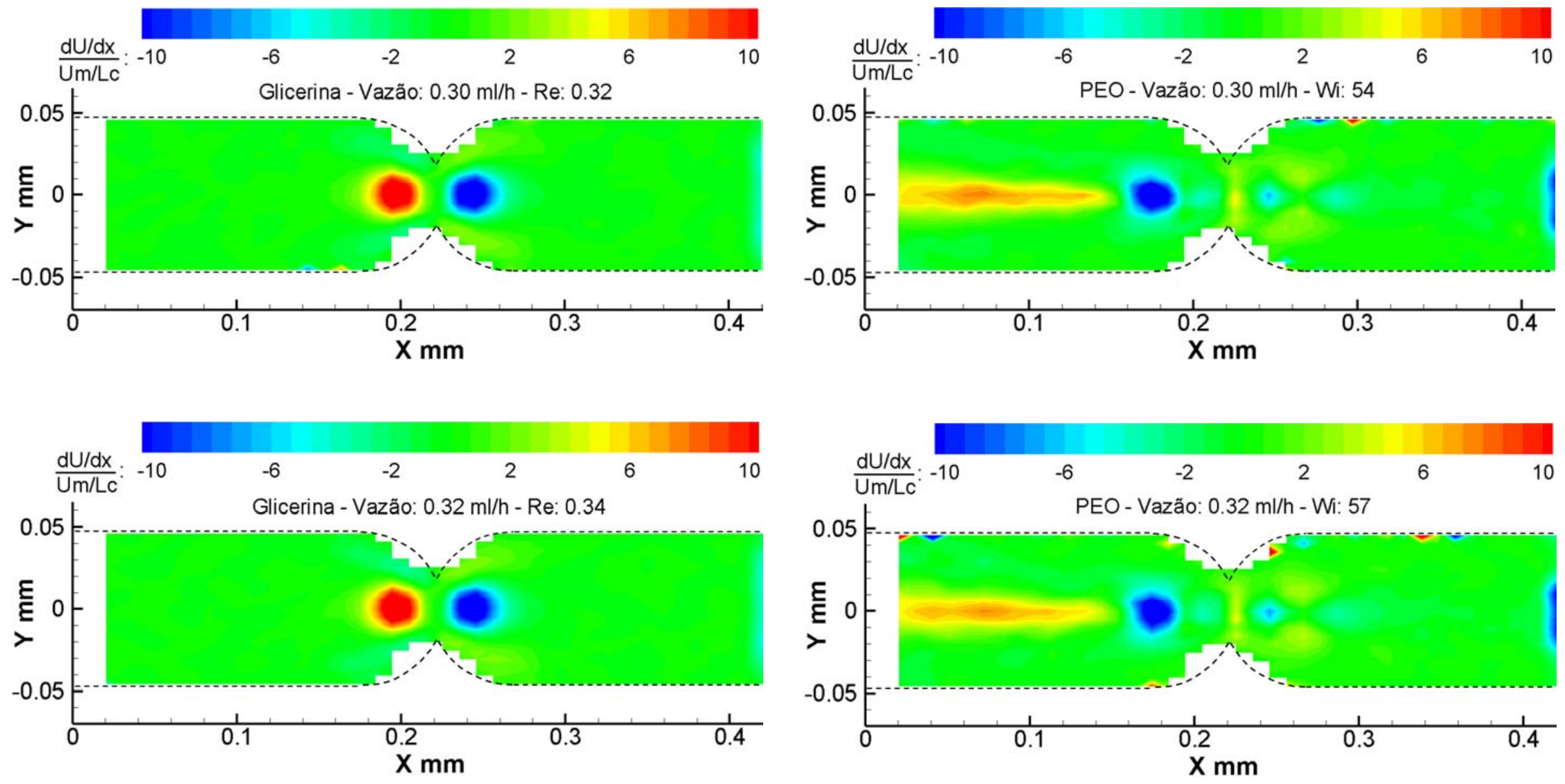

Figura 169 - Taxa de deformação para a solução de glicerina e $P E O$ às vazões de injeção $Q=0,30 \mathrm{ml} / \mathrm{h}$ e $Q=0,32 \mathrm{ml} / \mathrm{h}$ 
Todos os campos de taxa de deformação para a solução de glicerina mostraram uma simetria no escoamento, típico de um escoamento laminar de fluido Newtoniano a baixos números de Reynolds $(\operatorname{Re} \leq 0,34)$.

A taxa de deformação longe da garganta (no microcanal reto) é bem menor do que a taxa de deformação perto da garganta. É importante lembrar a baixa correlação de sinal/ruído no centro da constrição devido às partículas grudadas na parede do microcanal.

No caso da solução viscoelástica de PEO, o comportamento citado anteriormente é observado apenas às menores vazões de injeção $Q \leq 0,6 \mathrm{ml} / \mathrm{h}$. A única diferença é a presença de pequenos vórtices à montante da constrição, afetando localmente o escoamento.

Quando os efeitos elásticos foram suficientemente fortes $(Q>0,06 \mathrm{ml} / \mathrm{h})$, os campos de taxa de deformação começaram a perder simetria devido ao incremento da viscosidade extensional no escoamento gerado pelas altas taxas de extensão na região da garganta.

Conforme a vazão foi aumentada, o forte fluxo extensional foi deslocado à montante da garganta devido ao crescimento dos vórtices elásticos. Foi observada também uma extensão axial não homogênea ao longo da linha central à montante da garganta, com aceleração e desaceleração do escoamento. De fato, este comportamento é devido à natureza tridimensional do escoamento onde o núcleo de alta velocidade do fluxo já não aparece na linha central do eixo. Entretanto, à saída da garganta é caracterizada pela relaxação das moléculas do polímero (liberação da energia armazenada) retornando novamente para um escoamento bidimensional. 


\section{6 \\ Comentários Finais}

\section{1. Conclusões}

A presente investigação apresentou um estudo do comportamento dinâmico do escoamento da solução polimérica de PEO $\left(C=0,1 \%\right.$ e $\left.P M=8 \times 10^{6} \mathrm{~g} / \mathrm{mol}\right)$ escoando através de um microcanal com garganta, representando em forma simples o escoamento de soluções poliméricas através de uma garganta de poro.

Medidas da queda de pressão e medidas do campo de velocidade do escoamento da solução polimérica de PEO foram realizados com a finalidade de quantificar o efeito da elasticidade do polímero no escoamento quando for comparado com uma solução viscosa de glicerina em água (escoamento Newtoniano). A solução de glicerina em água foi preparada a igual viscosidade da solução polimérica.

Para vazões menores que $Q<2,0 \mathrm{ml} / \mathrm{h}(\operatorname{Re}<8,2)$, os valores da queda de pressão do escoamento da água medidas através do canal com constrição exibiram uma resposta linear característico de um escoamento de Stokes de um fluido Newtoniano. Caso contrário, para vazões $Q \geq 2,0 \mathrm{ml} / \mathrm{h}(R e \geq 8,2)$ foi observado um desvio do comportamento linear devido a efeitos inerciais observados a altas vazões de injeção.

O escoamento da solução do PEO apresentou uma queda de pressão extra acima do valor observado para a solução viscosa de glicerina com igual viscosidade e mesmas condições de fluxo para vazões acima de um valor crítico. A queda de pressão extra foi detectada na condição crítica de $0,06 \mathrm{ml} / \mathrm{h}<Q_{\text {crit }}<0,08 \mathrm{ml} / \mathrm{h}$ $\left(11<W i_{c r i t}<14\right)$. Abaixo do valor crítico $W_{c r i t}$, a taxa de extensão na entrada da garganta não foi alta o suficiente para causar um aumento significativo da viscosidade extensional e o escoamento apresentou um comportamento Newtoniano similar à resposta linear da queda de pressão da solução de glicerina (puramente viscosa). Acima do valor crítico $W_{\text {crit }}$, a taxa de extensão foi alta o 
suficiente para que os efeitos elásticos do polímero aumentem a viscosidade extensional no escoamento capaz de originar uma queda de pressão extra. $\mathrm{Na}$ máxima condição do escoamento estudada $(Q=0,32 \mathrm{ml} / \mathrm{h}, W i=57)$, a queda de pressão da solução de PEO foi 7 vezes maior do valor obtido da solução de glicerina. Devido a que os experimentos foram realizados a $R e<0,34$ não são esperadas contribuições inerciais nas medidas da queda de pressão.

A técnica de micro-PIV foi utilizada para caracterizar e quantificar a cinemática associada com o fluxo viscoelástico em escala micro e em uma ampla faixa de condições de escoamento.

Os campos de velocidade média dos escoamentos estudados foram obtidos através da media amostral de 500 pares de imagens consecutivas e utilizando a janela de interrogação de 32x16 pixels. A resolução das medidas foi um vetor para cada 5,12 $\mu \mathrm{m}$ na direção axial do escoamento.

Os campos vetoriais de velocidade média e as linhas de corrente do escoamento da água mostraram a geração de vórtices à jusante da constrição, coincidindo com o início do comportamento não linear observado nas medidas da queda de pressão a partir da vazão de injeção $Q \geq 2,0 \mathrm{ml} / \mathrm{h}(R e \geq 8,2)$, indicando que as forças inerciais passaram a ser relevantes na cinemática do escoamento. A presença e o crescimento dos vórtices foram visualizados também através de simulação numérica utilizando o software Comsol.

Para o caso da solução polimérica de PEO a baixas vazões de injeção, tanto os campos vetoriais de velocidade média como as linhas de corrente apresentaram uma simetria em relação ao plano da constrição similar aos campos vetoriais obtidos do escoamento Newtoniano da solução viscosa de glicerina em água, com efeitos inerciais desprezíveis. Quando o escoamento atingiu o valor crítico de número de Weissenberg $11<W i_{\text {crit }}<14$, o campo vetorial de velocidade da solução polimérica exibiu um incremento de velocidade no centro da constrição maior do que observado com a solução de glicerina, como resultado do aumento da viscosidade extensional local. À medida que o número de Weissenberg foi aumentado, outras regiões do escoamento foram afetadas em magnitude e direção. Para a condição do escoamento de $Q=0,32 \mathrm{ml} / \mathrm{h} \quad(W i=57)$, a velocidade máxima à montante da constrição do escoamento da solução de PEO foi 5 vezes maior do valor obtido da 
solução de glicerina. Além disso, as linhas de corrente do escoamento da solução de PEO mostraram a presença e crescimento de vórtices na entrada da constrição.

Os campos de velocidade instantâneo dos escoamentos foram obtidos através de um par de imagens consecutivas e representados através de linhas de corrente. A janela de interrogação de $64 \times 32$ pixels foi utilizada para aumentar a relação sinal/ruído devido à falta de partículas nas imagens, e a resolução das medidas foi um vetor para cada 10,24 $\mu \mathrm{m}$ na direção axial do escoamento.

Os campos instantâneos do escoamento de água mostraram três padrões de fluxo. O regime típico de escoamento de Stokes $(R e \leq 4,1)$, o regime de linhas de corrente divergentes $(4,1<R e<8,2)$ e o regime de vórtices simétricos $(R e \geq 8,2)$. Todos os regimes mostraram ser independente do tempo, indicando um escoamento laminar em regime permanente estável.

A evolução temporal do escoamento da solução de glicerina e PEO foram analisadas nas condições de fluxo de $0,02 \mathrm{ml} / \mathrm{h} \leq Q \leq 0,32 \mathrm{ml} / \mathrm{h}$.

No caso da solução de glicerina foi observado só o padrão de escoamento de Stokes, embora a maiores números de Reynolds o padrão do escoamento pode ser alterado quando as forças inerciais se tornem importantes.

No caso da solução polimérica de PEO foi visualizado o desenvolvimento de cinco regimes de fluxo no espaço paramétrico Wi-Re estudado. A tabela 8 apresenta as principais características encontradas nos regimes de escoamento associado com as medidas da queda de pressão extra e a evolução do crescimento dos vórtices na entrada da constrição. 
PUC-Rio - Certificação Digital No 1313509/CA

\begin{tabular}{|c|c|c|c|}
\hline Regime & $\begin{array}{l}\text { Queda de pressav exua } \\
\text { adimensionalizado } \Delta P_{N}\end{array}$ & $\begin{array}{l}\text { tannaniu aumicisıonal do } \\
\text { vórtice } \chi\end{array}$ & Conclusão \\
\hline I: Tipo Newtoniano $(W i<1,3)$ & $\begin{array}{l}\text { Ausência da queda de } \\
\text { pressão extra } \Delta P_{N}=0\end{array}$ & Ausência de vórtices $\chi=0$ & $\begin{array}{l}\text { Linhas de corrente simétrica em relação ao plano } \\
\text { da garganta, similar ao padrão do escoamento da } \\
\text { solução de glicerina. Forças viscosas dominantes. }\end{array}$ \\
\hline $\begin{array}{l}\text { Início de formação de vórtices } \\
W i_{\text {vort }}=1,3\end{array}$ & $\Delta P_{N}=0$ & $\begin{array}{l}\text { Tamanho inicial dos vórtices } \\
\qquad \chi=0,14\end{array}$ & $\begin{array}{l}\text { Início dos efeitos elásticos afetando apenas o } \\
\text { escoamento local na constrição. }\end{array}$ \\
\hline $\begin{array}{l}\text { II: Crescimento de vórtices } \\
\text { simétrico estável }(1,3 \leq W i<4)\end{array}$ & $\Delta P_{N}=0$ & $\begin{array}{l}\text { O tamanho do vórtice superior } \\
\chi_{s} \text { e inferior } \chi_{i} \text { são iguais }\end{array}$ & $\begin{array}{l}\text { Dependência fraca do tamanho dos vórtices com o } \\
\text { número de } W i \text {. Escoamento estável no tempo. }\end{array}$ \\
\hline $\begin{array}{l}\text { III: Crescimento de vórtices } \\
\text { assimétrico estável }\left(4 \leq W i<W i_{c r i t}\right)\end{array}$ & $\Delta P_{N}=0$ & $\begin{array}{l}\text { O tamanho do vórtice superior } \\
\text { e inferior são diferentes }\end{array}$ & $\begin{array}{l}\text { Pouco incremento do comprimento dos vórtices } \\
\text { com o aumento do número de } W i \text {. }\end{array}$ \\
\hline $\begin{array}{l}\text { Início da instabilidade elástica } \\
\left(11<W i_{c r i t}<14\right)\end{array}$ & $\begin{array}{l}\text { Início da queda de pressão } \\
\text { extra: } 1,24<\Delta P_{N}<1,30\end{array}$ & $\begin{array}{l}\chi_{s} \approx 0,43 \\
\chi_{i} \approx 0,47\end{array}$ & $\begin{array}{l}\text { O início da instabilidade no escoamento } \\
\text { acompanhado do início da queda de pressão extra. } \\
\text { Os efeitos elásticos se tornam dominantes. }\end{array}$ \\
\hline $\begin{array}{l}\text { IV: Crescimento de vórtices } \\
\text { assimétrico instável }\left(W i_{c r i t} \leq W i<29\right)\end{array}$ & $\begin{array}{l}\text { Acelerando rápido } \\
1,30<\Delta P_{N}<3,27\end{array}$ & $\begin{array}{c}\text { Crescimento rápido } \\
0,43<\chi_{s}<0,79 ; 0,47<\chi_{i}<0,84\end{array}$ & $\begin{array}{l}\text { Vórtices variando de tamanho e desaparecendo no } \\
\text { tempo. }\end{array}$ \\
\hline $\begin{array}{l}\text { V-1: Escoamento desordenado } \\
(29 \leq W i<50)\end{array}$ & $\begin{array}{l}\text { Acelerando rápido } \\
3,27<\Delta P_{N}<6,67\end{array}$ & $\begin{array}{c}\text { Crescimento rápido } \\
0,79<\chi_{s}<1,40 ; 0,84<\chi_{i}<1,58\end{array}$ & \multirow{2}{*}{$\begin{array}{l}\text { Formação de recirculações tanto à montante como } \\
\text { à jusante da constrição. Escoamento } \\
\text { tridimensional, instável e dependente do tempo } \\
\text { mostrando mudança de direção no escoamento. } \\
\text { Em Wi>50, as cadeias poliméricas estão atingindo } \\
\text { a sua extensão máxima. }\end{array}$} \\
\hline $\begin{array}{l}\text { V-2: Escoamento desordenado } \\
(50<W i<57)\end{array}$ & $\begin{array}{l}\text { Valor quase constante } \\
\text { atingindo um patamar: } \\
6,67<\Delta P_{N}<6,82\end{array}$ & $\begin{array}{l}\text { Crescimento quase constante } \\
\qquad \begin{array}{c}1,40<\chi_{s}<1,49 \\
1,58<\chi_{i}<1,67\end{array}\end{array}$ & \\
\hline
\end{tabular}

Tabela 8 - Resumo dos padrões do escoamento da solução polimérica de PEO relacionado com as medidas da queda de pressão e os vórtices à montante da constrição. 
Quando foi analisada a velocidade local em uma região do escoamento da solução de PEO à montante da constrição a partir dos campos de velocidade instantâneos, além do incremento de velocidade (visualizado também nos campos de velocidade médio), maiores flutuações de velocidade foram observadas acima $Q \geq 0,18 \mathrm{ml} / \mathrm{h}$, devido a que a elasticidade do polímero alterou a estabilidade cinemática do escoamento. Para a condição do escoamento de $Q=0,32 \mathrm{ml} / \mathrm{h}$ (Wi=57), a flutuação de velocidade local do escoamento da solução de PEO analisado foi $30 \%$ maior do valor obtido da solução de glicerina. Também foi revelado o crescimento da velocidade local associado com as medidas da queda de pressão extra no escoamento.

As flutuações de velocidade observadas em toda a região do escoamento das soluções de glicerina e PEO foram determinadas através dos campos de desvio padrão. Antes da condição crítica do escoamento $W_{\text {crit }}$, os campos de desvio padrão da solução viscoelástica de PEO mostraram flutuações de velocidade bastante similares do que observados com os campos da solução Newtoniana de glicerina. Depois da condição crítica $W i_{c r i t}$, diferentes regiões do escoamento da solução polimérica de PEO apresentaram maiores flutuações de velocidade do que visto no escoamento da glicerina, com maior intensidade à montante da constrição devido à alta viscosidade extensional com o aumento da taxa de extensão. O escoamento de PEO à saída da garganta foi afetado pela elasticidade das cadeias poliméricas que ainda não conseguiram restabelecer sua configuração original causando maiores flutuações de velocidade.

As taxas de deformação dos campos de velocidade média no escoamento da solução de PEO revelaram diferentes gradientes de velocidade à medida que a condição do escoamento foi alterada. No regime estável $\left(W i<W i_{c r i t}\right)$, os campos de taxa de deformação da solução de PEO revelaram uma simetria típica de um fluido Newtoniano (similar aos campos de taxa de deformação da solução de glicerina), confirmando a natureza viscosa ainda dominante no escoamento. No regime instável $\left(W i>W i_{c r i t}\right)$, a simetria do escoamento foi quebrada pelo aumento da viscosidade extensional formando um escoamento de natureza tridimensional com diferentes taxas extensionais variando no espaço e tempo. 
Quando o escoamento da solução viscoelástica de PEO (à concentração de $0,1 \%$ em peso e $P M=8 \times 10^{6} \mathrm{~g} / \mathrm{mol}$ ) passando através de uma constrição foi submetido a diferentes condições do escoamento, as medições da queda de pressão combinado com os resultados da técnica de micro-PIV revelaram o início de uma instabilidade elástica global no escoamento acompanhado de um aumento da queda de pressão a partir de uma condição crítica do escoamento $W i_{c r i t}$ causado pelos efeitos elásticos da solução viscoelástica de PEO. Este aumento da queda de pressão no escoamento ao vencer as forças capilares que retêm os gânglios de óleo podem levar a uma mobilização deles, resultando em uma diminuição da saturação de óleo residual e, consequentemente, uma maior recuperação de óleo. Além disso, as vazões de injeção utilizadas em nossa investigação foram bastante próximas às condições de fluxo em escoamento nas gargantas de poros das rochas dos reservatórios do que comparado com a literatura.

Finalmente, a evolução detalhada do escoamento da solução polimérica de PEO mostrou diferentes regimes de fluxo que podem fornecer informação valiosa para um melhor entendimento da resposta complexa das soluções poliméricas escoando através dos poros das rochas naturais dos reservatórios e possa ser relevante para investigações futuras.

\section{2 . Sugestões}

Estudos futuros deveriam incluir os efeitos da variação dos parâmetros geométricos e das propriedades viscoelásticas sobre o escoamento $(R e, W i, E l)$, com a finalidade de investigar possíveis padrões de escoamento ainda não descobertos na literatura que possam ser úteis para um melhor entendimento das respostas complexas dos fluidos viscoelásticos quando sejam submetidos a condições particulares.

Os resultados experimentais desta investigação podem ser utilizados para validar simulações numéricas com modelos constitutivos viscoelásticos capazes de predizer estes comportamentos complexos de interações da elasticidade e inércia no escoamento passando através de constrições. 
Para o sistema de micro-PIV, uma maior resolução espacial no campo de visualização do microscópio assim como uma câmera de alta velocidade permitirá estudar regiões com maiores gradientes de velocidade e detalhes de algumas regiões de interesse (região dos vórtices e a interface entre o escoamento secundário e primário) quando as condições foram diferentes às avaliadas nesta investigação. Seria interessante ampliar as investigações experimentais sobre a estrutura 3D do escoamento com o apoio da técnica confocal micro-velocimetria por imagem de partículas para obter informação adicional dos mecanismos que governam a cinemática dos escoamentos viscoelásticos escoando através de constrições modelados como poros dos reservatórios. 


\section{Referências bibliográficas}

ADRIAN, R. J.; YAO, C. S. Development of pulsed laser velocimetry for measurement of fluid flow. Eighth Biennial Symposium on turbulence, $G$. Patterson and J. L. Zakin, Eds., University of Missouri-Rolla, 1983.

ADRIAN, R. J. Scattering particle characteristics and their effect on pulsed laser measurements of fluid flow: speckle velocimetry vs. particle image velocimetry. Appl Opt, vol. 23, pp. 1690-1691, 1984.

ADRIAN, R. J. Twenty years of particle image velocimetry. Experiments in Fluids, vol. 39, pp. 159-169, 2005.

AGARWALL, A. D.; MASHELKAR, R. A. Migration of macromolecules under flow: The physical origin and engineering implications. Journal Chemical Engineering Science, vol. 49, pp. 1693-1717, India, 1994.

ALVES, M. A.; PINHO, F. T.; OLIVEIRA, P. J. Visualizations of Boger fluid flows in a 4:1 square-square contraction. Journal American Institute of Chemical Engineers, vol. 51, pp. 2908-2922, 2005.

ANNA, S. L.; MCKINLEY, G. H. Elasto-capillary thinning and breakup of model elastic liquids. Journal Rheology, vol. 45(1), pp. 115-138, 2001.

ARNOLDS, O.; BUGGISCH, H.; SACHSENHEIMER, D.; WILLENBACHER, N. Capillary breakup extensional rheometry (CaBER) on semi-dilute and concentrated polyethyleneoxide (PEO) solutions. Journal Rheology Acta, vol. 49, pp. 1207-1217, 2010. 
ASHRAF, M.; ALVAREZ, H.; JAGGI, R. Sustainably managing a strategic resource. SBC Energy Perspectives, Winter, 2012.

BAILEY, F. E.; KOLESKE, J. V. Poly(ethylene oxide). New York: Academic Press, pp. 1-173, 1976.

BAZILEVSKY, A. V.; ENTOV, V. M.; ROZHKOV, A. N. Liquid filament microrheometer and some of its applications. In Proc. Third European Rheology Conference, Edinburg, 1990.

BAZILEVSKY, A. V.; ENTOV, V. M.; LERNER, M. M.; ROZHKOV, A. N. Failure of polymer solution filaments, Polymer Science Ser. A (translated from Vysokomolekulyarnye Soedineniya Ser. A, pp. 474-482), vol. 39 (3), pp. 316-324, 1997.

BEEBE, D. J.; MENSING, G. A.; WALKER, G. M. Physics and Applications of Microfluidics in Biology. Annual Review Biomedical Engineering, pp. 262-276, 2002.

BHARDWAJ, A.; MILLER, E.; ROTHSTEIN, J. P. Filament stretching and capillary breakup extensional rheometry measurements of viscoelastic wormlike micelle solutions. Journal of Rheology, vol. 51, pp. 693-719, 2007.

BIRD, R. B.; ARMSTRONG, R. C.; HASSAGER, O. Dynamics of polymeric liquids. Fluid Mechanics, Vol. 1, New York: Wiley, 1987.

BIRD, R. B.; CURTISS, C. F.; ARMSTRONG, R. C.; HASSAGER, O. Dynamics of polymeric liquids. Fluid Mechanics, Vol. 2: Kinetic theory, New York: Wiley, 1987.

BOEK, E. S.; PADDING, J. T.; ANDERSON, V. J.; BRIELS, W. J.; CRAWSHAW, J. P. Flow of entangled workmlike micellar fluids: 
Mesoscopic simulations, rheology and $\mu$-PIV experiments. Journal of Non-Newtonian Fluid Mechanical, vol. 146, pp. 11-21, UK, 2007.

BOGER, D. V. Model polymer fluid systems. Pure and Applied Chemistry. vol. 57 (7), pp. 921-930, 1985.

BORBAS, C. T. Predicting reservoir performance by incorporating pore geometry. SPWLA 35 $5^{\text {th }}$ Annual Logging Symposium, 1994.

BRYANT, P. W.; NEUMANN, R. F.; MOURA, M. J. B.; STEINER, M.; CARVALHO, M. S.; FEGER, C. Quantitative $\mu$-PIV Measurements of Velocity Profiles. Cornell University Library ArXiv.org, pp. 1-20, Brazil, 2014.

CARTALOS, U.; PIAU, J. M. Creeping flow regimes of low concentration polymer solutions in thick solvents through an orifice die. Journal of Non-Newtonian Fluid Mechanical, vol. 45, pp. 231-85, France, 1992.

CLARKE, A.; HOWE M.; MITCHELL, J.; STANILAND, J.; HAWKES, L. A.; LEEPER, K. Mechanism of anomalously increased oil displacement with aqueous viscoelastic polymer solution. The Royal Society of Chemistry, vol. 11, pp. 3536-3541, 2015.

CLARKE, A.; HOWE, M.; MITCHELL, J.; STANILAND, J.; HAWKES, L. A. How viscoelastic polymer flooding enhances displacement efficiency. Journal Society of Petroleum Engineers, SPE-174654-MS, pp. 1-20, 2015.

DEALY, J. M. Weissenberg and Deborah numbers - Their definition and use. Rheology bulletin, v. 79(2), p. 14-18, 2010. Journal of Non-Newtonian Fluid Mechanical, vol. 45, pp. 231-285, France, 1992.

DEANO, L. C., GALINDO, R. F. J.; OLIVEIRA, M. S. N; ALVES, M. A.; $\mathrm{PINHO}, \mathrm{F}$. T. Boger fluid flow through hyperbolic contraction 
microchannels. $3^{\text {rd }}$ Micro and Nano Flows Conference, pp. 1-7, Greece, 2011.

DEGRÉ, G.; PIERRE, J.; TABELING, P.; LEROUGE, S.; CLOITRE, M.; AJDARY, A. Rheology of complex fluids by particle image velocimetry in microchannels. Journal Applied Physics Letters 89, France, 2006.

DINIC, J.; ZHANG, Y.; NALLELY, L. J.; SHARMA, V. Extensional relaxation times of dilute, aqueous polymer solutions. American Chemical Society, vol. 4(7), pp. 804-808, USA, 2015.

DOLOMITE MICROFLUIDICS GUIDE. Disponível em: https://www.dolomite-microfluidics.com/. Acesso em: julho 2014.

DONTULA, P.; MACOSKO, C. W.; SCRIVEN, L. E. Model elastic liquids with water-soluble polymers. Journal American Institute of Chemical Engineers, vol. 44, pp. 1247-1255, USA, 1998.

EINSTEIN, A. On the movement of small particles suspended in a stationary liquid demanded by the molecular-kinetic theory of heat. In: Theory of Brownian movement. Dover publications Inc., New York, pp. 118, 1905.

ENTOV, V. M.; HINCH, E. J. Effect of a spectrum of relaxation times on the capillary thinning of a filament of elastic liquid. Journal NonNewtonian Fluid Mechanics, vol.72, pp. 31-53, 1997.

FAN, L. T.; HWANG, C. L. Bibliography of hydrodynamic entrance region flow. Special Report 67, Kansas State University Bull, pp. 1-17, 1966.

FU, T.; CARRIER, O.; FUNFSCHILLING, D.; MA, Y.; LI, H. Newtonian and non-Newtonian flows in microchannels: Inline rheological 
characterization. Journal of Chemical Engineering Technology, vol. 39, pp. 987-992, China, 2015.

GALINDO, R. F. J.; CAMPO, L. D.; SOUSA, P. C.; RIBEIRO, V. M.; OLIVERIRA, M. S. N.; ALVES, M. A.; PINHO, F. T. Viscoelastic instabilities in micro-scale flows. Experimental Thermal and Fluid Science, Vol. 59, pp. 128-139, 2014.

GAURI, V.; KOELLING, K. W. Extensional rheology of concentrated poly(ethylene oxide) solutions. Journal Rheologica Acta, Vol. 36, pp. 555567, 1997.

GOODMAN, J. W. Introduction to Fourier Optics. McGraw-Hill Physical and Quantum Electronics series, pp 0-287, 1968.

GRAESSLEY, W. W. Polymer chain dimensions and the dependence of viscoelastic properties on concentration, molecular weight and solvent power. Polymer 21, vol. 21, pp. 258-262, USA, 1980.

GROISMAN, A.; STEINBERG, V. Elastic turbulence in a polymer solution flow. Journal of Science Nature, vol. 405, pp. 53-55, Israel, 2000.

GROISMAN, A.; ENZELBERGER, M.; QUATE, R. S. Microfluidic memory and control devices. Journal of Science AAAS, vol. 300, pp. 955-958, USA, 2003.

GROISMAN, A.; QUATE, R. S. A microfluidic rectifier: Anisotropic flow resistance at low Reynolds numbers. Letters review physical, vol. 92, pp. 094501-(1-4), USA, 2004.

GULATI, S.; MULLER, S. J.; LIEPMANN, D. Quantifying viscoelastic behavior of DNA-Laden flows in microfluidic systems. Conference on Microtechnologies in Medicine and Biology, pp. 282-285, USA, 2005. 
GULATI, S.; MULLER, S. J.; LIEPMANN, D. Direct measurements of viscoelastic flows of DNA in a 2:1 abrupt planar micro-contraction. Journal of Non-Newtonian Fluid Mechanics, vol. 155, pp. 51-66, USA, 2008.

GULATI, S.; MULLER, S. J.; LIEPMANN, D. Flow of DNA solutions in a microfluidic gradual contraction. American Institute of Physics, vol. 9, pp. 054102 (1-16), USA, 2015.

GUTIERREZ, J. A. F. Escoamento de gotas de óleo através de micro capilares. Dissertação de mestrado. Pontifícia Universidade Católica do Rio de Janeiro, Brasil, 2013.

HAWARD, SIMON J.; LI, ZHUO; LIGHTER, D.; THOMAS, B.; ODELL, A. J.; YHUAN, X. Flow of dilute to semi-dilute polystyrene solutions through a benchmark 8:1 planar abrupt micro-contraction. Journal of Non-Newtonian Fluid Mechanics, vol. 165, pp. 1654-1669, UK, $2010 a$.

HAWARD, SIMON J.; ODELL, J. A.; LI, ZHUO; YHUAN, X. The rheology of polymer solution elastic strands in extensional flow. Rheologica Acta DOI 10.1007/s00397-010-0453-x, UK, 2010b.

HINCAPIE, R. E.; ROCK, A.; WEGNER, J.; GANZER, L. Oil mobilization by viscoelastic flow instabilities effects during polymer EOR: A porescale visualization approach. Journal of Society of Petroleum Engineers, SPE-185489-MS, pp. 1-14, Argentina, 2017.

HOMSY, G. M. Viscous fingering in porous media. Journal of Fluid Mechanics, vol. 19, pp. 271-311, 1987.

INOUÉ, S.; SPRING, K. Video Microscopy. Plenum Press, second edition, 1997. 
KEANE, R. D.; ADRIAN, J. A. Optimization of particle image velocimeters. Part I: Double pulsed systems. Measurements Sicence and Techology, pp. 1202-1215, 1990.

LANDAU, L. D.; LIFSHITZ, E. M. Fluid Mechanics. Pergamon Books Oxford Ltd., second edition, England, 1987.

LANGHAAR, H. L. Steady flow in the transition length of a straight tube. Journal of Applied Mechanics, vol. 9, pp. 55-58, 1942.

LANZARO, A. Microscopic flows of aqueous polyacrylamide solutions: A quantitative study. Thesis, University of Manchester, UK, 2011.

LANZARO, A.; YUAN, X-F. Effects of contraction on non-linear dynamics of semi-dilute, highly polydisperse PAAm solutions in microfluidics. Journal of Non-Newtonian Fluid Mechanics, vol. 166, pp. 1064-1075, UK, 2011.

LANZARO, A.; YUAN, X-F. A quantitative analysis of spatial extensional rate distribution in nonlinear viscoelastic flows. Journal of NonNewtonian Fluid Mechanics, vol. 207, pp. 32-41, UK, 2014.

LANZARO, A.; LI, Z.; YUAN, X-F. Quantitative characterization of high molecular weight polymer solutions in microfluidic hyperbolic contraction flow. Microfluidics and Nanofluidics, vol. 18, pp. 819-828, 2015.

LARSON, R. G. Instabilities in viscoelastic flows. Journal of Rheologica Acta 31, pp. 213-263, USA, 1992.

LEE, D.; KIM, Y.; HYUN, A. K. Effect of elasticity number and aspect ratio on the vortex dynamics in 4:1 micro-contraction channel flow. Journal of Rheology Korea-Australia, vol. 26, pp. 335-340, 2014. 
LEE, D.; HYUN, A. K. Flow patterns in 4:1 micro-contraction flows of viscoelastic fluids. Journal Rheology Korea-Australia, vol. 27, pp. 65-73, 2015.

LEE, S. J.; KIM, S. Advanced particle-based velocimetry techniques for microscale flows. Microfluidics and Nanofluidics, vol. 6, pp. 577-588, 2009.

LI, Z.; YUAN, X.; HAWARD, S. J.; ODELL, J. A.; YEATES, S. Non-linear dynamics of semi-dilute polydisperse polymer solutions in microfluidics: effects of flow geometry. Rheology, vol. 50, pp. 277-290, 2011.

LI, Z.; YUAN, X.; HAWARD, S. J.; ODELL, J. A.; YEATES, S. Non-linear dynamics of semi-dilute polydisperse polymer solutions in microfluidics: A study of a benchmark flow problem. Journal of NonNewtonian Fluid Mechanics, vol. 166, pp. 951-963, UK, 2011.

LI, Z.; HAWARD, J. S. Viscoelastic flow development in planar microchannels. Rheology, vol. 19, pp. 1123-1137, 2015.

MANUALS \& PROTOCOLS 04 MARCH 2003: Produced by Molecular Probes, Inc. Disponível em: https://www.thermofisher.com/order/catalog/ product/F13082. Acesso em: 15 maio 2014.

MCKINLEY, G. H.; TRIPATHI, A. How to extract the Newtonian viscosity from capillary breakup measurements in a filament rheometer. Journal Rheology, vol. 44, pp. 653-670, 2000.

MCKINLEY, H. G.; RODD, E. L.; OLIVEIRA, S. N. M.; COOPER-WHITE, J. Extensional flows of polymer solutions in microfluidic converging/diverging geometries. Journal of Central South University of Technology, pp. 6-9, 2007. 
MEINHART, C. D.; WERELEY, S. T.; SANTIAGO, J. G. PIV measurements of a microchannel flow. Experiments in Fluids, vol. 27, pp. 414-419, 1999.

MEINHART, C. D.; WERELEY, S. T.; SANTIAGO, J. A PIV algorithm for estimating time-average velocity fields. Journal of Fluids Engineering, vol. 122, pp. 285-289, 2000.

MEINHART, C. D.; WERELEY, S. T.; GRAY, M. H. B. Volume illumination for two-dimensional particle image velocimetry. Measurements Science and Technology, vol. 11, pp. 809-814, 2000.

MELO, M. A.; LINS, A. G.; SILVA, P.G. Lessons Learned from polymer flooding pilots in Brazil. Society of Petroleum Engineers, pp. 1-17, Brazil, 2017.

MIRANDA, L. N. Análise do deslocamento de óleo por soluções poliméricas em microescala. Dissertação de mestrado. Pontifícia Universidade Católica do Rio de Janeiro, Brasil, 2015.

Microfluidic applications in the pharmaceutical, life sciences, In-Vitro diagnostic, and medical device markets report, Yole. Disponível em: http://www.yole.fr/iso_album/illus_microfluidicapplications_market_yole_ju ne2015.jpg. Acesso em: maio 2016.

MOFFATT, H. K. Viscous and resistive eddies near a sharp corner. Journal of Fluid Mechanics, vol. 18, part 1, pp. 1-18, UK, 1963.

MOHAMMAD, A. K.; SUSZYNSKI, W. J.; GRIFFITH, W. B.; PUJARI, S.; FRANCIS, L. F.; CARVALHO, M. S. Effect of viscoelasticity on stability of liquid curtain. Journal of Non-Newtonian Fluid Mechanics, vol. 257, pp. 83-94, 2018. 
NEVES, O. M. N.; ALVES, A. M.; MCKINLEY, H. G.; PINHO, T. F. Extensional flow through microfabricated hyperbolic contractions. Conferência nacional de métodos numéricos em mecânica dos fluidos e termodinâmica, pp. 1-17, Portugal, 2006.

NEVES, O. M. N.; ALVES, A. M.; MCKINLEY, H. G.; PINHO, T. F. Extensional flow water and a semi-dilute aqueous solution polyethylene oxide through microfabricated hyperbolic contractions. 13th International Symposia on Applications of Laser Techniques to fluid Mechanics, pp. 1-15, Portugal, 2006.

NEVES, O. M. N.; AFONSO, A. M.; PINHO, F. T.; ALVES, M. A. High Deborah number flows through 3D contractions at the microscale. NSTI-Nanotech, vol. 2, pp. 497-500, 2011.

NEW WAVE RESEARCH. Operator's Manual: Solo III-Nd: YAG Laser. USA, Revision A, June 2001.

NGUYEN, N. T.; WERELEY, S. T. Fundamentals and applications of microfluidics. $2^{\text {a }}$ edition, pp. 55-109, Artech House, INC., 2006.

OLSEN, M. G.; ADRIAN, R. J. Out-of-focus effects on particle image visibility and correlation in microscopic particle image velocimetry. Experiments in Fluids, vol. 29, pp. S166-S174, (2000a).

OLSEN, M. G.; ADRIAN, R. J. Brownian motion and correlation in particle image velocimetry. Optics \& Laser Technology, vol. 32, pp. 621627, (2000b).

PARETO, S. M. C. Escoamento de soluções poliméricas através de capilar com garganta. Dissertação de mestrado. Pontifícia Universidade Católica do Rio de Janeiro, Brasil, 2015. 
PENG, X. F.; PETERSON, G. P. Convective heat transfer and flow friction for water flow in microchannel structures. International Journal of Heat and Mass Transfer, vol. 39, pp. 2599-2608, 1996.

PETER, S. T. Contraction/Expansion flow of dilute elastic solutions in microchannels. Masters dissertation, DEM, MIT, 2004.

PICKERING, C. J. D.; HALLIWELL, N. LSP and PIV: Photographic film noise. Applied Optics, vol. 23, pp. 2961-2969, 1984.

PRASAD, A. K.; ADRIAN, R. J.; LANDRETH, C. C.; OFFUTT, P. W. Effect of resolution on the speed and accuracy of particle image velocimetry interrogation. Experiments in Fluids, vol. 13, pp. 105-116, 1992.

PRASAD, A. K. Particle Image Velocimetry. Current Science, vol. 79, pp. $51-60,2000$.

RAFFEL, M.; WILLERT, C. E.; WERELEY, S.; KOMPENHANS, J. Particle Image Velocimetry - A Practical Guide. $2^{\text {nd }}$ Edition Springer, pp. 1-448, 2007.

RODD, L. E.; SCOTT, T. P.; COOPER-WHITE, JUSTIN J.; MCKINLEY, G. $\mathrm{H}$. Capillary break-up rheometry of low-viscosity elastic fluids. Journal Applied Rheology, pp. 1-22, 2004.

RODD, L. E.; SCOTT, T. P.; BOGER, D. V.; COOPER-WHITE, J. J.; MCKINLEY, G. $H$. The inertio-elastic planar entry flow of low-viscosity elastic fluids in micro-fabricated geometries. Journal of Non-Newtonian Fluid Mechanics, vol. 129, pp. 1-22, 2005.

RODD, L. E.; COOPER-WHITE, J. J.; BOGER, D. V.; MCKINLEY, G. H. Role of the elasticity number in the entry flow of dilute polymer solutions in micro-fabricated contraction geometries. Journal of NonNewtonian Fluid Mechanics, vol. 143 pp. 170-191, 2007. 
RODD, L. E.; LEE, D.; HYUN, A. K.; COOPER-WHITE, J. J. The importance of downstream events in microfluidic viscoelastic entry flows: Consequences of increasing the constriction length. Journal of Non-Newtonian Fluid Mechanics, vol. 165 pp. 1189-1203, 2010.

ROTHSTEIN, P. J.; McKINLEY, G. H. Extensional flow of a polystyrene Boger fluid through a 4:1:4 axisymmetric contraction/expansion. Journal of Non-Newtonian Fluid Mechanics, vol. 86, pp. 61-88, USA, 1999.

ROTHSTEIN, P. J.; McKINLEY, G. H. The axisymmetric contractionexpansion: the role of extensional rheology on vortex growth dynamics and the enhanced pressure drop. Journal of Non-Newtonian Fluid Mechanics, vol. 98, pp. 33-63, USA, 2001.

SANTIAGO, J. G.; WERELEY, S.T.; MEINHART, C. D.; BEEDE, D. J.; ADRIAN, R. J. A particle image velocimetry system for microfluidics. Experiments in Fluids, vol. 25, pp. 316-319, Springer-Verlag, 1998.

SCHÜMMER, P.; TEBEL, K. H. A new elongational rheometer for polymer solutions. Journal of Non-Newtonian Fluid Mechanics, vol. 12, pp. 331-347, 1983.

SHELL BUILDING A SUSTAINABLE ENERGY FUTURE. Disponível em: http://reports.shell.com/sustainability-report/2013/our-approach/building-asustainable-energy-future.html. Acesso em: março de 2016.

SHENG, J. Synergistic mechanics of asp flooding. Disponível em: http://www.upstreampumping.com/article/production/synergisticmechanisms-asp-flooding. Acesso em: março de 2016.

SOUSA, P. C. Entry flow of viscoelastic fluids at macro-and microscale. Thesis, Universidade do Porto, Portugal, 2010. 
SOUSA, P. C.; PINHO, F. T.; OLIVEIRA, M. S. N.; ALVES, M. A. Efficient microfluidic rectifiers for viscoelastic fluid flow. Journal of NonNewtonian Fluid Mechanics, vol. 165, pp. 652-671, Portugal, 2010.

SOUSA, P. C.; PINHO, F. T.; OLIVEIRA, M. S. N.; ALVES, M. A. High performance microfluidic rectifiers for viscoelastic fluid flow. Journal of Royal Society of Chemistry, vol. 2, pp. 920-929, Portugal, 2011.

SOUSA, P. C.; VEJA, E. J.; SOUSA, R. G.; MONTANERO, J. M.; ALVES, $M$. A. Measurements of relaxation times in extensional flow of weakly viscoelastic polymer solutions. Journal Rheologica Acta, vol. 56, pp. 1120, 2017.

STELTER, M.; BRENN, G.; YARIN, A. L.; SINGH, R. P.; DURST, F. Validation and application of a novel elongational device for polymer solutions. Journal Applied Rheology, vol. 44(3), pp. 595-616, 2000.

TIAN, W. C.; FINEHOUT, E. Microfluidics for biological applications. Springer Science Business Media LLC, pp. 35-82, USA, 2008.

TIRTAATMADJA, V.; MCKINLEY, G. H; COOPER-WHITE, J. J. Drop formation and breakup of low viscosity elastic fluids: Effects of molecular weight and concentration. Journal of Physics of Fluids, vol. 18, pp. 043101 (1-18), 2006.

TROUTON, F. T. On the coefficient of viscous traction and its relation to that of viscosity. Journal of the Royal Society of London, pp. 426-440, 1906.

TRUST SCIENCE INNOVATION. User's Guide: Particle Image Velocimetry - Insight 4GTM. USA, Revision A, June 2011. 
WHITE, S. A.; GOTSIS, A. D.; BAIRD, D. G. Review of the entry flow problem: experimental and numerical. Journal of Non-Newtonian Fluid Mechanics, vol. 24, pp. 121-160, Netherlands, 1987.

WERELEY, S. T.; GUI, L.; MEINHART, C. D. Advanced algorithms for microscale particle image velocimetry. AIAA Journal, vol. 40, pp. 10471055, 2002.

WERELEY, S. T.; MEINHART, C. D. Micron-resolution particle image velocimetry in micro-and nano-scale diagnostic techniques. SpringerVerlag, 2005. 


\section{Apêndice A}

\section{A.1 Calibração do transdutor de pressão}

\section{A.1.1. Bancada experimental do sistema de calibração}

A bancada experimental utilizada para calibrar o transdutor de pressão diferencial da Validyne Modelo DP15 é composta do sistema de injeção e o sistema de medição de pressão, como apresentada na figura 170a.
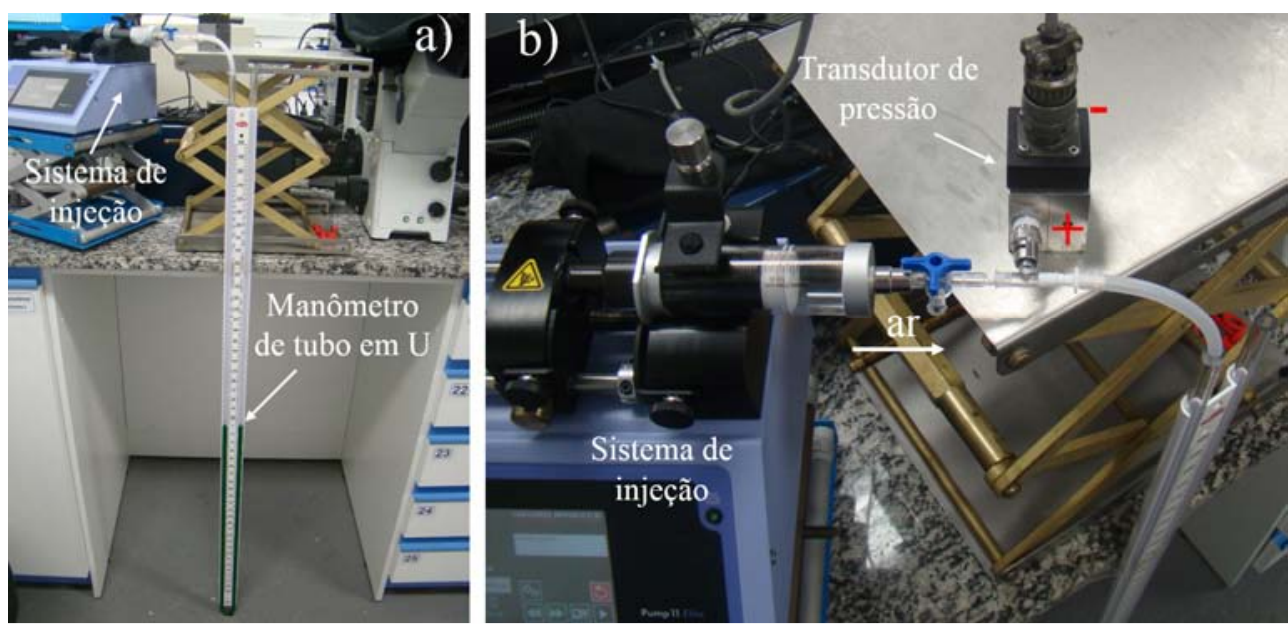

Figura 170 - a) Bancada experimental de calibração do transdutor de pressão. b) Montagem do sistema de injeção

O fluido utilizado durante o processo de calibração foi o ar. $\mathrm{O}$ ar foi injetado utilizando uma bomba de seringa de infusão continua, modelo Harvard Apparatus Elite 11 e, com uma exatidão de $\pm 0,5 \%$ nas medições. Além disso, uma seringa de vidro Hamilton Gastight ${ }^{\circledR}$ série 1000, válvula plástica de três vias, conectores e mangueiras foram utilizadas na montagem do circuito (figura 170b).

O diafragma do transdutor de pressão possui uma faixa de pressão de 0-1,25 psi. O transdutor de pressão tem uma exatidão de $0,25 \%(\approx 0,003$ psi). A câmera positiva (+) do transdutor foi conectada à linha de injeção de ar e a câmera negativa (-) conectada à atmosfera, como mostrada na figura $170 \mathrm{~b}$. 
O transdutor de pressão foi calibrado utilizando o manômetro de tubo em U da Dwyer ${ }^{\circledR}$ Flex-Tube $^{\circledR}$, serie 1221. A coluna esquerda do manômetro em U foi conectada à linha de injeção de ar e a coluna direita aberta à atmosfera. O fluido do manômetro é um corante fluorescente de cor verde diluído em água destilada (massa específica de $1,00 \mathrm{~g} / \mathrm{cm}^{3}$ ). A faixa de medição é de 500-0-500 mm w.c. (coluna de água) e sua menor divisão é de 2 mm w.c. ( $\approx 0,003$ psi) de igual precisão do transdutor de pressão.

\section{A.1.2. Procedimento de calibração}

A calibração foi realizada para determinar a relação linear entre o sinal elétrico do sensor e a pressão aplicada. O ganho e o zero (offset), coeficientes desta relação, foram obtidos nas unidades a serem utilizados. O procedimento da calibração é descrito a seguir:

1. Primeiro, a mistura de água destilada com corante foi inserida no interior do manômetro em U até atingir o nível de referência zero. Depois o sistema de injeção e o transdutor de pressão foram conectados ao manômetro;

2. Durante o processo de calibração, o ar foi injetado a uma vazão constante de $20 \mathrm{ml} / \mathrm{h}$ por meio da bomba de seringa Harvard Elite 11;

3. Antes de iniciar a injeção (bomba de seringa desligada), a aquisição de dados do sinal do transdutor em $\mathrm{mV}$ foi realizada a cada 0,25 segundos no intervalo de 2 minutos para a altura de referência zero do manômetro em U;

4. Após iniciar a injeção (bomba de seringa ligada), a aquisição de dados foi realizada a cada $35 \mathrm{~mm}$ de coluna de água $(\approx 0,05 \mathrm{psi})$. Quando o menisco atingia a altura de medição, a bomba de seringa era parada e imediatamente eram coletados os dados de sinal do transdutor. Finalizada a aquisição de dados, a bomba era ligada novamente até atingir a próxima altura de medição;

5. Finalmente, com os dados dos sinais do transdutor para as diferentes alturas do manômetro foi obtido a curva linear de calibração do transdutor de 
pressão, os coeficientes e suas incertezas utilizando o método dos mínimos quadrados, como indica a figura 171. O software Qtiplot foi utilizado para processar os dados.

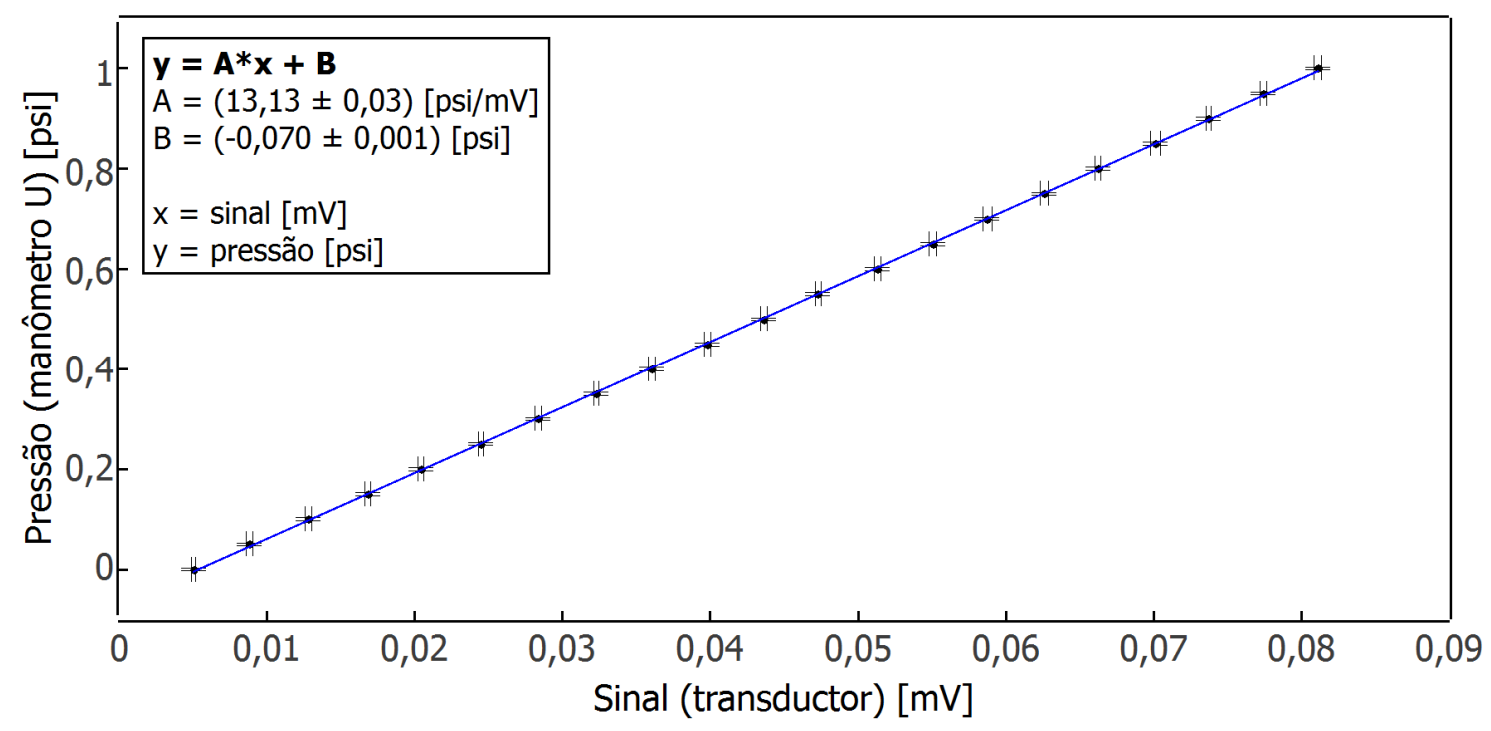

Figura 171 - Curva de calibração do transdutor de pressão 